بسم الله الرحمن الرحيم 


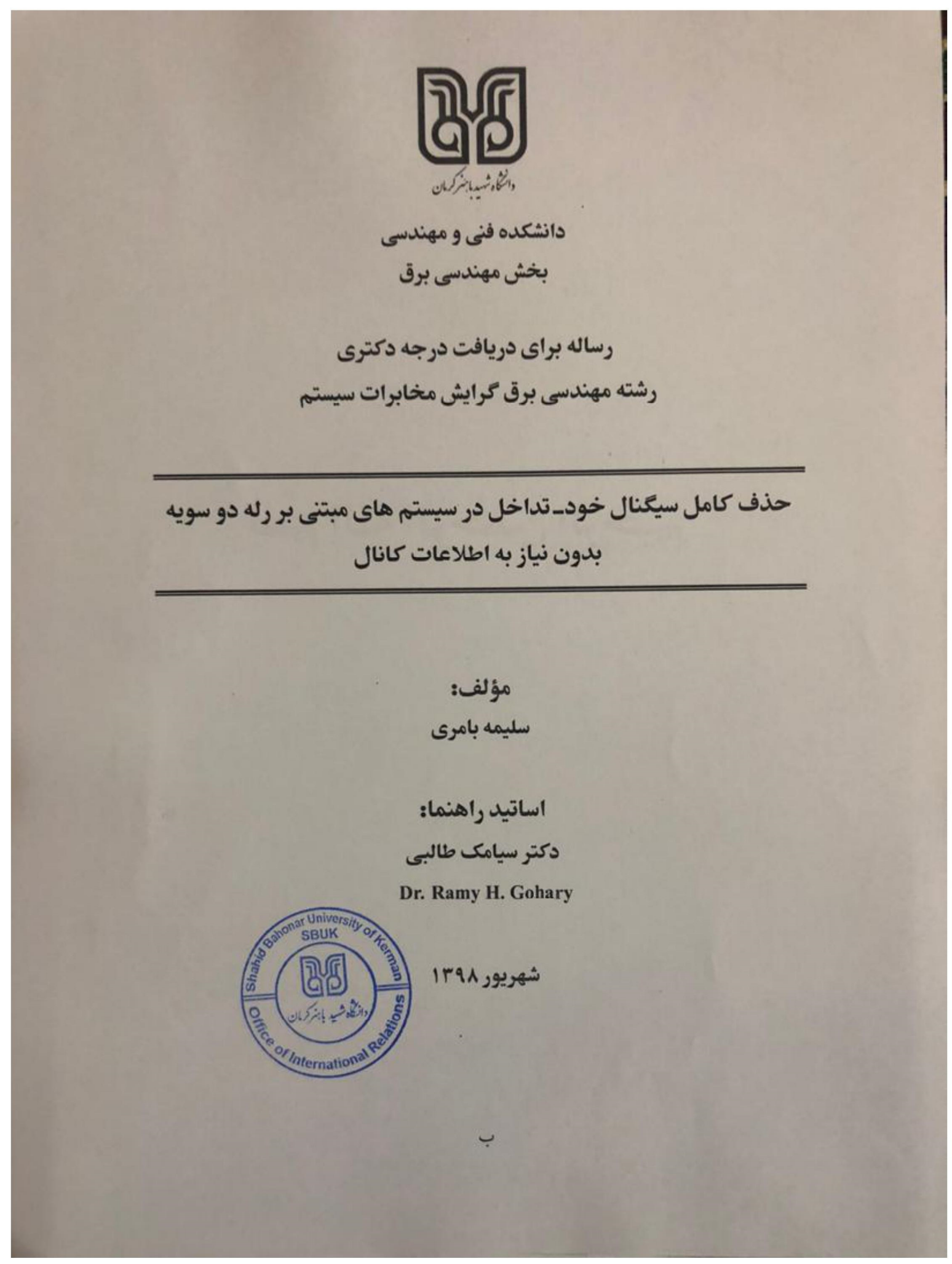




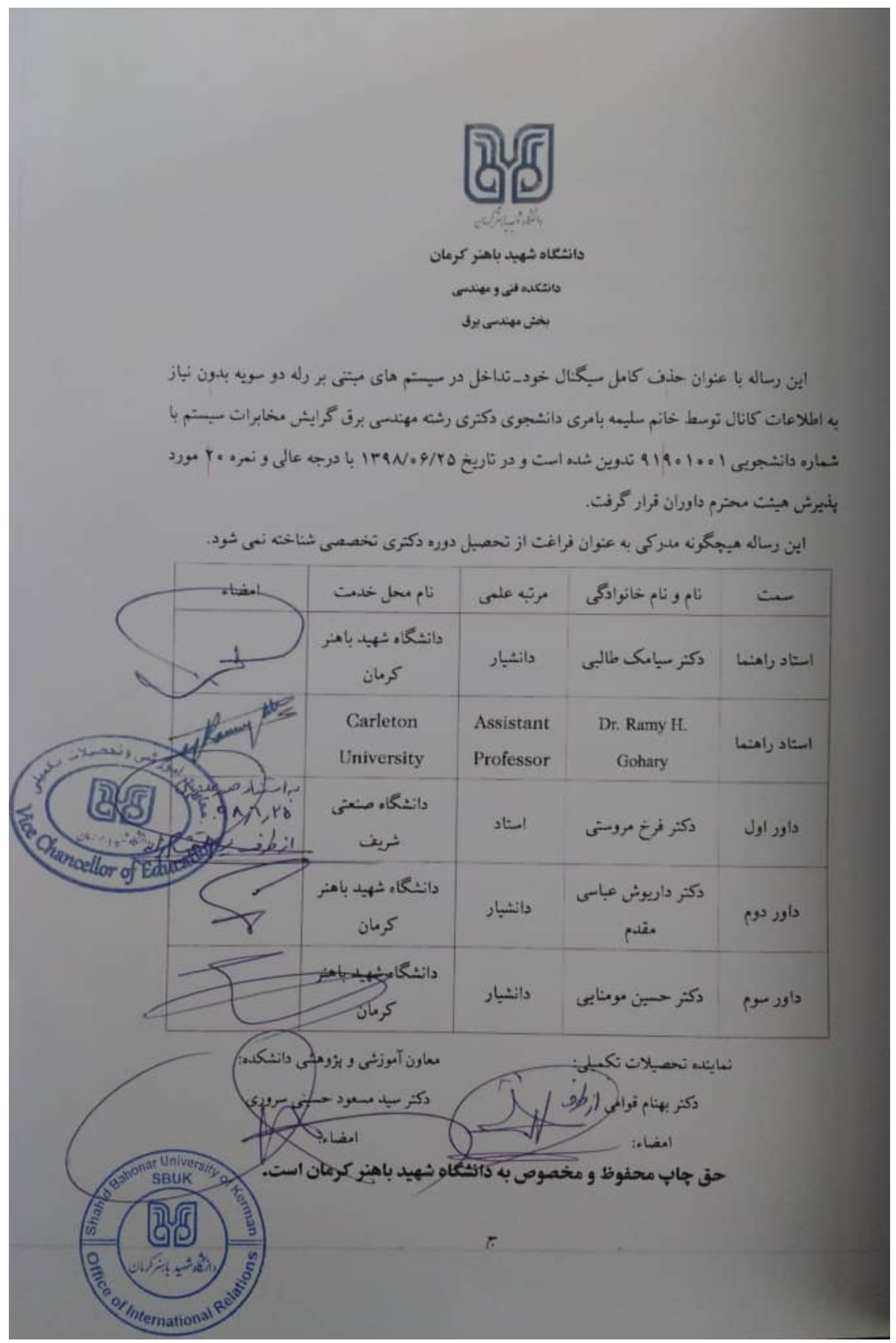




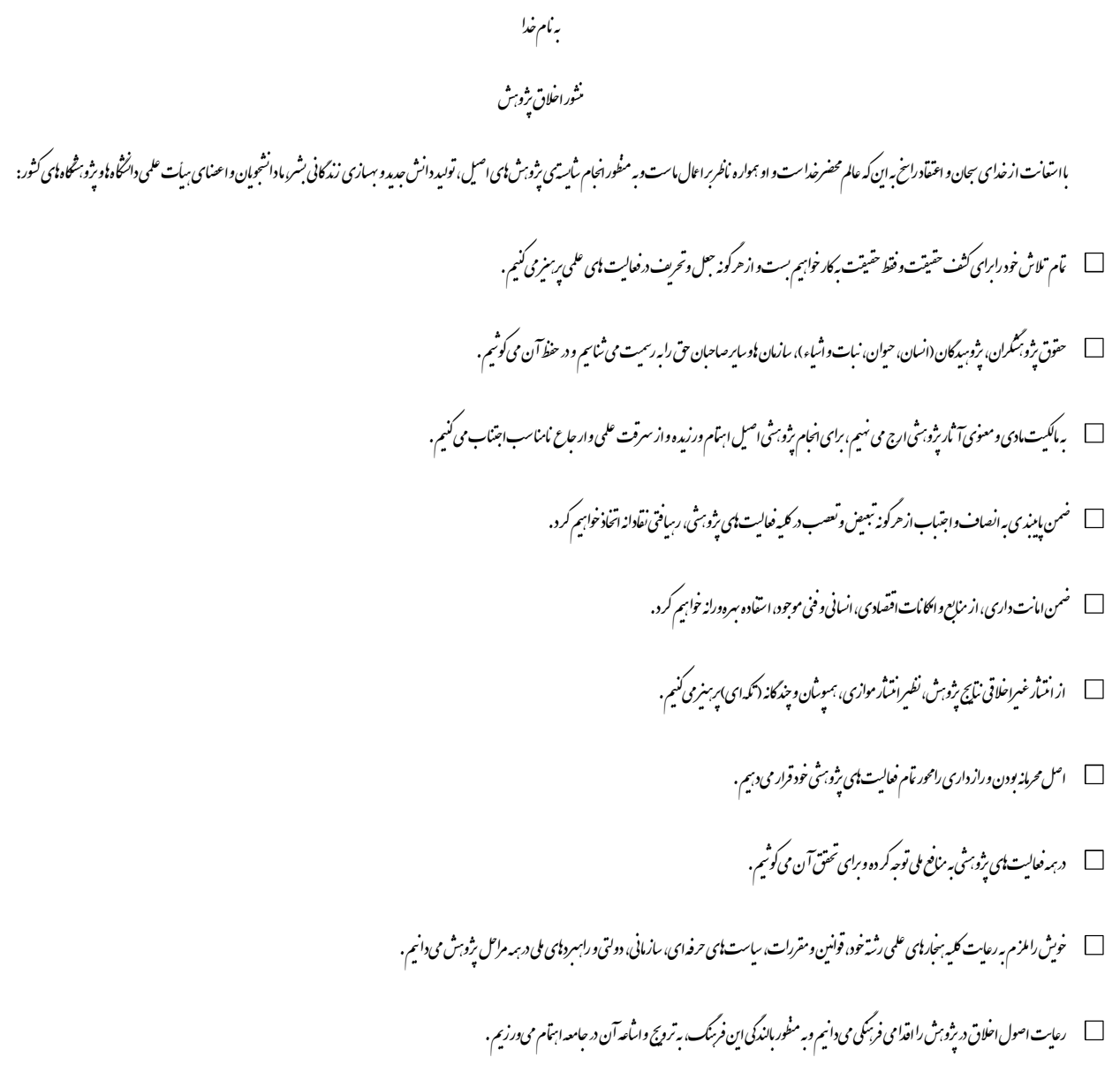




\section{(อ)

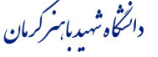

تعهدنامه

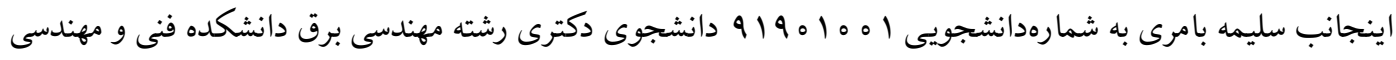

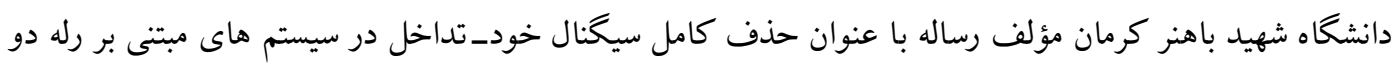
سويه بدون نياز به اطلاعات كانال تحت راهنمايى دكتر سيامك طالبى و Dr. Ramy H. Gohary تأييد مى كنم كه اين رساله نتيجه يزّوهش اينجانب مى باشد و در عين حال كه موضوع آن تكرارى نيست، در صورت استفاده از منابع

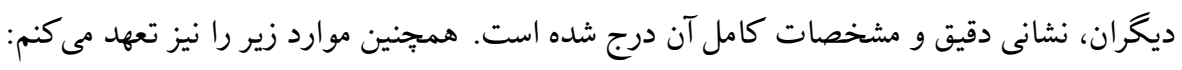

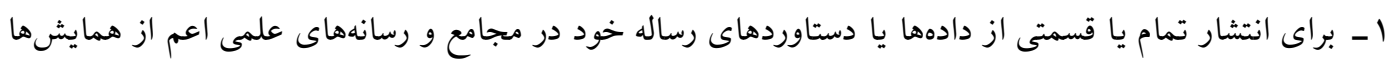

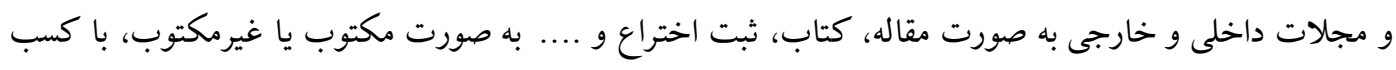
مجوز از دانشگاه شهيد باهنر كرمان و استاد(اساتيد) راهنما اقدام نمايم. ץ - ازدرج اسامى افراد خارج از كميته رساله در جمع نويسندگان مقاله هاى مستخرج از رساله، بدون مجوز استاد(اساتيد) راهنما اجتناب نمايم و اسامى افراد كميته رساله را در جمع نويسندكان مقاله درج نمايم.

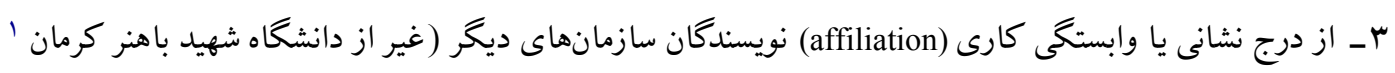
) در مقالههاى مستخرج از رساله بدون تأييد استاد(اساتيد) راهنما اجتناب نمايم. F _ كليه ضوابط و اصول اخلاقى مربوط به استفاده از موجودات زنده يا بافتهاى آنها را براى انجام رساله رعايت نمايم.

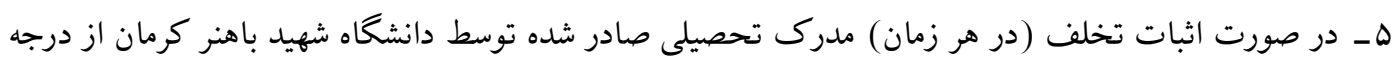
اعتبار ساقط و اينجانب هيج گونه ادعايى نخواهم داشت. كليه حقوق مادى و معنوى اين اثر (مقالات مستخرج، برنامه

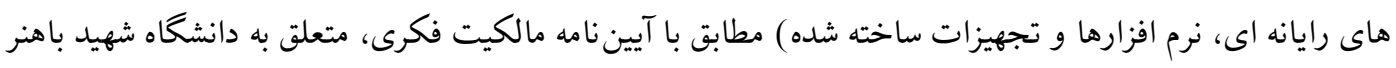

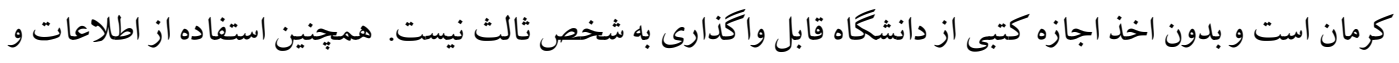
نتايج اين رساله بدون ذكر مرجع مجاز نمى باشد. جنانجه مبادرت به عملى خلاف اين تعهدنامه محرز گردد، دانشعاه

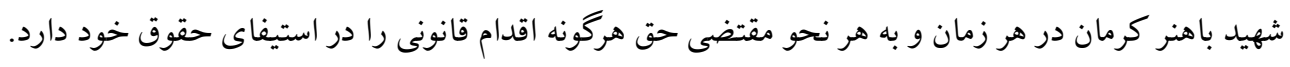
نام و نام خانوادگى دانشجو: سليمه بامرى امضا و تاريخ:

بخش مهندسى برق، دانشكده فنى و مهندسى، دانشكاه شهيد باهنر كرمان، كرمان، ايران. 
تقديم به:

$$
\begin{aligned}
& \text { به پِر، مادر و همسرم به ياس حمايت ها و تشويق هاى بى دريغ شان. } \\
& \text { به دو دختر عزيزم به ياس صبر و همراهى شان. }
\end{aligned}
$$




\section{تشكر و قدردانى:}

اكنون كه به ياري خداوند اين دوره را به يايان رسانيدهام، لازم است از اساتيد راهنماي بزركوارم

Ramy H. Gohary جناب آقاي دكتر سيامك طالبى در دانشگاه شهيد باهنر كرمان و جناب آقاى دكتر در دانشگاه Carleton به باس زحمات بي شائبه شان در طي انجام اين تحقيق سِاس گزاري نمايم. تا ابد مديون و سياس گزار يدر و مادر عزيزم هستم كه همواره حامى و مشوق من بوده اند و هر جه دارم از دعاى خير ايشان است.

با تمام وجود قدردان زحمات و حمايت هاى همسر مهربانم هستم كهمواره مشكلات مسير را براى من هموار نموده است. 
استفاده از رله در مخابرات مشاركتى برقرارى ارتباط قابل اطمينان را در نرخهاى ارسال بالا، خصوصا زمانى كه ارتباط مستقيم بين مبدا و مقصد وجود ندارد، فراهم مى سازد. شبكه هاى بى سيم مبتنى بر رله را مى توان به دو گروه شبكههاى يك سويه و دو سويه تقسيم بندى كرد. در شبكههاى يك سويه جهار فاز و شبكهاى دو سويه تنها به دو فاز براى تبادل اطلاعات بين دو مبدا نياز مى باشد. در شبكههاى دو سويه دو مبدا همزمان بيام هاى خود را به رله ها ارسال مى كنند كه اين امر سبب مى شود سيكنال دريافتى در رلهها و در نتيجه سيخنال دريافتى در هر مبدا مجموع دو سيخنال ارسالى باشد. بخشى از سيخنال دريافتى در هر مبدا كه توسط خود آن مبدا ارسال شده است سيخنال خود_تداخل ناميده مىشود كه به شدت كارايى سيستم را كاهش مىدهد. به همين دليل سيخنال خود_تداخل بايد قبل از آشكارسازى در هر مبدا حذف شود و حذف آن به در دسترس بودن اطلاعات كانال بستخى دارد. اخر اطلاعات كانال به طور كامل در دسترس باشند حذف سيخنال خود_تداخل آسان است و در غير اين صورت اين امر يك جالش محسوب مى گردد. تا كنون جندين روش براى حذف سيخنال خود_تداخل در شبكه هاى دو سويه بدون اطلاعات كانال بيشنهاد شده است. اما اين روش ها به دليل مبتنى بودن بر تخمين ضرايب محوشدگى كانال، تخمين سيگنال خود_تداخل و يا تخمين نويز قادر به حذف كامل سيكنال خود_تداخل نبوده اند. براى رفع اين مشكل ما يك روش جديد براى حذف كامل سيخنال خود_تداخل در شبكه هاى دوسويه با رله هاى تقويت و ارسال نيمه_كامل ارائه مى دهيم. در اين روش هر رله با تعداد زوجى آنتن فعال سيخنال دريافتى خود را تواما در حوزه زمان و مكان به گونه ایى بردازش مى كند كه منجر به حذف كامل سيگنال خود_تداخل مى گردد. اين روش اولين روش موجود براى حذف كامل سيخنال خود_تداخل است اما محدوديت آن داشتن تعداد زوج آنتن در هر رله مى باشد. براى رفع اين مشكل، روشى ديخر براى حذف كامل سيگنال خود_تداخل ارائه مى دهيم كه در آن هر رله تنها به يك آنتن نياز دارد و از روش تغيير-حالت ارسال استفاده مى شود. عملكرد هر دو روش مورد تحليل رياضى قرار گرفته و با هم مقايسه مى گردد. با استفاده از روش دوم كه عملكرد بهترى دارد، يك مصالحه بين نرخ ارسال و احتمال خطا براى دو كد الموتى و (Y SP( استخراج مى گردد كه نشان مى دهد در نرخ ارسال بالا استفاده از كد الموتى با دو رله احتمال خطاى كمترى دارد نسبت به كد SP(Y)

وازگًان كليدى:مخابرات مشاركتى، شبكهاى دو سويه، سيخنال خود_تداخل. 


$$
\begin{aligned}
& \text { فصل اول: } \\
& \text { 1 } 1
\end{aligned}
$$

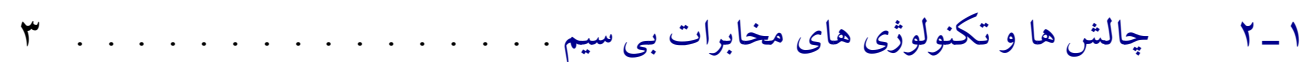

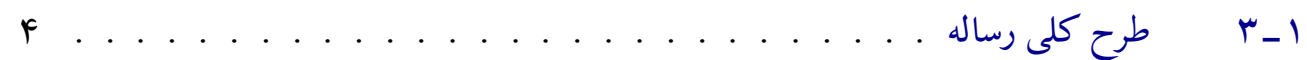

$$
\begin{aligned}
& 9
\end{aligned}
$$

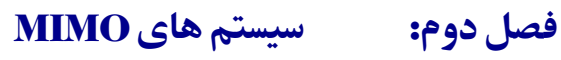

$$
\begin{aligned}
& \checkmark \ldots \ldots \ldots \ldots \ldots \ldots \ldots \ldots \text {........................... } 1-r
\end{aligned}
$$

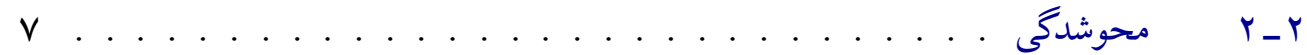

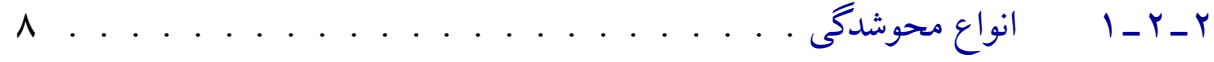

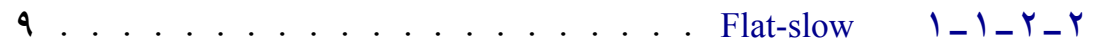

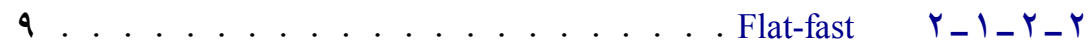

$$
\begin{aligned}
& \text { q......... Frequency selective-slow } r_{-} l_{-} r_{-} r \\
& \text { q........... Frequency selective-fast } r_{-} l_{-} r_{-} r
\end{aligned}
$$

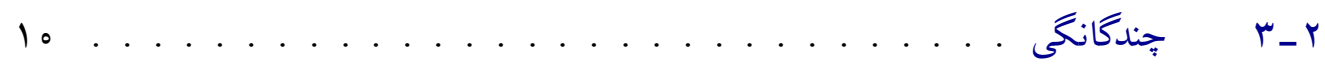

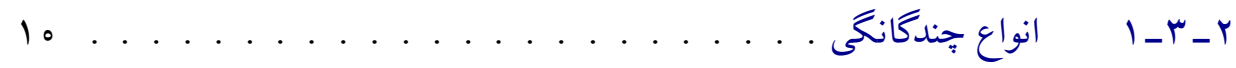

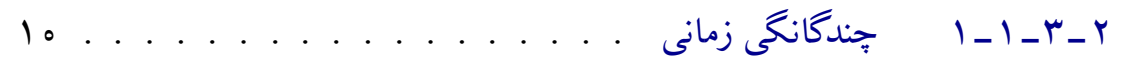

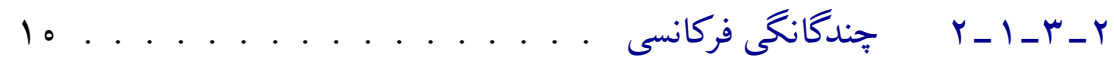

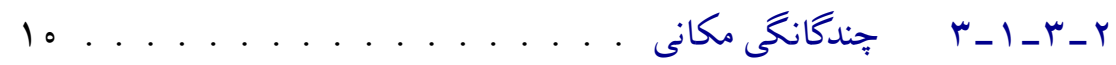

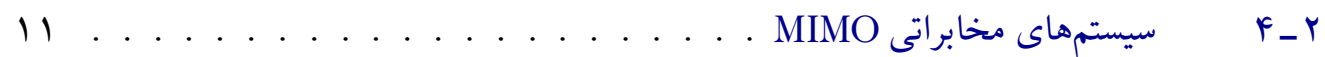

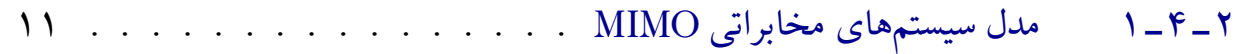

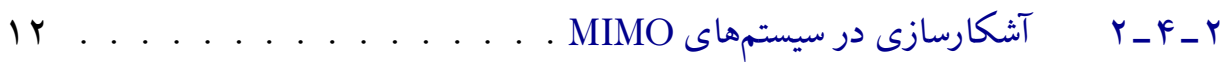

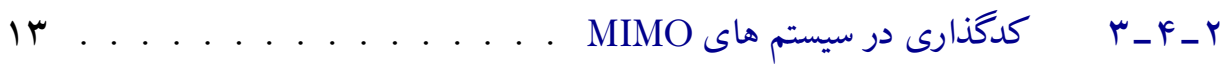

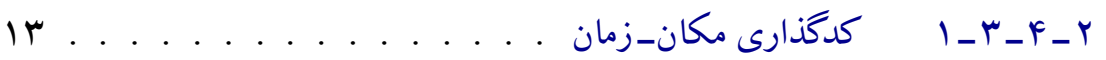




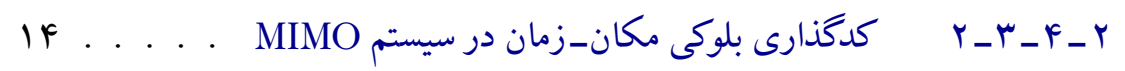

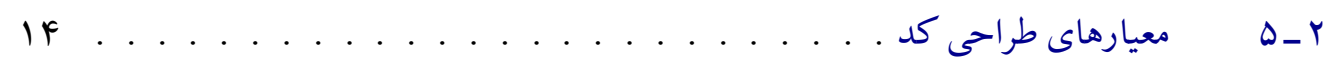

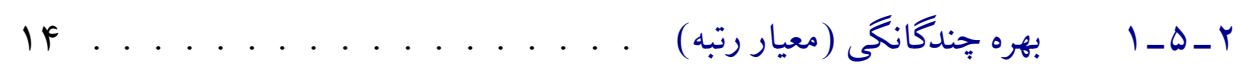

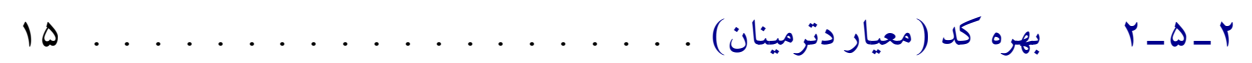

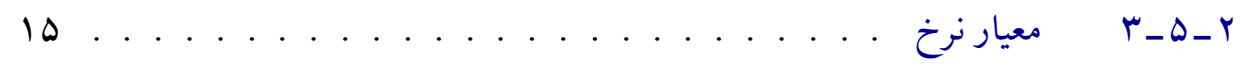

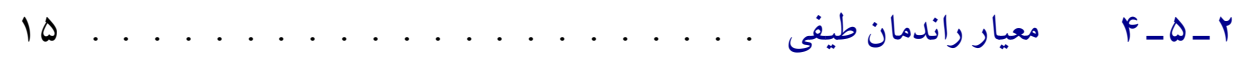

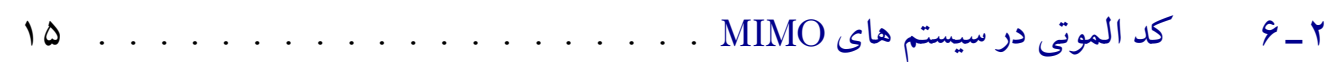

$$
\begin{aligned}
& \text { كدگذارى بلوكى مكان-زمان تفاضلى . . . . . . . . . . . . . . . . . . . . . . . . . . . . }
\end{aligned}
$$

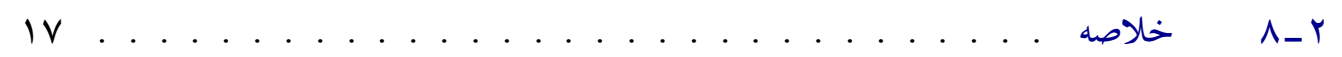

$$
\begin{aligned}
& 11
\end{aligned}
$$

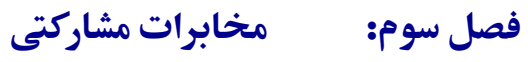

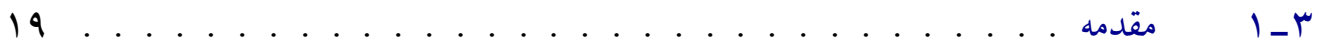

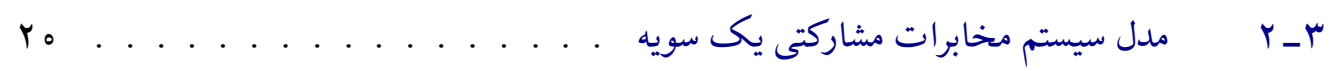

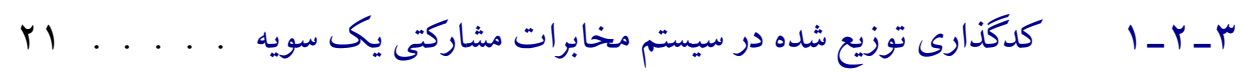

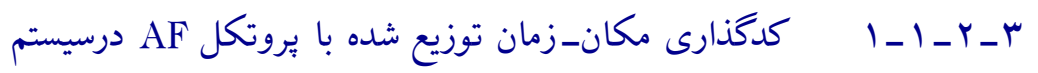

$$
\begin{aligned}
& \text { مخابرات مشاركتى يكسويه . . . . . . . . . . . . . . . . . . . . . }
\end{aligned}
$$

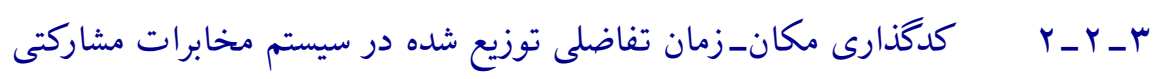

$$
\begin{aligned}
& \text { يك }
\end{aligned}
$$

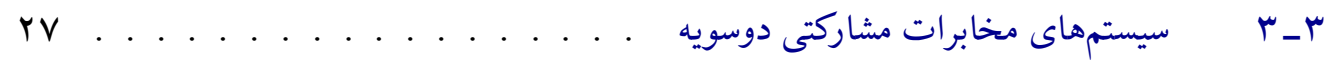

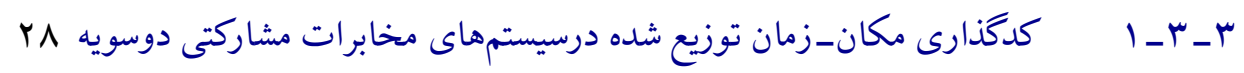

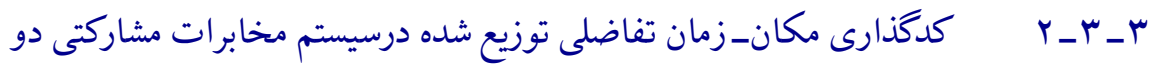

$$
\begin{aligned}
& \text { سويه . . . . . . . . . . . . . . . . . . . . . . . . . . . . . . . . . . . . . }
\end{aligned}
$$

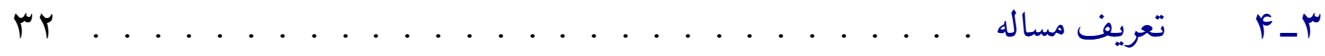

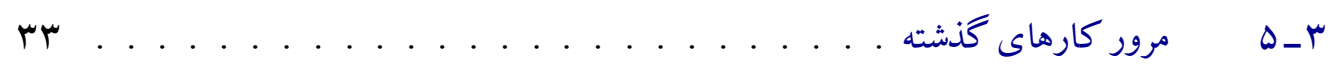

$$
\begin{aligned}
& \text { r }
\end{aligned}
$$

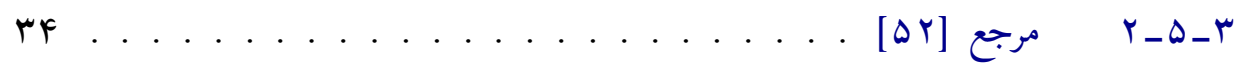




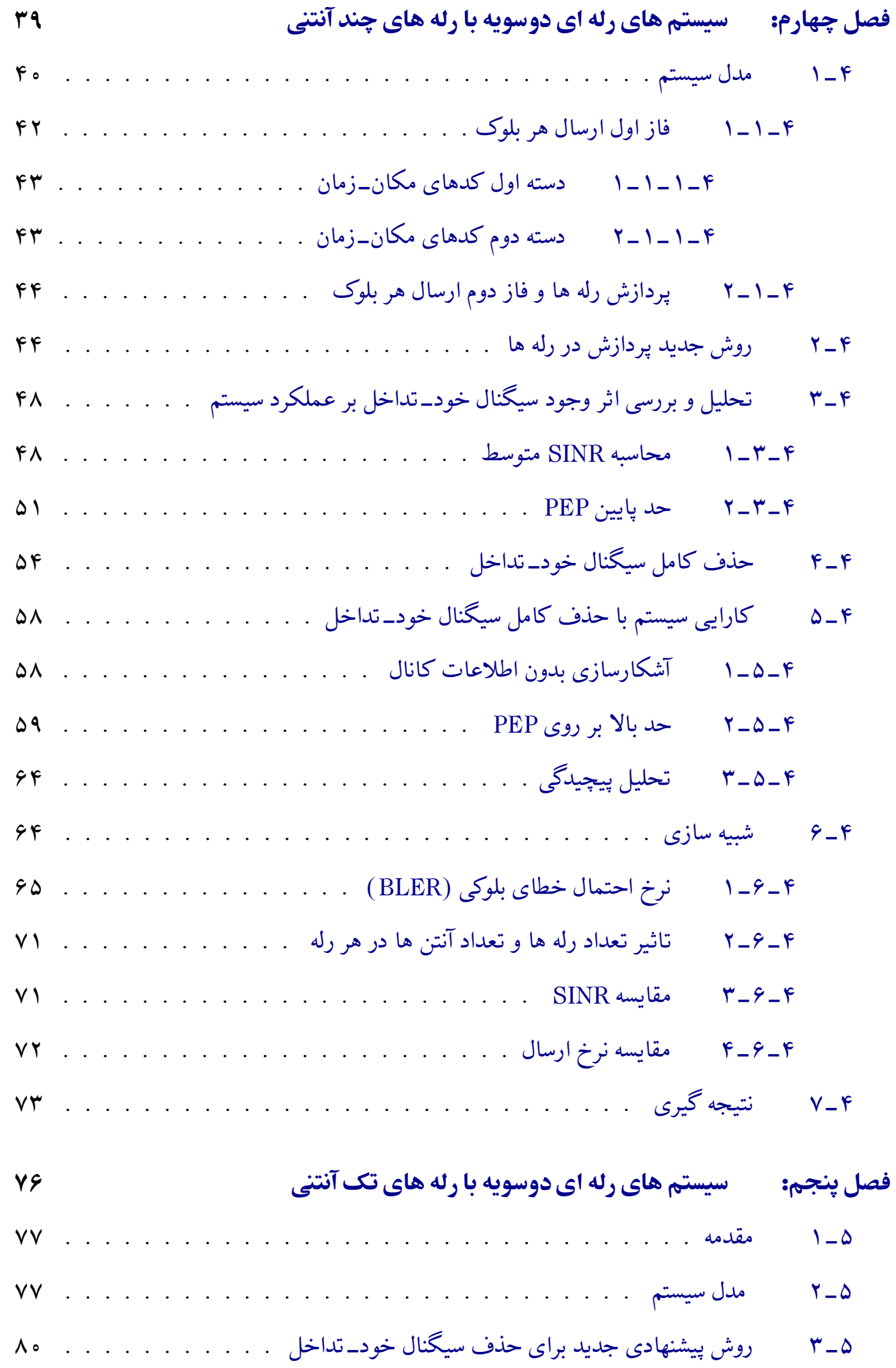




$$
\begin{aligned}
& \text { ه }
\end{aligned}
$$

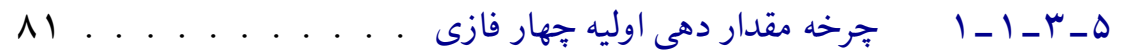

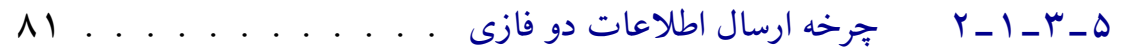

$$
\begin{aligned}
& \text { ه }
\end{aligned}
$$

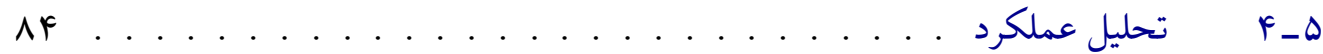

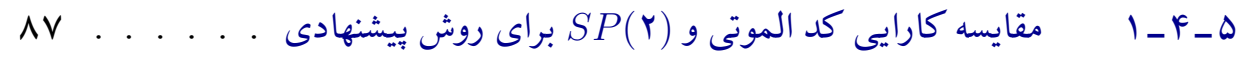

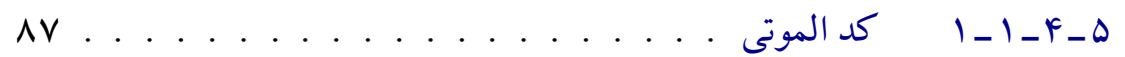

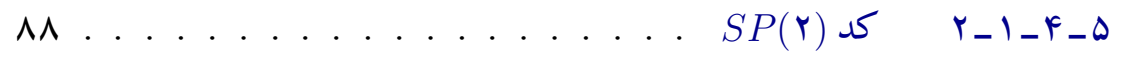

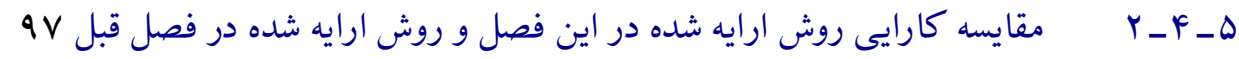

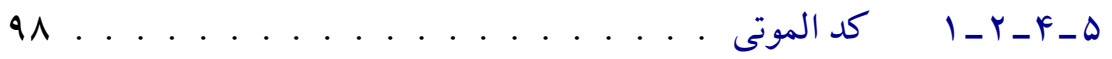

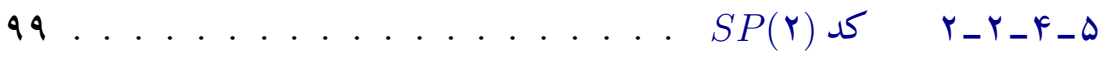

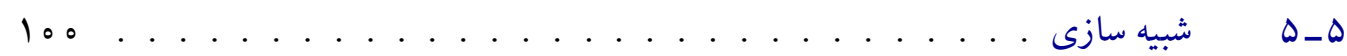

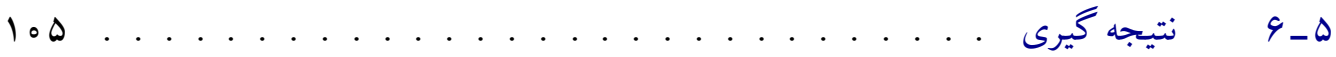

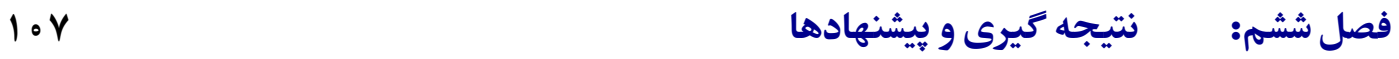

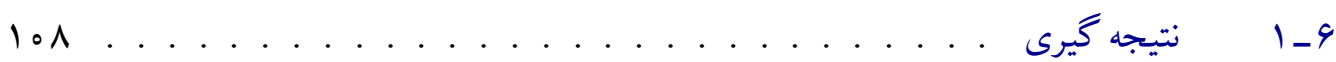

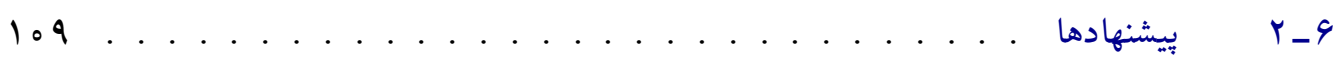




\section{فهرست جداول}

V 


\section{فهرست اشكال}

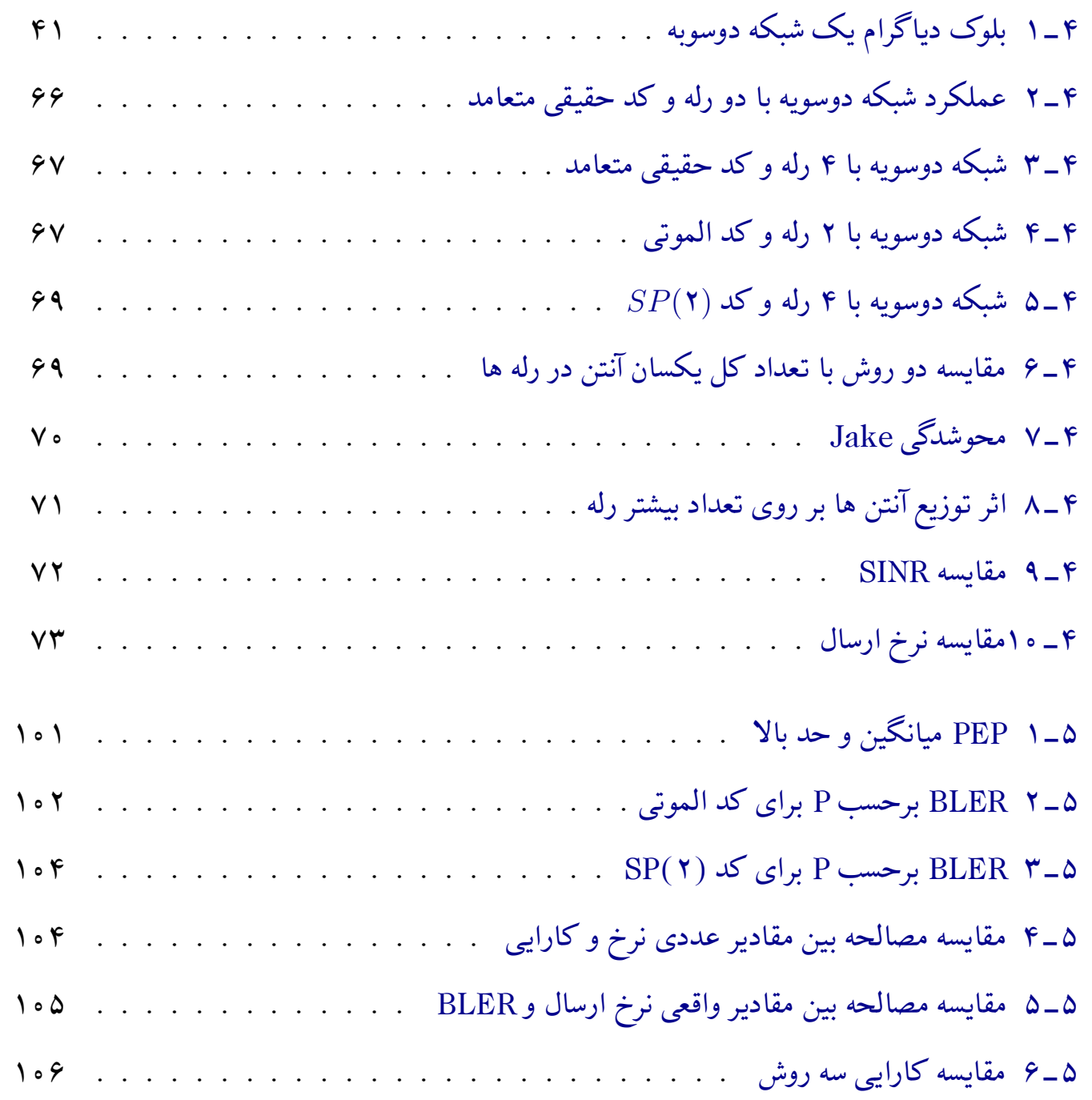




$$
\text { مقلمهل و كليات تحقيق اول: }
$$




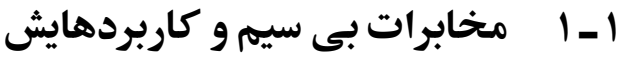

مخابرات بى سيم به يك جزء جدايى نايذير از فعاليتهاى بشر در كل جهان تبديل شده است. گستره وسيعى از تكنولوزى ها، سرويس ها و كاربردها توسط مخابرات بى سيم براى رفع نيازهاى بشر توسعه داده

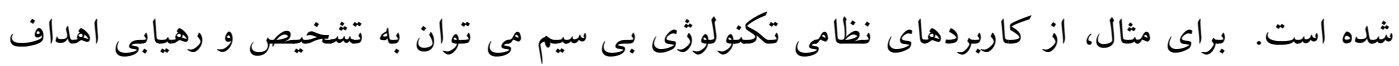
دشمن، تشخيص حمله هاى شيميايى و بيولوزيكى و كنترل وسايل نقليه ى رباتيك بدون سرنشين اشاره كرد.

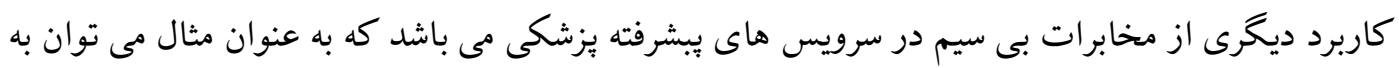

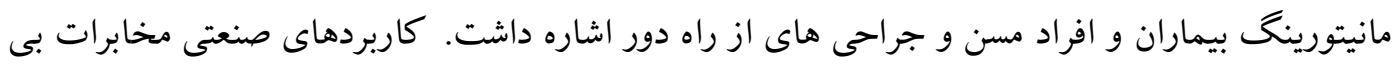
سيم شامل مانيتورينگ مراحل بيشرفت يك فرايند و اتوماسيون مى باشد.

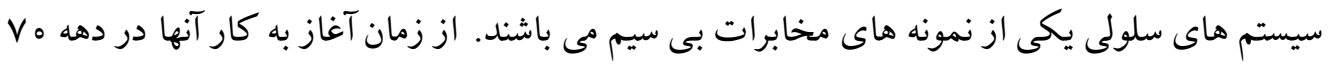

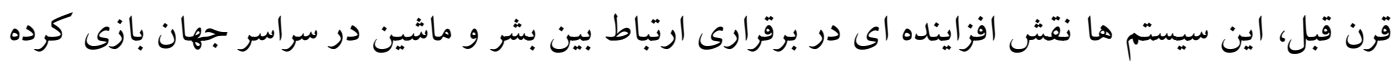

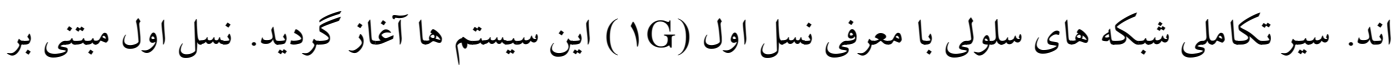
ارسال آنالوگ و تنها قادر به ارسال سيخنال هاى صدا بوده است. پس از آن نسل دوم (YG) ) مبتى بر ارسال ديجتال بوده و با استاندارد Global System for Mobile (GSM) به صورت تجارى مورد استفاده

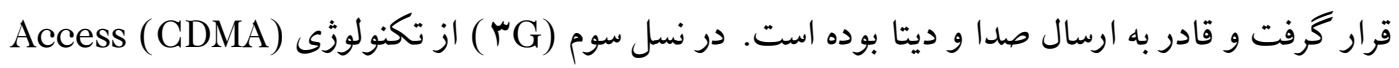
Code -Division Multiple از نسل جهارم (FG) شبكه هاى سلولى استفاده مى شود كه تكنولوزى (LTE) Term Evolution ( را فراهم كرده و علاوه بر ارسال صدا، ديتا و ويديو امكان دسترسى به اينترنت بهن باند را نيز فراهم كرده است. نسل آينده شبكه هاى سلولى نسل بنجم (هG) است كه هدف آن دسترسى بدون قطعى به اطلاعات در

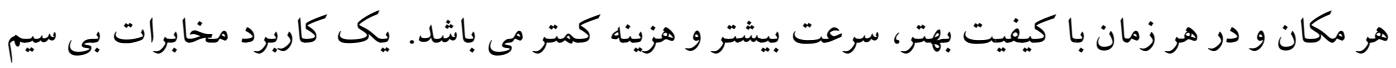
اينترنت اشيا است كه عضو جدايى نايذير از نسل بنجم شبكه هاى سلولى مى باشد. اينترنت اشيا به بيليون ها وسيله اطلاق مى شود كه از طريق اينترنت به هم متصل هستند و امكان مانيتور و كنترل كردن آنها از راه

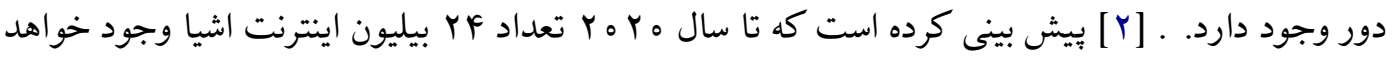
داشت كه به معنى تقريبا F وسيله براى هر فرد در جهان مى باشد [1 ] [ ل 


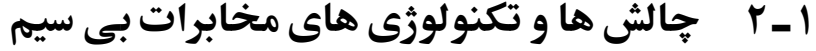

در حند دهه اخير، مخابرات بى سيم به دليل مزاياى زيادى كه نتيجه ع عدم نياز به واسط فيزيكى براى انتقال بيام بين مبدا و مقصد مى باشند مورد توجه قرار خرفته است. بنابراين مخابرات بى سيم مى تواند ارتباط را در مناطقى كه امكان ارتباط باسيم وجود ندارد را برقرار كند.

على رغم مزاياى مخابرات بى سيم، جنبه ها و جالش هاى مختلفى بايد در مورد اين سيستم ها در نظر كرفته شود از جمله مى توان به تاخير در بردازش و انتشار سيكنال، قابليت اطمينان آشكارسازى، بِبجِيدگى و

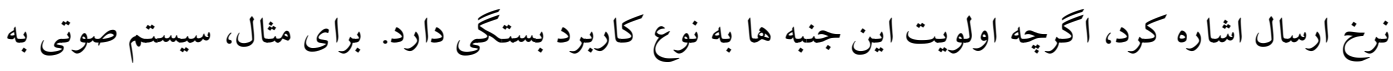

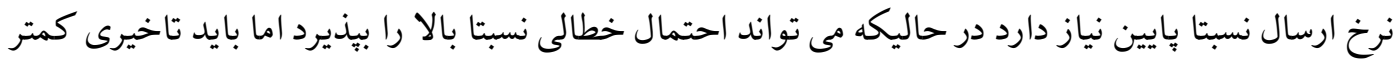
از ms o ما داشته باشد تا توسط گوش تشخيص داده نشود [Yo]. در مقايسه، سيستم ارسال ديتا به نرخ ارسال بالاو احتمال خطالى بايين نياز دارد در حاليكه نسبت به تاخير زياد حساس نمى باشد. يكى ديخر از

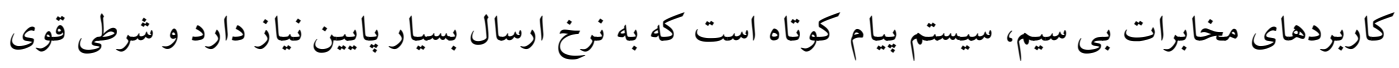

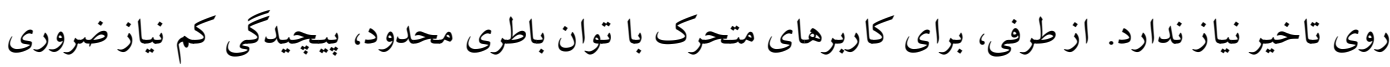

براى حفظ يكى ارتباط به موقع، مطمئن در هر مكان، نسل بنجم به تكنولوزى هاى بى سيم قوى متكى

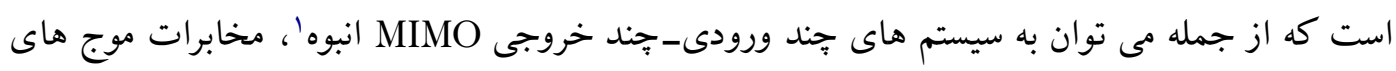



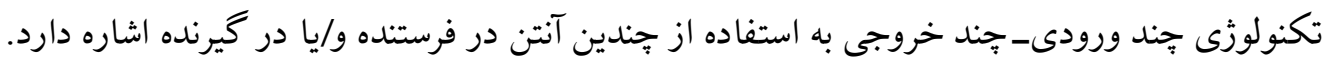
اين سيستم ها به دلايلى همجون بهبود قابل توجه در قابليت اطمينان و راندمان طيفى سيستم هاى بى سيم مورد توجه بسيار قرار گرفته اند [Y ] . به همين دليل تكنكلوزى MIMO به يك جز جدايى نإيذير در بسيارى از

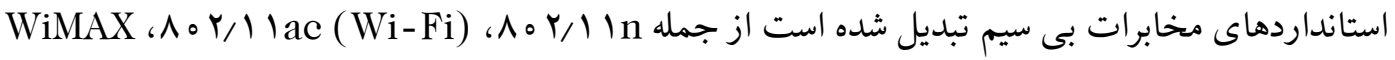
و Long Term Evolution (LTE) . سيستم جند ورودى-جند خروجى انبوه از مزاياى افزايش زياد تعداد آنتن ها در فرستنده و/يا گيرنده بهره مى برد. بطوريكه با اتصال صدها آنتن به ايستكاه بايه، نرخ ارسال

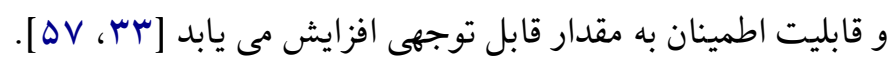

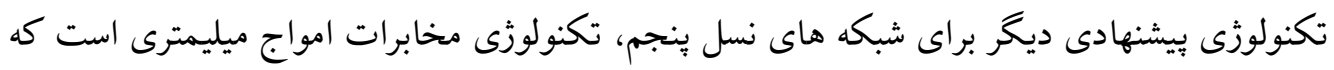

ultra-dense $^{r} \quad$ Millimeter wave $^{r} \quad$ Massive multiple-input multiple-output (MIMO)' Cooperative communications ${ }^{\uparrow}$ 


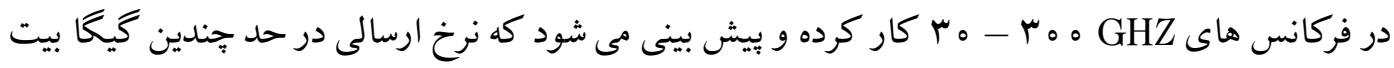

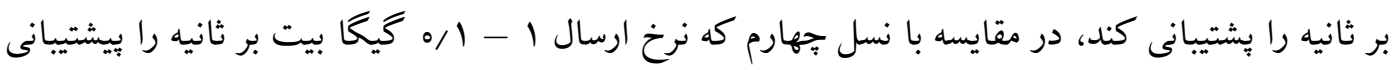
مى كند. اخرجه استفاده از امواج ميليمترى جالش هاى جديدى از جمله كاهش رنج ارسال به حدود ه 10 متر به دليل تضعيف زياد اين امواج در انتشار در فضاى آزاد، را مطرح مى كند. اين نقطه ضعف توسط

تكنولوزى هايى مانند شبكه هاى فوق حجيم و مخابرات مشاركتى قابل برطرف شدن است [سب، وب]. در شبكه هاى فوق حجيم، تعداد بسيار زيادى سلول هاى كوجّى مورد استفاده قرار مى گيرنده تا بر محدوديت رنج امواج ميليمترى غلبه كنند. سلول هاى بسيار كوجگ كه با نام فمتو و ييكو شناخته مى شوند باعث افزايش نرخ استفاده مجدد از فركانس ها را در رنج هاى كوجّى مانند 100 - 10 متر مى شوند. جذب هوايى امواج ميليمترى، تضعيف سيخنال را افزايش مى دهد. اين امر اخرجه در نگاه اول يك عيب محسوب مى شود اما با تضعيف زيادتر سيخنال هاى تداخلى ناشى از ايستگاه هاى دور باعث ايزوله شدن هر

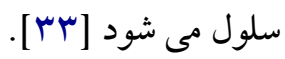
در مخابرات مشاركتى، تعدادى از گرهه ها به عنوان رله به ساير گره ها براى ارسال اطلاعاتشان كمك مى كنند. مخابرات مشاركتى با يردازش سيخنال ها بين فرستدنه و گيرنده، رنج ارسال را افزايش مى دهد. به عنوان مثال در باند فركانسى Y^ GHZ كه يك كانديد براى نسل ينجم مى باشد، سيخنال هاى بى سيم به احتمال بيشترى بر روى خط مستقيم منتشر شده و با احتمال كمى موانع را دور زده و از آنها عبور مى كنند. بنابراين براى تحويل يكيارجه سيگنال، استفاده از شبكه هاى مبتنى بر رله در نسل بنجم مخابرات بى سيم

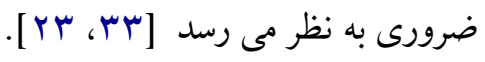

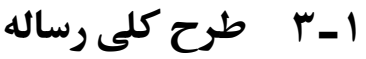

ما به طور خلاصه المان هاى سيستم هاى جندورودى_جندخروجى و مخابرات مشاركتى در شبكه هاى مبتنى بر رله مرور مى كنيم. در فصل r اصول پايه مخابرات جندورودى-جندخروجى را مطرح كرده و در فصل ץ به مرور اصول بايه مخابرات مشاركتى و شبكه هاى مبتنى بر رله مى بردازيم. علاوه برآن در فصل "، جإلش حذف سيگنال خود_تداخل در سبكه هاى مبتنى بر رله اى كه دسترسى به اطلاعات كانال ندارند را مطرح مى كنيم. درفصل F، يك روش براى حذف كامل و دقيق سيخنال خود_تداخل در شبكه هاى دوسويه بدون اطلاعات كانال كه داراى رله هاى جند آنتى مى باشند ارائه داده و آن را تحليل مى كنيم. تا آنجا كه مى دانيم اين روش، اولين ركش براى حذف كامل و دقيق سبخنال خود تداخل مى باشد اخرجه 
داراى محدوديت داشتن جندين آنان در هر رله مى باشد. براى غلبه بر محدوديت داشتن جندين رله به معنى سخت افزار و هزينه بيشتر است، در فصل ه روش جديدى براى حذف سيخنال خود_تداخل ارائه مى دهيم

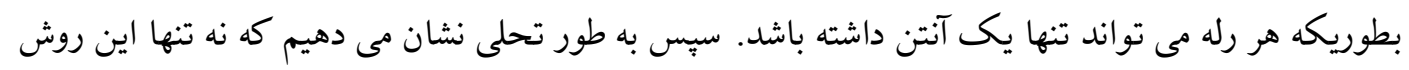

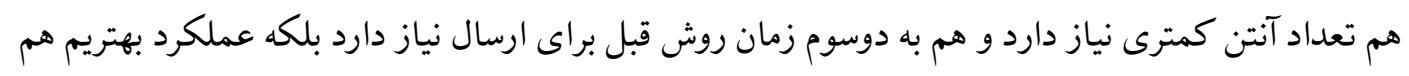

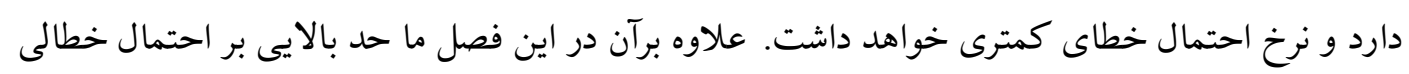

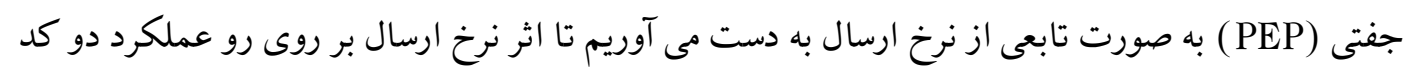

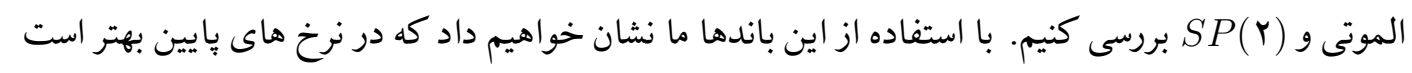

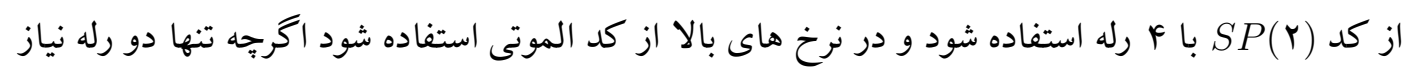
دارد. در فصل 9 ما به ارائه يك خلاصه از كار خود و بيشنهادهايى براى كارهاى آينده مى بردازيم. 
فصل دوم:

سيستم هاى MIMO 
ميزان استفاده از وسايل ارتباطى بىسيم روزبهروز در حال افزايش است. عدم نياز به سيمكى، نصب

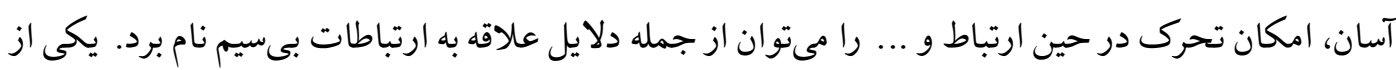

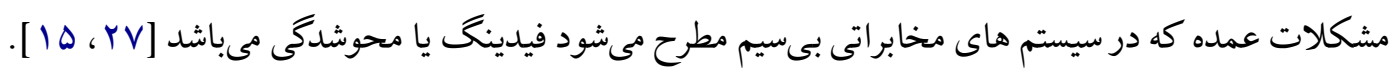

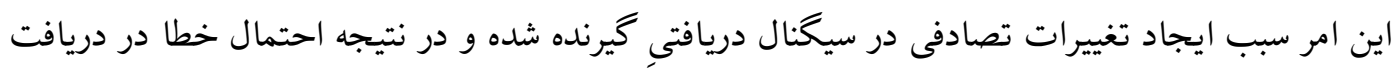

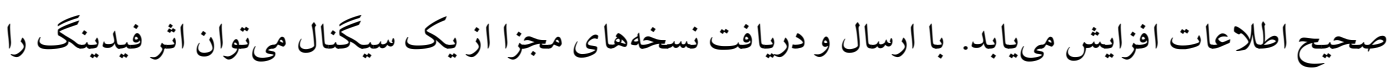

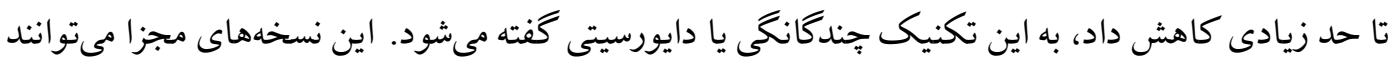
در زمانهاى متفاوت، مكانهاى متفاوت و يا فركانسهاى متفاوت توليد و ارسال شوند. يكى از روشهاى

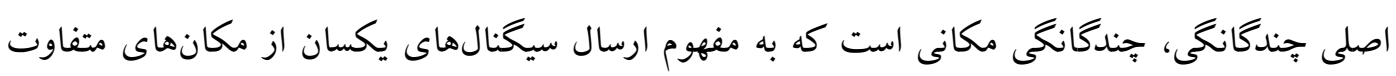

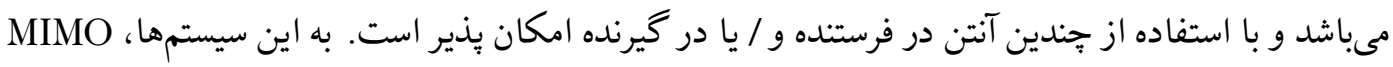

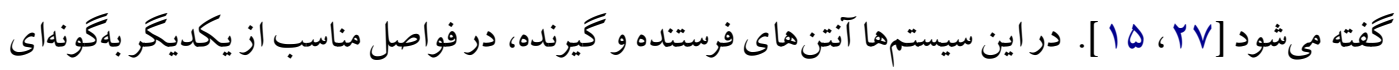

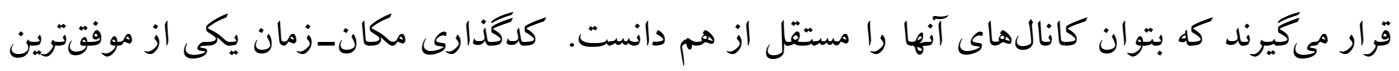

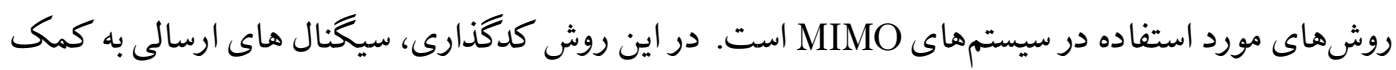
دو يا جند آنتن ارسالى(مكان) و در زمانهاى مختلف (زمان) ارسال مى شوند.

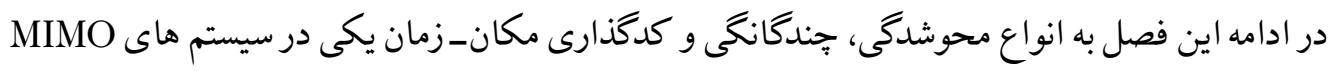
مى بردازيم.

\section{r-r}

سيخنالهاى عبورى از محيط در مخابرات بىسيم تحت تاثير عوامل متعددى خراب مىشود. يكى از

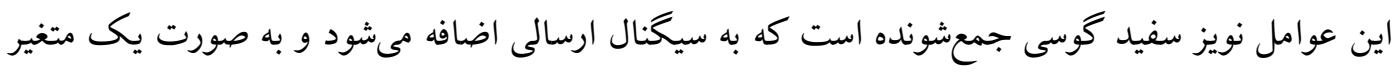
تصادفى با توزيع گوسى و ميانخين صفر مدل مى گردد. عامل مخرب ديخر مسيرهاى متعددى است كه سيخنال

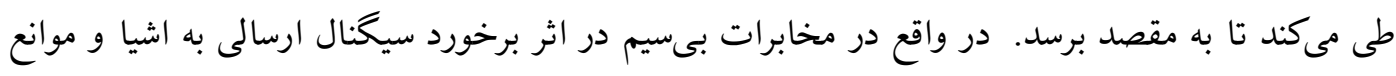

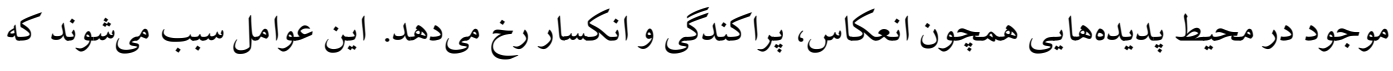

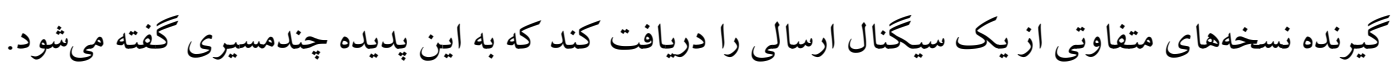

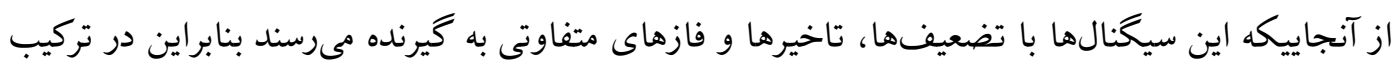


خطى آنها، امكان كاهش توان سيكنال دريافتى وجود دارد. به اين كاهش توان، فيدينخ يا محوشدىى

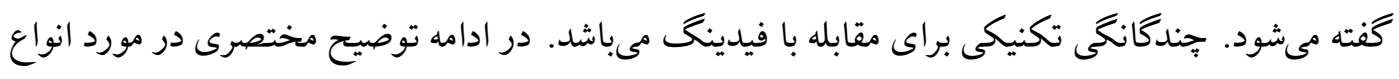

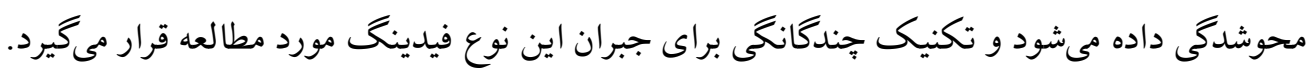

\section{(1-r-r انواع محوشدىى}

همان طور كه كفتيم در كانالهاى محو شونده جندين نسخه از سيخنال ارسالى با تاخيرهاى متفاوت

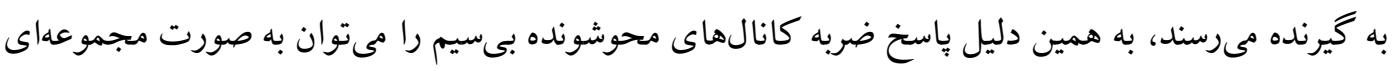
از توابع ضربه مدل كرد. محوشدگى بر مبناى دو عامل مستقل گستره زمانى تاخيرهاى خجندمسيرى و بديديده

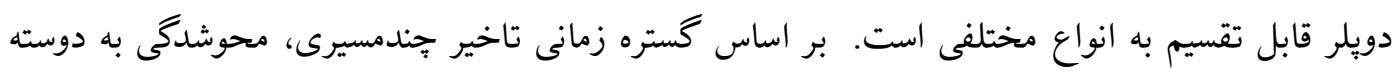

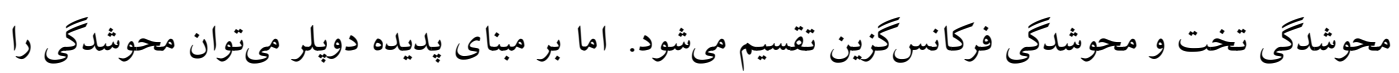

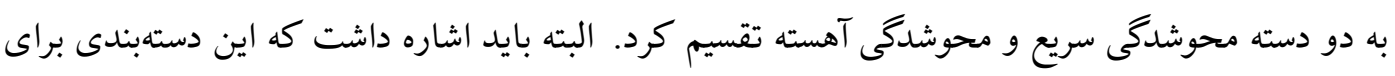

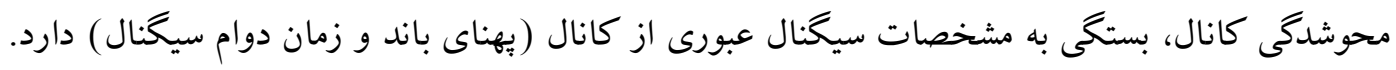

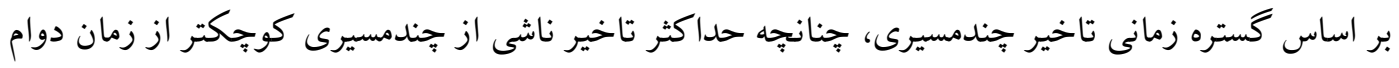

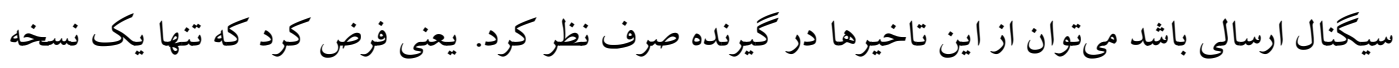

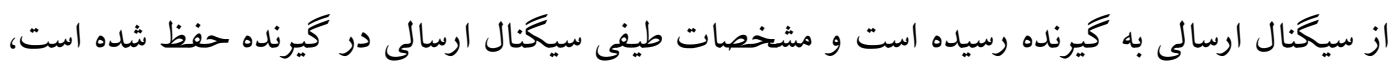
در اين صورت ياسخ ضربه كانال تنها يك ضربه خواهد بود. در اين شرايط از ديد حوزه فركانس، كانال

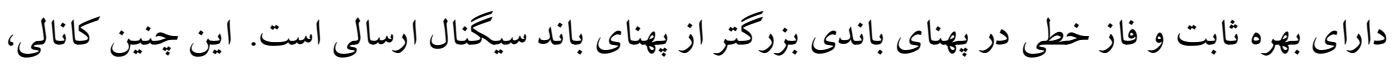

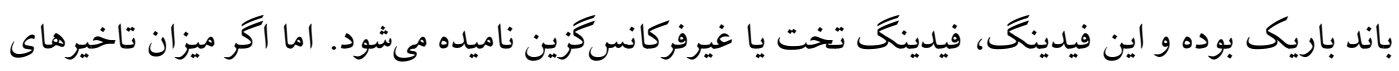

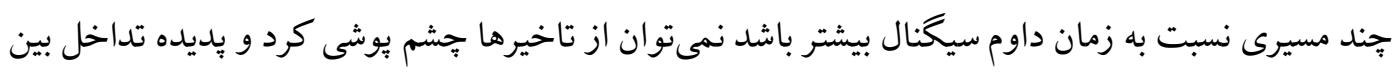

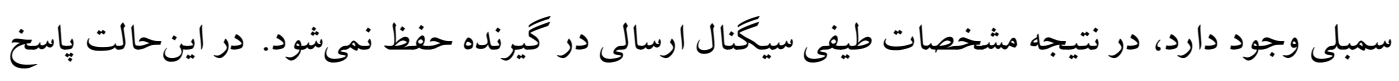
ضربه كانال با جندين ضربه تخمين زده مىشود كه اين ضربهها داراى دامنه و تاخيرهاى متفاوت و مستقل هستند. در اين شرايط از ديد حوزه فركانس، كانال داراى بهرهى ثابت در بهناى باندى كوجيكتر از بهناى

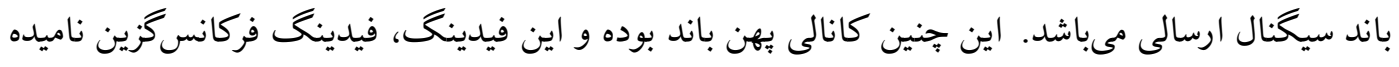

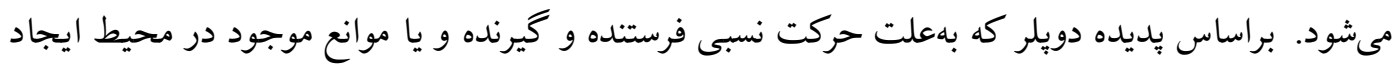

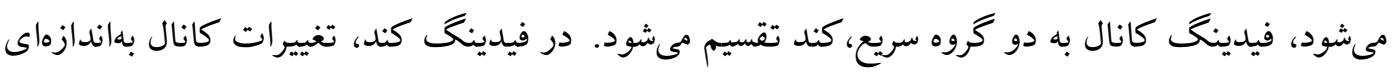

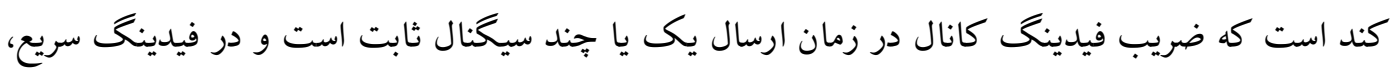


كانال در زمان ارسال يك سيخنال هم تغيير مىكند. بر اساس اين دو بِيدهى مستقل، كانالهاى محوشونده را مىتوان به جهار گروه تقسيم كرد:

Flat-slow $1-1-r-r$

بهناى باند سيخنال كوخجكت از بهناى باند همبستخى كانال و زمان دوام سمبل كوخكتر از زمان همبستى

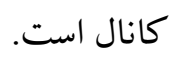

\section{Flat-fast $r-1-r-r$}

بهناى باند سيخنال كوخكتر از بهناى باند همبستخى كانال و زمان دوام سمبل كوخكتر از زمان همبستى

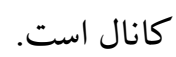

Frequency selective-slow $r-1-r-r$

بهناى باند سيخنال بزرگتر از بهناى باند همبستخى كانال و زمان دوام سمبل كوجكتر از زمان همبستى

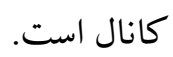

\section{Frequency selective-fast $r-1-r-r$}

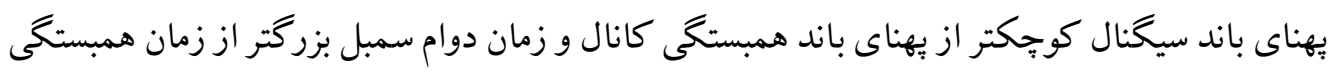

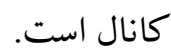

در اينجا بايد متذكر شد كه منظور از بهناى باند همبستى كانال، فاصله فركانسى بين دو سيخنال است

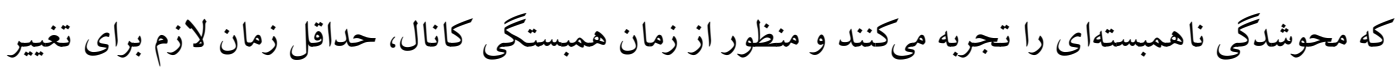

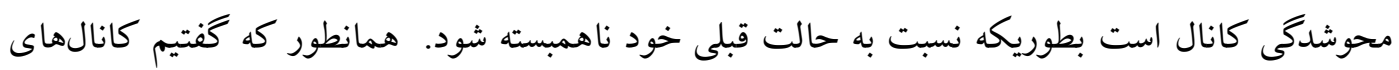
محوشونده با باسخ ضربه متغير با زمان مدل مىشوند، كه اين پاسخ ضربه شامل يك يا جندين تابع ضربه

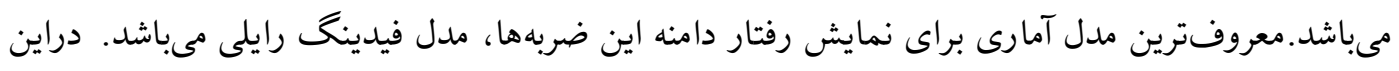

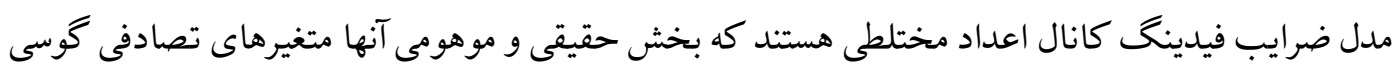

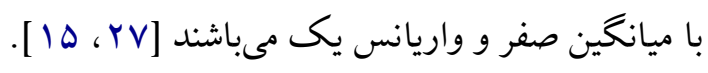




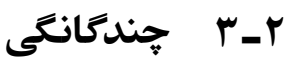

در سيستماى مخابراتى بىسيم، فيدينگ سبب مىشود كدگشايى سيگنال دريافتى دجار خطا شود و

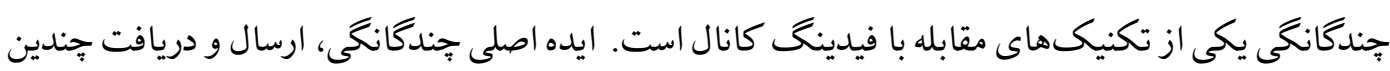
نسخه از يك سيخنال است بهكونهاى كه اين نسخها فيدينخهاى متفاوتى را تجربه مىكنند. در اين حالت احتمال آنكه تمام نسخهها فيدينگ شديدى تحمل كنند كم شده و درنتيجه احتمال آشكارسازى صحيح افزايش مىيابد. تكنيكهاى جندانانحى براساس اينكه در حوزه مكان، زمان يا فركانس بهكار گرفته شوند، دستهبندى مىشوند كه در ادامه به معرفى آنها مىيردازيم.

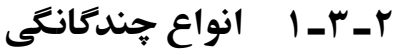

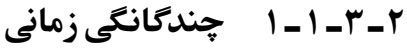

جندكانگى زمانى با ارسال يك سيكنال در بازههاى زمانى مختلف حاصل مىشود. فاصله بين اين بازههاى زمانى بايد به اندازهاى انتخاب شود كه فيدينگ كانال در اين بازهها ناهمبسته باشد. براى اين منظور فاصله اين بازههاى زمانى بايد از زمان همبستخى كانال بيشتر باشد.

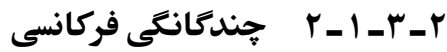

در جندكانگى فركانسى از تعدادى فركانس مختلف براى ارسال يك سيكنال استفاده مىشود. فاصله بين اين فركانسها بةكونهاى انتخاب مىشود كه سيخنالهاى ارسالى، فيدينخهاى ناهمبستهاى را در حوزه فركانس تجربه كنند. براى اين منظور، فاصله بين فركانسهاى مختلف بايد از بهناى باند همبستخى كانال بيشتر باشد.

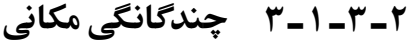

جندكانگى مكانى كه در اغلب سيستمهاى مخابرات بىسيم مورد استفاده قرار مىگيرد، از طريق تعبيه جندين آنتن در فرستنده يا گيرنده و يا هر دو بياده سازى مىشود. فاصله بين آنتنها بايد حداقل برابر با نصف طول موج سيخنال انتخاب شود كه سيخنالها با فيدينخهاى ناهمبسته به گيرنده برسند. گيرندهاى

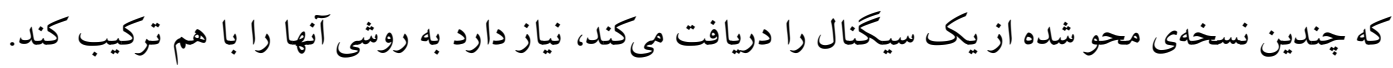

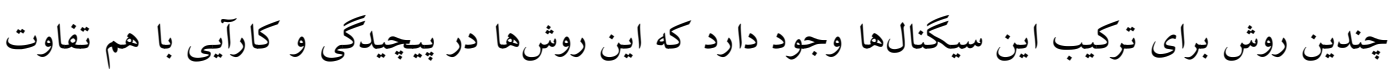


دارند. از مهمترين روشهاى تركيب سيخنال در گيرنده مىتوان به روشMRC اشاره كرد. اطلاعات بيشتر در اين مورد در مرجع [Y] قابل دسترس است.

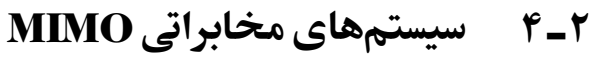

در اواسط دهه م999 1 ، استفاده از سيستمهاى جُند ورودى- جند خروجى يا MIMO بيشنهاد داده شد. ايده استفاده از جند آنتن در فرستنده و گيرنده بود. كانالهاى متفاوت موجود بين هر جفت آنتن فرستنده و كيرنده به دو صورت قابل استفاده هستند. روش اول، استفاده از اين كانالها براى ارسال سيخنالهاى يكسان با هدف رسيدن به بهره جندگانگى بالا و كاهش نرخ خطاى بيت در گيرنده مىباشد كه به تكنيكهاى كدگذارى معروف هستند. روش دوم، استفاده از اين كانالها براى ارسال سيخنالهاى متفاوت مىباشد كه هultiplexing و و افزايش نرخ ارسال دا ده مىباشد كه به تكنيكهاى رسيدن بهره

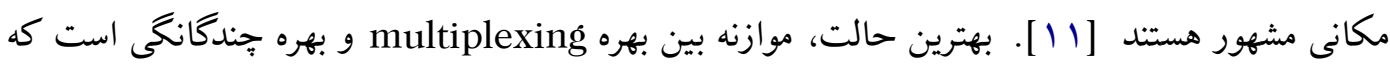
مىتوان هم به نرخ بالاى ارسال و هم به BER كم دست يافت. جهت اطلاعات بيشتر در اين مورد مىتوان به مرجع [11] مراجعه كرد.

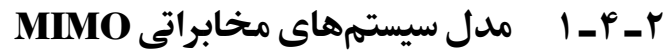

فرض كنيد فرستندهاى با N ضريب فيدينخ كانال بين آنتن i فرستنده و آنتن ز گيرنده با ${ }^{\prime}$ ب نمايش داده شود كه اندازه آن متغير تصادفى رايلى است. در فرستنده ابتدا بيتهاى ورودى با توجه به نوع تينش به سمبلهاى متناظر نگاشته مىشوند.

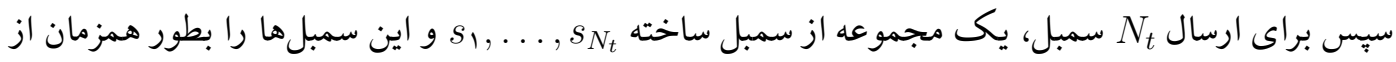

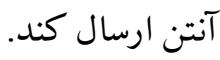

هر آنتن گيرنده، سمبل هاى ارسالى از همه آنتنهاى فرستنده را دريافت مىكند كه البته تحت تاثير فيدينگ كانال و نويز گوسى جمعشونده قرار گرفتهاند. اكر نشاندهنده نويز در آنتن گيرنده باشد، سيخنال دريافتى در آنتن عبارتست از [rV [ [ [

$$
y_{j}=\sum_{i=1}^{N_{t}} h_{i j} s_{i}+n_{j}
$$




$$
\begin{aligned}
& \text { كه } n_{j} \text { نويز در ز امين آنتن است. رابطه بالا را مىتوان به فرم ماتريسى زير نمايش داد: } \\
& {\left[\begin{array}{c}
y_{1} \\
y_{r} \\
\vdots \\
y_{N_{r}}
\end{array}\right]=\left[\begin{array}{cccc}
h_{11} & h_{\uparrow \uparrow} & \ldots & h_{\uparrow N_{t}} \\
h_{\Upsilon 1} & h_{\Upsilon r} & \ldots & h_{\uparrow N_{t}} \\
\vdots & \vdots & \vdots & \vdots \\
h_{N_{r}} & h_{N_{r}} & \ldots & h_{N_{r} N_{t}}
\end{array}\right]\left[\begin{array}{c}
s_{\uparrow} \\
s_{r} \\
\vdots \\
s_{N_{t}}
\end{array}\right]+\left[\begin{array}{c}
n_{\uparrow} \\
n_{r} \\
\vdots \\
n_{N_{r}}
\end{array}\right]} \\
& \boldsymbol{y}=\boldsymbol{H} \boldsymbol{s}+\boldsymbol{n}
\end{aligned}
$$

كه فيدينگ كانال است كه با عنوان information CSI : شناخته مىشود.

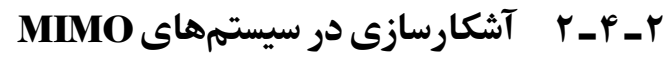

آشكارسازى در گيرنده به يكى از دو روش همدوس و يا ناهمدوس انجام مىشود [YV]. در آشكارسازى

همدوس گيرنده به CSI نياز دارد ، بنابراين گيرنده ابتدا ضرايب فيدينگ كانال را تخمين مىزند و سيس از آنها براى كدگثايي سيخنال دريافتى استفاده مىكند. براى اينكه امكان تخمين كانال براى گيرنده فراهم شود، در يكى از روشهاى شناخته شده فرستنده بايد سيخنالهاى مشخصى (يايلوت) را ارسال كند و گيرنده با اطلاع از اين بايلوتها به تخمين كانال بيردازد. تخمين كانال باعث افزايش بيجيدگى گيرنده ، كاهش نرخ ارسالى ، اتلاف زمان و بهناى باند مىشود. براى رفع اين مشكلات كه در بعضى سيستمها موجب غير عملى بودن تخمين كانال مىشود، آشكارسازى ناهمدوس مطرح شده است. در آشكارسازى ناهمدوس گيرنده بدون نياز به CSI به كدگشايبِ سيگنال دريافتى ميردازد. يكى از بركاربردترين آشكارسازها، آشكارساز بيشترين شباهت (ML) مىباشد كه در هر دو روش همدوس و ناهمدوس استفاده مىشود.

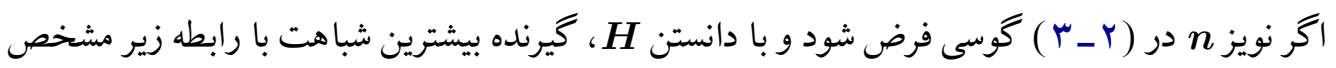

$$
\hat{\boldsymbol{s}}=\arg \min _{\boldsymbol{s}}\|\boldsymbol{y}-\boldsymbol{H} \boldsymbol{s}\|^{r} . \quad \quad(\boldsymbol{r}-r)
$$




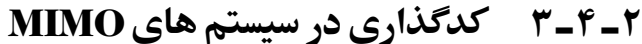

ساختار سيخنال ارسالى در يك سيست MIMO تاثير زيادى بر عملكرد سيستم دارد علاوه بر اين،

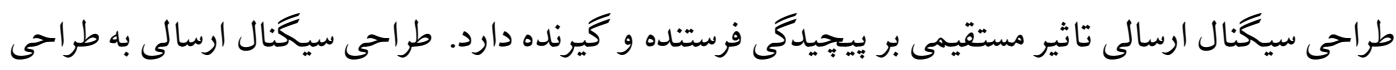
كد و يا كدكذارى معروف است و تحقيقات زيادى براى بهدست آوردن كدهاى مناسبِ سيستمهاى MIMO

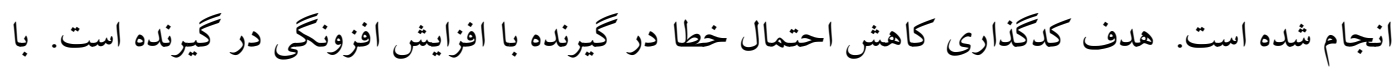
توجه به مشخصات كانال در سيستمهاى MIMO مىتوان روشهاى كدگذارى را به سه دسته تقسيم كرد.


تخت مناسب مىباشند. دسته دوم و سوم روشهاى كدكذارى مكان_فركانس و مكان_زمان-فركانس هستند

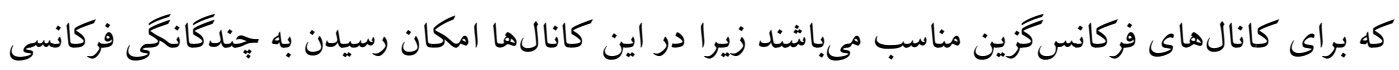
وجود دارد در حاليكه كدهاى مكان-زمان توانايى رسيدن به جندكانگحى فركانسى را ندارند.

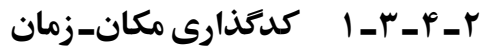

كدگذارى مكان-زمان تكنيكى است كه نسخهاى مختلفى از دنباله اطلاعات را بهصورت سمبلهاى

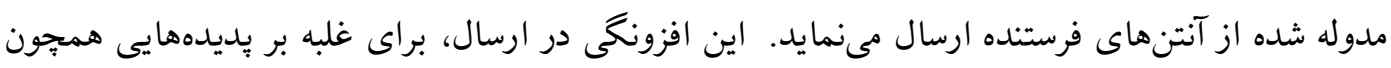

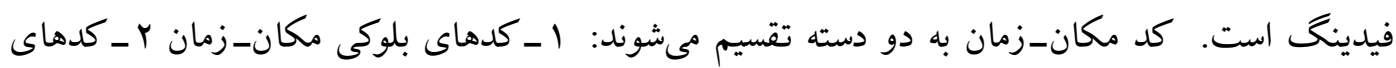

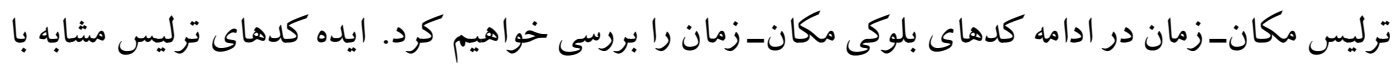
كدهاى كانولوشنال است و به طور دقيقتر مشابه مدولاسيون كدشدهى ترليس مىباشد. تفاوت اصلى كدهاى

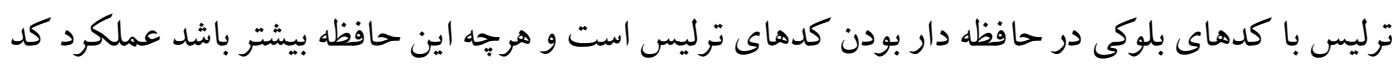

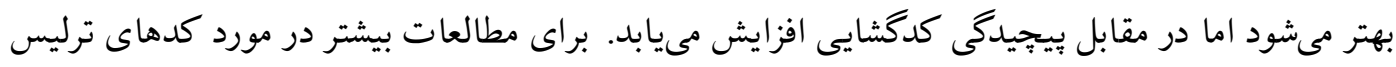

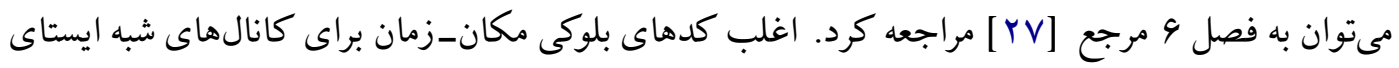
رايلى طراحى شدهاند (كه كانال در طى ارسال يك بلوك از اطلاعات به طول ثابت است) . در كدهاى بلوكى

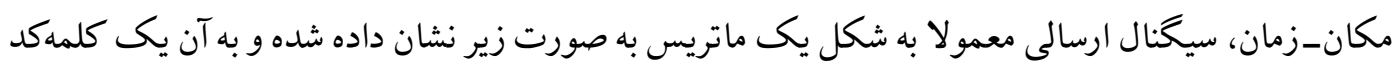

$$
\boldsymbol{S}=\left[\begin{array}{cccc}
s_{11} & s_{1 r} & \ldots & s_{\uparrow M_{t}} \\
\vdots & \vdots & \ldots & \vdots \\
s_{T}, & s_{T r} & \ldots & s_{T M_{t}}
\end{array}\right] \quad \text { (ه-r) }
$$


سطرهاى ماتريس كد بيانخر شماره بازه زمانى و ستونهاى آن بيانغر شماره آنتن فرستنده است. به عبارت ديخر s

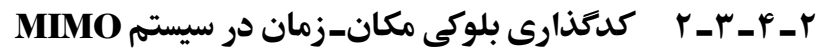

رابطه بين كد بلوكى مكان-زمان ارسالى و سيخنال دريافتى در باند بايه براى يك سيستم MIMO با

كانال شبه ايستاى رايلى كه داراى N

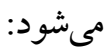

$$
\boldsymbol{Y}=\boldsymbol{S H}+\boldsymbol{N},
$$

كه در آن ماتريس ضرايب فيدينگ كانال مىباشند. $\boldsymbol{H} \in \mathbb{C}^{N_{t} \times N_{r}}$ كه همهى درايههاى آن متغيرهاى كوسى مختلط مستقل از هم با ميانخين صفر مىباشند.

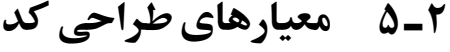

در ادامه معيارهايى را معرفى مى كنيم، كه با كمك آنها مىتوان كدها را با هم مقايسه كرد و عملكرد آنها را مورد بررسى قرار داد.

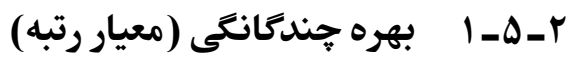

بهره جندكانكى

$$
G_{d}=-\lim _{p \rightarrow \infty} \frac{\log P_{e}(p)}{\log p}, \quad(\mathrm{~V}-\mathrm{r})
$$

كه (p) احتمال خطا و p توان است. همان طور كه قبلا اشاره كرديم بهره جندكانگى برابر است با تعداد

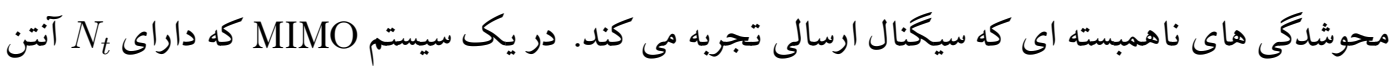
فرستنده و N آنتن گيرنده مىباشد، حداكثر حندكانكى اى كه يك كد مكان-زمان در كانال شبه ايستا

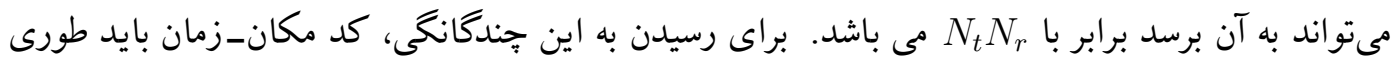
طراحى شود كه ماتريس تفاضل دو كد يعنى 


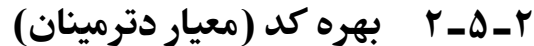

براى رسيدن به بهره كد ماكزيمم بايد دترمينان

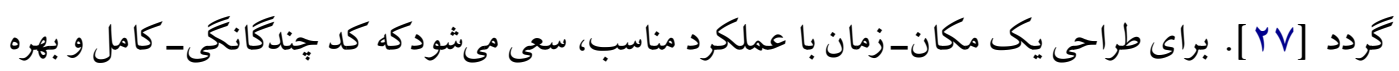

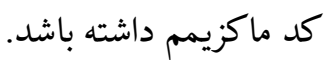

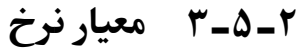

معيار ديخر در مورد كدهاى مكان_زمان، نرخ (ريت) كد مىباشد (R) كه نسبت تعداد سمبلهاى ارسالى (L) به تعداد بازههاى زمانى (T) مىباشد كه فرستنده براى ارسال استفاده كرده است:

$$
\begin{aligned}
& R=\frac{L}{T} . \\
& \text { معيار كارآيى طيفى يك كد مكان_زمان عبارتست از: } \\
& \zeta=\frac{R}{B} \mathrm{bit} / \mathrm{sec} / \mathrm{Hz},
\end{aligned}
$$

\section{MIMO ك- كد الموتى در سيستم هاى}

در سال 1991 يك كد بلوكى مكان_زمان توسط الموتى براى دو آنتن فرستده ارائه كرديد، ماتريس

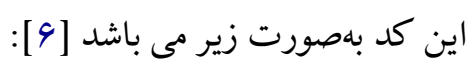

$$
\left[\begin{array}{cc}
s_{1} & s_{r} \\
-s_{r}^{*} & s_{i}^{*}
\end{array}\right] .
$$

يكى از خصوصيات جالب اين كد، گيرنده ML بسيار سادهى آن مى باشد كه منجر به استفاده عملى از

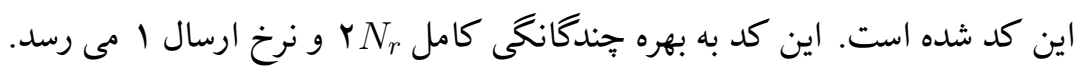

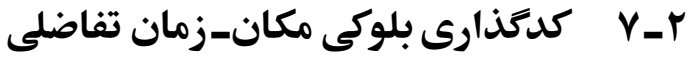

در برخى شرايط، تخمين ضرايب فيدينگ كانال براى گيرنده برهزينه و بيجيده است در اينكونه موارد

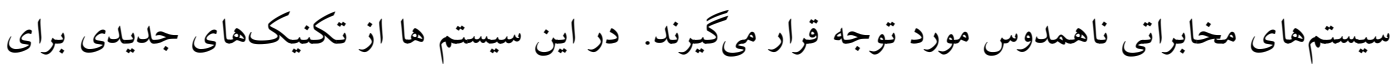


كدگذارى به نام كدگذارى تفاضلى استفاده مىشود، بطوريكه گيرنده براى آشكارسازى نيازى به اطلاعات

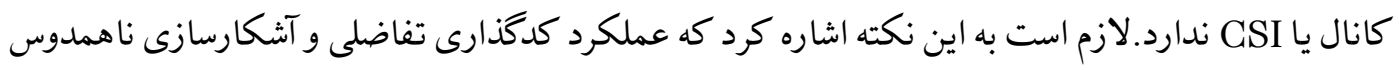

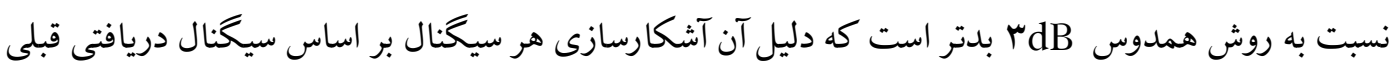
است كه با نويز و فيدينگ خراب شده است. در اداهه يكى از روشهاى كدكذارى تفاضلى و آشكارسازى ناهمدوس را براى سيستمهاى MIMO

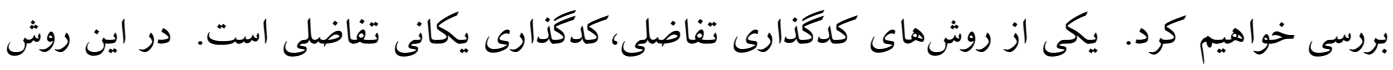

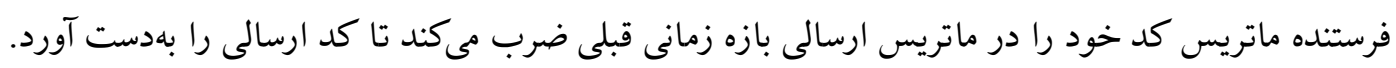
معادله تفاضلى سيخنال ارسالى

$$
\boldsymbol{S}^{(t)}=\boldsymbol{U}^{(t)} \boldsymbol{S}^{(t-1)}, \quad \boldsymbol{S}^{(\bullet)}=\boldsymbol{I}_{M_{t}},
$$

ماتريس يكانى

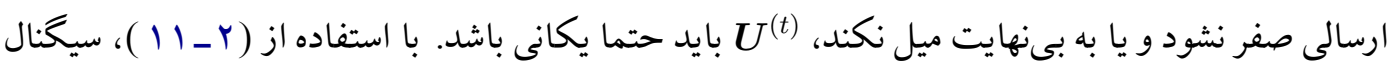
دريافتى برابر است با

$$
\boldsymbol{Y}^{(t)}=\boldsymbol{S}^{(t)} \boldsymbol{H}^{(t)}+\boldsymbol{N}^{(t)}
$$

كه و ماتريس نويز در بازه زمانى t باشند. اخر كانال در طول بهورت زير در مى آيد:

$$
\begin{aligned}
\boldsymbol{Y}^{(t)} & =\boldsymbol{U}^{(t)} \boldsymbol{S}^{(t-1)} \boldsymbol{H}^{(t-1)}+\boldsymbol{N}^{(t)}, \\
& =\boldsymbol{U}^{(t)}\left(\boldsymbol{Y}^{(t-1)}-\boldsymbol{N}^{(t-1)}\right)+\boldsymbol{N}^{(t)}, \\
& =\boldsymbol{U}^{(t)} \boldsymbol{Y}^{(t-1)}+\boldsymbol{W}^{(t)},
\end{aligned}
$$

$$
\text { كه نويز معادل }
$$

$$
\boldsymbol{W}^{(t)}=\boldsymbol{N}^{(t)}-\boldsymbol{U}^{(t)} \boldsymbol{N}^{(t-1)}
$$


از آنجاييكه

$$
\begin{aligned}
& \text { بود. بنابراين آشكارساز بيشترين شباهت به صورت زير قابل استفاده است } \\
& \hat{\boldsymbol{U}}^{(t)}=\min _{\boldsymbol{U}}\left\|\boldsymbol{Y}^{(t)}-\boldsymbol{U} \boldsymbol{Y}^{(t-1)}\right\|^{r} .
\end{aligned}
$$

تا كنون، ما به صورت خلاصه سيستم هاى MIMO و يككد مكان-زمان معروف را كه در اين سيستم

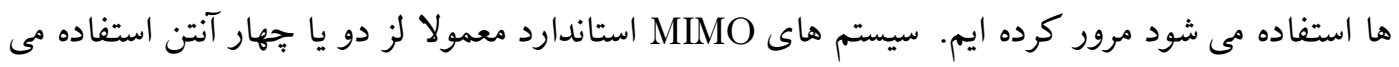
كنند، درحاليكه سيستم Massive MIMO يك سيستم MIMO است كه در آن از تعداد بسيار زيادى آنتن استفاده مى شود. Massive MIMO كه مى تواند كه ارتباط با خندين كاربر را به طور همزمان و با نرخ ارسال بالا و كارايى ثابت حفظ كند يك بخش جدايى نابذير در شبكه هاى هG بيش رو مى باشد [ [بr، هV]. تعدادى از زمينه هاى تحقيق در Massive MIMO جه در صنعت و پهه در دانشگاه عبارتند از تحليل كارآيى

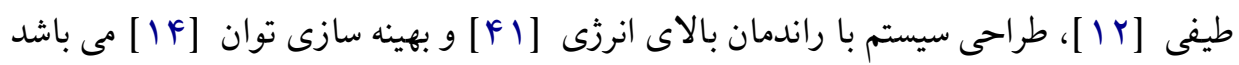

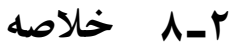

در اين بخش به طور خلاصه مفاهيم محوشدگى و خندكانگحى را مرور كرده و انواع آن ها را معرفى كرديم.

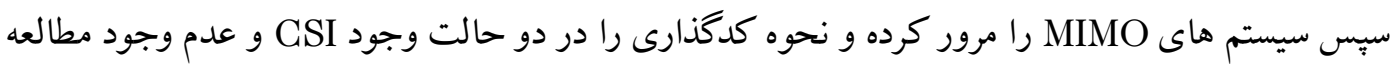
كرديم. در فصل بعد به مخابرات مشاركتى و مفاهيم مربوطه مى بردازيم. 


$$
\begin{aligned}
& \text { فصل سوم: } \\
& \text { مخابر ات مشاركتى }
\end{aligned}
$$


سيستمهاى بىسيمى كه در فصل قبل معرفى شدند، سيستمهاى مخابراتى نقطه_بهـ_نقطه ناميده مىشوند كه تنها دو كاربر دارند، يك فرستنده (مبدا) و يك گيرنده (مقصد). افزايش تقاضا براى خدمات مخابراتى بىسيم، باعث رشد قابل توجه شبكههاى بىسيم شده است. شبكههاى بىسيم شامل تعداد زيادى كاربر يا كره هستند كه از كانالهاى بىسيم استفاده مىكنند. ماهيت بِخشى كانال بىسيم موجب مىشود تا اطلاعات ارسالى توسط يك گره، براى گرههاي ديخر نيز قابل دريافت باشد. در ديد اول اين خصوصيت ممكن است به نظر دردسرساز باشد، اما مىتوان از اين خاصيت در جهت رفع مشكلات سيستمهاى مخابراتى نقطه به نقطه استفاده كرد به اين ترتيب كه گرهها (كاربرها) مىتوانند براى ارسال اطلاعات به مقصد به طور مشاركتى به يكديخر كمك مىكنند. اين سيستمها، سيستمهاى مخابرات مشاركتى ناميده مىشوند. در اين مخابرات سعى مىشود با بهرهيرى از ساير گرهها، كه به عنوان رله شناخته مىشوند، مسير يا مسيرهاى بهترى بين مبدا و مقصد ايجاد كرد. در سالهاى اخير بروتكلهاى متعددى در جهت استفاده از رله براى مشاركت بيشنهاد

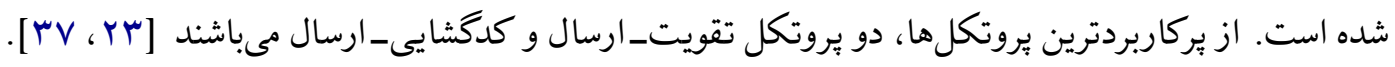
در بروتكل تقويت_ارسال، رلهها سيخنال دريافتى را تقويت كرده و براى مقصد ارسال مىكنند در حاليكه در يروتكل كدگشايى_ارسال، رلهها سيخنال دريافتى را ابتدا كدگشايى سهيس كدگذارى و درنهايت براى مقصد ارسال مىكنند. همانطور كه در فصل قبل بيان گرديد با كدگذارى مكان-زمان مىتوان دايورسيتى مكانى يك سيستم MIMO را استخراج كرده و باعث افزايش اطمينان يك كانال محوشونده بىسيم گرديد. با مطرح شIMO شن مخابرات مشاركتى، محققين سعى كردهاند با استفاده از كدهاى طراحى شده براى سيستمهاى در سيستمهاى مخابرات مشاركتى به دايورسيتى مكانى ناشى از آنتنهاى رلهها برسند. كدهاى طراحى شده و استفاده شده در سيستمهاى مخابرات مشاركتى با عنوان كدهاى "توزيع شده” شناخته مىشوند كه دليل آن را در ادامه توضيح داد خواهد شد. نويسندكان [ب0] از كدهاى مكان-زمان انتشار خطى استفاده كرده و يك روش كدگذارى مكان-زمان توزيع شده جديد بيشنهاد دادهاند. در [ro] طراحى كدهاى مكانزمان توزيع شده با استفاده از كدهاى متعامد حقيقى، متعامد مختلط و شبه متعامد انجام و كدگشايى با ويجِيدگى كم براى اين كدها ارئه شده است. مشابه با سيستمهاى MIMO ، كدگشايى در مخابرات مشاركتى نيز به دو روش همدوس و ناهمدوس انجام مىشود. اكر امكان تخمين كانال براى گرههاى گيرنده وجود داشته باشد، كدگشايى در آنها به روش همدوس و در غير اينصورت كدگشايى به روش ناهمدوس انجام 
مىشود. براى كدگشايى به روش ناهمدوس، فرستنده بايد اطلاعات خود را با روشهاى تفاضلى كد كند تا در هر زمان گيرنده بتواند براى كدگشايى از سيخنالهاى دريافتى زمانهاى قبل استفاده كند. به اين نحوه كدگذارى در سيستمهاى مخابرات مشاركتى، كدگذارى تفاضلى توزيعشده گفته مىشود. از سويى در اغلب يزووهش هاى انجام شده سيستمهاى مخابرات مشاركتى نيمهـ دوطرفه درنظر گرفته شدهاند. به عبارت ديخر، گرهها نمىتوانند عمل دريافت و ارسال را همزمان در يك باند فركانسى انجام دهند. در اين سيستمها، اخر هدف تبادل اطلاعات بين دو گره باشد يعنى دو گره بخواهند بهطور متقابل براى يكديخر اطلاعات ارسال كنند اين عمل در جهار فاز انجام مىشود. دو فاز براى ارسال اطلاعات از گره اول به گره دوم و دو فاز براى ارسال اطلاعات از گره دوم به گُه اول، كه اين امر سبب اتلاف امكانات سيستم از جمله بهناى باند، زمان، توان و... مىشود (به اين شبكهها اصطلاحا، شبكه مشاركتى يك سويه گفته مىشود). يكى از روشهايى كه براى رفع اين مشكل مطرح شده است، استفاده از سيستمهاى دوسويه است [F4، هQF]. در سيستمهاى دوسويه تبادل اطلاعات بين دو گره در دو فاز انجام مىشود، در فاز اول دو گره سيخنالهاى خود را همزمان براى رلهها و در فاز دوم رله ها سيگنالهاى خود براى دو گره ارسال مىكنند. براى جلوگيرى از اتلاف امكانات سيستم، شبكههاى دوسويهى بدون نياز به ضرايب فيدينگ كانال مورد توجه قرار گرفته اند. در اين سيستمها نيز بايد از روشهاى كدگذارى تفاضلى توزيع شده استفاده كرد با در نظر تمهيدات خاصى كه مخصوص كدگشايى در اين سيستمها است. در سال هاى اخير شبكهاى دوسويهى از جنبه هاى مختلفى

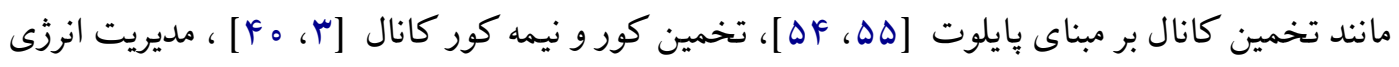

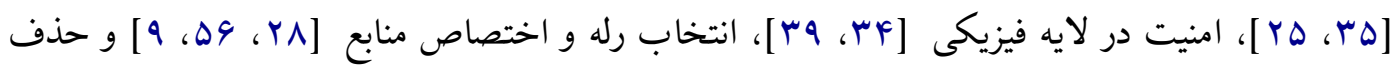

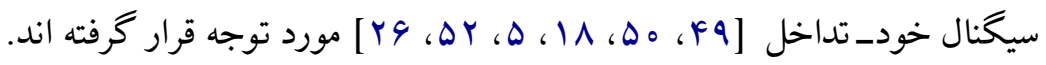
در ادامه به مطالعه مدل سيستم مخابرات مشاركتى و كدگذارى در شبكههاى يكسويه و دوسويه و حذف

$$
\text { سيخنال خود_تداخل مىبردازيم. }
$$

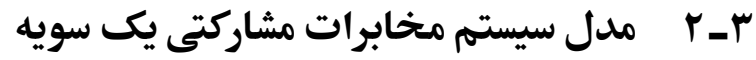

يك شبكه بىسيم با N رله كه بهصورت تصادفى و مستقل از هم در محيطى بخش شدهاند در نظر مى گيريم كه هر رله داراى يك آنتن در حالت نيمه دوطرفه است. يك گره به عنوان مبدا و يك گره به عنوان مقصد هر دو با يك آنتن وجود دارند. فرض بر اين است كه بين مبدا و مقصد كانال مستقيمى وجود ندارد.

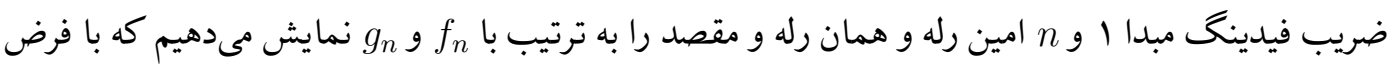


كانال رايلى تخت شبه ايستا، اين ضرايب بهصورت متغير تصادفى گوسى مختلط با ميانخين صفر و واريانس ا مدل مىشوند كه در طول ارسال يك يا جند كد ثابت مىمانند. جون كانال تخت در نظر گرفته شده است، كدگذارى مكان-زمان توزيع شده براى رسيدن به حداكثر دايورسيتى موجود مناسب است. در سيستم مخابرات مشاركتى، ارسال از مبدا تا مقصد در دو فاز انجام مىشود. فرستنده بيتهاى ورودى را مدوله كرده و سمبلهاى ارسالى را توليد، در فاز اول آنها را براى رلهها ارسال مىكند. رلهها سيخنالهاى دريافتى خود را بردازش كرده، سيخنالهاى ارسالى خود را توليد و در فاز دوم بهطور همزمان آنها را براى مقصد ارسال مىكنند.

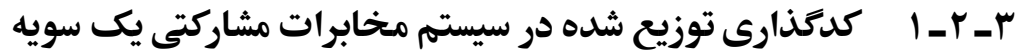

براى آشنايى با نحوه مشاركت رلهها و كدگذارى توزيع شده در شبكهاى يكسويه، با در نظرگرفتن مدل سيستم بالا ، كد مكان-زمان توزيع شده را كه از يروتكل AF استفاده مىكند را مرور خواهيم كرد [1/] ].

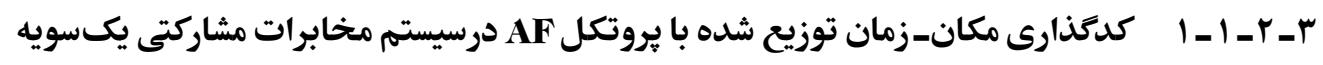

در بروتكل تقويت_ارسال بر خلاف بروتكل كدگشايى و ارسال، به اطلاعات كانال در رله ها نياز نمى باشد زيرا رله ها بردار اطلاعات دريافتى از مبدا را كدگشايى نمى كنند. به همين علت اتلاف زمان و توان در روش تقويت و ارسال كمتر خواهد بود. در ادامه روش كدگذارى مكان-زمان توزيع شده برمبناى كد مكان_زمان انتشار خطى' [Y I ] توضيح داده مى شود. اين روش، دستيابى به دايورسيتى _كامل را تضمين خواهد كرد. ارسال اطلاعات از مبدا تا مقصد در دو فاز انجام مى شود . در فاز اول مبدا اطلاعات خود را براى رلهها پِخش مى كند، رله ها با بردازش سيخنالهاى دريافتى خود، در فاز دوم سيخنالهاى توليدى خود را براى مقصد ارسال مى كنند.

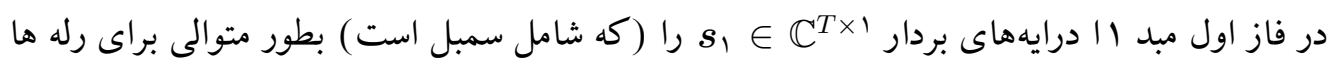
ارسال مىكند. . توسط رله n عبارتست از:

$$
\boldsymbol{r}_{n}=\sqrt{P_{1}} \boldsymbol{s}_{1} f_{n}+\boldsymbol{z}_{n}, \quad n=1, \ldots, N
$$

كه هP توان متوسط ارسالى، 


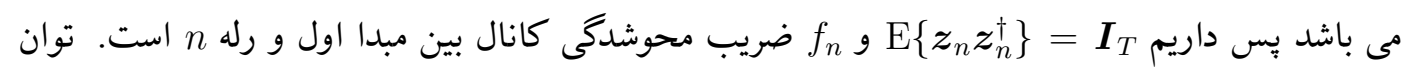
ميانغين سيخنال دريافتى در رله برابر است با:

$$
\begin{aligned}
\mathrm{E}\left\{\boldsymbol{r}_{n}^{\dagger} \boldsymbol{r}_{n}\right\} & =\mathrm{E}\left\{P_{1}\left|f_{n}\right|^{\uparrow} \boldsymbol{s}_{1}^{\dagger} \boldsymbol{s}_{\uparrow}\right\}+\mathrm{E}\left\{\boldsymbol{z}_{n}{ }^{\dagger} \boldsymbol{z}_{n}\right\} \\
& =\left(P_{1}+1\right) T .
\end{aligned}
$$

براى رسيدن به حداكثر دايورسيتى از ايده كدهاى مكان-زمان LD در ساخت سيخنال ارسالى از رله

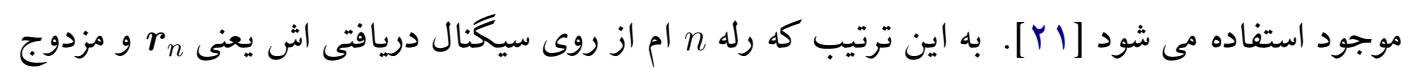
مختلط آن، سيخنال t t را براى ارسال مى سازد:

$$
\boldsymbol{t}_{n}=\beta_{n}\left(\boldsymbol{A}_{n} \boldsymbol{r}_{n}+\boldsymbol{B}_{n} \boldsymbol{r}_{n}^{*}\right)
$$

كه

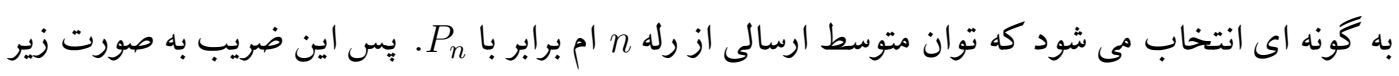
انتخاب مى گردد

$$
\begin{aligned}
\mathrm{E}\left\{\boldsymbol{t}_{n}^{\dagger} \boldsymbol{t}_{n}\right\}= & \beta_{n}^{\curlyvee} \mathrm{E}\left\{\left(\boldsymbol{A}_{n} \boldsymbol{r}_{n}+\boldsymbol{B}_{n} \boldsymbol{r}_{n}^{*}\right)^{\dagger}\left(\boldsymbol{A}_{n} \boldsymbol{r}_{n}+\boldsymbol{B}_{n} \boldsymbol{r}_{n}^{*}\right)\right\}, \\
= & \beta_{n}^{\text {}} \mathrm{E}\left\{\boldsymbol{r}_{n}^{\dagger} \boldsymbol{A}_{n}^{\dagger} \boldsymbol{A}_{n} \boldsymbol{r}_{n}+\boldsymbol{r}_{n}^{\dagger} \boldsymbol{A}_{n}^{\dagger} \boldsymbol{B}_{n} \boldsymbol{r}_{n}^{*}+\boldsymbol{r}_{n}^{T} \boldsymbol{B}_{n}^{\dagger} \boldsymbol{A}_{n} \boldsymbol{r}_{n}+\boldsymbol{r}_{n}^{T} \boldsymbol{B}_{n}^{\dagger} \boldsymbol{B}_{n} \boldsymbol{r}_{n}^{*}\right\} \\
= & \beta_{n}^{\curlyvee} \operatorname{Tr}\left(\boldsymbol{A}_{n}^{\dagger} \boldsymbol{A}_{n} \mathrm{E}\left\{\boldsymbol{r}_{n} \boldsymbol{r}_{n}^{\dagger}\right\}+\boldsymbol{A}_{n}^{\dagger} \boldsymbol{B}_{n} \mathrm{E}\left\{\boldsymbol{r}_{n}^{*} \boldsymbol{r}_{n}^{\dagger}\right\}+\boldsymbol{B}_{n}^{\dagger} \boldsymbol{A}_{n} \mathrm{E}\left\{\boldsymbol{r}_{n} \boldsymbol{r}_{n}^{T}\right\}\right. \\
& \left.+\boldsymbol{B}_{n}^{\dagger} \boldsymbol{B}_{n} \mathrm{E}\left\{\boldsymbol{r}_{n}^{*} \boldsymbol{r}_{n}^{T}\right\}\right) \\
= & P_{n} T .
\end{aligned}
$$

با استفاده از نتيجه مى گيريم

$$
\beta_{n}=\sqrt{\frac{P_{n} T}{\left(P_{\uparrow}+1\right) \operatorname{Tr}\left(\boldsymbol{A}_{n}^{\dagger} \boldsymbol{A}_{n}+\boldsymbol{B}_{n}^{\dagger} \boldsymbol{B}_{n}\right)}} .
$$

براى تضمين شرط توان داريم

$$
\operatorname{Tr}\left(\boldsymbol{A}_{n}^{\dagger} \boldsymbol{A}_{n}+\boldsymbol{B}_{n}^{\dagger} \boldsymbol{B}_{n}\right)=T
$$


كه نتيجه مى دهد:

$$
\beta_{n}=\sqrt{\frac{P_{n}}{P_{1}+1}}
$$

در فاز دوم رلهها بطور همزمان سيخنالهاى خود را براى مقصد ارسال مى كنند. در مقصد، سيگنال

دريافتى ، مجموع سيخنالهاى دريافتى از رله ها مىباشد و برابر است با:

$$
\boldsymbol{y}_{\curlyvee}=\sum_{n=1}^{N} g_{n} \boldsymbol{t}_{n}+\boldsymbol{v}_{\curlyvee}
$$

كه I× است يا •

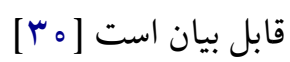

$$
\boldsymbol{y}_{r}=\boldsymbol{S}_{\boldsymbol{l}} \boldsymbol{h}+\boldsymbol{w}
$$

$$
\boldsymbol{S}_{1}=\left[\begin{array}{cc}
\boldsymbol{C}_{1} \hat{\boldsymbol{s}}_{1}, \ldots, & \left.\boldsymbol{C}_{N} \hat{\boldsymbol{s}}_{N}\right]
\end{array}\right.
$$

كد مكان-زمان دريافت شده در مبدا ب و

$$
\boldsymbol{h}=\sqrt{P_{1}}\left[\begin{array}{c}
\beta_{1} \hat{f}_{1} g_{1} \\
\vdots \\
\beta_{N} \hat{f}_{N} g_{N}
\end{array}\right],
$$

بردار معادل كانال و در نهايت

$$
\boldsymbol{w}=\sum_{n=1}^{N} \beta_{n} g_{n} \boldsymbol{C}_{n} \hat{\boldsymbol{z}}_{n}+\boldsymbol{v}_{\curlyvee}
$$

نويز معادل است و

$$
\begin{cases}\boldsymbol{C}_{n}=\boldsymbol{A}_{n}, \hat{f}_{n}=f_{n}, \hat{\boldsymbol{z}}_{n}=\boldsymbol{z}_{n}, \hat{\boldsymbol{s}}_{n}=\boldsymbol{s}_{\uparrow} & \text { if } \boldsymbol{B}_{n}=\circ \\ \boldsymbol{C}_{n}=\boldsymbol{B}_{n}, \hat{f}_{n}=f_{n}^{*}, \hat{\boldsymbol{z}}_{n}=\boldsymbol{z}_{n}^{*}, \hat{\boldsymbol{s}}_{n}=\boldsymbol{s}_{\uparrow}^{*} & \text { if } \boldsymbol{A}_{n}=\circ .\end{cases}
$$

روابط بالا بيان مى كند كه اكر م اطلاعات است و اخر ه 
است. ماتريس \S Sشابه با ماتريس كد مكان-زمان در سيستم MIMO مىباشد در حاليكه هر ستون اين

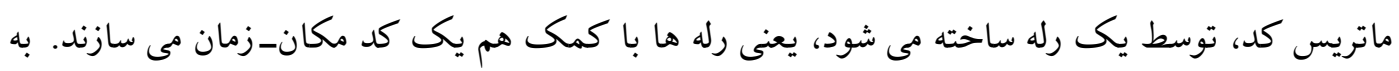
همين دليل از نام "كد مكان-زمان توزيع شده" استفاده مىشود تا تاكيد شود اين كد بهصورت توزيع شده و توسط جندين رله توليد شده است.

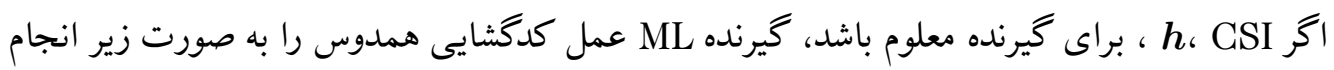

$$
\overline{\boldsymbol{S}}_{\uparrow}=\arg \min _{\boldsymbol{S}_{\uparrow}}\left\|\boldsymbol{y}_{\curlyvee}-\boldsymbol{S}, \boldsymbol{h}\right\|^{\Upsilon} .
$$

مى دهد:

اكنون فرض مى كنيم CSI موجود نباشد، در اين حالت از كدگذارى تفاضلى استفاده مى شود كه در

$$
\text { بخش بعد مرور مى شود. }
$$

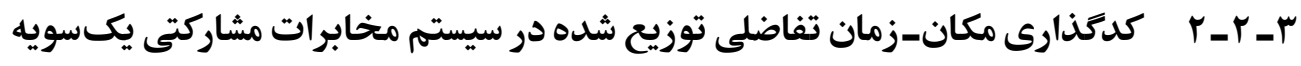

كدهاى مكان-زمان توزيع شده متناظر با كدهاى مكان-زمان سيستمهاى MIMO هستند، كه درآنها

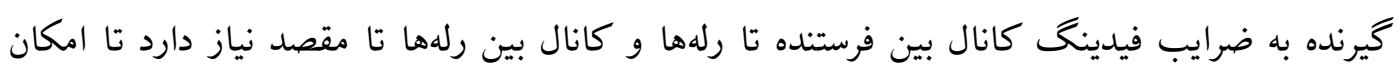

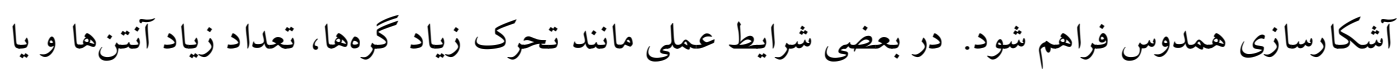

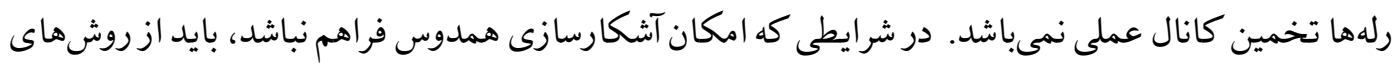

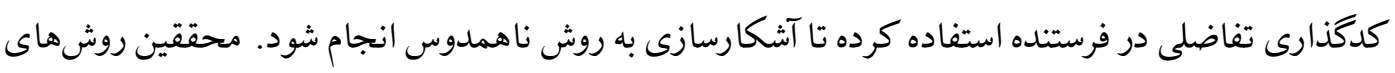
كدكذارى تفاضلى سيستم هاى MIMO را در سيستمهاى مخابرات مشاركتى وارد و با روشهاى كدكذارى توزيع شده تلفيق كردهاند، كدهاى حاصل از اين روش كدهاى تفاضلى توزيع شده ناميده مى تشود.

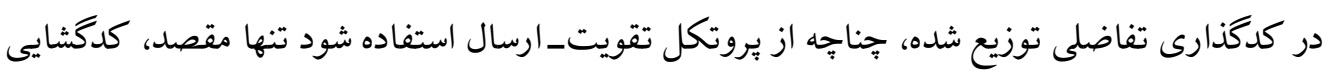

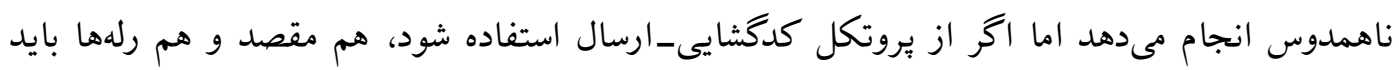
كدگثايى ناهمدوس انجام دهند. فرض مى كنيم $1=N$ و ارسال متوالى T سمبل را يك بلوكى مى ناميم. در كدگذارى تفاضلى، سيخنال

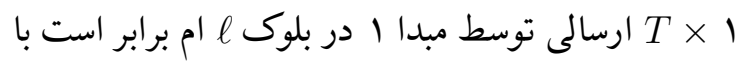

$$
\begin{aligned}
& \boldsymbol{s}_{\uparrow}^{(\ell)}=\boldsymbol{U}_{\uparrow}^{(\ell)} \boldsymbol{s}_{\uparrow}^{(\ell-1)},
\end{aligned}
$$

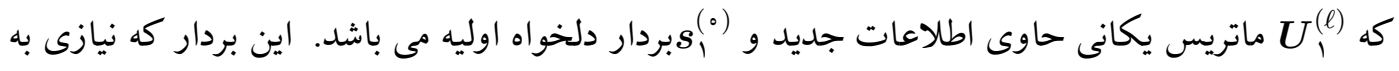


دانستن آن در گيرنده نمى باشد به گونه اى انتخاب مى شود كه

$$
\begin{aligned}
& \mathrm{E}\left\{\boldsymbol{s}_{1}^{(0)} \boldsymbol{s}_{1}^{(0)^{\dagger}}\right\}=\boldsymbol{I}_{N}, \\
& \mathrm{E}\left\{\boldsymbol{s}_{1}^{(\ell)} \boldsymbol{s}_{1}^{(\ell)^{\dagger}}\right\}=\boldsymbol{I}_{N} \text { ، اين شرط تضمين مى كند كه در هـ }(19)
\end{aligned}
$$

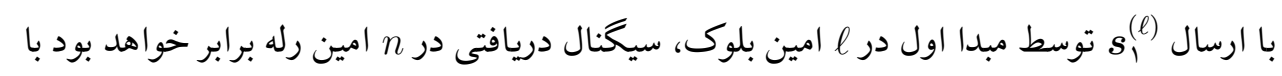

$$
\boldsymbol{r}_{n}^{(\ell)}=\sqrt{P_{1}} s_{1}^{(\ell)} f_{n}^{(\ell)}+\boldsymbol{z}_{n}^{(\ell)}, \quad n=1, \ldots, N
$$

كه توان ارسالى از مبدا ا و و كه درايه هاى

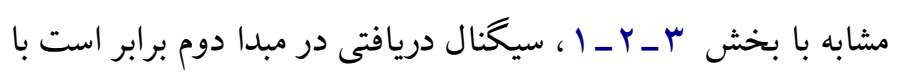

$$
\begin{aligned}
& \boldsymbol{y}_{\uparrow}^{(\ell)}=\boldsymbol{S}_{\uparrow}^{(\ell)} \boldsymbol{h}^{(\ell)}+\boldsymbol{w}^{(\ell)}, \\
& \boldsymbol{S}_{\uparrow}^{(\ell)}=\left[\boldsymbol{C}_{1} \hat{\boldsymbol{s}}_{1}^{(\ell)}, \ldots, \quad \boldsymbol{C}_{N} \hat{\boldsymbol{s}}_{N}^{(\ell)}\right], \\
& \boldsymbol{h}^{(\ell)}=\sqrt{P_{1}}\left[\begin{array}{c}
\beta_{1} \hat{f}_{1}^{(\ell)} g_{\uparrow}^{(\ell)} \\
\vdots \\
\beta_{N} \hat{f}_{N}^{(\ell)} g_{N}^{(\ell)}
\end{array}\right], \\
& \text { و نويز دريافتب در مبدا دوم برابر است با } \\
& \boldsymbol{w}^{(\ell)}=\sum_{n=1}^{N} \beta_{n} g_{n}^{(\ell)} \boldsymbol{C}_{n} \hat{\boldsymbol{z}}_{n}^{(\ell)}+\boldsymbol{v}_{n}^{(\ell)},
\end{aligned}
$$

$$
\begin{aligned}
& \left\{\begin{array}{l}
\boldsymbol{C}_{n}=\boldsymbol{A}_{n}, \hat{f}_{n}^{(\ell)}=f_{n}^{(\ell)}, \hat{\boldsymbol{z}}_{n}^{(\ell)}=\boldsymbol{z}_{n}^{(\ell)}, \hat{\boldsymbol{s}}_{n}^{(\ell)}=\boldsymbol{s}_{1}^{(\ell)} \quad \text { if } \boldsymbol{B}_{n}=。 \\
\boldsymbol{C}_{n}=\boldsymbol{B}_{n}, \hat{f}_{n}^{(\ell)}=f_{n}^{(\ell)^{*}}, \hat{\boldsymbol{z}}_{n}^{(\ell)}=\boldsymbol{z}_{n}^{(\ell)^{*}}, \hat{\boldsymbol{s}}_{n}^{(\ell)}=\boldsymbol{s}_{1}^{(\ell)^{*}} \quad \text { if } \boldsymbol{A}_{n}=。 .
\end{array} \quad(\boldsymbol{r} \boldsymbol{r} \mathbf{r})\right.
\end{aligned}
$$



$$
\begin{aligned}
& \boldsymbol{S}_{1}^{(\ell)}=\left[\boldsymbol{C}_{1} \hat{\boldsymbol{U}}_{1}^{(\ell)} \hat{\boldsymbol{s}}_{1}^{(\ell-1)}, \ldots, \boldsymbol{C}_{N} \hat{\boldsymbol{U}}_{1}^{(\ell)} \hat{\boldsymbol{s}}_{N}^{(\ell-1)}\right],
\end{aligned}
$$




$$
\begin{aligned}
& \begin{cases}\hat{\boldsymbol{U}}_{1}^{(\ell)}=\boldsymbol{U}_{1}^{(\ell)} & \text { if } \boldsymbol{B}_{n}=\circ \\
\hat{\boldsymbol{U}}_{1}^{(\ell)}=\boldsymbol{U}_{1}^{(\ell)^{*}} & \text { if } \boldsymbol{A}_{n}=\circ\end{cases} \\
& \left\{\begin{array}{l}
\boldsymbol{U}_{1}^{(\ell)} \boldsymbol{A}_{n}=\boldsymbol{A}_{n} \boldsymbol{U}_{1}^{(\ell)} \\
\boldsymbol{U}_{1}^{(\ell)} \boldsymbol{B}_{n}=\boldsymbol{B}_{n} \boldsymbol{U}_{\uparrow}^{(\ell)^{*}}
\end{array}\right. \\
& \text { يس داريم } \\
& \boldsymbol{S}_{1}^{(\ell)}=\boldsymbol{U}_{1}^{(\ell)}\left[\boldsymbol{C}_{1} \hat{\boldsymbol{s}}_{\uparrow}^{(\ell-1)}, \ldots, \boldsymbol{C}_{N} \hat{\boldsymbol{s}}_{N}^{(\ell-1)}\right] \\
& =\boldsymbol{U}_{1}^{(\ell)} \boldsymbol{S}_{1}^{(\ell-1)} \text {. } \\
& \text { با جايغذارى (rצ_r ) در (r) } \\
& \boldsymbol{y}_{\uparrow}^{(\ell)}=\boldsymbol{U}_{1}^{(\ell)} \boldsymbol{S}^{(\ell-1)} \boldsymbol{h}^{(\ell-1)}+\boldsymbol{w}^{(\ell)}, \\
& =\boldsymbol{U}_{\uparrow}^{(\ell)} \boldsymbol{y}_{\curlyvee}^{(\ell-1)}+\hat{\boldsymbol{w}}^{(\ell)} \\
& \hat{\boldsymbol{w}}^{(\ell)}=\boldsymbol{w}^{(\ell)}-\boldsymbol{U}^{(\ell)} \boldsymbol{w}^{(\ell-1)} .
\end{aligned}
$$

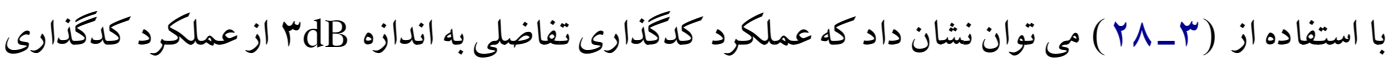
معمولى بدتر است كه دليل آن دو برابر شدن توان نويز در حين آشكارسازى است.

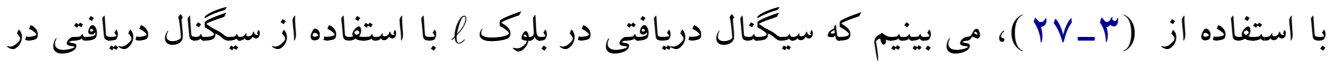

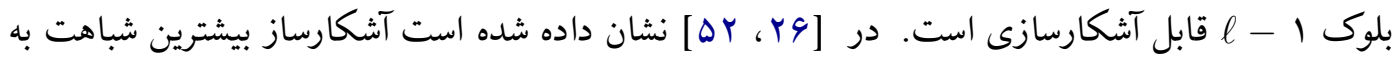

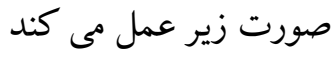

$$
\overline{\boldsymbol{U}}_{1}^{(\ell)}=\arg \min _{\boldsymbol{U}_{1}}\left\|\boldsymbol{y}_{r}^{(\ell)}-\boldsymbol{U}_{1}^{(\ell)} \boldsymbol{y}_{r}^{(\ell-1)}\right\|^{r}
$$

كه نشان مى دهد براى آشكارسازى به CSI نيازى نمى باشد. 


\section{r-r سيستمهاى مخابرات مشاركتى دوسويه}

ايده اوليه استفاده از شبكههاى مشاركتى دوسويه اولين بار توسط شانون [FV] در سال ال199 19. مطرح شد. در سال هاى اخير به دليل اينكه در اين شبكهها نسبت به شبكههاى يكسويه از اتلاف انرزى، زمان، بهناى باند و... جلوگيرى مىشود، مورد توجه قرار گرفتهاند. در اين روش دو مبدا بهطور همزمان سيخنالهاى خود را براى رله ارسال مىكنند بنابراين رله مجموع اين دو سيخنال را دريافت مىكند. رله تقويت و ارسال سيخنال دريافت شده را تقويت كرده و براى دو مبدا بازيخش مىكند. هر مبدا سهم سيخنال ارسالى خود را از سيخنال دريافتى اش كم كرده و سيس سيخنال ارسالى از مبدا ديخر را كدگشايى مىكند. ما فرض مى كنيم كه ارسال از دو مبدا در فاز اول و ارسال از رله ها در فاز دوم به طور همزمان و سنكرون اتفاق مى افتد. به اين ترتيب ما در هيج كدام از اين دو فاز با عدم همزمانى سيخنال هاى دريافتى مواجه نيستيم. در واقع، در سيستم هاى دوسويه با جندين رله، دو نوع ناهمزمانى امكان دارد كه رخ دهد كه هر دو به شدت كارايى سيستم را كاهش مى دهند. در نوع اول كه در فاز اول رخ مى دهد سيخنال هاى دريافتى در رله ها ناسنكرونباشند. در نوع دوم كه در فاز دوم رخ مى دهد، سيخنال هاى دريافتى در هر مبدا ناسنكرون مى باشند كه اين نوع ناهمزمانى سبب از دست رفتن بهره جندكانكى مى شود. در مقالات به روش هاى غلبه بر اين موضوع در شبكه هاى

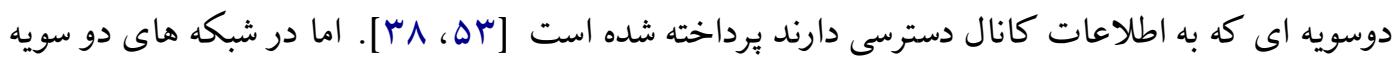
ى بدون اطلاعات كانال اين موصوع مورد بررسى قرار نكرفته است و مى تواند يك زمينه جديد براى مطالعه در آينده فراهم كند. كدگذارى مكان-زمان توزيع شده براى شبكهاى دوسويه بيشنهاد شده است در شبكه هاى دوسويه استفاده شده است. اغلب كارهاى انجام شده در كدگذارى مكان-زمان توزيع شده در شبكههاى دو سويه، با فرض در دسترس بودن CSI از كدگشايى همدوس استفاده كردهاند. درشبكههايى دوسويهاى كه تخمين كانال عملى نباشد به علت در اختيار نبودن CSI ، بايد از روشهاى كدگذارى تفاضلى و آشكارسازى ناهمدوس استفاده شود. در ادامه بهطور مختصر كدكذارى مكان-زمان توزيع شده در يك شبكه مشاركتى دوسويه با آشكارسازى همدوس (شبكهاى دوسويه همدوس) را توضيح خواهيم داد و سجس مرورى مختصر بر كارهاى انجام شده در شبكههاى دوسويه با آشكارسازى ناهمدوس (شبكه دوسويه ناهمدوس) انجام خواهيم داد. 


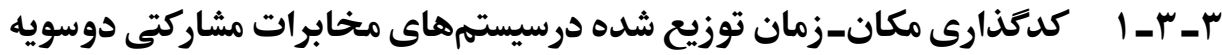

براى بررسى شبكه مشاركتى دوسويه همدوس، يك شبكه شامل N رله در نظر مىگيريم، كه هدف آن تبادل اطلاعات دو گره مبدا از طريق رله ها مىباشد. فرض مىكنيم رلهها از بروتكل تقويت و ارسال استفاده كرده و شبكه نيمه دوطرفه مىباشد.

در شبكههاى دوسويه تبادل اطلاعات بين دو گره مبدا در دو فاز انجام مىگيرد. در فاز اول، هر دوگره مبدا ا و Y به ترتيب بردارهاى اطلاعات بـ براى رلهها ارسال مىكنند بطوريكه سيكنال دريافتى ب×

$$
\boldsymbol{r}_{n}=\sqrt{P_{1}} s_{1} f_{n}+\sqrt{P_{\curlyvee}} s_{\curlyvee} g_{n}+\boldsymbol{z}_{n}, \quad n=1, \ldots, N, \quad\left(\boldsymbol{\Gamma}{ }_{-} \boldsymbol{r}\right)
$$

كه $f_{n}$ و $f_{n}$ مستقل با ميانگين صفر و واريانس يك مىباشند. صفر و واريانس يك در رله مىباشد يعنى E\{ $\left\{\boldsymbol{z}_{n} \boldsymbol{z}_{n}^{\dagger}\right\}=\boldsymbol{I}_{T}$.بنابراين توان سيخنال دريافتى در رله n ام برابر است با

$$
\begin{aligned}
& \mathrm{E}\left\{\boldsymbol{r}_{n}^{\dagger} \boldsymbol{r}_{n}\right\}=\mathrm{E}\left\{P_{1}\left|f_{n}\right|^{\curlyvee} \boldsymbol{s}_{1}^{\dagger} \boldsymbol{s}_{\uparrow}\right\}+\mathrm{E}\left\{P_{\Upsilon}\left|g_{n}\right|^{\curlyvee} \boldsymbol{s}_{\Upsilon}{ }^{\dagger} \boldsymbol{s}_{\Upsilon}\right\}+\mathrm{E}\left\{\boldsymbol{z}_{\boldsymbol{n}}^{\dagger} \boldsymbol{z}_{n}\right\} \\
& =\left(P_{1}+P_{r}+1\right) T \text {. }
\end{aligned}
$$

سبس هر رله سيخنال دريافتى خود را بردازش مىكند تا بردار t براى ارسال توليد كند

$$
\begin{aligned}
\boldsymbol{t}_{n} & =\beta_{n}\left(\boldsymbol{A}_{n} \boldsymbol{r}_{n}+\boldsymbol{B}_{n} \boldsymbol{r}_{n}^{*}\right), \\
& =\beta_{n} \boldsymbol{A}_{n}\left(\sqrt{P_{\uparrow}} s_{\uparrow} f_{n}+\sqrt{P_{\curlyvee}} s_{\curlyvee} g_{n}\right)+\beta_{n} \boldsymbol{B}_{n}\left(\sqrt{P_{\imath}} s_{\uparrow}^{*} f_{n}^{*}+\sqrt{P_{\curlyvee}} s_{r}^{*} g_{n}^{*}\right) \\
& +\beta_{n}\left(\boldsymbol{A}_{n} \boldsymbol{z}_{n}+\boldsymbol{B}_{n} \boldsymbol{z}_{n}^{*}\right),
\end{aligned}
$$

كه انتخاب مىشوند و n ضريب تقويت در رله مىباشد كه

$$
\beta_{n}=\sqrt{\frac{P_{n} T}{\left(P_{1}+P_{\Upsilon}+1\right) \operatorname{Tr}\left(\boldsymbol{A}_{n}^{\dagger} \boldsymbol{A}_{n}+\boldsymbol{B}_{n}^{\dagger} \boldsymbol{B}_{n}\right)}} .
$$

براى اطمينان از برقرارى شروط توان داريم Tr $\left(\boldsymbol{A}_{n}^{\dagger} \boldsymbol{A}_{n}+\boldsymbol{B}_{n}^{\dagger} \boldsymbol{B}_{n}\right)=T$ كه نتيجه مى دهد

$$
\beta_{n}=\sqrt{\frac{P_{n}}{P_{1}+P_{r}+1}} .
$$




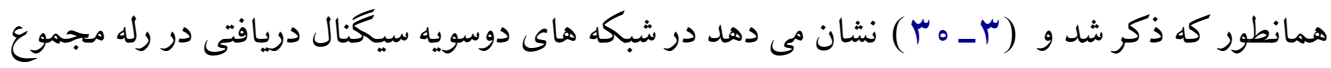
سيخنالهاى ارسالى از دو مبدا مىباشد. در فاز دوم همه رلهها بطور همزمان سيخنالهاى خود

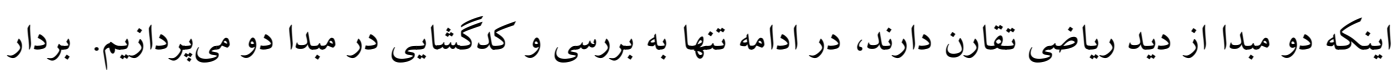

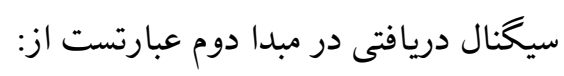

$$
\begin{aligned}
\boldsymbol{y}_{\curlyvee} & =\sum_{n=1}^{N} g_{n} \boldsymbol{t}_{n}+\boldsymbol{v}, \\
& =\sum_{n=1}^{N} \beta_{n}\left(\sqrt{P_{\uparrow}}\left(\boldsymbol{A}_{n} \boldsymbol{s}_{\uparrow} f_{n} g_{n}+\boldsymbol{B}_{n} \boldsymbol{s}_{\uparrow}^{*} f_{n}^{*} g_{n}\right)+\sqrt{P_{\curlyvee}}\left(\boldsymbol{A}_{n} s_{\curlyvee} g_{n}^{\curlyvee}+\boldsymbol{B}_{n} s_{\curlyvee}^{*}\left|g_{n}\right|^{\curlyvee}\right)\right)+\boldsymbol{w},
\end{aligned}
$$

$$
\boldsymbol{w}=\sum_{n=1}^{N} \beta_{n} g_{n}\left(\boldsymbol{A}_{n} \boldsymbol{z}_{n}+\boldsymbol{B}_{n} \boldsymbol{z}_{n}^{*}\right)+\boldsymbol{v} .
$$

$A_{n} A_{n}=0$ كه يكانى و o بازنويسى خواهد شد [IV]

$$
\begin{gathered}
\boldsymbol{y}_{\curlyvee}=\boldsymbol{S}, \boldsymbol{h}_{\uparrow}+\boldsymbol{S}_{\curlyvee} \boldsymbol{h}_{\curlyvee}+\boldsymbol{w}, \\
\boldsymbol{S}_{i}=\left[\begin{array}{ll}
\boldsymbol{C}_{\uparrow} \hat{s}_{i, 1}, \ldots, \boldsymbol{C}_{N} \hat{\boldsymbol{s}}_{i, N}
\end{array}\right],
\end{gathered}
$$$$
\text { كه براى r , I= }
$$

ماتريس كد مكان-زمان دريافت شده در مبدا دوم و توليد شده توسط مبدا i ام مى باشد و

$$
\begin{aligned}
& \boldsymbol{h}_{\uparrow}=\sqrt{P_{\curlywedge}}\left[\begin{array}{c}
\beta_{1} \hat{f}_{\uparrow} g_{\curlywedge} \\
\vdots \\
\beta_{N} \hat{f}_{N} g_{N}
\end{array}\right], \quad \boldsymbol{h}_{\curlyvee}=\sqrt{P_{\curlyvee}}\left[\begin{array}{c}
\beta_{1} \hat{g}_{1} g_{\curlywedge} \\
\vdots \\
\beta_{N} \hat{g}_{N} g_{N}
\end{array}\right], \quad(\boldsymbol{\kappa} \circ-\boldsymbol{r}) \\
& \text { كه ، و و } \\
& \boldsymbol{w}=\sum_{n=1}^{N}\left(\beta_{n} g_{n} \boldsymbol{C}_{n} \hat{\boldsymbol{z}}_{n}\right)+\boldsymbol{v},
\end{aligned}
$$


نويز معادل است و

$$
\begin{cases}\boldsymbol{C}_{n}=\boldsymbol{A}_{n}, \hat{f}_{n}=f_{n}, \hat{g}_{n}=g_{n}, \hat{\boldsymbol{z}}_{n}=\boldsymbol{z}_{n}, \hat{\boldsymbol{s}}_{i, n}=\boldsymbol{s}_{i} & \text { if } \boldsymbol{B}_{n}=\circ \\ \boldsymbol{C}_{n}=\boldsymbol{B}_{n}, \hat{f}_{n}=f_{n}^{*}, \hat{g}_{n}=g_{n}^{*}, \hat{\boldsymbol{z}}_{n}=\boldsymbol{z}_{n}^{*}, \hat{\boldsymbol{s}}_{i, n}=\boldsymbol{s}_{i}^{*} & \text { if } \boldsymbol{A}_{n}=\circ .\end{cases}
$$

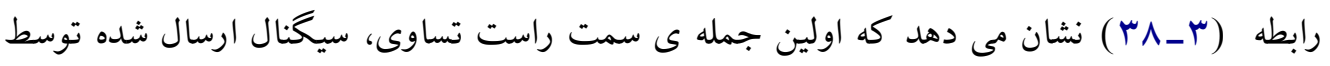
مبدا يك است و سيخنال مطلوب بوده و جمله دوم سيخنال ارسالى توسط خود مبدا دوم مى باشد و سيخنال خود_تداخل ناميده مى شود. در نهايت جمله سوم نويز است كه ناشى از ارسال هر در مبدا مى باشد. بنابراين مبدا r با داشتن اطلاع از CSI كانال، يعنى \ خود_تداخل را از سيخنال دريافتىاش حذف مى كند:

$$
\begin{aligned}
\hat{\boldsymbol{y}}_{\curlyvee} & =\boldsymbol{y}_{\curlyvee}-\boldsymbol{S}_{\curlyvee} \boldsymbol{h}_{\curlyvee}, \\
& =\boldsymbol{S}_{\uparrow} \boldsymbol{h}_{\uparrow}+\boldsymbol{w} .
\end{aligned}
$$

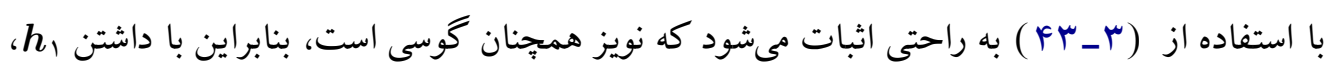
مبدا Y مىتواند از گيرنده ML براى آشكارسازى همدوس اطلاعات ارسالى از مبدا ا استفاده كند:

$$
\overline{\boldsymbol{S}}_{\uparrow}=\arg \min _{\boldsymbol{S}_{\uparrow}}\left\|\hat{\boldsymbol{y}}_{\Upsilon}-\boldsymbol{S}_{\uparrow} \boldsymbol{h}_{\uparrow}\right\|^{r}
$$

جنانجه به دلايلى تخمين كانال امكانيذير نباشد، حذف سيخنال خود_تداخل بسيار مشكل خواهد بود.

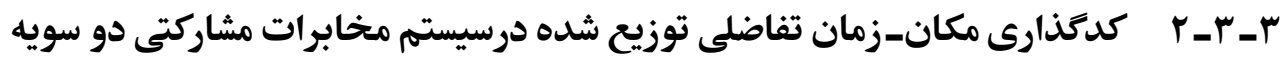

در اين بخش به كدگذارى مكان-زمان توزيع شده مى بردازيم وقتى كه CSI در اختيار نمى باشد.

درفاز اول، دو مبدا اطلاعات خود را به صورت تفاضلى كد كرده و سيخنالهاى كد شده خود را بطور همزمان براى تمام رلهها ارسال مىكنند. اكر فرض كنيم بردارهاى ارسالى توسط مبدا ا و ب در بلوك ل ام به ترتيب

$$
\begin{aligned}
& \boldsymbol{r}_{n}^{(\ell)}=\sqrt{P_{\uparrow}} s_{\uparrow}^{(\ell)} f_{n}^{(\ell)}+\sqrt{P_{r}} s_{r}^{(\ell)} g_{n}^{(\ell)}+\boldsymbol{z}_{n}^{(\ell)}, \quad n=1, \ldots, N \\
& \boldsymbol{s}_{i}^{(\ell)}=\boldsymbol{U}_{i}^{(\ell)} \boldsymbol{s}_{i}^{(\ell-1)}, \quad i=1, \boldsymbol{r},
\end{aligned}
$$


كه (l) مى كند

$$
\mathrm{E}\left\{\boldsymbol{s}_{i}^{(\bullet)} \boldsymbol{s}_{i}^{(\bullet)^{\dagger}}\right\}=\boldsymbol{I}_{N}, \quad i=\mathbf{1}, \boldsymbol{r},
$$

اين شرط تضمين مى كند كه در هر l ؛ كوسى با ميانخين صفر و واريانس يك باشند،

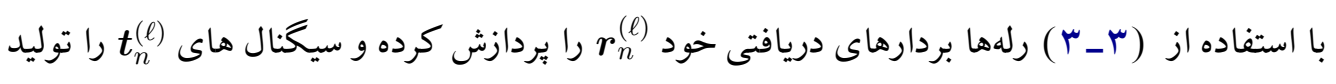

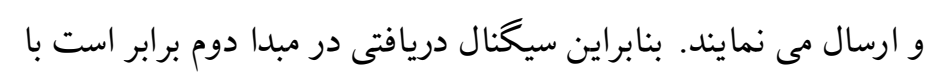

$$
\boldsymbol{y}_{\uparrow}^{(\ell)}=\boldsymbol{S}_{\uparrow}^{(\ell)} \boldsymbol{h}_{\uparrow}^{(\ell)}+\boldsymbol{S}_{\uparrow}^{(\ell)} \boldsymbol{h}_{\uparrow}^{(\ell)}+\boldsymbol{w}^{(\ell)}
$$

كه

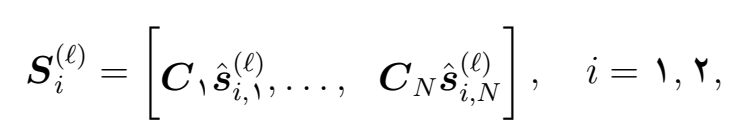

$$
\boldsymbol{h}_{\uparrow}^{(\ell)}=\sqrt{P_{\uparrow}}\left[\begin{array}{c}
\beta_{1} \hat{f}_{\uparrow}^{(\ell)} g_{\uparrow}^{(\ell)} \\
\vdots \\
\beta_{N} \hat{f}_{N}^{(\ell)} g_{N}^{(\ell)}
\end{array}\right], \quad \boldsymbol{h}_{r}^{(\ell)}=\sqrt{P_{\curlyvee}}\left[\begin{array}{c}
\beta_{1} \hat{g}_{\uparrow}^{(\ell)} g_{\uparrow}^{(\ell)} \\
\vdots \\
\beta_{N} \hat{g}_{N}^{(\ell)} g_{N}^{(\ell)}
\end{array}\right]
$$

كه

$$
\boldsymbol{w}^{(\ell)}=\sum_{n=1}^{N} \beta_{n} g_{n}^{(\ell)} \boldsymbol{C}_{n} \hat{\boldsymbol{z}}_{n}^{(\ell)}+\boldsymbol{v}_{n}^{(\ell)},
$$

$$
\begin{aligned}
& \left\{\begin{array}{l}
\boldsymbol{C}_{n}=\boldsymbol{A}_{n}, \hat{f}_{n}^{(\ell)}=f_{n}^{(\ell)}, \hat{\boldsymbol{z}}_{n}^{(\ell)}=\boldsymbol{z}_{n}^{(\ell)}, \hat{\boldsymbol{s}}_{i, n}^{(\ell)}=\boldsymbol{s}_{i}^{(\ell)} \quad \text { if } \boldsymbol{B}_{n}=。 \\
\boldsymbol{C}_{n}=\boldsymbol{B}_{n}, \hat{f}_{n}^{(\ell)}=f_{n}^{(\ell)^{*}}, \hat{\boldsymbol{z}}_{n}^{(\ell)}=\boldsymbol{z}_{n}^{(\ell)^{*}}, \hat{\boldsymbol{s}}_{i, n}^{(\ell)}=\boldsymbol{s}_{i}^{(\ell)^{*}} \quad \text { if } \boldsymbol{A}_{n}=0 .
\end{array} \quad\left(\Delta \boldsymbol{r}_{\mathbf{r}} \boldsymbol{r}\right)\right.
\end{aligned}
$$

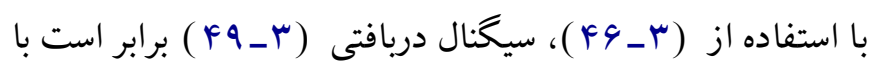

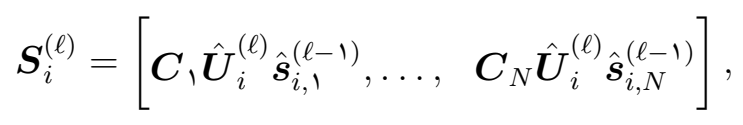




$$
\begin{aligned}
& \begin{cases}\hat{\boldsymbol{U}}_{i}^{(\ell)}=\boldsymbol{U}_{i}^{(\ell)} & \text { if } \boldsymbol{B}_{n}=。 \\
\hat{\boldsymbol{U}}_{i}^{(\ell)}=\boldsymbol{U}_{i}^{(\ell)^{*}} & \text { if } \boldsymbol{A}_{n}=\circ\end{cases} \\
& i=1, \text { به علاوه اكر براى هر n و r } \\
& \left\{\begin{array}{l}
\boldsymbol{U}_{i}^{(\ell)} \boldsymbol{A}_{n}=\boldsymbol{A}_{n} \boldsymbol{U}_{i}^{(\ell)} \\
\boldsymbol{U}_{i}^{(\ell)} \boldsymbol{B}_{n}=\boldsymbol{B}_{n} \boldsymbol{U}_{i}^{(\ell)^{*}}
\end{array}\right. \\
& \boldsymbol{S}_{i}^{(\ell)}=\boldsymbol{U}_{i}^{(\ell)}\left[\boldsymbol{C}_{1} \hat{\boldsymbol{s}}_{i, 1}^{(\ell-1)}, \ldots, \boldsymbol{C}_{N} \hat{\boldsymbol{s}}_{i, N}^{(\ell-1)}\right] \\
& =\boldsymbol{U}_{i}^{(\ell)} \boldsymbol{S}_{i}^{(\ell-1)}, \quad i=1, \boldsymbol{r} .
\end{aligned}
$$

براى آشكارسازى، مبدا دوم بايد ابتدا سيخنال خود_تداخل را حذف كند. از آنجايى كه اطلاعات كانال در سيستم موجود نيست، حذف اين سيخنال سرراست نمى باشد. اخيرا در تحقيقات معدودى به اين مساله برداخته شده، كه در ادامه دو مورد آنها را بررسى خواهيم كرد.

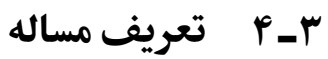

نشان داده شد كه در شبكه هاى دوسويه، دو مبدا بطور همزمان سيخنال هاى خود را براى رله ها ارسال مى كنند كه سبب دريافت سيخنال خود_تداخل در هر مبدا مى شود. سيخنال خود_تداخل به شدت عملكرد سيستم را خصوصا در SINR هاى بالا تخريب مى كند. براى رسيدن به عملكرد مطلوب، سيخنال خودـ تداخل بايد در هر مبدا قبل از آشكارسازى حذف گردد. سختى اين عمل به وجود يا عدم وجود CSI بستگى دارد: اكر CSI در دسترس باشد حذف سيخنال خود_تداخل سرراست است اما در صورت عدم وجود CSI اين كار يك مساله جالش برانخيز محسوب مى شود. در مقالات روش هاى متفاوتى براى حذف اثر سيخنال خود_تداخل در شبكه هاى دوسويه بدون دسترسى به CSI براى رله هاى تقويت و ارسال

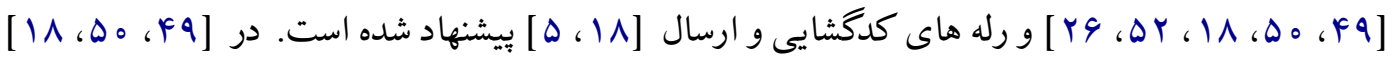
تمركز بر روى شبكه هاى تك رله ایى است كه در آنها نمى توان از كدهاى مكان-زمان توزيع شده استفاده كرده و به بهره جندگانكى دست يافت. استفاده از جندين رله كدگشايى و ارسال در [ه] مورد مطالعه قرار 
كرفته است. اين روش قابليت تعميم به رله هاى خجند آنتنى را ندارد. در [بr] شبكه هاى دوسويه بدون CSI

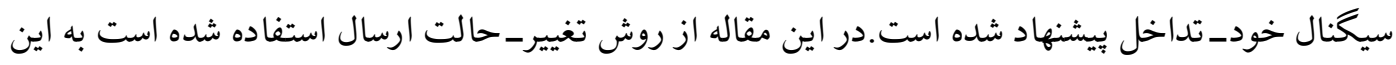
ترتيب كه ارسال برداهاى اوليه در جهار فاز و مانند ارسال در شبكه هاى يكى سويه انجام مى گيرد و پس از آن دو مبدا اطلاعات خود را در دو فاز كه روش معمول شبكه هاى دو سويه است مبادله مى كند. در اين

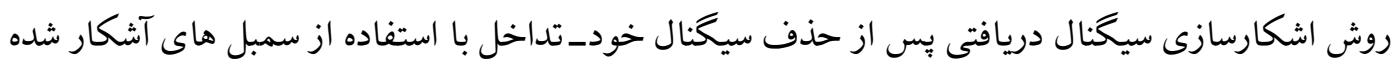
ى بازه زمانى قبل انجام مى گيرد كه اين امر سبب يخش شدن خطاى آشكارسازى و error floor مى گردد. روش ديخرى در [4Y] براى شبكه هاى دوسويه با جندين رله تقويت و ارسال تك آنتى بيشنهاد شده است. در اين روش بايد گيرنده براى بازه اى به طول زمان همبستخى كانال تاخير داشته و صبر كند تا بتواند كانال

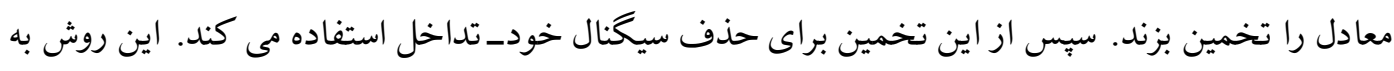
دليل وجود خطاى تخمين قابليت حذف كامل سيخنال خود_تداخل را ندارد و بهره جندكانگى در توان هاى

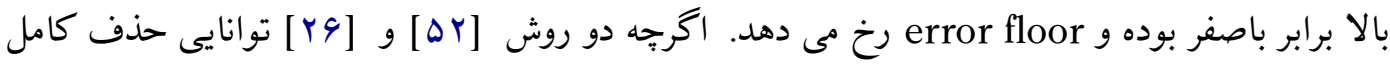

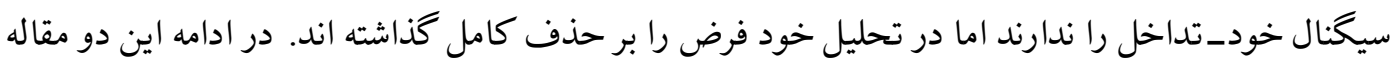
را كه مرتبط ترين كارها باكار ما هستند مورد مطالعه قرار مى دهيم.

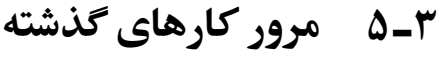

اخيرا در تحقيقات معدودى به مساله حذف سيخنال خود_ تداخل بدون اطلاعات كانال برداخته

شده، كه در ادامه دو مورد آنها را بررسى خواهيم كرد.

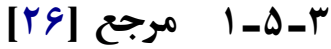

همانطور كه در بخش قبل توضيح داده شد سيكنال دريافتى در مبدا دو يك شبكه دوسويه برابر است با

$$
\begin{gathered}
\boldsymbol{y}_{\uparrow}^{(\ell)}=\boldsymbol{S}_{\uparrow}^{(\ell)} \boldsymbol{h}_{\uparrow}^{(\ell)}+\boldsymbol{S}_{\uparrow}^{(\ell)} \boldsymbol{h}_{\uparrow}^{(\ell)}+\boldsymbol{w}^{(\ell)} \\
\boldsymbol{S}_{i}^{(\ell)}=\boldsymbol{U}_{i}^{(\ell)} \boldsymbol{S}_{i}^{(\ell-1)}, \quad i=1, \curlyvee .
\end{gathered}
$$

در اين مقاله با توجه به مشخصات آمارى ضرايب فيدينگ كانال، يك روش براى تخمين كور كانال 


$$
\begin{aligned}
& \text { بيشنهاد شده است. اكر } \\
& \operatorname{Tr}\left(\boldsymbol{C}_{n} \boldsymbol{C}_{n}^{\dagger}\right)=N, \quad \operatorname{Tr}\left(\boldsymbol{C}_{n} \boldsymbol{C}_{m}^{\dagger}\right)=\bullet, m \neq n \\
& \left(\Delta V_{-} r\right)
\end{aligned}
$$

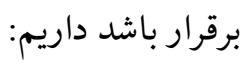

$$
\begin{aligned}
& \mathrm{E}\left\{\boldsymbol{S}_{r}^{(\ell)^{\dagger}} \boldsymbol{y}_{r}^{(\ell)}\right\}=\sqrt{P_{r}} N \boldsymbol{h}_{\curlyvee}, \\
& \text { و در نتيجه } \\
& \hat{\boldsymbol{h}}_{\curlyvee} \approx \frac{1}{N L \sqrt{P_{\curlyvee}}} \sum_{k=1}^{L} \boldsymbol{S}_{\curlyvee}^{(\ell-k)^{\dagger}} \boldsymbol{y}_{\curlyvee}^{(\ell-k)}, \\
& \hat{\boldsymbol{y}}_{\Upsilon}^{(\ell)}=\boldsymbol{y}_{\Upsilon}^{(\ell)}-\sqrt{P_{\Upsilon}} \boldsymbol{S}_{\Upsilon}^{(\ell)} \hat{\boldsymbol{h}}_{\curlyvee}, \\
& =\sqrt{P_{\uparrow}} \boldsymbol{S}_{\uparrow}^{(\ell)} \boldsymbol{h}_{\uparrow}^{(\ell)}+\boldsymbol{w}^{(\ell)}, \\
& =\boldsymbol{U}_{1}^{(\ell)} \hat{\boldsymbol{y}}_{\uparrow}^{(\ell-1)}+\hat{\boldsymbol{w}}^{(\ell)}, \\
& \hat{\boldsymbol{w}}^{(\ell)}=\boldsymbol{w}^{(\ell)}-\boldsymbol{U}_{1}^{(\ell)} \boldsymbol{w}^{(\ell-1)}
\end{aligned}
$$

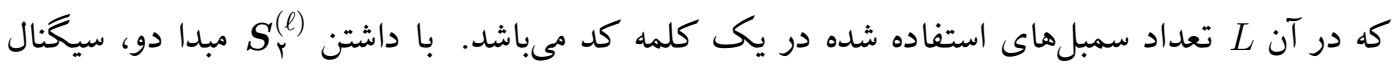

ثابت مىشود نويز معادل سيستم كيرنده ML براى آشكارسازى ناهمدوس استفاده كرد:

$$
\overline{\boldsymbol{U}}_{1}^{(\ell)}=\underset{\boldsymbol{U}_{1}^{(\ell)}}{\arg \min _{\Upsilon}}\left\|\hat{\boldsymbol{y}}_{\boldsymbol{r}}^{(\ell)}-\boldsymbol{U}_{1}^{(\ell)} \hat{\boldsymbol{y}}_{\Upsilon}^{(\ell-1)}\right\|^{r}
$$

اين روش داراى نقطه ظعف خطاى تخمين و تاخير در تخمين كانال مى باشد. به دليل خطاى تخمين اين روش نمى تواند سيخنال خود_تداخل را به طور كامل حذف كند و اين امر به شدت عملكرد سيستم را تخريب مى كند.

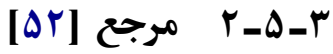

روش ييشنهادى در اين مقاله با جهار فاز شروع مىشود كه دقيقا مشابه سيستمهاى يكسويه است. يّ از آن در دو فاز تبادل اطلاعات بين دو گره انجام مىشود. همانطور كه ذكر شد مرحله شروع كه مقداردهى 
اوليه است در جهار فاز انجام مىگيرد و فرض بر اين است كه در اين خهار فاز اوليه ضرايب فيدينگ كانال ثابت مىباشند. در فاز اول مبدا يك، بردار ا × $T$ م مقداردهى اوليهى رلهها ارسال مىكند و بردار دريافتى در رله عبارتست از:

$$
\boldsymbol{r}_{\mathrm{o}, n}^{s}=\sqrt{P_{\uparrow} T} f_{\mathrm{o}, n} \boldsymbol{s}_{\mathrm{。}}+\boldsymbol{v}_{\mathrm{o}, n} \quad n=1, \ldots, N,
$$

ضريب فيدينگ كانال بين مبدا يك تا رله و $f_{0, n}$ همانى

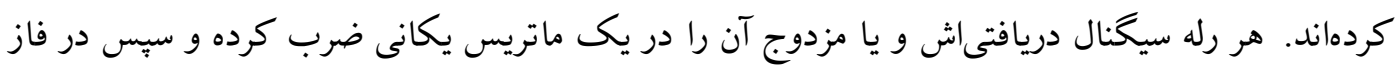

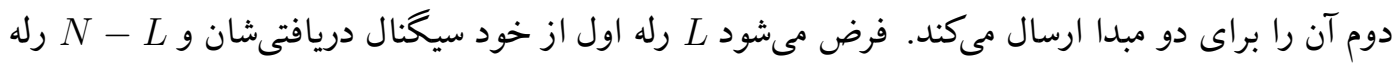
باقيمانده از مزدوج سيخنال دريافتىان استفاده كرده و سيكنال ارسالىشان را به فرم زير مىسازند:

$$
\begin{array}{r}
\boldsymbol{t}_{\mathrm{o}, n}^{s}=\sqrt{\frac{P_{r}}{P_{1}+1}} \boldsymbol{A}_{n} \boldsymbol{r}_{\mathrm{o}, n}^{s}, \quad n=1, \ldots, L, \\
\boldsymbol{t}_{\mathrm{o}, n}^{d}=\sqrt{\frac{P_{r}}{P_{1}+1}} \boldsymbol{A}_{n} \boldsymbol{r}_{\mathrm{o}, n}^{s^{*}}, \quad n=L+1, \ldots, N,
\end{array}
$$

ماتريس هاى

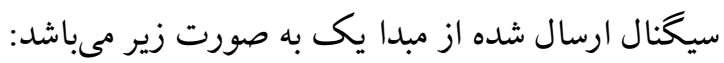

$$
\boldsymbol{y}_{\mathrm{o}, \mathrm{nr}}^{s}=\sqrt{\frac{P_{\uparrow} P_{\mathrm{r}} T}{P_{1}+1}} \boldsymbol{S}_{\circ} \boldsymbol{h}_{\circ}+\boldsymbol{n}_{\circ}^{s},
$$

در رابطه بالا o بردار نويز معادل سيستم و ماتريس كد هS و بردار كانال معادل .h به فرم زير مىباشند:

$$
\begin{aligned}
& \boldsymbol{S}_{\circ}=\left[\begin{array}{llllll}
\boldsymbol{A}_{1} s_{\mathrm{o}}, & \ldots, & \boldsymbol{A}_{L} s_{\mathrm{o}}, & \boldsymbol{A}_{L+1} s_{\mathrm{o}}^{*}, & \ldots, & \boldsymbol{A}_{N} s_{\circ}^{*}
\end{array}\right],
\end{aligned}
$$

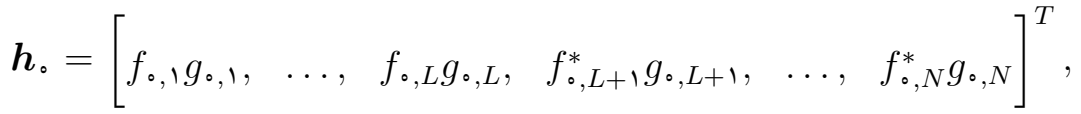

$$
\begin{aligned}
& \boldsymbol{n}_{\mathrm{\circ}}^{s}=\sqrt{\frac{P_{r}}{P_{1}+1}}\left(\sum_{n=1}^{L} \boldsymbol{A}_{n} g_{\circ, n} \boldsymbol{v}_{\circ, n}^{s}+\sum_{n=L+1}^{N} \boldsymbol{A}_{n} g_{\circ, n} \boldsymbol{v}_{\mathrm{o}, n}^{s^{*}}\right)+\boldsymbol{w}_{\circ}^{s},
\end{aligned}
$$

مقدارهى اوليه توسط مبدا دو نيز بطور مشابه انجام مىشود. در فاز سوم مبدا دو، بردار مقداردهى اوليهى

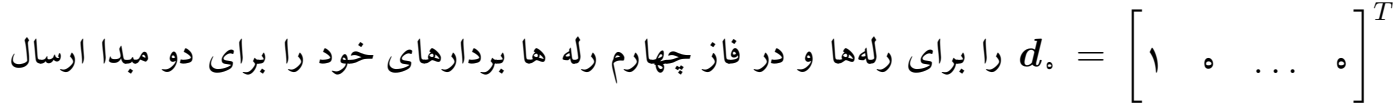

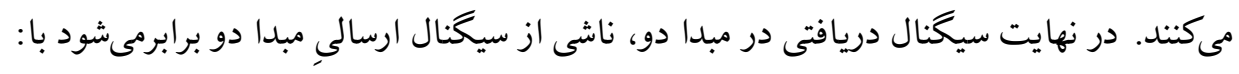

$$
\boldsymbol{y}_{\circ, \mathrm{nr}}^{d}=\sqrt{\frac{P_{r} P_{r} T}{P_{\curlyvee}+1}} D_{\circ} \boldsymbol{g}_{\circ}+\boldsymbol{n}_{\circ}^{d},
$$




$$
\begin{aligned}
& \boldsymbol{D} \circ=\left[\begin{array}{llllll}
\boldsymbol{A}_{1} \boldsymbol{d} 。 & \ldots & \boldsymbol{A}_{L} \boldsymbol{d} 。 & \boldsymbol{A}_{L+1} \boldsymbol{d}_{\circ}^{*} & \ldots & \boldsymbol{A}_{N} \boldsymbol{s}_{\circ}^{*}
\end{array}\right],
\end{aligned}
$$

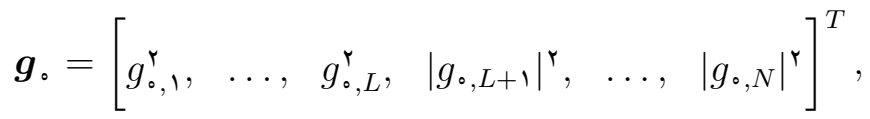

$$
\begin{aligned}
& \boldsymbol{n}_{\circ}^{d}=\sqrt{\frac{P_{r}}{P_{1}+1}}\left(\sum_{n=1}^{L} \boldsymbol{A}_{n} g_{\circ, n} \boldsymbol{v}_{\circ, n}^{d}+\sum_{n=L+1}^{N} \boldsymbol{A}_{n} g_{\circ, n} \boldsymbol{v}_{\circ, n}^{d^{*}}\right)+\boldsymbol{w}_{\circ}^{d},
\end{aligned}
$$
در انتهاى جهار فازِ مقداردهى اوليه، مبدا يك سيخنال هاى و كدگشايى تفاضلى به آنها نياز مىباشد. در ادامه براى سادگى تنها مبدا دو را مورد بررسى قرار مىدهيم و از زيرنويس مربوطه كه نشاندهنده شماره مبدا است صرف نظر مىكنيم. يّ از مرحله مقدار دهى اوليه، تبادل اطلاعات بين دو گره مبدا در دو فاز آغاز مىشود. در فاز اول مبدا يك و دو بردارهاى سيخنال خود يعنى ו

$$
\begin{aligned}
& \text { بخش مىكنند. سيخنال دريافتى در رله nn ام برابر است با بال } \\
& \boldsymbol{r}_{\uparrow, n}=\sqrt{P_{\uparrow} T} f_{\backslash, n} \boldsymbol{s}_{\uparrow}+\sqrt{P_{\curlyvee} T} g_{\uparrow, n} \boldsymbol{d}_{\uparrow}+\boldsymbol{v}_{\uparrow, n} . \quad\left(V^{r}-\boldsymbol{r}\right) \\
& \text { سيخنال ارسالى از رله n ام برابر است با } \\
& \boldsymbol{t}_{\uparrow, n}=\sqrt{\frac{P_{r}}{P_{1}+P_{r}+1}} \boldsymbol{A}_{n} \boldsymbol{r}_{\uparrow, n}, \quad n=1, \ldots, L,
\end{aligned}
$$

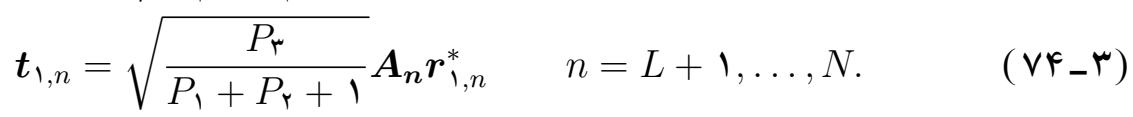

$$
\begin{aligned}
& \text { و در نهايت سيخنال دريافتى در مبدا دو برابر است با: } \\
& \boldsymbol{y}_{1}=\sqrt{\frac{P_{1} P_{r} T}{P_{1}+P_{r}+1}} \boldsymbol{S}_{\uparrow} \boldsymbol{h}_{1}+\sqrt{\frac{P_{r} P_{r} T}{P_{1}+P_{r}+1}} \boldsymbol{D}_{\curlywedge} \boldsymbol{g}_{1}+\boldsymbol{n}_{1}, \\
& \boldsymbol{S}_{\backslash}=\left[\begin{array}{llllll}
\boldsymbol{A}_{\uparrow} \boldsymbol{s}_{1} & \ldots & \boldsymbol{A}_{L} \boldsymbol{s}_{1} & \boldsymbol{A}_{L+1} \boldsymbol{s}_{\uparrow}^{*} & \ldots & \boldsymbol{A}_{N} \boldsymbol{s}_{\uparrow}^{*}
\end{array}\right]
\end{aligned}
$$

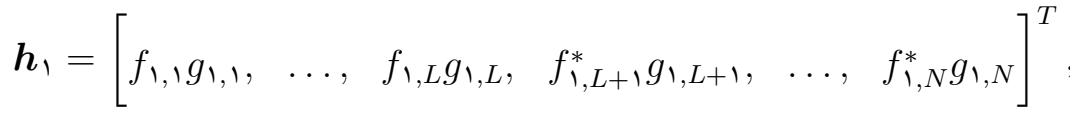




$$
\begin{aligned}
& \boldsymbol{D}_{\backslash}=\left[\begin{array}{llllll}
\boldsymbol{A}_{\uparrow} \boldsymbol{d}_{1} & \ldots & \boldsymbol{A}_{L} \boldsymbol{d}_{\backslash} & \boldsymbol{A}_{L+1} \boldsymbol{d}_{\uparrow}^{*} & \ldots & \boldsymbol{A}_{N} \boldsymbol{d}_{\uparrow}^{*}
\end{array}\right],
\end{aligned}
$$

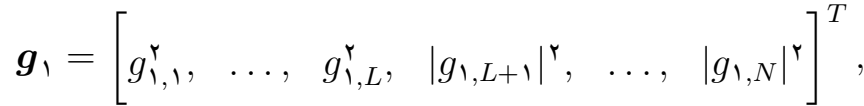

$$
\begin{aligned}
& \boldsymbol{n}_{\backslash}=\sqrt{\frac{P_{\curlyvee}}{P_{\uparrow}+P_{\curlyvee}+1}}\left(\sum_{n=1}^{L} \boldsymbol{A}_{n} g_{\circ, n} \boldsymbol{v}_{\circ, n}^{d}+\sum_{n=L+1}^{N} \boldsymbol{A}_{n} g_{\circ, n} \boldsymbol{v}_{\circ, b}^{d^{*}}\right)+\boldsymbol{w}_{\uparrow}^{d} .
\end{aligned}
$$

با فرض تغيير كند كانال مىتوان در نظر گرفت 。

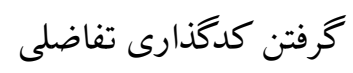

$$
s_{\uparrow}=U_{\uparrow} s_{0} \quad D_{\uparrow}=V, d 。
$$

و با در نظر گرفتن جابجايى يذير بودن ضرب ماتريسهاى رلهها در ماتريسهاى يكانى، كه براى كدگذارى

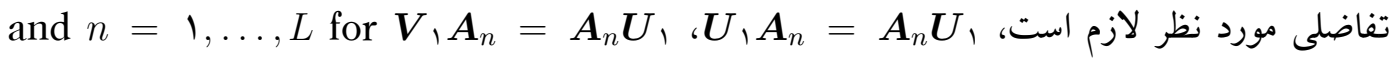

$$
\begin{aligned}
& \text { داريم, } \boldsymbol{V}_{n}=\boldsymbol{A}_{n} \boldsymbol{V}_{\uparrow}^{\dagger} \boldsymbol{U}, \boldsymbol{A}_{n}=\boldsymbol{A}_{n} \boldsymbol{U}_{\uparrow}^{\dagger}
\end{aligned}
$$

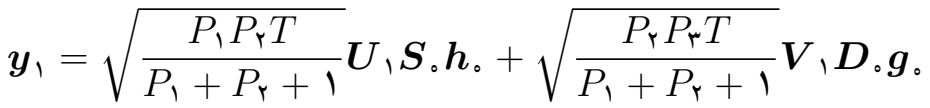

$$
\begin{aligned}
& =\sqrt{\frac{P_{1}+1}{P_{1}+P_{\Upsilon}+1}} U_{1}\left(\boldsymbol{y}_{\circ}^{s}-\boldsymbol{n}_{\circ}^{s}\right)+\sqrt{\frac{P_{\Upsilon}+1}{P_{1}+P_{\Upsilon}+1}} V_{1}\left(\boldsymbol{y}_{\circ}^{d}-\boldsymbol{n}_{\circ}^{d}\right)+\boldsymbol{n}_{\circ} \\
& =\sqrt{\frac{P_{1}+1}{P_{1}+P_{r}+1}} \boldsymbol{U}, \boldsymbol{y}_{\circ}^{s}+\sqrt{\frac{P_{r}+1}{P_{1}+P_{r}+1}} \boldsymbol{V}, \boldsymbol{y}_{\circ}^{d}+\hat{\boldsymbol{n}}_{1}, \\
& \hat{\boldsymbol{n}}_{\backslash}=\boldsymbol{n}_{1}-\sqrt{\frac{P_{1}+1}{P_{1}+P_{r}+1}} \boldsymbol{U}, \boldsymbol{n}_{\mathrm{\circ}}^{s}-\sqrt{\frac{P_{r}+1}{P_{1}+P_{r}+1}} \boldsymbol{V}, \boldsymbol{n}_{\circ}^{d} .
\end{aligned}
$$

از آنجايى كه مبدا دو سيحنال هاى ارسالى خود , را در اختيار دارد، مىتواند را از رابطه زير

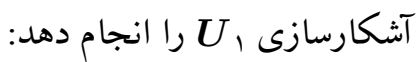

$$
\hat{\boldsymbol{U}}_{1}=\arg \min _{\boldsymbol{U}_{1}}\left\|\boldsymbol{y}_{1}-\sqrt{\frac{P_{1}+1}{P_{1}+P_{r}+1}} \boldsymbol{U} \boldsymbol{y}_{\circ}^{s}-\sqrt{\frac{P_{r}+1}{P_{1}+P_{r}+1}} \boldsymbol{V}, \boldsymbol{y}_{\circ}^{d}\right\|^{r} \quad(\wedge r-\boldsymbol{r})
$$

بعد از بهدست آمدن ,

$$
\overline{\boldsymbol{n}}_{1}=\boldsymbol{y}_{1}-\sqrt{\frac{P_{1}+1}{P_{1}+P_{\curlyvee}+1}} \hat{\boldsymbol{U}}_{\backslash} \boldsymbol{y}_{\circ}^{s}-\sqrt{\frac{P_{r}+1}{P_{1}+P_{\curlyvee}+1}} \boldsymbol{V}, \boldsymbol{y}_{\circ}^{d},
$$

اين نويز ناشى از ارسال هر دو مبدا مىباشد. مبدا دو بطور تقريبى نيمى از اين نويز را به ارسال از مبدا يك و

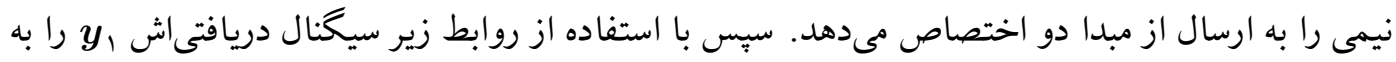


دو سيگنال مجزا تفكيك مىكند كه يك سيكنال ناشى از ارسال مبدا يك و يك سيكنال ناشى از مبدا دو

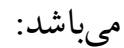

$$
\begin{aligned}
& \boldsymbol{y}_{1}=\hat{\boldsymbol{y}}_{1}^{s}+\hat{\boldsymbol{y}}_{1}^{d}, \\
& \hat{\boldsymbol{y}}_{1}^{s}=\sqrt{\frac{P_{1}+1}{P_{1}+P_{r}+1}} \hat{\boldsymbol{U}}_{\backslash} \boldsymbol{y}_{\circ}^{s}+\frac{\overline{\boldsymbol{n}}_{\backslash}}{r}, \\
& \hat{\boldsymbol{y}}_{1}^{d}=\sqrt{\frac{P_{r}+1}{P_{1}+P_{r}+1}} \hat{\boldsymbol{V}}, \boldsymbol{y}_{\circ}^{d}+\frac{\overline{\hat{\boldsymbol{n}}}_{\backslash}}{r},
\end{aligned}
$$

مبدا از دو سيخنال تقريبى بالا براى آشكارسازى در بلوى ץ استفاده مىكند و اين روند براى تمام بلوك ها تكرار مىشود. يعنى براى بلوك k داريم:

$$
\boldsymbol{y}_{k}=\sqrt{\frac{P_{1} P_{r} T}{P_{\uparrow}+P_{\boldsymbol{r}}+1}} \boldsymbol{S}_{k} \boldsymbol{h}_{k}+\sqrt{\frac{P_{\curlyvee} P_{r} T}{P_{1}+P_{\curlyvee}+1}} D_{k} \boldsymbol{g}_{k}+\boldsymbol{n}_{k},
$$

$$
\boldsymbol{y}_{k}=\sqrt{\frac{P_{1}+1}{P_{1}+P_{\mathrm{r}}+1}} \boldsymbol{U}_{k} \boldsymbol{y}_{k-1}^{s}+\sqrt{\frac{P_{\mathrm{r}}+1}{P_{1}+P_{\mathrm{r}}+1}} \boldsymbol{V}_{k} \boldsymbol{y}_{k-1}^{d}+\hat{\boldsymbol{n}}_{k},
$$

$$
\begin{aligned}
& \hat{\boldsymbol{n}}_{k}=\boldsymbol{n}_{k}-\sqrt{\frac{P_{1}+1}{P_{1}+P_{\mathrm{r}}+1}} \boldsymbol{U}_{k-1} \boldsymbol{n}_{k-1}^{s}-\sqrt{\frac{P_{\mathrm{r}}+1}{P_{1}+P_{\mathrm{r}}+1}} \boldsymbol{V}_{k} \boldsymbol{n}_{k-1}^{d} . \\
& \text { با استفاده از نوير تخمين زد شده } \\
& \hat{\boldsymbol{y}}_{k-1}^{s}=\sqrt{\frac{P_{1}+1}{P_{1}+P_{r}+1}} \hat{\boldsymbol{U}}_{k-1} \hat{\boldsymbol{y}}_{k-r}^{s}+\frac{\overline{\boldsymbol{n}}_{k-1}}{P_{r}+1}, \\
& \hat{\boldsymbol{y}}_{k-1}^{d}=\sqrt{\frac{P_{\mathrm{r}}+1}{P_{1}+P_{\mathrm{r}}+1}} \hat{\boldsymbol{V}}_{k-1} \hat{\boldsymbol{y}}_{k-\mathrm{r}}^{d}+\frac{\overline{\boldsymbol{n}}_{1}}{\mathrm{r}} \text {. } \\
& \text { در نهايت براى حذف سيكنال خود_تداخل و آشكارسارى داريم } \\
& \hat{\boldsymbol{U}}_{k}=\arg \min _{\boldsymbol{U}_{k}}\left\|\boldsymbol{y}_{k}-\sqrt{\frac{P_{\mathbf{1}}+1}{P_{\mathbf{1}}+P_{\boldsymbol{r}}+1}} \boldsymbol{U}_{k} \hat{\boldsymbol{y}}_{k-1}^{s}-\sqrt{\frac{P_{\boldsymbol{r}}+1}{P_{1}+P_{\boldsymbol{r}}+1}} \boldsymbol{V}_{k} \hat{\boldsymbol{y}}_{k-1}^{d}\right\|^{\Upsilon} . \quad\left(\boldsymbol{q}_{0} \boldsymbol{r} \boldsymbol{r}\right)
\end{aligned}
$$

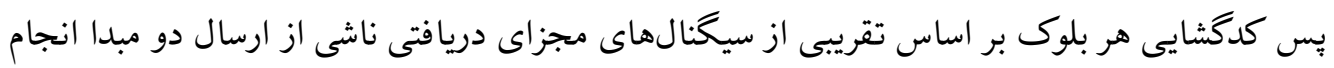

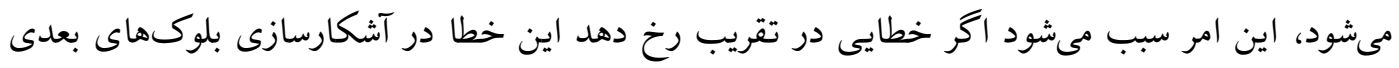
انتشار يابد. براى رفع اين مشكل بايد مقدار دهى اوليه جهار فازى هر קند وقت يكبار تكرار شود كه باعث ناكارآمدى اين روش مىشود. 


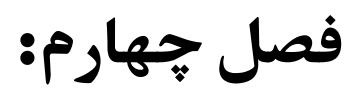

$$
\text { سيستم هاى رله اى دوسويه با رله هاى جند آنتنى }
$$


همان طور كه در فصل هاى قبل اشاره شد، شبكه هاى بى سيم مبتنى بر رله دوسويه به علت بهره بردارى مفيد از منابع موجود، نسبت به شبكه هاى بى سيم مبتنى بر رله يك سويه، جايگاه ويزه اى در نسل بعدى ارتباطات بى سيم خواهند داشت. به طور دقيق تر در شبكه هاى بى سيم مبتنى بر رله يك سويه، براى تبادل اطلاعات بين دو مبدا به جهار فاز نياز است. در فاز اول، اولين مبدا اطلاعات خود را براى تمامى رله ها ارسال مى كند و رله ها، يُ از بردازش سيخنال هاى دريافتى، در فاز دوم سيخنال هاى خود را به طور همزمان براى دومين مبدا ارسال مى كنند. به همين ترتيب دو فاز براى ارسال اطلاعات از دومين مبدا به اولين مبدا نياز است، بنابراين جمعا جهار فاز براى تبادل طلاعات مورد استفاده قرار مى گيرد. در حاليكه در شبكه هاى بى سيم مبتنى بر رله دوسويه، اين امر تنها در دو فاز انجام مى گردد: در فاز اول دو مبدا به طور همزمان اطلاعات خود را براى تمام رله ها ارسال مى كنند و رله ها، بِ از يردازش سيخنال هاى دريافتى، در فاز دوم به طور همزمان سيخنال هاى خودا براى هر دو مبدا ارسال مى كنند. ارسال همزمان اطلاعات از سوى دو مبدا براى رله سبب مى شود كه سيخنال دريافتى در رله ها تركيبى (مجموعى) از اطلاعات ارسالى هر دو مبدا باشد. در بروتكل تقويت_ارسال (amplify-and-forward:AF) كه در اين تحقيق در نظر گرفته شده است، رله ها سيخنال دريافتى خود را تنها تقويت كرده و به سوى دو مبدا ارسال مى نمايند. به اين ترتيب، سيخنال دريافتى در هر مبدا علاوه بر اينكه شامل اطلاعات ارسالى از مبدا ديخر، سيگنال مطلوب، مى باشد شامل اطلاعات ارسالى خودش، سيخنال خود_تداخل، نيز مى باشد. وجود سيخنال خود_تداخل در هنگام آشكارسازى، اثر مخرب جدى بر عملكرد و كارآيى سيستم خواهد داشت، بنابراين حذف اين سيخنال قبل از آشكارسازى از اهميت ويزه ایى برخوردار است. از آنجا كه هر مبدا اطلاعات ارسالى خود را در اختيار دارد جناجٍه ضرايب محوشدگى كانال ها را نيز در اختيار داشته باشد، حذف كامل سيخنال خود_تداخل امر ساده ایى خواهد بود. بييجيدگى حذف اين سيخنال وقتى مطرح مى شود كه هيج يك از دو مبدا و رله ها اطلاعاتى از ضرايب محوشدگى كانال ها نداشته باشند. در اين فصل، ما يك روش جديد بردازش طلاعات در رله ها ارايه مى دهيم كه قادر است كه سيخنال خود_تداخل را در هر مبدا از شبكه هاى بى سيم مبتنى بر رله دوسويه به طول كامل و نه تقريبى حذف نمايد.

\section{ץ-1 مدل سيستم}

شبكه هاى بى سيم مبتنى بر رله دوسويه اى كه ما در تحقيق خود در نظر گرفته ايم شامل دو مبدا تك آنتى و N رله جند آنتنى مى باشد. فرض بر اين است كه n امين رله داراى M $M_{n}$ آنتن مى باشد. سيستم از 


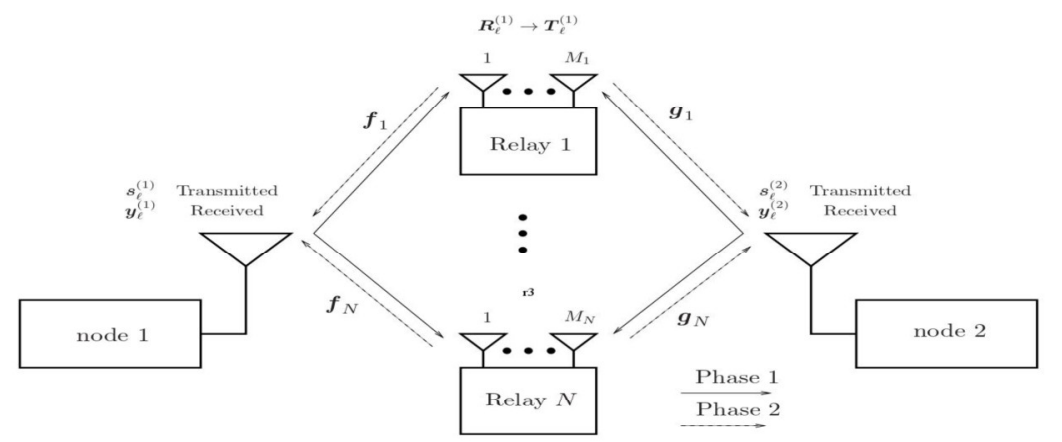

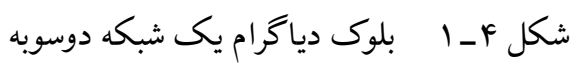

نوع نيم-دوطرفه است به اين معنى كه آنتن ها نمى توانند به طور همزمان عمل ارسال و دريافت را انجام دهند. كانال بين اولين مبدا تا رله n ام با بردار بردار، معرف ضريب محوشدگى بين مبدا اول با آنتن m ام از رله n ام مى باشد. به طور مشابه، كانال بين دومين مبدا تا رله n ام با بردار

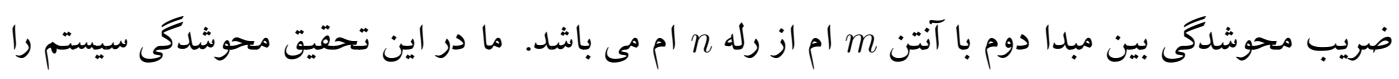

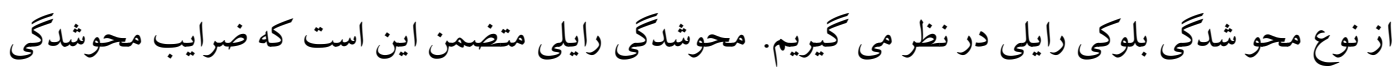

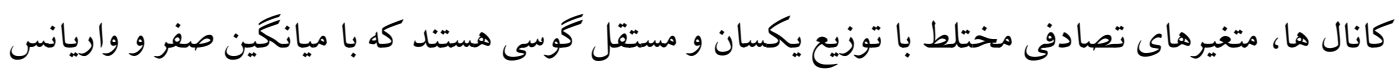

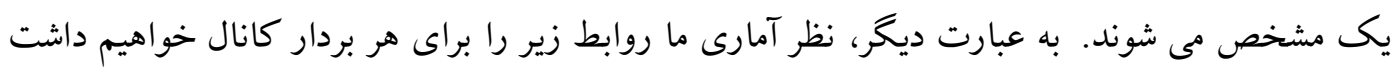
E $\left\{\boldsymbol{f}_{n} \boldsymbol{f}_{n}^{\dagger}\right\}=\mathrm{E}\left\{\boldsymbol{g}_{n} \boldsymbol{g}_{n}^{\dagger}\right\}=\boldsymbol{I}_{M_{n}}$ محوشدگى كانال ها در دوره زمانى همبستخى كانال ثابت مى باشند و بعد از آن به صورت مستقل تغيير مى دى كنיد.

شبكه مورد نظر در اينجا از نوع كانال_نآ كاه مى باشد. به اين معنى كه هيج يكى از دو مبدا و رله ها از ضرايب محوشدىى كانال ها اطلاع ندارند. در نهايت براى تكميل مدل سيستم در نظر خرفته شده بايد اشاره

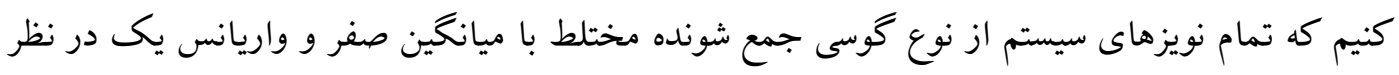

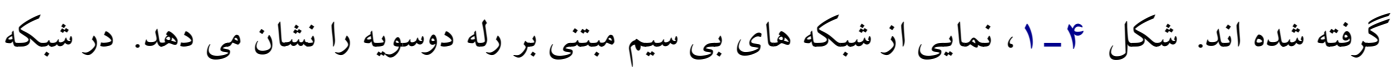


هاى كانال_نآكاه، از روش سيگنالينگ تفاضلى در مبدا استفاده مى شود. در اين روش سيگنالينگ، هر مبدا به جاى ارسال اطلاعاتش به صورت مستقيم آن را به صورت تركيبى با سيخنال ارسالى قبلى ارسال مى كند. به اين ترتيب اين امكان براى گيرنده به وجود مى آيد كه بتواند در هر بازه براى اشكارسازى از سيكنال دريافتى در بازه زمانى قبل استفاده كند و ديخر براى آشكارسازى به ضرايب محوشدگى كانال ها نياز نداشته باشد. در ادامه نحوه سيخنالينخ تفاضلى به تفصيل ارايه خواهد شد. ما كدهاى مكان-زمان قابل استفاده به صورت تفاضلى در شبكه هاى بى سيم مبتنى بر رله را به دو دسته تقسيم مى كنيم. در دسته اول، كد مكان-زمان تركيب خطى از سمبل هاى ارسالى است و در دسته دوم، كدمكان-زمان تركيب خطى از سمبل ها ارسالى و مزدوج مختلط آن ها مى باشد. نحوه ارسل دو مبدا در شبكه براى اين دو دسته كد متفاوت است اما نحوه آشكارسازى يكسان مى باشد. براى هر دو دسته كدهاى معرفى شده، مبدا $i$ اطلاعات خود را در بردارهاى إ) روش سيخناليخ تفاضلى زير آماده مى كنند:

$$
\boldsymbol{s}_{i}^{(\ell)}=\boldsymbol{U}_{i}^{(\ell)} \boldsymbol{s}_{i}^{(\ell-1)}, \quad i=1, r, \quad \ell=1, \ldots, L-1,
$$

كه L معرف تعداد بلوك هايى است كه كانال در طول ارسال آن ها ثابت مى باشدو (يونيتارى) است كه اطلاعات جديد مبدا i در آن قرار دارد. ساختار اين ماتريس با توجه به كد مكان-زمانى كه در سيستم استفاده مى شود مشخص مى گردد كه در بخش شبيه سازى مثال هايى از اين كدها مورد بررسى قرار خواهد گرفت. بايد اشاره داشت كه (०) يك بردار براى مقداردهى اوليه است كه به صورت

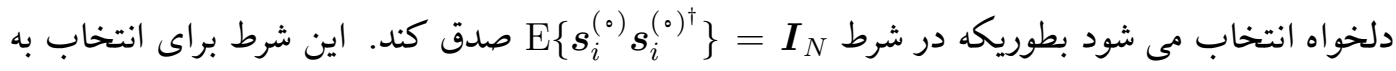
همراه شرط يكانى بودن سبب مى شود كه براى هر بردار ارسالى شرط زير برقرار باشد

$$
. i=1, r, \ell=1, \ldots, L-1
$$

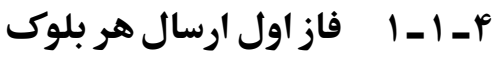

اين فاز براى دو دسته كدهاى مكان-زمان معرفى شده متفاوت است كه در ادامه توضيح داده خواهد 


\section{† ـ ـ ـ ـ دسته اول كدهاى مكان-زمان}


سيخنال دريافتى در n امين رله به صورت زير خواهد بود: $\boldsymbol{R}_{n}^{(\ell)}=\sqrt{P_{\imath}} \boldsymbol{s}_{\uparrow}^{(\ell)} \boldsymbol{f}_{n}^{T}+\sqrt{P_{\curlyvee}} \boldsymbol{s}_{r}^{(\ell)} \boldsymbol{g}_{n}^{T}+\boldsymbol{V}_{n}^{(\ell)}$,

$$
n=1, \ldots, N, \quad \ell=1, \ldots, L-1, \quad\left(r_{-} \boldsymbol{F}\right)
$$

كه رله است. $P_{i}$ متوسط توان ارسالى توسط مبدا i ام مى باشد و ماتريس شونده در n امين رله در بلوك ل ام مى باشد. از آنجاييكه تمام درايه هاى ماتريس نويز متغيرهاى تصادفى مستقل و با توزيع يكسان مختلط گوسى و با مينخين صفر و واريانس يك هستند لذا براى اين ماتريس رابطه زير برقرار است:

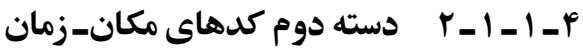

در اين دسته، هر مبدا i در بلوك $ا$ ام بردار خود ها ارسال مى كند. بنابراين سيخنال دريافتى در امين رله به صورت زير خواهد بود:

$$
\begin{aligned}
\boldsymbol{R}_{n}^{(\ell)}= & \sqrt{P_{\uparrow}}\left[\boldsymbol{s}_{\uparrow}^{(\ell)^{T}}, \overline{\boldsymbol{s}}_{\uparrow}^{(\ell)^{T}}\right]^{T} \boldsymbol{f}_{n}^{T}+\sqrt{P_{\curlyvee}}\left[\boldsymbol{s}_{\uparrow}^{(\ell)^{T}}, \overline{\boldsymbol{s}}_{r}^{(\ell)^{T}}\right]^{T} \boldsymbol{g}_{n}^{T} \\
& +\boldsymbol{V}_{n}^{(\ell)}, \quad n=1, \ldots, N, \ell=1, \ldots, L-1,
\end{aligned}
$$

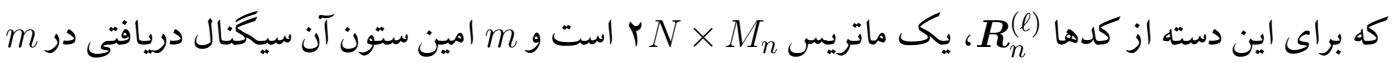

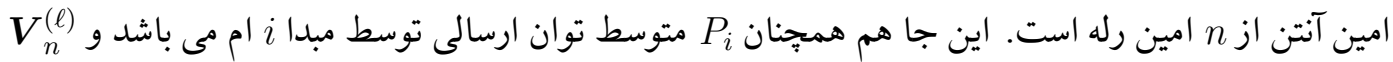
ماتريس نويز گوسى جمع شونده در nامين رله در بلوك ل ام مى باشد. به همان دلايل ذكر شده در مورد دسته اول كدها و با توجه به اينكه در دسته دو كدها سايز ماتريس نويز متفاوت است لذا اين ماتريس در رابطه زير

$$
\text { صدق مى كند: }
$$

بنابراين تفاوت اين دو دسته كد، در سايز سيخنال هاى دريافتى در رله ها مى باشد. 


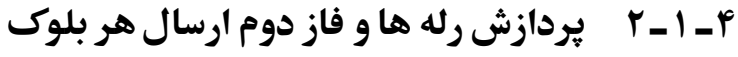

بس از اينكه رله ها به طور كامل سيگنال هاى خود را دريافت كردند آن ها را بردازش مى كند. فرض

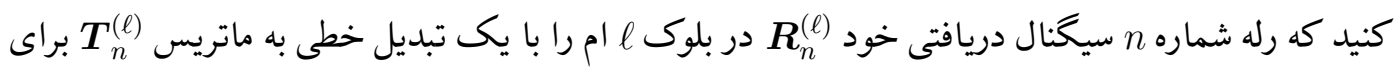

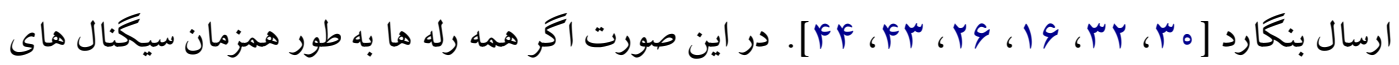
(ا

$$
\boldsymbol{y}_{\uparrow}^{(\ell)}=\sum_{n=1}^{N} \boldsymbol{T}_{n}^{(\ell)} \boldsymbol{f}_{n}+\boldsymbol{z}_{\uparrow}^{(\ell)}, \quad \boldsymbol{y}_{\uparrow}^{(\ell)}=\sum_{n=1}^{N} \boldsymbol{T}_{n}^{(\ell)} \boldsymbol{g}_{n}+\boldsymbol{z}_{\uparrow}^{(\ell)},
$$

در روابط بالا (l) كه (l) با دقت بيشترى مورد بررسى قرار بخيرند. اين دو معادله نشان مى دهند كه سيخنال دريافتى در هر رله مجموع دو سيخنال ارسالى توسط دو مبدا است. دليل اين امر، ارسال همزمان اطلاعات دو مبدا براى رله ها در يكى فاز است. از آنجاييكه رله ها توسط يك تبديل خطى سيخنال دريافتى خود را به سيخنال ارسالى تبديل مى كنند، لذا سيخنال ارسالى رله ها و در نتيجه سيخنال دريافتى در هر مبدا مجموع دو سيخنال ارسالى از دو مبدا خواهد بود. به عبارت ديگر سيخنال دريافتى در هر مبدا شامل يك سيخنال مطلوب، همان اطلاعات ارسالى از مبدا ديخر، و يك سيخنال نامطلوب، سيخنال ارسالى از خود مبدا، است. قبلا هم اشاره كرديم كه اين سيخنال نامطلوب يا سيخنال خود_تداخل به شدت باعث كاهش كارآيى سيستم مى شود. در بخش بعد ما يكى روش جديد بردازش در رله را معرفى مى كنيم كه مى تواند سيخنال خود تداخل را به طور كامل و دقيق در هر مبدا حذف نمايد.

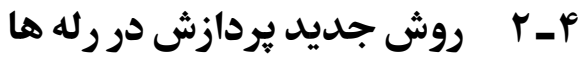

در روش سيخنالينگ DDST' معمول، سيخنال دريافتى در هر رله فقط در حوزه زمان بردازش مى شود حتى اكر هر رله داراى جندين آنتن باشد. به عبارت ديخر وقتى رله داراى جندين آنتن است از سيخنال دريافتى در هر آنتن براى براى توليد سيگنال ارسالى از آنتن استفاده مى شود. اين نحوه يردازش سبب مى گردد كه نتوان از بتانسيل وجود سيخنال هاى دريافتى در ساير آنتن هاى هر رله استفاده نمود. به عبارت ديخر، امكان يردازش در حوزه مكان در روش معمول DDST از دست خواهد رفت. ما در ادامه روشى ارائه خواهيم داد 
در آن علاوه بر بردازش در حوزه زمان، امكان بردازش در حوزه مكان فراهم مى شود به طوريكه اين بردازش سبب حذف سيكنال خود_تداخل در هر مبدا مى گردد. به عبارت دقيق تر، ما در روش بيشنهادى خود براى يردازش در رله ها، از تمامى سيخنال هاى دريافتى در آنتن هاى يك رله براى توليد سيكنال ارسالى از هر

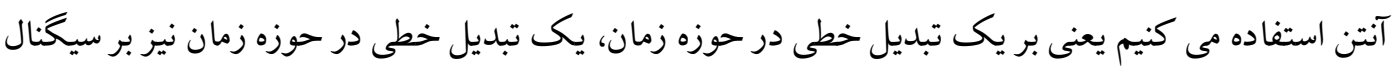
دريافتى در هر رله اعمال مى كنيم. اين تبدبل خطى در حوزه مكان طورى مى شود كه باعث حذف سئ سيخنال خود_تداخل در هر مبدا بدون هيج بردازش اضافه مى گردد.

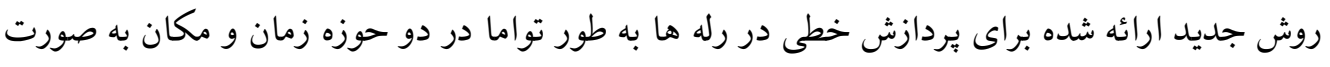

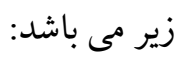

$$
\boldsymbol{T}_{n}^{(\ell)}=\beta_{n} \boldsymbol{C}_{n} \boldsymbol{R}_{n}^{(\ell)} \boldsymbol{X}_{n}, \quad \boldsymbol{X}_{n} \in \mathbb{C}^{M_{n} \times M_{n}}, \quad n=1, \ldots, N .
$$

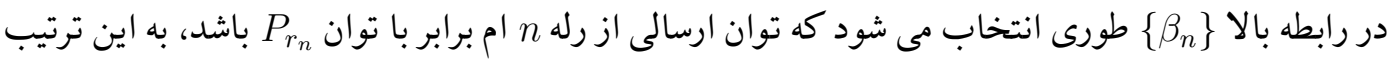

$$
\beta_{n}=\sqrt{\frac{N P_{r_{n}}}{\mathrm{E}\left\{\operatorname{Tr}\left(\boldsymbol{C}_{n} \boldsymbol{R}_{n}^{(\ell)} \boldsymbol{X}_{n} \boldsymbol{X}_{n}^{\dagger} \boldsymbol{R}_{n}^{(\ell) \dagger} \boldsymbol{C}_{n}^{\dagger}\right)\right\}}}
$$

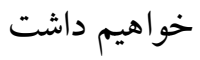

در رابطه (F_ه)، ماتريس استفاده مى شود. براى اطمينان از برقراى شرط محدوديت توان در هر رله، رابطه زير را خواهيم $\left\{C_{n}\right\}$

$$
\operatorname{Tr}\left(\boldsymbol{C}_{n} \boldsymbol{C}_{n}^{\dagger}\right)=N
$$

ساختار ماتريس

$$
\begin{aligned}
& \text { دارد يا به دسته دوم و ساختار كلى آن به صورت زير مى باشد: }
\end{aligned}
$$

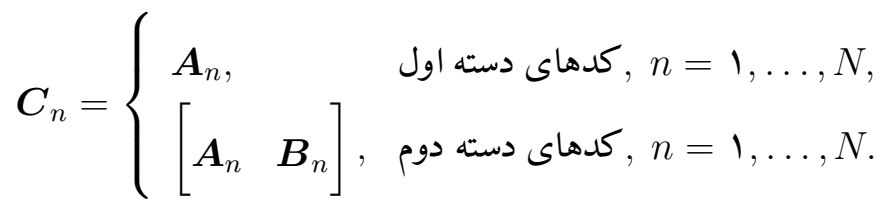

انتخاب ماتريس هاى DDST DD استفاده شده در سيستم بستخى دارد. به عنوان مثال براى كد حقيقى_متعامد كه در دسته اول كدهاى DDST قرار مى گيرد اين ماتريس ها عبارتند از 


$$
A_{\curlyvee}=\boldsymbol{J}, A_{1}=I_{\curlyvee}
$$

$$
\boldsymbol{J}=\left[\begin{array}{cc}
0 & -1 \\
1 & 0
\end{array}\right],
$$

و براى كد معروف الموتى كه در دسته دوم كدهاى DDST قرار مى گيرد اين ماتريس ها عبارتند از

$$
\text { . } B_{r}=J, A_{r}=\text { 。 } B_{\uparrow}=\text { 。 }
$$

در حالت كلى، جون ما هيج اطلاعاتى از ضرايب فيدينگ كانال ها نداريم لذا آنها را با توزيع يكسان در نظر مى گيريم. اين امر سبب مى شود كه اين ماتريس ها را يكانى انتخاب كنيم زيرا در غير اينصورت، توزيع توان بر روى كانال ها يكسان نخواهد بود و ممكن است كه به يك كانال ضعيف توان بالايى اختصاص

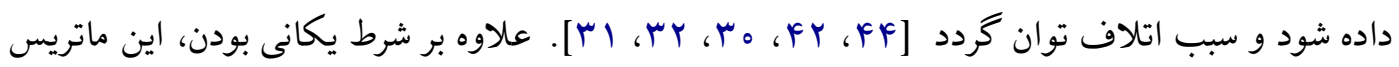
ها بايد شرايط ديگرى را نيز برآورده سازند. به طور خاص، براى اينكه در گيرنده بتوان عمل آشكارسازى

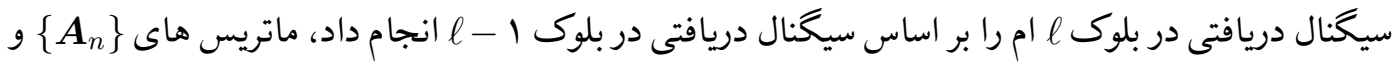
$\left\{\boldsymbol{U}_{i}^{(\ell)}\right\}$ ، بايد در شرط جابجايى بذيرى با ماتريس هاى يكانى استفاده شده در سيخنالينخ تفاضلى ، صدق كنند، يعنى بايد داشته باشيم [Yr]،

$$
\begin{aligned}
\boldsymbol{U}_{i}^{(\ell)} \boldsymbol{A}_{n}=\boldsymbol{A}_{n} \boldsymbol{U}_{i}^{(\ell)}, \quad \text { and } \quad \boldsymbol{U}_{i}^{(\ell)} \boldsymbol{B}_{n} & =\boldsymbol{B}_{n} \overline{\boldsymbol{U}}_{i}^{(\ell)} \\
& i=\mathbf{1}, \boldsymbol{r}, n=1, \ldots, N, \ell=1, \ldots, L-1 .
\end{aligned}
$$

اين شرايط براى ماتريس هاى مورد استفاده در رله ها وجود دارد و در بخش بعد ما يك سرى شرايط جديد براى ماتريس هاى به دست خواهيم آورد كه باعث حذف كامل سيخنال خود_تداخل، بدون اطلاع از ضرايب محوشدگى كانال، مى گردد.

اكنون سعى خواهيم كرد سيخنال هاى دريافتى در مبدا اول را به صورت تابعى از سيخنال هاى ارسالى به دست آوريم. بايد به اين نكته اشاره كرد كه از اين به بعد ما تنها در مورد مبدا اول بحث خواهيم كرد و به علت تقارن رياضى و فيزيكى موجود همه روابط براى مبدا دوم به راحتى قابل استخراج است. با استفاده از

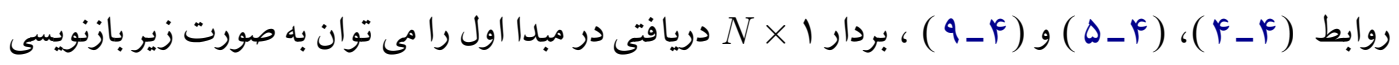

$$
\boldsymbol{y}_{\uparrow}^{(\ell)}=\sqrt{P_{\uparrow}} \boldsymbol{S}_{\uparrow}^{(\ell)} \boldsymbol{h}_{\uparrow}+\sqrt{P_{\curlyvee}} \boldsymbol{S}_{r}^{(\ell)} \boldsymbol{h}_{\curlyvee}+\boldsymbol{w}_{\uparrow}^{(\ell)}
$$




$$
\text { كه ماتريس }
$$$$
\boldsymbol{S}_{i}^{(\ell)}=\left[\boldsymbol{C}, \boldsymbol{\theta}_{i}^{(\ell)}, \ldots, \boldsymbol{C}_{N} \boldsymbol{\theta}_{i}^{(\ell)}\right] \in \mathbb{C}^{N \times N}
$$

$$
i=1, r, \quad \ell=1, \ldots, L-1
$$

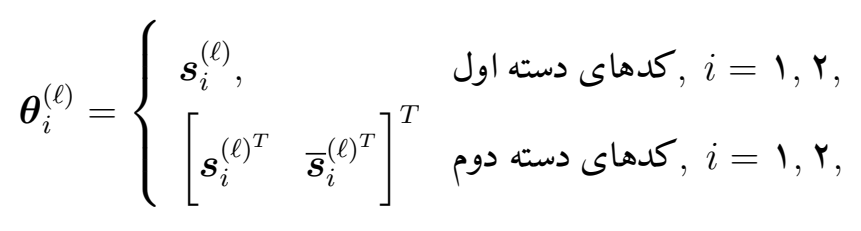

و بردارهاى كانال هاى معادل يعنى \ و و

$$
\begin{gathered}
\boldsymbol{h}_{\uparrow}=\left[\beta_{\uparrow} \boldsymbol{f}_{\uparrow}^{T} \boldsymbol{X}_{\uparrow} \boldsymbol{f}_{1}, \ldots, \beta_{N} \boldsymbol{f}_{N}^{T} \boldsymbol{X}_{N} \boldsymbol{f}_{N}\right]^{T}, \\
\boldsymbol{h}_{\curlyvee}=\left[\beta_{\uparrow} \boldsymbol{g}_{\uparrow}^{T} \boldsymbol{X}, \boldsymbol{f}_{\uparrow}, \ldots, \beta_{N} \boldsymbol{g}_{N}^{T} \boldsymbol{X}_{N} \boldsymbol{f}_{N}\right]^{T},
\end{gathered}
$$

$$
\text { و نهايتا بردار }
$$

$$
\boldsymbol{w}_{\uparrow}^{(\ell)}=\sum_{n=1}^{N} \beta_{n} \boldsymbol{C}_{n} \boldsymbol{V}_{n}^{(\ell)} \boldsymbol{X}_{n} \boldsymbol{f}_{n}+\boldsymbol{z}_{\uparrow}^{(\ell)} .
$$

رابطه (₹ ـ 1 ) نشان مى دهد كه اولين جمله در سمت راست تساوى شامل سيكنال ارسال شده توسط خود مبدا اول و به عبارتى سگنال خود_ تداخل است. دومين جمله در سمت راست اين تساوى سيخنال ارسال شده توسط مبدا دوم و يا به عبارتى سيخنال مطلوب است. در نهايت سومين جمله در سمت راست اين تساوى

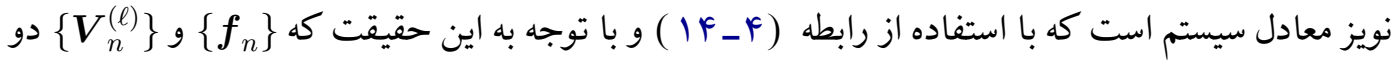
به دو مستقل از هم و هر يك با ميانخين صفر مى باشند، مى توان ميانخين و ماتريس كوواريانس اين نويز را

$$
\text { به صورت زير به دست آورد: }
$$

$$
\Sigma_{\boldsymbol{w}_{\curlywedge}}=\mathrm{E}\left\{\boldsymbol{w}_{\uparrow}^{(\ell)} \boldsymbol{w}_{\uparrow}^{(\ell)^{\dagger}}\right\}=\sum_{n=1}^{N} \beta_{n}^{\curlyvee} M_{n} \boldsymbol{C}_{n} \boldsymbol{C}_{n}^{\dagger}+\boldsymbol{I}_{N}
$$

توزيع نويز (l) شده است، توزيع ؟

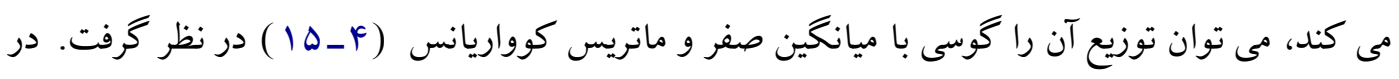
تئورى اطلاعات نشان داده شده است كه نويز گوسى جمع شونده بدترين نوع نويز شونده هى باشد. يعنى براى 


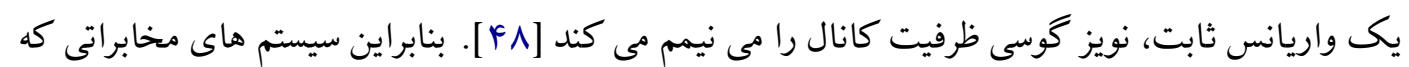
تحت فرض گوسى بودن نويز طراحى مى شوند در عمل عملكرد مناسبى دارند. در بخش بعد بطور خاص بر روى اثر سيخنال خود تداخل بر روى كارايى سيستم مى بردازيم.

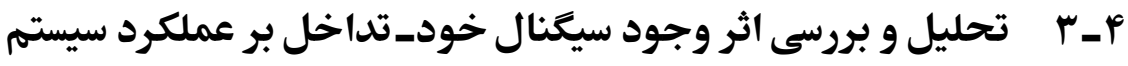

در اين بخش به بررسى اثر وجود سيكنال خود_تداخل بر روى SINR و PEP سيستم مى بردازيم و نشان خواهيم داد اكر اين سيكنال نامطلوب به طور كامل حذف نشود با افزايش توان ارسالى هم SINR و هم PQ مقادير ثابتى (كه به توان بستخى ندارند) همخرا مى شوند. اين امر سبب مى شود كه با افزايش توان دايورسيتى سيستم صفر شده و error floor در سيستم رخ بدهد. ما در اين بخش فرض مى كنيم سيخنال

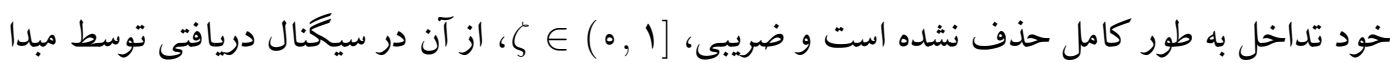

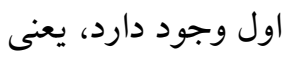

$$
\boldsymbol{y}_{\uparrow}^{(\ell)}=\zeta \sqrt{P_{\uparrow}} \boldsymbol{S}_{\uparrow}^{(\ell)} \boldsymbol{h}_{\uparrow}+\sqrt{P_{\curlyvee}} \boldsymbol{S}_{\curlyvee}^{(\ell)} \boldsymbol{h}_{\curlyvee}+\boldsymbol{w}_{\uparrow}^{(\ell)}
$$

بدون از دست دادن كليت مساله، از اين به بعد در كل اين فصل فرض مى كنيم كه توان هر مبدا و رله ضريبى از يك توان دلخواه است به عبارت ديخر

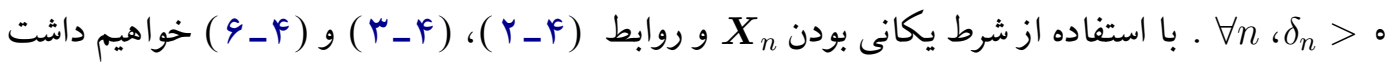

$$
\beta_{n}=\sqrt{\frac{\delta_{n} P}{M_{n}\left(\left(1+\delta_{0}\right) P+1\right)}} .
$$

\section{SINR}

در اين بخش به بررسى اثر سيخنال خود تداخل بر روى SINR متوسط مبدا اول مى بردازيم، براى مبدا دوم محاسبات بطور مشابه مى باشد. براى محاسبه SINR متوسط مبدا اول، نياز است كه توان متوسط سيخنال مطلوب دريافتى در مبدا اول، توان متوسط سيخنال خود_تداخل در مبدا اول وتوان متوسط نويز معادل دريافتى در مبدا اول را محاسبه نماييم.

توان متوسط سيكنال مطلوب دريافتى در مبدا اول برابر است با

$$
\mathrm{E}\left\{\left(\boldsymbol{S}_{\curlyvee}^{(\ell)} \boldsymbol{h}_{\curlyvee}\right)^{\dagger}\left(\boldsymbol{S}_{\curlyvee}^{(\ell)} \boldsymbol{h}_{\curlyvee}\right)\right\}=N \sum_{n=1}^{N} \beta_{n}^{\curlyvee} M_{n} .
$$




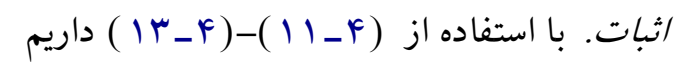

$\mathrm{E}\left\{\left(\boldsymbol{S}_{\curlyvee}^{(\ell)} \boldsymbol{h}_{\curlyvee}\right)^{\dagger}\left(\boldsymbol{S}_{\curlyvee}^{(\ell)} \boldsymbol{h}_{\curlyvee}\right)\right\}=\mathrm{E}\left\{\sum_{n=1}^{N} \sum_{q=1}^{N} \beta_{n} \beta_{q} \boldsymbol{f}_{n}^{\dagger} \boldsymbol{X}_{n}^{\dagger} \overline{\boldsymbol{g}}_{n} \boldsymbol{\theta}_{\curlyvee}^{(\ell)} \boldsymbol{C}_{n}^{\dagger} \boldsymbol{C}_{q} \boldsymbol{\theta}_{\curlyvee}^{(\ell)} \boldsymbol{g}_{q}^{T} \boldsymbol{X}_{q} \boldsymbol{f}_{q}\right\}$

$$
\begin{aligned}
& =\mathrm{E}\left\{\sum_{n=1}^{N} \beta_{n}^{r} \operatorname{Tr}\left(\boldsymbol{X}_{n}^{\dagger} \overline{\boldsymbol{g}}_{n} \boldsymbol{\theta}_{r}^{(\ell) \dagger} \boldsymbol{C}_{n}^{\dagger} \boldsymbol{C}_{n} \boldsymbol{\theta}_{r}^{(\ell)} \boldsymbol{g}_{n}^{T} \boldsymbol{X}_{n}\right)\right\} \\
& =\mathrm{E}\left\{\sum_{n=1}^{N} \beta_{n}^{r} \operatorname{Tr}\left(\boldsymbol{\theta}_{r}^{(\ell)^{\dagger}} \boldsymbol{C}_{n}^{\dagger} \boldsymbol{C}_{n} \boldsymbol{\theta}_{r}^{(\ell)}\right) \operatorname{Tr}\left(\boldsymbol{X}_{n}^{\dagger} \overline{\boldsymbol{g}}_{n} \boldsymbol{g}_{n}^{T} \boldsymbol{X}_{n}\right)\right\},
\end{aligned}
$$

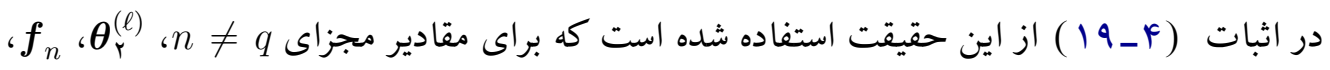
界 $\boldsymbol{g}_{q}$ و $\boldsymbol{g}_{n}$ ، $\boldsymbol{f}_{q}$ مختلطش جايگزين شده، نسبت به آوردن (11_F_ ) استفاده شده است.

توان متوسط سيخنال خود_تداخل در مبدا اول با استفاده از رابطه زير محاسبه مى شود:

$$
\mathrm{E}\left\{\left(\boldsymbol{S}_{\uparrow}^{(\ell)} \boldsymbol{h}_{\uparrow}\right)^{\dagger}\left(\boldsymbol{S}_{\uparrow}^{(\ell)} \boldsymbol{h}_{\uparrow}\right)\right\}=N \sum_{n=1}^{N} \beta_{n}^{\curlyvee} \alpha_{n},
$$

$$
\alpha_{n}=r \sum_{k=1}^{M_{n}}\left|x_{k k}^{(n)}\right|^{r}+\sum_{k=1}^{M_{n}} \sum_{j=k+1}^{M_{n}}\left|x_{k j}^{(n)}+x_{j k}^{(n)}\right|^{r}, \quad n=1, \ldots, N
$$

$$
\text { و }
$$

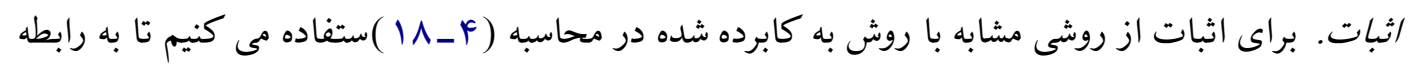
زير برسيم

$$
\begin{aligned}
\mathrm{E}\left\{\left(\boldsymbol{S}_{1}^{(\ell)} \boldsymbol{h}_{\uparrow}\right)^{\dagger}\left(\boldsymbol{S}_{\uparrow}^{(\ell)} \boldsymbol{h}_{\uparrow}\right)\right\} & =\mathrm{E}\left\{\sum_{n=1}^{N} N \beta_{n}^{r} \boldsymbol{f}_{n}^{\dagger} \boldsymbol{X}_{n}^{\dagger} \overline{\boldsymbol{f}}_{n} \boldsymbol{f}_{n}^{T} \boldsymbol{X}_{n} \boldsymbol{f}_{n}\right\} \\
& =N \sum_{n=1}^{N} \beta_{n}^{r} \mathrm{E}\left\{\boldsymbol{f}_{n}^{\dagger} \boldsymbol{X}_{n}^{\dagger} \overline{\boldsymbol{f}}_{n} \boldsymbol{f}_{n}^{T} \boldsymbol{X}_{n} \boldsymbol{f}_{n}\right\},
\end{aligned}
$$

براى محاسبه سمت راست (Y (Y Y )، m امين درايه از بردار با

$\mathrm{E}\left\{\boldsymbol{f}_{n}^{\dagger} \boldsymbol{X}_{n}^{\dagger} \overline{\boldsymbol{f}}_{n} \boldsymbol{f}_{n}^{T} \boldsymbol{X}_{n} \boldsymbol{f}_{n}\right\}$ 


$$
\begin{aligned}
& =\mathrm{E}\left\{\sum_{m=1}^{M_{n}} \sum_{q=1}^{M_{n}} \sum_{m_{\bullet}=1}^{M_{n}} \sum_{q_{\circ}=1}^{M_{n}} f_{n m} f_{n q} \bar{f}_{n m_{\circ}} \bar{f}_{n q_{\circ}} x_{m q}^{(n)} \bar{x}_{m \circ q_{\circ}}^{(n)}\right\} \\
& =\mathrm{E}\left\{\sum_{m=1}^{M_{n}}\left|f_{n m}\right|^{\kappa}\left|x_{m m}^{(n)}\right|^{r}\right\}+\mathrm{E}\left\{\sum_{m=1}^{M_{n}} \sum_{q=1}^{M_{n}}\left|f_{n m}\right|^{r}\left|f_{n q}\right|^{r}\left|x_{m q}^{(n)}\right|^{r}\right\} \\
& +\mathrm{E}\left\{\sum_{m=1}^{M_{n}} \sum_{q=1}^{M_{n}}\left|f_{n m}\right|^{r}\left|f_{n q}\right|^{r} x_{m q}^{(n)} \bar{x}_{q m}^{(n)}\right\}+\mathrm{E}\left\{\sum_{m=1}^{M_{n}} \sum_{m_{\circ}=1}^{M_{n}} f_{n m}^{r} \bar{f}_{n m_{\circ}}^{r} x_{m m}^{(n)} \bar{x}_{m \circ}^{(n)} m_{\circ}\right\} \\
& =r \sum_{m=1}^{M_{n}}\left|x_{m m}^{(n)}\right|^{r}+\sum_{m=1}^{M_{n}} \sum_{q=m+1}^{M_{n}}\left|x_{m q}^{(n)}+x_{q m}^{(n)}\right|^{r}, \\
& =\alpha_{n} \text {. }
\end{aligned}
$$

در به دست آوردن رابطه (YF_F) از اين حقيقت استفاده كرده ايم كه براى m، q، .m، هاى مجزا، ضرايب محوشدگى كانال ميانگين صفر و واريانس يك مى باشند. اين امر سبب مى شود كه جملات غير صفر در (YM_F) به صورت زير باشند:

$$
\begin{aligned}
& m=q=m_{\circ}=q_{\circ}-1 \\
& q=q_{\circ}, m=m_{\bullet}-r \\
& q=m_{\circ}, m=q_{\circ}-r \\
& m_{\circ}=q \circ g=q-r
\end{aligned}
$$

كه به ترتيب F جمله (YF_F) را نتيجه مى دهند. براى محاسبه اولين جمله در (YF_F) از رابطه زير استفاده شده است

$\left(Y V_{-} r\right)$

$$
\mathrm{E}\left\{\left|f_{n m}\right|^{\uparrow}\right\}=\mathrm{E}\left\{\Re\left(f_{n m}\right)^{\uparrow}\right\}+\mathrm{E}\left\{\Im\left(f_{n m}\right)^{\uparrow}\right\}+r \mathrm{E}\left\{\Re\left(f_{n m}\right)^{r}\right\} \mathrm{E}\left\{\Im\left(f_{n m}\right)^{r}\right\}=r .
$$

محاسبه دومين و سومين سيخما جمله سرراست است و براى محاسبه ججهارمين سيخما در اين تساوى از رابطه زير استفاده شده است

$$
\begin{aligned}
& \mathrm{E}\left\{f_{n m}^{r}\right\}=\mathrm{E}\left\{\Re\left(f_{n m}\right)^{r}\right\}-\mathrm{E}\left\{\Im\left(f_{n m}\right)^{r}\right\}+r \mathrm{E}\left\{\Re\left(f_{n m}\right) \Im\left(f_{n k}\right)\right\}=\circ . \quad\left(\boldsymbol{r}_{-} \boldsymbol{F}\right) \\
& \text { با تركيب (Y }
\end{aligned}
$$


در نهايت توان متوسط نويز در مبدا اول برابر است با

$$
\mathrm{E}\left\{\boldsymbol{w}_{1}^{(\ell)^{\dagger}} \boldsymbol{w}_{1}^{(\ell)}\right\}=\operatorname{Tr}\left(\mathrm{E}\left\{\boldsymbol{w}_{1}^{(\ell)} \boldsymbol{w}_{1}^{(\ell)^{\dagger}}\right\}\right)=N \sum_{n=1}^{N} \beta_{n}^{\curlyvee} M_{n}+N
$$

اثبات. با اسنفاده از استقلال ل

$$
\mathrm{E}\left\{\boldsymbol{w}_{\uparrow}^{(\ell)} \boldsymbol{w}_{\uparrow}^{(\ell)^{\dagger}}\right\}=\mathrm{E}\left\{\sum_{n=1}^{N} \beta_{n}^{\curlyvee} \boldsymbol{C}_{n} \boldsymbol{V}_{n}^{(\ell)} \boldsymbol{X}_{n} \boldsymbol{f}_{n} \boldsymbol{f}_{n}^{\dagger} \boldsymbol{X}_{n}^{\dagger} \boldsymbol{V}_{n}^{(\ell)^{\dagger}} \boldsymbol{C}_{n}^{\dagger}\right\}+\mathrm{E}\left\{\boldsymbol{z}_{1}^{(\ell)} \boldsymbol{z}_{1}^{(\ell)^{\dagger}}\right\} . \quad(\boldsymbol{r} \circ-\boldsymbol{F})
$$

$\mathrm{E}\left\{\boldsymbol{V}_{n}^{(\ell)} \boldsymbol{V}_{n}^{(\ell)^{\dagger}}\right\}=M_{n} \boldsymbol{I}_{N}$ and $\mathrm{E}\left\{\boldsymbol{f}_{n} \boldsymbol{f}_{n}^{\dagger}\right\}=\boldsymbol{I}_{M_{n}} \boldsymbol{X}_{n} \boldsymbol{X}_{n}^{\dagger}=\boldsymbol{I}_{M_{n}}$ با رابطه (roبرابى كدهاى دسته اول و E\{ شود.

اكنون كه توان متوسط هر سه سيخنال مطلوب، خود_تداخل و نويز محاسبه شده، با استفاده از ( ( IN ) )

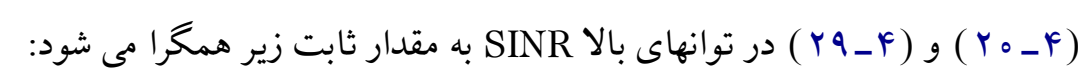

$$
\operatorname{SINR}=\frac{\delta_{\bullet} P^{r} \sum_{n=1}^{N} \delta_{n}}{\zeta^{\Upsilon} P^{r} \sum_{n=1}^{N} \frac{\alpha_{n} \delta_{n}}{M_{n}}+\left(1+\sum_{n=。}^{N} \delta_{n}\right) P+1} .
$$

همانطور كه مشاهده مى شود اين رابطه بيان مى دارد كه اخر سيخنال خو تداخل به طور كامل حذف اتف

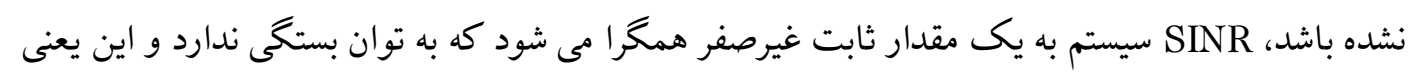

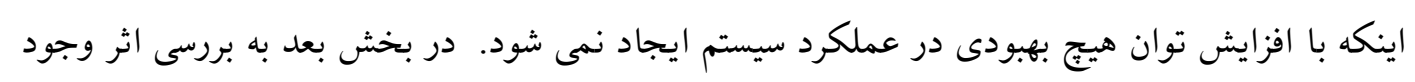
سيخنال خود تداخل بر روى PEP مى بردازيم.

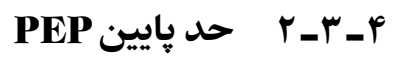

در اين بخش براى بررسى اثر سيحنال خود_تداخل بر روى احتمال خطاى سيستم، يك حد بايين براى

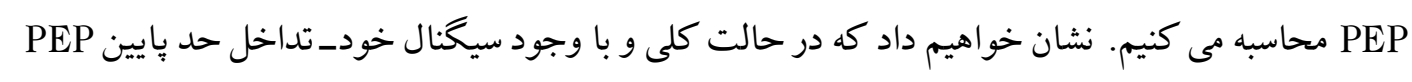

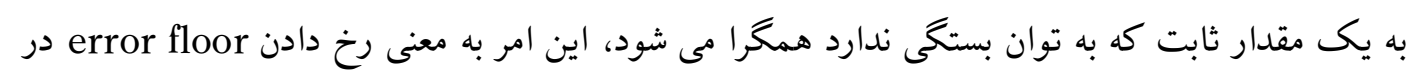

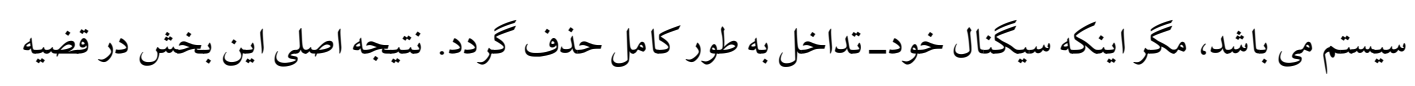
زير خلاصه شده است.

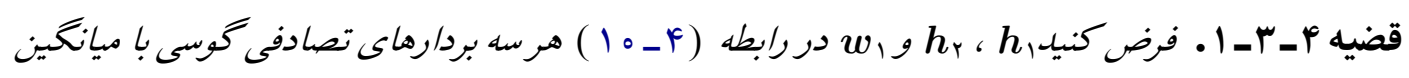
صفروبه ترتيب با ماتريس كوواريانس 


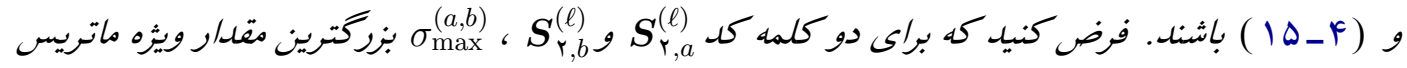

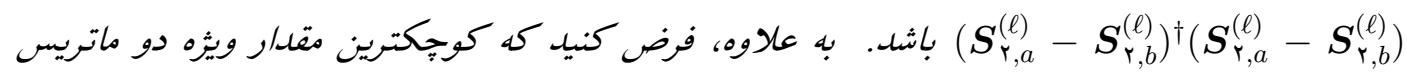

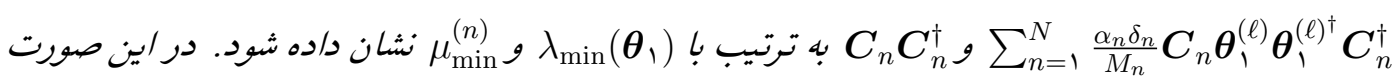
متناظر با خطاى آثكارسازى PEP

$$
\begin{aligned}
& \operatorname{Pr}\left(\boldsymbol{S}_{\curlyvee, a}^{(\ell)} \rightarrow \boldsymbol{S}_{\mathrm{r}, b}^{(\ell)}\right) \geq \mathrm{E}_{\boldsymbol{\theta}_{\uparrow}^{(\ell)}}\left\{Q\left(\sqrt{\Delta_{\uparrow}}\right)\right\}, \\
& \Delta_{1} \triangleq \frac{r^{-1} \delta_{\circ} \hat{\sigma}_{\max } \sum_{n=1}^{N} \delta_{n}}{\zeta^{r} \lambda_{\min }\left(\boldsymbol{\theta}_{1}^{(\ell)}\right)+\left(1+\delta_{\circ}+\sum_{n=1}^{N} \delta_{n} \mu_{\min }^{(n)}\right) P^{-1}+P^{-r}} . \\
& \text { اثبات. براى بيدا كردن يك حد بايين براى PEP مى توانيم بنويسيم: } \\
& \operatorname{Pr}\left(\boldsymbol{S}_{\uparrow, a}^{(\ell)} \rightarrow \boldsymbol{S}_{\curlyvee, b}^{(\ell)}\right)=\mathrm{E}_{\boldsymbol{\theta}_{\uparrow}^{(\ell)}, \boldsymbol{h}_{\curlyvee}}\left\{\operatorname{Pr}\left(\boldsymbol{S}_{\curlyvee, a}^{(\ell)} \rightarrow \boldsymbol{S}_{\curlyvee, b}^{(\ell)} \mid \boldsymbol{h}_{\curlyvee}, \boldsymbol{\theta}_{\uparrow}^{(\ell)}\right)\right\} .
\end{aligned}
$$

با استفاده از رابطه (F-19)، مشروط به دانستن ميانگين صفر هستند، بردار (l)

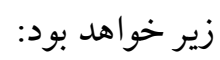

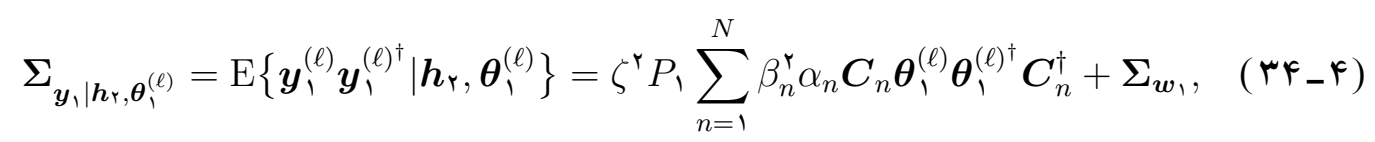

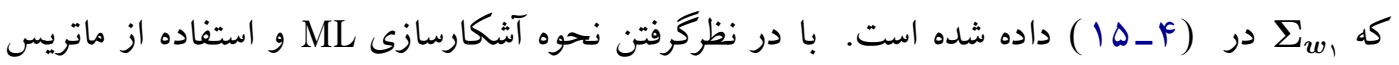
كوواريانس بالا، مى توان نوشت:

$$
\begin{aligned}
& \mathrm{E}_{\boldsymbol{\theta}_{\Gamma}^{(\ell),}, \boldsymbol{h}_{\curlyvee}}\left\{\operatorname{Pr}\left(\boldsymbol{S}_{\curlyvee, a}^{(\ell)} \rightarrow \boldsymbol{S}_{\curlyvee, b}^{(\ell)} \mid \boldsymbol{h}_{\curlyvee}, \boldsymbol{\theta}_{\uparrow}^{(\ell)}\right)\right\}
\end{aligned}
$$

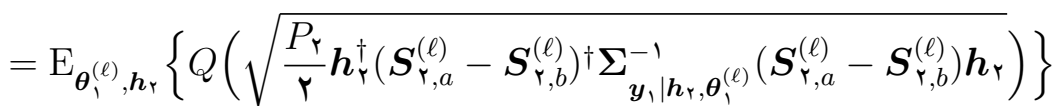

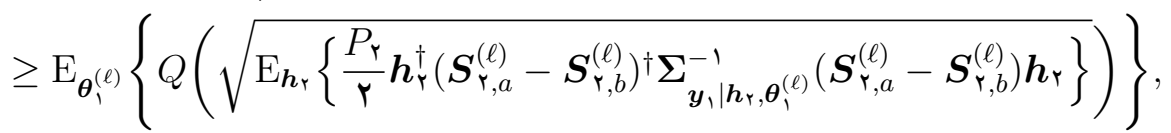

$\left(r \Delta_{-} F\right)$



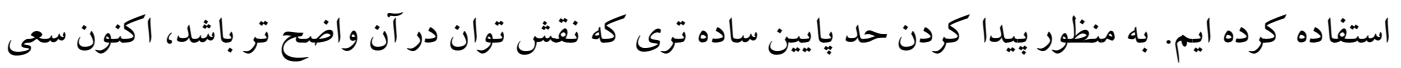
مى كنيم يك حد مناسب براى (l) استفاده كرده و داريم

$\Sigma_{\boldsymbol{y} \backslash \mid \boldsymbol{h}_{\curlyvee}, \boldsymbol{\theta}_{\uparrow}^{(\ell)}}$ 


$$
\begin{aligned}
& =\frac{P^{r}}{\left(1+\delta_{0}\right) P+1}\left(\zeta^{r} \sum_{n=1}^{N} \frac{\alpha_{n} \delta_{n}}{M_{n}} \boldsymbol{C}_{n} \boldsymbol{\theta}_{1}^{(\ell)} \boldsymbol{\theta}_{1}^{(\ell)^{\dagger}} \boldsymbol{C}_{n}^{\dagger}+\frac{1}{P} \sum_{n=1}^{N} \delta_{n} \boldsymbol{C}_{n} \boldsymbol{C}_{n}^{\dagger}+\frac{\left(1+\delta_{0}\right) P+1}{P^{r}} \boldsymbol{I}_{N}\right) \\
& \succeq \frac{P^{r}}{\left(1+\delta_{0}\right) P+1}\left(\zeta^{r} \lambda_{\min }\left(\boldsymbol{\theta}_{1}^{(\ell)}\right)+\left(\boldsymbol{1}+\delta_{\circ}+\sum_{n=1}^{N} \delta_{n} \mu_{\min }^{(n)}\right) P^{-1}+P^{-r}\right) \boldsymbol{I}_{N}, \quad(\boldsymbol{r} \boldsymbol{q}-\boldsymbol{r})
\end{aligned}
$$

كه ( $\sum_{n=1}^{N} \frac{\alpha_{n} \delta_{n}}{M_{n}} \boldsymbol{C}_{n} \boldsymbol{\theta}_{1}^{(\ell)} \boldsymbol{\theta}_{1}^{(\ell)^{\dagger}} \boldsymbol{C}_{n}^{\dagger}$ و های $\boldsymbol{\Psi}\left(\boldsymbol{S}_{r, a}^{(\ell)}, \boldsymbol{S}_{r, b}^{(\ell)}\right)=$ = مى $\boldsymbol{C}_{n} \boldsymbol{C}_{n}^{\dagger}$ : باشد و $\left(\boldsymbol{S}_{\mathrm{r}, a}^{(\ell)}-\boldsymbol{S}_{r, b}^{(\ell)}\right)^{\dagger}\left(\boldsymbol{S}_{\mathrm{r}, a}^{(\ell)}-\boldsymbol{S}_{\mathrm{r}, b}^{(\ell)}\right)$

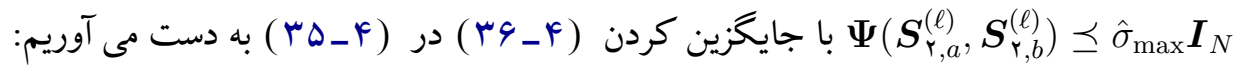

$$
\begin{aligned}
& \mathrm{E}_{\boldsymbol{\theta}_{\uparrow}^{(\ell)}, \boldsymbol{h}_{\curlyvee}}\left\{\operatorname{Pr}\left(\boldsymbol{S}_{\boldsymbol{r}_{,}, a}^{(\ell)} \rightarrow \boldsymbol{S}_{\curlyvee, b}^{(\ell)} \mid \boldsymbol{h}_{\curlyvee}, \boldsymbol{\theta}_{\uparrow}^{(\ell)}\right)\right\} \\
& \geq \mathrm{E}_{\boldsymbol{\theta}_{1}^{(\ell)}}\left\{Q\left(\sqrt{\left.\mathrm{E}_{\boldsymbol{h}_{\curlyvee}}\left\{\frac{r^{-1} \delta_{\bullet} P\left(\left(1+\delta_{\circ}\right) P+1\right) \hat{\sigma}_{\max } \boldsymbol{h}_{\curlyvee}^{\dagger} \boldsymbol{h}_{\curlyvee}}{P^{\curlyvee} \zeta^{\Upsilon} \lambda_{\min }\left(\boldsymbol{\theta}_{1}^{(\ell)}\right)+P\left(1+\delta_{0}+\sum_{n=1}^{N} \delta_{n} \mu_{\min }^{(n)}\right)+1}\right\}\right)}\right\} .\right.
\end{aligned}
$$

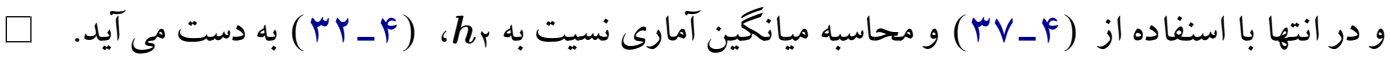
در اين جا اين حد بايين به دست آمده براى PEP را تفسير مى كنيم. با توجه به تعاريف ارائه شده براى ( كه براى هر دو دسته كد معرفى شده،

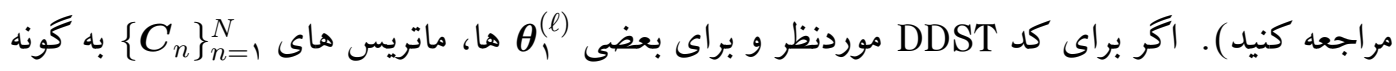

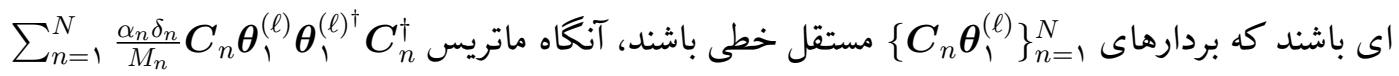

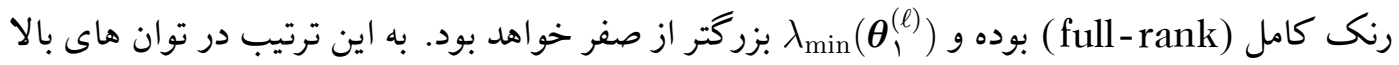
P ، جمله غالب در مخرج (·) تابع • >

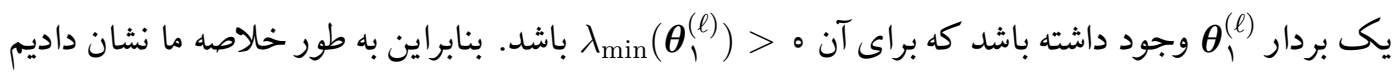
كه در صورت عدم حذف كامل مولفه خود_تداخل، احتما خطاى جفتى PEP از يك مقدار ثابت كه به P بستخى ندارد و بزرگتر از صفر است، بزرگتر خواهد بود و اين يعنى رخ دادن error floor و جندگانگى' صفر. اين نتايج تحليلى در بخش شبيه سازى تصريق خواهند شد. اكنون كه مى دانيم وجود هر مقدار از مولفه سيكُال خود_تداخل جهه اثرى ير روى عملكرد سيستم دارد در بخش بعد يك روش براى حذف كامل اين سيخنال ارائه خواهيم كرد. 


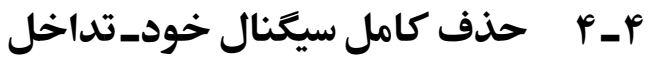

در بخش قبل ديديم كه اكر سيخنال خود_تداخل به طور كامل حذف نشده نباشد براى م متوسط هر مبدا و PEP هر دو به مقادير مثبت غير صفر همخرا مى شوند و اين امر باعث مى شود كه جندگانخى سيستم صفر شود و error floor رخ دهد. اكنون ما روشى ارائه مى دهم كه سيخنال خود_ تداخل را به طور كامل حذف مى كند و سبب مى شود كه براى م SINR ، $P \rightarrow$ متوسط هر مبدا به سمت بى نهايت رفته و PEP به سمت صفر برود. براى اين منظور ما قضيه زير را داريم:

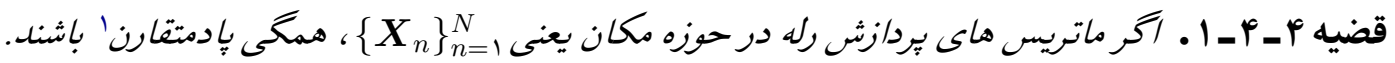
SINR اثبات. براى بيدا كردن ماتريس هاى SINR ماكزيمم مى كند، بايد توجه كنيم كه اين ماتريس ها توسط ضرايب \} حذف اثر سيكنال-خودتداخل ماتريس هاى

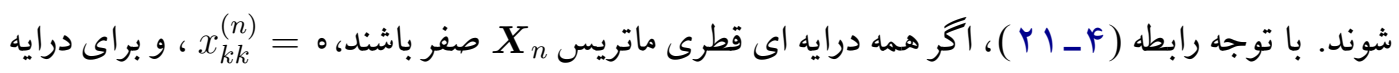
هاى غير قطر اصلى رابطه عبارت ديخر، اين دو شرط با هم به اين مفهوم است كه ماتريس هاى اين همان مطلب ارائه شده در قضيه بالا مى باشد.

تاكنون نشان داديم كه انتخاب ماتريس هاى

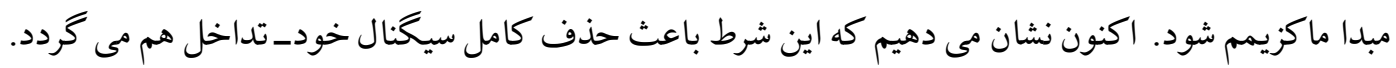

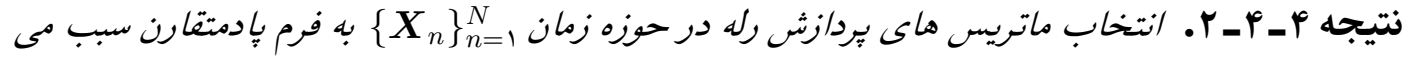

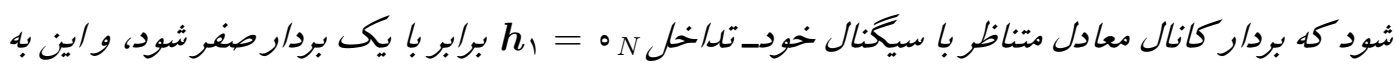
معنى حذف كامل (نه تقريبى) سيخنال خود تداخل مى باشد.

اثبات. با توجه به رابطه (F ـ ـ ) مى دانيم كه بردار كانال معادل متناظر با سيخنال خود تداخل، بردار مى باشد. فرض كنيد درايه ام بردار ا لذا داريم: كه نهايتا به مفهوم S $\gamma_{n}=。$ 
تا كنون دو شرط براى انتخاب ماتريس هاى إئ يكانى باشند براى تامين توزيع يكسان توان بر روى كانال هاى مختلف و Y ) بايد بادمتقارن باشند براى حذف كامل سيخنال خود_تداخل. تركيب اين دو شرط لم زير را نتيجه مى دهد:

لم f-f ماتريس ها زوج باشل.

$\left|\boldsymbol{X}_{n}\right|=(-1)^{M_{n}}\left|\boldsymbol{X}_{n}\right|$ : مى توات. مى دانيم كه براى ماتريس بِادمتقارن اين تساوى بيان مى دارد كه براى $M_{n}$ هاى فرد بايد ه $\left|\boldsymbol{X}_{n}\right|$ باشد. از طرفى يكانى بودن اين ماتريس ها $M_{n}$ كود $\boldsymbol{X}_{n}$ بايد زوج باشد تا ماتريسى بتواند به طور همزمان يكانى و بِادمتقارن باشد.

از آنجايى كه Mn به تعدا آنتن هاى فعال در رله اشاره مى كند لذا براى عملكرد صحيح روش بيشنهاد شده براى حذف كامل سيگنال خوـ تداخل در هر رله بايد تعداد زوجى آنتن فعال براى ارسال اطلاعات استفاده شود. قضيه زير روش ساخت ماتريس ها يكانى يادمتقارن


$\boldsymbol{\Phi}_{n} \in \mathbb{C}^{r K \times r K}$ بورت زير باشد: يكى ماتريس يكانى است. ماتريس X باشند و رو روى دايره به شعاع واحد قرار د/شته باشند، يعنى اين درايه ها بايد به صورت باشند كه

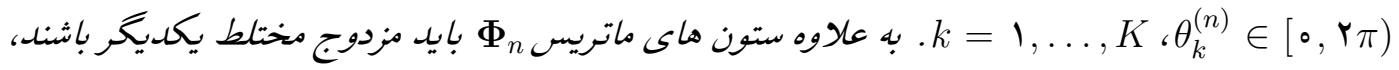
يعنى /ين ماتريس

$$
\mathbf{\Phi}_{n}=\left[\phi_{1}^{(n)}, \bar{\phi}_{1}^{(n)}, \ldots, \phi_{K}^{(n)}, \bar{\phi}_{K}^{(n)}\right]
$$

باشله. اين ماتريس يكانى با استغاده /ز يك ماتريس دلخواه حقيقى متعامد مانند ماتريس QQ ف با استغاده /ز رابطه زير ساخته مى شود: $\boldsymbol{Q}_{n}=\left[\boldsymbol{q}_{\uparrow}^{(n)}, \boldsymbol{q}_{\curlyvee}^{(n)}, \ldots, \boldsymbol{q}_{\curlyvee K}^{(n)}\right] \in \mathbb{R}^{\Upsilon K \times \Upsilon K}, \quad \boldsymbol{\phi}_{k}^{(n)}=\frac{1}{\sqrt{r}}\left(\boldsymbol{q}_{\curlyvee k-1}^{(n)}+j \boldsymbol{q}_{\curlyvee k}^{(n)}\right), \quad k=1, \ldots, K$. 


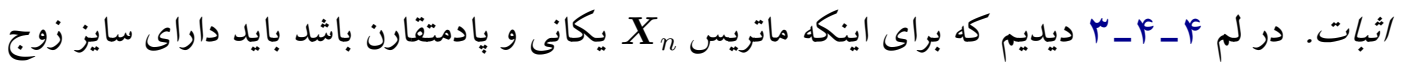
باشد لذا در اين اثبات فرض مى كنيم كه

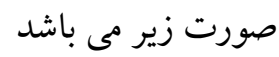

$$
\boldsymbol{X}_{n}=\boldsymbol{\Phi}_{n} \boldsymbol{\Lambda}_{n} \boldsymbol{\Phi}_{n}^{\dagger}
$$

كه ماتريس قطرى

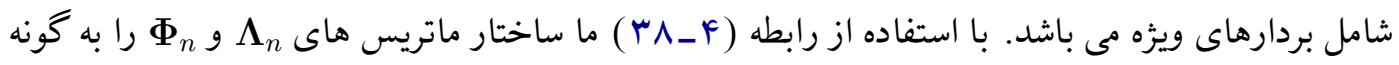
اي بيدا مىكنيم كه ماتريس با ماتريس

له $. n=1, \ldots, N ، k=1, \ldots, K ، \theta_{k}^{(n)} \in[0, r \pi)$

اثبات. براى اثبات توجه داريم كه k امين مقدار ويزه هر ماتريس يكانى

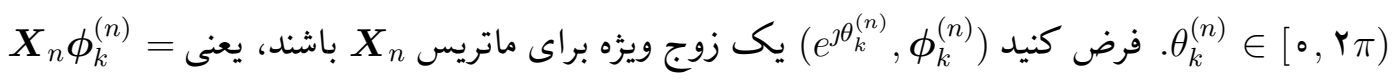
تر

$$
\begin{aligned}
& \text { ترانهاده تاثيرى بر روى مقادير ويرُه ندارد داريم } \\
& \boldsymbol{X}_{n}^{T} \boldsymbol{\psi}_{k}^{(n)}=e^{\jmath \theta_{k}^{(n)}} \boldsymbol{\psi}_{k}^{(n)} .
\end{aligned}
$$

با استفاده از اين حقيقت كه

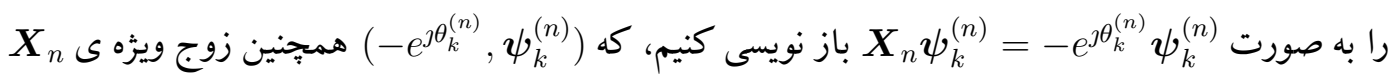
مى باشد. بنا براين مقادير ويزه هر ماتريس يكانى بادمتقارن

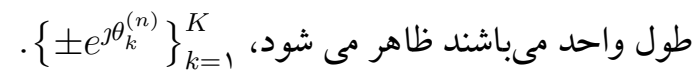
اكنون ويزگى هاى ماتريس يكانى باشد. نتيجه در لم زير آمده است.

لم كى ماتريس يكانى و پادمتقارن X

$$
\Phi_{n}=\left[\begin{array}{lllll}
\phi_{1}^{(n)}, & \bar{\phi}_{1}^{(n)}, & \ldots, & \phi_{K}^{(n)}, & \bar{\phi}_{K}^{(n)}
\end{array}\right] .
$$


اثبات. اخر فرض كنيم داريم

$$
\boldsymbol{X}_{n} \boldsymbol{\phi}_{k}^{(n)}=e^{\jmath \theta_{k}^{(n)}} \boldsymbol{\phi}_{k}^{(n)}, \quad \boldsymbol{X}_{n} \boldsymbol{\phi}_{k+1}^{(n)}=-e^{\theta_{k}^{(n)}} \boldsymbol{\phi}_{k+1}^{(n)}, \quad k=1, \ldots, K .
$$

با استفاده از يعنى منجر مى شود كه بيان مى كند $\boldsymbol{X}_{n}^{\dagger}=\boldsymbol{\Phi}_{n} \boldsymbol{\Lambda}_{n}^{\dagger} \boldsymbol{\Phi}_{n}^{\dagger}$ (ץ)_F)

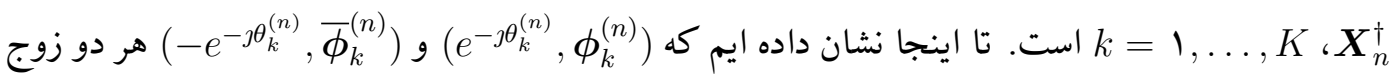
ويزه ى .

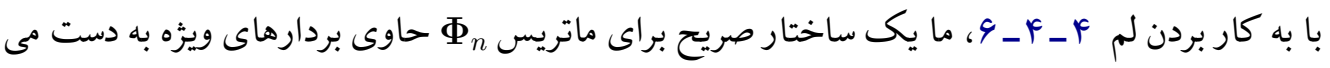

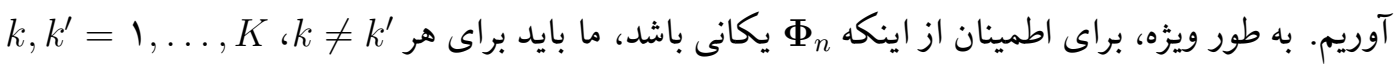
داشته باشيم

$$
\left\|\phi_{k}^{(n)}\right\|^{\curlyvee}=1, \quad \phi_{k}^{(n)^{\dagger}} \bar{\phi}_{k}^{(n)}=0, \quad \phi_{k}^{(n)^{\dagger}} \phi_{k^{\prime}}^{(n)}=0, \quad \phi_{k}^{(n)^{\dagger}} \bar{\phi}_{k^{\prime}}^{(n)}=0 .
$$

ما براى ساخت $\phi_{k}^{(n)}=$ ماتريس

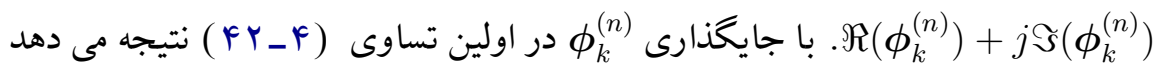
$\left\|\Re\left(\phi_{k}^{(n)}\right)\right\|^{r}+\left\|\Im\left(\phi_{k}^{(n)}\right)\right\|^{r}=1, \quad k=1, \ldots, K$, و با جايكذارى در دومين تساوى از (Fr_F ) (Fr) داريم $\left\|\Re\left(\phi_{k}^{(n)}\right)\right\|^{\curlyvee}=\left\|\Im\left(\phi_{k}^{(n)}\right)\right\|^{\curlyvee}, \quad \Re\left(\phi_{k}^{(n)}\right)^{T} \Im\left(\phi_{k}^{(n)}\right)=0, \quad k=1, \ldots, K . \quad\left(\mathcal{F}_{-} \mathcal{F}\right)$ $k=1, \ldots, K ،\left\|\Re\left(\phi_{k}^{(n)}\right)\right\|^{r}=\left\|\Im\left(\phi_{k}^{(n)}\right)\right\|^{r}=\frac{1}{\gamma}$ به

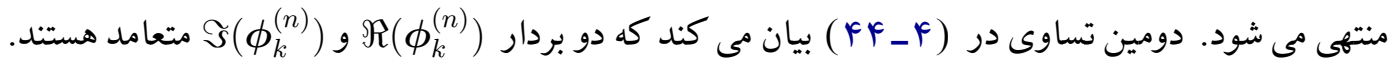

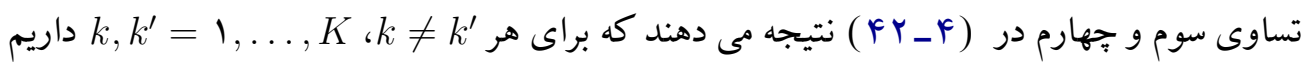
$\Re\left(\phi_{k}^{(n)}\right)^{T} \Re\left(\phi_{k^{\prime}}^{(n)}\right)+\Im\left(\phi_{k}^{(n)}\right)^{T} \Im\left(\phi_{k^{\prime}}^{(n)}\right)=\circ, \quad \Im\left(\phi_{k}^{(n)}\right)^{T} \Re\left(\phi_{k^{\prime}}^{(n)}\right)=\Re\left(\phi_{k}^{(n)}\right)^{T} \Im\left(\phi_{k^{\prime}}^{(n)}\right)$, 


$$
\Re\left(\phi_{k}^{(n)}\right)^{T} \Re\left(\phi_{k^{\prime}}^{(n)}\right)=\Im\left(\phi_{k}^{(n)}\right)^{T} \Im\left(\phi_{k^{\prime}}^{(n)}\right), \quad \Im\left(\phi_{k}^{(n)}\right)^{T} \Re\left(\phi_{k^{\prime}}^{(n)}\right)+\Re\left(\phi_{k}^{(n)}\right)^{T} \Im\left(\phi_{k^{\prime}}^{(n)}\right)=0 .
$$

با تركيب اولين تساوى در (F) متعامد هستند و (n) دومين تساوى در (F)

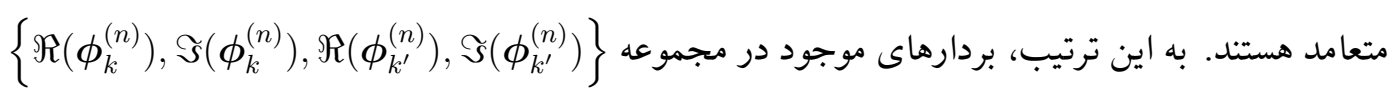
دو به دو متعامد مى باشند براى

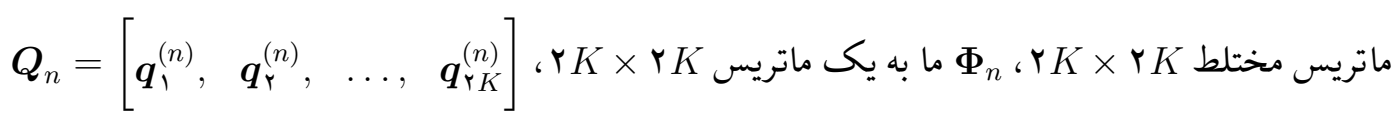
حقيقى متعامد نياز داريم، يعنى ${ }_{n}$ يك ماتريس حقيقى با ستون هاى متعامد با طول واحد است. با به كار $\phi_{k}^{(n)}=\frac{1}{\sqrt{r}}\left(\boldsymbol{q}_{\curlyvee k-1}^{(n)}+{ }^{\prime}\right.$

$$
\text { 年 } \left.j \boldsymbol{q}_{\uparrow k}^{(n)}\right), k=1, \ldots, K,
$$

اين قضيه روش ساخت ماتريس هاى يكانى بادمتقارن براى بردازش زمانى در رله ها را ارايه كرد. در بخش بعد ما اثر اين ماتريس ها را بر روى كارايى سيستم به دست مى آوريم.

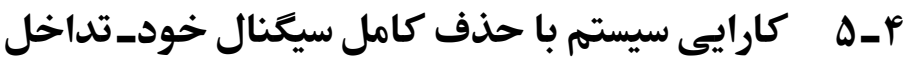

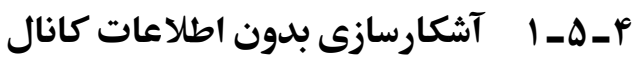

تاكنون نشان داديم انتخاب ماتريسهاى إن

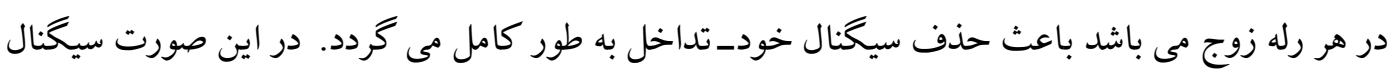
دريافتى در مبدا اول به صورت زير قابل بيان است

$$
\boldsymbol{y}_{\uparrow}^{(\ell)}=\sqrt{P_{\curlyvee}} \boldsymbol{S}_{\curlyvee}^{(\ell)} \boldsymbol{h}_{\curlyvee}+\boldsymbol{w}_{\uparrow}^{(\ell)} .
$$

اين رابطه تنها وقتى معتبر مى باشد كه سيخنال خود_تداخل به طور كامل حذف شده باشد. اخر جه بسيارى از مقالات بدون حذف كامل سيخنال خود_تداخل از اين سيخنال دريافتى براى تحليل خود استفاده كرده

براى تحليل كارايى وقتى كه سيكنال خود_تداخل به طور كامل حذف شده است، از رابطه (F - 1 ) و

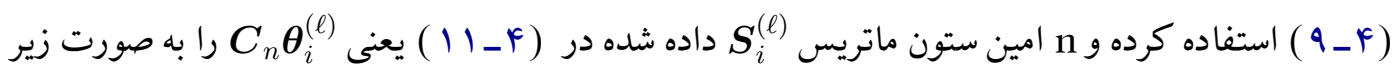


يازنويسى مى كنيم

$$
\boldsymbol{S}_{i}^{(\ell)}=\left[\begin{array}{lll}
\boldsymbol{U}_{i}^{(\ell)} \boldsymbol{C}_{1} \boldsymbol{\theta}_{i}^{(\ell-1)} & \ldots & \boldsymbol{U}_{i}^{(\ell)} \boldsymbol{C}_{N} \boldsymbol{\theta}_{i}^{(\ell-1)}
\end{array}\right]=\boldsymbol{U}_{i}^{(\ell)} \boldsymbol{S}_{i}^{(\ell-1)}
$$

با استفاده از اين رابطه در (FV_F) سيخنال دريافتى در مبدا اول به صورت زير قابل بيان است

$$
\boldsymbol{y}_{\uparrow}^{(\ell)}=\boldsymbol{U}_{\uparrow}^{(\ell)} \boldsymbol{y}_{\uparrow}^{(\ell-1)}+\boldsymbol{w}_{\uparrow}^{(\ell)}-\boldsymbol{U}_{\uparrow}^{(\ell)} \boldsymbol{w}_{\uparrow}^{(\ell-1)}
$$

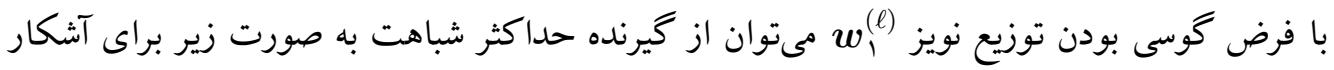

$$
\text { سازى استفاده كرد }
$$

$$
\arg \min _{\boldsymbol{U}_{r}}\left\|\boldsymbol{\Sigma}_{\boldsymbol{w}}^{-\frac{1}{r}}\left(\boldsymbol{y}_{\uparrow}^{(\ell)}-\boldsymbol{U}_{r}^{(\ell)} \boldsymbol{y}_{\uparrow}^{(\ell-1)}\right)\right\|^{r}
$$

كه , محو شدگى كانال احتياجى ندارد. در بخش بعد يك حد بالا بر روى PEP با استفاده از اين آشكارساز به دست مى آوريم.

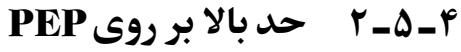

قضيه زير يك حد بالا بر روى PEP وقتى كه سيخنال خود_تداخل به طور كامل حذف شده است و از آشكارساز ماكزيمم شباهت رابطه (Fq_F ) استفاده مىشود را ارايه مى كند. قضيه f _ ـ ـ ا • وقتى ماتريس هاى

$$
\operatorname{Pr}\left(\boldsymbol{S}_{r, a}^{(\ell)} \rightarrow \boldsymbol{S}_{r, b}^{(\ell)}\right) \leq\left(P G_{c}\left(\boldsymbol{S}_{r, a}^{(\ell)}, \boldsymbol{S}_{r, b}^{(\ell)}\right)\right)^{-G_{d}}
$$

$$
G_{d}=N
$$

$$
\begin{aligned}
& G_{c}\left(\boldsymbol{S}_{r, a}^{(\ell)}, \boldsymbol{S}_{r, b}^{(\ell)}\right)=\frac{\delta_{\circ}}{1 \varphi}\left|\left(\boldsymbol{S}_{r, a}^{(\ell)}-\boldsymbol{S}_{r, b}^{(\ell)}\right)^{\dagger}\left(\boldsymbol{S}_{r, a}^{(\ell)}-\boldsymbol{S}_{r, b}^{(\ell)}\right)\right|^{\frac{1}{N}} g_{c}\left(M_{n}\right)^{-\frac{1}{N}}, \\
& g_{c}\left(M_{n}\right) \triangleq \frac{\left(1+\delta_{\circ}+N \sum_{n=1}^{N} \delta_{n}\right)^{N}}{\prod_{n=1}^{N} \delta_{n}} \operatorname{Pr}\left(\left\|\boldsymbol{f}_{n}\right\|^{\curlyvee} \leq M_{n}\right)
\end{aligned}
$$




$$
\begin{gathered}
+\frac{\left(1+\delta_{\circ}\right)^{N}+N^{N} \sum_{n=1}^{N}\left(\frac{\delta_{n}}{M_{n}}\right)^{N} \frac{\left(N+M_{n}-1\right) !}{\left(M_{n}-1\right) !}}{\prod_{n=1}^{N} \delta_{n}} \\
\times \operatorname{Pr}\left(\left\|\boldsymbol{f}_{n}\right\|^{r}>M_{n}\right) .
\end{gathered}
$$

بهره جندانظى و بهره كدينگ را به ترتيب /رائه مى دهند.

اثبات. براى به دست آوردن يك حد بالا بر روى احتمال خطاى جفتى PEP ارسال

داريم

$$
\operatorname{Pr}\left(\boldsymbol{U}_{r, a}^{(\ell)} \rightarrow \boldsymbol{U}_{r, b}^{(\ell)}\right)=\mathrm{E}_{\boldsymbol{f}_{n}, \boldsymbol{g}_{n}}\left\{\operatorname{Pr}\left(\boldsymbol{U}_{\boldsymbol{r}, a}^{(\ell)} \rightarrow \boldsymbol{U}_{r, b}^{(\ell)} \mid \boldsymbol{f}_{n}, \boldsymbol{g}_{n}\right)\right\}
$$

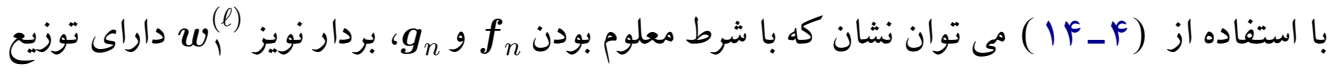
كوسى با ميانخين صفر و ماتريس كوواريانس مشروط باشد. همجنين با شرط معلوم بودن

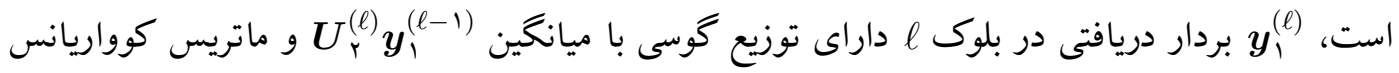

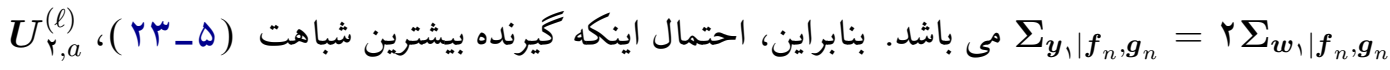
را با

$$
\operatorname{Pr}\left(\boldsymbol{U}_{r, a}^{(\ell)} \rightarrow \boldsymbol{U}_{r, b}^{(\ell)} \mid \boldsymbol{f}_{n}, \boldsymbol{g}_{n}\right)=Q\left(\frac{1}{\sqrt{r}}\left\|\boldsymbol{\Sigma}_{\boldsymbol{y}_{\wedge} \mid \boldsymbol{f}_{n}, \boldsymbol{g}_{n}}^{-\frac{1}{r}}\left(\boldsymbol{U}_{r, a}^{(\ell)}-\boldsymbol{U}_{r, b}^{(\ell)}\right) \boldsymbol{y}_{\uparrow}^{(\ell-1)}\right\|\right) . \quad(\Delta \boldsymbol{F}-\boldsymbol{F})
$$

در توان هاى بالا P، ما مى توانيم از جمله نويز در (FV_F_F) و (F) صرف نظر كرده و با تقريب خوبى

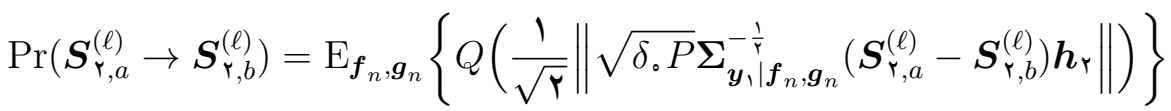

$$
\begin{aligned}
& \leq \mathrm{E}_{\boldsymbol{f}_{n}, \boldsymbol{g}_{n}} e^{-\frac{\delta_{\circ} P}{\Lambda} \boldsymbol{h}_{\curlyvee}^{\dagger}\left(\boldsymbol{S}_{\curlyvee, a}^{(\ell)}-\boldsymbol{S}_{\curlyvee, b}^{(\ell)}\right)^{\dagger} \boldsymbol{\Sigma}_{\boldsymbol{y}, \mid \boldsymbol{f}_{n}, \boldsymbol{g}_{n}}^{-1}\left(\boldsymbol{S}_{\curlyvee, a}^{(\ell)}-\boldsymbol{S}_{\curlyvee, b}^{(\ell)}\right) \boldsymbol{h}_{\curlyvee}},
\end{aligned}
$$

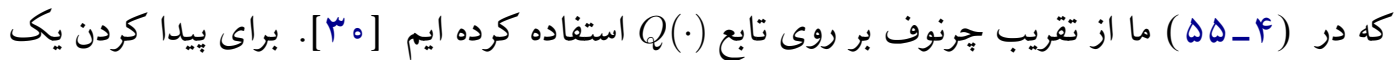
حد مناسب كه نقش P، ${ }^{\prime}$ و $M_{n}$ وا واضح نشان دهد، ما يك حد بر روى با استفاده از

$$
\Sigma_{\boldsymbol{y}_{、} \mid \boldsymbol{f}_{n}, \boldsymbol{g}_{n}} \preceq \sigma_{\boldsymbol{y}}, \boldsymbol{I}_{N}
$$


$\boldsymbol{h}_{\curlyvee}=\boldsymbol{F g}$ كه

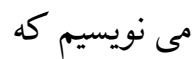

$$
\boldsymbol{F}=\operatorname{diag}\left(\beta, \boldsymbol{f}_{1}^{T} \boldsymbol{X}_{1}^{T}, \ldots, \beta_{N} \boldsymbol{f}_{N}^{T} \boldsymbol{X}_{N}^{T}\right), \quad \boldsymbol{g}=\left[\boldsymbol{g}_{1}^{T}, \ldots, \boldsymbol{g}_{N}^{T}\right]^{T}
$$

$$
\text { با جايكذارى ( }
$$

$$
\operatorname{Pr}\left(\boldsymbol{S}_{r, a}^{(\ell)} \rightarrow \boldsymbol{S}_{r, b}^{(\ell)}\right) \leq \mathrm{E}_{\boldsymbol{f}_{n}, \boldsymbol{g}_{n}} e^{-\frac{\delta_{\sigma} P}{\sigma \alpha \boldsymbol{y}_{\mathrm{r}}} \boldsymbol{g}^{\dagger} \boldsymbol{F}^{\dagger} \boldsymbol{\Psi}\left(\boldsymbol{S}_{\mathrm{r}, a}^{(\ell)}, \boldsymbol{S}_{\mathrm{r}, b}^{(\ell)}\right) \boldsymbol{F} \boldsymbol{g}},
$$

كه

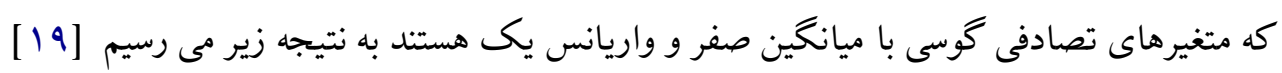

$$
\operatorname{Pr}\left(\boldsymbol{S}_{\mathrm{r}, a}^{(\ell)} \rightarrow \boldsymbol{S}_{\mathrm{r}, b}^{(\ell)}\right) \leq \mathrm{E}_{\boldsymbol{f}_{n}}\left|\boldsymbol{I}_{N}+\frac{\delta_{\bullet} P}{\Lambda \sigma_{\boldsymbol{y}_{1}}} \boldsymbol{\Psi}\left(\boldsymbol{S}_{\mathrm{r}, a}^{(\ell)}, \boldsymbol{S}_{\mathrm{r}, b}^{(\ell)}\right) \boldsymbol{F} \boldsymbol{F}^{\dagger}\right|^{-1} .
$$

در توان هاى P بالا مى توان از عدد يك در مخرج ،б صرف نظر كرده و در نتيجه خواهيم داشت

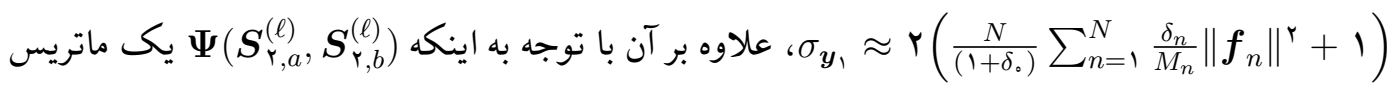
مثبت معين اكيد است، ماتريس همانى

$$
\begin{aligned}
& \text { نتيجه مى دهد }
\end{aligned}
$$

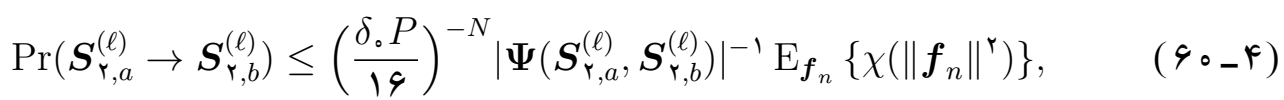

كه ميكيريم : است با

$$
\mathrm{E}_{\boldsymbol{f}_{n}}\left\{\chi\left(\left\|\boldsymbol{f}_{n}\right\|^{\curlyvee}\right)\right\}=\Xi_{1} \operatorname{Pr}\left(\left\|\boldsymbol{f}_{n}\right\|^{\curlyvee} \leq M_{n}\right)+\Xi_{\boldsymbol{r}} \operatorname{Pr}\left(\left\|\boldsymbol{f}_{n}\right\|^{\curlyvee}>M_{n}\right),
$$

$$
\Xi_{1}=\mathrm{E}_{\boldsymbol{f}_{n}}\left\{\chi\left(\left\|\boldsymbol{f}_{n}\right\|^{\Upsilon}\right) \mid\left\|\boldsymbol{f}_{n}\right\|^{\Upsilon} \leq M_{n}\right\}, \quad \Xi_{\boldsymbol{r}}=\mathrm{E}_{\boldsymbol{f}_{n}}\left\{\chi\left(\left\|\boldsymbol{f}_{n}\right\|^{\Upsilon}\right) \mid\left\|\boldsymbol{f}_{n}\right\|^{\Upsilon}>M_{n}\right\} .
$$

اكرجه اين انتخاب براى بازه ها، محاسبات را ساده مى كند اما لزوما نزديك ترين باند را توليد نمى كند.

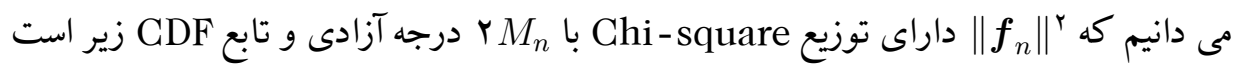

$$
\operatorname{Pr}\left(\left\|\boldsymbol{f}_{n}\right\|^{r} \leq M_{n}\right)=1-e^{-M_{n}} \sum_{m=。}^{M_{n}-1} \frac{1}{m !} M_{n}^{m} .
$$




$$
\begin{aligned}
& \text { براى ادامه اثبات ما دو لم زبر را ارائه مى كنيم. } \\
& \text { لم }{ }^{+} \\
& \Xi_{1} \leq \frac{\left(1+\delta_{\circ}+N \sum_{n=1}^{N} \delta_{n}\right)^{N}}{\prod_{n=1}^{N} \delta_{n}} . \\
& \text { اثبات. براى } \\
& \Xi_{1} \leq \mathrm{E}_{\boldsymbol{f}_{n}}\left\{\frac{\left(1+\delta_{\circ}+N \sum_{n=1}^{N} \delta_{n}\right)^{N}}{\prod_{n=1}^{N} \frac{\delta_{n}}{M_{n}}\left\|\boldsymbol{f}_{n}\right\|^{r}}\right\} .
\end{aligned}
$$

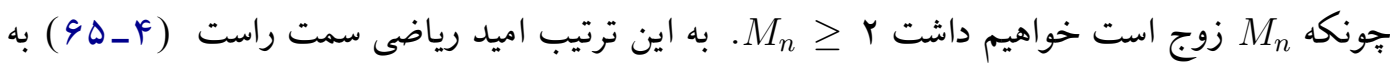

$$
\begin{aligned}
& \text { راحتى قابل محاسبه است و حد ارائه شده در لم به دست مى آيد. } \\
& \text { لم ץ _هـ-r • براى } \\
& \Xi_{\Upsilon} \leq \frac{\left(1+\delta_{\circ}\right)^{N}+N^{N} \sum_{n=1}^{N}\left(\frac{\delta_{n}}{M_{n}}\right)^{N} \frac{\left(N+M_{n}-1\right) !}{\left(M_{n}-1\right) !}}{\prod_{n=1}^{N} \delta_{n}} . \\
& \text { اثبات. از آنجاييكه } \\
& \Xi_{\boldsymbol{r}} \leq \mathrm{E}_{\boldsymbol{f}_{n}}\left\{\frac{\left(1+\delta_{\circ}+N \sum_{n=1}^{N} \frac{\delta_{n}}{M_{n}}\left\|\boldsymbol{f}_{n}\right\|^{\boldsymbol{r}}\right)^{N}}{\prod_{n=1}^{N} \delta_{n}}\right\} \\
& \leq \mathrm{E}_{\boldsymbol{f}_{n}}\left\{\frac{\left(1+\delta_{\circ}\right)^{N}+N^{N} \sum_{n=1}^{N}\left(\frac{\delta_{n}}{M_{n}}\left\|\boldsymbol{f}_{n}\right\|^{r}\right)^{N}}{\prod_{n=1}^{N} \delta_{n}}\right\} \text {, }
\end{aligned}
$$

كه نامساوى اول با استفاده از از نامساوى Jensen به دست آمده است. در نهايت، با محاسبه اميد رياضى سمت راست (FV_F)، باند داده شده در لم به دست مى آيد.

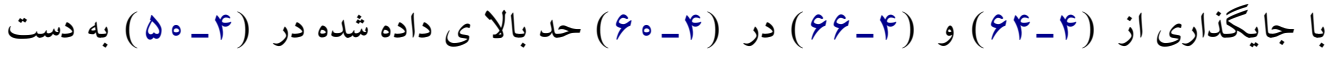

اين قضيه بيان مىكند كه بهره جندگانگى تنها به تعداد رله ها بستخى دارد و به تعداد آنتن ها در هر رله 1

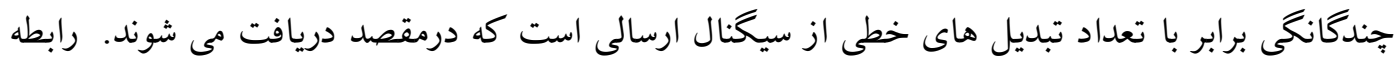

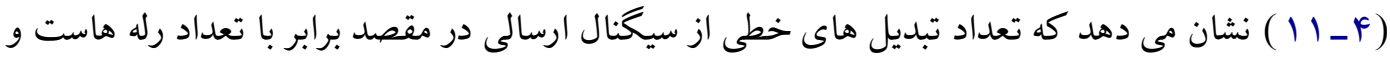


ربطى به تعداد آنتن ها ندارد. به عبارت ديخر هر ستون از ماتريس دريافتى تنها يك تبديل خطى از سيخنال ارسالى است و تعداد اين ستون ها برابر با تعداد رله ها مى باشد. علاوه بر اين، اين قضيه بيان مى كند كه

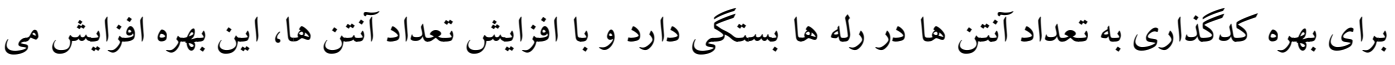
يابد و به يك مقدار ثابت هم خرا مى شود. براى توصيف با جزئيات بيشتر ما

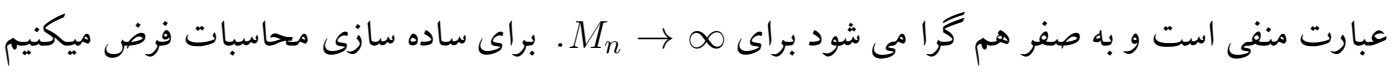

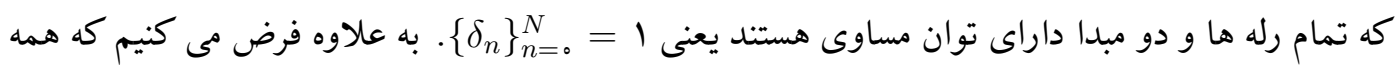

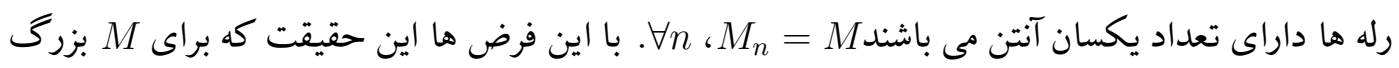

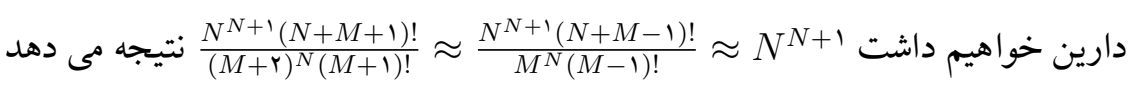
$g_{c}(M+\boldsymbol{r})-g_{c}(M)=\left(\left(\boldsymbol{r}+N^{\Upsilon}\right)^{N}-\boldsymbol{r}^{N}-N^{N+1}\right)\left(\operatorname{Pr}\left(\left\|\boldsymbol{f}_{n}\right\|^{\boldsymbol{r}} \leq M+\boldsymbol{r}\right)-\operatorname{Pr}\left(\left\|\boldsymbol{f}_{n}\right\|^{\boldsymbol{r}} \leq M\right)\right)$.

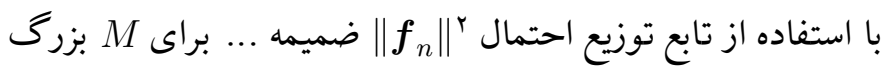
$\operatorname{Pr}\left(\left\|\boldsymbol{f}_{n}\right\|^{r} \leq M+r\right)-\operatorname{Pr}\left(\left\|\boldsymbol{f}_{n}\right\|^{r} \leq M\right) \nearrow 。$.

يعنى براى هر مقدار بزرگ و محدود

$$
\operatorname{Pr}\left(\left\|\boldsymbol{f}_{n}\right\|^{r} \leq M+r\right)-\operatorname{Pr}\left(\left\|\boldsymbol{f}_{n}\right\|^{r} \leq M\right)<。
$$

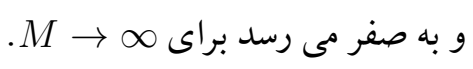

اين امر تصديق مىكند كه بهره كدگذارى با افزايش M ، ، افزايش بيدا مىكند و به يك مقدار ثابت همخرا

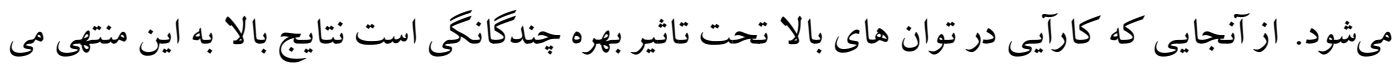
شوند كه افزايش رله ها تاثير بيشترى بر بهبود كارآيى دارد تا افزايش تعداد آنتن ها در هر رله.

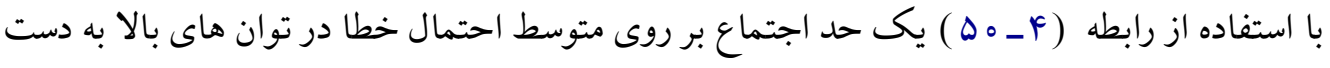
مى آوريم. فرض كنيد

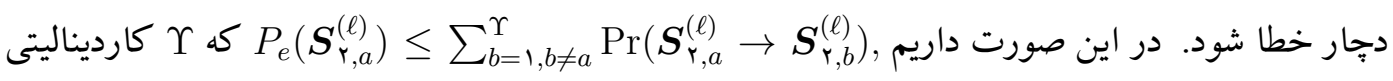
BLER = $\frac{1}{\Upsilon} \sum_{a=1}^{\Upsilon} P_{\mathrm{e}}\left(\boldsymbol{S}_{\mathrm{r}, a}^{(\ell)}\right)$ به اين ترتيب باند بالا بر احتمال خطا به صورت زير خواهد بود

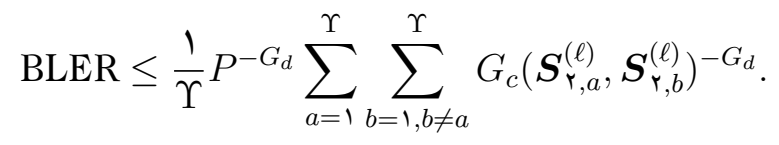




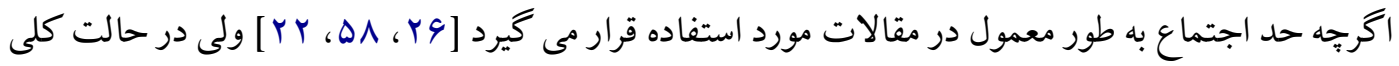

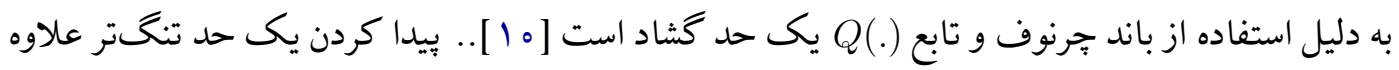
بر آن كه سخت به نظر مى رسد ممكن است ديد مناسبى نسبت به بارامتر هايى كه كارايى سيستم را كنترل

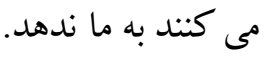

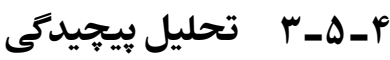

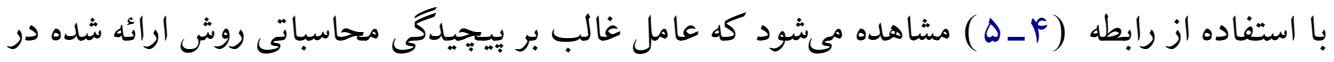
اين فصل حاصل ضرب سه ماتريس مرتبه است. (

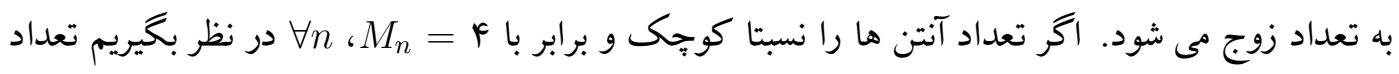

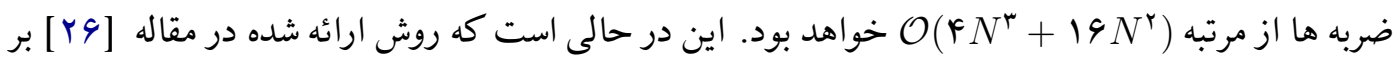
مبناى تخمين كانال براى حذف سيخنال خود_تداخل است مرتبه محاسبات آن از مرتبه مى باشد. به اين مرتبه محاسباتى هر دو روش از مرتبه توان سوم N مى باشد در حالى كه روش ارائه شده در اين فصل قابليت حذف سيكنال خود داخل را به طور كامل دارد.

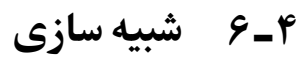

در اين بخش، ما عملكرد روش بيشنهادى خود را با با روش بيشنهادى [Y [Y] براى كدهاى Y × Y و

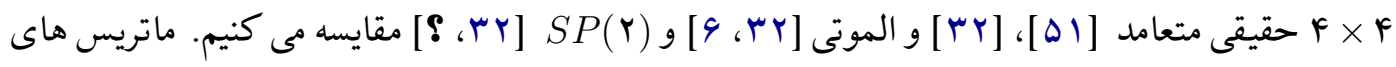
يكانى و يادمتقارن يردازش در رله ها را به صورت ف ف

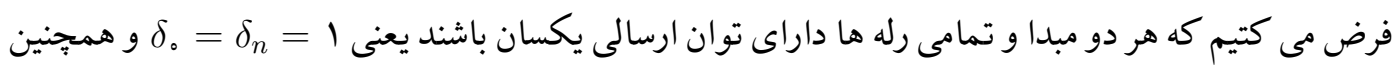

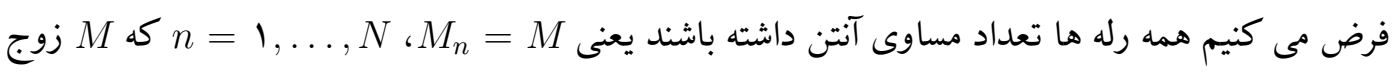


ri= , r 
در اين بخش ما BLER روش ارائه شده در اين فصل و [צY] را براى كدهاى DDST متفاوت باهم

$$
\text { مقايسه مى كنيم. }
$$

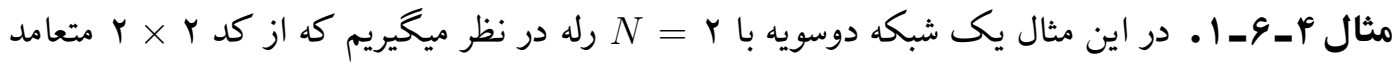

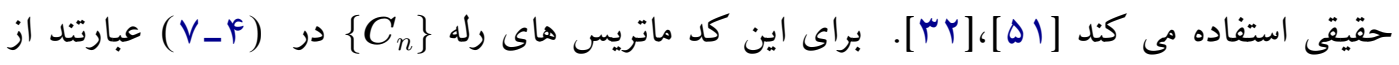


PAM انتخاب مى شوند. توجه داريم كه اين ماتريس ها در

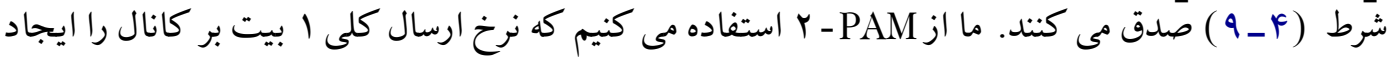

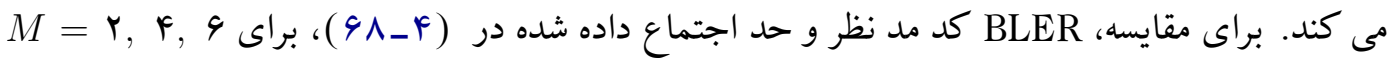

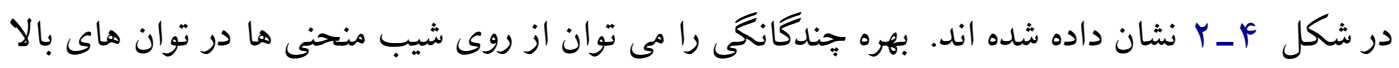
خواند. به عنوان مثال براى دو نقطه (

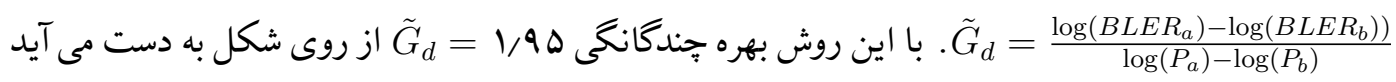

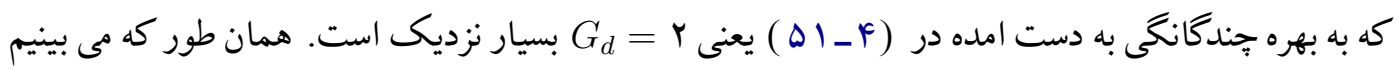

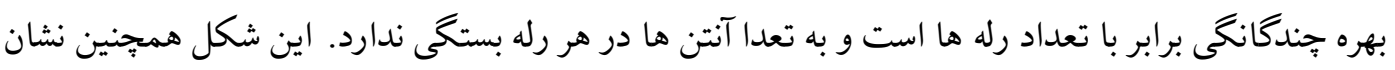

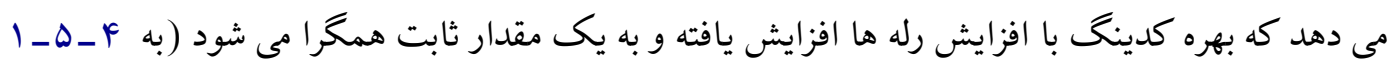

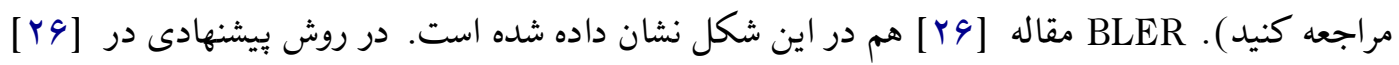

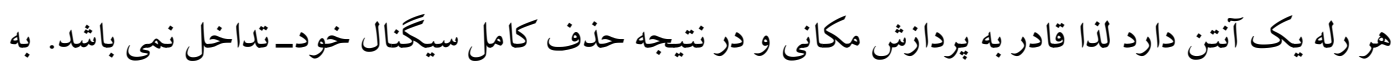

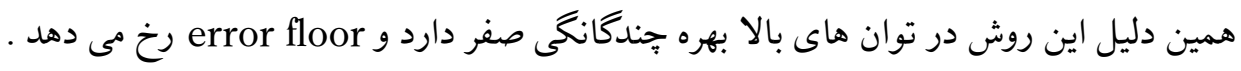

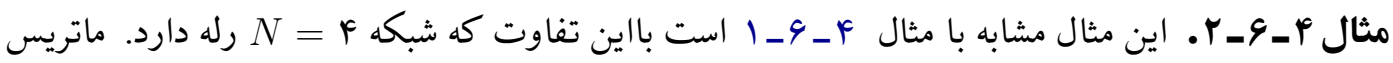

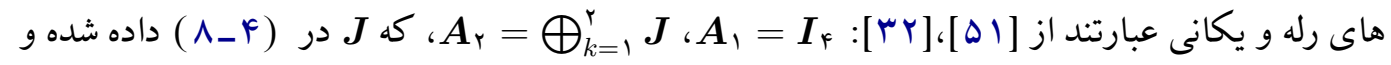

$$
A_{\uparrow}=\left[\begin{array}{cccc}
0 & 0 & -1 & 0 \\
0 & 0 & 0 & 1 \\
1 & 0 & 0 & 0 \\
0 & -1 & 0 & 0
\end{array}\right], A_{\uparrow}=\left[\begin{array}{cccc}
0 & 0 & 0 & -1 \\
0 & 0 & -1 & 0 \\
0 & 1 & 0 & 0 \\
1 & 0 & 0 & 0
\end{array}\right],
$$




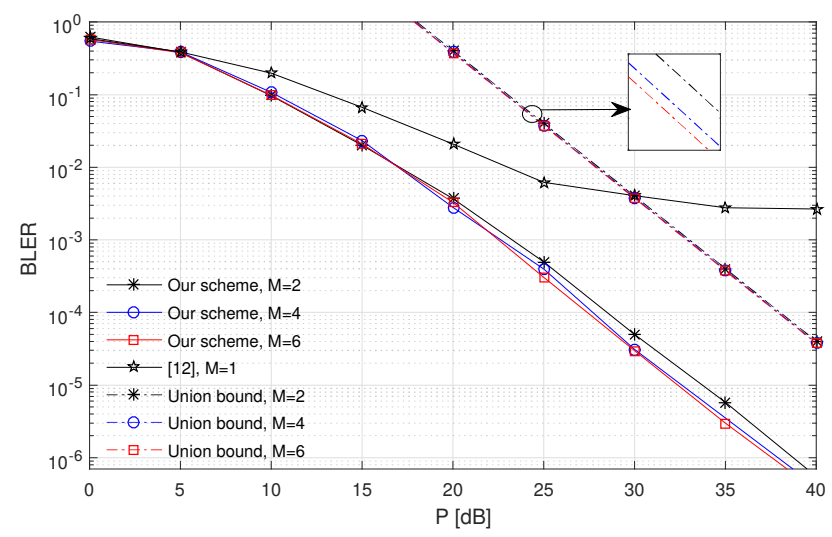

شكل r-F r Fملكرد شبكه دوسويه با دو رله و كد حقيقى متعامد

$$
\boldsymbol{U}_{i}^{(\ell)}=\left[\begin{array}{cccc}
{[r] u_{\uparrow}^{(\ell)}} & -u_{r}^{(\ell)} & -u_{r}^{(\ell)} & -u_{r}^{(\ell)} \\
u_{r}^{(\ell)} & u_{\uparrow}^{(\ell)} & u_{r}^{(\ell)} & -u_{r}^{(\ell)} \\
u_{r}^{(\ell)} & -u_{r}^{(\ell)} & u_{r}^{(\ell)} & u_{r}^{(\ell)} \\
u_{r}^{(\ell)} & u_{r}^{(\ell)} & -u_{r}^{(\ell)} & u_{\uparrow}^{(\ell)}
\end{array}\right] .
$$

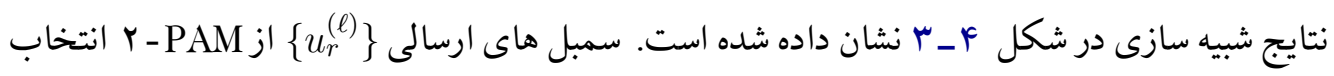
مى شوند كه نرخ ارسال ا را موجب مى شود. با استفاده از اين شكل بهره جندگانكى كه در توان هاى متوسط $G_{d}=F$ خوانده مى شود برابر با rodB مى باشد. دليل اين تفاوت آن است كه P به اندازه كافى بزرگ نمى باشد كه عامل غالب در عملكرد سيستم باشد. اين شكل مانند مثال قبل وابستخى بهره كدينخ را به تعدا آنتن ها و همخرايى آن را نشان مى دهد. صـ

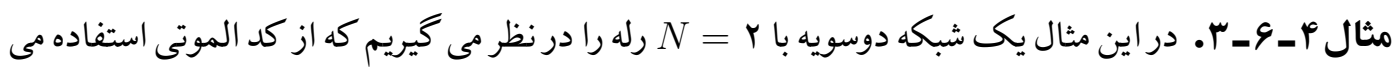
كند [4]، [Y [r]

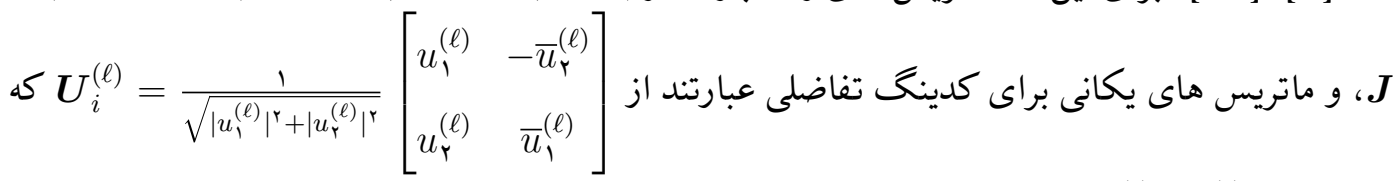
سمبل هاى (l) $u_{\uparrow}^{(\ell)} u_{r}^{(\ell)}$ مى تواند از هر منظومه مختلطى مثل PSK و QAM انتخاب شوند. روش ارائه شده در اين فصل براى ارسال N سمبل به NN بازه زمانى نياز دارد درحاليكه روش بيشنهادى در [Y4] به بازه زمانى نياز دارد. بنابراين براى مقايسه منصفانه، ما سمبل هاى ارسالى توسط دو روش را از منظومه هاى متفاوت انتخاب مى كنيم تا نرخ ارسال دو روش تقريبا يكسان باشد. يس براى نرخ ارسال r سمبل هاى

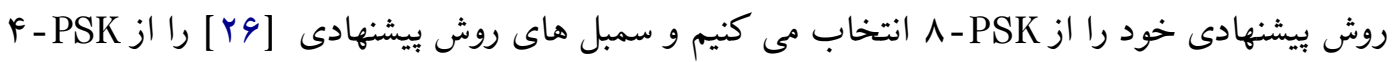




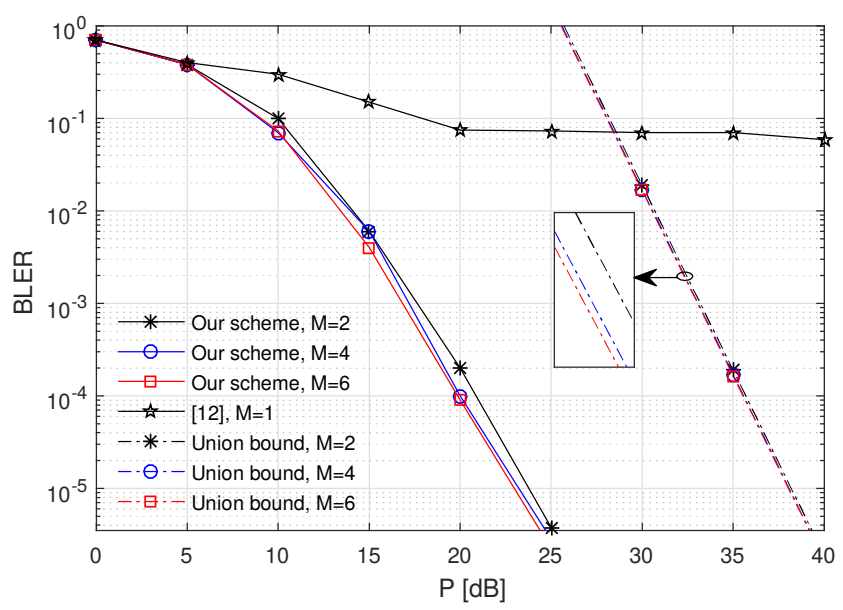

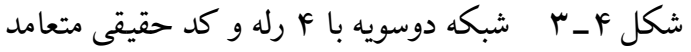

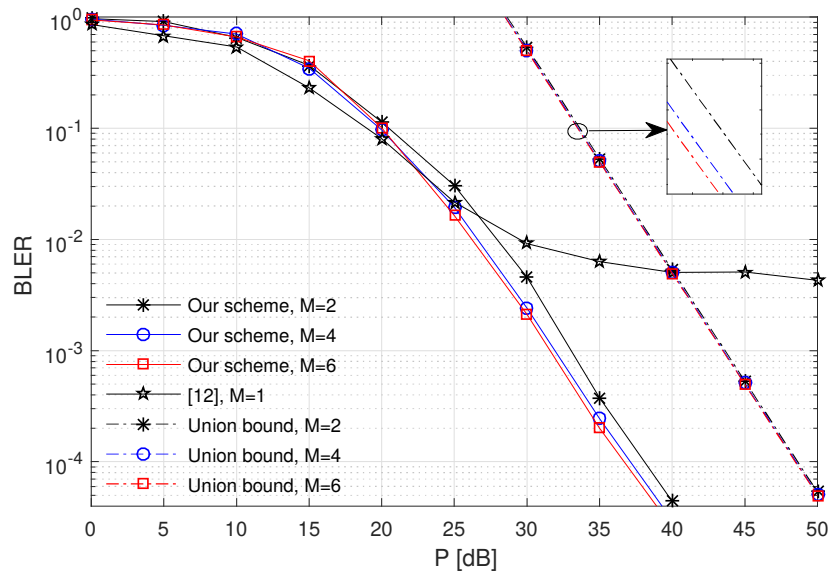

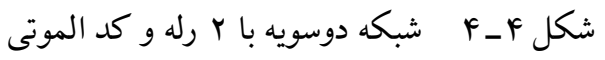

انتخاب مى كنيم. BLER هر دو روش در شكل F_F نشان داده شده است. اين شكل نشان مى دهد كه در

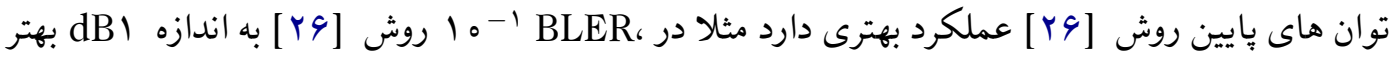
عمل مى كند. حال انكه در توان هاى بالا روش بيشنهادى ما بسيار بهتر از [Y9] عمل مى كند، به عنوان مثال در BLER روش بيشنهادى ما با افزايش توان با شيبى نزديك به تعداد رله ها كه همان بهره جندكانكى است كاهش

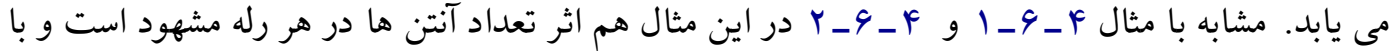
افزايش M بهره كدينخ به يك مقدار ثابت همخرا مى شود.

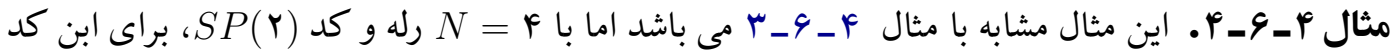




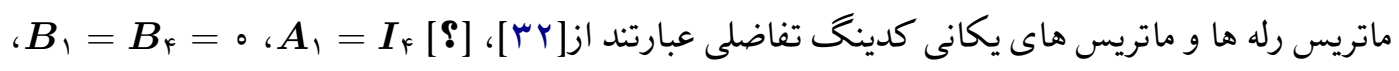

$$
\begin{aligned}
& \text { ، } \boldsymbol{B}_{\boldsymbol{r}}=\bigoplus_{k=1}^{r} \boldsymbol{J} \text { ، } \boldsymbol{A}_{\boldsymbol{r}}=\boldsymbol{A}_{\boldsymbol{r}}=\text { 。 } \\
& B_{r}=\left[\begin{array}{cccc}
0 & 0 & -1 & 0 \\
0 & 0 & 0 & -1 \\
1 & 0 & 0 & 0 \\
0 & 1 & 0 & 0
\end{array}\right], A_{r}=\left[\begin{array}{cccc}
0 & 0 & 0 & 1 \\
0 & 0 & -1 & 0 \\
0 & -1 & 0 & 0 \\
1 & 0 & 0 & 0
\end{array}\right] \text {, } \\
& \boldsymbol{U}_{i}^{(\ell)}=\left[\begin{array}{cccc}
u_{\uparrow}^{(\ell)} & -\bar{u}_{r}^{(\ell)} & -\bar{u}_{r}^{(\ell)} & u_{r}^{(\ell)} \\
u_{r}^{(\ell)} & \bar{u}_{\uparrow}^{(\ell)} & -\bar{u}_{r}^{(\ell)} & -u_{r}^{(\ell)} \\
u_{r}^{(\ell)} & -\bar{u}_{r}^{(\ell)} & \bar{u}_{\uparrow}^{(\ell)} & -u_{r}^{(\ell)} \\
u_{r}^{(\ell)} & \bar{u}_{r}^{(\ell)} & \bar{u}_{r}^{(\ell)} & u_{\uparrow}^{(\ell)}
\end{array}\right] \text {. }
\end{aligned}
$$

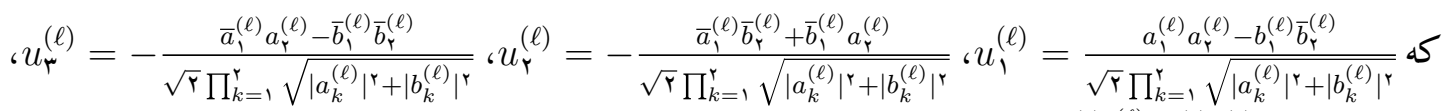
هاى هن هن $\mathbb{G}_{k}, \mathbb{F}_{k}, a_{k}^{(\ell)} \in \mathbb{F}_{k}, b_{k}^{(\ell)} \in \mathbb{G}_{k}, k=1, r, ، u_{r}^{(\ell)}=\frac{a_{1}^{(\ell)} b_{r}^{(\ell)}+b_{1}^{(\ell)} a_{r}^{(\ell)}}{\sqrt{r} \prod_{k=1}^{r} \sqrt{\left|a_{k}^{(\ell)}\right|^{r}+\left|b_{k}^{(\ell)}\right|^{r}}}$ and PSK

براى روش بيشنهادى خود، ما سمبل هاى (l) r -PSK

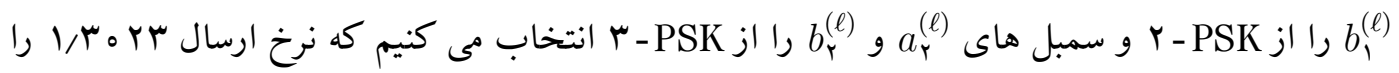
ايجاد مى كنند. نتايج شبيه سازى در شكل F Fـ ه نمايش داده شده اند. اين شكل هم ماند مثال هاى قبل نتايج تحليلى به دست آمده در مورد بهره جندگانگى و بهره كدينگ را تصديق مى كند. در مثال هاى قبل مقايسه روش بيشنهادى در اين فصل و روش بيشنهادى در [Y9] باهم مقايسه شدند در حاليكه هر دو روش از تعداد مساوى رله استفاده مى كردند. از آنجاييكه روش ما در هر رله تعداد زوجى آنتن وجود دارد و در روش [Y4] هر رله تنها يك آنتن دارد تعداد كل آنتن ها در رله ها يكسان نمى باشد. مقايسه اي كه هر دو روش تعداد كل آنتن يكسانى در رله ها داشته باشند مفيد خواهد بود، اين مقايسه در مثال زير ارائه شده است.

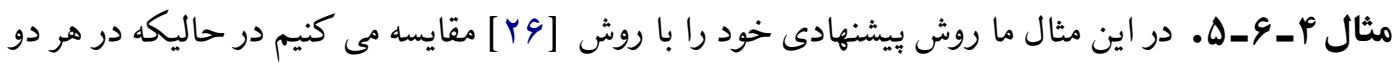
روش تعداد كل آنتن ها در رله ها برابر با F است. جون كه روش ما هر رله بايد تعداد زوجى آنتن داشته باشد 


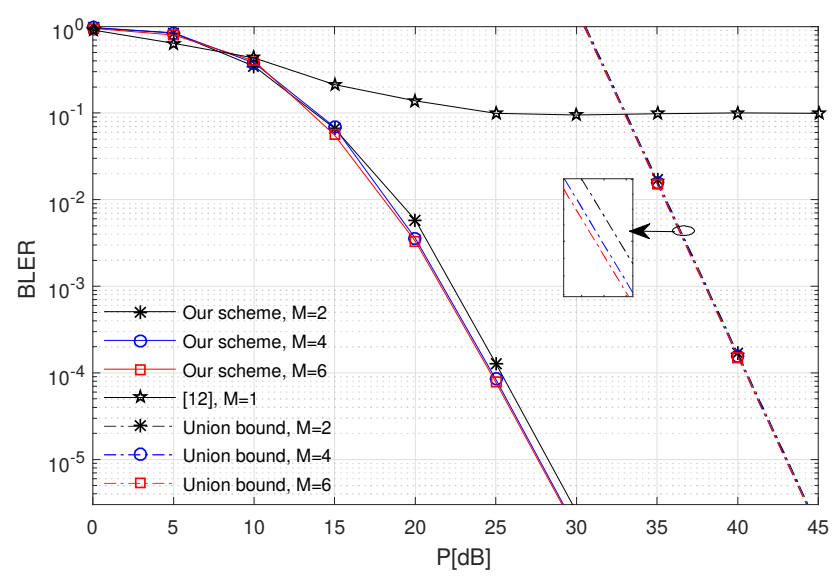

شكل F

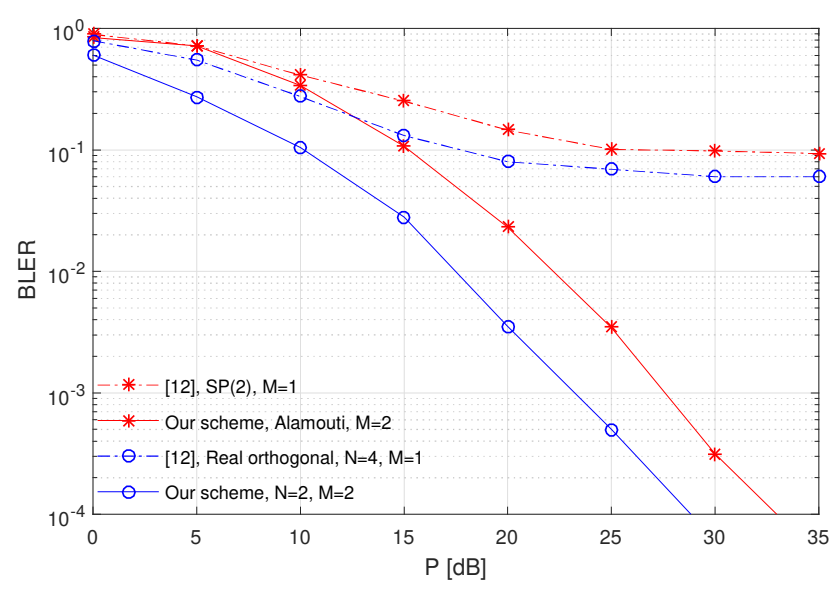

شكل F_F مقايسه دو روش با تعداد كل يكسان آنتن در رله ها

ما فرض مى كنيم كه دو رله دو آنتى داريم و براى روش [Yצ] فرض مى كنيم كه F رله تك آنتى داريم. براى شبكه ای كه دو رله دارد از دو كد ب × r حقيقى متعامد و الموتى استفاده مى كنيم و براى شبكه اى كه F رله دارد از دو كد \& × F حقيقى متعامد و (Y SP( استفاده مى كنيم. در جهت مقايسه منصفانه براى كدهاى حقيقى متعامد، سمبل ها را از Y-PAM انتخاب مى كتيم كه نرخ ارسال ا بيت بر كانال را توليد مى كند. براى كد الموتى سمبل ها را از F-PSK انتخاب مى كنيم كه نرخ س ا ا را توليد مى كند و براى

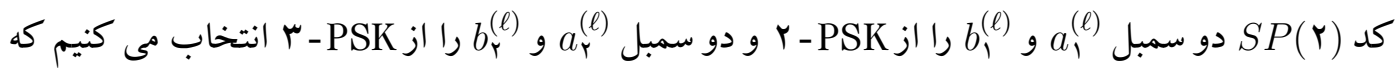

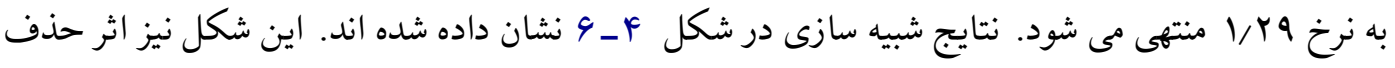
كامل سيخنال خود_تداخل را در روش بيشنهادى و عملكرد بهتر آن را نشان مى دهد. 


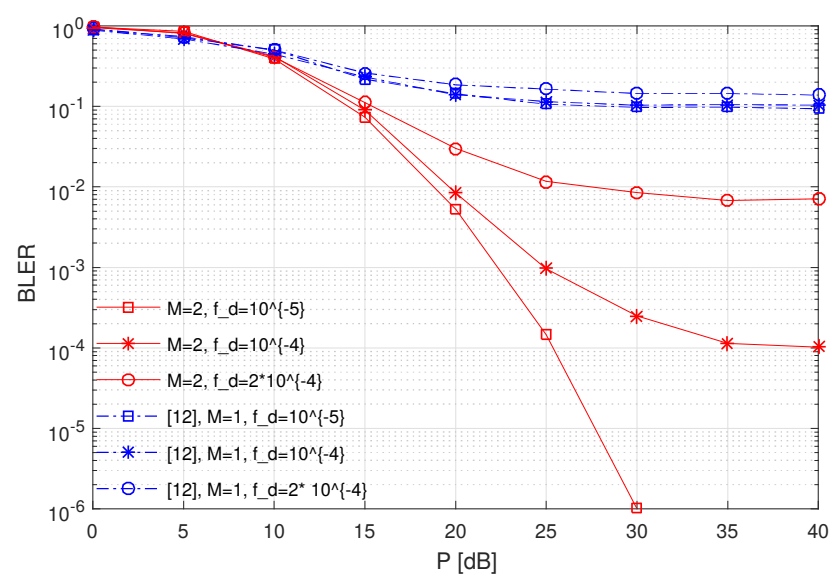

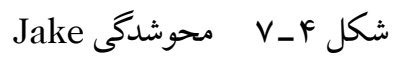

در مثال هاى قبل كانال ها با محو شدگى بلوكى در نظر گرفته شدند به اين معنى كه ضرايب محوشدگى كانال در طول زمان همبستگى كانال ثابت مى مانند. در بسيارى از موارد عملى ضرايب محوشدگى بيوسته با زمان تغيير مى كنند. مدل هاى آمارى متفاوتى براى اين كانال ها ارائه شده كه يكى ار آنها محوشدگى Jake است. در اين مدل همبستخى بين ضرايب كانال به حركت دو مبدا و رله ها بستخى دارد. اكر فرض كنيم [k] f ضريب محوشدگى را در زمان k نشان دهد آنگاه در مدل Jake خودهمبستخى اين ضريب كانال از f ماكزيمم فركانس دويلر نرماليزه شده مى باشد. اكنون ما عملكرد روش بيشنهادى در اين فصل و روش

$$
\text { [Y [ ] [ا در اين كانال ها بررسى مى كنيم. }
$$

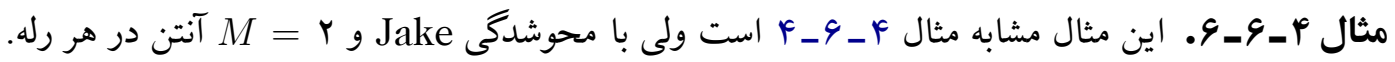
براى ساده سازى فرض مى كنيم كه همه ى كانال ها داراى ff يكسان باشند. نتايج شبيه سازى براى

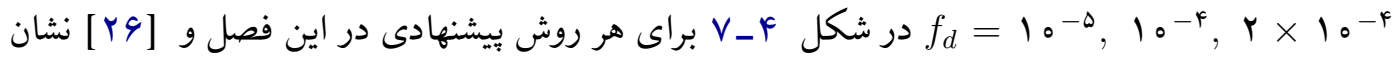
داده شده است. با توجه به اين شكل مشاهده مى كنيم در ه-ه با P كاهش مى يابد در حاليكه روش [9 [ ] از $P=r \circ d B$ شروع به مسطح شدن مى كند. به عنوان مثال

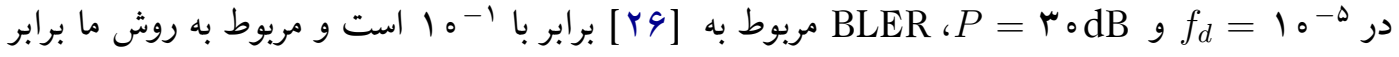
4-ه ا است. با افزايش fd منحنى هاى هر دو روش شروع به مسطح شدن مى كنند؛ روش ما از

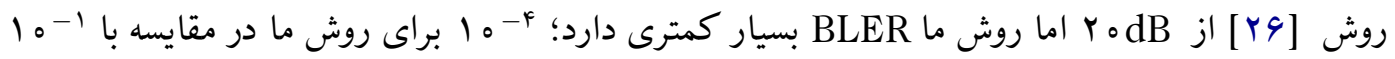

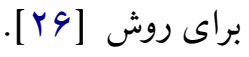




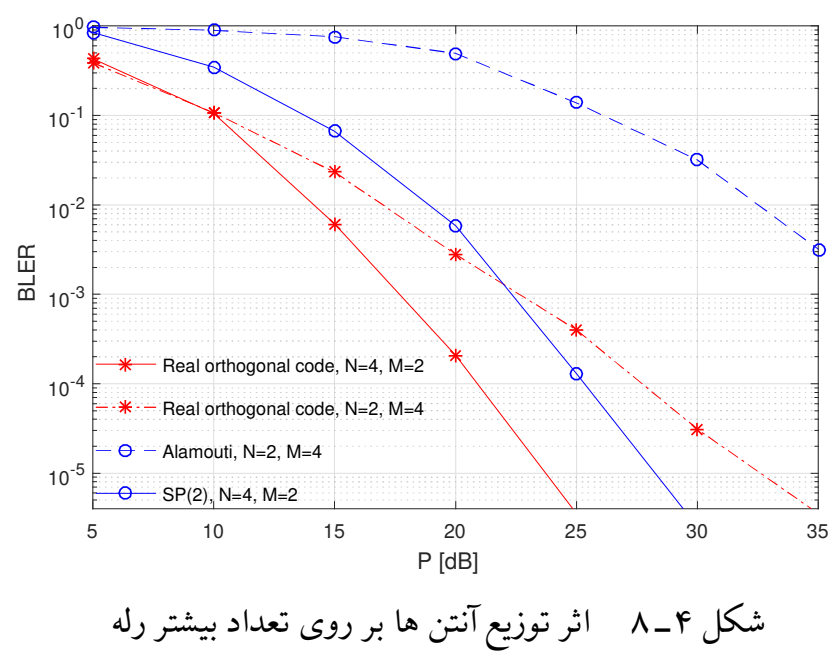

\section{تاثير تعداد رله ها و تعداد آنتن ها در هر رله}

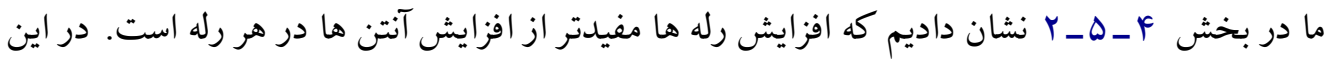
بخش اين نتيجه را با شبيه سازى تصديق مى كنيم. براى اين منظور ما تعداد كلى ^ آنتن را در رله ها در نظر كرفته و دو حالت متفاوت را در نظر مى گيرم. در حالت اول فرض مى كنيم كه در هر رله داريم و در حالت دوم فرض مى كنيم كه r $N=$ رله و $M=$ رآنتن در هر رله داريم. نتايج شبيه سازى در شكل F_N نشان داده شده است. اين شكل نشان مى دهد كه حالت اول با F رله بسبار عملكرد

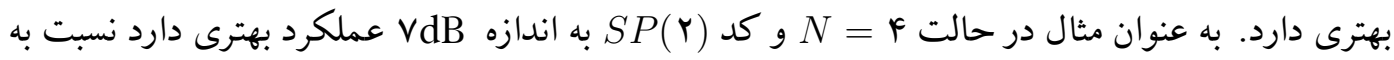
حالتى كه شبكه r N Nله دارد و كد الموتى استفاده مى شود. اين شكل همجنان نشان مى دهد كه نرخ

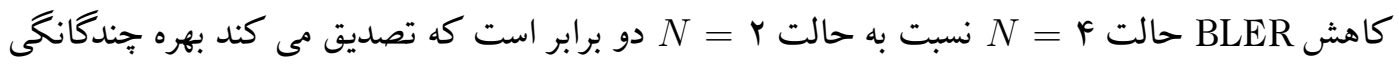

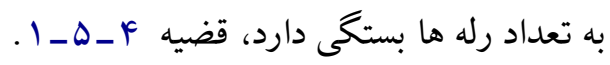

\section{SINR مقايسه P-Y P}

در اين بخش ما مقادير عددى مربوط به متوسط SINR متناظر با روش بيشنهادى خود و روش [Y4] را

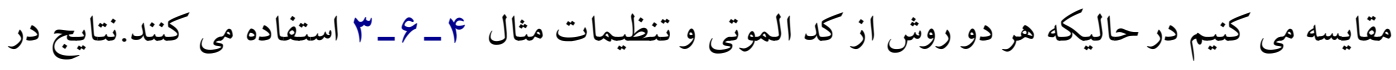
شكل F_q نشان داده شده است. اين شكل نشان مى دهد كه، در روش بيشنهادى ما به دليل حذف كامل سيخنال خود_تداخل SINR به طور خطى و بدون محدوديت با افزايش P، افزايش مى يابد. در حاليكه، حذف ناكامل سيكنال خود_تداخل در روش [Yצ] سبب مى شود كه SINR اشباع شود. اين شكل در 


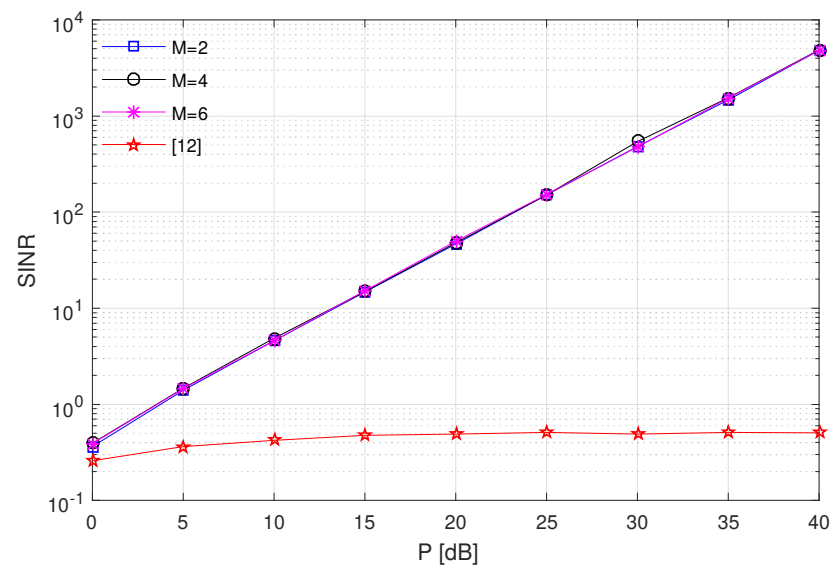

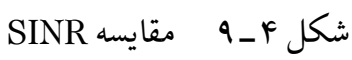

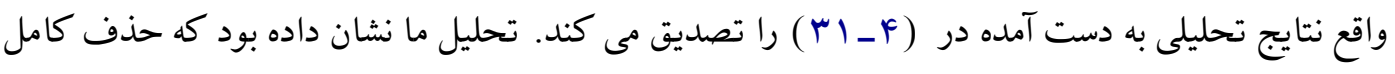
سيخنال خود_تداخل باعث

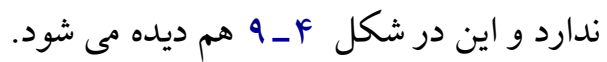

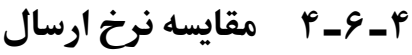

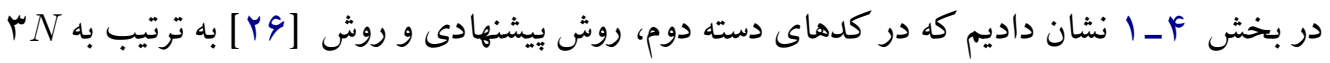
و Y Y بازه زمانى براى ارسال نياز دارند. اين تفاوت، وجود يك مصالحه بين نرخ ارسال و حذف كامل سيخنال خود_تداخل را نشان مى دهد. توجه داريم كه اين مصالحه در مورد كدهاى دسته اول وجود ندارد جونكه هر دو روش

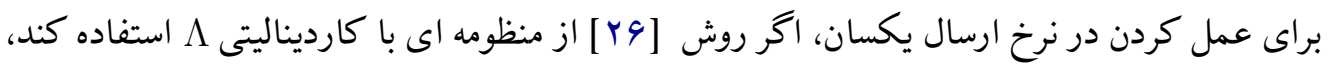
روش ييشنهادى ما از منظومه اى با كارديناليتى ب/r/ استفاده مى كند. براى ييدا كردن اين مصالحه ما هر دو روش را برحسب نرخ ارسال R براى PLER F ـ ا نشان داده شده است. اين شكل نشان مى دهد كه در PdB ما عمل مى كند. دليل اين امر هم آن است كه در توان هاى بايين سيخنال خود_تداخل تاثيرى بر عملكرد سيستم ندارد و عامل غالب بر عملكرد سيستم كارديناليتى منظومه است. در حاليكه در توان هاى بالا ، به دليل اينكه در روش [צr] سيخنال خود_تداخل كاملل حذف نشده است و اثر آن بر BLER غالب خواهد 


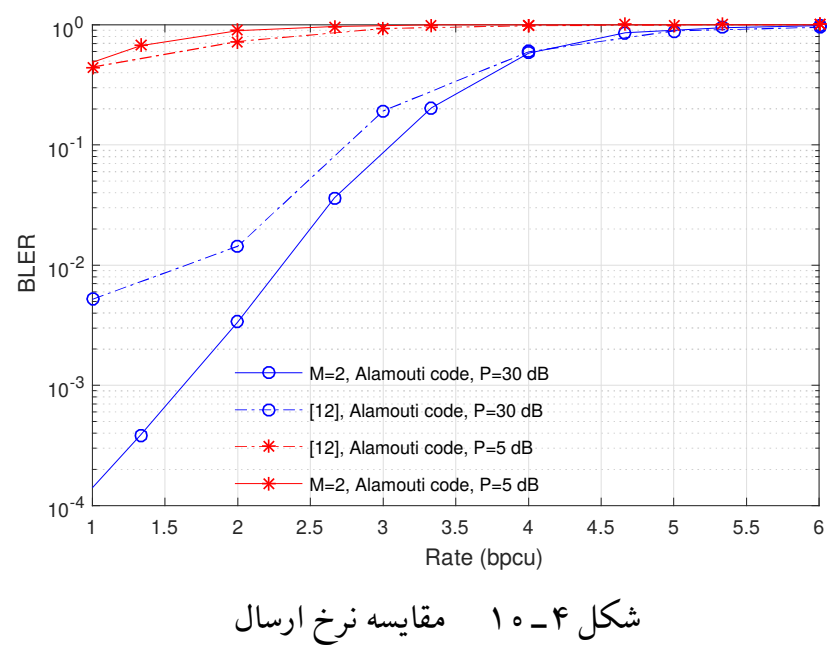

ن Y-Y

در اين فصل يك روش سيخنالينخ براى شبكه هاى دوسويه ارائه كرديم كه در آنها دو مبدا تك آنتى اطلاعات خود را از طريق رله هاى جند آنتى مبادله مى كند. در اين شبكه هيجكدام از دو مبدا و رله ها نال به ضرايب محوشدگى كانال دسنرسى ندارند. بر خلاف ساير روش هاى موجود، در روش بيشنهادى هر رله

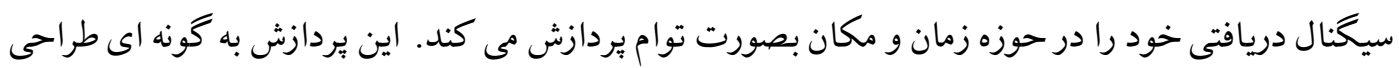

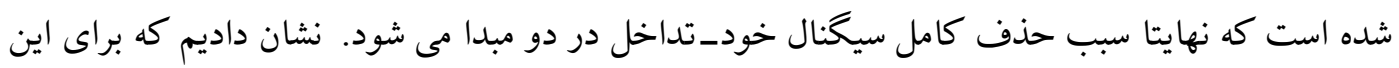
منظور بايد تعداد آنتن هاى فعال در هر رله زوج باشد و ماتريس هايى كه رله ها براى بردازش در حوزه مكان

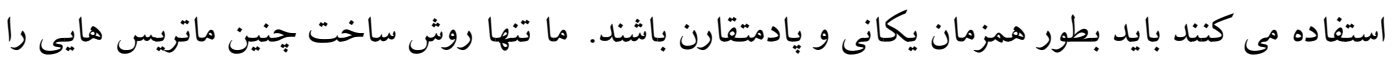
نيز ارايه كرده ايم. براى تحليل اثر سيخنال خود_تداخل بر روى عملكرد سيستم ما ابتدا يك حد بايين براى PEP به دست

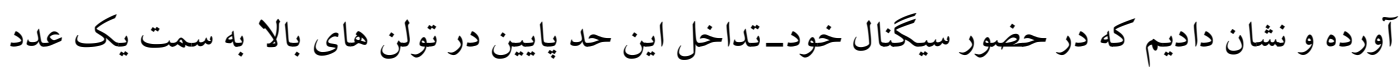
مثبت غير صفر مى رود. علاوه بر آن با محاسبه SINR متوسط نشان داديم با وجود سيكنال خود_ تداخل براى توان هاى بسيار بالا، SINR به سمت يك عدد معين ميل مى كند كه مطلوب نمى باشد. به عبارت

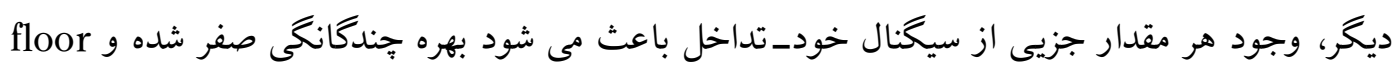
رخ دهد. علاده براين نشان داديم كه روش بيشنهادى با حذف كامل سبخنال خود_تداخل به به بهره

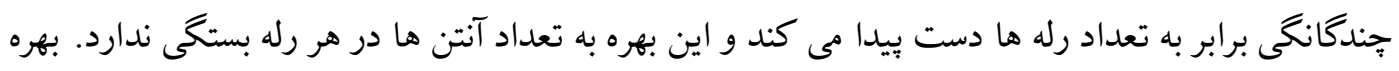


كدينگ به تعداد آنتن ها وابسته است و با افزايش تعداد آنتن ها اين بهره افزايش يافته و به يك عدد ثابت همخرا مى شود.

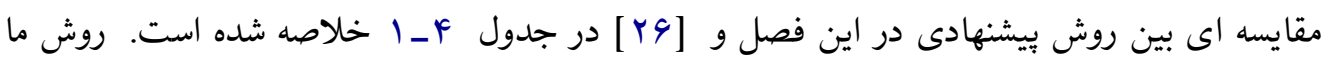
سيخنال خود_تداخل را بدون تخمين كانال حذف مى كند در حاليكه روش بيشنهادى در [بك از يك تخمبن كور براى به دست آوردن كانال معادل و حذف سيخنال خود_تداخل استفاده مى كند. با فرض اينكه سيخنال خود_تداخل به طور كامل حذف شود ، تحليل ارائه شده در [ب9] نشان مى دهد كه اين روش به بهره جِندكانكى برابر با تعداد رله ها دست مى يابد. اكرجه، اين فرض به دليل استفاده از تخمين و وجود

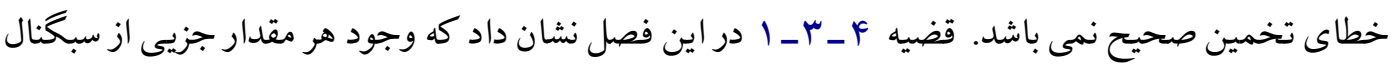
خود_تداخل سبب مى شود بهره جندگانگى صفر شده و error floor رخ دهد. 


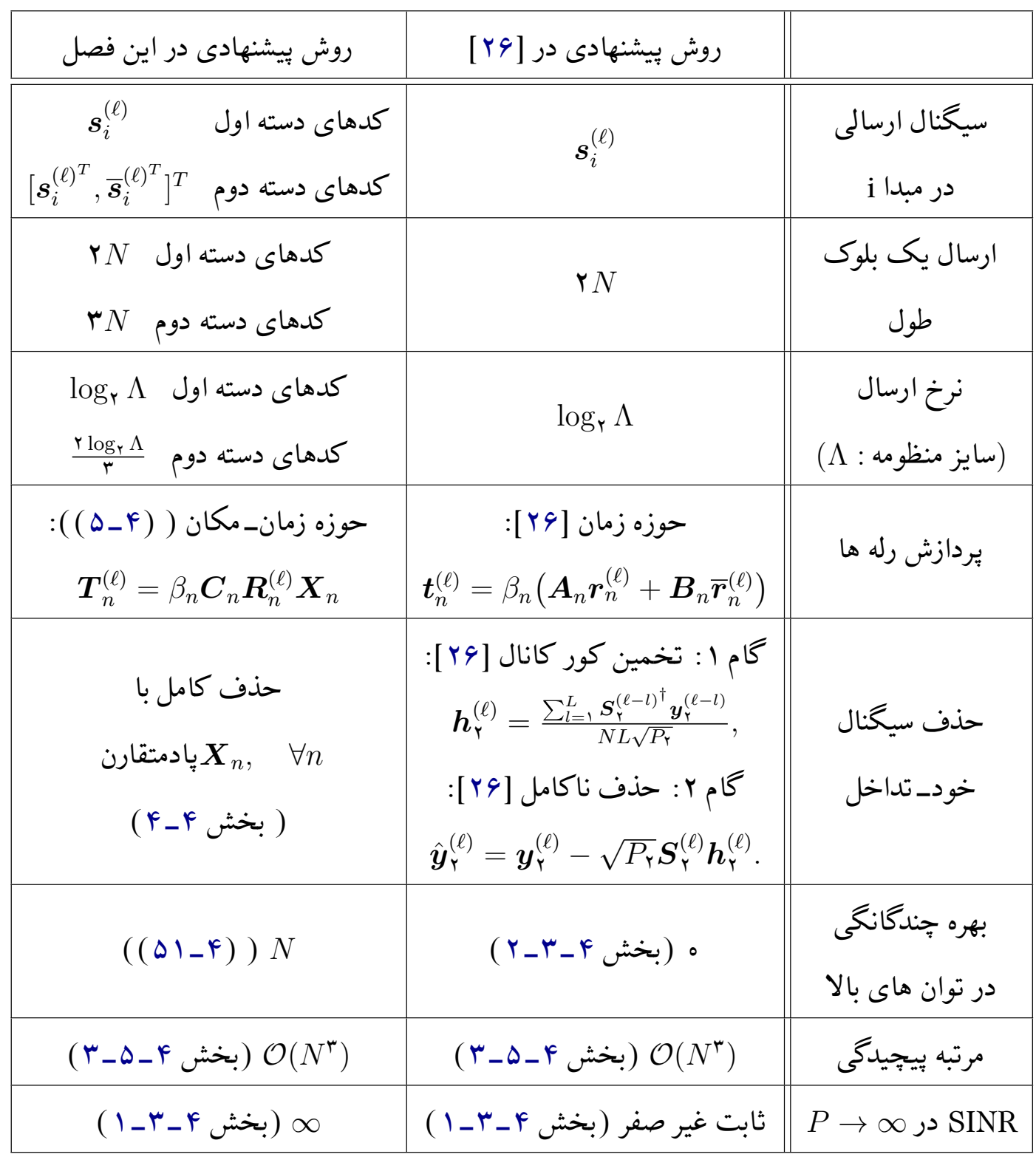

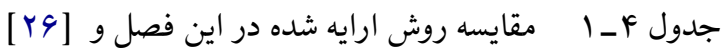

Vo 


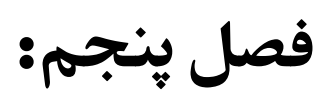

سيستم هاى رله اى دوسويه با رله هاى تك آنتى 
تا آنجا كه مى دانيم روش ارائه شده در فصل قبل تنها روش موجود براى حذف سيگنال خود تداخل در شبكه هاى دو سويه ى بدون اطلاعات كانال مى باشد اگرجه اين روش داراى محدوديت داشتن جندين آنتن در رله مى باشد. براى غلبه بر اين محدوديت، روش جديدى در اين فصل ارائه خواهد شد. اين روش سيخُال خود تداخل را شبكه هاى رله اى با رله هاى تك آنتنى را كاملاً حذف خواهد كرد. ارسال در اين روش مشابه با روش بيشنهاد شده در مقاله[Or] مى باشد. در اين روش ابتدا بردار هاى مرجع در جهار فاز بين دو مبدا رد و بدل مى شوند، اين مرحله جرخه اوليه سازى ناميده مى شود. بر خلاف مقاله وووو اين بردار ها براى تخمين سيگنال خود تداخل استفاده نمى شوند بلكه براى حذف كامل سيگنال خود تداخل مورد استفاده قرار مى گيرند. پِ از جرخه اوليه سازى، جرخه ارسال اطلاعات در دو فاز آغاز مى كردد.

براى ارزيابى عملكرد اين روش يك حد بالا براى احتمال خطاى جفتى به دست مى آوريم و از روى اين حد بالا بهره جندگانكى را به دست مى آوريم. اين بهره كه برابر با تعداد رله هاست با بهره به دست آمده در روش فصل قبل برابر است با اين تفاوت كه اكنون هر رله تنها يك آنتن دارد. علاوه بر اين، با مقايسه حد بالاى خطاى جفتى نشان خواهيم داد كه سيستم بيشنهاد شده در اين فصل كارايى بهترى دارد اگرجه هر دو سيستم سيخنال خود_داخل را به صورت كامل حذف مى نمايد. بيان ديخر، سيستم يِينهاد شده در اين فصل نه تنها تعداد كمترى آنتن در رله ها و زمان كمترى براى ارسال سيخنال استفاده مى كند بلكه احتمال خطاى كمترى نيز دارد. در ادامه كار، دو كد الموتى و(Y) SP( را در نظر گرفته و حد بالاى احتمال خطا را براى آنها به صورت تابعى از نرخ ارسال به دست مى آوريم. نشان خواهيم داد كه در نرخهاى ارسال بايين، استفاده از كد (Y SP( و در نرخ هاى بالا استفاده از كد الموتى مفيد مى باشد اكرجه كد الموتى نسبت به كد (r SP( تنها دو رله استفاده مى كند.

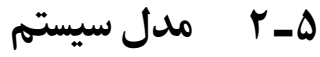

شبكه ایى را در نظر مىگيريم كه در آن دو مبدا تك آنتن از طريق N رله تكى آنته

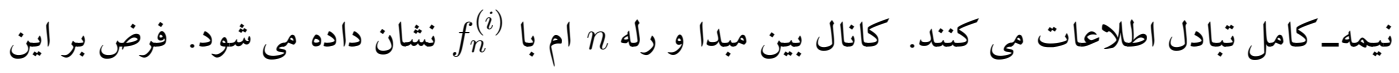
است كه اين كانال ها از هم مستقل بوده و داراى توزيع رايلى با ميانگين صفر و واريانس يك مى باشند. 
هيج اطلاعاتى در مورد ضرايب محوشدگى كانال ها در اختيار رله ها و دو مبدا نمى باشد. نويز دريافتى در رله ها و دو مبدا نيز مستقل از هم و داراى توزيع يكسان گوسى با ميانگين صفر و واريانس يك مى باشند. در روش بيشنهادى، ارسال سيخنال ابتدا با جهار فاز جرخه مقداردهى اوليه شروع شده و بعد با دوفاز جرخه ارسال اطلاعات ادامه بيدا مى كند، كه در ادامه با جزئيات بيشترى بررسى خواهد شد. از آنجايى كه هيج اطلاعاتى در مورد ضر ايب محوشدگى كانال در شبكه موجود نمى باشد، يك روش مفيد براى بهرهبردارى از شبكه، استفاده از روش كدگذارى زمانــ مكان مى باشد.

در فاز اول جرخه ارسال اطلاعات، دو مبدا اطلاعات خود را به صورت تفاضلى كدگذارى كرده و به طور همزمان در N بازه زمانى به رله ها ارسال مى كنند. رله ها سيخنال دريافتى خود را بردازش و سيس به سمت Y مبدا در N بازه زمانى ارسال مى نمايند. به اين ترتيب هر جرخه ارسال اطلاعات شامل rN بازه زمانى مى باشد. فرض بر اين است كه در L جرخه ارسال اطلاعات، يا به عبارتى NL Y بازه زمانى، ضرايب محوشدگى كانال ثابت بماند. در فاز اول جرخه ارسال اطلاعات دو مبدا از طريق رابطه زير سيكنال خود را

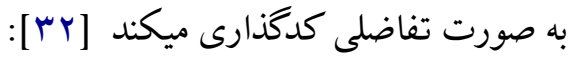

$$
\boldsymbol{s}_{i}^{(\ell)}=\boldsymbol{U}_{i}^{(\ell)} \boldsymbol{s}_{i}^{(\ell-1)}, \quad i=1, \boldsymbol{r}, \quad \ell=\boldsymbol{r}, \ldots, L
$$

كه كد مكان- زمان استفاده شده در شبكه وابسته است [Yr [Y]. سيخنال (I) يك بردار نرمالريزه شده است كه نيازى به دانستن آن از قبل نمى باشد. با استفاده از رابطه ( هـ 1 ) سيكنال دريافتى در بايان فاز اول از جرخه ارسال ا ام در رله n ام به صورت زير مى باشد

$$
\boldsymbol{r}_{n}^{(\ell)}=\sqrt{P_{1}} f_{n}^{(1)} \boldsymbol{s}_{\uparrow}^{(\ell)}+\sqrt{P_{r}} f_{n}^{(\Upsilon)} \boldsymbol{s}_{r}^{(\ell)}+\boldsymbol{z}_{n}^{(\ell)}, \quad n=1, \ldots, N, \quad \ell=1, \ldots, L, \quad\left(\Upsilon_{-}-\Delta\right)
$$

در اين رابطه $P_{i}$ توان متوسط ارسالى توسط مبدا $i$ ام و سيخنال دريافتى خود و مزدوج مختلط آن را به صورت خطى يردازش كرده و سيخنال إن ارسال توليد مى نمايد

$$
\boldsymbol{t}_{n}^{(\ell)}=\beta_{n}\left(\boldsymbol{A}_{n} \boldsymbol{r}_{n}^{(\ell)}+\boldsymbol{B}_{n} \overline{\boldsymbol{r}}_{n}^{(\ell)}\right), \quad n=1, \ldots, N, \quad \ell=1, \ldots, L,
$$

در اين رابطه مكان-زمان استفاده شده در شبكه بستخى دارد. براى اطمينان از اينكه توان متوسط ارسالى از هر رله برابر 
با مقدار مشخص

$$
\beta_{n}=\sqrt{\frac{N P_{r_{n}}}{\left(P_{1}+P_{\boldsymbol{r}}+1\right) \operatorname{Tr}\left\{\boldsymbol{A}_{n} \boldsymbol{A}_{n}^{\dagger}+\boldsymbol{B}_{n} \boldsymbol{B}_{n}^{\dagger}\right\}}}, \quad \text { and } \operatorname{Tr}\left(\boldsymbol{A}_{n} \boldsymbol{A}_{n}^{\dagger}+\boldsymbol{B}_{n} \boldsymbol{B}_{n}^{\dagger}\right)=N .
$$

براى اينكه هر مبدا بتواند سيخنال دريافتى در هر بازه زمانى را با استفاده از سيخنال دريافتى در بازه زمانى قبلى آشكارسازى كند بايد ماتريس هاى رله ها و ماتريس يكانى حاوى سمبلهاى اطلاعات در رابطه ضرب خاصيت جابجايى بذير داشته باشند. به عبارت ديخر بايد داشته باشيم:

$$
\boldsymbol{U}_{i}^{(\ell)} \boldsymbol{A}_{n}=\boldsymbol{A}_{n} \boldsymbol{U}_{i}^{(\ell)} \text {, and } \boldsymbol{U}_{i}^{(\ell)} \boldsymbol{B}_{n}=\boldsymbol{B}_{n} \overline{\boldsymbol{U}}_{i}^{(\ell)}, \quad i=1, \boldsymbol{r}, n=1, \ldots, N, \ell=\boldsymbol{r}, \ldots, L .
$$

در فاز دوم جرخه ارسال اطلاعات، رله ها سيخنال هاى خود را به سوى دو مبدا ارسال مى كنند. به اين

$$
\begin{aligned}
& \text { ترتيب سيگنال دريافتى در مبدا i به صورت زير است: } \\
& \boldsymbol{y}_{i}^{(\ell)}=\sum_{n=1}^{N} f_{n}^{(i)} \boldsymbol{t}_{n}^{(\ell)}+\boldsymbol{v}_{i}^{(\ell)}, \quad i=1, r, \quad \ell=1, \ldots, L,
\end{aligned}
$$

كه

$$
\begin{aligned}
\boldsymbol{y}_{i}^{(\ell)}= & \sqrt{P_{1}}\left(\sum_{n=1}^{N} \beta_{n} f_{n}^{(i)} f_{n}^{(1)} \boldsymbol{A}_{n}\right) \boldsymbol{s}_{1}^{(\ell)}+\sqrt{P_{1}}\left(\sum_{n=1}^{N} \beta_{n} f_{n}^{(i)} \bar{f}_{n}^{(1)} \boldsymbol{B}_{n}\right) \overline{\boldsymbol{s}}_{1}^{(\ell)} \\
& +\sqrt{P_{r}}\left(\sum_{n=1}^{N} \beta_{n} f_{n}^{(i)} f_{n}^{(\boldsymbol{~ ( ) ~}} \boldsymbol{A}_{n}\right) \boldsymbol{s}_{r}^{(\ell)}+\sqrt{P_{r}}\left(\sum_{n=1}^{N} \beta_{n} f_{n}^{(i)} \bar{f}_{n}^{(\Upsilon)} \boldsymbol{B}_{n}\right) \overline{\boldsymbol{s}}_{r}^{(\ell)} \\
& +\boldsymbol{w}_{i}^{(\ell)}, \quad i=1, \boldsymbol{r}, \ell=1, \ldots, L,
\end{aligned}
$$

$$
\boldsymbol{w}_{i}^{(\ell)}=\sum_{n=1}^{N} \beta_{n} f_{n}^{(i)}\left(\boldsymbol{A}_{n} \boldsymbol{z}_{n}^{(\ell)}+\boldsymbol{B}_{n} \overline{\boldsymbol{z}}_{n}^{(\ell)}\right)+\boldsymbol{v}_{i}^{(\ell)}, \quad i=1, \mathrm{r}, \quad \ell=1, \ldots, L .
$$

نويز معادل دريافتى در مبدا i مى باشد. ماتريس كوواريانس اين بردار نويز به صورت زير محاسبه مى گردد: با توجه به اينكه يك مى باشند داريم $\Sigma_{\boldsymbol{w} \backslash}=\mathrm{E}\left\{\sum_{n=1}^{N} \sum_{m=1}^{N} \beta_{n} \beta_{m} f_{n}^{(1)} \bar{f}_{m}^{(1)}\left(\boldsymbol{A}_{n} \boldsymbol{z}_{n}^{(\ell)}+\boldsymbol{B}_{n} \overline{\boldsymbol{z}}_{n}^{(\ell)}\right)\left(\boldsymbol{A}_{m} \boldsymbol{z}_{m}^{(\ell)}+\boldsymbol{B}_{m} \overline{\boldsymbol{z}}_{m}^{(\ell)}\right)^{\dagger}\right\}+\mathrm{E}\left\{\boldsymbol{v}_{n}^{(\ell)} \boldsymbol{v}_{n}^{(\ell)^{\dagger}}\right\}$ 


$$
=\sum_{n=1}^{N} \beta_{n}^{\Upsilon}\left(\boldsymbol{A}_{n} \boldsymbol{A}_{n}^{\dagger}+\boldsymbol{B}_{n} \boldsymbol{B}_{n}^{\dagger}\right)+\boldsymbol{I}_{N} .
$$

با توجه به رابطه (ه_V ) مشاهده مى كنيم كه در سيخنال دريافتى توسط مبدا اول، جمله اول و دوم اين رابطه شامل سيخنال ارسال شده از خود مبدا اول است كه سيخنال خود_تداخل ناميده مىشود و جمله سوم و جهارم حاوى سيخنال ارسالى از مبدا r مى باشد كه سيخنال مطلوب براى آشكار سازى است. سيخنال خود_تداخل اخر به طور كامل از سيخنال دريافتى قبل از آشكار سازى حذف نشود كارايى سيستم به شدت كاهش بيدا مى كند.

تاكنون ارسال در دو فاز مورد بحث قرار گرفته است. ارسال در جهار فاز مشابه همين حالت است، با اين تفاوت كه دو مبدا در يك زمان سيكنال هاى خود را به سوى رله ها ارسال نمى كنند. در فاز اول مبدا ا سيخنال خود را به رله ها مىفرستد، در فاز دوم رلهها سيخنالهاى خود را به سوى مبدا دوم مىفرستند. در فاز سوم، مبدا ب سيخنال خود را به سوى رله ها فرستاده و در فاز F، رله ها سيخنال هاى خود را به سوى مبدا اول ارسال مىكنند. بنابراين سيگنال دريافتى در فاز اول در رله ها همان سيخنال رابطه (ه_r ) است كه در آن است (l) $s_{r}^{(\ell)}$ مقدار دهى اوليه كه F فاز است براى حذف كامل سيگنال هاى خود تداخل در جرخه ارسال اطلاعات كه دو فاز است مورد استفاده قرار مى گيرند.

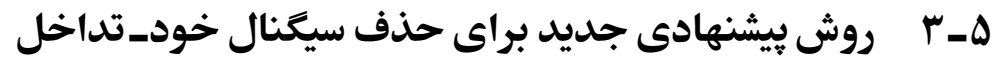

در اين بخش روش ارائه شده براى حذف سيگنال خود_تداخل را با استفاده از روش ارسال تغييرحالت (mode-switching ) ارائه خواهيم كرد. بايد توجه داشت كه اين روش ارسال تغيير-حالت در

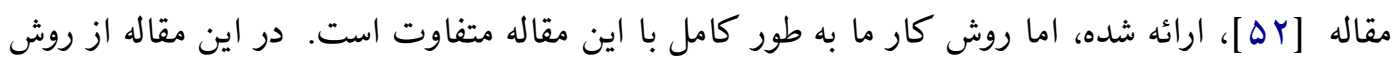
تغيير-حالت براى تخمين سيگنال خود_تداخل استفاده مى شود در حالى كه ما براى حذف كامل سيگنال خود_تداخل از آن استفاده خواهيم كرد.

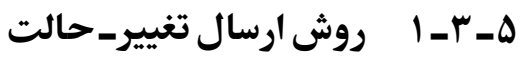

روش ارسال تغيير-حالت با جهار فاز شروع شده و سيس به دو فاز تغيير حالت مى دهد كه در ادامه

$$
\text { جزئيات بيشتر توضيح داده خواهد شد. }
$$




\section{هـ-r ـ ا ـ ا جرخه مقدار دهى اوليه جهار فازى}

در جرخه مقداردهى اوليه، دو مبدا بردارهاى مرجع خود را در جهار فاز مبادله مى كنند. ما در اينجا توصيف رياضى مربوط به مبدا اول را ارائه كرده و توصيف رياضى مربوط به مبدا دوم مشابه خواهد بود. در فاز اول جرخه مقدار دهى اوليه، مبدا اول بردار مرجع خود إن

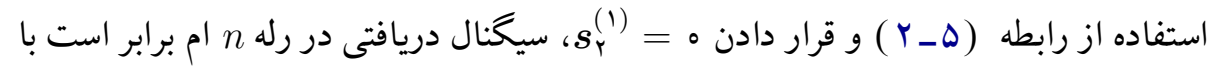

$$
\boldsymbol{r}_{n}^{(1)}=\sqrt{P_{1}} f_{n}^{(1)} \boldsymbol{s}_{1}^{(1)}+\boldsymbol{z}_{n}^{(1)}, \quad n=1, \ldots, N
$$

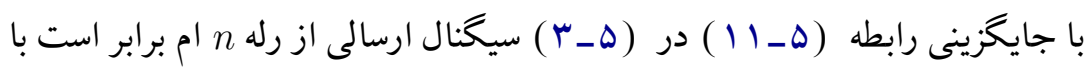

$\boldsymbol{t}_{n}^{(1)}=\sqrt{P_{1}} \beta_{n}^{\prime} f_{n}^{(1)} \boldsymbol{A}_{n} \boldsymbol{s}_{1}^{(1)}+\sqrt{P_{1}} \beta_{n}^{\prime} \bar{f}_{n}^{(1)} \boldsymbol{B}_{n} \overline{\boldsymbol{s}}_{1}^{(1)}+\beta_{n}^{\prime} \boldsymbol{A}_{n} \boldsymbol{z}_{n}^{(1)}+\beta_{n}^{\prime} \boldsymbol{B}_{n} \overline{\boldsymbol{z}}_{n}^{(1)}, \quad n=1, \ldots, N$.

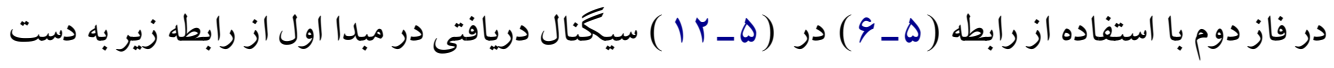

مى آيد

$$
\boldsymbol{y}_{\uparrow}^{(1)}=\sqrt{P_{\uparrow}}\left(\sum_{n=1}^{N} \beta_{n}^{\prime} f_{n}^{(1)^{r}} \boldsymbol{A}_{n}\right) \boldsymbol{s}_{\uparrow}^{(1)}+\sqrt{P_{\uparrow}}\left(\sum_{n=1}^{N} \beta_{n}^{\prime}\left|f_{n}^{(1)}\right|^{r} \boldsymbol{B}_{n}\right) \overline{\boldsymbol{s}}_{\uparrow}^{(1)}+\boldsymbol{w}_{\uparrow}^{(1)}, \quad\left(1 r_{-} \Delta\right)
$$

كه در آن

$$
\text { كه در آن }
$$

مشابه با فاز اول و دوم، در فاز سوم مبدا دوم بردار مرجع خود را براى رله ها ارسال مىكند و در فاز F رله ها سيخُال هاى خود را براى مبدا اول مى فرستند. يّ از اتمام جرخه مقداردهى اوليه، خرخه ارسال

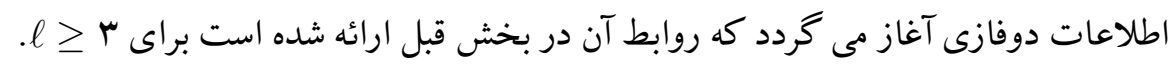

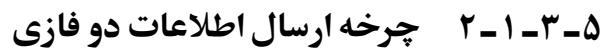

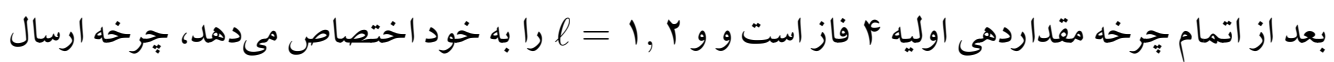
اطلاعات دوفازى آغاز مىشود. سيخنال هاى دريافت شده در رله ها و ارسال شده از رله ها و سيخنال دريافت شده توسط مبدا اول، توسط روابط ( ( 


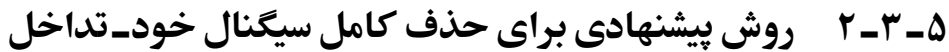

در روش بيشنهادى براى حذف كامل سيكنال خود_تداخل، مبدا اول سيكنال دريافتى اش در فاز دوم خرخه مقدار دهى اوليه را براى حذف سيخنال خود_تداخل در جرخه هاى ارسال اطلاعات استفاده مى كند. توصيف رياضى مربوط به مبدا اول در اينجا ذكر مى شود و توصيف رياضى مربوط به مبدا دوم به صورت

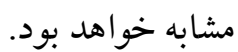

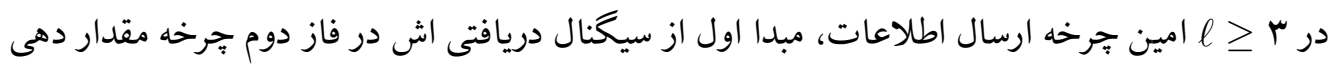

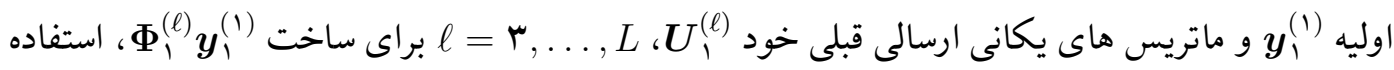
مى كند كه

$$
\boldsymbol{\Phi}_{\uparrow}^{(\ell)} \triangleq \prod_{k=r}^{\ell} \boldsymbol{U}_{1}^{(k)}, \quad \ell=r, \ldots, L .
$$

كه در نتيجه

$$
\boldsymbol{\Phi}_{\uparrow}^{(\ell)} \boldsymbol{y}_{\uparrow}^{(1)}=\sqrt{P_{1}}\left(\sum_{n=1}^{N} \beta_{n}^{\prime} f_{n}^{(1)^{r}} \boldsymbol{A}_{n}\right) \boldsymbol{s}_{1}^{(1)}+\sqrt{P_{1}}\left(\sum_{n=1}^{N} \beta_{n}^{\prime}\left|f_{n}^{(1)}\right|^{r} \boldsymbol{B}_{n}\right) \overline{\boldsymbol{s}}_{1}^{(1)}+\boldsymbol{\Phi}_{\uparrow}^{(\ell)} \boldsymbol{w}_{\uparrow}^{(1)} .
$$

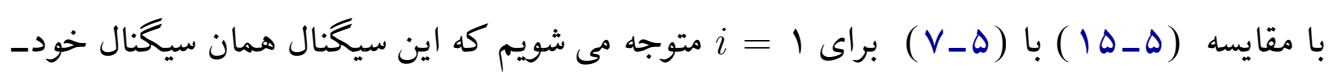
تداخل دريافت شده در مبدا اول به اضافه يك جمله نويز اضافى مى باشد. اكنون با استفاده از اين سيكنال

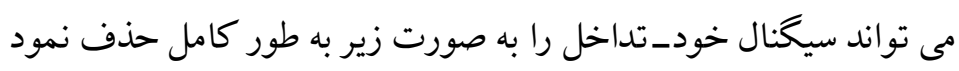

$$
\begin{aligned}
\hat{\boldsymbol{y}}_{\uparrow}^{(\ell)} & =\boldsymbol{y}_{\uparrow}^{(\ell)}-\sqrt{\frac{P_{\uparrow}+1}{P_{\uparrow}+P_{\curlyvee}+1}} \boldsymbol{\Phi}_{\uparrow}^{(\ell)} \boldsymbol{y}_{\uparrow}^{(1)} \\
& =\sqrt{P_{\curlyvee}}\left(\sum_{n=1}^{N} \beta_{n} f_{n}^{(1)} f_{n}^{(\curlyvee)} \boldsymbol{A}_{n}\right) \boldsymbol{s}_{\uparrow}^{(\ell)}+\sqrt{P_{\curlyvee}}\left(\sum_{n=1}^{N} \beta_{n} f_{n}^{(1)} \bar{f}_{n}^{(\curlyvee)} \boldsymbol{B}_{n}\right) \overline{\boldsymbol{s}}_{\uparrow}^{(\ell)}+\hat{\boldsymbol{w}}_{\uparrow}^{(\ell)},(19-\Delta)
\end{aligned}
$$

$$
\hat{\boldsymbol{w}}_{1}^{(\ell)}=\boldsymbol{w}_{1}^{(\ell)}-\sqrt{\frac{P_{1}+1}{P_{1}+P_{\mathrm{r}}+1}} \boldsymbol{\Phi}_{\uparrow}^{(\ell)} \boldsymbol{w}_{1}^{(1)}
$$

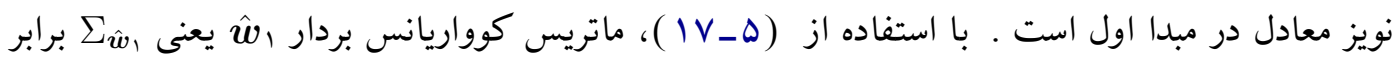
است با ماست

$$
\Sigma_{\hat{\boldsymbol{w}}_{1}}=\mathrm{E}\left\{\hat{\boldsymbol{w}}_{1}^{(\ell)} \hat{\boldsymbol{w}}_{1}^{(\ell)^{\dagger}}\right\}
$$




$$
\begin{aligned}
& =\mathrm{E}\left\{\boldsymbol{w}_{1}^{(\ell)} \boldsymbol{w}_{1}^{(\ell)^{\dagger}}\right\}+\frac{P_{1}+1}{P_{1}+P_{r}+1} \mathrm{E}\left\{\boldsymbol{\Phi}_{1}^{(\ell)} \boldsymbol{w}_{1}^{(1)} \boldsymbol{w}_{1}^{(1)^{\dagger}} \boldsymbol{\Phi}_{1}^{(\ell)^{\dagger}}\right\} \\
& =\Sigma_{\boldsymbol{w}_{1}}+\frac{P_{1}+1}{P_{1}+P_{r}+1} \mathrm{E}\left\{\boldsymbol{\Phi}_{1}^{(\ell)} \Sigma_{\boldsymbol{w}_{1}} \boldsymbol{\Phi}_{1}^{(\ell)^{\dagger}}\right\} .
\end{aligned}
$$

همانطور كه در (19 19 ) مشاهده مى شود سيخنال خود تداخل به طور كامل حذف شده است و اين در حالى است كه مقاله [Y [ه] اخرجّه از روش ارسال تغيير حالت استفاده مى كند اما قادر به حذف كامل سيخنال خود تداخل نيست. بلكه از اين روش براى تخمين سيخنال خود تداخل و روز استفاده ميكند و براى آشكار سازى در هر جرخه ارسال اطلاعات از سيخنال آشكار شده در خرخه قبل استفاده مىكند كه اين موضوع سبب يخش و گسترش خطا در طول در طول آشكارسازى مى گردد. با استفاده از خاصيت جابجايى بذير در ضربه داده شده در رابطه ( هـ ه )خواهيم داشت: $\hat{\boldsymbol{y}}_{1}^{(\ell)}=\boldsymbol{U}_{r}^{(\ell)}\left(\sqrt{P_{r}}\left(\sum_{n=1}^{N} \beta_{n} f_{n}^{(1)} f_{n}^{(\curlyvee)} \boldsymbol{A}_{n}\right) \boldsymbol{s}_{r}^{(\ell-1)}+\sqrt{P_{r}}\left(\sum_{n=1}^{N} \beta_{n} f_{n}^{(1)} \bar{f}_{n}^{(\curlyvee)} \boldsymbol{B}_{n}\right) \overline{\boldsymbol{s}}_{r}^{(\ell-1)}\right)^{\left(1 q_{-}-\Delta\right)}+\hat{\boldsymbol{w}}_{1}^{(\ell)}$. روش ييشنهادى قابليت حذف كامل سيخنال خود داخل را در ازاى افزودن يك جمله جديد به دست آورده است در ادامه نشان خواهيم داد عليرغم افزودن نويز باز هم روش ييشنهادى از روشهاى بهتر عمل خواهد

$$
\begin{aligned}
\hat{\boldsymbol{y}}_{\uparrow}^{(\ell)} & =\boldsymbol{U}_{r}^{(\ell)}\left(\hat{\boldsymbol{y}}_{\uparrow}^{(\ell-1)}-\hat{\boldsymbol{w}}_{\uparrow}^{(\ell-1)}\right)+\hat{\boldsymbol{w}}_{\uparrow}^{(\ell)}, \\
& =\boldsymbol{U}_{\uparrow}^{(\ell)} \hat{\boldsymbol{y}}_{\uparrow}^{(\ell-1)}+\boldsymbol{\eta}_{\uparrow}^{(\ell)}, \quad \ell=r, \ldots, L,
\end{aligned}
$$

كه در آن

$$
\boldsymbol{\eta}_{1}^{(\ell)} \triangleq \hat{\boldsymbol{w}}_{\uparrow}^{(\ell)}-\boldsymbol{U}_{r}^{(\ell)} \hat{\boldsymbol{w}}_{\uparrow}^{(\ell-1)}, \quad \ell=\boldsymbol{r}, \ldots, L
$$

نويز معادل است. با استفاده از اين حقيقت كه ضرايب محو شدگى كانال و تمام نويزهاى دريافتى همخى گوسى مستقل با ميانگين صفر هستند، نويز باشند. اكر جهه ما براى ساده سازى محاسبات و فرض مى كنيم كه همگى گوسى با ميانخين صفر و داراى ماتريس هاى كواريانس ,

$$
\Sigma_{\boldsymbol{\eta}_{1}}=\mathrm{E}\left\{\boldsymbol{\eta}_{\uparrow}^{(\ell)} \boldsymbol{\eta}_{\uparrow}^{(\ell)^{\dagger}}\right\}
$$




$$
\begin{aligned}
& =\mathrm{E}\left\{\hat{\boldsymbol{w}}_{1}^{(\ell)} \hat{\boldsymbol{w}}_{1}^{(\ell)^{\dagger}}\right\}+\mathrm{E}\left\{\boldsymbol{U}_{r}^{(\ell)} \hat{\boldsymbol{w}}_{1}^{(\ell-1)} \hat{\boldsymbol{w}}_{\uparrow}^{(\ell-1)^{\dagger}} \boldsymbol{U}_{r}^{(\ell)^{\dagger}}\right\}, \\
& =\Sigma_{\hat{\boldsymbol{w}}_{1}}+\mathrm{E}\left\{\boldsymbol{U}_{r}^{(\ell)} \Sigma_{\hat{\boldsymbol{w}}_{1}} \boldsymbol{U}_{r}^{(\ell)^{\dagger}}\right\} .
\end{aligned}
$$

با فرض گوسى بودن نويز مىتوان از گيرنده حداكثر_شباهت براى آثكار سازى استفاده كرد:

$$
\begin{aligned}
& \arg \min _{\boldsymbol{U}_{\curlyvee}}\left\|\boldsymbol{\Sigma}_{\boldsymbol{\eta}_{\uparrow}}^{-\frac{1}{r}}\left(\hat{\boldsymbol{y}}_{1}^{(\ell)}-\sqrt{\frac{P_{1}+1}{P_{1}+P_{\curlyvee}+1}} \boldsymbol{U}_{r}^{(\ell)} \hat{\boldsymbol{y}}_{1}^{(\ell-1)}\right)\right\|^{r} \\
& \text { براى =ץ = إ براى } \\
& \arg \min _{\boldsymbol{U}_{r}}\left\|\boldsymbol{\Sigma}_{\boldsymbol{\eta}_{1}}^{-\frac{1}{r}}\left(\hat{\boldsymbol{y}}_{1}^{(\ell)}-\boldsymbol{U}_{r}^{(\ell)} \hat{\boldsymbol{y}}_{1}^{(\ell-1)}\right)\right\|^{r} .
\end{aligned}
$$

توجه مىكنيم كه بازه هاى زمانى Y, Y = = ب براى ارسال بردارهاى مرجع استفاده شده اند و نيازى به

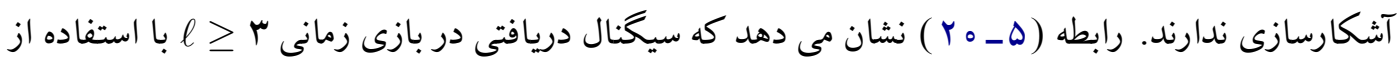
سيخنال دريافتى در بازى زمانى 1 - l قابل آشكارسازى است و نيازى به ضرايب محو شدگى كانال ندارد. اين همان مزيت استفاده از كد كذارى تفاضلى در اين كانال ها مى باشد. در بخش آينده كارايى سيستم را تحليل خواهيم كرد.

\section{ه-p}

براى نشان دادن كارايى و عملكرد روش بيشنهاد شده در اين بخش يك حد بالا بر روى PEP به دست مى آوريم. با استفاده از اين حد بالا نشان مى دهيم كه اين روش بهره جند كانكى برابر با روش ارائه شده در فصل قبل به دست مى آورد. اخرجّه اين روش داراى رله هاى تك آنتنى است در مقايسه با روش فصل قبل كه از رله هاى جند آنتنى مجبور به استفاده بود. براى ساده كردن تحليل خود فرض را بر اين مى گذاريم كه نويز إ است . حد بالاى PEP در قضيه زير بيان شده است .

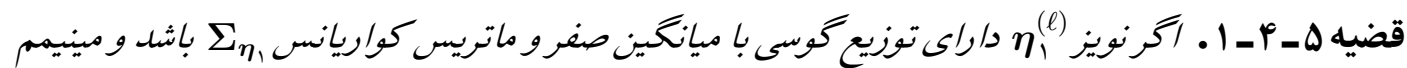
مقدار ويثه ماتريس

$$
\lambda_{\min } \gg \boldsymbol{F} \sigma_{1} .
$$




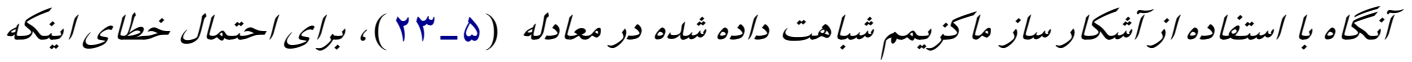

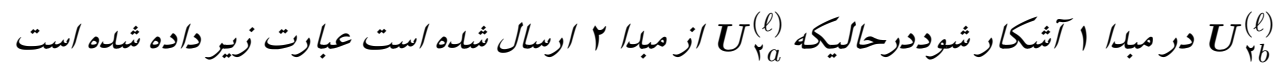

$$
\begin{aligned}
\text { PEP } & =\operatorname{Pr}\left(\boldsymbol{U}_{\curlyvee a}^{(\ell)} \rightarrow \boldsymbol{U}_{\curlyvee b}^{(\ell)}\right) \\
& \leq\left(\boldsymbol{\kappa}_{\sigma_{1}}\right)^{N}\left|\boldsymbol{\Omega}_{a b}^{(\ell)}\right|^{-1}\left|\boldsymbol{\Sigma}_{\hat{\boldsymbol{y}}}\right|^{-1},
\end{aligned}
$$

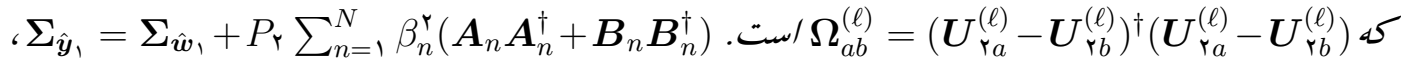

$$
\begin{aligned}
& \text { } \\
& \sigma_{1}=r\left(1+\frac{P_{1}+1}{P_{1}+P_{r}+1}\right)\left(1+N \sum_{n=1}^{N} \beta_{n}^{r}\right) .
\end{aligned}
$$

اثبات. مشابه با روش استخراج حد بالاى PEP ارائه شده در مقاله [1] احتمال خطاى PEP اشكارسازى Uر مبدا اول در حالى كه $U_{r b}^{(\ell)}$

$$
\begin{aligned}
\operatorname{Pr}\left(\boldsymbol{U}_{\curlyvee a}^{(\ell)} \rightarrow\right. & \left.\boldsymbol{U}_{\curlyvee b}^{(\ell)}\right) \leq \\
& E_{\hat{\boldsymbol{y}}_{\uparrow}^{(\ell-1)}}\left\{\exp \left\{-\frac{1}{\kappa_{\sigma}} \hat{\boldsymbol{y}}_{\uparrow}^{(\ell-1)^{\dagger}} \boldsymbol{\Omega}_{a b}^{(\ell)} \hat{\boldsymbol{y}}_{\uparrow}^{(\ell-1)}\right\}\right\},
\end{aligned}
$$

كه راست رابطه (rV_ه ) با استفاده از است. براى به دست آوردن اين رابطه ما در ماتريس هاى كووريانس از اين حقيقت استفاده كرده ايم كه براى هر ماتربس كدهاى DDST مورد استفاده.

براى محاسبه اميد رياضى بر حسب (1) دست آوريم. با استفاده از اين حقيقت كه تمام درايه هاى

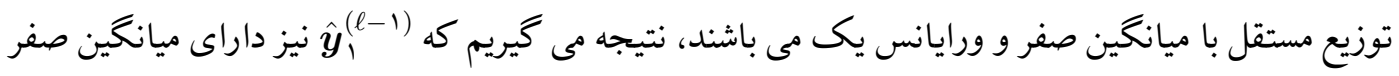
و ماتريس كواريانس زير

$$
\Sigma_{\hat{\boldsymbol{y}},}=\operatorname{Pr}_{\mathrm{r}} \sum_{n=1}^{N} \beta_{n}^{\curlyvee}\left(\boldsymbol{A}_{n} \boldsymbol{A}_{n}^{\dagger}+\boldsymbol{B}_{n} \boldsymbol{B}_{n}^{\dagger}\right)+\Sigma_{\hat{\boldsymbol{w}},},
$$

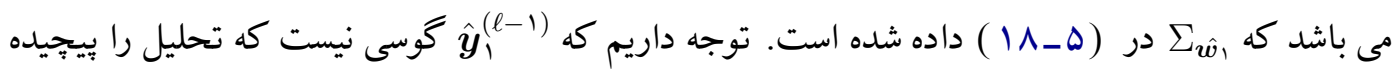

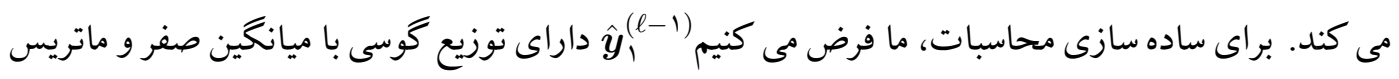




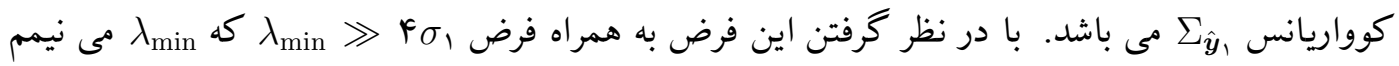

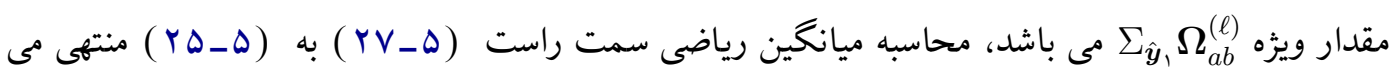

توجه داريم كه جمله اضافى موجود در نويز ( IV_A ) باعث ايجاد يك جمله اضافى در ماتريس كواريانس نويز مىشود. به طور ويزه جمله اول در ماتريس كواريانس نويز , در اين فصل و فصل قبل مشترك مى باشد، در حاليكه جمله دوم مختص روش ارون ارئه شده در اين فصل است.

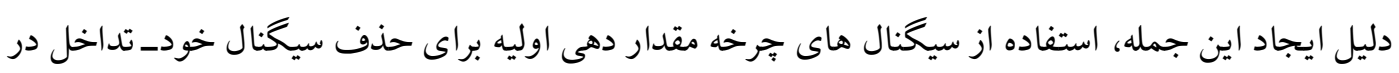
جرخه ارسال اطلاعات مى باشد.

باند بالاى ارائه شده در قضيه هـF - - اثر تعداد رله ها و توان ارسالى از دو مبدا و رله ها را مشخص مى كند. اخر فرض كنيم توان ارسالى دو مبدا و تمام رله ها با هم مساوى است اين قضيه مىتواند سادهتر شود. براى نتيجه ه-r $P E P \leq\left(r r+19 N^{r}\right)^{N} P^{-N}\left|\boldsymbol{\Omega}_{a b}^{(\ell)}\right|^{-1}\left|\sum_{n=1}^{N} \boldsymbol{A}_{n} \boldsymbol{A}_{n}^{\dagger}+\boldsymbol{B}_{n} \boldsymbol{B}_{n}^{\dagger}\right|^{-1}$.

اثبات. برايى ساده سازى محاسبات فرض مى كنيم كه دو مبدا و تمامى رله ها داراى توان متوسط ارسالى يكسان مى باشند يعنى $\beta_{n}^{\Upsilon}=\frac{P}{r P+1}$ $\boldsymbol{A}_{n} \boldsymbol{A}_{n}^{\dagger}+\boldsymbol{B}_{n} \boldsymbol{B}_{n}^{\dagger} \preceq$ است و براى لـ

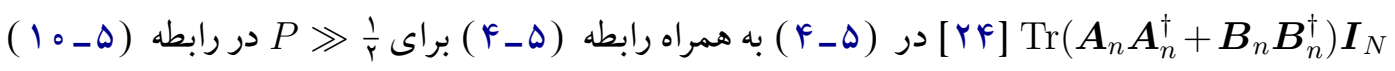

$$
\text { به به }
$$

استفاده از اين رابطه در (

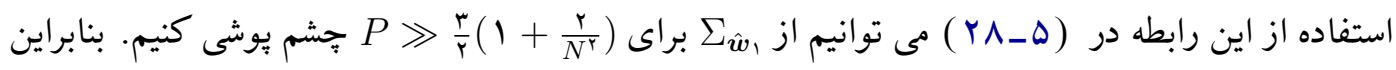
براى

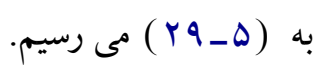

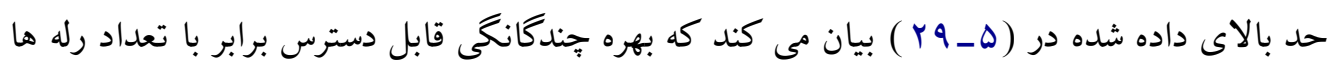

$$
G_{d}=N
$$


كه برابر با بهره جندانانحى به دست آمده توسط روش ارائه شده در فصل قبل مى باشد در حاليكه آن روش حداقل به دو آنتن در هر رله نياز دارد اين در حالى است كه اين روش تنها به يك آنتن در هر نياز دارد و بهره كدينگ اين روش برابر است با درن

$$
G_{c}=\left(r r+19 N^{r}\right)^{-1}\left|\boldsymbol{\Omega}_{a b}^{(\ell)}\right|^{\frac{1}{N}}\left|\sum_{n=1}^{N} \boldsymbol{A}_{n} \boldsymbol{A}_{n}^{\dagger}+\boldsymbol{B}_{n} \boldsymbol{B}_{n}^{\dagger}\right|^{\frac{1}{N}} .
$$

براى ادامه تحليل خود در ادامه دو مقايسه را ارائه خواهيم كرد. اول كارايى روش بيشنهاد شده با استفاده از دو كد الموتى و (Y SP(Y بررسى مى شود و دوم كارايى اين روش با روش ارائه شده در فصل قبل مورد

$$
\text { مقايسه قرار مى گيرد. }
$$

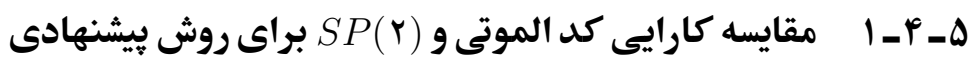

براى به دست آوردن يك مصالحه بين نرخ ارسال و كارايى سيسم DDST وقتى كه از كد الموتى و يا SP(Y) خواهيم آورد. اين باندها به يك نتيجه غير شهودى منتهى مىشوند و آن اين است كه با افزايش تعداد رله ها

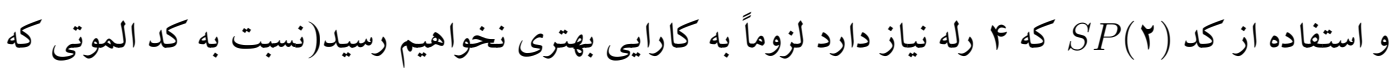

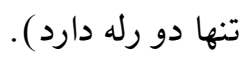

$$
\text { ه }
$$

براى كد الموتى، دو ماتريس يكانى حاوى سمبلهاى اطلاعات ارسال شده از مبدا دوم داراى ساختار

$$
\text { زير مى باشند }
$$

$$
\begin{aligned}
& \boldsymbol{U}_{r r}^{(\ell)}=\left[\begin{array}{cc}
u_{r r, 1}^{(\ell)} & u_{r r, r}^{(\ell)} \\
-\bar{u}_{r r, r}^{(\ell)} & \bar{u}_{r r, 1}^{(\ell)}
\end{array}\right], \quad r=a, b . \\
& \text { براى اين كد، مصالحه بينPEP و نرخ ارسال در قضيه زير ارائه شده است. }
\end{aligned}
$$

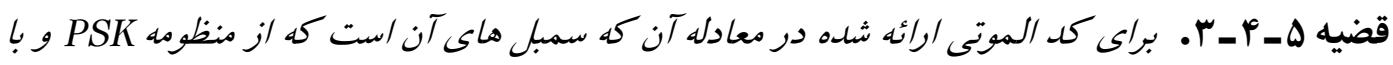

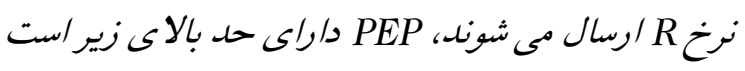

$$
P E P_{1} \leq \frac{\left(9(r+P)^{-1}\right)^{r}}{\sin ^{r}\left(\pi r^{-R}\right)}
$$

شرط برقرارى /ين قضيه رابطه (هF_ ( ) /ست. 
اثبات. براى دو ماتريس اطلاعات مجزا با ساختار داده شهه در (هـ ابم) داريم [V]

$$
\left|\boldsymbol{\Omega}_{a b}^{(\ell)}\right|=\left(\left|u_{\curlyvee a, 1}^{(\ell)}-u_{\curlyvee b, 1}^{(\ell)}\right|^{\curlyvee}+\left|u_{\uparrow a, \uparrow}^{(\ell)}-u_{\curlyvee b, r}^{(\ell)}\right|^{\curlyvee}\right)^{\curlyvee}
$$

اين رابطه وقتى مينيمم مىشود كه يكى از دو جمله صفر باشد و ديخرى نيز مينيمم گردد. از آنجايى كه مى دانيم مينيمم فاصله بين دو سمبل انتخاب شده از 1 -PSK برابر است با

$$
\left|\Omega_{a b}^{(\ell)}\right| \geq 19 \sin ^{\kappa}\left(\frac{\pi}{M}\right)
$$

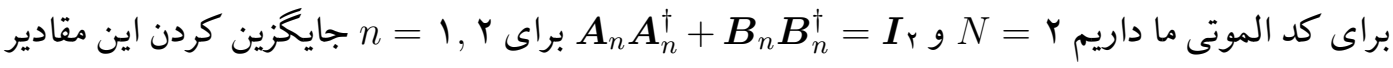
و استفاده از اين حقيقت كه مى رسيم با استفاده از اين مقادير و حد روى | (l) به (ro-O)

$$
\operatorname{PEP} \leq \frac{\left(\mathbf{q}(\boldsymbol{r}+P)^{-1}\right)^{r}}{\sin ^{\varphi}\left(\frac{\pi}{M}\right)}
$$

منجر مىشود. از آنجايى كه در كد الموتى DDST هر مبدا دو سمبل را از منظومه -PSK يكسان در طى

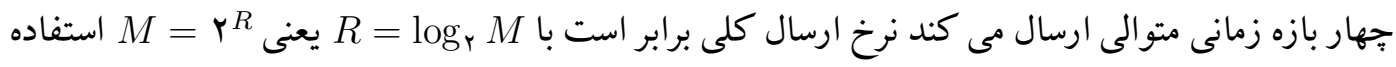

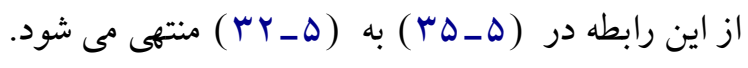

توجه داريم كه اين حد بالا به سيكنال هاى ارسالى a و بستخى ندارد و بنابراين حدى برروى ماكزيمم

PEP

$$
S P(r) \text { r } r-1-r
$$

براى كد (Y SP(Y ماتريس يكانى حاوى سمبل هاى ارسالى داراى ساختار زير است

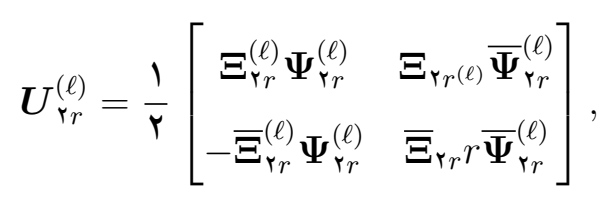

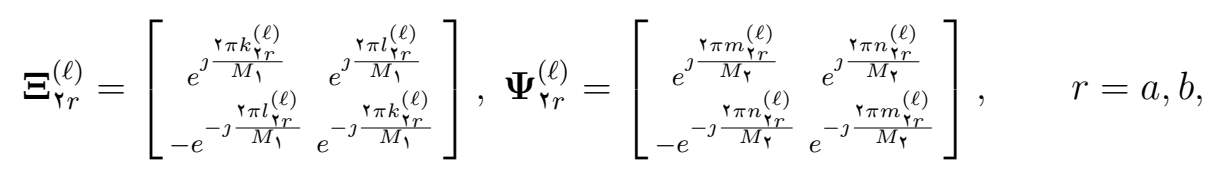


كه معرف كارديناليتى منظومه هاى PSK مى باشند. انتخاب M و M M بايد به صورت اعداد فرد و نسبت به هم اول باشد تا رسيدن به حداكثر دايورسيتى را تضمين كند. بنابراين در تحليل خود ما M و r شرايط انتخاب خواهيم كرد. براى به دست اوردن مصالحه بين كارايى و نرخ ارسال براى كد (Y SP( به دو

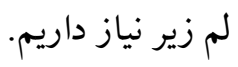

لم ه-f داريم $m \in\left\{1, \ldots, M_{r}-1\right\},\left\{1, \ldots, M_{1}-1\right\}$

$$
\min _{k, m}\left|k M_{r}-m M_{1}\right|=1 .
$$

اثبات. براى اثبات اين لم، ما با بيدا كردن يك حد بِايين بر روى | نسبت به هم اول هستند و $\} \in\left\{1, \ldots, M_{r}-1\right\}$ g $k \in\left\{1, \ldots, M_{1}-1, \ldots\right.$ داد كه اين باند هميشه قابل دسترس است. نشان مى دهيم كه براى هر مقدار صحيح k و m و \M و r

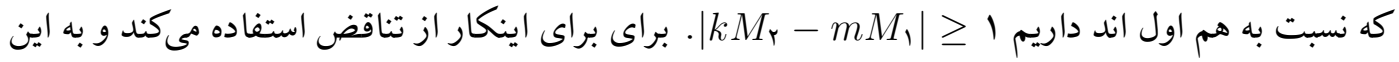
ترتيب كه فرض مىكنيم ه يذير باشد يعنى مىرسيم كه بايد $m \in\left\{1, \ldots, M_{r}-1\right\}$ باشد و اين غيرممكن است جون كه بنابراين نتيجه مى گيريم كه م كه براى هر دو عدد صحيح نسبت به هم اول IM و YM دارند كه به مى نيمم مقدار اين رابطه رسيد. توجه داريم كه رابطه | $\left|k M_{r}-m M_{1}\right|=1$ به اين معنى است كه

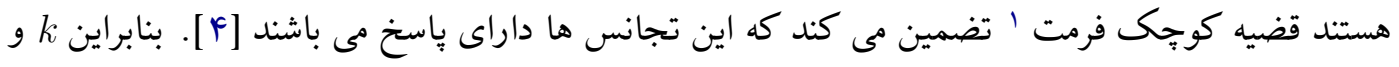
m $\left|k M_{r}-m M_{1}\right|=1$ و اثبات وجود دارد كامل مى شود. لم ه-f

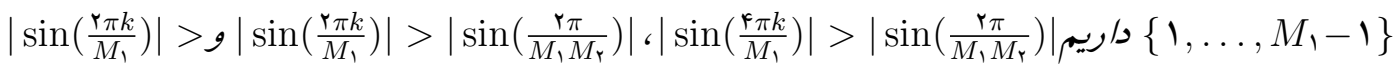
$\cdot\left|\sin \left(\frac{\pi}{M_{1} M_{\mathrm{r}}}\right)\right|$

Fermat's Little Theorem' 
اثبات. براى اثبات اين لم به ما توجه داريم كه براى a معين جواب نامساوى | از دو بازه (a) مى دهيم كه زاويه

$$
\cdot\left[\pi-\frac{r \pi}{M_{\uparrow} M_{r}}, \pi+\frac{r \pi}{M_{\uparrow} M_{r}}\right]
$$

اول، فرض مى كنيم كه r ممكن است يس معنى آن است r ها صدق كند برابر است با بيدا كردن جواب براى يكى از تساوى هاى زير إ -

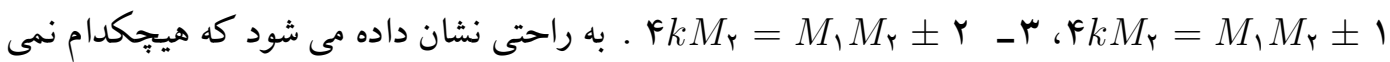
$\frac{\digamma_{\pi k}}{M_{\uparrow}} \notin\left[-\frac{r \pi}{M_{\uparrow} M_{\Upsilon}}, \frac{r \pi}{M_{\uparrow} M_{\Upsilon}}\right]$ توانند پاسخ داشته باشند يس و مشابه بقيه موارد نيز اثبات مى شوند. با استفاده از اين دو لم، اكنون مى توان مصالحه ى بين كارايى و نرخ ارسال را براى كد (Y SP( در قضيه زير ارائه كرد.

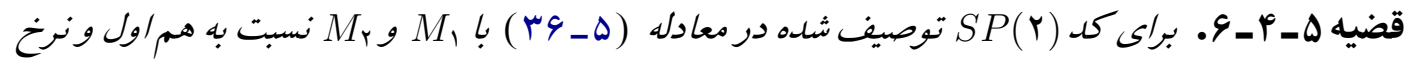
ارسال R ، حد بالا را براى PEP به صورت زير است

$$
P E P_{r} \leq \frac{\left(r \vee\left(\frac{q}{r}+r P\right)^{-1}\right)^{r}}{\left(\sin ^{r}(\pi r-r R+1) \pm r \sin ^{r}(\pi r-r R+1) \sin ^{r}\left(\pi r^{-r R}\right)\right)^{r}},
$$

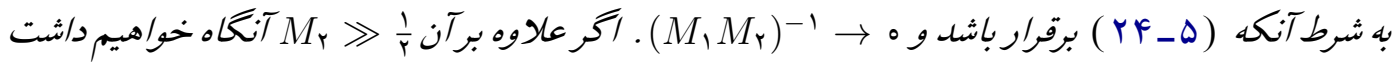

$$
P E P_{r} \leq \frac{\left(r \vee(q+r P)^{-1}\right)^{r}}{\sin ^{\wedge}\left(\pi r^{-r R}\right)} .
$$

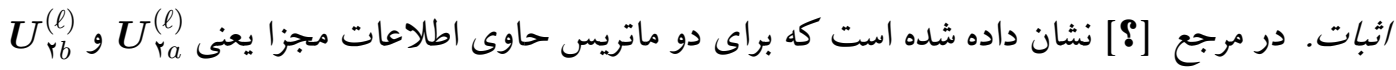
داريم

$$
\left|\boldsymbol{U}_{r a}^{(\ell)}-\boldsymbol{U}_{r b}^{(\ell)}\right|=\frac{1}{\xi}|\alpha|^{r}\left(q+\frac{1}{q}\right)^{r}+\frac{1}{q}\left|q \beta-\frac{\bar{\beta}}{q}\right|^{r},
$$




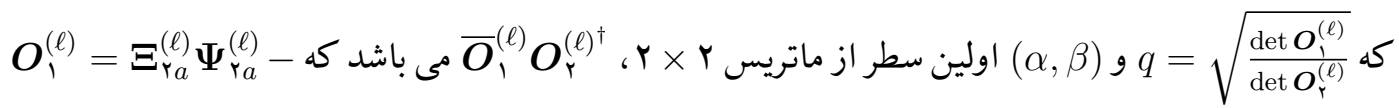

$$
\begin{aligned}
& \boldsymbol{O}_{r}^{(\ell)}=\boldsymbol{\Xi}_{r a}^{(\ell)} \overline{\boldsymbol{\Psi}}_{r a}^{(\ell)}-\boldsymbol{\Xi}_{r b}^{(\ell)} \overline{\boldsymbol{\Psi}}_{r b}^{(\ell)}, \boldsymbol{\Xi}_{r b}^{(\ell)} \boldsymbol{\Psi}_{r b}^{(\ell)} \\
& \alpha=r e^{-\jmath \frac{\xi_{\pi} k_{r a}^{(\ell)}}{M_{1}}}+r e^{-\jmath \frac{\xi_{\pi} l_{r a}^{(\ell)}}{M_{1}}}+r e^{-\jmath \frac{\xi_{\pi} k_{r b}^{(\ell)}}{M_{1}}}+r e^{-\jmath \frac{\xi_{\pi} l_{r b}^{(\ell)}}{M_{1}}} \\
& -r X\left(e^{-j \frac{r \pi\left(k_{r a}^{(\ell)}+k_{r b}^{(\ell)}\right)}{M_{\uparrow}}}+e^{-j \frac{r \pi\left(l_{r a}^{(\ell)}+l_{r b}^{(\ell)}\right)}{M_{\uparrow}}}\right)
\end{aligned}
$$

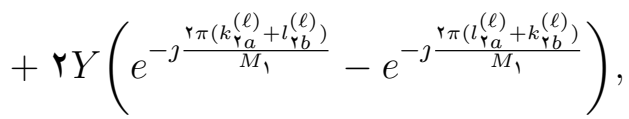

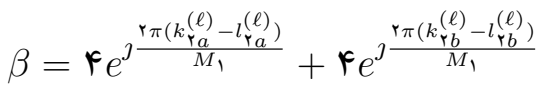

$$
\begin{aligned}
& -r X\left(e^{\frac{\gamma \pi\left(k_{r a}^{(\ell)}-l_{r b}^{(\ell)}\right)}{M_{\uparrow}}}-e^{j \frac{r\left(l_{r a}^{(\ell)}-k_{r b}^{(\ell)}\right)}{M_{\uparrow}}}\right) \\
& -r Y\left(e^{j \frac{r \pi\left(k_{r a}^{(\ell)}-k_{r b}^{(\ell)}\right)}{M_{1}}}+e^{j \frac{r \pi\left(l_{r a}^{(\ell)}-l_{r b}^{(\ell)}\right)}{M_{\uparrow}}}\right), \\
& X \triangleq \cos \left(r \pi \frac{m_{r a}^{(\ell)}-m_{r b}^{(\ell)}}{M_{r}}\right)+\cos \left(r \pi \frac{n_{r a}^{(\ell)}-n_{r b}^{(\ell)}}{M_{r}}\right), \\
& Y \triangleq \cos \left(r \pi \frac{m_{r a}^{(\ell)}+n_{r b}^{(\ell)}}{M_{r}}\right)-\cos \left(r \pi \frac{n_{r a}^{(\ell)}+m_{r b}^{(\ell)}}{M_{r}}\right) .
\end{aligned}
$$

[? [? نشان داده است كه براى اعداد صحيح ו صفر است. استفاده از اين حقيقت كه

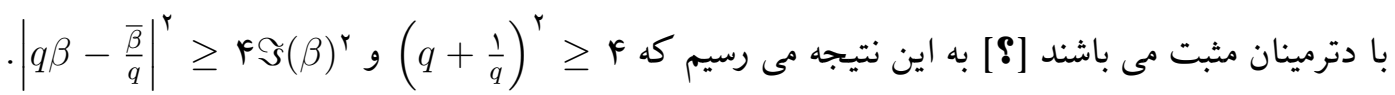
بنابراين، داريم

$$
\left|\boldsymbol{U}_{r a}^{(\ell)}-\boldsymbol{U}_{r b}^{(\ell)}\right| \geq \Re(\alpha)^{r}+\Im(\alpha)^{r}+\Im(\beta)^{r}
$$

يك حد بالا بر سمت راست رابطه ( (ه F-F ) در دو قدم به دست مى آيد. در گام اول، ما شرط نسبت به هم اول بودن I و M M را در نطر نمى گيريم يعنى فرض مى كتيم كه يك عدد صحيح مانند c وجود دارد كه

$$
l_{r a}^{(\ell)}=m_{r a}^{(\ell)}=n_{r a}^{(\ell)}=k_{r b}^{(\ell)}=l_{r b}^{(\ell)}=n_{r b}^{(\ell)}=\circ,
$$

باعث مى شود كه سمت راست (هـ_r دوم، فرص مى كنيم I 


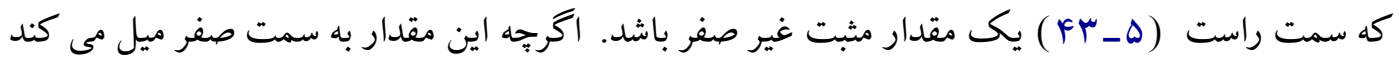

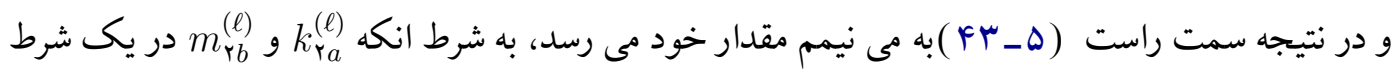

$$
\text { خاص صدق كرده و م } \rightarrow \text {. }
$$

گام اول: فرض كرده ب و M M M اعداد صحيح نسبت به هم اول نمى باشند و نشان مىدهيم كه مى نيمم

$\Re(\alpha)^{r}=$ = كه $\left|U_{r a}^{(\ell)}-U_{r b}^{(\ell)}\right|$

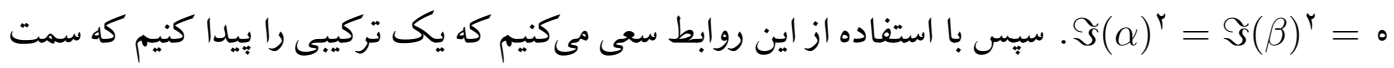
راست معادله (ه-Fr_) برابر با صفر شود. اينها سه معادله غير خطى هستند كه تعداد مجهولات از تعداد معادلات بيشتر است بنابراين فرض مى كنيم كه ه دنبال

$$
\begin{aligned}
& \text { كردن • } \\
& \Re(\alpha)=r \cos \left(r \pi \frac{k_{\curlyvee a}^{(\ell)}}{M_{\uparrow}}\right)\left(r \cos \left(r \pi \frac{k_{\curlyvee a}^{(\ell)}}{M_{\uparrow}}\right)-(X-Y)\right) \\
& +(\boldsymbol{r}-\mathrm{r}(X+Y)) \\
& \Im(\alpha)=r \sin \left(r \pi \frac{k_{r a}^{(\ell)}}{M_{\uparrow}}\right)\left(r \cos \left(r \pi \frac{k_{r a}^{(\ell)}}{M_{\uparrow}}\right)-(X-Y)\right), \\
& \Im(\beta)=r \sin \left(r \pi \frac{k_{r a}^{(\ell)}}{M_{\uparrow}}\right)(r-(X+Y)),
\end{aligned}
$$

كه X و Y در ( $X$ ( طور همزمان صفر شوند، $X-Y=r \cos \left(r \pi \frac{k_{r a}^{(\ell)}}{M_{1}}\right)$ و $X+Y=r$ است كه نتيجه مى دهد

$$
X=1+\cos \left(r \pi \frac{k_{r a}^{(\ell)}}{M_{\uparrow}}\right), Y=1-\cos \left(r \pi \frac{k_{r a}^{(\ell)}}{M_{\uparrow}}\right) .
$$

با جايخزينى


مى توان نشان داد كه براى هر $m_{r b}^{(\ell)}=c k_{r a}^{(\ell)}$ دارد بطورى كه و و

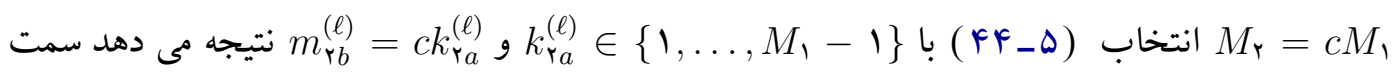




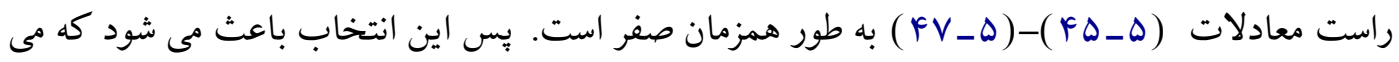

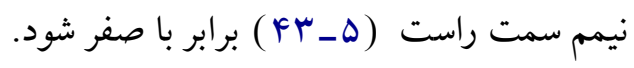
كام دوم: اكنون فرض مى كنيم كه M و M M M M (F) ) را تضمين نمى كند. به عبارت (FF_ه) ديخر در حالتى كه \ و Y M نسبت به هم اول هستند انتخاب به دست آمده در كام اول نمى تواند نتيجه دهد كه مى نيمم سمت راست رابطه ( ه-Fr) برابر با صفر باشد. براى بيدا كردن اين مقدار مينيمم غير صفر ما فرض مى كنيم كه با جايخزينى

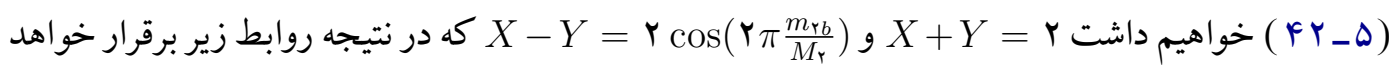

$$
\begin{aligned}
& \Re(\alpha)=\boldsymbol{r} \cos \left(r \pi \frac{k_{r a}^{(\ell)}}{M_{\uparrow}}\right)\left(\cos \left(r \pi \frac{k_{r a}^{(\ell)}}{M_{\uparrow}}\right)-\cos \left(r \pi \frac{m_{r b}^{(\ell)}}{M_{\curlyvee}}\right)\right), \\
& \Im(\alpha)=-\boldsymbol{r} \sin \left(r \pi \frac{k_{r a}^{(\ell)}}{M_{\uparrow}}\right)\left(\cos \left(r \pi \frac{k_{r a}^{(\ell)}}{M_{\uparrow}}\right)-\cos \left(r \pi \frac{m_{r b}^{(\ell)}}{M_{\curlyvee}}\right)\right), \\
& \Im(\beta)=\bullet,
\end{aligned}
$$

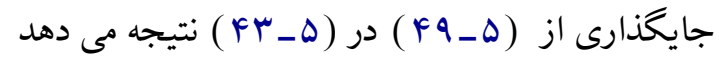

$$
\left|\boldsymbol{U}_{r a}^{(\ell)}-\boldsymbol{U}_{r b}^{(\ell)}\right| \geq 19\left(\cos \left(r \pi \frac{k_{r a}^{(\ell)}}{M_{\uparrow}}\right)-\cos \left(r \pi \frac{m_{r b}^{(\ell)}}{M_{r}}\right)\right)^{r} .
$$

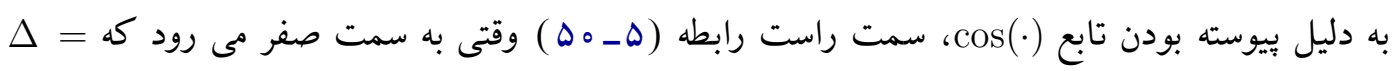

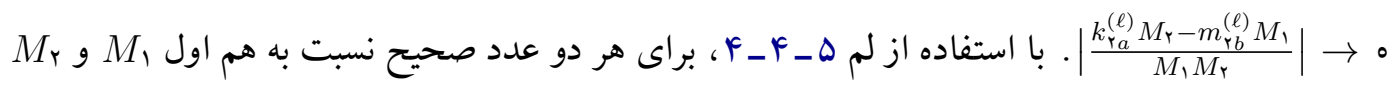
اعداد صحيح است كه اعداد صحيح براى به دست آوردن يك حد بر روى PEP به عنوان به صورت يك تابع از نرخ ارسال R ما مى توانيم كه سمت راست رابطه (هـ ه ه ) را به صورت زير بازنويسى كنيم

$$
\begin{aligned}
& \left|\boldsymbol{U}_{r a}^{(\ell)}-\boldsymbol{U}_{r b}^{(\ell)}\right| \\
& \geq \min \left\{q \boldsymbol{r} \sin ^{\curlyvee}\left(\pi \frac{k_{r a}^{(\ell)} M_{\curlyvee}+m_{r b}^{(\ell)} M_{\curlywedge}}{M_{\uparrow} M_{\curlyvee}}\right)\right.
\end{aligned}
$$




$$
\begin{aligned}
& \left.\times \sin ^{r}\left(\pi \frac{k_{r a}^{(\ell)} M_{r}-m_{r b}^{(\ell)} M_{\uparrow}}{M_{\uparrow} M_{r}}\right)\right\} \\
\geq & q r \sin ^{r}\left(\frac{r k_{r a}^{(\ell)} \pi}{M_{\uparrow}} \pm \frac{\pi}{M_{\uparrow} M_{r}}\right) \sin ^{r}\left(\frac{\pi}{M_{\uparrow} M_{r}}\right) \\
= & 19 \sin ^{r}\left(\frac{r \pi k_{r a}^{(\ell)}}{M_{\uparrow}}\right) \sin ^{r}\left(\frac{r \pi}{M_{\uparrow} M_{r}}\right) \\
& +9 r \cos ^{r}\left(\frac{r k_{r a}^{(\ell)} \pi}{M_{\uparrow}}\right) \sin ^{r}\left(\frac{\pi}{M_{\uparrow} M_{r}}\right) \\
& \pm r r \sin \left(\frac{r k_{r a}^{(\ell)} \pi}{M_{\uparrow}}\right) \sin \left(\frac{r \pi}{M_{\uparrow} M_{r}}\right) \sin ^{r}\left(\frac{\pi}{M_{\uparrow} M_{r}}\right) \\
\geq & 19 \sin ^{r}\left(\frac{r \pi}{M_{\uparrow} M_{r}}\right) \pm r r \sin ^{r}\left(\frac{r \pi}{M_{\uparrow} M_{r}}\right) \sin ^{r}\left(\frac{\pi}{M_{\uparrow} M_{r}}\right) .
\end{aligned}
$$

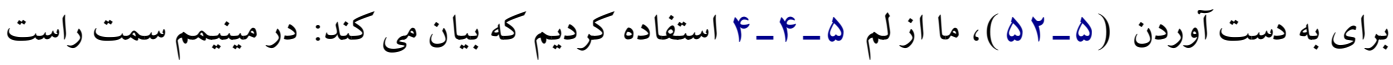

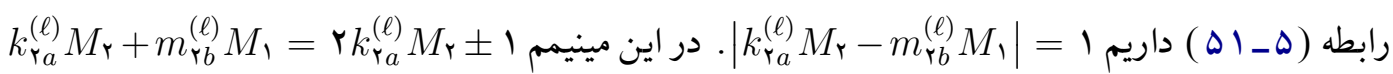

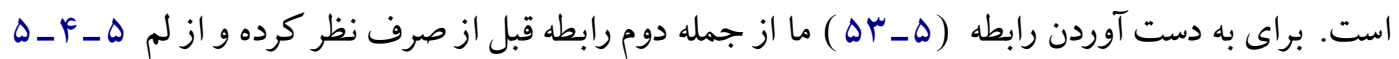

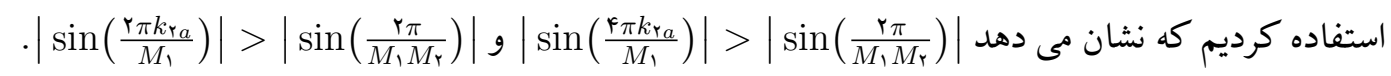
از آنجايى كه كد (r SP( طى ^ بازه زمانى ارسال مى كند نرخ ارسال براى اين كد برابر است با با بـ $R=\frac{\log _{r}\left(M_{1} M_{\Upsilon}\right)}{r}$ بيت بر كانال كه نتيجه مى دهد در رابطه ( ه_ (ه تقريباً برابر با

$$
\begin{aligned}
& \text { كه } \\
& \left|\Omega_{a b}^{(\ell)}\right| \geq 9 \mathcal{F}^{\Upsilon} \sin ^{\wedge}\left(\frac{\pi}{M_{1} M_{\curlyvee}}\right) .
\end{aligned}
$$

با جايخذارى

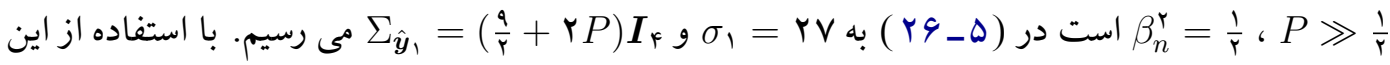
مقادير در حد بالاى روى |

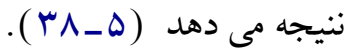

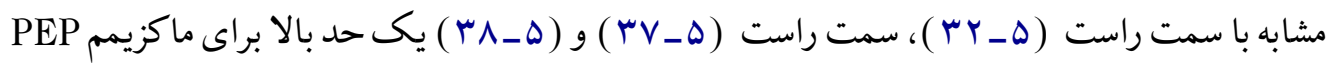




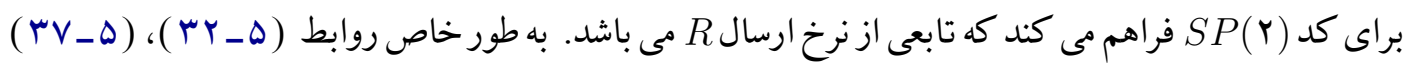

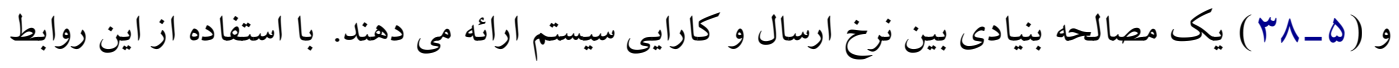

$$
\text { نتيجه زير را داريم. }
$$

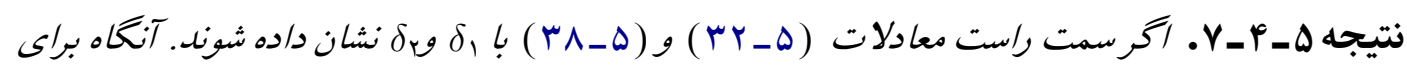
يك توان ارسالى ثابت P يك نرخ ارسال . R وجود دارد به طورى كه

$\delta_{\mathrm{r}}<\delta_{1}$, for $R<R_{\mathrm{o}}, \quad$ and $\quad \delta_{\mathrm{r}}>\delta_{1}$, otherwise .

$(\Delta \Delta-\Delta)$

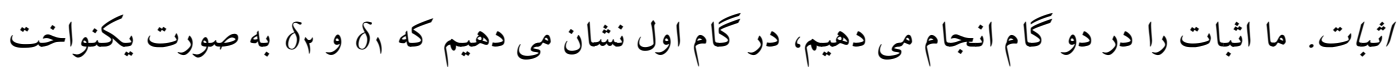

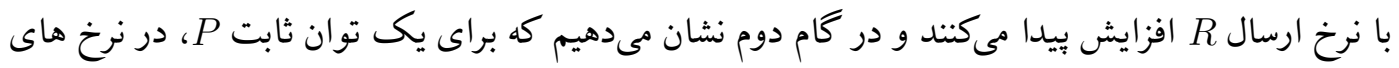

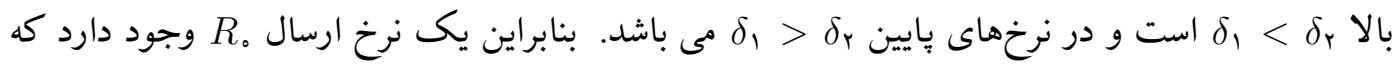
رابطه (ه_ (ه) ) را تضمين مى كند. كام اول: ما داريم

$$
\delta_{1}=\left(\frac{q}{(\boldsymbol{r}+P) \sin ^{r}\left(\pi r^{-R}\right)}\right)^{r}, \quad \delta_{r}=\left(\frac{r \curlyvee}{(q+r P) \sin ^{r}\left(\pi r^{-r R}\right)}\right)^{r} .
$$

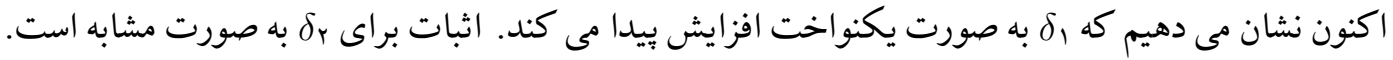

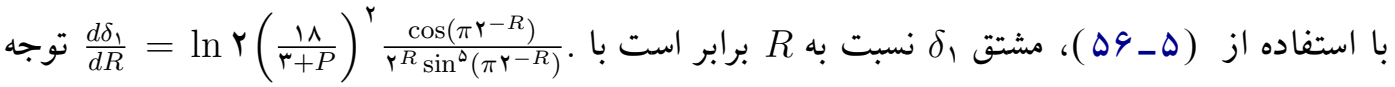
داريم كه براى ا $R$ زاويه $R$ زائ هر دو مثبت بوده و در نتيجه ال بصورت اكيدا يكنواخت با R افزايش مى يابد البته به شرط ا > R.

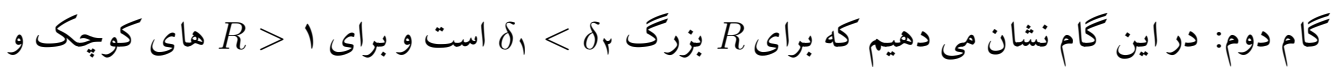

$$
\begin{aligned}
& \text { مقادير به انداره كافى بزرگ P داريم r > > }
\end{aligned}
$$

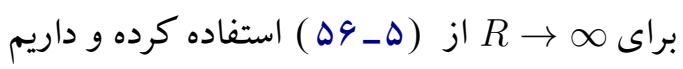

$$
\begin{aligned}
& \frac{\delta_{1}}{\delta_{r}}=\left(\frac{q(q+r P)^{r} \sin ^{r}\left(\pi r^{-r R}\right)}{r V^{r}(r+P) \sin ^{r}\left(\pi r^{-R}\right)}\right)^{r}, \\
& \approx\left(\frac{\pi^{r}(\boldsymbol{q}+r P)^{r}}{\Lambda 1(r+P) r^{q R}}\right)^{r} \rightarrow \circ,
\end{aligned}
$$

كه براى به دست آوردن (هـ_ه

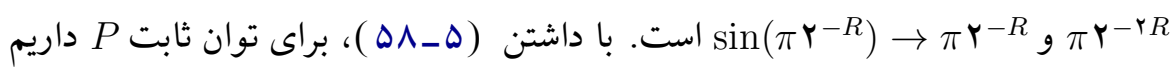

$$
\delta_{1}<\delta_{\mathrm{r}}, \quad \text { for } \quad R \rightarrow \infty \text {. }
$$




$$
\begin{aligned}
& \text { براى ا ل\ } R \text { با استفاده از (ه ه ه ) داريم } \\
& \frac{\delta_{1}}{\delta_{r}}=\frac{(q+r P)^{r}}{\mathbb{1}^{r}(r+P)^{r}} .
\end{aligned}
$$

از آنجايى كه توان P در صورت كسر بزركتر از مخرج است، بِ يس مقدار P وجود دارد كه در آن اס از

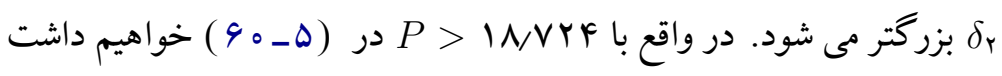

$$
\delta_{1}>\delta_{r}, \quad \text { for } \quad R \searrow 1 \text {. }
$$

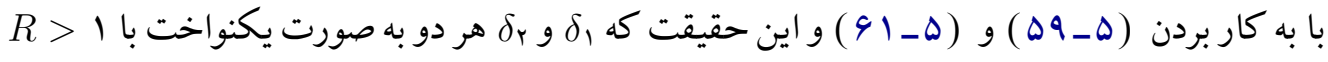
افزايش مى يابند، اثبات تمام مى شود.

اين نتيجه بيان مىكند كه براى يك توان ارسالى ثابت P ، با افزايش نرخ ارسال، PEP متناظر با كد منتاظر با كد الموتى افزايش مى يابد. عبارتى ديگر اين نتيجه بيان مى كند كه براى SPP(Y) يك توان ارسالى ثابت در نرخ هاى ارسال پايين بهتر از كد (Y SP( و براى نرخ هاى ارسالى بالا از كد الموتى استفاده شود، اخرجه كد الموتى تنها دو رله استفاده مى كند در حالى كه كد (Y SP جهار رله استفاده مى كند. دليل اين امر هم اين است كه براى عمل كردن در يك نرخ ارسال يكسان كد الموتى منظومه اى

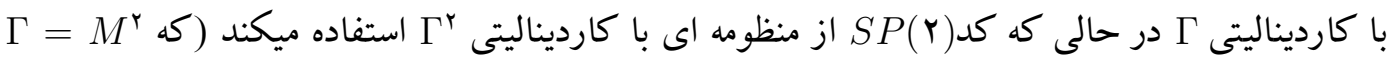
براى كد الموتى با منظومه M-PSK و $M$ و $\cdot\left(\cdot M_{r}-\mathrm{PSK}\right.$

در توان هاى يايين عامل غالب(اثرگذار) بر احتمال خطا، فاصله بين سمبل هاى منظومه مى باشد در حالى كه در توان هاى بالا عامل اثرگذار بر احتمال خطا بهره جندگانگى (يعنى تعداد رله ها ) است. به همين دليل است كه در توان هاى ارسالى كم، در نرخ ارسال بايين كد الموتى كه فاصله سمبل هايش زياد است

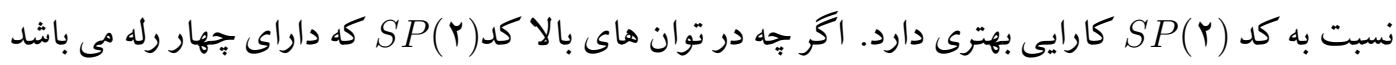
نسبت به كد الموتى كه دو رله دارد كارايى بهترى خواهد داشت. به عبارت ديخر هيج كدام از دو كد الموتى و (Y SP (Y در تمام نرخ هاى ارسال كارايى بهترى نسبت به ديخرى نخواهند داشت. اين نتايج در بخش شبيه سازى تصديق خواهند شد. 


\section{ه مقايسه كارايى روش ارايه شده در اين فصل و روش ارايه شده در فصل قبل r-P}

در اين بخش كارايى دو روش ارائه شده در اين فصل و فصل قبل كه هر دو قادر به حذف كامل سيخنال

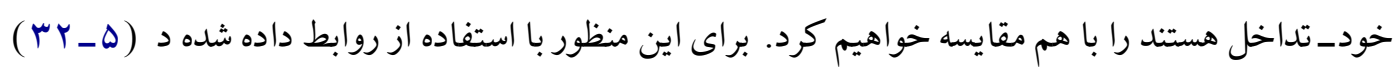
و (ه_^r) )، حد اجتماع را بر روى متوسط نرخ احتمال خطا به دست مىآوريم.

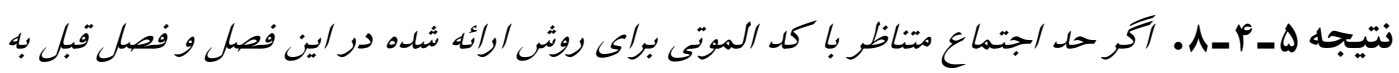



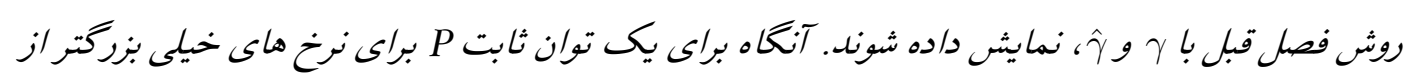
$R \gg$ L I,rard 'bpcu

$$
\begin{aligned}
& \rho<\hat{\rho}, \quad \text { and } \\
& \gamma<\hat{\gamma} .
\end{aligned}
$$

اثبات. اثبات را در دو كام انجام مى دهيم. در گام اول باند هاى اجتماع را براى دو روش ارائه شده در اين

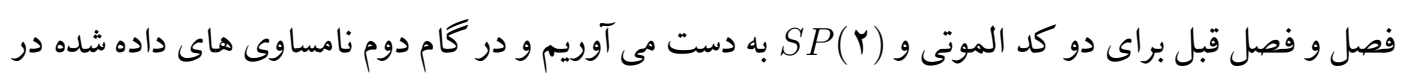

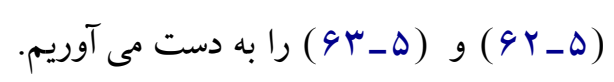

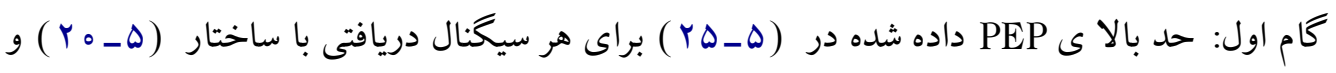

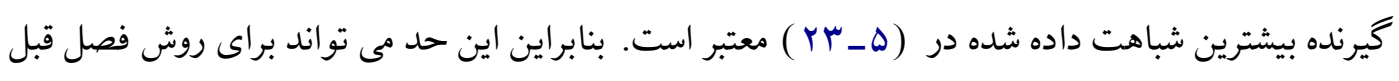

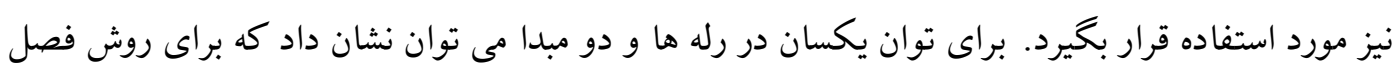

$$
\begin{aligned}
& \text { قبل داريم } \\
& \sigma_{\backslash}=\Upsilon\left(1+N \sum_{n=1}^{N} M_{n} \beta_{n}^{\Upsilon}\right), \\
& \Sigma_{\hat{\boldsymbol{y}}_{1}}=\Sigma_{\boldsymbol{w}_{1}}+\mathrm{E}\left\{\boldsymbol{U}_{r}^{(\ell)} \Sigma_{\boldsymbol{w}}, \boldsymbol{U}_{r}^{(\ell)^{\dagger}}\right\} \\
& \Sigma_{\boldsymbol{w}},=\boldsymbol{I}_{N}+\sum_{n=1}^{N} \beta_{n}^{\curlyvee} M_{n}\left(\boldsymbol{A}_{n} \boldsymbol{A}_{n}^{\dagger}+\boldsymbol{B}_{n} \boldsymbol{B}_{n}^{\dagger}\right), \\
& \beta_{n}^{r}=\frac{P}{M_{n}(\Upsilon P+1)},
\end{aligned}
$$




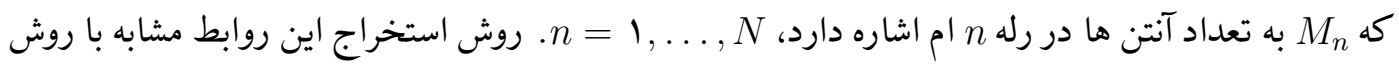
ارايه شده در بخش هاى قبل فصل جارى مى باشد.

اخر كارديناليتى

داده مى شود

$$
\text { BLER } \leq \frac{1}{\Gamma} \sum_{a=1}^{\Gamma} \sum_{b=1, a \neq b}^{\Gamma} \operatorname{Pr}\left(\boldsymbol{U}_{\curlyvee a}^{(\ell)} \rightarrow \boldsymbol{U}_{\curlyvee b}^{(\ell)}\right),
$$

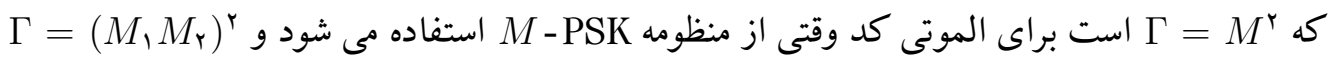

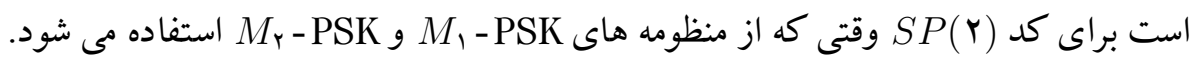

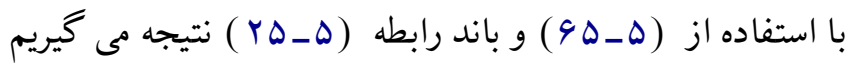

$$
\operatorname{BLER} \leq \frac{1}{\Gamma} \sum_{a=1}^{\Gamma} \sum_{b=1, a \neq b}^{\Gamma}\left(\boldsymbol{F} \sigma_{1}\right)^{N}\left|\boldsymbol{\Omega}_{a b}^{(\ell)}\right|^{-1}\left|\boldsymbol{\Sigma}_{\hat{\boldsymbol{y}}}\right|^{-1} .
$$

اكنون هدف ما اين است كه سمت راست رابطه (هـ 99) را براى دو روش اين فصل و فصل قبل براى دو كد الموتى و (r) SP( به دست آوريم.

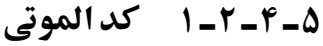

فرض مى كنيم كه R به نرخ ارسال براى دو روش ارائه شده در اين فصل به فصل قبل اشاره كند وقتى كه هر دو روش از كد الموتى استفاده مى كنند. براى اين كد داريم

$$
N=\boldsymbol{r}, \quad \text { and } \quad \boldsymbol{A}_{n} \boldsymbol{A}_{n}^{\dagger}+\boldsymbol{B}_{n} \boldsymbol{B}_{n}^{\dagger}=\boldsymbol{I}_{\boldsymbol{\Upsilon}}, \quad n=\mathbf{1}, \boldsymbol{\Upsilon} .
$$

براى روش ارائه شده در اين فصل كد الموتى r سمبل از M-PSK را در خهار بازه زمانى ارسال مى كند

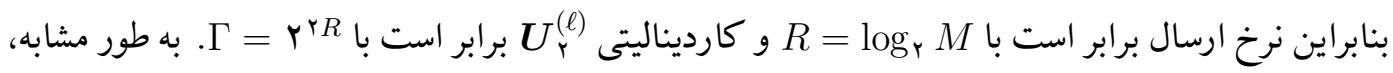

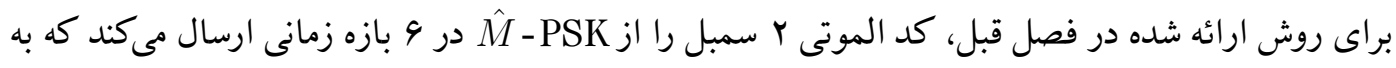

$$
\text { نرخ ارسال }
$$

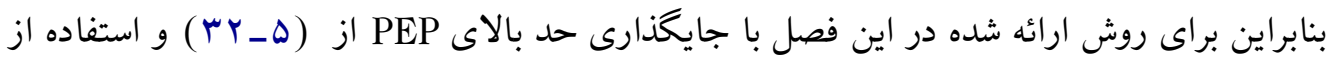
年

$$
\rho=\left(\frac{q}{r+P}\right)^{r} \frac{r^{r}-1}{\sin ^{\varphi}\left(\pi r^{-R}\right)} .
$$


براى روش فصل قبل با جايكذارى در (ه ( |

$$
\hat{\rho}=\left(\frac{q}{r+P}\right)^{r} \frac{r^{r} R}{\sin ^{\varphi}\left(\pi r^{-\frac{r}{r} R}\right)} .
$$

\section{$S P(r)$ r r r-r- $r_{-}$}

مشابه با روش كد الموتى، فرض مى كنيم كه R به نرخ ارسال براى هر دو روش ارائه شده در اين فصل

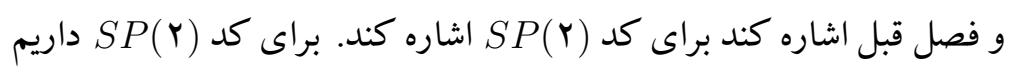

$$
N=\mathcal{F}, \quad \text { and } \quad \boldsymbol{A}_{n} \boldsymbol{A}_{n}^{\dagger}+\boldsymbol{B}_{n} \boldsymbol{B}_{n}^{\dagger}=\boldsymbol{I}_{\boldsymbol{\kappa}}, \quad n=1, \ldots, \boldsymbol{\mathcal { F }} .
$$

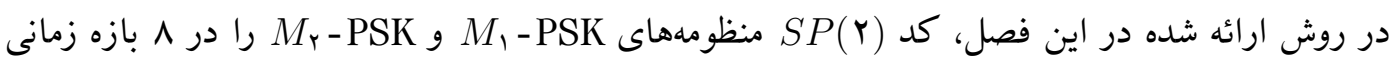
استفاده مىكند كه منجر به نرخ ارسال

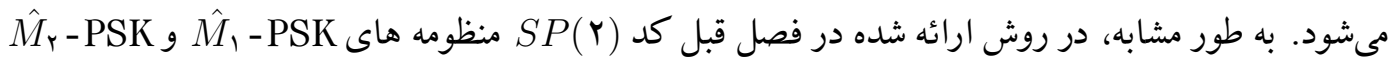

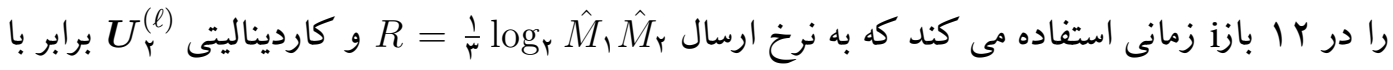

$$
\text { من } \hat{\Gamma}=r^{\varphi R}
$$

بنابراين براى روش ارائه شده در در اين فصل با جايكذارى حد بالاى PEP داده شده در (ه_^ץ) و

$$
\begin{aligned}
& \text { استفاده از } \\
& \gamma=\left(\frac{r V}{q+r P}\right)^{r} \frac{r^{F R}-1}{\sin ^{\wedge}\left(\pi r^{-r R}\right)} .
\end{aligned}
$$

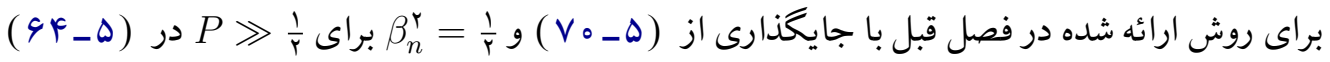
نتيجه مى دهد

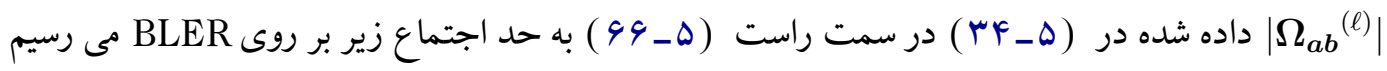

$$
\hat{\gamma}=\left(\frac{q}{r+r P}\right)^{r} \frac{r^{\varphi}-1}{\sin ^{\wedge}\left(\pi r^{-r R}\right)} .
$$

كام دوم: براى كد الموتى با دو سمبل از

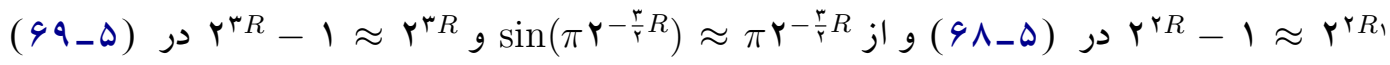
استفاده مى كنيم. يكى مقايسه بين م و م براى مقدار معينى از P فورا (هـ ب و) را نتيجه مى دهد. 
براى كد (Y)

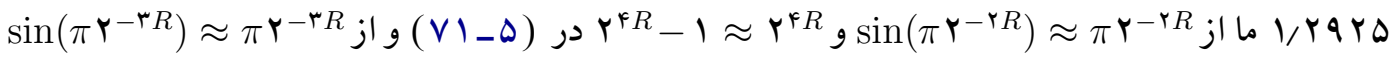
و فورا (ه_r (4) رانتيجه مى گيريم و به اين ترتيب اثبات تكميل مى شود.

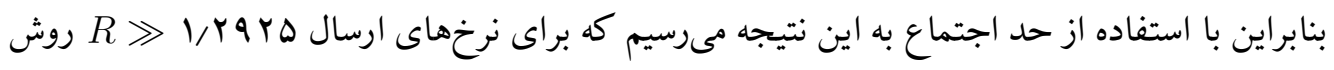
اين فصل كه از رله هاى تكى آنتى استفاده مىكنند كارايى بهترى نسبت به روش ارائه شده در فصل قبل كه

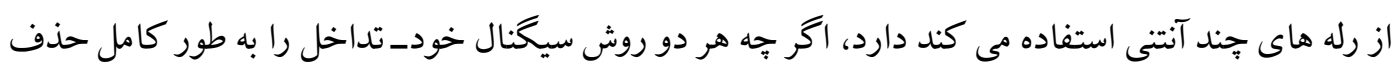
مى نمايد.

دليل اين امر هم در اين است كه در مقادير بالاى نسبت سيخنال به نويز، نويز تنها باعث انحراف جزئى حول سمبل هاى منظومه ارسالى مى شود به اين ترتيب عامل غالب بر احتمال خطا مى نيمم فاصله بين سمبلهاى منظومه است. نتيجه بالا بيان مىكند كه اكر جه روش اين فصل توان نويز را دو برابر مى كند اما از منظومهاى استفاده ميكند كه كارديناليتى آن توان سوم مجذور كارديناليتى منظومه استفاده شده توسط روش

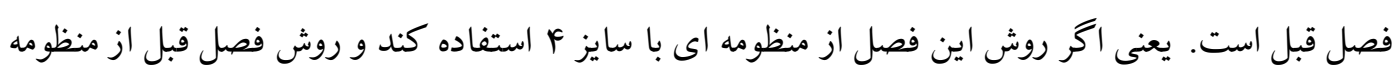
اى با سايز ^ بايد استفاده كند و وقتى كه روش اين فصل از منظومه هاى با سايز FF استفاده مى كند روش فصل قبل بايد از منظومه اى با سايز Y I استفاده كند. مى بينيم كه افزايش جزئى سايز منظومه براى روش اين فصل باعث افزايش بسيار سريع در سايز منظومه ى فصل قبل خواهد شد. اين در حالى است كه ماتريس كواريانس نويز روش اين فصل نسبت به روش فصل قبل تنها دو برابر شده است.

\section{هـ}

در اين بخش نتايج تحليل به دست آمده در بخش هاى قبلى توسط شبيه سازى كامبيوترى تصديق مىشوند. براى انجام اين كار ما نرخ احتمال خطاى بلوكى را براى دو روش اين فصل و فصل قبل را براى دو كد الموتى و كد (Y SP S باهم مقايسه خواهيم كرد. علاوه بر اين، براى روش ارائه شده در اين فصل، احتمال خطاى كد الموتى و (Y SP S را با هم ديخر مقايسه خواهيم كرد تا نتايج تحليلى مصالحه بين نرخ ارسال و كارايى به دست آمده در بخش قبل تصديق گردد. در شبيه سازى فرض بر اين است كه كانال ها

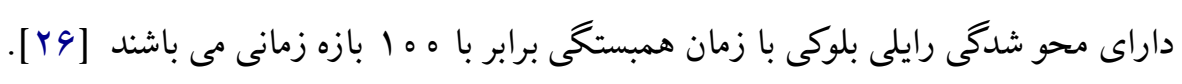
توجه داريم كه براى ارسال N سمبل روش ارائه شده در اين فصل N r بازه زمانى را استفاده مىكند 


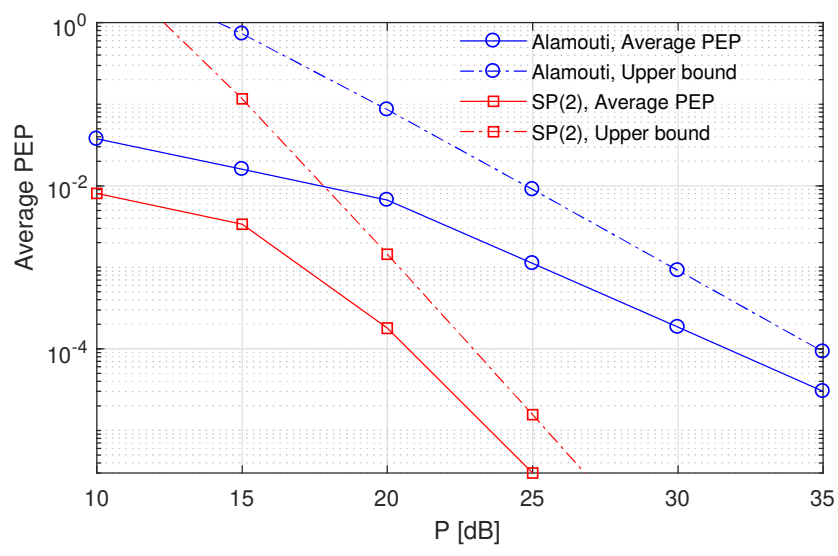

شكل ه ه - ميانگين و حد بالا PEP

در حالى كه روش بيشنهاد شده در فصل قبل NN بازه زمانى را استفاده خواهد كرد. بنابراين، براى داشتن يك مقايسه منصفانه از منظومه هاى PSK با كارديناليتى متفاوت استفاده خواهيم كرد تا نرخ ارسال يكسانى براى دو روش داشته باشيم.

مثال هـ ـهـ ا ـ در اين مثال ميزان دقت باند حد بالاى PEP به دست آمده در رابطه (هـ Y ) بررسى مى شود. براى اين منظور متوسط PEP و متوسط حد بالا بر PEP براى دو كد (Y SP و الموتى به دست آمده و در شكل هـ - ا نمايش داده شده اند.

براى كد الموتى ما از منظومه QPSK استفاده كرده ايم كه به نرخ ارسال دو بيت بر كانال منتهى مىشود

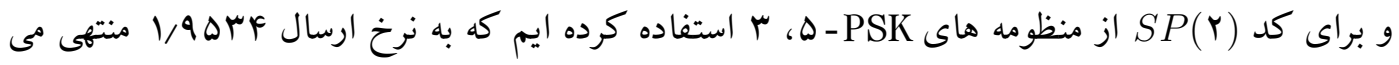
شود. اين شكل نتايج تحليلى به دست آمده را تصديق مى كند. همانطور كه مشاهده مى كنيم با افزايش توان ارسالى فاصله بين حد بالا و متوسط PEP كاهش مىيابد. به عنوان مثال براى كد الموتى در BLER برابر با

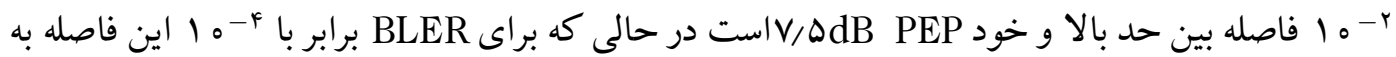

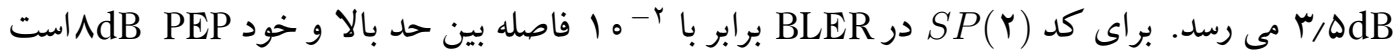

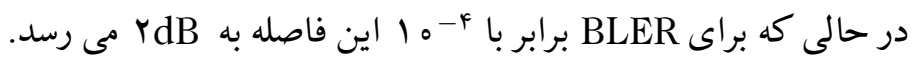
مثال هـ ـ ـ • ـ در اين مثال عملكرد دو روش ارائه شده در اين فصل و فصل قبل را با هم مقايسه مى كنيم در حالى كه هر دو روش از كد الموتى استفاده مىكنند. براى كد الموتى ماتريس هاى بردازش در رله ها 


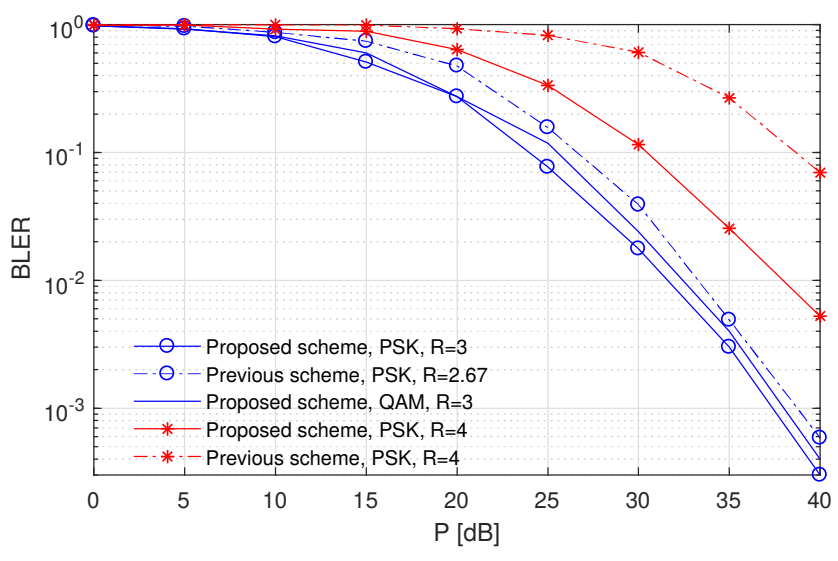

شكل ه- BLER برحسب P براى كد الموتى

عبارتند از

$$
A_{1}=I_{\curlyvee}, \quad B_{1}=A_{\curlyvee}=\circ, \quad B_{\curlyvee}=\left[\begin{array}{ll}
0 & -1 \\
1 & 0
\end{array}\right] . \quad\left(\Upsilon^{r}-\Delta\right)
$$$$
\text { نتايج شبيه سازى در شكل هـr نشان داده شده اند. }
$$

روش ارائه شده در اين فصل از منظومه هاى

ارسال ب و \& در حالى كه روش فصل قبل از منظومه هاى 9F-PSK، 19 استفاده مىكند تا نرخ هاى ارسال

$$
\text { T و F/9V }
$$

اين شكل نشان مى دهد كه روش ارائه شده در اين فصل كارايى و عملكرد بهترى نسبت به روش ارائه

شده در فصل قبل در تمام نرخهاى ارسال خواهد داشت كه منطبق با نتايج تحليلى به دست آمده در نتيجه

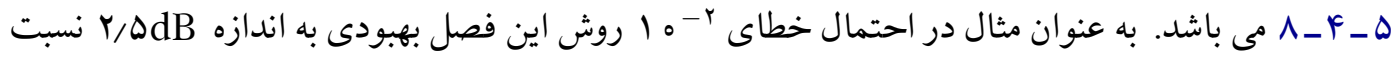

$$
\text { به روش فصل قبل در نرخ ارسال ب بيت بر كانال خواهد داشت . }
$$

براى تصديق بهره جندگانگى تحليلى به دست آمده در بخش هاى قبل ما اين بهره را از روى اين شكل

نيز به دست مىآوريم كه برابر است با شيب منحنى احتمال خطا. براى كد الموتى در م

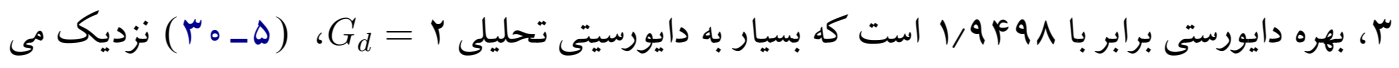
باشد. علاوه بر اين علاوه بر اين احتمال خطاى كد الموتى براى سمبلهايى از ^-QAM نشان داده شده است كه بيان كننده ان است كد الموتى به ماكزيمم دايورسيتى مىرسد حالا جه از منظومه PSK استفاده كند 
مثال هـهـ"r. در اين مثال عملكرد دو روش ارائه شده در اين فصل و فصل قبل را با هم مقايسه مى كنيم

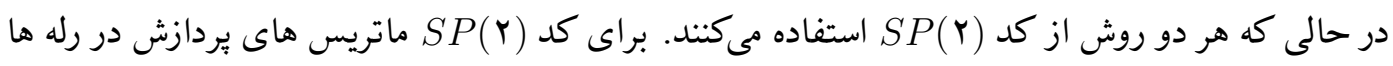

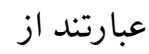

$$
\begin{gathered}
\boldsymbol{A}_{\uparrow}=\boldsymbol{I}_{\uparrow}, \boldsymbol{B}_{1}=\boldsymbol{A}_{\uparrow}=\boldsymbol{A}_{\uparrow}=\boldsymbol{B}_{\uparrow}=0, \\
\boldsymbol{B}_{\curlyvee}=\left[\begin{array}{llll}
0 & 0 & 0 & -1 \\
0 & 0 & 1 & 0 \\
0 & -1 & 0 & 0 \\
1 & 0 & 0 & 0
\end{array}\right], \quad \boldsymbol{B}_{\uparrow}=\left[\begin{array}{cccc}
0 & 0 & -1 & 0 \\
0 & 0 & 0 & -1 \\
1 & 0 & 0 & 0 \\
0 & 1 & 0 & 0
\end{array}\right], \boldsymbol{A}_{\uparrow}=\left[\begin{array}{cccc}
0 & 0 & 0 & 1 \\
0 & 0 & -1 & 0 \\
0 & -1 & 0 & 0 \\
1 & 0 & 0 & 0
\end{array}\right] .
\end{gathered}
$$

روش ارائه شده در اين فصل از منظومه هاى PSK - ه، ب استفاده ميكند كه نرخ ارسال ه D 1/ بيت بر كانال را مى سازد، همجنين از منظومه هاى PSK - 11، ب استفاده مى كند كه نرخ ك/ه را توليد مى كند.

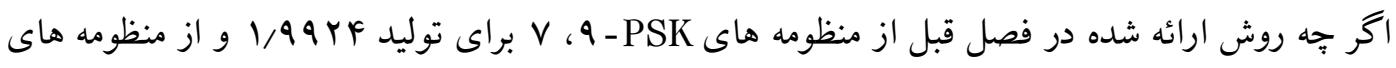

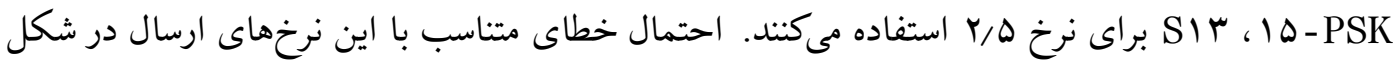

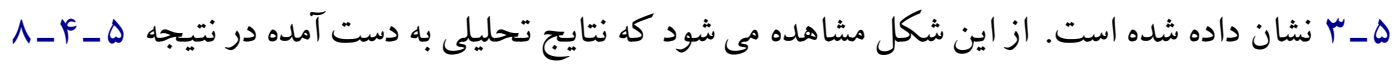
تصديق مىشود و روش ارائه شده در اين فصل كارايى و عملكرد بهترى نسبت به روش ارائه شده در فصل

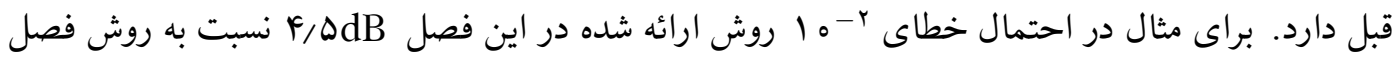

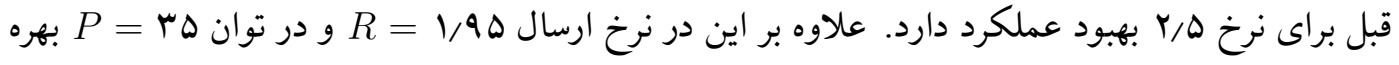

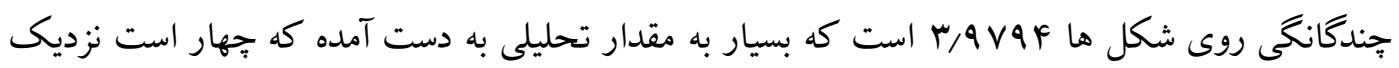

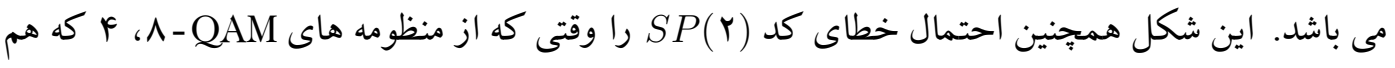

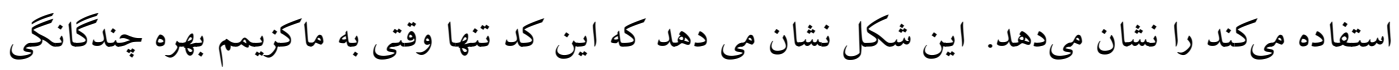
دست بيدا مى كند كه از منظومه هاى فرد نسبت به هم اول استفاده كند.

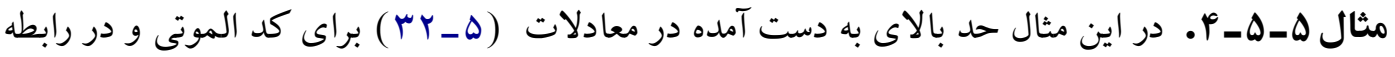

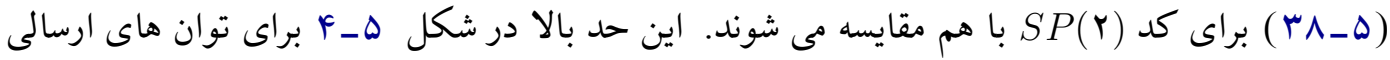

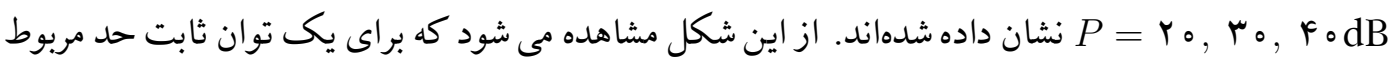

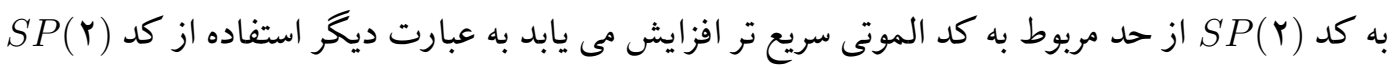






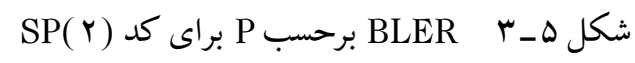

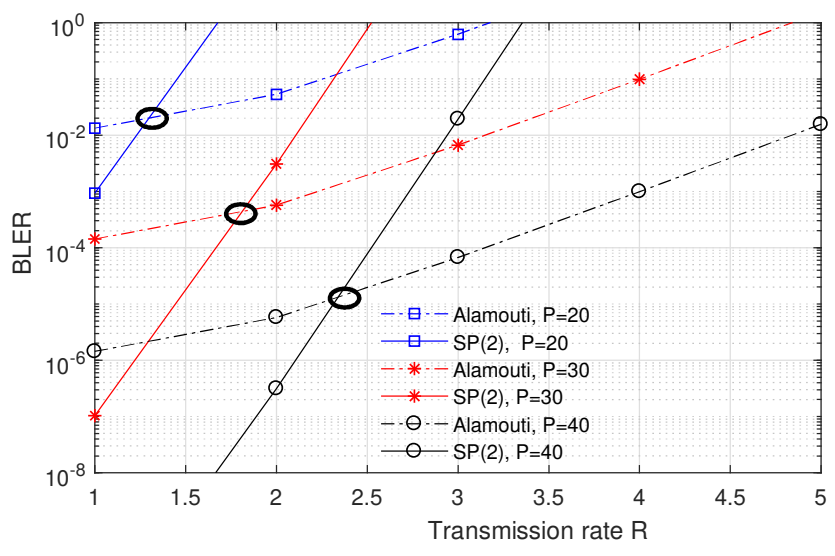

شكل ه_F مقايسه مصالحه بين مقادير عددى نرخ و كارايى

در نرخ هاى بايين و استفاده از كد الموتى در نرخ هاى بالا مفيد مى باشد.

در شكل هـ ه مقادير شبيه سازى شده در نرخ هاى مختلف نشان داده شده است. از منظومه هاى مثال

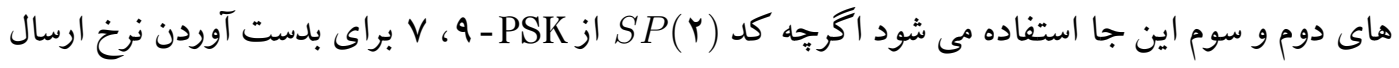
ه

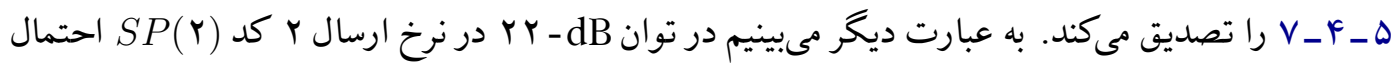

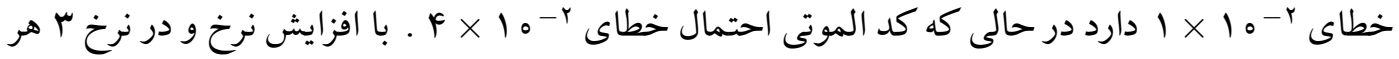

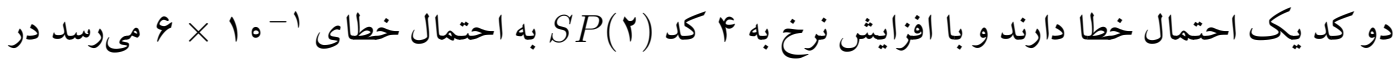

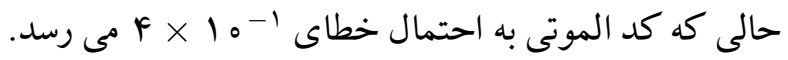




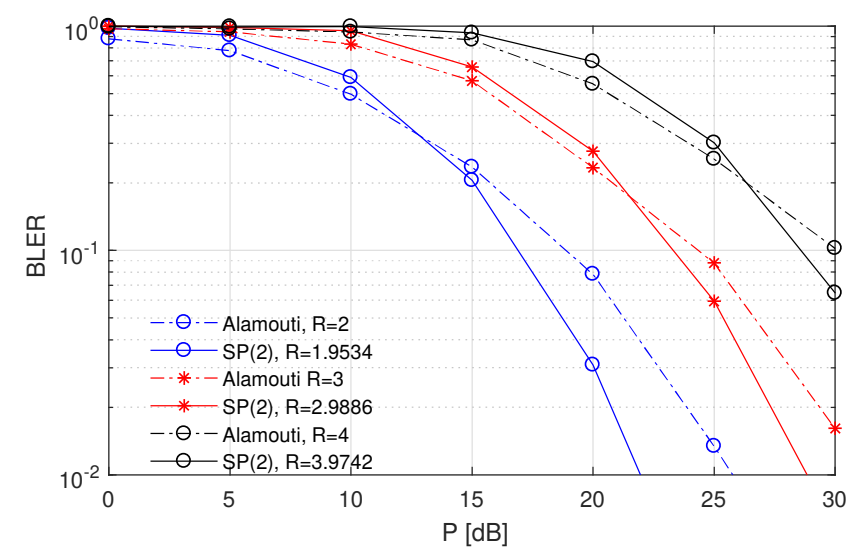

شكل هـ ه مقايسه مصالحه بين مقادير واقعى نرخ ارسال و BLER

مثال هـهــه • در اين مثال مقايسه ای از سه روش نشان داده شده است. روش ارائه شده در اين فصل و فصل قبل و روش ارائه شده در مقاله [ [Or]. در حالى كه هرسه از كد الموتى استفاده مىكند، براى روش ارائه شده در اين فصل و [Y U ] از منظومه F-PSK استفاده مى شود كه نرخ r توليد كند و براى توليد همان نرخ

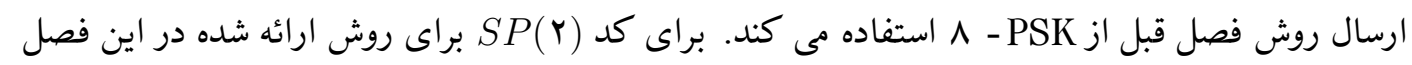


ارائه شده در اين فصل هم از روش فصل قبل و هم از مقاله [Or] بهتر عمل مى كند جهه براى كد الموتى و جّه براى كد (Y SP(Y. مشاهده مىكنيم كه روش ارائه شده در مقاله [Y [O] به دليل خطاى ايجاد شده در تخمين كانال قادر به حذف كامل سيخنال خود_تداخل نيست و در توان هاى بالا داراى بهره جندگانكى صفر مى

\section{ه-9 نتيجه كيرى}

در اين فصل شبكه هاى دوسويه اى را در نظر گرفتيم كه در آنها دو مبدا تكى آنتى اطلاعات خود را از طريق جندين رله تك آنتى مبادله مى كنند. ما يك روش براى حذف كامل سيخنال خود_تداخل در

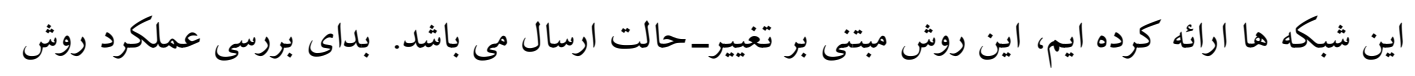
ييشنهادى، باند بالايى بر PEP براى روش بيشنهادى در اين فصل و فصل قبل به دست آورديم. با استفاده از اين باندها نشان داديم كه روش اين فصل اكرجه از رله هاى تكـ_آنتنى استفاده مى كنند اما عملكرد بهترى نسبت به روش فصل قبل دارد كه از رله هاى جند آنتى استفاده مى كند. علاوه براين، ما حدهاى جديدى 


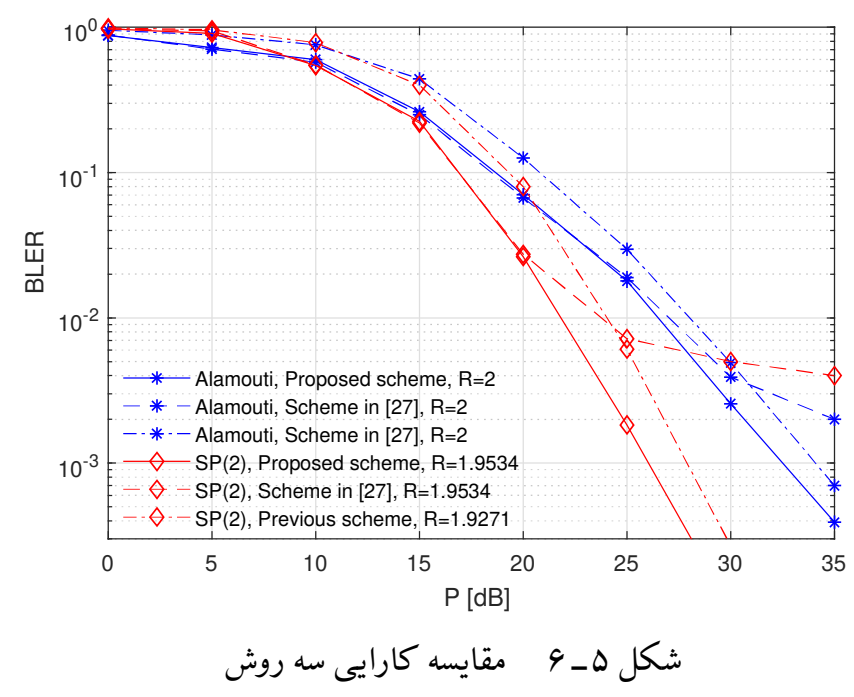

بر روى BLER براى دو كد الموتى و (Y SPR به دست آورده و با استفاده از اين حدها يك مصالحه بين عملكرد و نرخ ارسال براى اين دو كد استخراج كرديم. اين مصالحه نشان مى دهد كه در نرخ هاى ارسال بالاتر بهتر است كه از كد المدتى استفاده كنيم كه به دو رله نياز دارد و در نرخ هاى بايين تر بهتر هست كه از كد (Y) SP( استفاده كنيم كه به جهار رله نياز دارد. 
فصل ششه:

نتيجه كيرى و پيشنهادها 


\section{9-1 نتيجه كيرى}

در اين رساله، ما ابتدا به معرفى اصول بايه مخابرات بى سيم، سيستم هاى MIMO و مخابرات مشاركتى

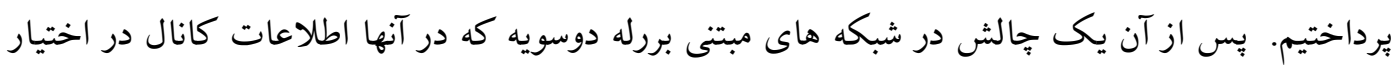
نمى باشد را معرفى كرديم. اين خالش كه حذف سيخنال خود_تداخل است در تعداد محدودى تحقيق مورد مطالعه قرار گرفته است و روش هايى براى حذف آن بيشنهاد شده كه هيجكدام قادر به حذف كامل و دقيق اين سيخنال نمى باشند. ما ابتدا به طور تحليلى اثر وجود هرميزان كم از سيخنال خود_تداخل را بررسى كرديم. نشان داديم كه وجود سبخنال خود_تداخل باعث مى شود كه بهره جندكانكى سيستم صفر شده و رخ دهد. سيس دو روش براى حذف كامل اين سيگنال ارائه داديم. در روش اول هر رله نياز دارد كه تعداد زوجى آنتن داشته باشد. روش بردازش نوينى براى بردازش توام مكان-زمان در هررله بيشنهاد داده و بطور تحليلى نشان داديم كه اين روش بردازش در رله ها قادر است سيخنال خود_تداخل را به طور كامل از سيخنال دريافتى دو مبدا حذف نمايد. نشان داديم كه با اين روش بهره جهندكانكى به دست آمده برابر با تعداد رله ها مى باشد و ربطى به تعداد آنتن ها در هر رله ندارد. در عوض تعداد آنتن ها در هر رله بر روى بهره كدينگ اثر دارد. به طوريكه با افزايش تعداد آنتن ها اين بهره افزايش مى يابد و به يك مقدار ثابت همخرا مى شود. علاوه براين، نشان داديم كه افزايش تعداد رله ها از افزايش تعداد آنتن ها در هر رله نتيجه بهترى بر عملكرد سيستم دارد. تا آنجا كه مى دانيم روش اول بيشنهادى تنها روش موجود براى حذف كامل و دقيق سيخنال خودتداخل مى باشد. اما اين روش داراى محدوديت داشتن جندين آنتن در هر رله است كه به مفهوم سخت افزار و هزينه بيشتر مى باشد. براى غلبه بر اين نقطه ضعف، روش ديخرى براى حذف كامل سيخنال خود_تداخل بيشنهاد داديم. اين روش در شبكه هاى كه هر رله تنها يك آنتن دارد قابل استفاده است. هزينه داده شده براى امكان اين امر، استفاده از نحوه ارسال تغيير-حالت است كه در آن ارسال با جهار فاز شبيه شبكه هاى يك سويه شروع شده و سيس به حالت دوفازى سوييج مى كند. به طور تحليلى عملكرد اين روش را بررسى كرده و نشان داديم كه نه تنها اين روش تعداد آنتن كمتر و به زمان ارسال كمتر نياز دارد بلكه عملكرد بهتر و نرخ احتمال خطاى كمترى دارد. علاوه برآن، ما حد بالايى بر احتمال خطاى جفتى به صورت تابعى ازنرخ ارسال به دست آورده و نشان داديم كه در نرخ هاى يايين بهتر است از كد (Y) SP با F رله استفاده شود و در نرخ هاى بالا از كد الموتى استفاده شود اگرجه تنها دو رله نياز دارد. 


\section{r-9}

تحقيق در اين زمينه، مسيرهاى براى تحقيقات آينده مشخص كررده است. از جمله مى توان به موارد

$$
\text { زير اشاره كرد: }
$$

• در اين تحقيق حذف سيخنال خود_تداخل در رله هاى تقويت و ارسال مورد بررسى و مطالعه قرار گرفت. ديخر روش هاى بردازش در رله مانند كدگثايى وارسال، فشرده سازى و ارسال، كوانتيزه كردن و ارسال و...موضوعات جديدى براى تحقيق مى باشند.

• در اين تحقيق از روش تفاضلى استفاده شده كه سمبل هاى جديد اطلاعات در ماتريس هاى يكانى قرار مى گرفتند. اين ما را به شبكه هاى با دو و بجهار رله محدود كرده است. بيدا كردن روش هاى نهاى جديدى براى كدكذارى تفاضلى كه بتوان از تعدا بيشتر رله استفاده كرد جذاب مى باشد.

• در اينجا ما از اشكارساز بيشترين شباهت استفاده كرديم كه تعداد جستجوى بسيار زياد براى

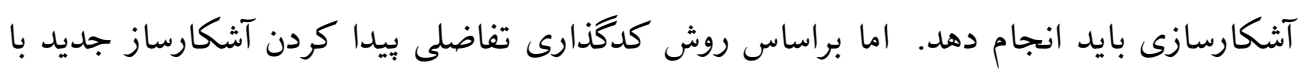
بيجيدگى كمتر مى تواند يك موضوع تحقيق در آينده باشد. • ما به حذف سبحنال خود_تداخل در شبكه هاى دوسويه نيمه_كامل برداختيم. حذف اين سبگنال در شبكه هاى دوسويه كامل موضوع جالبى براى تحقيق خواهد بود.

• از آنجاييكه در اين تحقيق حذف سيخنال خود_تداخل براى كانال هاى رايلى مورد بررسى قرار

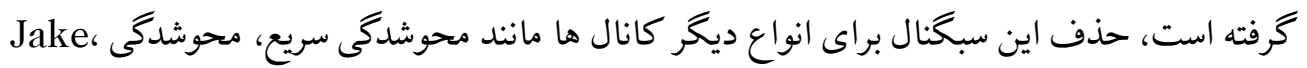
محوشدكى ريسين و ناكاكامى موضوعات جديدى براى مطالعه مى باشند.

• حذف سيكنال خود تداخل در شبكه هاى دو سويه اي كه به اطلاعات كامال دسترسى ندارند و ارسال از دو مبدا و يا رله ها ناهمزمانمى باشد يك زمينه تحقيقاتى جديد و جداب براى كارهاى آينده است. 


$$
\text { منابع و مآخذ }
$$


[1] https://crtc.gc.ca/eng/publications/reports/policymonitoring/ 2018/cmr3a.htm.

[2] https://www.businessinsider.com/there-will-be-34-billion-iotdevices-installed-on-earth-by-2020-2016-5.

[3] Abdallah S., Psaromiligkos I. N., Blind channel estimation for amplify-and-forward twoway relay networks employing $M$-PSK modulation, IEEE Transactions on Signal Processing, vol. 60, no. 7, pp. 3604-3615, July 2012.

[4] Adams W. W., Goldstein L. J., Introduction to Number Theory, Prentice Hall, 1976.

[5] Alabed S. J., Paredes J. M., Gershman A. B., A simple distributed space-time coded strategy for two-way relay channels, IEEE Transactions on Wireless Communications, vol. 11, no. 4, pp. 1260-1265, April 2012.

[6] Alamouti S. M., A simple transmit diversity technique for wireless communications, IEEE Journal on Selected Areas in Communications, vol. 16, no. 8, pp. 1451-1458, Oct. 1998.

[7] Bameri S., Gohary R. H., Talebi S., Lambadaris I., On the tradeoff between rate and pairwise error performance of Alamouti and SP(2) space-time block codes, 2018 IEEE 19th International Workshop on Signal Processing Advances in Wireless Communications (SPAWC), Kalamata, 2018, pp. 1-4.

[8] Bameri S., Talebi S., Gohary R. H., Yanikomeroglu H., A novel self-interference cancellation scheme for channel-unaware differential space-time two-way relay networks, IEEE Transactions on Wireless Communications, vol. 17, no. 2, pp. 1226-1241, Feb. 2018.

[9] Bastami A. H., Habibi S., Cognitive MIMO two-way relay network: joint optimal relay selection and spectrum allocation, IEEE Transactions on Vehicular Technology, vol. 67, no. 7, pp. 5937-5952, July 2018. 
[10] Behnamfar F., Alajaji F., Linder T., Tight error bound for space-time orthogonal block codes under slow Rayleigh flat fading, IEEE Transactions on Communications, vol. 53, no. 6, pp. 952-956, June 2005.

[11] Biglieri E., Calderbank R., Constantinides A., Goldsmith A., Paulraj A., Poor H. V., MIMO Wireless Communications, Cambridge University Press, New York, NY, USA, 2010.

[12] Björnson E., Larsson E. G., Debbah M., Massive MIMO for maximal spectral efficiency: How many users and pilots should be allocated?, IEEE Transaction on Wireless Communications, vol.15, pp.1293-1308, February 2016.

[13] Boyd S., Vandenberghe L., Convex Optimization, Cambridge University Press, Cambridge, 2004.

[14] Cheng H. V., Björnson E., Larsson E. G., Optimal pilot and payload power control in singlecell massive MIMO systems, IEEE Transactions on Signal Processing, vol.65, pp. 23632378, May 2017.

[15] Clerckx B., Oestges C., MIMO Wireless Networks: Channels, Techniques and Standards for Multi-Antenna, Multi-User and Multi-Cell Systems, Academic Press : Oxford, UK, 2013.

[16] Cui T., Gao F., Ho T., Nallanathan A., Distributed space-time coding for two-way wireless relay networks, IEEE Transactions on Signal Processing, vol. 57, no. 2, pp. 658-671, February 2009.

[17] Cui T., Gao F., Ho T., Nallanathan A, Distributed space-time coding for two-way wireless relay networks, In 2008 IEEE International Conference on Communications, pp. 3888-3892, May 2008. 
[18] Cui T., Gao F., Tellambura C., Differential modulation for two-way wireless communications: a perspective of differential network coding at the physical layer, IEEE Transactions on Communications, vol. 57, no. 10, pp. 2977-2987, October 2009.

[19] Dogandzic A., Chernoff bounds on pairwise error probabilities of space-time codes, IEEE Transactions on Information Theory, vol. 49, no. 5, pp. 1327-1336, May 2003.

[20] Goldsmith A., Wireless Communications, Cambridge University Press, Cambridge, 2005.

[21] Hassibi ab., Hochwald B.M., High-rate codes that are linear in space and time, IEEE Transactions on Information Theory, vol. 48, pp. 1804-1824, July 2002.

[22] Hochwald B. M., Sweldens W., Differential unitary space-time modulation, IEEE Transactions on Vehicuarl Technology, vol. 48, no. 12, pp. 2041-2052, December 2000.

[23] Hong W.P., Huang W.J., Kuo C.C.J., Cooperative Communications and Networking: Technologies and System Design, Springer US, 2010.

[24] Horn R.A., Johnson C.R., Matrix Analysis, Cambridge University Press, NewYork, 1985.

[25] Qiu Y.Hu,C., Chen Y., Lyapunov optimized two-way relay networks with stochastic energy harvesting, IEEE Transactions on Wireless Communications, pp. 1-13, 2018.

[26] Huo Q., Song L., Li Y., Jiao B., A distributed differential space-time coding scheme with analog network coding in two-way relay networks, IEEE Transactions on Signal Processing, vol. 60, no. 9 pp.4998-5004, September 2012.

[27] Jafarkhani H., Space-Time Coding: Theory and Practice, Cambridge University Press, New York, 2005.

[28] Jia X., Zhang C., Kang J., Kim I., Joint beamforming design and time allocation for wireless powered asymmetric two-way multi-relay network, IEEE Transactions on Vehicular Technology, pp. 1-14, 2018. 
[29] Jing Y., Hassibi B., Design of fully diverse multiple-antenna codes based on SP(2), IEEE Transactions on Information Theory, vol. 50, pp. 2639-2656, November 2004.

[30] Jing Y., Hassibi B., Distributed space-time coding in wireless relay networks, IEEE Transactions on Wireless Communications, vol. 5, no. 12, pp. 3524-3536, December 2006.

[31] Jing Y., Jafarkhani H., Using orthogonal and quasi-orthogonal designs in wireless relay networks, IEEE Transactions on Information Theory, vol. 53, no. 11, pp. 4106-4118, November 2007.

[32] Jing Y., Jafarkhani H., Distributed differential space-time coding for wireless relay networks, IEEE Transactions on Communications, vol. 56, no. 7, pp. 1092-1100, July 2008.

[33] Kanatas A. G., Nikita K. S., Mathiopoulos P., New Directions in Wireless Communications Systems From Mobile to 5G, CRC Press, 2018.

[34] Lee K., Hong J., Choi H., Quek T. Q. S., Wireless-powered two-way relaying protocols for optimizing physical layer security, IEEE Transactions on Information Forensics Security, vol. 14, no. 1, pp.162-174, January 2019.

[35] Li W., Ku M., Chen Y., Ray Liu K. J., On outage probability for two-way relay networks with stochastic energy harvesting, IEEE Transactions on Communications, vol. 64, no. 5, pp. 1901-1915, May 2016.

[36] Lin Z., Du. X., Chen H., Ai B., Chen Z., Wu D., Millimeter-wave propagation modeling and measurements for 5g mobile networks, IEEE Wireless Communications, vol. 26, no. 1, pp. 72-77, February 2019.

[37] Liu K.J.R, Sadek A.k., Su W., Kwasinski A., Cooperative Communications and Networking, Cambridge University Press, New York, 2009. 
[38] Liu Y., Zhang W., Ching P. C, Time-reversal space-time codes in asynchronous two-way relay networks, IEEE Transactions on Wireless Communications, vol. 15, pp. 1729-1741, March 2016.

[39] Mamaghani M. T., Kuhestani A., Wong K., Secure two-way transmission via wirelesspowered untrusted relay and external jammer, IEEE Transactions on Vehicular Technology, pp. 1-15, 2018.

[40] Masjedi M., Doost-Hoseini A. M., Naghsh M. M., S. Gazor S., Partially blind joint channel estimation and symbol detection in amplify-and-forward two-way relay systems, IEEE Transactions on Communications, pp. 1-9, 2018.

[41] Mohammed S.K., Impact of transceiver power consumption on the energy efficiency of zeroforcing detector in massive MIMO systems, IEEE Transactions on Communications, vol. 62, pp. 3874-3890, November 2014.

[42] Oggier F., Hassibi B., A coding scheme for wireless networks with multiple antenna nodes and no channel information, 2007 IEEE International Conference on Acoustics, Speech and Signal Processing - ICASSP '07, Honolulu, pp. III-413-III-416, 2007.

[43] Oggier F., Hassibi B., An algebraic coding scheme for wireless relay networks with multipleantenna nodes, IEEE Transactions on Signal Processing, vol. 56, no. 7, pp. 2957-2966, Jul 2008.

[44] Oggier F., Hassibi B., Cyclic distributed space-time codes for wireless relay networks with no channel information, IEEE Transactions on Information Theory, vol. 56, no. 1, pp. 250 265, January 2010.

[45] Popovski P., Yomo H., Physical network coding in two-way wireless relay channels, 2007 IEEE International Conference on Communications, Glasgow, 2007, pp. 707-712, June 2007. 
[46] Rankov B., Wittneben A., Achievable rate regions for the two-way relay channel, 2006 IEEE International Symposium on Information Theory, Seattle, WA, pp. 1668-1672, July 2006.

[47] Shannon C. E., Two-way Communication Channels, In Proceedings of the Fourth Berkeley Symposium on Mathematical Statistics and Probability, Volume 1: Contributions to the Theory of Statistics, pages 611-644, Berkeley, Calif., 1961. University of California Press.

[48] Shomorony I., Avestimehr A. S., Worst-case additive noise in wireless networks, IEEE Transactions on Information Theory, vol. 59, pp. 3833-3847, June 2013.

[49] Song L., Hong G., Jiao B., Debbah M., Joint relay selection and analog network coding using differential modulation in two-way relay channels, IEEE Transaction on Vehicular Technology, vol. 59, pp. 2932-2939, July 2010.

[50] Song L., Li Y., Huang A., Jiao B., Vasilakos A. V., Differential modulation for bidirectional relaying with analog network coding, IEEE Transactions on Signal Processing, vol. 58, no. 7, pp. 3933-3938, July 2010.

[51] Tarokh V., Jafarkhani H., Calderbank A. R., Space-time block codes from orthogonal designs, IEEE Transactions on Information Theory, vol. 45, pp. 1456-1467, July 1999.

[52] Utkovski Z., Yammine G., Lindner J., A distributed differential space-time coding scheme for two-way wireless relay networks, 2009 IEEE International Symposium on Information Theory, Seoul, pp. 779-783, June 2009.

[53] Wang H., Xia X., Yin Q., A linear analog network coding for asynchronous two-way relay networks, IEEE Transactions on Wireless Communications, vol. 9, pp. 3630-3637, December 2010 . 
[54] Xie X., Peng M., Zhao B., Wang W., Hua Y., Maximum a posteriori based channel estimation strategy for two-way relaying channels, IEEE Transactions on Wireless Communications, vol. 13, no. 1, pp. 450-463, January 2014.

[55] Zhang S., Gao F., Pei C., Optimal training design for individual channel estimation in twoway relay networks, IEEE Transactions on Signal Processing, vol. 60, no. 9, pp. 4987-4991, September 2012.

[56] Zhang Y., Ge J., Men J., Ouyang F., Zhang C., Joint relay selection and power allocation in energy harvesting AF relay systems with ICSI, IET Microwaves, Antennas Propagation, vol. 10, no. 15, pp. 1656-1661, 2016.

[57] Zhao L., Zhao H., Zheng K., Xiang W., Massive MIMO in 5G Networks: Selected Applications, Springer International Publishing, 2018.

[58] Zummo S. A., Yeh P. C., Stark W. E., A union bound on the error probability of binary codes over block-fading channels, IEEE Transactions on Vehicular Technology, vol. 45, no. 6, pp. 2085-2093, November 2005. 


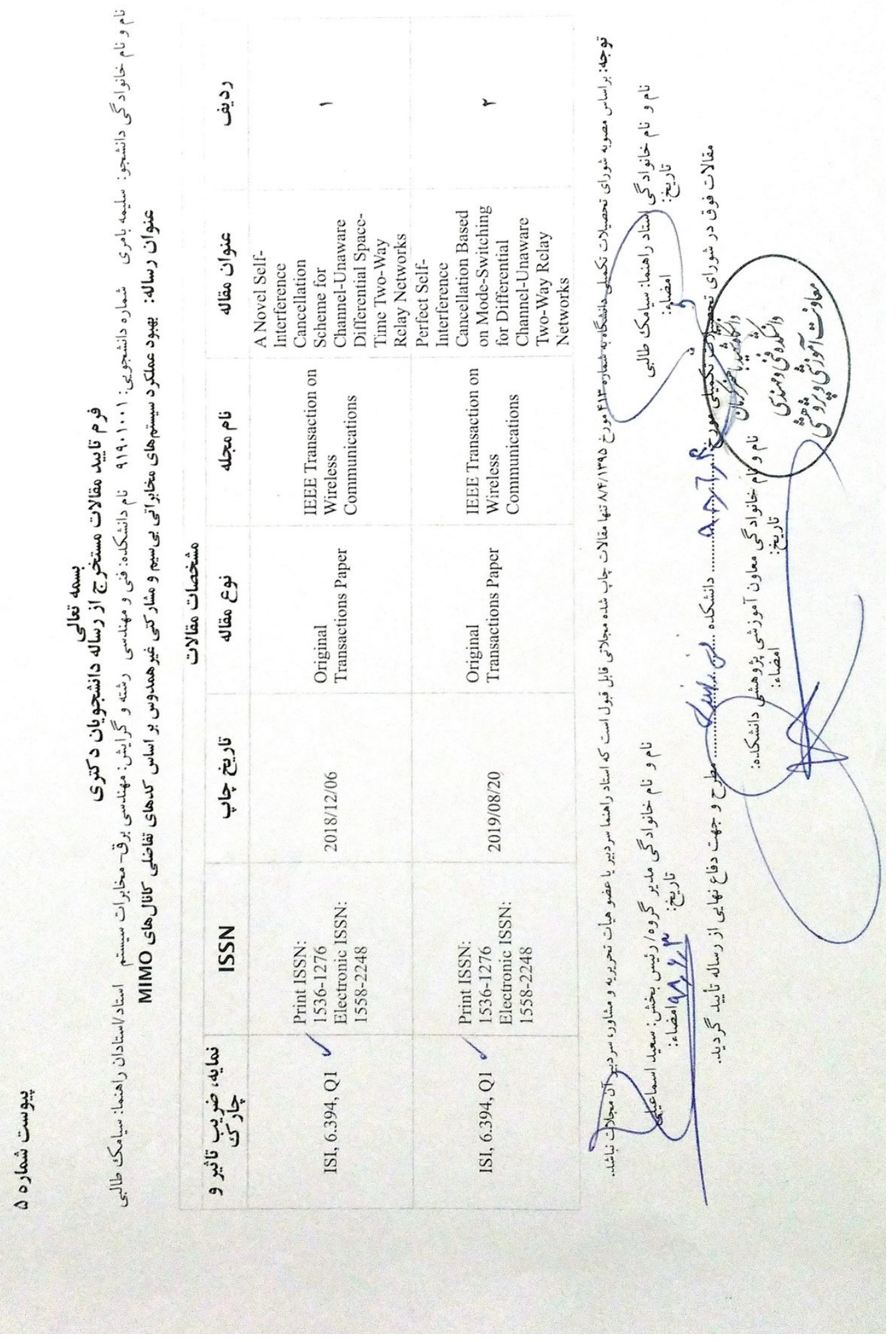




\section{Abstract}

The presence of multiple relays in wireless networks enables reliable communication of high data rates in many practical situations, notably those in which the channel between the source and destination are not line-of-sight with potentially deep fades. Relay networks can be classified into two categories: one-way relay networks (OWRNs) and two-way relay networks (TWRNs). In OWRNs, a pair of nodes requires four phases to exchange information.In TWRNs, a pair of nodes requires only two phases to exchange information. During the first phase, both nodes send their messages to the relays at the same time which results in interference at the relays in the first communication phase, which upon broadcasting in the second phase, results in self-interference (SI). Unless properly accounted for, SI can result in severe deterioration in the system performance, especially at high signal-to-noise ratios (SNRs). Therefore, it is necessary that self-interfering signals are eliminated at the respective receivers. The difficulty of performing this task depends on channel state information (CSI) availability: when CSI is available, eliminating SI is straightforward, but when CSI is not available, eliminating SI constitutes a challenging problem.

In this thesis, we propose two perfect SI cancellation schemes. The first scheme is proposed for TWRNs with multiple-antenna relays. Each relay performs linear processing on its received signals jointly in space and time which will cancel SI perfectly. Our analysis shows that perfect cancellation is not possible if any relay were to have an odd number of active antennas. To the best of our knowledge, this scheme is the first scheme proposed for perfect SI cancellation in channelunaware relay networks. However, this scheme is limited to have an even number of antennas at each relay. To overcome this drawback, the second scheme perfect SI cancellation is proposed for TWRNs with single-antenna relays in which nodes use mode-switching transmission. The performance of both schemes are analytically analyzed and compared. Using the second scheme which has better performance, a trade-off between transmission rate and error probability for the Alamouti code and $S P(2)$ codes is obtained. This trade-off shows that for higher rates, using the Alamouti code is more beneficial even though it uses two relays instead of the four used by the SP(2) code.

Keywords: Cooperative communication, two-way relay networks, self-interference signal. 


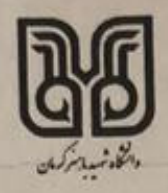

Shahid Bahonar University of Kerman

Faculty of Engineering

Department of Electrical Engineering

Perfect Self-Interference Cancellation In Channel-Unaware

Two-Way Relay Networks

\section{Prepared by:}

Salime Bameri

Supervisor:

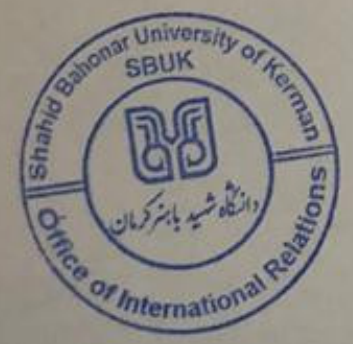

Dr. Siamak Talebi

Co-supervisor:

Dr. Ramy H. Gohary

A Thesis Submitted as a Partial Fulfillment of the Requirements for the

Degree of Doctor of Philosophy in Electrical Engineering (Ph.D.)

September 2019 



\title{
Perfect Self-Interference Cancellation in Channel-Unaware Two-Way Relay Networks
}

\author{
by
}

Salime Bameri, M.Sc.

A dissertation submitted to the

Faculty of Graduate and Postdoctoral Affairs

in partial fulfillment of the requirements for the degree of

\section{Doctor of Philosophy in Electrical Engineering}

\author{
Shahid Bahonar University of Kerman \\ Electrical Engineering Department \\ kerman, Iran \\ and \\ Ottawa-Carleton Institute for Electrical and Computer Engineering \\ Department of Systems and Computer Engineering \\ Carleton University \\ Ottawa, Ontario \\ September, 2019 \\ (C) Copyright \\ Salime Bameri, 2019
}




\title{
Perfect Self-Interference Cancellation in Channel-Unaware Two-Way Relay Networks
}

by

Salime Bameri, M.Sc.

A dissertation submitted to the

Faculty of Graduate and Postdoctoral Affairs

in partial fulfillment of the requirements for the degree of

\section{Doctor of Philosophy in Electrical Engineering}

\author{
Shahid Bahonar University of Kerman \\ Electrical Engineering Department \\ kerman, Iran \\ and
}

Ottawa-Carleton Institute for Electrical and Computer Engineering

Department of Systems and Computer Engineering

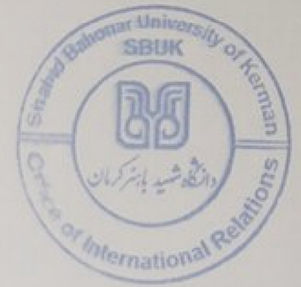

Carleton University

Ottawa, Ontario

September, 2019

(C) Copyright

Salime Bameri, 2019 


\section{Abstract}

The presence of multiple relays in wireless networks enables reliable communication of high data rates in many practical situations, notably those in which the channel between the source and destination are not line-of-sight with potentially deep fades. Relay networks can be classified into two categories: one-way relay networks (OWRNs) and two-way relay networks (TWRNs). In OWRNs, a pair of nodes requires four phases to exchange information. Two phases are used for transmission from the first node to the second one and the remaining two phases are used for transmission in the reverse direction. In TWRNs, a pair of nodes requires only two phases to exchange information. During the first phase, both nodes send their messages to the relays at the same time. After processing, relays broadcast their signals to both nodes during the second phase. The fact that in TWRNs the two nodes send their signals to the relays on the same physical channel results in interference at the relays in the first communication phase, which upon broadcasting in the second phase, results in self-interference (SI). Unless properly accounted for, SI can result in severe deterioration in the system performance, especially at high signal-to-noise ratios (SNRs). To achieve desirable performance at high SNRs, it is necessary that self-interfering signals are eliminated at the respective receivers. The difficulty of performing this task depends on channel state information (CSI) availability: when CSI is available, eliminating SI is straightforward, but when CSI is not available, eliminating SI constitutes a challenging problem.

In this thesis, we propose two perfect SI cancellation schemes. The first scheme is proposed for TWRNs with multiple-antenna relays. Each relay performs linear processing on its received signals jointly in space and time. This is in contrast with currently available processing strategies, which consider linear processing in time only. In particular, it will be shown that a special design for the space processing matrix will cancel SI perfectly. Our analysis shows that perfect cancellation is not possible if any relay were to have an odd number of active antennas. To the best of our knowledge, 
this scheme is the first scheme proposed for perfect SI cancellation in channel-unaware relay networks. However, this scheme is limited to have an even number of antennas at each relay. To overcome this drawback, the second scheme perfect SI cancellation is proposed for TWRNs with single-antenna relays. In this scheme, transmission begins with a four-phase OWRN-like initialization cycle to send reference vectors in order to enable nodes to cancel SI perfectly. Subsequently, transmission is switched to two-phase data transmission cycle to exchange information between the nodes. In fact, the vectors received by the nodes during the initialization cycle will enable them to cancel SI perfectly during the subsequent data transmission cycles. This scheme not only omits SI perfectly in the networks with the least number of antennas but also outperforms the other proposed scheme at all transmission rates. 
To my parents and my husband Alireza for their endless encouragement, love, and support.

To my adorable angels, Fateme and Yasaman, for their patience and happily coming to school with me. 


\section{Acknowledgments}

I would like to thank my supervisors, Professor Siamak Talebi at Shahid Bahonar University of Kerman and Professor Ramy H. Gohary at Carleton University. I could not complete this education journey without their support, guidance, and encouragement.

I am forever indebted to my father and my mother for kecping their support, encouragement and prayers alive. I would like to give my deepest gratitude to my husband Alireza for his love, support and patience.

Thank you, God, for giving me the strength to continue this journey when I felt I could not finish. 


\section{Table of Contents}

Abstract

Acknowledgments vi vi vis

Table of Contents vii

1 Introduction $\quad 1$

1.1 Wireless Communications and Applications . . . . . . . . . . . . . 1

1.2 Wireless Communication Challenges and Technologies . . . . . . . . 2

1.3 Thesis Outline . . . . . . . . . . . . . . . . . . . 4

2 MIMO Systems $\mathbf{5}$

2.1 Introduction . . . . . . . . . . . . . . . . . 5

2.2 Fading . . . . . . . . . . . . . . . . . . 6

2.2.1 Various Types of Fading . . . . . . . . . . . . . 6

2.3 Diversity . . . . . . . . . . . . . . . . . 8

2.3.1 Various Types of Diversity . . . . . . . . . . . . . 8

2.4 MIMO Systems . . . . . . . . . . . . . . . . . . . . 9

2.4.1 MIMO System Model . . . . . . . . . . . . . . . . . . . 9

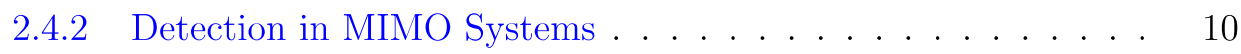

2.4 .3 Coding in MIMO Systems . . . . . . . . . . . . . . . 11

2.5 Space-Time Code Design Criteria . . . . . . . . . . . . . . . . . 12

2.5.1 Diversity Gain . . . . . . . . . . . . . . . . . . 12

2.5 .2 Coding Gain . . . . . . . . . . . . . . . . . 12

2.5.3 Transmission Rate . . . . . . . . . . . . . . . . 13

2.5.4 Spectral efficiency . . . . . . . . . . . . . . . . . 13

2.6 Alamouti Code in MIMO Systems . . . . . . . . . . . . . . . . . 13 
2.6.1 Differential Space-Time Block Coding In MIMO Systems . . . 14

2.7 Summary . . . . . . . . . . . . . . . . . . . . . . 15

3 Cooperative Communication $\quad 16$

3.1 Introduction . . . . . . . . . . . . . . . . . . . . 16

3.2 One-Way Relay Networks . . . . . . . . . . . . . . . . . . . . 18

3.2.1 Distributed Space-Time Coding In One-Way Relay Networks . 18

3.2.2 Distributed Differential Space-time Coding In One-Way Relay Networks . . . . . . . . . . . . . . . . . . 21

3.3 Two-Way Relay Networks . . . . . . . . . . . . . . . . . . . . . 23

3.3.1 Distributed Space-Time Coding In Two-Way Relay Networks . 24

3.3.2 Distributed Differential Space-Time Coding in Two-Way Relay Networks . . . . . . . . . . . . . . . . . . . 27

3.4 Problem Definition . . . . . . . . . . . . . . . . . . . . . . . . . . 29

3.5 Proposed Schemes To Self-Interference Cancellation In ChannelUnaware Two-Way Relay Networks . . . . . . . . . . . . . . . . . 30

3.5.1 Proposed Scheme In $[1] \ldots \ldots$. . . . . . . . . . . . . . . 30

3.5 .2 Proposed Scheme In [2] . . . . . . . . . . . . . . . . . . . 32

3.6 Summary . . . . . . . . . . . . . . . . . . 36

4 TWRNS with Multiple-Antenna Relays $\quad 37$

4.1 Introduction . . . . . . . . . . . . . . . . 37

4.2 System Model . . . . . . . . . . . . . . . . . . . . . . 38

4.2.1 First Transmission Phase . . . . . . . . . . . . . . . . 39

4.2.2 Linear Processing at the Relays and the Second Transmission Phase ...................... . . . 40

4.3 Joint Relay Processing in Space and Time . . . . . . . . . . . . . . . 41

4.4 System Performance Analysis in the Presence of Self-Interference . . 44

4.4.1 The Effect of Self-Interference on SINR . . . . . . . . . . . 45

4.4 .2 Lower Bound on PEP . . . . . . . . . . . . . . . 45

4.5 Perfect Self-Interference cancellation . . . . . . . . . . . . . . 47

4.6 Performance Analysis Under Perfect Self-Interference Cancellation 49

4.6.1 Asymptotically Optimal Channel-Unaware Symbol Detection . 49

4.6.2 An Upper Bound on the PEP . . . . . . . . . . . . . . . 50

4.6.3 Computational Complexity Analysis . . . . . . . . . . . 52 
4.7 Simulation . . . . . . . . . . . . . . . . . . . 52

4.7.1 Block Error Rate Performance . . . . . . . . . . . . . . . . 52

4.7.2 Effect of Number of Relays and Number of Antennas per Relay 59

4.7 .3 SINR Performance . . . . . . . . . . . . . . . . . 61

4.7.4 Rate Performance . . . . . . . . . . . . . . . . . . . . 61

4.8 Summary . . . . . . . . . . . . . . . . . . . . . 62

4.9 Conclusion . . . . . . . . . . . . . . . . . . . . 63

$5 \quad$ TWRNs with Single-Antenna Relays $\quad \mathbf{6 5}$

5.1 Introduction . . . . . . . . . . . . . . . . . . . 65

5.2 System Model . . . . . . . . . . . . . . . . . . . . . 67

5.3 A Novel Scheme for Perfect SI Cancellation . . . . . . . . . . . . . . 69

5.3.1 A Mode-Switching Transmission Scheme . . . . . . . . . . 70

5.3.2 Proposed SI Cancellation Scheme . . . . . . . . . . . . . 71

5.4 Performance Analysis . . . . . . . . . . . . . . . . . . . . . . . . 73

5.4.1 Performance Comparison Between the Alamouti and $S P(2)$ Codes for the Proposed Scheme . . . . . . . . . . . 76

5.4.2 Performance Comparison Between the Scheme Proposed Herein and the One Proposed in Chapter 4 . . . . . . . . . . 79

5.5 Simulation . . . . . . . . . . . . . . . . . . 80

5.6 Conclusion . . . . . . . . . . . . . . . . . . . 86

6 Summary and Future Works $\quad 88$

6.1 Summary . . . . . . . . . . . . . . . . . . 88

6.2 Future Works . . . . . . . . . . . . . . . . . . . . . . . 89

$\begin{array}{ll}\text { List of References } & 91\end{array}$

Appendix A Appendices $\quad \mathbf{9 5}$

A.1 Proof of $(4.15),(4.18)$ and $(4.19) \ldots \ldots \ldots . \ldots . \ldots 95$

A.1.1 Proof of $(4.15) \ldots \ldots \ldots \ldots \ldots$

A.1.2 Proof of $(4.18) \ldots \ldots \ldots \ldots$

A.1.3 Proof of $(4.19) \ldots \ldots \ldots \ldots$

A.2 Proof of Theorem 1 . . . . . . . . . . . . . . . . 97

A.3 Proof of Theorem $3 \ldots \ldots \ldots$

A.4 Proof of Theorem 4 . . . . . . . . . . . . . . . . . 101 
A.5 Computing Covariance Matrices . . . . . . . . . . . . . . . 103

A.6 Proof of Theorem 5 . . . . . . . . . . . . . . . . . . . . . . . . . 104

A.7 Proof of Corollary 2 . . . . . . . . . . . . . . . 106

A.8 Proof of Theorem $6 \ldots \ldots \ldots \ldots$. . . . . . . . . . . . 106

A.9 Proof of Lemma 2 . . . . . . . . . . . . . . . . . . 107

A.10 Proof of Lemma $3 \ldots \ldots$. . . . . . . . . . . . . . . 107

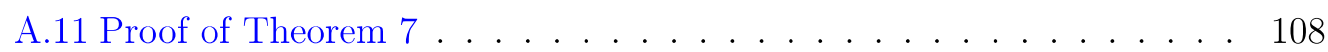

A.12 Proof of Corollary 3 . . . . . . . . . . . . . . . . . . . . . 112

A.13 Proof of Corollary 4 . . . . . . . . . . . . . . . . . . 113 


\section{List of Tables}

4.1 Comparison of the scheme proposed herein and [1]. . . . . . . . . . 64 


\section{List of Figures}

4.1 Block diagram of a TWRN . . . . . . . . . . . . . . . . . 38

4.2 Performance of a TWRN with $N=2$ relays and $2 \times 2$ real orthogonal code. . . . . . . . . . . . . . . . . . 5 53

4.3 Performance of a TWRN with $N=4$ relays and $4 \times 4$ real orthogonal code. . . . . . . . . . . . . . . . . . 54

4.4 Performance of a TWRN with $N=2$ relays and $2 \times 2$ Alamouti code. 56

4.5 Performance of a TWRN with $N=4$ relays and $4 \times 4 S P(2)$ code . . 57

4.6 Performance comparison when the total number of relay antennas is equal to 4. . . . . . . . . . . . . . . . . . . . . 59

4.7 Jakes' fading channels with various $f_{d} \ldots \ldots \ldots$. . . . . . . . 60

4.8 Effect of distributing antennas over more relays. . . . . . . . . . . . 60

4.9 SINR performance. . . . . . . . . . . . . . . . . . . 62

4.10 Rate performance. . . . . . . . . . . . . . . . 63

5.1 Average PEP and upper bound. . . . . . . . . . . . . . 81

5.2 BLER vs. power for the Alamouti code. . . . . . . . . . . . 82

5.3 BLER vs. power for the $S P(2)$ code. . . . . . . . . . . 84

5.4 Numerical performance-rate trade-off comparison. . . . . . . . . . . . 85

5.5 Performance-rate trade-off comparison. . . . . . . . . . . . . . . . 85

5.6 Performance comparison with the schemes in $[2,3] \ldots \ldots 7$ 


\section{Chapter 1}

\section{Introduction}

\subsection{Wireless Communications and Applications}

Wireless communication has become an integral part of human activities worldwide. Its impact on our daily lives ranges from indoor gaming to warfare and spaceexploration. The size of the wireless communication industry can be inferred from the revenues of communication bodies in the global arena. For instance, the Canadian Radio-Television and Telecommunication Commission reported that the total Canadian telecommunications revenues reached 50.3 billion dollars in 2017 of which over 25 billion dollars pertain to the mobile sector alone [4].

Wireless communication comprises a wide range of technologies, services, and applications that have come into existence to meet a variety of needs. For instance, the military employs wireless technologies to identify and track enemy targets, to detect chemical and biological attacks and to control unmanned robotic vehicles. Another application of wireless communications is in the area of medical services. For instance, monitoring of patients and elderly people and remote surgeries are examples of wireless communication application in advanced medical services. Industrial applications of wireless communications include process monitoring and automation.

Among the most important embodiments of wireless communications are cellular systems. Since their inception in the seventies of the previous century, cellular systems have been playing an increasing role in connecting humans and machines around the globe. Wireless cellular technology began its journey with first generation (1G), which relied on analog transmission and supported voice signal transmission only, followed by $2 \mathrm{G}$, which relied on digital transmission commercially launched on the Global System for Mobile (GSM) standard and supported voice and data signal transmission. 
The $2 \mathrm{G}$ architecture was followed by $3 \mathrm{G}$ which provided Code-Division Multiple Access (CDMA) technology and supported voice, data and video signal transmission. Today's 4G architecture provides Long Term Evolution (LTE) and supports mobile broadband Internet access in addition to voice, data and video signal transmission. The forthcoming $5 \mathrm{G}$ architecture is designed with the goal of guaranteeing uninterrupted access to information anytime and anywhere with better quality, high speed and reduced cost. An emerging paradigm in wireless communications is the Internet of Things (IoT) which is expected to be integrated with 5G networks. IoT refers to the billions of Internet-connected devices which can be monitored and/or controlled remotely. Intelligence, Business Insider's premium research service, expects that there will be more than 24 Billion IoT devices on Earth by 2020, i.e., approximately four devices for every human being on the planet [5].

\subsection{Wireless Communication Challenges and Technologies}

Wireless communications has become popular in the last few decades due to a number of major advantages which stem from the fact that wireless communication disposes of using solid-state media for information-bearing waves to propagate between communicating entities. Hence, wireless communications can provide connectivity over ranges that are impossible or impractical to cover with the use of wired communication.

Despite the advantages offered by the wireless communications, several challenges and aspects must be considered including the delay incurred by processing and propagation, the reliability which the signal is detected, the complexity and the rate at which the data is transmitted. Below, we will further elaborate on these challenges. These aspects and challenges are not independent and inherent trade-offs exist among them. However, the priority of addressing a particular challenge is application dependent. For instance, voice systems require relatively low data rate and can tolerate a fairly high error probability, but the total delay must be less than about $100 \mathrm{~ms}$ otherwise it becomes noticeable by user [6]. In contrast, data systems require much higher data rates, small error probabilities and relaxed delay constraints. Another application of wireless communications is short messaging system which has very low data rate requirement and no hard delay constraint. On the other hand, for mobile 
users with limited battery power, low complexity is a crucial requirement.

Towards achieving ubiquitous, reliable and timely connectivity, the $5 \mathrm{G}$ architecture will rely on powerful wireless technologies including the massive multiple-input multi-output (MIMO) technology, millimeter wave communications, ultra-dense cellular systems and cooperative communications [7].

MIMO technology refers to using multiple antennas at the transmitter and/or receiver. This technology is known to significantly improve the reliability and the spectrum efficiency of a wireless system [6]. Hence, MIMO technologies have become an integral part of many wireless standards including 802.11n, 802.11ac (Wi-Fi), WiMAX and Long Term Evolution (LTE). The massive MIMO paradigm capitalizes on the benefits of increasing the number of antennas at the transmitter and/or the receiver. In particular, in this paradigm, hundreds of antennas attached to a base station provide significant gains in transmission data rate and reliability $[7,8]$.

Another technology proposed for $5 \mathrm{G}$ networks is millimeter wave communication technology which operates in the 30-300 GHz and is expected to support data rates of multiple Giga bits per second (Gbps) in comparison with the data rate of $0.1-1$ Gbps offered by $4 \mathrm{G}$ networks. However, employing the millimeter wave technology requires dealing with challenges which include the restriction of the transmission range to 100 meters due to the attenuation of millimeter waves in atmospheric propagation. This drawback can be partially overcome by using ultra-dense networks and cooperative communications $[7,9]$.

In ultra-dense networks, a large number of small cells are employed to overcome the limited coverage of the millimeter wave technology. Small size cells known as femto and pico cells allow higher frequency reuse rates with range of 10-200 meter. The atmospheric absorption of millimeter waves will increases the signal attenuation. Although at the first glance, this may be viewed as being negative, it increases the isolation of each cell by further attenuating the background interference from distant base station [7].

In cooperative communications, some nodes act as relays to assist other nodes to transmit their information. Relay technology extends radio range by processing wireless signals between the transmitter and the receiver. For instance, in the $28 \mathrm{GHz}$ band, which is a candidate for $5 \mathrm{G}$, wireless signals are more likely to move in straight lines and more unlikely to circumvent obstacles due to the nature of millimeter wave frequencies. Therefore, relay technology is critical to the seamless delivery of $5 \mathrm{G}$ 
services $[7,10]$.

In this thesis, our focus is on the use of MIMO systems in cooperative relay networks.

\subsection{Thesis Outline}

In this thesis, we briefly review the elements of MIMO systems and cooperative communication in relay networks.

We begin in Chapter 2 by reviewing the fundamentals of MIMO systems.

In Chapter 3, we provide a review of cooperative communication and relay networks. Moreover, Chapter 3 introduces the challenge of self-interference (SI) cancellation in channel-unaware two-way relay networks and available schemes proposed to overcome this challenge.

In Chapter 4, we develop and analyze a novel perfect SI cancellation for channelunaware two-way relay networks with multiple-antenna relays. To the best of our knowledge, this scheme is to date the only available technique to cancel SI perfectly in channel-unaware TWRNs, however with the restriction of having an even number of antennas at each relay.

To overcome the restriction of having multiple antennas at each relay, in Chapter 5 , we develop a new signalling scheme that enables SI to be perfectly cancelled when the relays have a single antenna each. We analytically show that this scheme not only produces operational and temporal savings by virtue of the fact that it uses one antenna per relay and two thirds the signalling time for transmission, but also provides better performance. Moreover, in this chapter, we derive upper bounds on the pairwise error probability as a function of the transmission rate to capture the effect of the data rate on the system performance for two codes; the Alamouti code and $S P(2)$ code. Using these bounds, it is shown that, for a fixed power, it is more beneficial to use the $S P(2)$ code, using 4 relays, for low transmission rates. However, for high transmission rates, the Alamouti code, using 2 relays, is more beneficial even though it uses half the number of relays.

In Chapter 6, we summarize the thesis and propose a few ideas for future research. 


\section{Chapter 2}

\section{MIMO Systems}

\section{$2.1 \quad$ Introduction}

Wireless communication technologies have been progressing for the past few decades due to advances in wireless hardware technology, and also the large demand for mobile access. Signals transmitted over the wireless channels suffer from the phenomenon which is called fading $[11,12]$. Fading causes some random changes including attenuation, large delays, and severe signal distortion at signal received at the receiver. Fading in the wireless channels can increase the probability of error at the receiver. In order to overcome the fading effects, several independent copies of the transmitted signal can be sent. Therefore, each copy of the signal experiences an independent fading and the probability that all the copies simultaneously experience deep fades, is an unlikely event. The technique of transmitting several copies of one signal is called diversity which is achievable in time, frequency, or space. The spatial diversity is one of the most popular used diversity schemes. In this scheme, one signal is transmitted over the different spatial channels which can be implemented by using several antennas at the transmitter and/or receiver. These communication systems are called multiple-input and multiple-output (MIMO) systems, in which antennas are located in the proper positions such that the pairwise channel can be seen as independent channels with independent fading. Space-time coding scheme is one of the most successful methods used in MIMO systems to extract spatial diversity $[11,12]$.

In the rest of this chapter, we will briefly review the different types of fading, different types of diversity. Then, we will explain transmission schemes over the MIMO systems. 


\section{$2.2 \quad$ Fading}

In wireless communications, due to existence of reflectors or scatters, the transmitted signal travels through multiple propagation paths. These signals arriving from different paths have different attenuation, phases and delays. Therefore, they may add up either constructively or destructively at the receiver. This phenomenon is called fading which can increase the error probability at the receiver. Different types of fading are briefly reviewed below.

\subsubsection{Various Types of Fading}

Signal propagating through a wireless channel experience different types of fading. The types of fading depends on the relation between the signal characteristic, such as bandwidth, symbol period, and the channel characteristic, such as delay spread and Doppler spread.

Based on the multipath time delay spread, the fading can be divided into two types: flat fading and frequency-selective fading. However based on the Doppler shift in the frequency, fading can be divided into two types: slow fading and fast fading. These four types fading will be discussed in the what follows.

\section{Flat Fading}

In flat fading, the channel has a constant gain and linear phase response over a bandwidth which is greater than the bandwidth of the transmitted signal. In the time domain, the impulse response of the channel can be modeled as an impulse function which can has time varying amplitude. In other words, in time domain, the width of the channel impulse response is smaller than the symbol period.

\section{Frequency-Selective Fading}

In frequency-selective fading, channel has a constant gain and linear phase over a bandwidth which is smaller than the transmitted signal bandwidth. In the time domain, the impulse response of the channel can be modeled as a number of impulse functions which fade independently which results in intersymbol interference (ISI). In other words, in time domain, the width of the channel impulse response is larger than the symbol period 


\section{Slow Fading}

To define the fast and slow fading, we need to define the coherence time of the channel. The coherence time is the duration of time in which the channel impulse response is effectively invariant. If the signal duration is smaller than the coherence time of the channel, the whole signal is affected similarly by the channel and the channel is a slow fading channel.

\section{Fast Fading}

In fast fading, the signal duration is larger than the coherence time of the channel. That is, the channel changes as fast as the different parts of the transmitted signal experience different channels. This is called fast fading which is the result of fast motion of the receiver or transmitter. Fast fading only deals with the rate of change of the channel due to motion and in practice, only occurs for very low data rates.

It should be noted that when a channel is specified as a fast or slow fading channel, it does not specify whether the channel is flat fading or frequency selective in nature. Therefore, we can have four type of fading channels: flat slow fading channel, flat fast fading channel, frequency-selective slow fading channel and frequency-selective fast fading channel. For instance, a flat fast channel is a channel in which the amplitude of the impulse function varies faster than the rate of change of the transmitted baseband signal.

The fading of the wireless channels can be modeled as a random variable with different type of distributions which depends on the properties of the propagation environment. For more information cf. [11,12].

\section{Rayleigh Fading Model}

Since the signal received at the transmitter depends on fast changing factors, statistical models are typically used to emulate the channel fading. Many fading models based different statistical distributions have been developed including Rayleigh fading channels, Rician fading channels and Nakagami-m fading channels. In this thesis, we make the assumption of Rayleigh fading channels in both MIMO systems and relay networks.

It can be shown that the fading coefficient of the channel can be presented by a complex random variable. In flat fading channels, the real and imaginary parts of the 
fade coefficient are zero-mean Gaussian random variables. Hence, the amplitude of fading coefficient is a Rayleigh random variable. This fading can be used to model a wireless channel when there is no line-of-sight between the transmitter and the receiver [11].

\subsection{Diversity}

Fading in the wireless channels increases the error probability at the receiver. The idea to overcome the fading is sending several copies of the transmitted signal such that these copies experience as much independent fading of each other as possible. In this case, it is more unlikely that all the copies experience a deep fade so that the probability of error detection decreases. There are several types of diversity which will be briefly explained below.

\subsubsection{Various Types of Diversity}

\section{Time diversity}

In this type of diversity, one signal is transmitted during different time slots. The distance of these time slots must be such that the channel has independent fading during that time slots. Hence, the distance between these time slots must be greater than the coherence time of the channel.

\section{Frequency diversity}

In this type of diversity, one signal is transmitted over different frequencies. The distance of these frequencies must be such that the channel has independent fading in the frequency domain. Hence, during that time slots. hence, the distance between these frequencies must be greater than the coherence frequency bandwidth of the channel.

\section{Spatial Diversity}

In this type of diversity, one signal is transmitted over different wireless channels. Spatial diversity can be provided by using several antennas at the transmitter and/or receiver. It is shown that if the distance between the antennas is greater or equal to the half of signal wavelength, the channels have independent fading. 


\subsection{MIMO Systems}

MIMO technology has rapidly gained in popularity due to its powerful capability to improve the system performance. This technology provides some benefits to meet the challenges posed by both the impairments in the wireless channel as well as resource constraints.

Below, we will briefly describe the advantages of MIMO systems including array gain, spatial diversity gain, spatial multiplexing gain and interference reduction [13].

Array gain is the increase in the signal to noise (SNR) of the receiver which can be obtained through the spatial processing at the receive antenna array and/or the spatial pre-processing at the transmit antenna array. Array gain improves resistance to noise and hence improves the coverage a wireless network.

Spatial diversity gain overcomes the fading by providing the receiver with multiple, ideally independent, copies of the transmitted signal in space domain. Diversity gain, which is the number of independent copies, improves the reliability of the wireless system.

Spatial multiplexing gain is the increase in data rate by transmitting multiple independent data streams within the bandwidth of operation. The spatial multiplexing gain improves the capacity of a wireless network.

Multiple users sharing the time and frequency in wireless system result in interference. MIMO system by exploiting spatial dimension can increase the separation between users. Interference reduction improves the coverage of wireless system.

In general, it may not be possible to exploit simultaneously all the benefits described above. However, using some combination of the benefits across a wireless network will result in improved capacity, coverage and reliability [13].

\subsubsection{MIMO System Model}

Consider a wireless system in which the transmitter with $N_{t}$ antennas sends information to the receiver with $N_{r}$ antennas. The channel between the $i$-th transmit antenna and the $j$-th receive antenna is shown by $h_{i j}$ which is supposed to be a random variable with Rayleigh distribution. At the transmitter, information bits are mapped to $L$ symbols which are used to generate $N_{t}$ new symbols $s_{1}, \ldots, s_{N_{t}}$. The symbols are transmitted at the $N_{t}$ transmit antennas simultaneously.

Each antenna at the receiver receive all transmitted symbols which are faded and 
a noise is added. Assuming slow and flat fading, the received signal at the $j$-th receive antenna is given by [11]

$$
y_{j}=\sum_{i=1}^{N_{t}} h_{i j} s_{i}+n_{j}
$$

where $n_{j}$ is the noise at the $j$-th receive antenna. The equation (2.1) can be shown in the vector form

$$
\left[\begin{array}{c}
y_{1} \\
y_{2} \\
\vdots \\
y_{N_{r}}
\end{array}\right]=\left[\begin{array}{cccc}
h_{11} & h_{12} & \ldots & h_{1 N_{t}} \\
h_{21} & h_{22} & \ldots & h_{1 N_{t}} \\
\vdots & \vdots & \vdots & \vdots \\
h_{N_{r} 1} & h_{N_{r} 2} & \ldots & h_{N_{r} N_{t}}
\end{array}\right]\left[\begin{array}{c}
s_{1} \\
s_{2} \\
\vdots \\
s_{N_{t}}
\end{array}\right]+\left[\begin{array}{c}
n_{1} \\
n_{2} \\
\vdots \\
n_{N_{r}}
\end{array}\right]
$$

or equivalently

$$
\boldsymbol{y}=\boldsymbol{H} \boldsymbol{s}+\boldsymbol{n}
$$

where $\boldsymbol{y} \in \mathbb{C}^{N_{r} \times 1}$ is the received vector, $\boldsymbol{H} \in \mathbb{C}^{N_{r} \times N_{t}}$ is the channel state information (CSI) matrix, $\boldsymbol{s} \in \mathbb{C}^{N_{t} \times 1}$ is the transmitted vector and $\boldsymbol{n} \in \mathbb{C}^{N_{r} \times 1}$ is the additive noise vector.

\subsubsection{Detection in MIMO Systems}

Receiver can detect the transmitted symbols using different detectors including maximum likelihood (ML) detector. Assuming Gaussian noise $\boldsymbol{n}$ in (2.3) and for known channel $\boldsymbol{H}$, the ML detection is given by

$$
\hat{\boldsymbol{s}}=\arg \min _{\boldsymbol{s}}\|\boldsymbol{y}-\boldsymbol{H} \boldsymbol{s}\|^{2}
$$

It can be seen that the ML detector in (2.4) need to have the CSI, i.e., $\boldsymbol{H}$. In order for the receiver to access the CSI, the transmitter sends some known pilot symbols and the receiver uses the received pilots to estimate the CSI [6]. CSI estimation increases the receiver complexity, decreases the transmission rate and increases the error probability due to estimation error. In order to overcome the CSI estimation problem, some transmission schemes including differential signalling are proposed in which the detector does not need to have CSI [11]. 


\subsubsection{Coding in MIMO Systems}

The structure of the transmitted signal affects the system performance and the complexity of the transmitter and the receiver. Designing a structure for the signal transmission is called coding scheme or code design.

Based on the channel characteristics, the coding schemes can be divided into three categories: space-time (ST) coding, space-frequency (SF) coding and space-timefrequency (STF) coding. The ST coding scheme is appropriate for the flat fading channels. However the SF and STF coding schemes are appropriate for frequencyselective channels because in these channels frequency diversity is achievable however the ST schemes are not able to obtain the frequency diversity.

In this thesis, our focus is on the ST signalling and it will be reviewed in the next section.

\section{Space-Time Coding}

In space-time coding scheme, symbols are sent from different antennas and during different time slots. Space-time codes can be divided into two categories: Space-time block codes (STBCs) and space-time trellis codes.

The idea of behind trellis codes is similar to convolutional codes. The spacetime trellis codes have the memory and it is the main difference between them and STBCs. Increasing the memory of the trellis codes improves the code performance but increases the detection complexity. For more information about the trellis codes cf. [11].

On the other hand, STBCs are without memory and are designed for the quasistatic channels. A channel is called quasi-static when the fading coefficient of the channel is constant over the block of $T$ symbol duration, and it is independent from block to block.

In STBC, the transmitted signal which is called codeword is shown with a matrix, that is,

$$
\boldsymbol{S}=\left[\begin{array}{cccc}
s_{11} & s_{12} & \ldots & s_{1 M_{t}} \\
\vdots & \vdots & \ldots & \vdots \\
s_{T 1} & s_{T 2} & \ldots & s_{T M_{t}}
\end{array}\right]
$$

wherein $s_{i j}$ is the transmitted symbol during the $i$-th time slot at the $j$-th transmit 
antenna.

In a MIMO system using space-time block coding with quasi-static channels between $N_{t}$ transmit antennas and $N_{r}$ receive antennas, the received signal is given by

$$
\boldsymbol{Y}=\boldsymbol{S H}+\boldsymbol{N}
$$

where $\boldsymbol{Y} \in \mathbb{C}^{T \times N_{r}}, \boldsymbol{S} \in \mathbb{C}^{T \times N_{t}}, \boldsymbol{H} \in \mathbb{C}^{N_{t} \times N_{r}}$ and $\boldsymbol{N} \in \mathbb{C}^{T \times N_{r}}$ are the received signal, the transmitted signal, the channel fading matrix and noise matrix at the receiver, respectively.

In order to compare different codes, several design criteria have been studied. These criteria will be introduced in the next section.

\subsection{Space-Time Code Design Criteria}

Different ST codes can be compared based on some criteria including diversity gain, coding gain, transmission rate and spectral efficiency.

\subsubsection{Diversity Gain}

The asymptotic diversity gain is defined as the negative slope of the error probability curve with respect to the transmitted power in the $\log$-log scale. If $G_{d}$ denotes the diversity gain, we have

$$
G_{d}=-\lim _{p \rightarrow \infty} \frac{\log P_{e}(p)}{\log p}
$$

wherein $P_{e}(p)$ is the probability of the error and $p$ is power.

As we mentioned before, the diversity gain is equal to the number of uncorrelated fading that a transmitted signal experience. In fact, in a MIMO system with $N_{t}$ transmit antennas and $N_{r}$ receive antennas, the maximum spatial diversity gain (order) that can be achieved by a STBC is $N_{t} N_{r}$. In order for a STBC to achieve this diversity gain, it must be designed such that the matrices $\boldsymbol{D}_{i j}=\boldsymbol{S}_{i}-\boldsymbol{S}_{j}, \forall i \neq j$ to be full-rank for all $i \neq j[11]$.

\subsubsection{Coding Gain}

The diversity gain determines the slope of error rate curves whereas the coding gain determines how far the error rate curve moves to the right or left with the same slope. 
It is shown that a code can obtain the maximum coding gain, if the minimum determinant of matrix $\boldsymbol{D}_{i j}^{\dagger} \boldsymbol{D}_{i j}$ over all the distinct codewords $\boldsymbol{S}_{i}$ and $\boldsymbol{S}_{j}$ is maximized.

\subsubsection{Transmission Rate}

For a STBC that transmits $L$ symbols during $T$ time slots, the rate of the code is given by

$$
R=\frac{L}{T}
$$

A well designed STBC has maximum diversity gain, high coding gain and high transmission rate.

\subsubsection{Spectral efficiency}

For a STBC, the spectral efficiency is given by

$$
\zeta=\frac{R}{B} \mathrm{bit} / \mathrm{sec} / \mathrm{Hz}
$$

where $R$ is transmission data rate and $B$ is the channel bandwidth.

Now, we will review some popular STBCs.

\subsection{Alamouti Code in MIMO Systems}

In 1998, a STBC for MIMO systems with two transmit antennas and for quasi-static flat fading channels was designed by Alamouti [14]. This code is given by

$$
\left[\begin{array}{cc}
s_{1} & s_{2} \\
-s_{2}^{*} & s_{1}^{*}
\end{array}\right] .
$$

The Alamouti code due to its structure has a simple linear detector, achieves the full diversity gain equal to $2 N_{r}$ and has transmission rate equal to 1 .

The receiver of ST codes needs to have access to full CSI. Since, in some wireless systems, CSI is not available, the differential STBCs were introduced. 


\subsubsection{Differential Space-Time Block Coding In MIMO Sys- tems}

In channel-unaware systems in which CSI is not available, the transmitter uses differential signaling to send information. Using differential signalling at the transmitter renders the receiver to detect the symbols using the signal received during the previous time slot without requiring CSI. It is shown that, the performance of non-coherent systems is $3-\mathrm{dB}$ worse than the coherent one.

Differential unitary space-time (DUST) coding is one popular differential signaling in MIMO systems. In the DUST signaling, the transmitted signal, $\boldsymbol{S}^{(t)} \in \mathbb{C}^{N_{t} \times N_{t}}$ at the $t$-th time slot is given by

$$
\boldsymbol{S}^{(t)}=\boldsymbol{U}^{(t)} \boldsymbol{S}^{(t-1)}, \quad \boldsymbol{S}^{(0)}=\boldsymbol{I}_{M_{t}},
$$

where $\boldsymbol{U}^{(t)} \in \mathbb{C}^{N_{t} \times N_{t}}$ is a unitary matrix containing the information symbols. Unitarity of $\boldsymbol{U}^{(t)}$ ensures that the transmitted signal $\boldsymbol{S}^{(t)}$ does not go to zero or infinity.

Using (2.11), the received signal at the receiver at the $t$-th time slot is

$$
\boldsymbol{Y}^{(t)}=\boldsymbol{S}^{(t)} \boldsymbol{H}^{(t)}+\boldsymbol{N}^{(t)}
$$

where $\boldsymbol{Y}^{(t)} \in \mathbb{C}^{T \times N_{r}}, \boldsymbol{S}^{(t)} \in \mathbb{C}^{T \times N_{t}}, \boldsymbol{H}^{(t)} \in \mathbb{C}^{N_{t} \times N_{r}}$ and $\boldsymbol{N}^{(t)} \in \mathbb{C}^{T \times N_{r}}$ are the received signal, the transmitted signal, the channel fading matrix and noise matrix at the receiver at tile slot $t$, respectively. Supposing that the channel coefficients are constant for $2 N_{t}$ time slots, that is, $\boldsymbol{H}^{(t)} \approx \boldsymbol{H}^{(t-1)}$. Using this fact along with (2.11) yields

$$
\begin{aligned}
\boldsymbol{Y}^{(t)} & =\boldsymbol{U}^{(t)} \boldsymbol{S}^{(t-1)} \boldsymbol{H}^{(t-1)}+\boldsymbol{N}^{(t)}, \\
& =\boldsymbol{U}^{(t)}\left(\boldsymbol{Y}^{(t-1)}-\boldsymbol{N}^{(t-1)}\right)+\boldsymbol{N}^{(t)}, \\
& =\boldsymbol{U}^{(t)} \boldsymbol{Y}^{(t-1)}+\boldsymbol{W}^{(t)},
\end{aligned}
$$

where the equivalent noise $\boldsymbol{W}^{(t)}$ is

$$
\boldsymbol{W}^{(t)}=\boldsymbol{N}^{(t)}-\boldsymbol{U}^{(t)} \boldsymbol{N}^{(t-1)}
$$

From (2.13), it can be seen that the signal received at the receiver does not depend on the channel matrix $\boldsymbol{H}^{(t)}$. Hence, when the channel stays constant during two 
transmission block, i.e., $2 M_{t}$, detection can be done without requiring CSI.

Since the information matrix $\boldsymbol{U}^{(t)}$ is unitary, the entries of equivalent noise $\boldsymbol{W}^{(t)}$ will be i.i.d Gaussian distributed. Therefore, the ML detector is given by

$$
\hat{\boldsymbol{U}}^{(t)}=\min _{\boldsymbol{U}}\left\|\boldsymbol{Y}^{(t)}-\boldsymbol{U} \boldsymbol{Y}^{(t-1)}\right\|^{2}
$$

So far, we briefly reviewed the MIMO systems and a well known space-time code used in MIMO systems. Standard MIMO systems tend to use two or four antennas whereas, massive MIMO is a MIMO system with an especially high number of antennas. Massive MIMO providing the ability of serving multiple users simultaneously with high data rates and consistent performance is an integral part of forthcoming $5 G[7,8]$. Some of the new research directions on massive MIMO in academia and industry are included spectral efficiency analysis [15], system design for high energy efficiency [16] and power optimization [17].

\subsection{Summary}

In this chapter we briefly reviewed the concept of fading and diversity in wireless communications and introduced different type of fading and diversity. Then we considered a MIMO system and discussed the signal transmission and symbol detection using space time signalling when CSI is available. When CSI is not available, we discussed differential space time signalling and we showed that the ML detection can be used based the signal received previously without invoking CSI. In the next chapter we will review the principals of cooperative communication. We will review signal transmission in relay networks when CSI is available and when it is not available. 


\section{Chapter 3}

\section{Cooperative Communication}

\subsection{Introduction}

In MIMO systems the transmitter and/or the receiver are equipped with multiple antennas to improve the system performance. However, in many modern communication systems, using multiple antennas is not feasible due to the limitation of the size, power and cost. Moreover, the transmission range in MIMO systems is limited. These limitations in MIMO systems motivate using cooperative communication systems in which, the transmitter sends the signal to some relays and these relays retransmit the signal to the receiver. In this case, the transmission range increases and antennas at the relays can form a virtual MIMO to provide spatial diversity. These cooperative communication systems are called relay networks in which different type of relaying schemes have been proposed. Some well known relaying schemes are [10,18]: amplify-and-forward (AF), decode-and-forward (DF), compress-and-forward (CF) relaying schemes and distributed-space-time (DST) coding scheme [19]. In these relaying schemes, in the first phase of transmission, the transmitter sends the signal to the relays, relays process the received signal and then send their signal to the receiver in the second phase of transmission. These relaying techniques will be briefly discussed below.

In the AF relaying scheme, the received signal at each relay antenna is amplified and forwarded to the receiver. However, this relaying scheme is simple but it amplifies the noise at the relays and this noise is forwarded to the receiver besides the desired signal.

In the DF relaying scheme, the received signal at each relay antenna is decoded and re-encoded and then forwarded to the receiver. Decoding at the relays increases 
the complexity of the system and on the other hand, decoding error at the relays propagate to the receiver. However, DF relaying without decoding error at the relays has high performance.

In the CF relaying scheme, the received signal at each relay antenna is quantized, compressed and the forwarded to the receiver.

In the DST signalling scheme, the transmitter sends a signal vector to the relays and the received vector at each relay antenna is linearly processed and then forwarded to the receiver. In this relaying scheme, the received signal at the receiver can be a space-time codeword. Hence, the diversity gain of that space-time code can be achievable.

In the relay networks, two nodes can communicate either in four phases or two phases. Using four phases, the relay network is called one-way relay network (OWRN) and using two phases, the relay network is called two-way relay network (TWRN). TWRNs increase the spectral efficiency compared to OWRNs.

In OWNRs, four communication phases are required for any two nodes to exchange their messages. Two phases are used for transmission from the first node to the second one and the remaining two phases are used for transmission in the reverse direction. Unfortunately, this transmission scheme renders OWRNs rather wasteful of the spectral resources available for communication. In contrast with OWRNs, in TWRNs, for two nodes to exchange information, they both send their messages to the relays simultaneously in the first phase. The relays process their received signals and in the second phase the relays broadcast a combination of these signals to both nodes [20,21]. Hence, it can be seen that TWRNs halves the number of phases required by OWRNs to perform the same task. However, this advantage of TWRNs comes at the cost of additional processing at the nodes and/or the relays. Different aspects of TWRNs are considered in the literature. These aspects include pilot-based channel estimation [22,23], blind and partially-blind channel estimation [24,25], energy management in energy harvesting TWRNs [26,27], physical layer security [28, 29], relay selection and resource allocation [30-32], in addition to self-interference (SI) cancellation in channel-unaware relay networks [1,2,33-36], which is the aspect considered in this thesis. TWRNs and SI cancellation schemes can support the future demand for high data consumption, high throughput services and low latency applications within the limited available spectrum for 5G communications and beyond.

In the next two sections, transmission in OWRNs and TWRNs will be explained 
with more details.

\subsection{One-Way Relay Networks}

In this section, we consider a half-duplex OWRN with two single-antenna nodes and $N$ AF single-antenna relays. The channel between node 1 and the $n$-th relay is denoted by $f_{n}$ and the corresponding channel for node 2 is denoted by $g_{n}$. The channels are assumed to be block Rayleigh fading and hence $f_{n}$ and $g_{n}$ are Gaussian distributed with zero mean and unit variance. For this OWRN, we explain transmission in two cases: transmission using distributed space-time (DST) signalling scheme when CSI is available and transmission using differential DST (DDST) signalling scheme when CSI is not available.

\subsubsection{Distributed Space-Time Coding In One-Way Relay Networks}

Now, we suppose that for the considered OWRN the CSI is available. In this network, DST signaling scheme will be explained.

As mentioned, in OWRNs, two nodes communicate in four phases. In the first phase, first node sends its signal vector to the relays and in the second phase relays send their signals to the second node. In the third phase second node sends its signal vector to the relays and in the fourth phase relays send their signals to the first node. We explain transmission in the two first phases and transmission in the second two phases it follows from symmetry.

In the first phase of transmission, node 1 sends its signal vector $\boldsymbol{s}_{1} \in \mathbb{C}^{T \times 1}$ to the relays. Signal vector $\boldsymbol{s}_{1}$ is normalized such that $\mathrm{E}\left\{\boldsymbol{s}_{1} \boldsymbol{s}_{1}^{\dagger}\right\}=\boldsymbol{I}_{T}$.

The signal received at the $n$-th relay, $\boldsymbol{r}_{n} \in \mathbb{C}^{T \times 1}$, is given by

$$
\boldsymbol{r}_{n}=\sqrt{P_{1}} \boldsymbol{s}_{1} f_{n}+\boldsymbol{z}_{n}, \quad n=1, \ldots, N
$$

where $P_{1}$ is the average transmission power at node 1 and $\boldsymbol{z}_{n} \in \mathbb{C}^{T \times 1}$ denotes the noise vector at the $n$-th relay. The entries of the $\boldsymbol{z}_{n}$ are assumed to be Gaussian distributed with zero mean and unit variance, that is, $\mathrm{E}\left\{\boldsymbol{z}_{n} \boldsymbol{z}_{n}^{\dagger}\right\}=\boldsymbol{I}_{T}$. Hence, the 
average power of the received signal $\boldsymbol{r}_{n}$ is

$$
\begin{aligned}
\mathrm{E}\left\{\boldsymbol{r}_{n}^{\dagger} \boldsymbol{r}_{n}\right\} & =\mathrm{E}\left\{P_{1}\left|f_{n}\right|^{2} \boldsymbol{s}_{\mathbf{1}}^{\dagger} \boldsymbol{s}_{\mathbf{1}}\right\}+\mathrm{E}\left\{\boldsymbol{z}_{n}^{\dagger} \boldsymbol{z}_{n}\right\} \\
& =\left(P_{1}+1\right) T .
\end{aligned}
$$

In the DST signalling scheme, to obtain the maximum diversity, relays use the linear dispersion signalling proposed in [37]. In this signalling scheme, the transmitted signal at the $n$-th relay, $\boldsymbol{t}_{n}$, is given by

$$
\boldsymbol{t}_{n}=\beta_{n}\left(\boldsymbol{A}_{n} \boldsymbol{r}_{n}+\boldsymbol{B}_{n} \boldsymbol{r}_{n}^{*}\right)
$$

where the matrices $\boldsymbol{A}_{n} \in \mathbb{C}^{T \times T}$ and $\boldsymbol{B}_{n} \in \mathbb{C}^{T \times T}$ are relay processing matrices and provide processing in the time domain. The particular choice of the matrices $\boldsymbol{A}_{n}, \boldsymbol{B}_{n}$ depends on the space-time code used in the network. Furthermore, the scalar $\beta_{n}$ is chosen to ensure that the average transmission power at the $n$-relay is equal to power budget $P_{n}$. To obtain $\beta_{n}$, we have

$$
\begin{aligned}
\mathrm{E}\left\{\boldsymbol{t}_{n}^{\dagger} \boldsymbol{t}_{n}\right\}= & \beta_{n}^{2} \mathrm{E}\left\{\left(\boldsymbol{A}_{n} \boldsymbol{r}_{n}+\boldsymbol{B}_{n} \boldsymbol{r}_{n}^{*}\right)^{\dagger}\left(\boldsymbol{A}_{n} \boldsymbol{r}_{n}+\boldsymbol{B}_{n} \boldsymbol{r}_{n}^{*}\right)\right\} \\
= & \beta_{n}^{2} \mathrm{E}\left\{\boldsymbol{r}_{n}^{\dagger} \boldsymbol{A}_{n}^{\dagger} \boldsymbol{A}_{n} \boldsymbol{r}_{n}+\boldsymbol{r}_{n}^{\dagger} \boldsymbol{A}_{n}^{\dagger} \boldsymbol{B}_{n} \boldsymbol{r}_{n}^{*}+\boldsymbol{r}_{n}^{T} \boldsymbol{B}_{n}^{\dagger} \boldsymbol{A}_{n} \boldsymbol{r}_{n}+\boldsymbol{r}_{n}^{T} \boldsymbol{B}_{n}^{\dagger} \boldsymbol{B}_{n} \boldsymbol{r}_{n}^{*}\right\} \\
= & \beta_{n}^{2} \operatorname{Tr}\left(\boldsymbol{A}_{n}^{\dagger} \boldsymbol{A}_{n} \mathrm{E}\left\{\boldsymbol{r}_{n} \boldsymbol{r}_{n}^{\dagger}\right\}+\boldsymbol{A}_{n}^{\dagger} \boldsymbol{B}_{n} \mathrm{E}\left\{\boldsymbol{r}_{n}^{*} \boldsymbol{r}_{n}^{\dagger}\right\}+\boldsymbol{B}_{n}^{\dagger} \boldsymbol{A}_{n} \mathrm{E}\left\{\boldsymbol{r}_{n} \boldsymbol{r}_{n}^{T}\right\}\right. \\
& \left.+\boldsymbol{B}_{n}^{\dagger} \boldsymbol{B}_{n} \mathrm{E}\left\{\boldsymbol{r}_{n}^{*} \boldsymbol{r}_{n}^{T}\right\}\right) \\
= & P_{n} T .
\end{aligned}
$$

Using the fact that $\mathrm{E}\left\{\boldsymbol{r}_{n} \boldsymbol{r}_{n}^{\dagger}\right\}=\mathrm{E}\left\{\boldsymbol{r}_{n}^{*} \boldsymbol{r}_{n}^{T}\right\}=\left(P_{1}+1\right) \boldsymbol{I}_{T}$ along with $\mathrm{E}\left\{\boldsymbol{r}_{n}^{*} \boldsymbol{r}_{n}^{\dagger}\right\}=$ $\mathrm{E}\left\{\boldsymbol{r}_{n} \boldsymbol{r}_{n}^{T}\right\}=0$ in (3.4) yields

$$
\beta_{n}=\sqrt{\frac{P_{n} T}{\left(P_{1}+1\right) \operatorname{Tr}\left(\boldsymbol{A}_{n}^{\dagger} \boldsymbol{A}_{n}+\boldsymbol{B}_{n}^{\dagger} \boldsymbol{B}_{n}\right)}} .
$$

To ensure that the relay power constraint is satisfied, we have

$$
\operatorname{Tr}\left(\boldsymbol{A}_{n}^{\dagger} \boldsymbol{A}_{n}+\boldsymbol{B}_{n}^{\dagger} \boldsymbol{B}_{n}\right)=T
$$


which yields

$$
\beta_{n}=\sqrt{\frac{P_{n}}{P_{1}+1}} .
$$

Using transmitted signal at the relays in (3.3), the received signal at the second node is given by

$$
\boldsymbol{y}_{2}=\sum_{n=1}^{N} g_{n} \boldsymbol{t}_{n}+\boldsymbol{v}_{2}
$$

where $\boldsymbol{v}_{2} \in \mathbb{C}^{T \times 1}$ is the noise vector at the second node. For the case that either $\boldsymbol{A}_{n}=\mathbf{0}$ and $\boldsymbol{B}_{n}$ is unitary or $\boldsymbol{B}_{n}=\mathbf{0}$ and $\boldsymbol{A}_{n}$ is unitary, using (3.3), the received signal $\boldsymbol{y}_{2}$ in (3.8) can be expressed in the following form [19]

$$
\boldsymbol{y}_{2}=\boldsymbol{S}_{1} \boldsymbol{h}+\boldsymbol{w}
$$

where

$$
\boldsymbol{S}_{1}=\left[\boldsymbol{C}_{1} \hat{\boldsymbol{s}}_{1}, \ldots, \boldsymbol{C}_{N} \hat{\boldsymbol{s}}_{N}\right]
$$

is the received space-time block code at the second node and

$$
\boldsymbol{h}=\sqrt{P_{1}}\left[\begin{array}{c}
\beta_{1} \hat{f}_{1} g_{1} \\
\vdots \\
\beta_{N} \hat{f}_{N} g_{N}
\end{array}\right]
$$

is the equivalent channel vector and finally

$$
\boldsymbol{w}=\sum_{n=1}^{N} \beta_{n} g_{n} \boldsymbol{C}_{n} \hat{\boldsymbol{z}}_{n}+\boldsymbol{v}_{2}
$$

is the equivalent total noise at the second node and

$$
\begin{cases}\boldsymbol{C}_{n}=\boldsymbol{A}_{n}, \hat{f}_{n}=f_{n}, \hat{\boldsymbol{z}}_{n}=\boldsymbol{z}_{n}, \hat{\boldsymbol{s}}_{n}=\boldsymbol{s}_{1} & \text { if } \boldsymbol{B}_{n}=\mathbf{0} \\ \boldsymbol{C}_{n}=\boldsymbol{B}_{n}, \hat{f}_{n}=f_{n}^{*}, \hat{\boldsymbol{z}}_{n}=\boldsymbol{z}_{n}^{*}, \hat{\boldsymbol{s}}_{n}=\boldsymbol{s}_{1}^{*} & \text { if } \boldsymbol{A}_{n}=\mathbf{0}\end{cases}
$$

These equations imply that when $\boldsymbol{B}_{n}=\mathbf{0}$, the $n$-th column of codeword $\boldsymbol{S}_{1}$ contains only the transmitted symbols and when $\boldsymbol{A}_{n}=\mathbf{0}$, the $n$-th column of codeword $\boldsymbol{S}_{1}$ contains only the conjugate of the transmitted symbols. The matrix code $\boldsymbol{S}_{1}$ is similar 
to the matrix code in a MIMO system while each column of that is generated with a relay antenna not a transmitter antenna.

Supposing that the equivalent channel vector $\boldsymbol{h}$, i.e., CSI, is available at the receiver, the ML detection is given by [19]

$$
\overline{\boldsymbol{S}}_{1}=\arg \min _{\boldsymbol{S}_{1}}\left\|\boldsymbol{y}_{2}-\boldsymbol{S}_{1} \boldsymbol{h}\right\|^{2}
$$

Now, we suppose that the CSI is not available and explain the differential signalling in a channel-unaware OWRN.

\subsubsection{Distributed Differential Space-time Coding In One- Way Relay Networks}

DDST signalling in relay networks is the counterpart of differential space-time coding in MIMO systems. In this section, we will describe DDST signalling for the OWRN considered in the previous section while CSI is not available..

Let $T=N$ and call the transmission of $T$ consecutive symbols a block. In the differential signalling, the $T \times 1$ vector transmitted at the first node at the $t$-th block transmission, $T \times 1$ is given by

$$
\boldsymbol{s}_{1}^{(\ell)}=\boldsymbol{U}_{1}^{(\ell)} \boldsymbol{s}_{1}^{(\ell-1)}
$$

where $\boldsymbol{U}_{1}^{(\ell)}$ is a unitary matrix containing the message symbols and $\boldsymbol{s}_{1}^{(0)}$ is an arbitrary initialization vector, which is not required to be known a priori at the receiver. The initialization vector is chosen such that satisfy

$$
\mathrm{E}\left\{\boldsymbol{s}_{1}^{(0)} \boldsymbol{s}_{1}^{(0)^{\dagger}}\right\}=\boldsymbol{I}_{N}
$$

this constraint ensures that at each block transmission $\ell$, we have $\mathrm{E}\left\{\boldsymbol{s}_{1}^{(\ell)} \boldsymbol{s}_{1}^{(\ell)^{\dagger}}\right\}=\boldsymbol{I}_{N}$. Transmitting the signal $\boldsymbol{s}_{1}^{(\ell)}$ at the first node during the $\ell$-th block, the signal received at the $n$-the relay at the $\ell$-th block is given by

$$
\boldsymbol{r}_{n}^{(\ell)}=\sqrt{P_{1}} \boldsymbol{s}_{1}^{(\ell)} f_{n}^{(\ell)}+\boldsymbol{z}_{n}^{(\ell)}, \quad n=1, \ldots, N
$$

where $P_{1}$ is the average transmission power at node 1 and $\boldsymbol{z}_{n}^{(\ell)} \in \mathbb{C}^{N \times 1}$ denotes the noise vector at the $n$-th relay and at the $\ell$-th transmission block. The entries of the 
$\boldsymbol{z}_{n}^{(\ell)}$ are assumed to be Gaussian distributed with zero mean and unit variance, that is, $\mathrm{E}\left\{\boldsymbol{z}_{n}^{(\ell)} \boldsymbol{z}_{n}^{(\ell)^{\dagger}}\right\}=\boldsymbol{I}_{N}$.

By following the DST signalling described in Section 3.2.1, the received signal at the second node is

$$
\boldsymbol{y}_{2}^{(\ell)}=\boldsymbol{S}_{1}^{(\ell)} \boldsymbol{h}^{(\ell)}+\boldsymbol{w}^{(\ell)}
$$

where

$$
\boldsymbol{S}_{1}^{(\ell)}=\left[\boldsymbol{C}_{1} \hat{\boldsymbol{s}}_{1}^{(\ell)}, \ldots, \boldsymbol{C}_{N} \hat{\boldsymbol{s}}_{N}^{(\ell)}\right]
$$

and the equivalent channel vector is

$$
\boldsymbol{h}^{(\ell)}=\sqrt{P_{1}}\left[\begin{array}{c}
\beta_{1} \hat{f}_{1}^{(\ell)} g_{1}^{(\ell)} \\
\vdots \\
\beta_{N} \hat{f}_{N}^{(\ell)} g_{N}^{(\ell)}
\end{array}\right]
$$

and the equivalent total noise at the second node is

$$
\boldsymbol{w}^{(\ell)}=\sum_{n=1}^{N} \beta_{n} g_{n}^{(\ell)} \boldsymbol{C}_{n} \hat{\boldsymbol{z}}_{n}^{(\ell)}+\boldsymbol{v}_{n}^{(\ell)}
$$

and

$$
\left\{\begin{array}{l}
\boldsymbol{C}_{n}=\boldsymbol{A}_{n}, \hat{f}_{n}^{(\ell)}=f_{n}^{(\ell)}, \hat{\boldsymbol{z}}_{n}^{(\ell)}=\boldsymbol{z}_{n}^{(\ell)}, \hat{\boldsymbol{s}}_{n}^{(\ell)}=\boldsymbol{s}_{1}^{(\ell)} \quad \text { if } \boldsymbol{B}_{n}=\mathbf{0} \\
\boldsymbol{C}_{n}=\boldsymbol{B}_{n}, \hat{f}_{n}^{(\ell)}=f_{n}^{(\ell)^{*}}, \hat{\boldsymbol{z}}_{n}^{(\ell)}=\boldsymbol{z}_{n}^{(\ell)^{*}}, \hat{\boldsymbol{s}}_{n}^{(\ell)}=\boldsymbol{s}_{1}^{(\ell)^{*}} \quad \text { if } \boldsymbol{A}_{n}=\mathbf{0} .
\end{array}\right.
$$

Using (3.15), the received signal (3.19) is

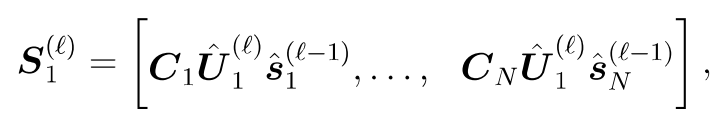

where

$$
\begin{cases}\hat{\boldsymbol{U}}_{1}^{(\ell)}=\boldsymbol{U}_{1}^{(\ell)} & \text { if } \boldsymbol{B}_{n}=\mathbf{0} \\ \hat{\boldsymbol{U}}_{1}^{(\ell)}=\boldsymbol{U}_{1}^{(\ell)^{*}} & \text { if } \boldsymbol{A}_{n}=\mathbf{0}\end{cases}
$$


and if for all $n$

$$
\left\{\begin{array}{l}
\boldsymbol{U}_{1}^{(\ell)} \boldsymbol{A}_{n}=\boldsymbol{A}_{n} \boldsymbol{U}_{1}^{(\ell)} \\
\boldsymbol{U}_{1}^{(\ell)} \boldsymbol{B}_{n}=\boldsymbol{B}_{n} \boldsymbol{U}_{1}^{(\ell)^{*}}
\end{array}\right.
$$

then we have

$$
\begin{aligned}
\boldsymbol{S}_{1}^{(\ell)} & =\boldsymbol{U}_{1}^{(\ell)}\left[\boldsymbol{C}_{1} \hat{\boldsymbol{s}}_{1}^{(\ell-1)}, \ldots, \boldsymbol{C}_{N} \hat{\boldsymbol{s}}_{N}^{(\ell-1)}\right] \\
& =\boldsymbol{U}_{1}^{(\ell)} \boldsymbol{S}_{1}^{(\ell-1)}
\end{aligned}
$$

Substituting from (3.26) in(3.18) and supposing that $\boldsymbol{h}^{(\ell)}=\boldsymbol{h}^{(\ell-1)}$ yields

$$
\begin{aligned}
\boldsymbol{y}_{2}^{(\ell)} & =\boldsymbol{U}_{1}^{(\ell)} \boldsymbol{S}^{(\ell-1)} \boldsymbol{h}^{(\ell-1)}+\boldsymbol{w}^{(\ell)} \\
& =\boldsymbol{U}_{1}^{(\ell)} \boldsymbol{y}_{2}^{(\ell-1)}+\hat{\boldsymbol{w}}^{(\ell)}
\end{aligned}
$$

where

$$
\hat{\boldsymbol{w}}^{(\ell)}=\boldsymbol{w}^{(\ell)}-\boldsymbol{U}^{(\ell)} \boldsymbol{w}^{(\ell-1)} .
$$

Using (3.28), it can be shown that, the performance of the DDST signalling has a 3 - $\mathrm{dB}$ loss compared to the performance of the DST signalling due to doubling the noise power.

From (3.27), it can be seen that the signal received at the second node at the $\ell$-th block can be detected using the signal received at the $\ell$-th block without requiring the channel information. In $[1,2]$ it is shown that the ML detection applicable to the received signal (3.27) is given by

$$
\overline{\boldsymbol{U}}_{1}^{(\ell)}=\arg \min _{\boldsymbol{U}_{1}}\left\|\boldsymbol{y}_{2}^{(\ell)}-\boldsymbol{U}_{1}^{(\ell)} \boldsymbol{y}_{2}^{(\ell-1)}\right\|^{2}, \quad \ell \geq 1,
$$

which shows CSI is not required for ML detection when we have $\boldsymbol{h}^{(\ell)}=\boldsymbol{h}^{(\ell-1)}$. In the next section, we will describe signalling in TWRNs.

\subsection{Two-Way Relay Networks}

In this section, we consider a half-duplex TWRN with two single-antenna nodes and $N$ AF single-antenna relays. We suppose that the transmission in both phases is simultaneous and synchronous, that is, we are not faced with the misalignment symbols 
either in the first phase at the relays or in the second phase at the nodes. In fact, in TWRNs with multiple relays, imperfect synchronization results in two types of symbol misalignment which consequently results in severe performance degradation. The first type of misalignment occurs in the first phase when simultaneous but asynchronous transmissions at nodes result in symbol misalignment at the relays. The second type of misalignment occurs in the second phase when asynchronous transmissions from relays result in symbol misalignment at the nodes, which then results in diversity loss in distributed space-time signalling. Some schemes are proposed in literature to overcome the symbol misalignment in channel-aware TWRNs [38, 39]. However, analogous schemes for channel-unaware TWRNs are not available but can be a topic for the future investigation.

The channel between node 1 and the $n$-th relay is denoted by $f_{n}$ and the corresponding channel for node 2 is denoted by $g_{n}$. The channels are assumed to be block Rayleigh fading and hence $f_{n}$ and $g_{n}$ are Gaussian distributed with zero mean and unit variance. For this TWRN, we explain transmission in two cases: transmission using DST coding scheme when CSI is available and transmission using DDST coding scheme when CSI is not available.

\subsubsection{Distributed Space-Time Coding In Two-Way Relay Networks}

Now, we suppose that for the considered TWRN the CSI is available. In this network, the DST signaling scheme will be explained.

As mentioned before, in TWRNs, two nodes communicate in two phases. In the first phase, both nodes send their signal vectors to the relays simultaneously and in the second phase relays broadcast their signals to both nodes.

More precisely, in the first phase of transmission, node 1 and node 2 send their signal vectors $\boldsymbol{s}_{1} \in \mathbb{C}^{T \times 1}$ and $\boldsymbol{s}_{2} \in \mathbb{C}^{T \times 1}$ to the relays simultaneously. Vector $\boldsymbol{s}_{i}$, $i=1,2$, containing the message symbols is normalized such that $\mathrm{E}\left\{\boldsymbol{s}_{i} \boldsymbol{s}_{i}^{\dagger}\right\}=\boldsymbol{I}_{T}$.

Signal received at the $n$-th relay, $\boldsymbol{r}_{n} \in \mathbb{C}^{T \times 1}$, is given by

$$
\boldsymbol{r}_{n}=\sqrt{P_{1}} \boldsymbol{s}_{1} f_{n}+\sqrt{P_{2}} \boldsymbol{s}_{2} g_{n}+\boldsymbol{z}_{n}, \quad n=1, \ldots, N
$$

where $P_{i}$ is the average transmission power at node $i, i=1,2$ and $\boldsymbol{z}_{n} \in \mathbb{C}^{T \times 1}$ denotes the noise vector at the $n$-th relay. The entries of the $\boldsymbol{z}_{n}$ are assumed to be Gaussian 
distributed with zero mean and unit variance, that is, $\mathrm{E}\left\{\boldsymbol{z}_{n} \boldsymbol{z}_{n}^{\dagger}\right\}=\boldsymbol{I}_{T}$. Hence, the average power of the received signal $\boldsymbol{r}_{n}$ is

$$
\begin{aligned}
\mathrm{E}\left\{\boldsymbol{r}_{n}^{\dagger} \boldsymbol{r}_{n}\right\} & =\mathrm{E}\left\{P_{1}\left|f_{n}\right|^{2} \boldsymbol{s}_{\mathbf{1}}^{\dagger} \boldsymbol{s}_{\mathbf{1}}\right\}+\mathrm{E}\left\{P_{2}\left|g_{n}\right|^{2} \boldsymbol{s}_{\mathbf{2}}^{\dagger} \boldsymbol{s}_{\mathbf{2}}\right\}+\mathrm{E}\left\{\boldsymbol{z}_{\boldsymbol{n}}^{\dagger} \boldsymbol{z}_{n}\right\} \\
& =\left(P_{1}+P_{2}+1\right) T .
\end{aligned}
$$

Using the linear dispersion signalling proposed in [37], the transmitted signal at the $n$-th relay, $\boldsymbol{t}_{n}$, is given by

$$
\begin{aligned}
\boldsymbol{t}_{n} & =\beta_{n}\left(\boldsymbol{A}_{n} \boldsymbol{r}_{n}+\boldsymbol{B}_{n} \boldsymbol{r}_{n}^{*}\right), \\
& =\beta_{n} \boldsymbol{A}_{n}\left(\sqrt{P_{1}} s_{1} f_{n}+\sqrt{P_{2}} s_{2} g_{n}\right)+\beta_{n} \boldsymbol{B}_{n}\left(\sqrt{P_{1}} s_{1}^{*} f_{n}^{*}+\sqrt{P_{2}} s_{2}^{*} g_{n}^{*}\right) \\
& +\beta_{n}\left(\boldsymbol{A}_{n} \boldsymbol{z}_{n}+\boldsymbol{B}_{n} \boldsymbol{z}_{n}^{*}\right),
\end{aligned}
$$

it can be shown that in order to the average transmission power at the $n$-relay is equal to power budget $P_{n}$, the scalar $\beta_{n}$ must be chosen as

$$
\beta_{n}=\sqrt{\frac{P_{n} T}{\left(P_{1}+P_{2}+1\right) \operatorname{Tr}\left(\boldsymbol{A}_{n}^{\dagger} \boldsymbol{A}_{n}+\boldsymbol{B}_{n}^{\dagger} \boldsymbol{B}_{n}\right)}} .
$$

To ensure that the relay power constraint is satisfied, we need to have $\operatorname{Tr}\left(\boldsymbol{A}_{n}^{\dagger} \boldsymbol{A}_{n}+\right.$ $\left.\boldsymbol{B}_{n}^{\dagger} \boldsymbol{B}_{n}\right)=T$ which yields

$$
\beta_{n}=\sqrt{\frac{P_{n}}{P_{1}+P_{2}+1}} .
$$

From (3.30), it can be seen that the received signal at each relay contains both transmitted signals, i.e. the signals transmitted from node 1 and node 2 .

Broadcasting $\boldsymbol{t}_{n}, n=1, \ldots, N$ at the relays during the second phase of transmission, the received signal at the second node is

$$
\begin{aligned}
\boldsymbol{y}_{2} & =\sum_{n=1}^{N} g_{n} \boldsymbol{t}_{n}+\boldsymbol{v} \\
& =\sum_{n=1}^{N} \beta_{n}\left(\sqrt{P_{1}}\left(\boldsymbol{A}_{n} \boldsymbol{s}_{1} f_{n} g_{n}+\boldsymbol{B}_{n} \boldsymbol{s}_{1}^{*} f_{n}^{*} g_{n}\right)+\sqrt{P_{2}}\left(\boldsymbol{A}_{n} \boldsymbol{s}_{2} g_{n}^{2}+\boldsymbol{B}_{n} \boldsymbol{s}_{2}^{*}\left|g_{n}\right|^{2}\right)\right)+\boldsymbol{w}
\end{aligned}
$$


where

$$
\boldsymbol{w}=\sum_{n=1}^{N} \beta_{n} g_{n}\left(\boldsymbol{A}_{n} \boldsymbol{z}_{n}+\boldsymbol{B}_{n} \boldsymbol{z}_{n}^{*}\right)+\boldsymbol{v}
$$

where $\boldsymbol{v} \in \mathbb{C}^{T \times 1}$ is the noise vector at the second node. For the case that either $\boldsymbol{A}_{n}=\mathbf{0}$ and $\boldsymbol{B}_{n}$ is unitary or $\boldsymbol{B}_{n}=\mathbf{0}$ and $\boldsymbol{A}_{n}$ is unitary, using (3.3), the received signal $\boldsymbol{y}_{2}$ in (3.36) can be expressed in the following form [40]

$$
\boldsymbol{y}_{2}=\boldsymbol{S}_{1} \boldsymbol{h}_{1}+\boldsymbol{S}_{2} \boldsymbol{h}_{2}+\boldsymbol{w}
$$

where for $i=1,2$

$$
\boldsymbol{S}_{i}=\left[\boldsymbol{C}_{1} \hat{\boldsymbol{s}}_{i, 1}, \ldots, \boldsymbol{C}_{N} \hat{\boldsymbol{s}}_{i, N}\right]
$$

is the received space-time block code at the second node generated by $i$-th node and

$$
\boldsymbol{h}_{1}=\sqrt{P_{1}}\left[\begin{array}{c}
\beta_{1} \hat{f}_{1} g_{1} \\
\vdots \\
\beta_{N} \hat{f}_{N} g_{N}
\end{array}\right], \quad \boldsymbol{h}_{2}=\sqrt{P_{2}}\left[\begin{array}{c}
\beta_{1} \hat{g}_{1} g_{1} \\
\vdots \\
\beta_{N} \hat{g}_{N} g_{N}
\end{array}\right]
$$

where $\boldsymbol{h}_{1}$ is the equivalent channel vector from the first node to the second node and $\boldsymbol{h}_{2}$ is the equivalent channel vector form the second node to the second node and finally

$$
\boldsymbol{w}=\sum_{n=1}^{N}\left(\beta_{n} g_{n} \boldsymbol{C}_{n} \hat{\boldsymbol{z}}_{n}\right)+\boldsymbol{v},
$$

is the equivalent total noise at the second node and for $i=1,2$

$$
\begin{cases}\boldsymbol{C}_{n}=\boldsymbol{A}_{n}, \hat{f}_{n}=f_{n}, \hat{g}_{n}=g_{n}, \hat{\boldsymbol{z}}_{n}=\boldsymbol{z}_{n}, \hat{\boldsymbol{s}}_{i, n}=\boldsymbol{s}_{i} & \text { if } \boldsymbol{B}_{n}=\mathbf{0} \\ \boldsymbol{C}_{n}=\boldsymbol{B}_{n}, \hat{f}_{n}=f_{n}^{*}, \hat{g}_{n}=g_{n}^{*}, \hat{\boldsymbol{z}}_{n}=\boldsymbol{z}_{n}^{*}, \hat{\boldsymbol{s}}_{i, n}=\boldsymbol{s}_{i}^{*} & \text { if } \boldsymbol{A}_{n}=\mathbf{0}\end{cases}
$$

From (3.38), It can be seen that the first component on the right hand side (RHS) corresponds to the signal transmitted by the other node (i.e., node 1), and hence, this component comprises the desired signal. The second component on the RHS of (3.38) corresponds to the signal transmitted by the same node during the first phase (i.e., node 2), that is, this component comprises self-interference (SI). Finally, the third component corresponds to the equivalent noise, which, from (3.41), contains 
contributions from both the first and the second transmission phases.

Now, we explain the ML detection at the node 2 for a TWRN with available CSI. Supposing that the equivalent channel vectors $\boldsymbol{h}_{1}$ and $\boldsymbol{h}_{2}$ are known at the nodes, the node 2 having its transmitted signal, i.e., $\boldsymbol{S}_{2}$, first subtract the self-interference component completely, that is

$$
\begin{aligned}
\hat{\boldsymbol{y}}_{2} & =\boldsymbol{y}_{2}-\boldsymbol{S}_{2} \boldsymbol{h}_{2}, \\
& =\boldsymbol{S}_{1} \boldsymbol{h}_{1}+\boldsymbol{w} .
\end{aligned}
$$

Finally, using (3.43) and having $\boldsymbol{h}_{1}$, the ML detection at the second mode is given by

$$
\overline{\boldsymbol{S}}_{1}=\arg \min _{\boldsymbol{S}_{1}}\left\|\hat{\boldsymbol{y}}_{2}-\boldsymbol{S}_{1} \boldsymbol{h}_{1}\right\|^{2} .
$$

Now, we suppose that the CSI is not available in a TWRN. In this case, cancelling the self-interference component is challenging. In the next section, we will explain the differential signalling in a channel-unaware TWRN and then we will review the schemes proposed self-interference cancellation without requiring CSI.

\subsubsection{Distributed Differential Space-Time Coding in Two- Way Relay Networks}

In this section, DDST signalling in the TWRN considered in the previous section will be explained while CSI is not available.

In the channel-unaware TWRNs, both nodes transmit their differentially encoded signal vectors simultaneously to the relays during the first transmission phase. Hence, the received signal at the $n$-th relay at the $\ell$ block transmission, $\boldsymbol{r}_{n}^{(\ell)}$, is given by

$$
\boldsymbol{r}_{n}^{(\ell)}=\sqrt{P_{1}} \boldsymbol{s}_{1}^{(\ell)} f_{n}^{(\ell)}+\sqrt{P_{2}} \boldsymbol{s}_{2}^{(\ell)} g_{n}^{(\ell)}+\boldsymbol{z}_{n}^{(\ell)}, \quad n=1, \ldots, N
$$

where $P_{i}$ is the average transmission power at the node $i=1,2$. Moreover,

$$
\boldsymbol{s}_{i}^{(\ell)}=\boldsymbol{U}_{i}^{(\ell)} \boldsymbol{s}_{i}^{(\ell-1)}, \quad i=1,2
$$

is the $N \times 1$ differentially encoded signal vector at the first phase of the $\ell$ block transmission and $\boldsymbol{U}_{i}^{(\ell)}$ is a unitary matrix containing the message symbols of the node $i=1,2$. The arbitrary initialization vector $\boldsymbol{s}_{i}^{(0)}$ which is not required to be 
known a priori at the receiver, satisfies

$$
\mathrm{E}\left\{\boldsymbol{s}_{i}^{(0)} \boldsymbol{s}_{i}^{(0)^{\dagger}}\right\}=\boldsymbol{I}_{N}, \quad i=1,2,
$$

this constraint ensures that at each block transmission $\ell$ we have $\operatorname{E}\left\{\boldsymbol{s}_{i}^{(\ell)} \boldsymbol{s}_{i}^{(\ell)^{\dagger}}\right\}=\boldsymbol{I}_{N}$, $i=1,2$. We note that the initialization vectors $\boldsymbol{s}_{i}^{(0)}, i=1,2$, can be used to synchronize transmissions at the nodes in the first phase.

In $(3.45), \boldsymbol{z}_{n}^{(\ell)} \in \mathbb{C}^{N \times 1}$ is the noise vector at the $n$-th relay and at the $\ell$-th block transmission. The entries of the $\boldsymbol{z}_{n}^{(\ell)}$ are assumed to be Gaussian distributed with zero mean and unit variance, that is, $\mathrm{E}\left\{\boldsymbol{z}_{n}^{(\ell)} \boldsymbol{z}_{n}^{(\ell)^{\dagger}}\right\}=\boldsymbol{I}_{N}$.

Using (3.3), the $n$-th relay linearly processes its received signal $\boldsymbol{r}_{n}^{(\ell)}$ and broadcast the signal $\boldsymbol{t}_{n}^{(\ell)}$. Hence, the received signal at the second node is given by

$$
\boldsymbol{y}_{2}^{(\ell)}=\boldsymbol{S}_{1}^{(\ell)} \boldsymbol{h}_{1}^{(\ell)}+\boldsymbol{S}_{2}^{(\ell)} \boldsymbol{h}_{2}^{(\ell)}+\boldsymbol{w}^{(\ell)}
$$

where

$$
\boldsymbol{S}_{i}^{(\ell)}=\left[\boldsymbol{C}_{1} \hat{\boldsymbol{s}}_{i, 1}^{(\ell)}, \ldots, \quad \boldsymbol{C}_{N} \hat{\boldsymbol{s}}_{i, N}^{(\ell)}\right], \quad i=1,2,
$$

and

$$
\boldsymbol{h}_{1}^{(\ell)}=\sqrt{P_{1}}\left[\begin{array}{c}
\beta_{1} \hat{f}_{1}^{(\ell)} g_{1}^{(\ell)} \\
\vdots \\
\beta_{N} \hat{f}_{N}^{(\ell)} g_{N}^{(\ell)}
\end{array}\right], \quad \boldsymbol{h}_{2}^{(\ell)}=\sqrt{P_{2}}\left[\begin{array}{c}
\beta_{1} \hat{g}_{1}^{(\ell)} g_{1}^{(\ell)} \\
\vdots \\
\beta_{N} \hat{g}_{N}^{(\ell)} g_{N}^{(\ell)}
\end{array}\right]
$$

where $\boldsymbol{h}_{i}^{(\ell)}$ is the channel vector from node $i$ to node 2 and the equivalent total noise at the second node is

$$
\boldsymbol{w}^{(\ell)}=\sum_{n=1}^{N} \beta_{n} g_{n}^{(\ell)} \boldsymbol{C}_{n} \hat{\boldsymbol{z}}_{n}^{(\ell)}+\boldsymbol{v}_{n}^{(\ell)}
$$

and

$$
\left\{\begin{array}{l}
\boldsymbol{C}_{n}=\boldsymbol{A}_{n}, \hat{f}_{n}^{(\ell)}=f_{n}^{(\ell)}, \hat{\boldsymbol{z}}_{n}^{(\ell)}=\boldsymbol{z}_{n}^{(\ell)}, \hat{\boldsymbol{s}}_{i, n}^{(\ell)}=\boldsymbol{s}_{i}^{(\ell)} \quad \text { if } \boldsymbol{B}_{n}=\mathbf{0} \\
\boldsymbol{C}_{n}=\boldsymbol{B}_{n}, \hat{f}_{n}^{(\ell)}=f_{n}^{(\ell)^{*}}, \hat{\boldsymbol{z}}_{n}^{(\ell)}=\boldsymbol{z}_{n}^{(\ell)^{*}}, \hat{\boldsymbol{s}}_{i, n}^{(\ell)}=\boldsymbol{s}_{i}^{(\ell)^{*}} \quad \text { if } \boldsymbol{A}_{n}=\mathbf{0} .
\end{array}\right.
$$

Using (3.46), the received signal (3.49) for $i=1,2$ is

$$
\boldsymbol{S}_{i}^{(\ell)}=\left[\boldsymbol{C}_{1} \hat{\boldsymbol{U}}_{i}^{(\ell)} \hat{\boldsymbol{s}}_{i, 1}^{(\ell-1)}, \ldots, \quad \boldsymbol{C}_{N} \hat{\boldsymbol{U}}_{i}^{(\ell)} \hat{\boldsymbol{s}}_{i, N}^{(\ell-1)}\right]
$$


where

$$
\begin{cases}\hat{\boldsymbol{U}}_{i}^{(\ell)}=\boldsymbol{U}_{i}^{(\ell)} & \text { if } \boldsymbol{B}_{n}=\mathbf{0} \\ \hat{\boldsymbol{U}}_{i}^{(\ell)}=\boldsymbol{U}_{i}^{(\ell)^{*}} & \text { if } \boldsymbol{A}_{n}=\mathbf{0} .\end{cases}
$$

Furthermore, if for all $n$ and $i=1,2$

$$
\left\{\begin{array}{l}
\boldsymbol{U}_{i}^{(\ell)} \boldsymbol{A}_{n}=\boldsymbol{A}_{n} \boldsymbol{U}_{i}^{(\ell)} \\
\boldsymbol{U}_{i}^{(\ell)} \boldsymbol{B}_{n}=\boldsymbol{B}_{n} \boldsymbol{U}_{i}^{(\ell)^{*}}
\end{array}\right.
$$

then we have

$$
\begin{aligned}
\boldsymbol{S}_{i}^{(\ell)} & =\boldsymbol{U}_{i}^{(\ell)}\left[\boldsymbol{C}_{1} \hat{\boldsymbol{s}}_{i, 1}^{(\ell-1)}, \ldots, \quad \boldsymbol{C}_{N} \hat{\boldsymbol{s}}_{i, N}^{(\ell-1)}\right] \\
& =\boldsymbol{U}_{i}^{(\ell)} \boldsymbol{S}_{i}^{(\ell-1)}, \quad i=1,2 .
\end{aligned}
$$

For detection, the second node must first cancel the SI component and then detects the transmitted symbols from the first node. Since, in channel-unaware TWRNs, CSI is not available SI cancellation is not straight forward like cancellation in channelaware TWRNs. In order to omit SI in channel-unaware TWRNs several schemes have been proposed. In the next section, we will review two of the proposed schemes.

\subsection{Problem Definition}

It was shown that, in TWRNs the two nodes send their signals to the relays on the same physical channel results in interference at the relays in the first communication phase, which upon broadcasting in the second phase, results in self-interference. Unless properly accounted for, self-interference can result in severe deterioration in the system performance, especially at high SNRs. Relays process their received signals. To achieve desirable performance at high SNRs, it is necessary that the signalling scheme ensures that self-interfering signals are eliminated at the respective receivers. The difficulty of performing this task depends on CSI availability: when CSI is available, eliminating self-interference is straightforward, but when CSI is not available, eliminating self-interference constitutes a challenging problem.

Several approaches for mitigating the effect of SI in channel-unaware TWRNs have been proposed in the literature for AF relays [1,2,33-35] and DF ones [35, 36]. 
The focus in [33-35] was on TWRNs with a single relay. As such, these schemes do not realize the diversity gain offered by multiple relays. The case of TWRNs with multiple relays was considered in [36]. Therein a differential signalling scheme for DF relays with one antenna was devised. This scheme does not work for the multipleantenna AF relays. In [2], a DDST signalling scheme is proposed for channel-unaware TWRNs with two single-antenna nodes and multiple single-antenna AF HD relays. The scheme proposed in [2] begins with a four-phase OWRN-like transmission, which we refer to as initiation cycle (IC). Subsequently, information is exchanged between the nodes using a two-phase TWRN-like approach, which we refer to as two-phase transmission cycle (TC). The scheme in [2] computes noise estimates and uses them for SI cancellation. The nodes subsequently use their decisions on previously detected symbols to detect currently received ones, which renders the scheme in [2] prone to error propagation. Another DDST signalling scheme has been proposed in [1] for TWRNs with single-antenna nodes and multiple single-antenna AF HD relays. In this scheme, the nodes wait for the duration of the channel coherence time to perform channel estimation and SI cancellation before detecting the transmitted symbols. Residual SI estimation error results in imperfect SI cancellation and consequently in severe performance degradation. Despite this fact, the analysis in [2] and [1] relies on the assumption that SI has been perfectly cancelled. In practice, the SI estimates used in the cancellation process are imperfect.

Next, we review the schemes proposed in [1] and [2] which are the most related to our work.

\subsection{Proposed Schemes To Self-Interference Can- cellation In Channel-Unaware Two-Way Relay Networks}

Now, we begin by reviewing the scheme proposed in [1] for SI in channel-unaware TWRNs with multiple single-antenna relays.

\subsubsection{Proposed Scheme In [1]}

In the previous section, it was shown that the received signal at the second node of

a channel-unaware TWRNs with $N$ relay is given by $\boldsymbol{y}_{2}^{(\ell)}=\boldsymbol{S}_{1}^{(\ell)} \boldsymbol{h}_{1}^{(\ell)}+\boldsymbol{S}_{2}^{(\ell)} \boldsymbol{h}_{2}^{(\ell)}+\boldsymbol{w}^{(\ell)}$ 
where $\boldsymbol{S}_{i}^{(\ell)}=\boldsymbol{U}_{i}^{(\ell)} \boldsymbol{S}_{i}^{(\ell-1)}, i=1,2$.

In this paper, a blind channel estimation is proposed. It is shown that, if the relay processing matrices satisfy

$$
\operatorname{Tr}\left(\boldsymbol{C}_{n} \boldsymbol{C}_{n}^{\dagger}\right)=N, \quad \operatorname{Tr}\left(\boldsymbol{C}_{n} \boldsymbol{C}_{m}^{\dagger}\right)=0, m \neq n
$$

we have

$$
\mathrm{E}\left\{\boldsymbol{S}_{2}^{(\ell)^{\dagger}} \boldsymbol{y}_{2}^{(\ell)}\right\}=\sqrt{P_{2}} N \boldsymbol{h}_{2}
$$

and hence $\boldsymbol{h}_{2}$ can be approximated as

$$
\hat{\boldsymbol{h}}_{2} \approx \frac{1}{N L \sqrt{P_{2}}} \sum_{k=1}^{L} \boldsymbol{S}_{2}^{(\ell-k)^{\dagger}} \boldsymbol{y}_{2}^{(\ell-k)},
$$

where $L$ denotes number of transmitted blocks during a coherence time of the channel. Afterwards, the second node; knowing the transmitted signal $\boldsymbol{S}_{2}^{(\ell)}$ by itself, uses this estimated channel to cancel the self-interference

$$
\begin{aligned}
\hat{\boldsymbol{y}}_{2}^{(\ell)} & =\boldsymbol{y}_{2}^{(\ell)}-\sqrt{P_{2}} \boldsymbol{S}_{2}^{(\ell)} \hat{\boldsymbol{h}}_{2}, \\
& =\sqrt{P_{1}} \boldsymbol{S}_{1}^{(\ell)} \boldsymbol{h}_{1}^{(\ell)}+\boldsymbol{w}^{(\ell)} \\
& =\boldsymbol{U}_{1}^{(\ell)} \hat{\boldsymbol{y}}_{2}^{(\ell-1)}+\hat{\boldsymbol{w}}^{(\ell)}
\end{aligned}
$$

where $\hat{\boldsymbol{w}}^{(\ell)}=\boldsymbol{w}^{(\ell)}-\boldsymbol{U}_{1}^{(\ell)} \boldsymbol{w}^{(\ell-1)}$. It is shown that $\hat{\boldsymbol{w}}^{(\ell)}$ is Gaussian and the following ML detector can be used

$$
\overline{\boldsymbol{U}}_{1}^{(\ell)}=\arg \min _{\boldsymbol{U}_{1}^{(\ell)}}\left\|\hat{\boldsymbol{y}}_{2}^{(\ell)}-\boldsymbol{U}_{1}^{(\ell)} \hat{\boldsymbol{y}}_{2}^{(\ell-1)}\right\|^{2}
$$

Due to the estimation, this scheme suffers from estimation error and processing delay. Therefore, perfect self-interference cancellation is not achievable because of estimation error. In practice, the estimation error causes performance degradation depending on estimation accuracy of $\hat{\boldsymbol{h}}_{2}$. However, in the performance analysis, it is assumed that the estimated channel is accurate and subsequently the self-interference is cancelled perfectly. 


\subsubsection{Proposed Scheme In [2]}

In this proposed scheme, transmission starts with a four phase one-way signalling. In this four phases, nodes send their arbitrary initialized vectors consequently. Afterwards, the nodes proceed to transmit their messages in the normal two-phase two-way signalling.

\section{Four-Phase Initialization}

In the first phase, node 1 sends the $T \times 1$ initialization vector $\boldsymbol{s}_{0}=\left[\begin{array}{llll}1 & 0 & \ldots & 0\end{array}\right]^{T}$. Hence, the signal received at the $n$-th relay is given by

$$
\boldsymbol{r}_{0, n}^{s}=\sqrt{P_{1} T} f_{0, n} \boldsymbol{s}_{0}+\boldsymbol{v}_{0, n}^{\prime} \quad n=1, \ldots, N
$$

where $\boldsymbol{v}_{1, n}^{(0)}$ is the Gaussian distributed noise vector with zero mean and identity covariance matrix, $\boldsymbol{I}_{T}$. Note that the superscript "s" and "d" denote that signal is originated from the node 1 and node 2 , respectively. Then, relays linearly process their received signals

$$
\begin{array}{r}
\boldsymbol{t}_{0, n}^{s}=\sqrt{\frac{P_{3}}{P_{1}+1}} \boldsymbol{A}_{n} \boldsymbol{r}_{0, n}^{s}, \quad n=1, \ldots, L, \\
\boldsymbol{t}_{0, n}^{d}=\sqrt{\frac{P_{3}}{P_{1}+1}} \boldsymbol{A}_{n} \boldsymbol{r}_{0, n}^{s^{*}}, \quad n=L+1, \ldots, N,
\end{array}
$$

where $\boldsymbol{A}_{n}, n=1, \ldots, N$ are relay processing matrices. Hence, the received signal at the second node is

$$
\boldsymbol{y}_{0, \mathrm{n} 2}^{s}=\sqrt{\frac{P_{1} P_{3} T}{P_{1}+1}} \boldsymbol{S}_{0} \boldsymbol{h}_{0}+\boldsymbol{n}_{0}^{s}
$$

where

$$
\begin{aligned}
& \boldsymbol{S}_{0}=\left[\begin{array}{llllll}
\boldsymbol{A}_{1} s_{0}, & \ldots, & \boldsymbol{A}_{L} \boldsymbol{s}_{0}, & \boldsymbol{A}_{L+1} \boldsymbol{s}_{0}^{*}, & \ldots, & \boldsymbol{A}_{N} \boldsymbol{s}_{0}^{*}
\end{array}\right] \\
& \boldsymbol{h}_{0}=\left[\begin{array}{llllll}
f_{0,1} g_{0,1}, & \ldots, & f_{0, L} g_{0, L}, & f_{0, L+1}^{*} g_{0, L+1}, & \ldots, & f_{0, N}^{*} g_{0, N}
\end{array}\right]^{T} \text {, } \\
& \boldsymbol{n}_{0}^{s}=\sqrt{\frac{P_{3}}{P_{1}+1}}\left(\sum_{n=1}^{L} \boldsymbol{A}_{n} g_{0, n} \boldsymbol{v}_{0, n}^{s}+\sum_{n=L+1}^{N} \boldsymbol{A}_{n} g_{0, n} \boldsymbol{v}_{0, n}^{s^{*}}\right)+\boldsymbol{w}_{0}^{s},
\end{aligned}
$$

where $\boldsymbol{w}_{0}^{s}$ is the noise at the first node during the second phase. 
In the third phase, node 2 sends its initialization vector $\boldsymbol{d}_{0}=\left[\begin{array}{llll}1 & 0 & \ldots & 0\end{array}\right]^{T}$ to the relays. Afterwards, relay process their received signal and broadcast the signals during the fourth phase. Finally, the signal received at the second node at the end of the fourth phase is given by

$$
\boldsymbol{y}_{0, \mathrm{n} 2}^{d}=\sqrt{\frac{P_{2} P_{3} T}{P_{2}+1}} \boldsymbol{D}_{0} \boldsymbol{g}_{0}+\boldsymbol{n}_{0}^{d}
$$

where

$$
\begin{aligned}
& \boldsymbol{D}_{0}=\left[\begin{array}{llllll}
\boldsymbol{A}_{1} \boldsymbol{d}_{0} & \ldots & \boldsymbol{A}_{L} \boldsymbol{d}_{0} & \boldsymbol{A}_{L+1} \boldsymbol{d}_{0}^{*} & \ldots & \boldsymbol{A}_{N} \boldsymbol{s}_{0}^{*}
\end{array}\right] \\
& \boldsymbol{g}_{0}=\left[\begin{array}{llllll}
g_{0,1}^{2}, & \ldots, & g_{0, L}^{2}, & \left|g_{0, L+1}\right|^{2}, & \ldots, & \left|g_{0, N}\right|^{2}
\end{array}\right]^{T}, \\
& \boldsymbol{n}_{0}^{d}=\sqrt{\frac{P_{3}}{P_{1}+1}}\left(\sum_{n=1}^{L} \boldsymbol{A}_{n} g_{0, n} \boldsymbol{v}_{0, n}^{d}+\sum_{n=L+1}^{N} \boldsymbol{A}_{n} g_{0, n} \boldsymbol{v}_{0, n}^{d^{*}}\right)+\boldsymbol{w}_{0}^{d},
\end{aligned}
$$

where $\boldsymbol{w}_{0}^{d}$ is the noise at the first node during the fourth phase.

At the end of fourth phase of initialization, node 1 has received signals $\boldsymbol{y}_{0, \mathrm{n} 2}^{s}$ and $\boldsymbol{y}_{0, n_{1}}^{d}$ and node 2 has received $\boldsymbol{y}_{0, n_{2}}^{s}$ and $\boldsymbol{y}_{0, \mathrm{n} 2}^{d}$. These signals contain information of the channels and will be used to detection.

\section{Two-phase Data Transmission}

After, four-phase initialization, two-phase transmission starts. That is, both nodes sent their signals to the relays in the first phase and relays broadcast their signals in the second phase. If $s_{1}$ and $\boldsymbol{d}_{1}$ denote the transmitted signals at the node 1 and node 2 , respectively, the signal received at the relay $n$ is

$$
\boldsymbol{r}_{1, n}=\sqrt{P_{1} T} f_{1, n} \boldsymbol{s}_{1}+\sqrt{P_{2} T} g_{1, n} \boldsymbol{d}_{1}+\boldsymbol{v}_{1, n}
$$

The transmitted signals at the relays $n=1, \ldots, N$ are

$$
\begin{aligned}
& \boldsymbol{t}_{1, n}=\sqrt{\frac{P_{3}}{P_{1}+P_{2}+1}} \boldsymbol{A}_{n} \boldsymbol{r}_{1, n}, \quad n=1, \ldots, L \\
& \boldsymbol{t}_{1, n}=\sqrt{\frac{P_{3}}{P_{1}+P_{2}+1}} A_{n} \boldsymbol{r}_{1, n}^{*} \quad n=L+1, \ldots, N .
\end{aligned}
$$


The received signal at the second node at the first block of data transmission is given by

$$
\boldsymbol{y}_{1}=\sqrt{\frac{P_{1} P_{3} T}{P_{1}+P_{2}+1}} \boldsymbol{S}_{1} \boldsymbol{h}_{1}+\sqrt{\frac{P_{2} P_{3} T}{P_{1}+P_{2}+1}} \boldsymbol{D}_{1} \boldsymbol{g}_{1}+\boldsymbol{n}_{1},
$$

where

$$
\begin{aligned}
& \boldsymbol{S}_{1}=\left[\begin{array}{llllll}
A_{1} s_{1} & \ldots & A_{L} s_{1} & A_{L+1} s_{1}^{*} & \ldots & A_{N} s_{1}^{*}
\end{array}\right] \\
& \boldsymbol{h}_{1}=\left[\begin{array}{llllll}
f_{1,1} g_{1,1}, & \ldots, & f_{1, L} g_{1, L}, & f_{1, L+1}^{*} g_{1, L+1}, & \ldots, & f_{1, N}^{*} g_{1, N}
\end{array}\right]^{T} \text {, } \\
& \boldsymbol{D}_{1}=\left[\begin{array}{llllll}
\boldsymbol{A}_{1} \boldsymbol{d}_{1} & \ldots & \boldsymbol{A}_{L} \boldsymbol{d}_{1} & \boldsymbol{A}_{L+1} \boldsymbol{d}_{1}^{*} & \ldots & \boldsymbol{A}_{N} \boldsymbol{d}_{1}^{*}
\end{array}\right],
\end{aligned}
$$

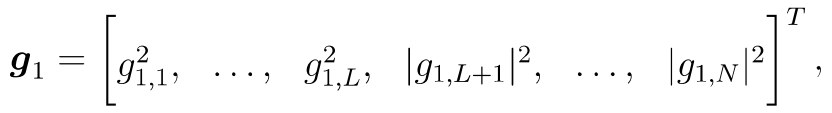

$$
\begin{aligned}
& \boldsymbol{n}_{1}=\sqrt{\frac{P_{3}}{P_{1}+P_{2}+1}}\left(\sum_{n=1}^{L} \boldsymbol{A}_{n} g_{0, n} \boldsymbol{v}_{0, n}^{d}+\sum_{n=L+1}^{N} \boldsymbol{A}_{n} g_{0, n} \boldsymbol{v}_{0, b}^{d^{*}}\right)+\boldsymbol{w}_{1}^{d} .
\end{aligned}
$$

Using the differential signalling at the nodes, i.e., $\boldsymbol{s}_{1}=\boldsymbol{U}_{1} \boldsymbol{s}_{0}$ and $\boldsymbol{D}_{1}=\boldsymbol{V}_{1} \boldsymbol{d}_{0}$, supposing that $\boldsymbol{h}_{1} \approx \boldsymbol{h}_{0}$ and $\boldsymbol{g}_{1} \approx \boldsymbol{g}_{0}$ along with the fact that $\boldsymbol{U}_{1} \boldsymbol{A}_{n}=\boldsymbol{A}_{n} \boldsymbol{U}_{1}$, $\boldsymbol{V}_{1} \boldsymbol{A}_{n}=\boldsymbol{A}_{n} \boldsymbol{U}_{1}$ for $n=1, \ldots, L$ and $\boldsymbol{U}_{1} \boldsymbol{A}_{n}=\boldsymbol{A}_{n} \boldsymbol{U}_{1}^{\dagger}, \boldsymbol{V}_{1} \boldsymbol{A}_{n}=\boldsymbol{A}_{n} \boldsymbol{V}_{1}^{\dagger}$ we have

$$
\begin{aligned}
\boldsymbol{y}_{1} & =\sqrt{\frac{P_{1} P_{2} T}{P_{1}+P_{2}+1}} \boldsymbol{U}_{1} \boldsymbol{S}_{0} \boldsymbol{h}_{0}+\sqrt{\frac{P_{2} P_{3} T}{P_{1}+P_{2}+1}} \boldsymbol{V}_{1} \boldsymbol{D}_{0} \boldsymbol{g}_{0} \\
& =\sqrt{\frac{P_{1}+1}{P_{1}+P_{2}+1}} \boldsymbol{U}_{1}\left(\boldsymbol{y}_{0}^{s}-\boldsymbol{n}_{0}^{s}\right)+\sqrt{\frac{P_{2}+1}{P_{1}+P_{2}+1}} \boldsymbol{V}_{1}\left(\boldsymbol{y}_{0}^{d}-\boldsymbol{n}_{0}^{d}\right)+\boldsymbol{n}_{0} \\
& =\sqrt{\frac{P_{1}+1}{P_{1}+P_{2}+1}} \boldsymbol{U}_{1} \boldsymbol{y}_{0}^{s}+\sqrt{\frac{P_{2}+1}{P_{1}+P_{2}+1}} \boldsymbol{V}_{1} \boldsymbol{y}_{0}^{d}+\hat{\boldsymbol{n}}_{1},
\end{aligned}
$$

where

$$
\hat{\boldsymbol{n}}_{1}=\boldsymbol{n}_{1}-\sqrt{\frac{P_{1}+1}{P_{1}+P_{2}+1}} \boldsymbol{U}_{1} \boldsymbol{n}_{0}^{s}-\sqrt{\frac{P_{2}+1}{P_{1}+P_{2}+1}} \boldsymbol{V}_{1} \boldsymbol{n}_{0}^{d} .
$$

Since the node 2 knows the transmitted signal by itself ,i.e., $\boldsymbol{V}_{1}$, it can cancel the self-interference and then detect $\boldsymbol{U}_{1}$ using

$$
\hat{\boldsymbol{U}}_{1}=\arg \min _{\boldsymbol{U}_{1}}\left\|\boldsymbol{y}_{1}-\sqrt{\frac{P_{1}+1}{P_{1}+P_{2}+1}} \boldsymbol{U}_{1} \boldsymbol{y}_{0}^{s}-\sqrt{\frac{P_{2}+1}{P_{1}+P_{2}+1}} \boldsymbol{V}_{1} \boldsymbol{y}_{0}^{d}\right\|^{2}
$$


Knowing $\hat{\boldsymbol{U}}_{1}$, it is proposed that node 2 estimates the noise $\hat{\boldsymbol{n}}_{1}$ with

$$
\overline{\boldsymbol{n}}_{1}=\boldsymbol{y}_{1}-\sqrt{\frac{P_{1}+1}{P_{1}+P_{2}+1}} \hat{\boldsymbol{U}}_{1} \boldsymbol{y}_{0}^{s}-\sqrt{\frac{P_{2}+1}{P_{1}+P_{2}+1}} \boldsymbol{V}_{1} \boldsymbol{y}_{0}^{d}
$$

this noise is due to transmission from node 1 and node 2 .

In order for the second node to subtract the self-interference component, it is proposed that node 2 virtually breaks down its received signal $\boldsymbol{y}_{1}$ into two components like

$$
\begin{aligned}
\boldsymbol{y}_{1} & =\hat{\boldsymbol{y}}_{1}^{s}+\hat{\boldsymbol{y}}_{1}^{d} \\
\hat{\boldsymbol{y}}_{1}^{s} & =\sqrt{\frac{P_{1}+1}{P_{1}+P_{2}+1}} \hat{\boldsymbol{U}}_{1} \boldsymbol{y}_{0}^{s}+\frac{\overline{\hat{\boldsymbol{n}}}_{1}}{2}, \\
\hat{\boldsymbol{y}}_{1}^{d} & =\sqrt{\frac{P_{2}+1}{P_{1}+P_{2}+1}} \hat{\boldsymbol{V}}_{1} \boldsymbol{y}_{0}^{d}+\frac{\frac{\hat{\boldsymbol{n}}_{1}}{2}}{}
\end{aligned}
$$

where $\hat{\boldsymbol{y}}_{1}^{s}$ is the estimation of the contribution from the first node and $\hat{\boldsymbol{y}}_{1}^{d}$ is the estimation of the contribution from the second node. From (3.85), it can be seen that the estimated noise $\overline{\hat{\boldsymbol{n}}}_{1}$ is shared between $\hat{\boldsymbol{y}}_{1}^{s}$ and $\hat{\boldsymbol{y}}_{1}^{d}$. Next, these estimated $\hat{\boldsymbol{y}}_{1}^{s}$ and $\hat{\boldsymbol{y}}_{1}^{d}$ will be used to detection of the second transmitted block.

This procedure will be continued for the next transmitted block. That is, in the $k$-th transmission block, the received signal at the second node is

$$
\boldsymbol{y}_{k}=\sqrt{\frac{P_{1} P_{3} T}{P_{1}+P_{2}+1}} \boldsymbol{S}_{k} \boldsymbol{h}_{k}+\sqrt{\frac{P_{2} P_{3} T}{P_{1}+P_{2}+1}} \boldsymbol{D}_{k} \boldsymbol{g}_{k}+\boldsymbol{n}_{k},
$$

where $\boldsymbol{S}_{k}, \boldsymbol{h}_{k}, \boldsymbol{D}_{k}, \boldsymbol{g}_{k}$ and $\boldsymbol{n}_{k}$ have the same structure as (3.76), (3.77), (3.78), (3.79) and (3.80) respectively. Using the differential signalling, $\boldsymbol{y}_{k}$ in (3.86) can be expressed as

$$
\boldsymbol{y}_{k}=\sqrt{\frac{P_{1}+1}{P_{1}+P_{2}+1}} \boldsymbol{U}_{k} \boldsymbol{y}_{k-1}^{s}+\sqrt{\frac{P_{2}+1}{P_{1}+P_{2}+1}} \boldsymbol{V}_{k} \boldsymbol{y}_{k-1}^{d}+\hat{\boldsymbol{n}}_{k}
$$

where

$$
\hat{\boldsymbol{n}}_{k}=\boldsymbol{n}_{k}-\sqrt{\frac{P_{1}+1}{P_{1}+P_{2}+1}} \boldsymbol{U}_{k-1} \boldsymbol{n}_{k-1}^{s}-\sqrt{\frac{P_{2}+1}{P_{1}+P_{2}+1}} \boldsymbol{V}_{k} \boldsymbol{n}_{k-1}^{d}
$$

Using the estimated $\hat{\boldsymbol{n}}_{k}$ in (3.88), the contribution of each node at the received signal 
at the second node is given by

$$
\begin{aligned}
& \hat{\boldsymbol{y}}_{k-1}^{s}=\sqrt{\frac{P_{1}+1}{P_{1}+P_{2}+1}} \hat{\boldsymbol{U}}_{k-1} \hat{\boldsymbol{y}}_{k-2}^{s}+\frac{\overline{\boldsymbol{n}}_{k-1}}{2}, \\
& \hat{\boldsymbol{y}}_{k-1}^{d}=\sqrt{\frac{P_{2}+1}{P_{1}+P_{2}+1}} \hat{\boldsymbol{V}}_{k-1} \hat{\boldsymbol{y}}_{k-2}^{d}+\frac{\overline{\boldsymbol{n}}_{1}}{2} .
\end{aligned}
$$

Finally, the self-interference cancellation and ML detection is given by

$$
\hat{\boldsymbol{U}}_{k}=\arg \min _{\boldsymbol{U}_{k}}\left\|\boldsymbol{y}_{k}-\sqrt{\frac{P_{1}+1}{P_{1}+P_{2}+1}} \boldsymbol{U}_{k} \hat{\boldsymbol{y}}_{k-1}^{s}-\sqrt{\frac{P_{2}+1}{P_{1}+P_{2}+1}} \boldsymbol{V}_{k} \hat{\boldsymbol{y}}_{k-1}^{d}\right\|^{2} .
$$

We saw that in this proposed scheme, the detection of each transmitted signal is based on the previous estimated signal. Hence, the error of estimation propagates into the detection of the next blocks. To overcome this problem, the four-phase initialization to be performed periodically.

\subsection{Summary}

So far we have shown that in TWRNs, the received signal at each communicating node contains the SI component. The self-interference signal must be cancelled. However, self-interference cancellation depends on the existence of the CSI at the nodes. In channel-unaware TWRNs, the SI cancellation is a challenging problem. To omit the SI signals, some schemes have been proposed which are not able to cancel SI perfectly.

In this thesis, in order to cancel SI perfectly, we will propose two schemes. The first scheme provides perfect SI cancellation by a novel processing at the relays. It will be shown this scheme is applicable in the TWRNs with multiple relays each with even number of active antennas. This scheme, to the best of our knowledge, is the first perfect SI cancellation proposed for channel-unaware TWRNs.

The second scheme provides perfect self-interference cancellation by processing at the nodes, not at relays, compared to the first proposed scheme. Hence, this scheme can be used in the TWRNs with multiple relays each with single antenna. This scheme not only cancels SI perfectly but also outperforms the first scheme proposed in this thesis. This is achievable at the cost of using a four-phase initialization phase followed by normal two-phase message transmission phases. 


\section{Chapter 4}

\section{TWRNS with Multiple-Antenna Relays}

\subsection{Introduction}

This chapter considers channel-unaware two-way relay networks in which two singleantenna nodes exchange information via multiple non-regenerative relays, each with

multiple antennas. A novel self-interference cancellation scheme for distributed differential space-time signalling is developed. Despite the absence of channel-state information, this scheme enables self-interference to be completely eliminated, thereby maximizing the signal-to-interference-plus-noise-ratio of the nodes. First, we obtain a lower bound on the pairwise error probability (PEP) under residual self-interference and we show that this bound approaches a non-zero constant at high signal-to-noise ratios (SNRs), indicating a zero diversity order and an asymptotic error floor. Second, we derive a necessary and sufficient condition for the proposed scheme to eliminate self-interference perfectly. Proper operation of this scheme requires the relays to have an even number of active antennas and for relays with odd number of active antennas, such a scheme does not exist. Third, we show that, when self-interference is cancelled perfectly, the error floor vanishes and an upper bound on the PEP approaches zero at high SNRs. In this case, it is shown that the diversity gain is equal to the number of relays and is independent of the number of antennas per relay. Finally, it is shown that the coding gain increases with increasing the number of antennas per relay and converges to a constant as the number of relay antennas becomes large. 


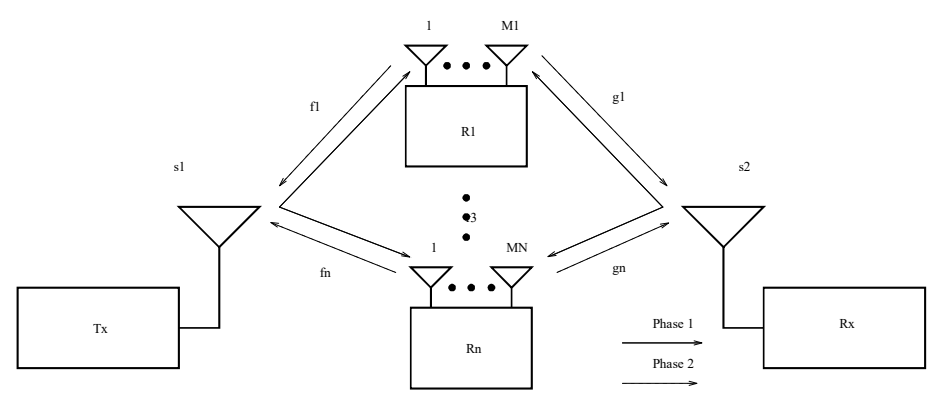

Figure 4.1: Block diagram of a TWRN.

\subsection{System Model}

We consider a channel-unaware half-duplex TWRN with two single-antenna nodes and $N$ AF relays as shown in Figure 4.1. The $n$-th relay has $M_{n}$ antennas which are used for both transmission and reception, $n=1, \ldots, N$. The vector channel between node 1 and the $n$-th relay is denoted by $\boldsymbol{f}_{n} \in \mathbb{C}^{M_{n}}$ and the corresponding channel for node 2 is denoted by $\boldsymbol{g}_{n} \in \mathbb{C}^{M_{n}}$. The $m$-th entry of $\boldsymbol{f}_{n}$ and the corresponding entry of $\boldsymbol{g}_{n}$ represent the channel between node 1 and node 2 , and the $m$-th antenna of relay $n$, respectively, $m=1, \ldots, M_{n}, n=1, \ldots, N$. The channels are assumed to be block Rayleigh fading and hence the entries of the channel vectors $\left\{\boldsymbol{f}_{n}\right\}$ and $\left\{\boldsymbol{g}_{n}\right\}$ are Gaussian distributed with zero mean and unit variance, i.e., $\mathrm{E}\left\{\boldsymbol{f}_{n} \boldsymbol{f}_{n}^{\dagger}\right\}=\mathrm{E}\left\{\boldsymbol{g}_{n} \boldsymbol{g}_{n}^{\dagger}\right\}=$ $\boldsymbol{I}_{M_{n}}$.

In the considered channel-unaware TWRN, neither the nodes nor the relays have access to CSI prior to detection. In this scenario, a convenient means for communication is the one offered by DDST. This scheme was used in [1] in channel-unaware signalling for the case when the relays have one antenna each. Unfortunately, the scheme proposed in [1] does not eliminate self-interference completely, resulting in a zero diversity gain, as will be shown below. To overcome this drawback, we herein use DDST, but with multiple antennas at each relay. For this scenario we will develop a signalling scheme that achieves a high-SNR diversity gain equal to the number of relays. The new relaying scheme is based on a novel approach for eliminating selfinterference perfectly at the multiple-antenna AF relays. Each relay linearly processes its received signal matrix containing the components transmitted from both nodes in the first phase and generates a new matrix, which is subsequently broadcast to the 
nodes in the second phase. The linear combinations at the relays are organized in such a way that the signal received at each of the two destination nodes appears as if it were generated by a particular space-time code.

We will consider two classes of DST codes involving linear and sesquilinear ${ }^{1}$ combinations of the transmitted symbols. Instances of the first class include real orthogonal codes [?], whereas instances of the second class include the Alamouti and the $S P(2)$ codes [41]. Detection for both classes is similar but transmission is slightly different as we elaborate below.

In both the linear and sesquilinear classes, the nodes organize their transmissions in $L$ blocks of $N$ symbols, each denoted by the $N \times 1$ vector, $\boldsymbol{s}_{i}^{(\ell)}, i=1,2, \ell=$ $1, \ldots, L-1$. More precisely, similar to [41], in the $\ell$-th block, each node differentially encodes its message as follows

$$
\boldsymbol{s}_{i}^{(\ell)}=\boldsymbol{U}_{i}^{(\ell)} \boldsymbol{s}_{i}^{(\ell-1)}, \quad i=1,2, \quad \ell=1, \ldots, L-1,
$$

where $\boldsymbol{U}_{i}^{(\ell)}$ is a unitary $N \times N$ matrix to which the message of node $i$ in the $\ell$-th block is mapped, and $s_{i}^{(0)}$ is an arbitrary initialization vector, which is not required to be known a priori. Moreover, using theses signals, two nodes can synchronize their transmissions. The vectors $\left\{\boldsymbol{s}_{i}^{(\ell)}\right\}$ are normalized so that $\mathrm{E}\left\{\boldsymbol{s}_{i}^{(\ell)} \boldsymbol{s}_{i}^{(\ell)^{\dagger}}\right\}=\boldsymbol{I}_{N}$, $i=1,2, \ell=1, \ldots, L-1$.

\subsubsection{First Transmission Phase}

In the first TWRN transmission phase, the nodes transmit their messages to the twoway relays. The particular structure of the signals emitted by the nodes depends on the class of signalling, linear or sesquilinear. We will discuss these classes separately.

\section{The Class of Linearly-Structured Codes}

In this class, node $i$ transmits the $\ell$-th block $\boldsymbol{s}_{i}^{(\ell)}, i=1,2$, during $N$ symbol durations. Hence, the received signal of the $n$-th relay, is given by

$$
\boldsymbol{R}_{n}^{(\ell)}=\sqrt{P_{1}} \boldsymbol{s}_{1}^{(\ell)} \boldsymbol{f}_{n}^{T}+\sqrt{P_{2}} \boldsymbol{s}_{2}^{(\ell)} \boldsymbol{g}_{n}^{T}+\boldsymbol{V}_{n}^{(\ell)}, \quad \begin{aligned}
& n=1, \ldots, N, \quad \ell=1, \ldots, L-1,
\end{aligned}
$$

\footnotetext{
${ }^{1}$ Sesquilinear combinations refer to those combinations that are linear in the symbols and their complex conjugates.
} 
where the $m$-th column of $\boldsymbol{R}_{n}^{(\ell)} \in \mathbb{C}^{N \times M_{n}}$, denoted by $\boldsymbol{r}_{n m}^{(\ell)}$, is the $N \times 1$ received vector at the $m$-th antenna of the $n$-th relay, $P_{i}$ is the average power of node $i, i=1,2$, and $\boldsymbol{V}_{n}^{(\ell)} \in \mathbb{C}^{N \times M_{n}}$ is the noise matrix observed during the $\ell$-th block at the $n$-th relay. Throughout, the entries of $\boldsymbol{V}_{n}^{(\ell)}$ are assumed to be Gaussian with zero mean and unit variance, whence $\mathrm{E}\left\{\operatorname{Tr}\left(\boldsymbol{V}_{n}^{(\ell) \dagger} \boldsymbol{V}_{n}^{(\ell)}\right)\right\}=N M_{n}$.

\section{The Class of Sesquilinearly-Structured Codes}

In this class, node $i$ transmits the $\ell$-th block $s_{i}^{(\ell)}$ followed by its complex conjugate, $\overline{\boldsymbol{s}}_{i}^{(\ell)}, i=1,2$. As we elaborate below, this step is necessary because otherwise, the relay, being non-regenerative, would not be able to eliminate self-interference perfectly without CSI. In this case, nodes consume $2 N$ symbol durations for transmitting the same information and the received signal of the $n$-th relay, $\boldsymbol{R}_{n}^{(\ell)}$, is given by

$$
\begin{aligned}
\boldsymbol{R}_{n}^{(\ell)}= & \sqrt{P_{1}}\left[\boldsymbol{s}_{1}^{(\ell)^{T}}, \overline{\boldsymbol{s}}_{1}^{(\ell)^{T}}\right]^{T} \boldsymbol{f}_{n}^{T}+\sqrt{P_{2}}\left[\boldsymbol{s}_{2}^{(\ell)^{T}}, \overline{\boldsymbol{s}}_{2}^{(\ell)^{T}}\right]^{T} \boldsymbol{g}_{n}^{T} \\
& +\boldsymbol{V}_{n}^{(\ell)}, \quad n=1, \ldots, N, \quad \ell=1, \ldots, L-1,
\end{aligned}
$$

where the definitions of $\boldsymbol{R}_{n}^{(\ell)},\left\{P_{i}\right\}$ and $\boldsymbol{V}_{n}^{(\ell)}$ are the same as in the previous case, with the exception that $\boldsymbol{R}_{n}^{(\ell)} \in \mathbb{C}^{2 N \times M_{n}}$ and $\boldsymbol{V}_{n}^{(\ell)} \in \mathbb{C}^{2 N \times M_{n}}$, whence $\mathrm{E}\left\{\operatorname{Tr}\left(\boldsymbol{V}_{n}^{(\ell) \dagger} \boldsymbol{V}_{n}^{(\ell)}\right)\right\}=$ $2 N M_{n}$.

\subsubsection{Linear Processing at the Relays and the Second Trans- mission Phase}

The relays, being non-regenerative, process their received signals without attempting to recover the signals transmitted from the nodes in the first phase. We will consider the case in which the relays perform linear processing on these signals. This approach was considered in $[?, ?, ?, 1,19,41]$, but processing in these references is performed in the time domain. Unlike the aforementioned references, herein we consider a general approach in which processing is performed jointly over space and time, as will be elaborated below.

Let the linear transformation at the $n$-th relay be denoted by $\mathbb{T}_{n}: \boldsymbol{R}_{n}^{(\ell)} \mapsto \boldsymbol{T}_{n}^{(\ell)}$, i.e., $\mathbb{T}_{n}$ maps the received matrix of the $n$-th relay during the $\ell$-th block to the matrix $\boldsymbol{T}_{n}^{(\ell)} \in \mathbb{C}^{N \times M_{n}}$. Our objective is to identify and analyze appropriate choices for $\mathbb{T}_{n}$ for both classes of codes. 
Upon receiving the entire matrix $\boldsymbol{R}_{n}^{(\ell)}$ at the end of the $\ell$-th block, the $n$-th relay generates and broadcasts $\boldsymbol{T}_{n}^{(\ell)}$ to the two nodes. The received signals of these nodes can be expressed as:

$$
\boldsymbol{y}_{1}^{(\ell)}=\sum_{n=1}^{N} \boldsymbol{T}_{n}^{(\ell)} \boldsymbol{f}_{n}+\boldsymbol{z}_{1}^{(\ell)}, \quad \boldsymbol{y}_{2}^{(\ell)}=\sum_{n=1}^{N} \boldsymbol{T}_{n}^{(\ell)} \boldsymbol{g}_{n}+\boldsymbol{z}_{2}^{(\ell)}
$$

where $\boldsymbol{z}_{i}^{(\ell)}$ are the $N \times 1$ noise vectors at the $i$-th node during the $\ell$-th received block.

The precise definition of $\left\{\boldsymbol{T}_{n}^{(\ell)}\right\}$ will be given in the next section. For now, however, we note that, because of linear processing at the relays, each of the matrices $\left\{\boldsymbol{T}_{n}^{(\ell)}\right\}$ contains two components (cf. Figure 4.1): the first corresponds to the desired signal of node $i$ which is transmitted by the other node, and the second corresponds to the self-interference generated by node $i$ 's own transmission in the first phase, $i=1,2$. In the next section, we will show that self-interference heavily impacts the system performance and unless perfectly cancelled, it will cause the high-SNR diversity gain to be zero. To alleviate this drawback, we will develop a signalling strategy that ensures achieving a diversity gain equal to the number of relays.

\subsection{Joint Relay Processing in Space and Time}

In the original DDST signalling, processing at the $n$-th relay, $\mathbb{T}_{n}$, is performed in the time domain only even when the relays have multiple antennas [19]. We will show that this signalling strategy will prevent self-interference from being perfectly cancelled. In particular, we will show that, if the number of active antennas at any relay is odd, temporal processing alone does not suffice to cancel self-interference perfectly. To alleviate this drawback, in this section, we develop a novel signalling approach for performing linear processing at the relays jointly in space and time. In particular, we define $\mathbb{T}_{n}$ to be the linear transformation that maps $\boldsymbol{R}_{n}^{(\ell)}$ to $\boldsymbol{T}_{\boldsymbol{n}}{ }^{(\ell)}$ via

$$
\boldsymbol{T}_{n}^{(\ell)}=\beta_{n} \boldsymbol{C}_{n} \boldsymbol{R}_{n}^{(\ell)} \boldsymbol{X}_{n}, \quad \boldsymbol{X}_{n} \in \mathbb{C}^{M_{n} \times M_{n}}, \quad n=1, \ldots, N
$$

To ensure that the average transmission power of relay $n$ is equal to a given power budget, $P_{r_{n}}$, the scalars $\left\{\beta_{n}\right\}$ must satisfy $\beta_{n}=\sqrt{\frac{N P_{r_{n}}}{\mathrm{E}\left\{\operatorname{Tr}\left(\boldsymbol{C}_{n} \boldsymbol{R}_{n}^{(\ell)} \boldsymbol{X}_{n} \boldsymbol{X}_{n}^{\dagger} \boldsymbol{R}_{n}^{(\ell) \dagger} \boldsymbol{C}_{n}^{\dagger}\right)\right\}}}$. The matrices $\left\{\boldsymbol{X}_{n}\right\}$ in (4.5) are used for processing in the space domain and the matrices 
$\left\{\boldsymbol{C}_{n}\right\}$ are used for processing in the time domain. To ensure that the relay power constraints are satisfied, we have

$$
\operatorname{Tr}\left(\boldsymbol{C}_{n} \boldsymbol{C}_{n}^{\dagger}\right)=N
$$

The structure of $\left\{\boldsymbol{C}_{n}\right\}$ is different for linear and sesquilinear codes. In particular,

$$
\boldsymbol{C}_{n}= \begin{cases}\boldsymbol{A}_{n}, & \text { for linear codes, } n=1, \ldots, N \\
{\left[\begin{array}{ll}
\boldsymbol{A}_{n} & \boldsymbol{B}_{n}
\end{array}\right],} & \text { for sesquilinear codes, } n=1, \ldots, N\end{cases}
$$

The choice of $\boldsymbol{A}_{n}, \boldsymbol{B}_{n} \in \mathbb{C}^{N \times N}$ depends on the space-time code used in the network, see e.g., [41]. For example, for the $2 \times 2$ linear real-orthogonal DST code, $\boldsymbol{A}_{1}=\boldsymbol{I}_{2}$ and $\boldsymbol{A}_{2}=\boldsymbol{J}$, where

$$
\boldsymbol{J}=\left[\begin{array}{cc}
0 & -1 \\
1 & 0
\end{array}\right]
$$

and, for the $2 \times 2$ sesquilinear Alamouti DST code, $\boldsymbol{A}_{1}=\boldsymbol{I}_{2}, \boldsymbol{B}_{1}=\mathbf{0}, \boldsymbol{A}_{2}=\mathbf{0}$ and $\boldsymbol{B}_{2}=\boldsymbol{J}$.

The matrices $\left\{\boldsymbol{A}_{n}\right\}_{n=1}^{N},\left\{\boldsymbol{B}_{n}\right\}_{n=1}^{N}$ and $\left\{\boldsymbol{X}_{n}\right\}_{n=1}^{N}$ must satisfy the power constraints. In addition, since the channels $\left\{\boldsymbol{f}_{n}\right\}$ and $\left\{\boldsymbol{g}_{n}\right\}$ in (4.2)-(4.4) are isotropically distributed (i.d.) and CSI is not available, maintaining the channels to be i.d. requires these matrices to be unitary. Otherwise, the power distribution across the relay antennas will be nonuniform, which compromises performance if high power is allocated to weak channels $[?, ?, ?, 19,41]$.

In addition to unitarity, $\left\{\boldsymbol{A}_{n}\right\},\left\{\boldsymbol{B}_{n}\right\}$ and $\left\{\boldsymbol{X}_{n}\right\}$ must satisfy other constraints. In particular, for the receivers to use the signal received in the $(\ell-1)$-th block to detect the signal received in the $\ell$-th block, the matrices $\left\{\boldsymbol{A}_{n}\right\}$ and $\left\{\boldsymbol{B}_{n}\right\}$, must commute with $\left\{\boldsymbol{U}_{i}^{(\ell)}\right\}$ in (4.1) [41], i.e.,

$$
\begin{aligned}
\boldsymbol{U}_{i}^{(\ell)} \boldsymbol{A}_{n}=\boldsymbol{A}_{n} \boldsymbol{U}_{i}^{(\ell)}, \quad \text { and } \quad \boldsymbol{U}_{i}^{(\ell)} \boldsymbol{B}_{n} & =\boldsymbol{B}_{n} \overline{\boldsymbol{U}}_{i}^{(\ell)} \\
& i=1,2, n=1, \ldots, N, \quad \ell=1, \ldots, L-1 .
\end{aligned}
$$

These relationships will be assumed to hold throughout. As for $\left\{\boldsymbol{X}_{n}\right\}$, in Section 4.5, we will derive additional conditions to ensure that these matrices can effect perfect 
elimination of self-interference despite the absence of CSI at the receivers.

To proceed with analysis, we use (4.4), (4.5) and (4.9) to express the $N \times 1$ received signal of node 1 in the following form; analysis for node 2 follows from symmetry.

$$
\boldsymbol{y}_{1}^{(\ell)}=\sqrt{P_{1}} \boldsymbol{S}_{1}^{(\ell)} \boldsymbol{h}_{1}+\sqrt{P_{2}} \boldsymbol{S}_{2}^{(\ell)} \boldsymbol{h}_{2}+\boldsymbol{w}_{1}^{(\ell)}
$$

where the $N \times N$ matrices $\left\{\boldsymbol{S}_{i}^{(\ell)}\right\}$ are given by

$$
\begin{aligned}
& \boldsymbol{S}_{i}^{(\ell)}=\left[\boldsymbol{C}_{1} \boldsymbol{\theta}_{i}^{(\ell)}, \ldots, \boldsymbol{C}_{N} \boldsymbol{\theta}_{i}^{(\ell)}\right] \in \mathbb{C}^{N \times N} \\
& i=1,2, \quad \ell=1, \ldots, L-1, \\
& \boldsymbol{\theta}_{i}^{(\ell)}= \begin{cases}\boldsymbol{s}_{i}^{(\ell)}, & \text { for linear codes, } i=1,2, \\
{\left[\begin{array}{ll}
\boldsymbol{s}_{i}^{(\ell)^{T}} & \overline{\boldsymbol{s}}_{i}^{(\ell)^{T}}
\end{array}\right]^{T}} & \text { for sesquilinear codes, } i=1,2,\end{cases}
\end{aligned}
$$

the $N \times 1$ equivalent channel and noise vectors, $\boldsymbol{h}_{1}, \boldsymbol{h}_{2}$ and $\boldsymbol{w}_{1}^{(\ell)}$ are respectively given by

$$
\begin{gathered}
\boldsymbol{h}_{1}=\left[\beta_{1} \boldsymbol{f}_{1}^{T} \boldsymbol{X}_{1} \boldsymbol{f}_{1}, \ldots, \beta_{N} \boldsymbol{f}_{N}^{T} \boldsymbol{X}_{N} \boldsymbol{f}_{N}\right]^{T}, \\
\boldsymbol{h}_{2}=\left[\beta_{1} \boldsymbol{g}_{1}^{T} \boldsymbol{X}_{1} \boldsymbol{f}_{1}, \ldots, \beta_{N} \boldsymbol{g}_{N}^{T} \boldsymbol{X}_{N} \boldsymbol{f}_{N}\right]^{T}, \\
\boldsymbol{w}_{1}^{(\ell)}=\sum_{n=1}^{N} \beta_{n} \boldsymbol{C}_{n} \boldsymbol{V}_{n}^{(\ell)} \boldsymbol{X}_{n} \boldsymbol{f}_{n}+\boldsymbol{z}_{1}^{(\ell)}
\end{gathered}
$$

The first term on the right hand side (RHS) of (4.10) characterizes the signal transmitted by the same node during the first phase, that is, this term comprises self-interference. The second term characterizes the signal transmitted by the other node (i.e., node 2) during the first phase, and hence, this term comprises the desired signal. Finally, the third term characterizes the equivalent noise, which, from (4.14), contains contributions from the first and second transmission phases. Using statistical independence of $\left\{\boldsymbol{f}_{n}\right\}$ and $\left\{\boldsymbol{V}_{n}^{(\ell)}\right\}$, we have $\mathrm{E}\left\{\boldsymbol{w}_{1}^{(\ell)}\right\}=\mathbf{0}$ and, cf. Appendix A.1.1,

$$
\Sigma_{\boldsymbol{w}_{1}}=\mathrm{E}\left\{\boldsymbol{w}_{1}^{(\ell)} \boldsymbol{w}_{1}^{(\ell)^{\dagger}}\right\}=\sum_{n=1}^{N} \beta_{n}^{2} M_{n} \boldsymbol{C}_{n} \boldsymbol{C}_{n}^{\dagger}+\boldsymbol{I}_{N}
$$


Since $\left\{\boldsymbol{f}_{n}\right\}$ are random and unknown and $\left\{\boldsymbol{V}_{n}^{(\ell)}\right\}$ are Gaussian distributed, the distribution of the equivalent noise $\boldsymbol{w}_{1}^{(\ell)}$ depends on the distribution of $\left\{\boldsymbol{f}_{n}\right\}$ and is generally not Gaussian. Finding the exact distribution of $\boldsymbol{w}_{1}^{(\ell)}$ is not only difficult, but might also prohibit drawing insight into the key elements that govern performance. To alleviate this difficulty, we will follow the approach in [41] to approximate $\boldsymbol{w}_{1}^{(\ell)}$ by a Gaussian random vector with zero mean and the covariance in (4.15). In fact, using the central limit theorem it can be verified that the distribution of $\boldsymbol{w}_{1}^{(\ell)}$ approaches the Gaussian one as $M_{n}$ grows, $\forall n$. From Information Theoretic respective, it is known that the Gaussian noise is the worst-case additive noise. That is, for a fixed noise variance, the Gaussian noise minimizes the capacity of a channel [?]. Therefore, invoking Gaussian assumption in the design process of a communication system provides performance guarantee in practice. This approximation will be used throughout.

\subsection{System Performance Analysis in the Presence of Self-Interference}

In this section, we show that self-interference causes both the signal to interference plus noise ratio (SINR) and the PEP to converge to finite strictly positive constants as the signalling power increases. This implies that, without perfect cancellation of self-interference, the diversity gain is asymptotically zero. Suppose that the received signal in (4.10) includes a fraction, $\zeta \in(0,1]$, of the self-interference component, i.e.,

$$
\boldsymbol{y}_{1}^{(\ell)}=\zeta \sqrt{P_{1}} \boldsymbol{S}_{1}^{(\ell)} \boldsymbol{h}_{1}+\sqrt{P_{2}} \boldsymbol{S}_{2}^{(\ell)} \boldsymbol{h}_{2}+\boldsymbol{w}_{1}^{(\ell)}
$$

For ease of exposition, we assume that the power of both nodes and each relay is a scalar multiple of a constant power, $P$, i.e., $P_{1}=P, P_{2}=\delta_{0} P, P_{r_{n}}=\delta_{n} P, n=$ $1, \ldots, N$, where $\delta_{n}>0, \forall n$. Using the unitarity of $\boldsymbol{X}_{n}$ along with the expressions in (4.2), (4.3) and (4.6) yields

$$
\beta_{n}=\sqrt{\frac{\delta_{n} P}{M_{n}\left(\left(1+\delta_{0}\right) P+1\right)}} .
$$




\subsubsection{The Effect of Self-Interference on SINR}

To illustrate the effect of self-interference on the novel signalling scheme, we compute the average SINR of node 1 . Analogous computation for node 2 is mutatis mutandis. Using (4.11)-(4.13), in Appendix A.1.2 we show that the average power of the desired signal in $(4.16)$ is

$$
\mathrm{E}\left\{\left(\boldsymbol{S}_{2}^{(\ell)} \boldsymbol{h}_{2}\right)^{\dagger}\left(\boldsymbol{S}_{2}^{(\ell)} \boldsymbol{h}_{2}\right)\right\}=N \sum_{n=1}^{N} \beta_{n}^{2} M_{n} .
$$

For the average power of self-interference in (4.16), in Appendix A.1.3 we show that

$$
\begin{gathered}
\mathrm{E}\left\{\left(\boldsymbol{S}_{1}^{(\ell)} \boldsymbol{h}_{1}\right)^{\dagger}\left(\boldsymbol{S}_{1}^{(\ell)} \boldsymbol{h}_{1}\right)\right\}=N \sum_{n=1}^{N} \beta_{n}^{2} \alpha_{n}, \\
\alpha_{n}=2 \sum_{k=1}^{M_{n}}\left|x_{k k}^{(n)}\right|^{2}+\sum_{k=1}^{M_{n}} \sum_{j=k+1}^{M_{n}}\left|x_{k j}^{(n)}+x_{j k}^{(n)}\right|^{2}, \quad n=1, \ldots, N,
\end{gathered}
$$

and $x_{l k}^{(n)}$ is the $l k$-th entry of $\boldsymbol{X}_{n}$. Finally, using (4.15) and (4.6), we have

$$
\mathrm{E}\left\{\boldsymbol{w}_{1}^{(\ell)^{\dagger}} \boldsymbol{w}_{1}^{(\ell)}\right\}=\operatorname{Tr}\left(\mathrm{E}\left\{\boldsymbol{w}_{1}^{(\ell)} \boldsymbol{w}_{1}^{(\ell)^{\dagger}}\right\}\right)=N \sum_{n=1}^{N} \beta_{n}^{2} M_{n}+N
$$

From (4.18), (4.19) and (4.21), the average SINR observed by node 1 can be readily seen to be

$$
\mathrm{SINR}=\frac{\delta_{0} P^{2} \sum_{n=1}^{N} \delta_{n}}{\zeta^{2} P^{2} \sum_{n=1}^{N} \frac{\alpha_{n} \delta_{n}}{M_{n}}+\left(1+\sum_{n=0}^{N} \delta_{n}\right) P+1} .
$$

Using (4.22), it can be seen that $\lim _{P \rightarrow \infty} \operatorname{SINR}=\frac{\delta_{0} \sum_{n=1}^{N} \delta_{n}}{\zeta^{2} \sum_{n=1}^{N} \frac{\alpha_{n} \delta_{n}}{M_{n}}}$. Thus, if self-interference is not perfectly cancelled at any of the relays, the SINR will converge to a strictly positive constant.

\subsubsection{Lower Bound on PEP}

To investigate the effect of self-interference on the error rate of the scheme proposed in Section 4.3, we will derive a lower bound on the PEP. We will show that, under general conditions, this bound converges to a strictly positive constant that does not depend on $P$, unless self-interference is perfectly cancelled. In other words, any self-interference causes an error floor. Our main result of this section is recorded in 
Theorem 1.

Theorem 1. Let $\boldsymbol{h}_{1}, \boldsymbol{h}_{2}$ and $\boldsymbol{w}_{1}$ in (4.10) be zero mean Gaussian random vectors with average covariance matrices that are given by $\boldsymbol{\Sigma}_{\boldsymbol{h}_{1}}=\operatorname{diag}\left(\beta_{1}^{2} \alpha_{1}, \ldots, \beta_{N}^{2} \alpha_{N}\right)$, $\boldsymbol{\Sigma}_{\boldsymbol{h}_{2}}=\operatorname{diag}\left(\beta_{1}^{2} M_{1}, \ldots, \beta_{N}^{2} M_{N}\right)$ and (4.15), respectively. Consider the two distributed space-time codewords $\boldsymbol{S}_{2, a}^{(\ell)}$ and $\boldsymbol{S}_{2, b}^{(\ell)}$. Let $\sigma_{\max }^{(a, b)}$ be the largest eigenvalue of $\left(\boldsymbol{S}_{2, a}^{(\ell)}-\right.$ $\left.\boldsymbol{S}_{2, b}^{(\ell)}\right)^{\dagger}\left(\boldsymbol{S}_{2, a}^{(\ell)}-\boldsymbol{S}_{2, b}^{(\ell)}\right)$ and let $\hat{\sigma}_{\max }=\max _{a, b} \sigma_{\max }^{(a, b)}$. In addition, let $\lambda_{\min }\left(\boldsymbol{\theta}_{1}\right)$ and $\mu_{\min }^{(n)}$ be the smallest eigenvalues of $\sum_{n=1}^{N} \frac{\alpha_{n} \delta_{n}}{M_{n}} \boldsymbol{C}_{n} \boldsymbol{\theta}_{1}^{(\ell)} \boldsymbol{\theta}_{1}^{(\ell)} \boldsymbol{C}_{n}^{\dagger}$ and $\boldsymbol{C}_{n} \boldsymbol{C}_{n}^{\dagger}$, respectively. Then, the probability of mistaking $\boldsymbol{S}_{2, a}^{(\ell)}$ for $\boldsymbol{S}_{2, b}^{(\ell)}$ satisfies:

$$
\begin{aligned}
& \operatorname{Pr}\left(\boldsymbol{S}_{2, a}^{(\ell)} \rightarrow \boldsymbol{S}_{2, b}^{(\ell)}\right) \geq \mathrm{E}_{\boldsymbol{\theta}_{1}^{(\ell)}}\left\{Q\left(\sqrt{\Delta_{1}}\right)\right\} \\
& \Delta_{1} \triangleq \frac{2^{-1} \delta_{0} \hat{\sigma}_{\max } \sum_{n=1}^{N} \delta_{n}}{\zeta^{2} \lambda_{\min }\left(\boldsymbol{\theta}_{1}^{(\ell)}\right)+\left(1+\delta_{0}+\sum_{n=1}^{N} \delta_{n} \mu_{\min }^{(n)}\right) P^{-1}+P^{-2}} .
\end{aligned}
$$

Proof. See Appendix A.2.

First, we note that $\lambda_{\min }\left(\boldsymbol{\theta}_{1}^{(\ell)}\right)$ and $\mu_{\min }^{(n)}$ do not depend on $P$. Furthermore, we note that, for both the linear and sesquilinear cases, $\boldsymbol{C}_{n} \boldsymbol{\theta}_{1}^{(\ell)}$ is an $N$-dimensional vector, $n=1, \ldots, N$, cf. (4.7), (4.12). Hence, if for the proposed relaying scheme and for some $\boldsymbol{\theta}_{1}^{(\ell)}$, the matrices $\left\{\boldsymbol{C}_{n}\right\}_{n=1}^{N}$ are such that the vectors $\left\{\boldsymbol{C}_{n} \boldsymbol{\theta}_{1}^{(\ell)}\right\}_{n=1}^{N}$ are linearly independent, the matrix $\sum_{n=1}^{N} \frac{\alpha_{n} \delta_{n}}{M_{n}} \boldsymbol{C}_{n} \boldsymbol{\theta}_{1}^{(\ell)} \boldsymbol{\theta}_{1}^{(\ell)^{\dagger}} \boldsymbol{C}_{n}^{\dagger}$ is full rank and $\lambda_{\min }\left(\boldsymbol{\theta}_{1}^{(\ell)}\right)$ is strictly greater than zero. Using (4.23), it can be seen that, in that case, the denominator of the argument of the Gaussian $Q(\cdot)$ function becomes dominated by $\lambda_{\min }\left(\boldsymbol{\theta}_{1}^{(\ell)}\right)$ when the power $P$ is sufficiently large. Since $Q(x)>0, \forall x$, it follows that the expectation on the RHS of (4.23) is strictly greater than zero if there is at least one realization of $\boldsymbol{\theta}_{1}^{(\ell)}$ for which $\lambda_{\min }\left(\boldsymbol{\theta}_{1}^{(\ell)}\right)>0$. Hence, we have shown that in the presence of self-interference, the PEP is lower bounded by a strictly positive constant, which implies an error floor and a zero diversity gain. In Section 4.7, this observation will be confirmed by numerical simulations and in the next section, we will provide a methodology for eliminating this interference perfectly without invoking CSI. 


\subsection{Perfect Self-Interference cancellation}

We have shown that self-interference causes the SINR and the PEP to approach strictly positive constants as $P \rightarrow \infty$, thereby implying an error floor and zero diversity gain. Now, we show that the scheme proposed in Section 4.3 enables selfinterference to be cancelled perfectly, which maximizes the SINR and allows it to go to infinity and the PEP to go to zero as $P \rightarrow \infty$.

Theorem 2. The average SINR for each node is maximized when the spatial processing matrices in (4.5) at all the relays, $\left\{\boldsymbol{X}_{n}\right\}_{n=1}^{N}$, are skew-symmetric ${ }^{2}$.

Proof. To find $\left\{\boldsymbol{X}_{n}\right\}$ that maximize the SINR, we note that those matrices affect the SINR expression through the nonnegative constants $\left\{\alpha_{n}\right\}$ in the denominator on the RHS of (4.22), where $\left\{\alpha_{n}\right\}_{n=1}^{N}$ are defined in (4.20). Hence, the optimal choice of $\left\{\boldsymbol{X}_{n}\right\}$ is the one that renders $\alpha_{n}=0, \forall n$. From (4.20), it can be seen that this condition can be only satisfied when all the diagonal entries of $\boldsymbol{X}_{n}$ are zero, i.e., $x_{k k}^{(n)}=0$, and all the off-diagonal entries satisfy $x_{k l}^{(n)}=-x_{l k}^{(n)}$, that is, this condition is satisfied if and only if $\boldsymbol{X}_{n}=-\boldsymbol{X}_{n}^{T}$, which proves the theorem.

We have shown that choosing $\left\{\boldsymbol{X}_{n}\right\}_{n=1}^{N}$ to be skew-symmetric maximizes the SINR for all $P$. We now show that this choice eliminates self-interference perfectly. From (4.19) we note that the nonnegative constants $\left\{\alpha_{n}\right\}$ in (4.22) are in fact due to self-interference. Hence, enforcing $\left\{\alpha_{n}\right\}_{n=1}^{N}$ to be zero is, in effect, the same as eliminating self-interference perfectly. Before discussing other ramifications of choosing $\left\{\boldsymbol{X}_{n}\right\}_{n=1}^{N}$ to be skew-symmetric, we note that eliminating self-interference was made possible by the novel spatial processing proposed in Section 4.3, but could not be effected by previously proposed techniques which restrict the relay received signals to be processed in time only. To elaborate on this observation, we have the following corollary.

Corollary 1. Setting the spatial processing matrices, $\left\{\boldsymbol{X}_{n}\right\}_{n=1}^{N}$, to be skew-symmetric yields $\boldsymbol{h}_{1}=\mathbf{0}_{N}$, i.e., the equivalent channel of self-interference is the all-zero $N \times 1$ vector.

Proof. From (4.10) and (4.13) it can be seen that the equivalent channel for the selfinterference component is the vector $\boldsymbol{h}_{1}$. To prove the statement of the corollary, we

\footnotetext{
${ }^{2}$ Note that cancelling self-interference requires $\boldsymbol{X}_{n}, n=1, \ldots, N$, to be skew-symmetric, rather than skew-Hermitian.
} 
use $\gamma_{n}$ to denote the $n$-th entry of $\boldsymbol{h}_{1}$, i.e., $\gamma_{n} \triangleq \boldsymbol{f}_{n}^{T} \boldsymbol{X}_{n} \boldsymbol{f}_{n}$. But since $\gamma_{n}$ is a scalar, we must have $\gamma_{n}=\gamma_{n}^{T}=\boldsymbol{f}_{n}^{T} \boldsymbol{X}_{n}^{T} \boldsymbol{f}_{n}=-\boldsymbol{f}_{n}^{T} \boldsymbol{X}_{n} \boldsymbol{f}_{n}$, which, together with the definition of $\gamma_{n}$, establishes the claim of the corollary.

We have shown that $\left\{\boldsymbol{X}_{n}\right\}_{n=1}^{N}$ must be: 1) unitary for the equivalent channel vectors to be i.d. (cf. Section 4.3), and 2) skew-symmetric for self-interference to be perfectly eliminated (cf. Theorem 1 and Corollary 1). Combining these conditions yields:

Lemma 1. For the matrix $\boldsymbol{X}_{n} \in \mathbb{C}^{M_{n} \times M_{n}}$ to be unitary and skew-symmetric, the dimension $M_{n}$ must be even, $n=1, \ldots, N$.

Proof. To prove this lemma, we note that any skew-symmetric matrix $\boldsymbol{X}_{n} \in \mathbb{C}^{M_{n} \times M_{n}}$ satisfies $\left|\boldsymbol{X}_{n}\right|=(-1)^{M_{n}}\left|\boldsymbol{X}_{n}\right|$. This implies that when $M_{n}$ is odd $\left|\boldsymbol{X}_{n}\right|=0$. However, for $\boldsymbol{X}_{n}$ to be unitary, the absolute value of $\left|\boldsymbol{X}_{n}\right|$ is equal to one. Hence, we conclude that $M_{n}$ must be even in order to admit a matrix $\boldsymbol{X}_{n}$ that is both unitary and skew-symmetric.

Combining this lemma with Corollary 1 yields that the number of active antennas per relay, must be even to ensure that the equivalent channels are i.d. and that selfinterference is perfectly eliminated. The following theorem provides the construction that ensures that a square $\left\{\boldsymbol{X}_{n}\right\}$ with even dimension is both unitary and skewsymmetric.

Theorem 3. Let the eigendecomposition of the unitary matrix $\boldsymbol{X}_{n}$ be given by ${ }^{3} \boldsymbol{X}_{n}=$ $\boldsymbol{\Phi}_{n} \boldsymbol{\Lambda}_{n} \boldsymbol{\Phi}_{n}^{\dagger}$ where $\boldsymbol{\Lambda}_{n} \in \mathbb{C}^{2 K \times 2 K}$, is diagonal, and $\boldsymbol{\Phi}_{n} \in \mathbb{C}^{2 K \times 2 K}$ is unitary, for some integer $K$. Then, $\boldsymbol{X}_{n}$ is skew-symmetric if and only if the diagonal entries of $\boldsymbol{\Lambda}_{n}$ are pairwise antipodal and lie on the unit circle, i.e., these entries are given by $\pm e^{j \theta_{k}^{(n)}}$, $\theta_{k}^{(n)} \in[0,2 \pi), k=1, \ldots, K$, and the columns of $\boldsymbol{\Phi}_{n}$ are pairwise conjugates, i.e., $\boldsymbol{\Phi}_{n}$ is given by $\boldsymbol{\Phi}_{n}=\left[\boldsymbol{\phi}_{1}^{(n)}, \overline{\boldsymbol{\phi}}_{1}^{(n)}, \ldots, \boldsymbol{\phi}_{K}^{(n)}, \overline{\boldsymbol{\phi}}_{K}^{(n)}\right]$. Furthermore, such a unitary matrix $\boldsymbol{\Phi}_{n}$ can be constructed from an arbitrary real orthogonal matrix $\boldsymbol{Q}_{n}=\left[\boldsymbol{q}_{1}^{(n)}, \boldsymbol{q}_{2}^{(n)}, \ldots, \boldsymbol{q}_{2 K}^{(n)}\right] \in$ $\mathbb{R}^{2 K \times 2 K}$ using $\boldsymbol{\phi}_{k}^{(n)}=\frac{1}{\sqrt{2}}\left(\boldsymbol{q}_{2 k-1}^{(n)}+j \boldsymbol{q}_{2 k}^{(n)}\right), k=1, \ldots, K$.

Proof. See Appendix A.3.

The result reported in this theorem renders the construction of general unitary skew-symmetric spatial processing matrices straightforward. In the next section we

\footnotetext{
${ }^{3}$ This decomposition exists because $\boldsymbol{X}_{n}$ is unitary and hence normal [45].
} 
will investigate the effect of using such matrices on the PEP attained by the TWRN under consideration.

\subsection{Performance Analysis Under Perfect Self- Interference Cancellation}

\subsubsection{Asymptotically Optimal Channel-Unaware Symbol De- tection}

So far, it is shown that choosing $\left\{\boldsymbol{X}_{n}\right\}_{n=1}^{N}$ in (4.5) to be skew-symmetric when the number of active antennas at the relays is even leads to perfect self-interference cancellation. Hence, the received signal of node 1 in (4.10) can be expressed as

$$
\boldsymbol{y}_{1}^{(\ell)}=\sqrt{P_{2}} \boldsymbol{S}_{2}^{(\ell)} \boldsymbol{h}_{2}+\boldsymbol{w}_{1}^{(\ell)}
$$

Although (4.24) is valid only when self-interference is cancelled perfectly, it is sometimes used to approximate the received signal when self-interference is partially cancelled [2], [1]. This approximation maybe somewhat misleading. Indeed, Section 4.4 shows that residual self-interference can cause serious SINR and PEP degradation, and results in zero diversity and error floor.

To analyze performance when self-interference is cancelled perfectly, we use (4.1) and (4.9) to write $\boldsymbol{C}_{n} \boldsymbol{\theta}_{i}^{(\ell)}$, the $n$-th column of $\boldsymbol{S}_{i}^{(\ell)}$ (cf. (4.11)), as $\boldsymbol{U}_{i} \boldsymbol{C}_{n} \boldsymbol{\theta}_{i}^{(\ell-l)}$ [41], [1]. Hence, we have

$$
\boldsymbol{S}_{i}^{(\ell)}=\left[\begin{array}{lll}
\boldsymbol{U}_{i}^{(\ell)} \boldsymbol{C}_{1} \boldsymbol{\theta}_{i}^{(\ell-1)} & \ldots & \boldsymbol{U}_{i}^{(\ell)} \boldsymbol{C}_{N} \boldsymbol{\theta}_{i}^{(\ell-1)}
\end{array}\right]=\boldsymbol{U}_{i}^{(\ell)} \boldsymbol{S}_{i}^{(\ell-1)}
$$

Using this in (4.24), the received signal of node 1 during the $\ell$-th block can be represented as

$$
\boldsymbol{y}_{1}^{(\ell)}=\boldsymbol{U}_{2}^{(\ell)} \boldsymbol{y}_{1}^{(\ell-1)}+\boldsymbol{w}_{1}^{(\ell)}-\boldsymbol{U}_{2}^{(\ell)} \boldsymbol{w}_{1}^{(\ell-1)}
$$

For close to maximum likelihood (ML) detection, the distribution of $\boldsymbol{w}_{1}^{(\ell)}$ is assumed to be Gaussian (cf. Section 4.3), yielding the following ML detector [1,41]:

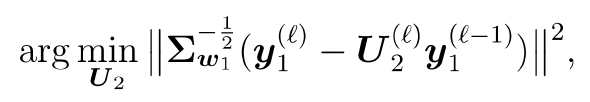


where $\boldsymbol{\Sigma}_{\boldsymbol{w}_{1}}$ is given in (4.15). The detector in (4.26) is channel-unaware because it is not a function of $\boldsymbol{f}_{n}$ and $\boldsymbol{g}_{n}$. An upper bound on the PEP achieved by this detector is derived next.

\subsubsection{An Upper Bound on the PEP}

The following theorem gives an upper bound on the PEP when self-interference is cancelled perfectly and the ML symbol detector (4.26) is used.

Theorem 4. When $\left\{\boldsymbol{X}_{n}\right\}_{n=1}^{N}$ are unitary skew-symmetric matrices, the high-power PEP satisfies

$$
\operatorname{Pr}\left(\boldsymbol{S}_{2, a}^{(\ell)} \rightarrow \boldsymbol{S}_{2, b}^{(\ell)}\right) \leq\left(P G_{c}\left(\boldsymbol{S}_{2, a}^{(\ell)}, \boldsymbol{S}_{2, b}^{(\ell)}\right)\right)^{-G_{d}}
$$

where $G_{d}$, the diversity gain, and $G_{c}$, the coding gain, are respectively given by

$$
\begin{gathered}
G_{d}=N \\
G_{c}\left(\boldsymbol{S}_{2, a}^{(\ell)}, \boldsymbol{S}_{2, b}^{(\ell)}\right)=\frac{\delta_{0}}{16}\left|\left(\boldsymbol{S}_{2, a}^{(\ell)}-\boldsymbol{S}_{2, b}^{(\ell)}\right)^{\dagger}\left(\boldsymbol{S}_{2, a}^{(\ell)}-\boldsymbol{S}_{2, b}^{(\ell)}\right)\right|^{\frac{1}{N}} g_{c}\left(M_{n}\right)^{-\frac{1}{N}} \\
g_{c}\left(M_{n}\right) \triangleq \frac{\left(1+\delta_{0}+N \sum_{n=1}^{N} \delta_{n}\right)^{N} \operatorname{Pr}\left(\left\|\boldsymbol{f}_{n}\right\|^{2} \leq M_{n}\right)}{\prod_{n=1}^{N} \delta_{n}} \\
+\frac{\left(1+\delta_{0}\right)^{N}+N^{N} \sum_{n=1}^{N}\left(\frac{\delta_{n}}{M_{n}}\right)^{N} \frac{\left(N+M_{n}-1\right) !}{\left(M_{n}-1\right) !}}{\prod_{n=1}^{N} \delta_{n}} \\
\times \operatorname{Pr}\left(\left\|\boldsymbol{f}_{n}\right\|^{2}>M_{n}\right)
\end{gathered}
$$

Proof. See Appendix A.4.

First, this theorem shows that the diversity gain characterizes the rate at which the PEP decays with $P$ and that the coding gain does not involve $P$. Hence, that slope of PEP, and subsequently the union bound is determined by $N$, the number of relays, and does not depend on the number of antennas at the relays, $\left\{M_{n}\right\}_{n=1}^{N}$. The reason for which the diversity gain is independent of the number of antennas at the relays is due to the fact that the diversity gain is determined by the number of linear transformations of the transmitted signals received at the destination. Using (4.11), it can be seen that, irrespective of the number of antennas, each relay generates one linear transformation of the transmitted signal at the destination node. That is, 
the proposed linear transformation at the relays results in each relay with multiple antennas generates only one column of the received matrix, leading to a diversity gain equal to the number of relays. Second, the coding gain increases with $M_{n}$ and converges to a constant at $M_{n} \rightarrow \infty$.

To elaborate, we show that $g_{c}\left(M_{n}+2\right)-g_{c}\left(M_{n}\right)$ is negative and converges to 0 at $M_{n} \rightarrow \infty$. For ease of exposition, we assume that all relays and both nodes use the same power, i.e., $\left\{\delta_{n}\right\}_{n=0}^{N}=1$, and that all relays have the same number of antennas, i.e., $M_{n}=M, \forall n$. Using these assumptions in (4.29) along with the fact that, for large $M, \frac{N^{N+1}(N+M+1) !}{(M+2)^{N}(M+1) !} \approx \frac{N^{N+1}(N+M-1) !}{M^{N}(M-1) !} \approx N^{N+1}$, yields $g_{c}(M+2)-g_{c}(M)=$ $\left(\left(2+N^{2}\right)^{N}-2^{N}-N^{N+1}\right)\left(\operatorname{Pr}\left(\left\|\boldsymbol{f}_{n}\right\|^{2} \leq M+2\right)-\operatorname{Pr}\left(\left\|\boldsymbol{f}_{n}\right\|^{2} \leq M\right)\right)$. Using the cumulative probability function (CDF) of $\left\|\boldsymbol{f}_{n}\right\|^{2}$ in (A.33) in Appendix A.4, it can be shown that, for large $M, \operatorname{Pr}\left(\left\|\boldsymbol{f}_{n}\right\|^{2} \leq M+2\right)-\operatorname{Pr}\left(\left\|\boldsymbol{f}_{n}\right\|^{2} \leq M\right) \nearrow 0$, i.e., for any large but finite $M, \operatorname{Pr}\left(\left\|\boldsymbol{f}_{n}\right\|^{2} \leq M+2\right)-\operatorname{Pr}\left(\left\|\boldsymbol{f}_{n}\right\|^{2} \leq M\right)<0$ and approaches 0 as $M \rightarrow \infty$. This confirms that $G_{c}$ increases with $M$ and converges to a constant as $M \rightarrow \infty$. Since high-power performance is dominated by the diversity gain [19], the aforementioned results yield that increasing the number of relays is more beneficial than increasing the number of antennas per relay.

Using (4.27), we obtain the union bound on the average block error rate (BLER) at high powers. To do so, let $P_{e}\left(\boldsymbol{S}_{2, a}^{(\ell)}\right)$ be the probability that node 2 sends the message $\boldsymbol{S}_{2, a}^{(\ell)}$ during the $\ell$-th block and node 1 makes an error in detecting it. A standard argument asserts that $P_{e}\left(\boldsymbol{S}_{2, a}^{(\ell)}\right) \leq \sum_{b=1, b \neq a}^{\Upsilon} \operatorname{Pr}\left(\boldsymbol{S}_{2, a}^{(\ell)} \rightarrow \boldsymbol{S}_{2, b}^{(\ell)}\right)$, where $\Upsilon$ denotes the cardinality of $\left\{\boldsymbol{S}_{2}^{(\ell)}\right\}$. For equi-probable messages, BLER $=\frac{1}{\Upsilon} \sum_{a=1}^{\Upsilon} P_{\mathrm{e}}\left(\boldsymbol{S}_{2, a}^{(\ell)}\right)$ and the bound on $P_{e}\left(\boldsymbol{S}_{2, a}^{(\ell)}\right)$ and (4.27) yield

$$
\mathrm{BLER} \leq \frac{1}{\Upsilon} P^{-G_{d}} \sum_{a=1}^{\Upsilon} \sum_{b=1, b \neq a}^{\Upsilon} G_{c}\left(\boldsymbol{S}_{2, a}^{(\ell)}, \boldsymbol{S}_{2, b}^{(\ell)}\right)^{-G_{d}}
$$

Although the union bound is commonly used in the literature [?,?,1], it is generally loose because of the Chernoff bound on the $Q(\cdot)$ function in the derivation of (4.27) and the number of terms in the summation [?]. Finding a tighter bound seems difficult, and even if such a bound were to be found, it may not yield insight into the key elements that govern performance. In contrast, examining the bound in (4.30) reveals that the terms in the summation do not depend on $P$, which implies that at high $P$, it will have approximately the same slope as the actual BLER, but with a gap that increases with $\Upsilon$. This observation will be confirmed in Section 4.7. 


\subsubsection{Computational Complexity Analysis}

Using (4.5), it can be seen that the complexity of the proposed signalling scheme is dominated by the multiplication of $\boldsymbol{C}_{n}, \boldsymbol{R}_{n}^{(\ell)}$ and $\boldsymbol{X}_{n}$. Hence the number of multiplications in this scheme is $\mathcal{O}\left(\sum_{n=1}^{N}\left(N^{2} M_{n}+N M_{n}^{2}\right)\right)$. However, Theorem 4 and the results in Section 4.7 below suggest choosing $M_{n}$ to be even and relatively small, e.g., $M_{n}=4$, $\forall n$. In this case, the number of multiplications of our scheme is $\mathcal{O}\left(4 N^{3}+16 N^{2}\right)$. In contrast, the scheme in [1] relies on blind channel estimation prior to interference cancellation. Hence in that scheme, processing at the relays, channel estimation and subsequent self-interference cancellation require $\mathcal{O}\left(N^{3}+L N^{2}\right)$ multiplications, where $L \geq 2 N$. Hence, the asymptotic computational complexity of both schemes grows cubically with $N$, but our scheme is able to cancel self-interference perfectly.

\subsection{Simulation}

In this section, we compare the performance of the scheme proposed herein with that of the one proposed in [1] for various DDST codes, including the (linear) $2 \times 2$ and $4 \times 4$ real orthogonal codes [?], [41] $]^{4}$ and the (sesquilinear) Alamouti [14,41], and $S P(2)[41,42]$ codes. For all examples, the skew-symmetric unitary matrices are chosen to be $\boldsymbol{X}_{n}=\bigoplus_{k=1}^{M_{n} / 2} \boldsymbol{J}$ (cf. (4.8)), the entries of $\left\{\boldsymbol{f}_{n}\right\},\left\{\boldsymbol{g}_{n}\right\},\left\{\boldsymbol{V}_{n}^{(\ell)}\right\}$ and $\left\{\boldsymbol{z}_{i}^{(\ell)}\right\}$ are zero mean Gaussian with unit variance. For ease of exposition, we will assume that both nodes and all relays use equal transmit powers, i.e., $\delta_{0}=\delta_{n}=1$, and equal number of antennas, i.e., $M_{n}=M, n=1, \ldots, N$, where $M$ is taken to be even, cf. Lemma 2. Without loss of generality, we will set the initialization vector $\boldsymbol{s}_{i}^{(0)}=\left[\begin{array}{lll}1 & \ldots & 1\end{array}\right]^{T}, i=1,2$, and for the examples with block fading channels, we will use the coherence time considered in [1], i.e., $T=100$.

\subsubsection{Block Error Rate Performance}

In this section we compare the BLER performance of the scheme proposed herein and the one proposed in [1] for various DDST codes. Example 1. In this example, we consider a TWRN with $N=2$ relays using the (linear) $2 \times 2$ real orthogonal code in [?], [41]. Using this code, the time domain relay matrices $\left\{\boldsymbol{C}_{n}\right\}$ in (4.7) are $\boldsymbol{C}_{1}=\boldsymbol{I}_{2}$

\footnotetext{
${ }^{4}$ We were unable to simulate the case with $8 \times 8$ real orthogonal codes because the relay matrices $\left\{\boldsymbol{A}_{n}\right\}$ and the corresponding unitary differential coding matrices $\left\{\boldsymbol{U}_{i}^{(\ell)}\right\}$ provided in [41] do not satisfy the commuting property in (4.9).
} 


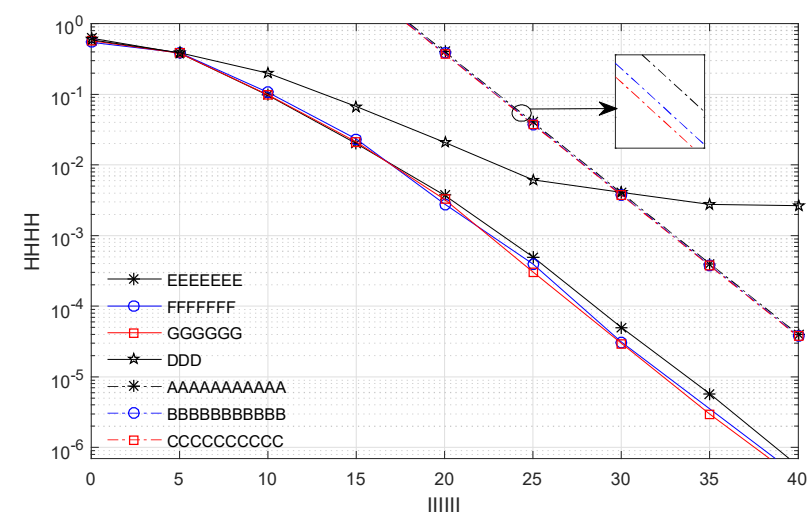

Figure 4.2: Performance of a TWRN with $N=2$ relays and $2 \times 2$ real orthogonal code.

and $\boldsymbol{C}_{2}=\boldsymbol{J}$, and the unitary matrices in (4.1) are $\boldsymbol{U}_{i}^{(\ell)}=\left[\begin{array}{cc}u_{1}^{(\ell)} & -u_{2}^{(\ell)} \\ u_{2}^{(\ell)} & u_{1}^{(\ell)}\end{array}\right]$, where $\left\{u_{r}^{(\ell)}\right\}$ is selected from the pulse amplitude modulation (PAM) constellation. Note that these matrices and the corresponding ones in the forthcoming examples satisfy the commuting property in (4.9). For this example, we use the 2-PAM constellation which results in an overall data rate of 1 bit per channel use (bpcu), i.e., 0.5 bpcu from node $i$ to node $j, i \neq j$.

For comparison, the BLER performance and the union bound (U. Bnd. in the figures) in (4.30) for the proposed DDST code are depicted in Figure 4.2 for the cases of $M=2,4$ and 6 antennas per relay. The high-power diversity gain of the proposed scheme can be deduced from Figure 4.2 by numerical evaluation of the gradient of the BLER curves. Taking the coordinates of two points in the high-power region of the curve, e.g., $\left(P_{a}, B L E R_{a}\right)$ and $\left(P_{b}, B L E R_{b}\right)$, the numerically evaluated diversity gain can be expressed as $\tilde{G}_{d}=\frac{\left.\log \left(B L E R_{a}\right)-\log \left(B L E R_{b}\right)\right)}{\log \left(P_{a}\right)-\log \left(P_{b}\right)}$. Performing this computation for the scenario in Figure 4.2 yields $\tilde{G}_{d}=1.95$, which is close to the diversity gain predicted by (4.28), namely, $G_{d}=2$. Note, that as predicted by (4.28), $G_{d}$ is determined by the numbers of relays, $N$, but not the number of antennas per relay, $M$, provided that $M \geq 2$. This is in contrast with the scheme in [1], whose performance is also depicted in Figure 4.2. In that scheme, each relay has one antenna, i.e., $M=1$, which prevents 


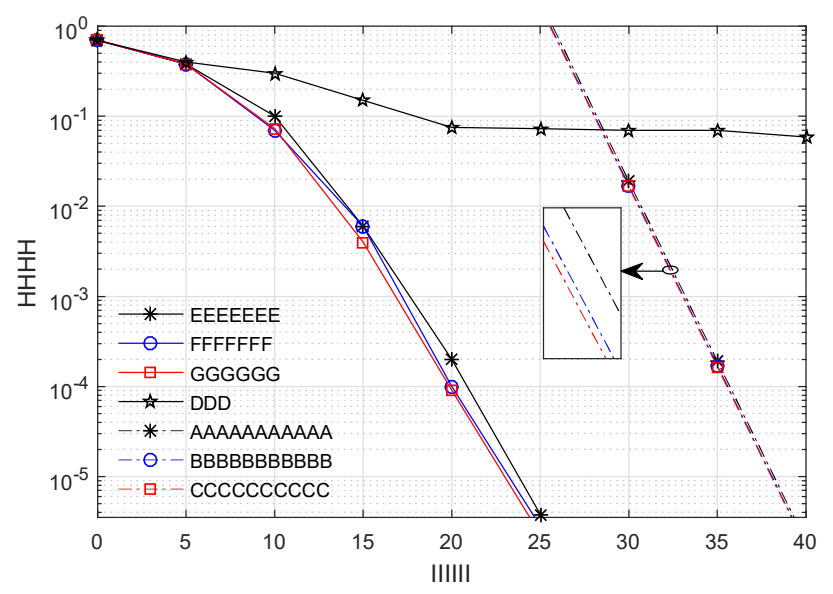

Figure 4.3: Performance of a TWRN with $N=4$ relays and $4 \times 4$ real orthogonal code.

the relays from spatial processing of their received signals and results in imperfect self-interference cancellation and zero high-power diversity order, cf. Theorem 1. Furthermore, Figure 4.2 confirms Theorem 4, which predicts that the coding gain in (4.29) increases and converges to a constant as $M$ increases, cf. zoomed bounds.

Example 2. The setup for this example resembles the one for Example 1 except with $N=4$ relays. The linearly-structured DDST code herein is the $4 \times 4$ real orthogonal code with the following time relay processing and constellation matrices [?], [41]: 


$$
\begin{aligned}
& \boldsymbol{A}_{1}=\boldsymbol{I}_{4}, \boldsymbol{A}_{2}=\bigoplus_{k=1}^{2} \boldsymbol{J}, \\
& \boldsymbol{A}_{3}=\left[\begin{array}{cccc}
0 & 0 & -1 & 0 \\
0 & 0 & 0 & 1 \\
1 & 0 & 0 & 0 \\
0 & -1 & 0 & 0
\end{array}\right], \boldsymbol{A}_{4}=\left[\begin{array}{cccc}
0 & 0 & 0 & -1 \\
0 & 0 & -1 & 0 \\
0 & 1 & 0 & 0 \\
1 & 0 & 0 & 0
\end{array}\right], \\
& \boldsymbol{U}_{i}^{(\ell)}=\left[\begin{array}{cccc}
{[r] u_{1}^{(\ell)}} & -u_{2}^{(\ell)} & -u_{3}^{(\ell)} & -u_{4}^{(\ell)} \\
u_{2}^{(\ell)} & u_{1}^{(\ell)} & u_{4}^{(\ell)} & -u_{3}^{(\ell)} \\
u_{3}^{(\ell)} & -u_{4}^{(\ell)} & u_{1}^{(\ell)} & u_{2}^{(\ell)} \\
u_{4}^{(\ell)} & u_{3}^{(\ell)} & -u_{2}^{(\ell)} & u_{1}^{(\ell)}
\end{array}\right]
\end{aligned}
$$

These matrices satisfy the commuting property in (4.9) and, in this example, the entries of $\left\{\boldsymbol{U}_{i}^{(\ell)}\right\},\left\{u_{r}^{(\ell)}\right\}$, are chosen from the 2-PAM constellation, yielding an overall rate of $1 \mathrm{bpcu}$.

The performance of the proposed scheme and the one in [1] are depicted in Figure 4.3. From this figure, the numerically evaluated diversity gain at moderate powers, e.g., $P=25 \mathrm{~dB}$, is $\tilde{G}_{d}=3.59$ while the analytically predicted diversity gain is $G_{d}=4$. This discrepancy is because, in Figure 4.3, $P$ is not sufficiently high for the diversity gain to dominate performance. Figure 4.3 also shows that the scheme in [1] does not have a diversity gain and produces an error floor at powers beyond $25 \mathrm{~dB}$. This figure, also shows that, similar to the case in Example 1, the coding gain converges to a constant, which agrees with the analytical results in Section 4.6.2.

Example 3. In this example, we consider a TWRN with $N=2$ relays using the (sesquilinear) DDST Alamouti code [14], [41]. For this code the matrices, $\left\{\boldsymbol{C}_{n}\right\}$ in (4.7), are constructed with $\boldsymbol{A}_{1}=\boldsymbol{I}_{2}, \boldsymbol{B}_{1}=\mathbf{0}, \boldsymbol{A}_{2}=\mathbf{0}$, and $\boldsymbol{B}_{2}=\boldsymbol{J}$, and the unitary differential encoding matrices are given by $\boldsymbol{U}_{i}^{(\ell)}=\frac{1}{\sqrt{\left|u_{1}^{(\ell)}\right|^{2}+\left|u_{2}^{(\ell)}\right|^{2}}}\left[\begin{array}{cc}u_{1}^{(\ell)} & -\bar{u}_{2}^{(\ell)} \\ u_{2}^{(\ell)} & \bar{u}_{1}^{(\ell)}\end{array}\right]$, where $u_{1}^{(\ell)}$ and $u_{2}^{(\ell)}$, are selected from any complex constellation, e.g., phase shift keying (PSK) and quadrature amplitude modulation (QAM) ones.

The signalling scheme proposed herein requires $3 N$ time slots, whereas, the scheme proposed in [1] requires $2 N$ times slots. Hence, for fair comparison, for the scheme 


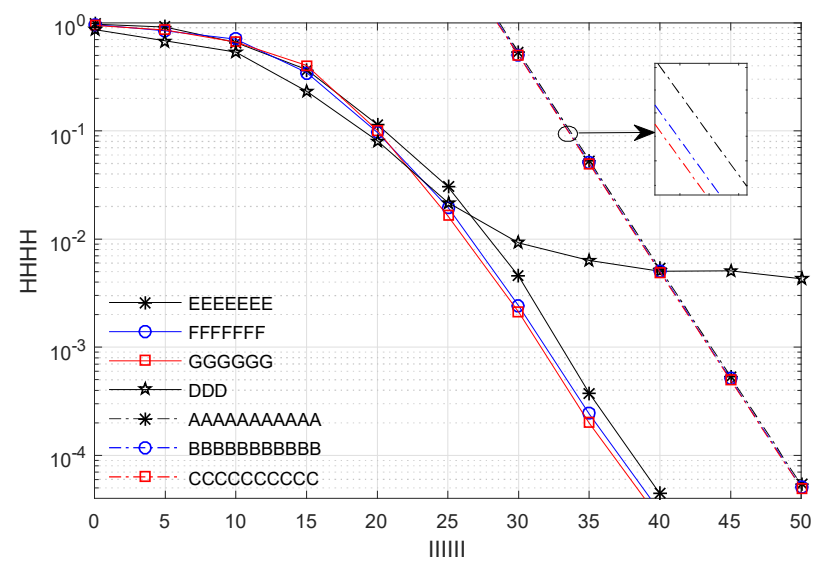

Figure 4.4: Performance of a TWRN with $N=2$ relays and $2 \times 2$ Alamouti code.

proposed herein we will choose $u_{1}^{(\ell)}$ and $u_{2}^{(\ell)}$ in $\boldsymbol{U}_{i}^{(\ell)}$ from the 8-PSK constellations and for the one proposed in [1], we will choose $u_{1}^{(\ell)}$ and $u_{2}^{(\ell)}$ in $\boldsymbol{U}_{i}^{(\ell)}$ from the 4-PSK constellations. These constellations ensure that both schemes operate at an overall data rate of 2 bpcu.

The performance of the proposed scheme and the one in [1] are shown in Figure 4.4. From this figure, it can be seen the scheme proposed in [1] exhibits better performance at low powers. For instance at a BLER of $10^{-1}$, the performance advantage of the scheme in [1] is about $1 \mathrm{~dB}$. However, at higher powers, the scheme proposed herein significantly outperforms the one in [1]. In particular, the BLER yielded by the scheme in [1] flattens out at $6 \times 10^{-3}$, whereas the BLER of our scheme continues to decay with $P$ with a diversity gain approximately equal to the number of relays, i.e., 2. Similar to the linear cases considered in Examples 1 and 2, increasing $M$ leads the coding gain to converge to a constant, as predicted in Section 4.4.2.

Example 4. The setup for this example resembles the one for Example 3 except with $N=4$ relays. In this case the sesquilinear code is $4 \times 4 S P(2)$ with the following time processing and constellation matrices [41], [42]: $\boldsymbol{A}_{1}=\boldsymbol{I}_{4}, \boldsymbol{B}_{1}=\boldsymbol{B}_{4}=\mathbf{0}$, 


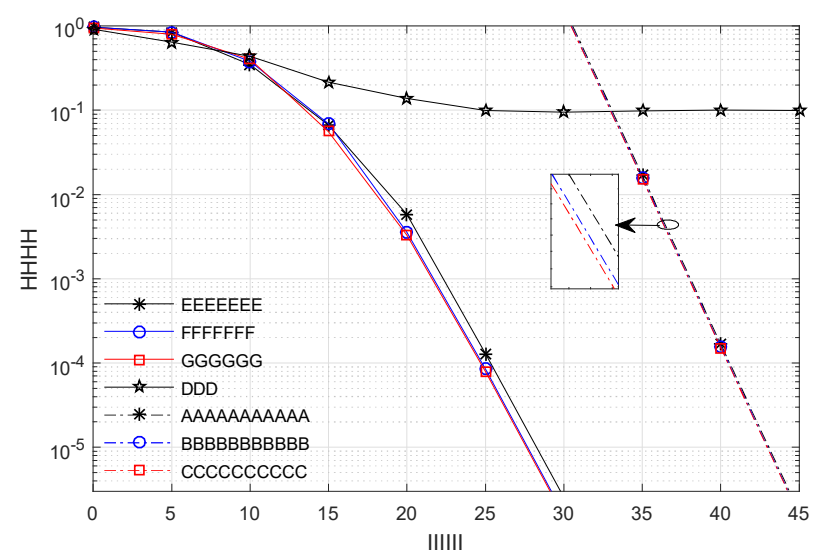

Figure 4.5: Performance of a TWRN with $N=4$ relays and $4 \times 4 S P(2)$ code

$$
\begin{aligned}
& \boldsymbol{A}_{2}=\boldsymbol{A}_{3}=\mathbf{0}, \boldsymbol{B}_{2}=\bigoplus_{k=1}^{2} \boldsymbol{J}, \\
& \boldsymbol{B}_{3}=\left[\begin{array}{cccc}
0 & 0 & -1 & 0 \\
0 & 0 & 0 & -1 \\
1 & 0 & 0 & 0 \\
0 & 1 & 0 & 0
\end{array}\right], \boldsymbol{A}_{4}=\left[\begin{array}{cccc}
0 & 0 & 0 & 1 \\
0 & 0 & -1 & 0 \\
0 & -1 & 0 & 0 \\
1 & 0 & 0 & 0
\end{array}\right], \\
& \boldsymbol{U}_{i}^{(\ell)}=\left[\begin{array}{cccc}
u_{1}^{(\ell)} & -\bar{u}_{2}^{(\ell)} & -\bar{u}_{3}^{(\ell)} & u_{4}^{(\ell)} \\
u_{2}^{(\ell)} & \bar{u}_{1}^{(\ell)} & -\bar{u}_{4}^{(\ell)} & -u_{3}^{(\ell)} \\
u_{3}^{(\ell)} & -\bar{u}_{4}^{(\ell)} & \bar{u}_{1}^{(\ell)} & -u_{2}^{(\ell)} \\
u_{4}^{(\ell)} & \bar{u}_{3}^{(\ell)} & \bar{u}_{2}^{(\ell)} & u_{1}^{(\ell)}
\end{array}\right] \text {. }
\end{aligned}
$$

These matrices satisfy the commuting property in (4.9) and, $u_{1}^{(\ell)}=$ $\frac{a_{1}^{(\ell)} a_{2}^{(\ell)}-b_{1}^{(\ell)} \bar{b}_{2}^{(\ell)}}{\sqrt{2} \prod_{k=1}^{2} \sqrt{\left|a_{k}^{(\ell)}\right|^{2}+\left|b_{k}^{(\ell)}\right|^{2}}}, u_{2}^{(\ell)}=-\frac{\bar{a}_{1}^{(\ell)} \bar{b}_{2}^{(\ell)}+\bar{b}_{1}^{(\ell)} a_{2}^{(\ell)}}{\sqrt{2} \prod_{k=1}^{2} \sqrt{\left|a_{k}^{(\ell)}\right|^{2}+\left|b_{k}^{(\ell)}\right|^{2}}}, u_{3}^{(\ell)}=-\frac{\bar{a}_{1}^{(\ell)} a_{2}^{(\ell)}-\bar{b}_{1}^{(\ell)} \bar{b}_{2}^{(\ell)}}{\sqrt{2} \prod_{k=1}^{2} \sqrt{\left|a_{k}^{(\ell)}\right|^{2}+\left|b_{k}^{(\ell)}\right|^{2}}}$, and $u_{4}^{(\ell)}=\frac{a_{1}^{(\ell)} \bar{b}_{2}^{(\ell)}+b_{1}^{(\ell)} a_{2}^{(\ell)}}{\sqrt{2} \prod_{k=1}^{2} \sqrt{\left|a_{k}^{(\ell)}\right|^{2}+\left|b_{k}^{(\ell)}\right|^{2}}}, a_{k}^{(\ell)} \in \mathbb{F}_{k}, b_{k}^{(\ell)} \in \mathbb{G}_{k}, k=1,2$, and $\mathbb{F}_{k}$ and $\mathbb{G}_{k}$ are PSK sets.

To obtain a rate for our scheme that is close to a rate supported by the scheme in [1], in our scheme, we choose $a_{1}^{(\ell)}$ and $b_{1}^{(\ell)}$ from the 5-PSK constellation and $a_{2}^{(\ell)}$ and $b_{2}^{(\ell)}$ from the 3-PSK constellation, yielding an overall data rate of $1.2925 \mathrm{bpcu}$. 
For the scheme in [1], $a_{1}^{(\ell)}$ and $b_{1}^{(\ell)}$ are chosen from the 2-PSK constellation and $a_{2}^{(\ell)}$ and $b_{2}^{(\ell)}$ are chosen from the 3-PSK constellations, yielding an overall data rate of $1.3023 \mathrm{bpcu}$.

In Figure 4.5, we depict the performance of the scheme proposed herein with the one in [1] along with the union bound in (4.30). As in the previous examples, Figure 4.5 confirms that the high-power diversity gain of the proposed scheme is $N=4$ and the coding gain converges to a constant with the increase of the number of relay antennas, $M$.

In the previous examples, the performance of the proposed scheme and the one in [1] were compared when both schemes used the same DDST code, i.e, the same number of relays. Since in the proposed scheme each relay uses an even number of antennas, whereas in the scheme in [1] each relay uses one antenna, the total number of antennas at the relays is not equal for the two schemes. Comparing the performance of these schemes when they use the same total number of relay antennas can be insightful. Such a comparison is provided in the next example.

Example 5. In this example, we compare the schemes proposed herein and in [1] when each uses a total of 4 antennas at the relays for both linear and sesquilinear codes. Since the proposed scheme uses an even number of antennas and [1] uses one antenna per relay, we consider two relays with two antennas each in the proposed scheme and four single-antenna relays in [1]. For $N=2$ relays, the proposed scheme uses the $2 \times 2$ real orthogonal and the Alamouti codes for the linear and sesquilinear codes, respectively. The corresponding codes for the scheme in [1] when $N=4$ relays are the $4 \times 4$ real orthogonal and the $S P(2)$ codes, respectively. For fair comparison, in the case of linear codes, we use 2-PAM constellation for both the $2 \times 2$ and $4 \times 4$ real orthogonal codes, resulting in an overall data rate of $1 \mathrm{bpcu}$. For sesquilinear codes, we use 4-PSK for the Alamouti code which results in a data rate of $1.33 \mathrm{bpcu}$ and we use 2-PSK for $a_{1}^{(\ell)}$ and $b_{1}^{(\ell)}$ and 3-PSK for $a_{2}^{(\ell)}$ and $b_{2}^{(\ell)}$ for the $S P(2)$ code which results in a data rate of 1.29 bpcu. Similar to the previous cases, Figure 4.6 confirms that perfect self-interference cancellation enables the proposed scheme to significantly outperform the one in [1].

In the previous examples, the channels were assumed to be block fading, whereby the fading coefficients remain constant throughout the coherence time $T$. However, in many scenarios, the channels undergo continuous temporal variations, which are usually captured by various statistical models including the Jakes' fading one [?]. In 


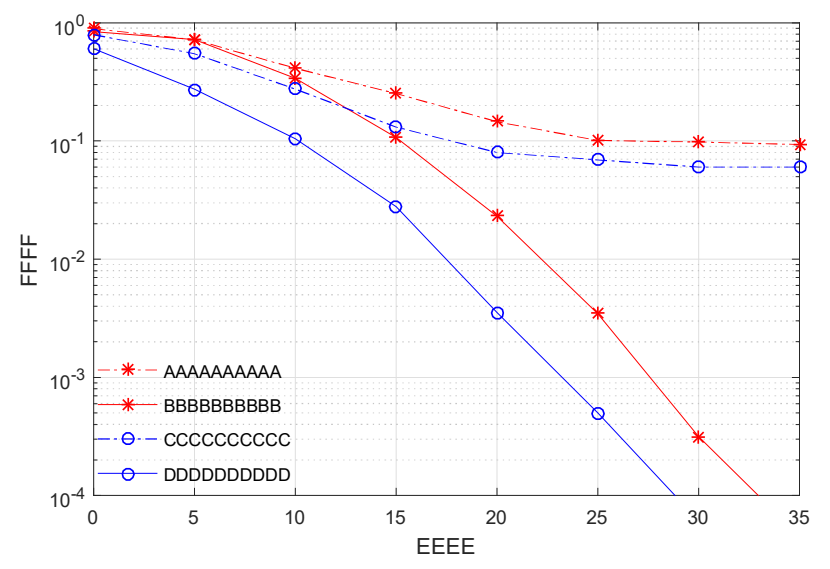

Figure 4.6: Performance comparison when the total number of relay antennas is equal to 4 .

this model the correlation parameters that characterize the channel variations depend on the mobility of the nodes and/or the relays. To elaborate, let $f[k]$ be a fading coefficient at time $k$. Then, in Jakes' model, the autocorrelation of this coefficient is $\mathrm{E}\left\{f[k] \bar{f}\left[k+k_{0}\right]\right\}=J_{0}\left(4 \pi k_{0} f_{d}\right)$, where $J_{0}(\cdot)$ is the zeroth-order Bessel function of the first kind, and $f_{d}$ is the maximum normalized Doppler frequency of the channel.

We now examine the scheme proposed herein and the one in [1] in Jake's fading channels.

Example 6. The set up in this example resembles the one in Example 4 but with Jakes' fading channels and $M=2$ antennas for each of the 4 relays. For simplicity, all channel coefficients are assumed to have the same $f_{d}$. The BLER performance comparison is provided in Figure 4.7 for $f_{d}=10^{-5}, 10^{-4}$ and $2 \times 10^{-4}$. From this figure, it can be seen that at $f_{d}=10^{-5}$, the BLER corresponding to scheme proposed herein continues to decay with $P$, whereas that corresponding to the scheme in [1] exhibits an error floor at $P=20 \mathrm{~dB}$. For instance, at $f_{d}=10^{-5}$ and $P=30 \mathrm{~dB}$, the scheme in [1] yields a BLER of $10^{-1}$, whereas our scheme yields a BLER of $10^{-6}$. Increasing $f_{d}$ to $10^{-4}$, the scheme proposed herein and the one in [1] begin to exhibit an error floor at about $P=35 \mathrm{~dB}$ and $P=20 \mathrm{~dB}$, respectively, but the scheme proposed herein exhibits a significantly lower BLER; $10^{-4}$ for our scheme versus $10^{-1}$ for the one in [1]. 


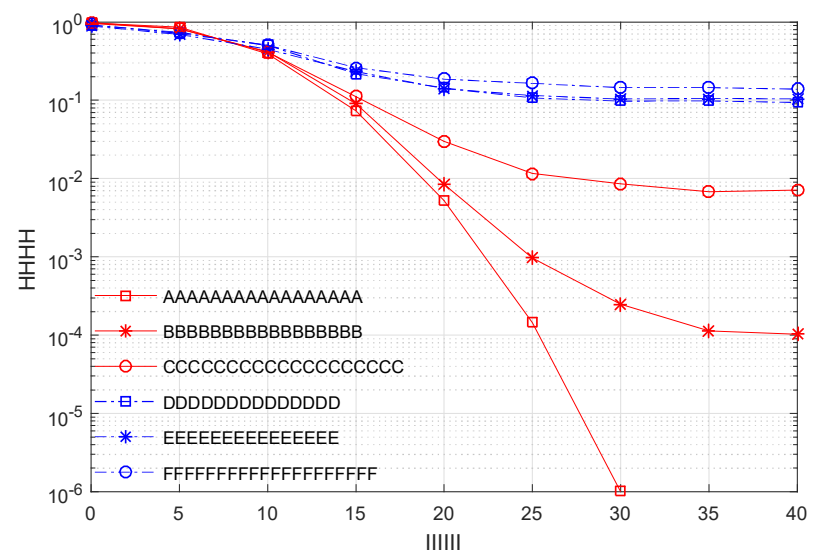

Figure 4.7: Jakes' fading channels with various $f_{d}$.

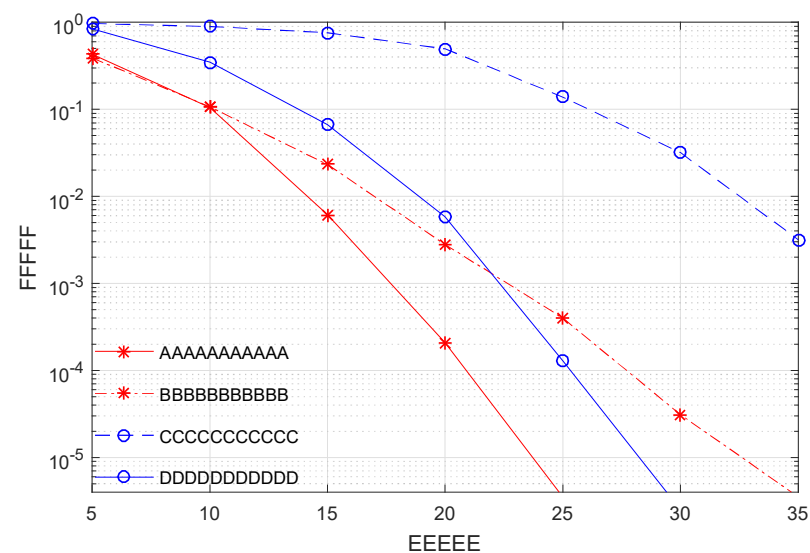

Figure 4.8: Effect of distributing antennas over more relays. 


\subsubsection{Effect of Number of Relays and Number of Antennas per Relay}

In Section 4.6.2 we showed that increasing the number of relays is more beneficial than increasing the number of antennas per relay. Herein, we further investigate this analytical finding. We consider a total of 8 antennas at the relays and two different cases. In the first case, we assume that there are $N=2$ relays, each with $M=4$ antennas, whereas in the second case we assume that there are $N=4$ relays, each with $M=2$ antennas. The BLERs corresponding to both cases for linear and sesquilinear codes are shown in Figure 4.8. From this figure it can be seen that, for both classes of codes, the setup with $N=4$ relays yields significantly lower BLERs. For instance, at a BLER of $10^{-4}$, the case with $N=4$ and sesquilinear codes has an advantage of $7 \mathrm{~dB}$ over its counterpart with $N=2$. This figure also shows that the rate of BLER decay is doubled when the number of relays is increased from $N=2$ to $N=4$. This confirms that the diversity gain depends only on the number of relays as predicted by Theorem 4 .

\subsubsection{SINR Performance}

In this section, we numerically evaluate the average SINR corresponding to the scheme proposed herein and the one proposed in [1] when both schemes use Alamouti code with the setup in Example 3. The simulation results are depicted in Figure 4.9. This figure shows that as $P$ increases, the perfect self-interference cancellation of the scheme proposed herein causes the SINR to exhibit linear unbounded increase. In contrast, imperfect cancellation of self-interference in the scheme in [1] causes the corresponding SINR to saturate. These numerical results conform to the analytical SINR expression in (4.22). Indeed, this expression predicts that perfect self-interference cancellation will yield $\left\{\alpha_{n}\right\}_{n=1}^{n=N}=0$, which further implies that the number of antennas per relay does not contribute to the SINR expression as confirmed in Figure 4.9.

\subsubsection{Rate Performance}

In Section 4.2, we showed that, for sesquilinear codes, the schemes proposed herein and in [1] consume $3 N$ and $2 N$ symbol durations, respectively. This difference induces 


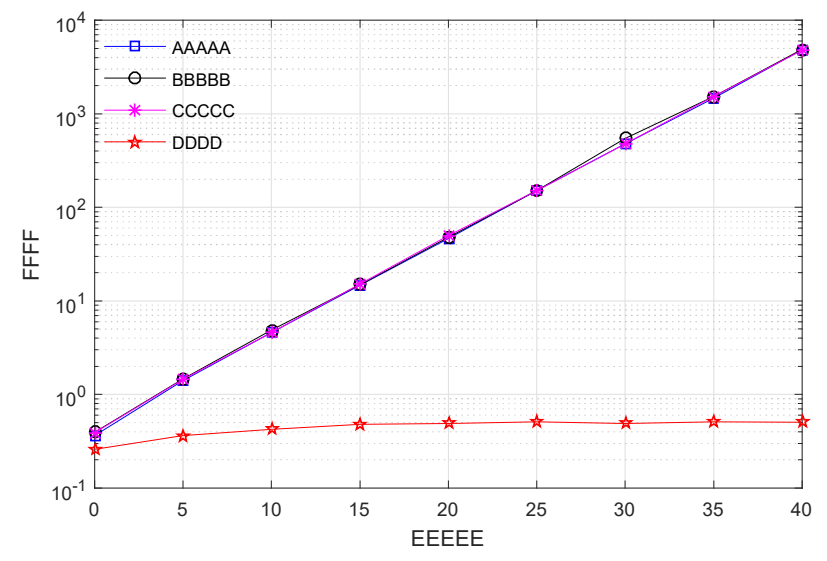

Figure 4.9: SINR performance.

a trade-off between the transmission rate per block and perfect self-interference cancellation $^{5}$. Hence, to operate at the same rate, if the cardinality of the constellation used in [1] is $\Lambda$, that of the constellation used in the scheme proposed herein must be $\Lambda^{3 / 2}$. To explore the trade-off invoked by this difference, we numerically evaluate the average BLER versus the transmission rate per block when both schemes use Alamouti code at $P=5$ and $P=30 \mathrm{~dB}$. This comparison is depicted in Figure 4.10, which shows that, at $P=5 \mathrm{~dB}$, the scheme in [1] performs slightly better. This is because, at low powers, the impact of self-interference is not large and the BLER is dominated by the constellation size. In contrast, at $P=30$, our proposed scheme exhibits better performance. This is because at high powers, if self-interference is not cancelled, its impact dominates the BLER.

\subsection{Summary}

The differences between the proposed scheme and the one in [1] are summarized in Table 4.1. The scheme proposed herein cancels the self-interference perfectly without estimating the channel whereas the scheme proposed in [1] uses blind estimates of the channel to cancel self-interference. Under the assumption that the channel can

\footnotetext{
${ }^{5}$ This trade-off does not exist in the case of linear codes, because in that case both schemes consume $2 N$ symbol durations.
} 


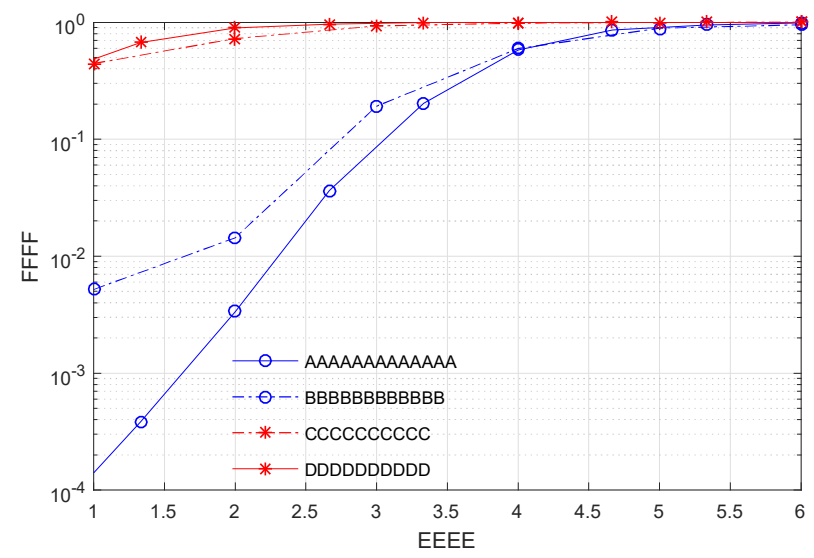

Figure 4.10: Rate performance.

be perfectly estimated, the analysis of the scheme in [1] shows that it achieves an asymptotic diversity gain equal to the number of relays. However, this assumption is particularly critical because acquiring accurate estimates require the channel to remain constant for a long time, which may not be the case in many practical scenarios. Theorem 1 herein asserts that imperfect estimation of the channel will result in residual self-interference, which will subsequently result in an error floor and a zero diversity.

\subsection{Conclusion}

In this chapter we proposed a novel signalling scheme for TWRNs in which two singleantenna nodes exchange information via multiple two-way relays, each with multiple antennas. Neither the relays nor the nodes have access to CSI. Unlike existing DDST methods, e.g., the scheme in [1], the novel signalling scheme proposed herein uses joint space-time processing of the relay received signals to eliminate self-interference perfectly at both nodes. We showed that perfect elimination of self-interference requires the space-domain relay processing matrices to be skew-symmetric and unitary, thereby implying that the number of active antennas at each relay must be even. Analyzing the effect of self-interference on the SINR and the PEP, we showed that, unless perfectly cancelled, residual self-interference will result in a zero diversity gain and an asymptotic error floor. Furthermore, we showed that using the scheme proposed herein enables a high-power diversity gain equal to the number of relays to be 


\begin{tabular}{|c|c|c|}
\hline & Scheme proposed in [1] & Scheme proposed herein \\
\hline $\begin{array}{c}\text { transmitted signal } \\
\text { at node } i\end{array}$ & $s_{i}^{(\ell)}$ & $\begin{array}{cc}\boldsymbol{s}_{i}^{(\ell)} & \text { linear codes } \\
{\left[\boldsymbol{s}_{i}^{(\ell)^{T}}, \overline{\boldsymbol{s}}_{i}^{(\ell)^{T}}\right]^{T}} & \text { sesquilinear codes }\end{array}$ \\
\hline $\begin{array}{c}\text { Block transmission } \\
\text { duration }\end{array}$ & $2 N$ & $\begin{array}{lc}2 N & \text { linear codes } \\
3 N & \text { sesquilinear codes }\end{array}$ \\
\hline $\begin{array}{c}\text { TWRN rate } \\
\Lambda: \text { constellation size }\end{array}$ & $\log _{2} \Lambda$ & $\begin{array}{cc}\log _{2} \Lambda & \text { linear codes } \\
\frac{2 \log _{2} \Lambda}{3} & \text { sesquilinear codes } \\
\end{array}$ \\
\hline Relay processing & $\begin{array}{c}\text { Time domain [1]: } \\
\boldsymbol{t}_{n}^{(\ell)}=\beta_{n}\left(\boldsymbol{A}_{n} \boldsymbol{r}_{n}^{(\ell)}+\boldsymbol{B}_{n} \overline{\boldsymbol{r}}_{n}^{(\ell)}\right)\end{array}$ & $\begin{array}{c}\text { Time-space domain (cf. (4.5)): } \\
\boldsymbol{T}_{n}^{(\ell)}=\beta_{n} \boldsymbol{C}_{n} \boldsymbol{R}_{n}^{(\ell)} \boldsymbol{X}_{n}\end{array}$ \\
\hline $\begin{array}{l}\text { Self-interference } \\
\text { cancellation }\end{array}$ & $\begin{array}{l}\text { Step 1: Blind channel estimation [1]: } \\
\qquad \boldsymbol{h}_{2}^{(\ell)}=\frac{\sum_{l=1}^{L} \boldsymbol{S}_{2}^{(\ell-l)^{\dagger}}}{N L \sqrt{P_{2}}} \\
\text { Step 2: non-perfect cancellation [1]: } \\
\hat{\boldsymbol{y}}_{2}^{(\ell)}=\boldsymbol{y}_{2}^{(\ell)}-\sqrt{P_{2}} \boldsymbol{S}_{2}^{(\ell)} \boldsymbol{h}_{2}^{(\ell)}\end{array}$ & $\begin{array}{c}\text { Perfect cancellation by } \\
\text { skew-symmetric } \boldsymbol{X}_{n}, \quad \forall n \\
\text { (cf. Section 4.5) }\end{array}$ \\
\hline $\begin{array}{l}\text { Diversity gain } \\
\text { at high powers }\end{array}$ & 0 (cf. Section 4.4.2) & $N($ cf. $(4.28))$ \\
\hline Complexity order & $\mathcal{O}\left(N^{3}\right)$ (cf. Section 4.6.3) & $\mathcal{O}\left(N^{3}\right)$ (cf. Section 4.6.3) \\
\hline SINR at $P \rightarrow \infty$ & A non-zero constant (cf. Section 4.4.1) & $\infty$ (cf. Section 4.4.1) \\
\hline
\end{tabular}

Table 4.1: Comparison of the scheme proposed herein and [1].

achieved, irrespective of the number of antennas per relay. Furthermore, we showed that the coding gain of the system increases and converges to a constant as the number of antennas per relay increases. 


\section{Chapter 5}

\section{TWRNs with Single-Antenna Relays}

\section{$5.1 \quad$ Introduction}

To the best of our knowledge, the scheme proposed in the previous chapter is to date the only available technique to cancel SI perfectly in channel-unaware TWRNs, however with the restriction of having an even number of antennas at each relay. To overcome this restriction, in this chapter, we seek to develop a new signalling scheme that enables SI to be perfectly cancelled in the absence of CSI when the relays have a single antenna each. This was not possible with previously proposed schemes, whether those that rely on statistical estimation, e.g., [2] and [1] or those that use multiple antennas at the relays proposed in Chapter 4. In the scheme proposed herein, the transmission strategy resembles that in [2]. More precisely, transmission begins with a four-phase OWRN-like IC to send reference vectors. Unlike [2], these vectors will not be used to estimate SI, but rather to enable nodes to cancel it directly. Upon IC completion, transmission is switched to two-phase TCs to exchange information between nodes. To assess performance, we derive an upper bound on the pairwise error probability (PEP), which is subsequently used to show that a diversity gain equal to the number of relays is achievable at high powers. This gain is equal to the diversity gain achieved by the scheme in Chapter 4, but without requiring the relays to have an even number of antennas each. The price for achieving this gain in the new scheme is the switching of modes from the four-phase IC to two-phase TCs. In contrast, this gain was achieved in Chapter 4 by using relays with multiple antennas and one and half the transmission time for DDST codes. Furthermore, comparing bounds on the PEP, we will show that the scheme proposed herein outperforms the one proposed in Chapter 4, even though both schemes perform perfect SI cancellation. In 
other words, the scheme proposed herein not only produces operational and temporal savings by virtue of the fact that it uses one antenna per relay and two thirds the signalling time for DDST codes, but also provides better performance. Next, we consider DDST with two special codes, viz., the Alamouti and $S P(2)$ codes. To capture the effect of the data rate on the system performance for these codes, we derive bounds on the PEP as a function of the transmission rate. Using these bounds, it will be shown that, for a fixed power, it is more beneficial to use the $S P(2)$ code for low transmission rates. However, for high transmission rates, the Alamouti code is more beneficial even though it uses half the number of relays.

In summary, the distinguishing features and contributions of the scheme proposed herein compared with existing literature including the scheme proposed in Chapter 4 are

- Perfect SI cancellation in TWRNs with single-antenna relays: in Chapter 4, it was shown that SI cannot be canceled perfectly in TWRNs with only two-way mode transmission unless each relay is equipped with an even number of antennas. In contrast, the scheme proposed herein uses mode-switching transmission to cancel SI completely in TWRNs with single-antenna relays. Mode-switching transmission is also used in [2], but in a fundamentally different form that results in error propagation; a drawback avoided by the scheme proposed herein.

- Less hardware: the scheme proposed herein uses the least number of antennas and hence, the least number of radio frequency (RF) chains. This results in reducing the implementation cost without compromising performance, as will be elaborated below.

- Superior performance: it is analytically and numerically shown that the scheme proposed herein outperforms the one proposed in Chapter 4 at any transmission rate. More precisely, using upper bounds on the average block error rate (BLER), we showed that the scheme proposed herein with single-antenna relays is more beneficial than using the scheme proposed in Chapter 4 with multiple-antenna relays, even though both schemes cancel SI perfectly.

- Lower latency: for transmitting $N$ symbols, the scheme proposed herein uses $2 N$ time slots whereas the one proposed in Chapter 4 uses $3 N$ time slots. Hence, the scheme proposed herein exhibits lower latency than the scheme in Chapter 4. 


\subsection{System Model}

We consider a scenario with two single-antenna nodes, node 1 and node 2 , and $N$ single-antenna AF HD relays [2]. The channel coefficients between node $i$ and relay $n$ are denoted by $f_{n}^{(i)}, i=1,2, n=1 \ldots, N$, which are assumed to be identically and independently distributed (i.i.d.) zero-mean unit-variance Gaussian random variables, giving rise to a standard Rayleigh fading model. No CSI is available at either the nodes or the relays, and the noises received by the nodes and the relays are i.i.d. zero-mean unit-variance Gaussian random variables.

The scheme proposed hereinafter requires the nodes to operate first in an OWRN mode followed by a TWRN one. The description of the latter subsumes that of the former. Hence, we will focus in this section on describing the TWRN mode with its two signalling phases.

Since in the considered TWRN no CSI is available, a convenient means for communication is the one offered by the DDST signalling scheme described in [2]. Using this scheme, the differentially coded signals are exchanged between nodes in two-phase TCs. In the first phase of any TC, the two nodes simultaneously send their signals to the relays in $N$ consecutive symbol durations. The relays process their received signals and in the second phase of the TC, they broadcast their signals in $N$ consecutive symbol durations. Hence, each TC contains $2 N$ symbol durations. It is assumed that during $L$ TCs, i.e., during $2 N L$ symbol durations, the channel coefficients remain constant. In particular, during the first phase of the $\ell$-th TC, node $i$ differentially encodes its message, $\boldsymbol{s}_{i}^{(\ell)} \in \mathbb{C}^{N \times 1}$, as follows [41]:

$$
\boldsymbol{s}_{i}^{(\ell)}=\boldsymbol{U}_{i}^{(\ell)} \boldsymbol{s}_{i}^{(\ell-1)}, \quad i=1,2, \quad \ell=2, \ldots, L
$$

where $\boldsymbol{U}_{i}^{(\ell)} \in \mathbb{C}^{N \times N}$ is a unitary matrix containing the new information symbols of node $i$ and its structure depends on the particular DDST code used in the network, e.g., Alamouti or $S P(2)$ [41]. Furthermore, $\boldsymbol{s}_{i}^{(1)}$ is an arbitrary initialization vector, which is not required to be known a priori. The vectors $\left\{\boldsymbol{s}_{i}^{(\ell)}\right\}$ are normalized so that $\mathrm{E}\left\{\boldsymbol{s}_{i}^{(\ell)} \boldsymbol{s}_{i}^{(\ell)^{\dagger}}\right\}=\boldsymbol{I}_{N}, \ell=1, \ldots, L$.

Using (5.1), the received signal of the $n$-th relay at the end of the first phase of the $\ell$-th TC is

$$
\boldsymbol{r}_{n}^{(\ell)}=\sqrt{P_{1}} f_{n}^{(1)} \boldsymbol{s}_{1}^{(\ell)}+\sqrt{P_{2}} f_{n}^{(2)} \boldsymbol{s}_{2}^{(\ell)}+\boldsymbol{z}_{n}^{(\ell)}, \quad n=1, \ldots, N, \quad \ell=1, \ldots, L,
$$


where $P_{i}$ is the average transmit power of the $i$-th node, $i=1,2$, and $\boldsymbol{z}_{n}^{(\ell)}$ is the $N \times 1$ noise vector at the $n$-th relay. The $n$-th relay linearly processes its received signal, $\boldsymbol{r}_{n}^{(\ell)}$, and its complex conjugate, $\overline{\boldsymbol{r}}_{n}^{(\ell)}$, to generate the signal $\boldsymbol{t}_{n}^{(\ell)} \in \mathbb{C}^{N \times 1}$ which is given by

$$
\boldsymbol{t}_{n}^{(\ell)}=\beta_{n}\left(\boldsymbol{A}_{n} \boldsymbol{r}_{n}^{(\ell)}+\boldsymbol{B}_{n} \overline{\boldsymbol{r}}_{n}^{(\ell)}\right), \quad n=1, \ldots, N, \quad \ell=1, \ldots, L,
$$

where $\boldsymbol{A}_{n}$ and $\boldsymbol{B}_{n}$ are $N \times N$ relay processing matrices that depend on the DDST code used in the network [41]. To ensure that the average transmission power of relay $n$ is equal to a given power budget, $P_{r_{n}}$, i.e., $\mathrm{E}\left\{\boldsymbol{t}_{n}^{(\ell)^{\dagger}} \boldsymbol{t}_{n}^{(\ell)}\right\}=N P_{r_{n}}$, we have

$$
\beta_{n}=\sqrt{\frac{N P_{r_{n}}}{\left(P_{1}+P_{2}+1\right) \operatorname{Tr}\left\{\boldsymbol{A}_{n} \boldsymbol{A}_{n}^{\dagger}+\boldsymbol{B}_{n} \boldsymbol{B}_{n}^{\dagger}\right\}}}, \quad \text { and } \quad \operatorname{Tr}\left(\boldsymbol{A}_{n} \boldsymbol{A}_{n}^{\dagger}+\boldsymbol{B}_{n} \boldsymbol{B}_{n}^{\dagger}\right)=N \text {. }
$$

In addition, for the receiver to detect the signal in the $\ell$-th TC using the one received in the $(\ell-1)$-th TC, the matrices $\left\{\boldsymbol{A}_{n}\right\}$ and $\left\{\boldsymbol{B}_{n}\right\}$ must commute with the matrices $\left\{\boldsymbol{U}_{i}^{(\ell)}\right\}[41]$, i.e.,

$$
\boldsymbol{U}_{i}^{(\ell)} \boldsymbol{A}_{n}=\boldsymbol{A}_{n} \boldsymbol{U}_{i}^{(\ell)}, \text { and } \boldsymbol{U}_{i}^{(\ell)} \boldsymbol{B}_{n}=\boldsymbol{B}_{n} \overline{\boldsymbol{U}}_{i}^{(\ell)}, \quad i=1,2, n=1, \ldots, N, \ell=2, \ldots, L .
$$

During the second phase of the $\ell$-th TC, the relays broadcast their signals, $\left\{\boldsymbol{t}_{n}^{(\ell)}\right\}$, to the nodes. Hence, the signal received at node $i$ at the end of the $\ell$-th TC, $\boldsymbol{y}_{i}^{(\ell)}$, is given by

$$
\boldsymbol{y}_{i}^{(\ell)}=\sum_{n=1}^{N} f_{n}^{(i)} \boldsymbol{t}_{n}^{(\ell)}+\boldsymbol{v}_{i}^{(\ell)}, \quad i=1,2, \quad \ell=1, \ldots, L,
$$

where $\boldsymbol{v}_{i}^{(\ell)}$ is the $N \times 1$ noise vector of node $i$ at the $\ell$-th TC. Substituting for $\boldsymbol{t}_{n}^{(\ell)}$ from (5.3) in (5.6), the received signal $\boldsymbol{y}_{i}^{(\ell)}$ in (5.6) can be expressed as

$$
\begin{aligned}
\boldsymbol{y}_{i}^{(\ell)}= & \sqrt{P_{1}}\left(\sum_{n=1}^{N} \beta_{n} f_{n}^{(i)} f_{n}^{(1)} \boldsymbol{A}_{n}\right) \boldsymbol{s}_{1}^{(\ell)}+\sqrt{P_{1}}\left(\sum_{n=1}^{N} \beta_{n} f_{n}^{(i)} \bar{f}_{n}^{(1)} \boldsymbol{B}_{n}\right) \overline{\boldsymbol{s}}_{1}^{(\ell)} \\
& +\sqrt{P_{2}}\left(\sum_{n=1}^{N} \beta_{n} f_{n}^{(i)} f_{n}^{(2)} \boldsymbol{A}_{n}\right) \boldsymbol{s}_{2}^{(\ell)}+\sqrt{P_{2}}\left(\sum_{n=1}^{N} \beta_{n} f_{n}^{(i)} \bar{f}_{n}^{(2)} \boldsymbol{B}_{n}\right) \overline{\boldsymbol{s}}_{2}^{(\ell)} \\
& +\boldsymbol{w}_{i}^{(\ell)}, \quad i=1,2, \ell=1, \ldots, L
\end{aligned}
$$


where $\boldsymbol{w}_{i}^{(\ell)}$ is the equivalent noise observed at node $i$ at the $\ell$-th TC, and is given by

$$
\boldsymbol{w}_{i}^{(\ell)}=\sum_{n=1}^{N} \beta_{n} f_{n}^{(i)}\left(\boldsymbol{A}_{n} \boldsymbol{z}_{n}^{(\ell)}+\boldsymbol{B}_{n} \overline{\boldsymbol{z}}_{n}^{(\ell)}\right)+\boldsymbol{v}_{i}^{(\ell)}, \quad i=1,2, \quad \ell=1, \ldots, L .
$$

The first and second terms of the signal received by node 1 in (5.7), i.e., $\boldsymbol{y}_{1}^{(\ell)}$, contain the signal transmitted from the same node in the first phase, i.e., $\boldsymbol{s}_{1}^{(\ell)}$. Hence, these two terms contain the so-called SI components of the signal received by node 1 . In contrast, the third and fourth terms contain only $\boldsymbol{s}_{2}^{(\ell)}$, which is the desired signal transmitted from node 2 in the previous phase. Unless perfectly eliminated, the SI component has a severe effect on the performance of the TWRN. Hence, this component must be cancelled before detection of the desired signal.

So far, we have focused our description on the two-phase transmission scheme underlying TWRNs. However, this description can be readily extended to the four-phase transmission scheme underlying OWRNs. In the four-phase transmission scheme, the two nodes do not transmit their signals simultaneously, that is, during the transmission time of node 1 , node 2 is listening, and vice versa. Hence, when node 1 is transmitting in the OWRN mode, the signal received at the relays is given by (5.2) by replacing $\boldsymbol{s}_{2}^{(\ell)}$ with zero. In the next section, we will show how the four-phase transmission scheme that underlies the OWRN mode can be used in conjunction with the TWRN mode to cancel SI perfectly for single-antenna relay networks.

\subsection{A Novel Scheme for Perfect SI Cancellation}

We provide a novel perfect SI cancellation scheme, which uses a mode-switching philosophy that resembles the one in [2]. However, it diverges from it in the way the received signals are processed at the nodes. In particular, the approach in [2] does not cancel SI perfectly, whereas the one proposed herein does. We describe the IC and TC transmission phases. Then, we propose a novel pre-detection processing procedure which enables the nodes to cancel SI perfectly. 


\subsubsection{A Mode-Switching Transmission Scheme}

The mode-switching transmission scheme, originally proposed in [2], begins with a four-phase IC followed by two-phase TCs, as will be elaborated below for completeness.

\section{The Four-Phase IC}

In the IC, the nodes exchange the reference vectors in a four-phase OWRN-like scheme. We will provide the mathematical description for node 1 in the IC. The corresponding description for node 2 follows mutatis mutandis.

In the first phase of the IC, node 1 sends an arbitrary initialization vector, $\boldsymbol{s}_{1}^{(1)} \in$ $\mathbb{C}^{N \times 1}$, to the relays. Hence, using (5.2), the received signal at the $n$-th relay is given by

$$
\boldsymbol{r}_{n}^{(1)}=\sqrt{P_{1}} f_{n}^{(1)} \boldsymbol{s}_{1}^{(1)}+\boldsymbol{z}_{n}^{(1)}, \quad n=1, \ldots, N .
$$

Using (5.9) in (5.3) yields that the transmitted signal of the $n$-th relay in the second phase of IC is

$\boldsymbol{t}_{n}^{(1)}=\sqrt{P_{1}} \beta_{n}^{\prime} f_{n}^{(1)} \boldsymbol{A}_{n} \boldsymbol{s}_{1}^{(1)}+\sqrt{P_{1}} \beta_{n}^{\prime} \bar{f}_{n}^{(1)} \boldsymbol{B}_{n} \overline{\boldsymbol{s}}_{1}^{(1)}+\beta_{n}^{\prime} \boldsymbol{A}_{n} \boldsymbol{z}_{n}^{(1)}+\beta_{n}^{\prime} \boldsymbol{B}_{n} \overline{\boldsymbol{z}}_{n}^{(1)}, \quad n=1, \ldots, N$.

Using (5.6) and (5.10), the signal received by node 1 can be seen to be

$$
\boldsymbol{y}_{1}^{(1)}=\sqrt{P_{1}}\left(\sum_{n=1}^{N} \beta_{n}^{\prime} f_{n}^{(1)^{2}} \boldsymbol{A}_{n}\right) \boldsymbol{s}_{1}^{(1)}+\sqrt{P_{1}}\left(\sum_{n=1}^{N} \beta_{n}^{\prime}\left|f_{n}^{(1)}\right|^{2} \boldsymbol{B}_{n}\right) \overline{\boldsymbol{s}}_{1}^{(1)}+\boldsymbol{w}_{1}^{(1)},
$$

where the $N \times 1$ equivalent noise vector is $\boldsymbol{w}_{1}^{(1)}=\sum_{n=1}^{N} \beta_{n}^{\prime} f_{n}^{(1)}\left(\boldsymbol{A}_{n} \boldsymbol{z}_{n}^{(1)}+\boldsymbol{B}_{n} \overline{\boldsymbol{z}}_{n}^{(1)}\right)+$ $\boldsymbol{v}_{1}^{(1)}$, and $\beta_{n}^{\prime}$ is equal to $\beta_{n}$ in (5.4) with $P_{2}$ set to zero, i.e., $\beta_{n}^{\prime}=\sqrt{\frac{P_{r_{n}}}{P_{1}+1}}$.

Analogous to the first and second phases of the IC, in the third phase, node 2 sends $\boldsymbol{s}_{2}^{(2)} \in \mathbb{C}^{N \times 1}$ to the relays, and the relays receive $\left\{\boldsymbol{r}_{n}^{(2)}\right\}$ and broadcast $\left\{\boldsymbol{t}_{n}^{(2)}\right\}$. In the fourth phase, the signal received by node 2 is $\left\{\boldsymbol{y}_{2}^{(2)}\right\}$. The expressions for $\left\{\boldsymbol{r}_{n}^{(2)}\right\}$, $\left\{\boldsymbol{t}_{n}^{(2)}\right\}$ and $\left\{\boldsymbol{y}_{2}^{(2)}\right\}$ respectively follow (5.9), (5.10) and (5.11) mutatis mutandis.

\section{The Two-Phase TC}

Following the four-phase IC, the nodes exchange their information in two-phase TCs which was explained in Section 5.2. Hence, at the $\ell$-th TC, $\ell \geq 3(\ell=1,2$ are 
occupied by the IC), the signals received and broadcast by the $n$-th relay are given by (5.2) and (5.3), respectively, and the signal received at the nodes are given by (5.7).

\subsubsection{Proposed SI Cancellation Scheme}

In this section, we develop a novel pre-detection scheme to enable SI to be cancelled perfectly. In this scheme, node 1 uses the signal it received during the second phase of IC, $\boldsymbol{y}_{1}^{(1)}$, and node 2 uses the signal it received during the fourth phase of IC, $\boldsymbol{y}_{2}^{(2)}$, to cancel the SI signals in the following TCs. The mathematical description for SI cancellation at node 1 is provided and the corresponding description for node 2 follows mutatis mutandis.

In the $\ell$-th TC, $\ell \geq 3(\ell=1,2$ are occupied by the IC), node 1 uses its received signal in the second phase of the IC, i.e., $\boldsymbol{y}_{1}^{(1)}$ in (5.11), and its transmitted unitary matrices, i.e., $\boldsymbol{U}_{1}^{(\ell)}, \ell=3, \ldots, L$, in (5.1), to obtain the vector $\boldsymbol{\Phi}_{1}^{(\ell)} \boldsymbol{y}_{1}^{(1)}$, where $\boldsymbol{\Phi}_{1}^{(\ell)} \in$ $\mathbb{C}^{N \times N}$ is given by

$$
\boldsymbol{\Phi}_{1}^{(\ell)} \triangleq \prod_{k=3}^{\ell} \boldsymbol{U}_{1}^{(k)}, \quad \ell=3, \ldots, L .
$$

Using (5.1) and the commuting condition in (5.5), the vector $\boldsymbol{\Phi}_{1}^{(\ell)} \boldsymbol{y}_{1}^{(1)}$ can be expressed as

$$
\boldsymbol{\Phi}_{1}^{(\ell)} \boldsymbol{y}_{1}^{(1)}=\sqrt{P_{1}}\left(\sum_{n=1}^{N} \beta_{n}^{\prime} f_{n}^{(1)^{2}} \boldsymbol{A}_{n}\right) \boldsymbol{s}_{1}^{(\ell)}+\sqrt{P_{1}}\left(\sum_{n=1}^{N} \beta_{n}^{\prime}\left|f_{n}^{(1)}\right|^{2} \boldsymbol{B}_{n}\right) \overline{\boldsymbol{s}}_{1}^{(1)}+\boldsymbol{\Phi}_{1}^{(\ell)} \boldsymbol{w}_{1}^{(1)} .
$$

Comparing (5.13) with (5.7) for $i=1$, it can be seen that $\boldsymbol{\Phi}_{1}^{(\ell)} \boldsymbol{y}_{1}^{(1)}$ contains only the SI component observed by node 1 in (5.7) during the $\ell$-th TC in addition to an equivalent noise component. Subtracting (5.13) from (5.7) yields an SI-free signal at node 1 , which we denote by $\hat{\boldsymbol{y}}_{1}^{(\ell)}$, where

$$
\begin{aligned}
\hat{\boldsymbol{y}}_{1}^{(\ell)} & =\boldsymbol{y}_{1}^{(\ell)}-\sqrt{\frac{P_{1}+1}{P_{1}+P_{2}+1}} \boldsymbol{\Phi}_{1}^{(\ell)} \boldsymbol{y}_{1}^{(1)} \\
& =\sqrt{P_{2}}\left(\sum_{n=1}^{N} \beta_{n} f_{n}^{(1)} f_{n}^{(2)} \boldsymbol{A}_{n}\right) \boldsymbol{s}_{2}^{(\ell)}+\sqrt{P_{2}}\left(\sum_{n=1}^{N} \beta_{n} f_{n}^{(1)} \bar{f}_{n}^{(2)} \boldsymbol{B}_{n}\right) \overline{\boldsymbol{s}}_{2}^{(\ell)}+\hat{\boldsymbol{w}}_{1}^{(\ell)}
\end{aligned}
$$

where

$$
\hat{\boldsymbol{w}}_{1}^{(\ell)}=\boldsymbol{w}_{1}^{(\ell)}-\sqrt{\frac{P_{1}+1}{P_{1}+P_{2}+1}} \boldsymbol{\Phi}_{1}^{(\ell)} \boldsymbol{w}_{1}^{(1)}
$$


is the equivalent noise at node 1. From (5.14), it can be seen that the proposed pre-detection scheme ensures perfect SI cancellation. We note that, even though the scheme in [2] switches the transmission mode from OWRN to TWRN, it uses this switching to compute noise estimates and uses them for SI cancellation. The nodes subsequently use their decisions on previously detected symbols to detect currently received ones, which renders the scheme in [2] prone to error propagation. In contrast with [2], in the current work, the signals received at the nodes during the IC are used to cancel SI perfectly in all subsequent TCs without estimating neither the noise nor SI. As such, the proposed scheme prevents the error propagation to occur. From (5.15), it can be seen that the advantage of our scheme comes at the cost of adding the variance of the noise observed in the IC to the variance of the noise observed in each TC. In spite of increasing the noise variance, we will show that the scheme proposed herein outperforms the schemes proposed in Chapter 4 and [2].

Using (5.1), and the commuting condition in (5.5), the SI-free signal in (5.14) can be expressed as

$\hat{\boldsymbol{y}}_{1}^{(\ell)}=\boldsymbol{U}_{2}^{(\ell)}\left(\sqrt{P_{2}}\left(\sum_{n=1}^{N} \beta_{n} f_{n}^{(1)} f_{n}^{(2)} \boldsymbol{A}_{n}\right) \boldsymbol{s}_{2}^{(\ell-1)}+\sqrt{P_{2}}\left(\sum_{n=1}^{N} \beta_{n} f_{n}^{(1)} \bar{f}_{n}^{(2)} \boldsymbol{B}_{n}\right) \overline{\boldsymbol{s}}_{2}^{(\ell-1)}\right)+\hat{\boldsymbol{w}}_{1}^{(\ell)}$,

which can be expressed as

$$
\begin{aligned}
\hat{\boldsymbol{y}}_{1}^{(\ell)} & =\boldsymbol{U}_{2}^{(\ell)}\left(\hat{\boldsymbol{y}}_{1}^{(\ell-1)}-\hat{\boldsymbol{w}}_{1}^{(\ell-1)}\right)+\hat{\boldsymbol{w}}_{1}^{(\ell)}, \\
& =\boldsymbol{U}_{2}^{(\ell)} \hat{\boldsymbol{y}}_{1}^{(\ell-1)}+\boldsymbol{\eta}_{1}^{(\ell)}, \quad \ell=3, \ldots, L,
\end{aligned}
$$

where

$$
\boldsymbol{\eta}_{1}^{(\ell)} \triangleq \hat{\boldsymbol{w}}_{1}^{(\ell)}-\boldsymbol{U}_{2}^{(\ell)} \hat{\boldsymbol{w}}_{1}^{(\ell-1)}, \quad \ell=3, \ldots, L
$$

Using (5.8) along with the fact that the channel coefficients, $\left\{f_{n}^{(i)}\right\}_{n=1}^{N}, i=1,2$, and the entries of the noise vectors, $\left\{\boldsymbol{z}_{n}^{(\ell)}\right\}_{n=1}^{N}$ are Gaussian independent random variables, it can be seen that the equivalent noise, $\boldsymbol{w}_{1}^{(\ell)}$, and subsequently $\hat{\boldsymbol{w}}_{1}^{(\ell)}$ and $\boldsymbol{\eta}_{1}^{(\ell)}$ are zero-mean but not Gaussian. However, to simplify exposition and to draw insight into the performance of the novel scheme, we will assume that all noise processes, i.e., $\boldsymbol{w}_{1}^{(\ell)}, \hat{\boldsymbol{w}}_{1}^{(\ell)}$ and $\boldsymbol{\eta}_{1}^{(\ell)}$, are Gaussian with covariance matrices $\boldsymbol{\Sigma}_{\boldsymbol{w}_{1}}, \boldsymbol{\Sigma}_{\hat{\boldsymbol{w}}_{1}}$ and $\boldsymbol{\Sigma}_{\boldsymbol{\eta}_{1}}$, respectively. (See Appendix A.5 for details of obtaining $\boldsymbol{\Sigma}_{\boldsymbol{w}_{1}}, \boldsymbol{\Sigma}_{\hat{\boldsymbol{w}}_{1}}$ and $\boldsymbol{\Sigma}_{\boldsymbol{\eta}_{1}}$.) With the Gaussian assumption on $\boldsymbol{\eta}_{1}^{(\ell)}$, the maximum likelihood (ML) detection rule becomes 
$\arg \min _{\boldsymbol{U}_{2}}\left\|\boldsymbol{\Sigma}_{\boldsymbol{\eta}_{1}}^{-\frac{1}{2}}\left(\hat{\boldsymbol{y}}_{1}^{(\ell)}-\sqrt{\frac{P_{1}+1}{P_{1}+P_{2}+1}} \boldsymbol{U}_{2}^{(\ell)} \hat{\boldsymbol{y}}_{1}^{(\ell-1)}\right)\right\|^{2}$ for the first TC, i.e., for $\ell=3$, whereas for subsequent TCs, i.e., for $\ell \geq 4$, it becomes

$$
\arg \min _{\boldsymbol{U}_{2}}\left\|\boldsymbol{\Sigma}_{\boldsymbol{\eta}_{1}}^{-\frac{1}{2}}\left(\hat{\boldsymbol{y}}_{1}^{(\ell)}-\boldsymbol{U}_{2}^{(\ell)} \hat{\boldsymbol{y}}_{1}^{(\ell-1)}\right)\right\|^{2}
$$

Note that the time slots $\ell=1,2$ are used for transmitting the initialization vectors, which do not need to be detected.

The ML detection rule in (5.19) implies that, at the $\ell$-th TC, the transmitted information, $\boldsymbol{U}_{2}^{(\ell)}$, can be detected using the signal received at the $(\ell-1)$-th TC without requiring CSI, which is the main advantage of differential signalling and perfect SI cancellation.

In the next section, we analyze the performance of the proposed scheme.

\subsection{Performance Analysis}

To demonstrate the advantages of the scheme proposed herein, we now derive an upper bound on the PEP. Using this bound, we will show that this scheme achieves the same diversity gain as the one in Chapter 4 albeit with a smaller number of relay antennas. It is worth noting that, due to its perfect SI cancellation, the scheme in Chapter 4 yields the best performance known to date. In other words, both the scheme proposed herein and the one proposed in Chapter 4 cancel SI perfectly, but the one proposed herein does so with a smaller number of antennas per relay, achieves the same diversity gain and a better performance than the one in Chapter 4.

To facilitate the derivation of an upper bound on the PEP, we will assume that the equivalent noise, $\boldsymbol{\eta}_{1}^{(\ell)}$, defined in (5.18) has a Gaussian distribution with zero mean and the covariance $\boldsymbol{\Sigma}_{\boldsymbol{\eta}_{1}}$ given in (A.41) in Appendix A.5. The PEP upper bound is recorded in the following theorem.

Theorem 5. Let $\boldsymbol{\eta}_{1}$ be Gaussian distributed with zero mean and the covariance matrix $\Sigma_{\eta_{1}}$ given in (A.41). Let the minimum eigenvalue of the matrix $\Sigma_{\hat{\boldsymbol{y}}_{1}} \boldsymbol{\Omega}_{a b}^{(\ell)}$ be

$$
\lambda_{\min } \gg 4 \sigma_{1}
$$

Then, using the $M L$ symbol detector in (5.19), the PEP of detecting $\boldsymbol{U}_{2 b}^{(\ell)}$ at the first 
node when $\boldsymbol{U}_{2 a}^{(\ell)}$ was transmitted by the second node is given by

$$
\begin{aligned}
P E P & =\operatorname{Pr}\left(\boldsymbol{U}_{2 a}^{(\ell)} \rightarrow \boldsymbol{U}_{2 b}^{(\ell)}\right) \\
& \leq\left(4 \sigma_{1}\right)^{N}\left|\boldsymbol{\Omega}_{a b}^{(\ell)}\right|^{-1}\left|\boldsymbol{\Sigma}_{\hat{\boldsymbol{y}}_{1}}\right|^{-1},
\end{aligned}
$$

where $\boldsymbol{\Omega}_{a b}^{(\ell)}=\left(\boldsymbol{U}_{2 a}^{(\ell)}-\boldsymbol{U}_{2 b}^{(\ell)}\right)^{\dagger}\left(\boldsymbol{U}_{2 a}^{(\ell)}-\boldsymbol{U}_{2 b}^{(\ell)}\right), \boldsymbol{\Sigma}_{\hat{\boldsymbol{y}}_{1}}=\boldsymbol{\Sigma}_{\hat{\boldsymbol{w}}_{1}}+P_{2} \sum_{n=1}^{N} \beta_{n}^{2}\left(\boldsymbol{A}_{n} \boldsymbol{A}_{n}^{\dagger}+\boldsymbol{B}_{n} \boldsymbol{B}_{n}^{\dagger}\right)$, $\boldsymbol{\Sigma}_{\hat{\boldsymbol{w}}_{1}}$ is given in (A.40) and

$$
\sigma_{1}=2\left(1+\frac{P_{1}+1}{P_{1}+P_{2}+1}\right)\left(1+N \sum_{n=1}^{N} \beta_{n}^{2}\right) .
$$

Proof. See Appendix A.6.

Before discussing the tightness of the bound in Theorem 5, we note that the additional noise term in (5.15) contributes an additional term in the covariance. In particular, the first term of $\boldsymbol{\Sigma}_{\hat{\boldsymbol{w}}_{1}}$ is common between both the scheme proposed herein and the one proposed in Chapter 4, whereas the second term appears only for the scheme herein and is due to using the signals received in the IC to cancel SI in subsequent TCs.

To draw more insight into the performance of the system, we focus attention on the case when both nodes and all the relays have the same power budget, i.e., $P_{1}=P_{2}=P_{r_{n}}=P, \forall n$. We now consider the tightness of the bound in (5.21). This tightness depends on the tightness of three bounds:

1. the Chernoff bound on the $Q(\cdot)$ function, i.e., $Q(x) \leq e^{-\frac{x^{2}}{2}}$, which is asymptotically tight as $x \rightarrow \infty$. This corresponds to $P \rightarrow \infty$ in our case.

2. the asymptotic bound $\left|\boldsymbol{I}_{N}+\frac{1}{4 \sigma_{1}} \sum_{\hat{\boldsymbol{y}}_{1}} \boldsymbol{\Omega}_{a b}^{(\ell)}\right|^{-1} \leq\left|\frac{1}{4 \sigma_{1}} \Sigma_{\hat{\boldsymbol{y}}_{1}} \boldsymbol{\Omega}_{a b}^{(\ell)}\right|^{-1}$. Since $\Sigma_{\hat{\boldsymbol{y}}_{1}} \boldsymbol{\Omega}_{a b}^{(\ell)}$ is strictly positive definite, at high $P, \lambda_{\min } \gg 4 \sigma_{1}$ and this bound is also tight.

3. an upper bound on the noise covariance matrix, i.e., $\Sigma_{\boldsymbol{\eta}_{1}} \preceq 4\left(1+N \sum_{n=1}^{N} \beta_{n}^{2}\right) \boldsymbol{I}_{N}$. To obtain this bound, we used the fact that $\boldsymbol{A}_{n} \boldsymbol{A}_{n}^{\dagger}+\boldsymbol{B}_{n} \boldsymbol{B}_{n}^{\dagger} \preceq \operatorname{Tr}\left(\boldsymbol{A}_{n} \boldsymbol{A}_{n}^{\dagger}\right) \boldsymbol{I}_{N}$. This bound hold for general $\left\{\boldsymbol{A}_{n}\right\}$ and $\left\{\boldsymbol{B}_{n}\right\}$, but for the Alamouti and $S P(2)$ codes considered herein, $\boldsymbol{A}_{n} \boldsymbol{A}_{n}^{\dagger}+\boldsymbol{B}_{n} \boldsymbol{B}_{n}^{\dagger}=\boldsymbol{I}_{N}, \forall n$ which results in tighter upper bound on the PEP. In particular, for these two codes, $\sigma_{1}=2\left(1+\frac{P_{1}+1}{P_{1}+P_{2}+1}\right)(1+$ $\left.\sum_{n=1}^{N} \beta_{n}^{2}\right)$ instead of $\sigma_{1}$ given in (5.22), which yields a bound tighter than the one reported in Theorem 5 . 
From this discussion, it can be seen that, for the Alamouti and $S P(2)$ codes considered herein, the upper bound on the PEP given in (5.21) is asymptotically tight as $P \rightarrow \infty$.

Despite its relative tightness, the bound provided in Theorem 5 obscures the effect of the number of relays and the individual power budget available at the nodes and the relays. When $P_{1}=P_{2}=P_{r_{n}}=P, \forall n$, the upper bound in (5.21) can be simplified, provided that $P \gg \frac{3}{2}\left(1+\frac{2}{N^{2}}\right)$. For this case, Theorem 5 yields the following corollary.

Corollary 2. Using the bound given in (5.21), for $P \gg \frac{3}{2}\left(1+\frac{2}{N^{2}}\right)$, the PEP of detecting $\boldsymbol{U}_{2 b}^{(\ell)}$ at the first node when $\boldsymbol{U}_{2 a}^{(\ell)}$ was transmitted by the second node is given by

$$
P E P \leq\left(32+16 N^{2}\right)^{N} P^{-N}\left|\boldsymbol{\Omega}_{a b}^{(\ell)}\right|^{-1}\left|\sum_{n=1}^{N} \boldsymbol{A}_{n} \boldsymbol{A}_{n}^{\dagger}+\boldsymbol{B}_{n} \boldsymbol{B}_{n}^{\dagger}\right|^{-1}
$$

Proof. See Appendix A.7.

The upper bound on PEP in (5.23) implies that the achievable diversity gain, $G_{d}$, is equal to the number of relays, that is,

$$
G_{d}=N
$$

which is the same as the diversity gain achieved by the scheme proposed in Chapter 4 by using at least two antennas at each relay, whereas the scheme proposed herein uses only one. For the coding gain, $G_{c}$, the expression in (5.23) shows that

$$
G_{c}=\left(32+16 N^{2}\right)^{-1}\left|\boldsymbol{\Omega}_{a b}^{(\ell)}\right|^{\frac{1}{N}}\left|\sum_{n=1}^{N} \boldsymbol{A}_{n} \boldsymbol{A}_{n}^{\dagger}+\boldsymbol{B}_{n} \boldsymbol{B}_{n}^{\dagger}\right|^{\frac{1}{N}} .
$$

To proceed with analysis, we provide two comparisons. The first compares two instances of the scheme proposed herein (when two and four relays are used with the Alamouti and $S P(2)$ codes, respectively). Whereas the second compares the performance of the scheme proposed herein and the one proposed in Chapter 4 for each of the two codes. 


\subsubsection{Performance Comparison Between the Alamouti and $S P(2)$ Codes for the Proposed Scheme}

To draw further insight into the performance-rate trade-off of DDST systems using the Alamouti and $S P(2)$ codes $[1,2,41]$, we will use (5.21) to obtain new bounds which will show that neither code outperforms the other at all rates. In other words, these bounds reveal the potentially nonintuitive fact that increasing the number of relays and using $S P(2)$ code does not necessarily yield better performance than using fewer relays with the Alamouti code.

\section{The Alamouti Code}

In the Alamouti code, two distinct unitary information matrices transmitted from node $2, \boldsymbol{U}_{2 a}^{(\ell)}$ and $\boldsymbol{U}_{2 b}^{(\ell)}$, are given by:

$$
\boldsymbol{U}_{2 r}^{(\ell)}=\left[\begin{array}{cc}
u_{2 r, 1}^{(\ell)} & u_{2 r, 2}^{(\ell)} \\
-\bar{u}_{2 r, 2}^{(\ell)} & \bar{u}_{2 r, 1}^{(\ell)}
\end{array}\right], \quad r=a, b .
$$

In this case, the PEP-transmission rate trade-off is recorded in the following theorem.

Theorem 6. For the Alamouti signalling scheme described in (5.25) with a PSK constellation and a transmission rate of $R$ bits per channel use (bpcu), the PEP is upper bounded by

$$
P E P_{1} \leq \frac{\left(9(3+P)^{-1}\right)^{2}}{\sin ^{4}\left(\pi 2^{-R}\right)},
$$

provided that (5.20) is satisfied.

Proof. See Appendix A.8.

Note that the RHS of (5.26) does not depend on $a$ and $b$, and hence it constitutes a bound on the maximum PEP. Next, we will derive an analogous bound for the $S P(2)$ code.

The $S P(2)$ Code

This code was used in [41] for DDST signalling over four-relay networks. In this code, 
two distinct information matrices transmitted from node 2 are given by [42]:

$$
\boldsymbol{U}_{2 r}^{(\ell)}=\frac{1}{2}\left[\begin{array}{cc}
\boldsymbol{\Xi}_{2 r}^{(\ell)} \boldsymbol{\Psi}_{2 r}^{(\ell)} & \boldsymbol{\Xi}_{2 r(\ell)} \overline{\boldsymbol{\Psi}}_{2 r}^{(\ell)} \\
-\overline{\boldsymbol{\Xi}}_{2 r}^{(\ell)} \mathbf{\Psi}_{2 r}^{(\ell)} & \overline{\boldsymbol{\Xi}}_{2 r} r \overline{\mathbf{\Psi}}_{2 r}^{(\ell)}
\end{array}\right]
$$

where

$$
\boldsymbol{\Xi}_{2 r}^{(\ell)}=\left[\begin{array}{cc}
e^{\jmath \frac{2 \pi k_{2 r}^{(\ell)}}{M_{1}}} & e^{\frac{2 \pi l_{2 r}^{(\ell)}}{M_{1}}} \\
-e^{-\jmath \frac{2 \pi l_{2 r}^{(\ell)}}{M_{1}}} & e^{-\jmath \frac{2 \pi k_{2 r}^{(\ell)}}{M_{1}}}
\end{array}\right], \boldsymbol{\Psi}_{2 r}^{(\ell)}=\left[\begin{array}{cc}
e^{\frac{2 \pi m_{2 r}^{(\ell)}}{M_{2}}} & e^{\jmath \frac{2 \pi n_{2 r}^{(\ell)}}{M_{2}}} \\
-e^{-\jmath \frac{2 \pi n_{2 r}^{(\ell)}}{M_{2}}} & e^{-\frac{2 \pi m_{2 r}^{(\ell)}}{M_{2}}}
\end{array}\right], \quad r=a, b,
$$

where the integers $k_{2 r}^{(\ell)}, l_{2 r}^{(\ell)} \in\left\{0, \ldots, M_{1}-1\right\}$, the integers $m_{2 r}, n_{2 r} \in\left\{0, \ldots, M_{2}-1\right\}$, and the integers $M_{1}$ and $M_{2}$ denote the cardinality of two distinct PSK constellations. Choosing $M_{1}$ and $M_{2}$ to be odd and co-prime ensures that the $S P(2)$ code achieves maximal diversity [42]. Hence, $M_{1}$ and $M_{2}$ will be chosen as such throughout our analysis.

To derive an upper bound on the PEP for the $S P(2)$ code, we derive the following two lemmas for any two PSK constellations with co-prime cardinalities and a common constellation point.

Lemma 2. Let $M_{1}$ and $M_{2}$ be odd and co-prime integers, then for $k \in\left\{1, \ldots, M_{1}-1\right\}$ and $m \in\left\{1, \ldots, M_{2}-1\right\}$,

$$
\min _{k, m}\left|k M_{2}-m M_{1}\right|=1
$$

Proof. See Appendix A.9.

Bézout's identity shows that for integers $M_{1}$ and $M_{2}$ with greatest common divisor $d$ there are integers (positive or negative) $k$ and $m$ such that $k M_{2}+m M_{1}=d$. Therefore, Bézout's identity guarantees that for co-prime integers $M_{1}$ and $M_{2}$ where $d=1$ there are integers $k$ and $m$ such that $k M_{2}+m M_{1}=1$. Beyond the Bézout's identity, in Lemma 2, it is shown that for odd and co-prime integers $M_{1}$ and $M_{2}$ there are integers $k$ and $m$ such that $k \in\left\{1, \ldots, M_{1}-1\right\}$ and $m \in\left\{1, \ldots, M_{2}-1\right\}$ and $\min _{k, m}\left|k M_{2}-m M_{1}\right|=1$.

The bound provided by this lemma on $\left|k M_{2}-m M_{1}\right|$ will be used in conjunction with the following lemma to obtain a lower bound on the determinant $\left|\boldsymbol{\Omega}_{a b}^{(\ell)}\right|$ in (5.21).

Lemma 3. Let $M_{1}$ and $M_{2}$ be odd and co-prime, then for any integer $k \in\left\{1, \ldots, M_{1}-\right.$ $1\},\left|\sin \left(\frac{4 \pi k}{M_{1}}\right)\right|>\left|\sin \left(\frac{2 \pi}{M_{1} M_{2}}\right)\right|,\left|\sin \left(\frac{2 \pi k}{M_{1}}\right)\right|>\left|\sin \left(\frac{2 \pi}{M_{1} M_{2}}\right)\right|$ and $\left|\sin \left(\frac{2 \pi k}{M_{1}}\right)\right|>\left|\sin \left(\frac{\pi}{M_{1} M_{2}}\right)\right|$. 
Proof. See Appendix A.10.

Using Lemma 2 and Lemma 3, we now obtain new upper bounds on the PEP for the $S P(2)$ code. In particular, we have the following theorem.

Theorem 7. For the $S P(2)$ signalling scheme described in (5.27) with $M_{1}$ and $M_{2}$ co-prime, and a transmission rate of $R$ bpcu, the PEP is upper bounded by

$$
P E P_{2} \leq \frac{\left(27\left(\frac{9}{2}+2 P\right)^{-1}\right)^{4}}{\left(\sin ^{4}\left(\pi 2^{-2 R+1}\right) \pm 2 \sin ^{2}\left(\pi 2^{-2 R+1}\right) \sin ^{2}\left(\pi 2^{-2 R}\right)\right)^{2}}
$$

provided that (5.20) is satisfied and $\left(M_{1} M_{2}\right)^{-1} \rightarrow 0$. If, in addition, $M_{2} \gg \frac{1}{2}$, the PEP satisfies

$$
P E P_{2} \leq \frac{\left(27(9+4 P)^{-1}\right)^{4}}{\sin ^{8}\left(\pi 2^{-2 R}\right)}
$$

Proof. See Appendix A.11.

Analogous to the RHS of (5.26), the RHSs of (5.28) and (5.29) provide an upper bound on the maximum PEP of the $S P(2)$ code in terms of the transmission rate. In particular, the bounds in (5.26), (5.28) and (5.29) expose a fundamental rateperformance trade-off. Using these bounds, we will prove the following result.

Corollary 3. Let the RHS of (5.26) and (5.29) be denoted by $\delta_{1}$ and $\delta_{2}$, respectively. Then, for a fixed power $P$, there exists a rate $R_{0}$, such that

$$
\delta_{2}<\delta_{1}, \text { for } R<R_{0}, \quad \text { and } \quad \delta_{2}>\delta_{1} \text {, otherwise. }
$$

Proof. See Appendix A.12.

This corollary implies that, for a given transmit power $P$, the PEP bound corresponding to the $S P(2)$ code grows faster with the transmission rate, $R$, than its Alamouti counterpart. This suggests that, for a fixed $P$, it is more beneficial to use the $S P(2)$ code for transmitting lower rates. However, for higher rates, using the Alamouti code is more beneficial even though it uses two relays instead of the four used by the $S P(2)$ code.

To gain insight into this result, we note that, to operate at the same rate, the Alamouti code uses a constellation with cardinality $\Gamma$ while the $S P(2)$ code uses a 
constellation with cardinality $\Gamma^{2}$ (where $\Gamma=M^{2}$ for the Alamouti code when the underlying constellation is $M$-PSK and $\Gamma=\left(M_{1} M_{2}\right)^{2}$ for the $S P(2)$ code when the underlying constellations are $M_{1}$-PSK and $M_{2}$-PSK.). At low powers, the BLER is dominated by the constellation size rather than the diversity gain (i.e., the number of relays). That is, the Alamouti code outperforms the $S P(2)$ one at low rates. However, at high powers, the diversity gain dominates the BLER, that is, the $S P(2)$ code outperforms the Alamouti code. In other words, neither the Alamouti code using two relays nor the $S P(2)$ code using four relays has better performance at all rates. This analytical result is verified by the numerical results in Section 5.5.

\subsubsection{Performance Comparison Between the Scheme Pro- posed Herein and the One Proposed in Chapter 4}

Both the scheme proposed herein and the one proposed in Chapter 4 provide perfect SI cancellation. In this section, we compare the performance of these two schemes. To do so, we use the PEP upper bounds for the Alamouti and $S P(2)$ codes given in (5.26) and (5.29), respectively, to obtain the union bound on the average BLER. The results are recorded in the following corollary.

Corollary 4. Let the union bound corresponding to the Alamouti code in the scheme proposed herein and the scheme proposed in Chapter 4 be denoted by $\rho$ and $\hat{\rho}$, respectively. Similarly, let the union bound corresponding to the $S P(2)$ code in the scheme proposed herein and the scheme proposed in Chapter 4 be denoted by $\gamma$ and $\hat{\gamma}$, respectively. Then, for any fixed power, $P$, and any rate $R \gg 1.2925$ bpcu, we have

$$
\begin{aligned}
& \rho<\hat{\rho}, \quad \text { and } \\
& \gamma<\hat{\gamma} .
\end{aligned}
$$

Proof. See Appendix A.13.

The results obtained in this section suggest that, at any rate $R \gg 1.2925 \mathrm{bpcu}$, using the scheme proposed herein with single-antenna relays is more beneficial than using the scheme proposed in Chapter 4 with multiple-antenna relays, even though both schemes cancel SI perfectly. To see that this result agrees with intuition, we note that, at high signal to noise ratios, noise results in small perturbations around the transmitted constellation points, which causes performance to be dominated by the 
minimum distance between those points. From the analysis leading to Corollary 3 , it can be seen that our scheme doubles the noise variance, but uses a constellation with a cardinality equal to the square of the cubic root of that used in the scheme proposed in Chapter 4. For instance, denoting the constellation size by $\Lambda$, when $\Lambda=4$ for the scheme proposed herein, we have $\Lambda=8$ for the scheme proposed in Chapter 4 , whereas, when $\Lambda=64$ for the scheme proposed herein, we have $\Lambda=512$ for the scheme proposed in Chapter 4. This shows that increasing the constellation size for the scheme proposed herein results in a fast increase in the constellation size of the scheme proposed in Chapter 4. However, for the current scheme, the noise covariance matrix is only twice the corresponding matrix of the scheme proposed in Chapter 4. This interaction between the noise variance and the cardinality of the constellations underlying each scheme is captured by the union bound and verified by simulations in Section 5.5 below.

\subsection{Simulation}

In this section, the analytical findings obtained in Section 5.4 will be confirmed by numerical results. To do so, the performance of the scheme proposed herein and the one proposed in [3] will be compared when both of them use the Alamouti and $S P(2)$ codes. Moreover, using the scheme proposed herein, we will compare the performance of the Alamouti code and the $S P(2)$ code to confirm the performance-rate trade-off results derived in Section 5.4. Throughout, we assume Rayleigh block-fading channels with coherence time equals to 100 time slots $[1,3]$.

We note that, for transmitting $N$ symbols, the scheme proposed herein uses $2 N$ time slots while the one proposed in [3] uses $3 N$ time slots. Hence, for fair comparison, in the following examples, the cardinality of the PSK constellations will be chosen to ensure approximately the same overall transmission rates.

In the simulation of the scheme proposed herein, each node uses the signals received in the IC to cancel SI in subsequent TCs. More precisely, before detection, the first node in each TC cancels SI using (5.14), which results in the equivalent noise $\hat{\boldsymbol{w}}_{1}^{(\ell)}$ in (5.15). The increase of the noise power induced by subtracting two independent noises in (5.15) affects the ML decision at node 1, i.e., the addition of IC noise variance to the TC noise variance is accounted for in simulations.

Example 1. In this example, we examine the tightness of the PEP upper bound 




Figure 5.1: Average PEP and upper bound.

given in (5.21). To do so, the average of the actual PEP and the average of the upper bound on the PEP given in (5.21) are depicted in Figure 5.1 for the Alamouti and $S P(2)$ codes. For the Alamouti code, we use a QPSK constellation yielding an overall rate of $2 \mathrm{bpcu}$. For the $S P(2)$ code, we use 3 and 5-PSK constellations yielding an overall rate of $1.9534 \mathrm{bpcu}$. From this figure, it can be seen that, in agreement with the analytical findings, increasing the power reduces the gap between the actual PEP and its upper bound. For instance, For the Alamouti code, the gap is $7.5 \mathrm{~dB}$ at $\mathrm{BLER}=10^{-2}$ and reduces to $3 \mathrm{~dB}$ at $\mathrm{BLER}=10^{-4}$, and for the $S P(2)$ code, the gap is $8 \mathrm{~dB}$ at $\mathrm{BLER}=10^{-2}$ and reduces to $2 \mathrm{~dB}$ at $\mathrm{BLER}=10^{-4}$.

Example 2. In this example, we consider the performance of the Alamouti code when both the scheme proposed herein and the one proposed in [3] are used. Hence, in (5.3) we set

$$
\boldsymbol{A}_{1}=\boldsymbol{I}_{2}, \quad \boldsymbol{B}_{1}=\boldsymbol{A}_{2}=\mathbf{0}_{2 \times 2}, \quad \boldsymbol{B}_{2}=\boldsymbol{J}_{2},
$$

where $\boldsymbol{J}_{2}=\left[\begin{array}{cc}0 & -1 \\ 1 & 0\end{array}\right]$. The BLER corresponding to this signalling scheme is depicted in Figure 5.2 at different rates.

For the scheme proposed herein, we use 8 and 16-PSK constellations, yielding overall rates of 3 and $4 \mathrm{bpcu}$, respectively. However, for the scheme proposed in [3], we use 16, 64-PSK constellations yielding overall rates of 2.67 and $4 \mathrm{bpcu}$, respectively

From this figure it can be seen that the scheme proposed herein outperforms the scheme proposed in [3] at all rates, which confirms the analytical findings given in 


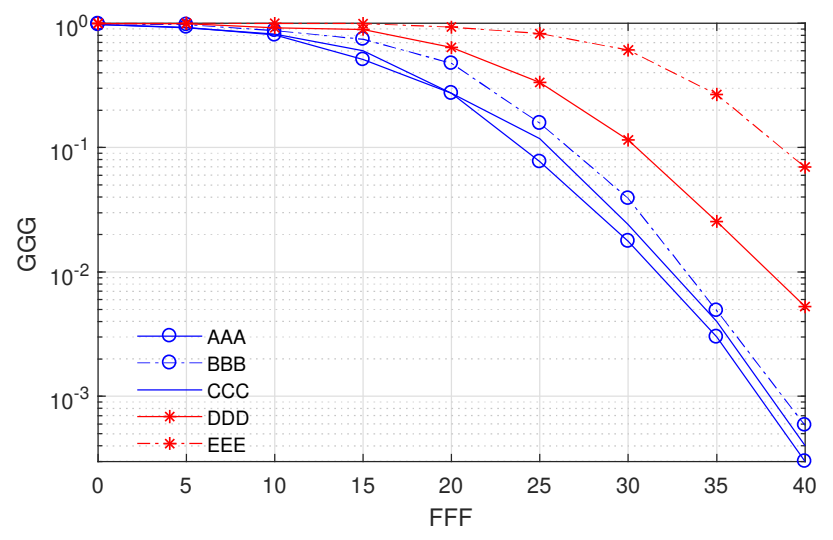

Figure 5.2: BLER vs. power for the Alamouti code.

Corollary 4. For instance at a BLER of $10^{-2}$, the proposed scheme exhibits a $2.5 \mathrm{~dB}$ advantage when the proposed scheme operates at a rate of $3 \mathrm{bpcu}$ whereas the scheme in [3] operates at a rate of $2.67 \mathrm{bpcu}$. Analogous gains are evident at other rates.

To confirm that the diversity gain suggested by the upper bound in (5.23) is indeed achieved by the proposed scheme, we consider the slopes of the BLER curves in Figure 5.2. From this figure, it can be seen that, at $P=40$ and $R=3 \mathrm{bpcu}$, the numerical diversity gain of the Alamouti code is 1.9498 which is close to the diversity gain predicted by the upper bounds on the PEP, namely, $G_{d}=2$, cf. (5.24). This figure also shows the performance of the proposed scheme when the symbols are drawn from an 8-QAM constellation, yielding an overall rate of $3 \mathrm{bpcu}$. This simulation confirms that the Alamouti code achieves full diversity when either PSK or QAM constellations are used in DDST signalling.

Example 3. In this example, we consider the performance of the $S P(2)$ code when both the scheme proposed herein and the one proposed in [3] are used. Hence, 
in (5.3) we set

$$
\begin{aligned}
& \boldsymbol{A}_{1}=\boldsymbol{I}_{4}, \boldsymbol{B}_{1}=\boldsymbol{A}_{2}=\boldsymbol{A}_{3}=\boldsymbol{B}_{4}=\mathbf{0}_{4 \times 4}, \\
& \boldsymbol{B}_{2}=\left[\begin{array}{cc}
\boldsymbol{0}_{2 \times 2} & \boldsymbol{J}_{2} \\
\boldsymbol{J}_{2} & \boldsymbol{0}_{2 \times 2}
\end{array}\right], \quad \boldsymbol{B}_{3}=\left[\begin{array}{cc}
\boldsymbol{0}_{2 \times 2} & -\boldsymbol{I}_{2} \\
\boldsymbol{I}_{2} & \boldsymbol{0}_{2 \times 2}
\end{array}\right], \\
& \boldsymbol{A}_{4}=\left[\begin{array}{cc}
\boldsymbol{0}_{2 \times 2} & -\boldsymbol{J}_{2} \\
\boldsymbol{J}_{2} & \boldsymbol{0}_{2 \times 2}
\end{array}\right],
\end{aligned}
$$

where $\boldsymbol{J}_{2}$ is given in (5.33). For the scheme proposed herein, we use 3 and 7-PSK constellations to yield an overall rate of $2.1961 \mathrm{bpcu}$, and 5 and 7-PSK constellations to yield an overall rate of $2.5646 \mathrm{bpcu}$. However, for the scheme proposed in [3], we use 7 and 9-PSK constellations to yield an overall rate of $1.9924 \mathrm{bpcu}$, and 13 and 15-PSK to yield and overall rate of $2.5358 \mathrm{bpcu}$.

The BLERs corresponding to these rates are depicted in Figure 5.3. From this figure it can be seen that, in agreement with the analytical findings in Corollary 4, the scheme proposed herein outperforms the scheme proposed in [3] at all rates. For instance, at a BLER of $10^{-2}$, the scheme proposed herein exhibits a $4.5 \mathrm{~dB}$ gain when the transmission rate is $2.5 \mathrm{bpcu}$. From Figure 5.3, the numerical diversity gain of the $S P(2)$ code is 3.9794 at $P=35$ and $R=1.95 \mathrm{bpcu}$ which is close to the diversity gain predicted by (5.24), viz., $G_{d}=4$. This figure also depicts the performance of the proposed scheme when the symbols are drawn from 4 and 8-QAM constellations, yielding an overall rate of $2.5 \mathrm{bpcu}$. From this figure, it can be seen that the $S P(2)$ code is not guaranteed to achieve full diversity unless its underlying constellations are co-prime PSKs [42].

The comparisons in the previous two examples focused on the BLER performance of the scheme proposed herein and the one proposed in [3] for both the Alamouti code and the $S P(2)$ one. These comparisons confirm the findings reported in Corollary 4, which establishes the superiority of the scheme proposed herein. In the next example, we further examine the behaviour of the scheme proposed herein by comparing its performance when the Alamouti and $S P(2)$ codes are used at different transmission rates.

Example 4 In this example, we begin by performing a numerical evaluation of 


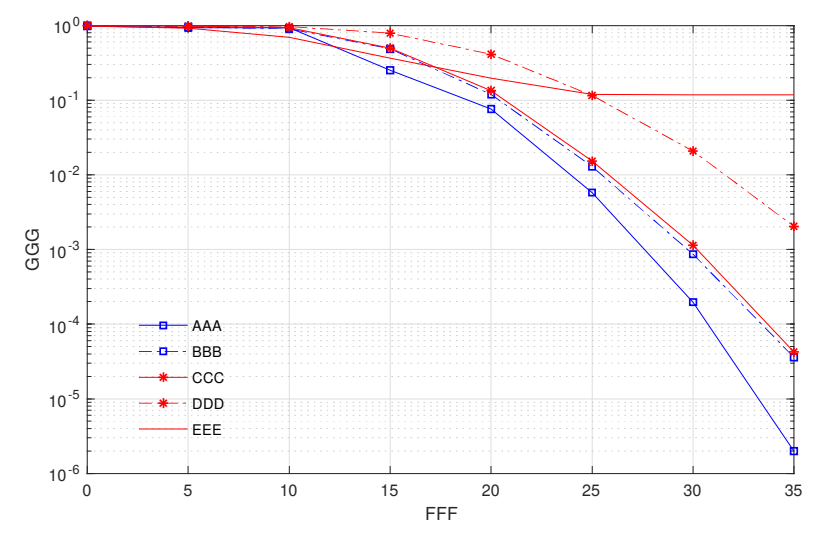

Figure 5.3: BLER vs. power for the $S P(2)$ code.

the PEP upper bound in (5.26) for the Alamouti code and the PEP upper bound in (5.29) for the $S P(2)$ code. These bounds are depicted in Figure 5.4 for $P=20,30$ and $40 \mathrm{~dB}$. From this figure it can be seen that, for a fixed $P$, the PEP upper bound on the $S P(2)$ code grows faster with the transmission rate, $R$, than its Alamouti counterpart. This is in line with the analytical results in Corollary 3 , which indicate that, at low rates, it is more beneficial to use the $S P(2)$ code, using four relays, but at higher rates, the Alamouti code, using two relays, yields better performance. To confirm the analytical findings, in Figure 5.5 we show the BLER simulation results of the two codes at different rates. The setups for the Alamouti and $S P(2)$ codes resemble the corresponding setups in Examples 2 and 3. However, for the $S P(2)$ code, we use 7 and 9-PSK constellations to obtain an overall rate of $2.9886 \mathrm{bpcu}$, and 13 and 19-PSK constellations to obtain an overall rate of 3.9742 bpcu. Figure 5.5 confirms the analytical results reported in Corollary 3 and illustrated in Figure 5.4. For instance, at $P=22 \mathrm{~dB}$ and a transmission rate of $2 \mathrm{bpcu}$, the $S P(2)$ code yields a BLER of $1 \times 10^{-2}$ whereas the Alamouti code yields a BLER of $4 \times 10^{-2}$. However, at a rate of $3 \mathrm{bpcu}$, both codes have the same BLER and at a the rate of $4 \mathrm{bpcu}$, the $S P(2)$ code yields a BLER of $6 \times 10^{-1}$ whereas the Alamouti code yields a BLER of $4 \times 10^{-1}$.

Example 5. This example provides a comparison between the scheme proposed herein, the one proposed in [2] and the one proposed in [3]. For the Alamouti code, both the scheme herein and the one in [2] use 4-PSK constellation yielding an overall 


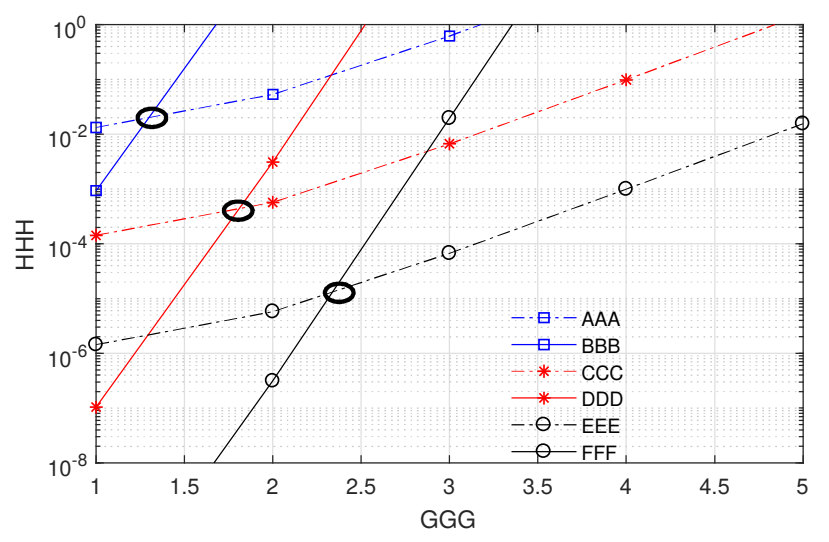

Figure 5.4: Numerical performance-rate trade-off comparison.



Figure 5.5: Performance-rate trade-off comparison. 
transmission rate of $R=2 \mathrm{bpcu}$. To have identical transmission rates, the scheme proposed in [3] uses 8-PSK constellation. For the $S P(2)$ code, both the scheme herein and the one in [2] use 3 and 5-PSK constellation yielding an overall transmission rate of $R=1.9534 \mathrm{bpcu}$. To have a transmission rate of $R=1.9271 \mathrm{bpcu}$, the scheme in [3] uses 5 and 11-PSK constellation.

The simulation results are given in Figure 5.6. From this figure, it can be seen that the scheme proposed herein outperforms the one proposed in [2] and the one proposed in [3] for both the Alamouti code and the $S P(2)$ code. For instance, in the case of using the Alamouti code, at a BLER of $2 \times 10^{-3}$, the proposed scheme yields a power gain of about $2 \mathrm{~dB}$ with respect to the scheme in [3] and a power gain of about $4.5 \mathrm{~dB}$ with respect to the scheme in [2]. This can be attributed to the fact that the scheme in [2] uses prior decisions to detect current symbols, which renders it prone to error propagation and error floor. Similar performance improvement can be seen in the case of using $S P(2)$ code in Figure 5.6. This figure also confirms the upper bounds given in Corollary 4 for the scheme proposed herein and the one proposed in [3]. We note that, at low powers, the impact of self-interference is not large and the BLER is dominated by the constellation size. Hence, the scheme proposed herein and the one proposed in [2] using the same constellation size have the same performance and outperform the scheme proposed in [3] using higher constellation size.

Furthermore, this figure shows that the scheme proposed in [2] and the one proposed in this chapter have the same performance at low powers. This is because, at low powers, the impact of SI is not large and BLER is dominated by the constellation size. Since, our proposed scheme and the one proposed in [2] use the same constellation at each rate, they have the same performance at low powers. In contrast, at high powers, the BLER performance is dominated by the diversity gain. The scheme proposed in [2] cannot cancel SI perfectly which yields zero diversity gain at high powers. Whereas, our proposed scheme cancels SI completely and consequently achieves a diversity gain equals to the number of relays at high power.

\subsection{Conclusion}

In this chapter we considered channel-unaware TWRNs in which two single-antenna nodes exchange information via multiple single-antenna relays. For these networks, 


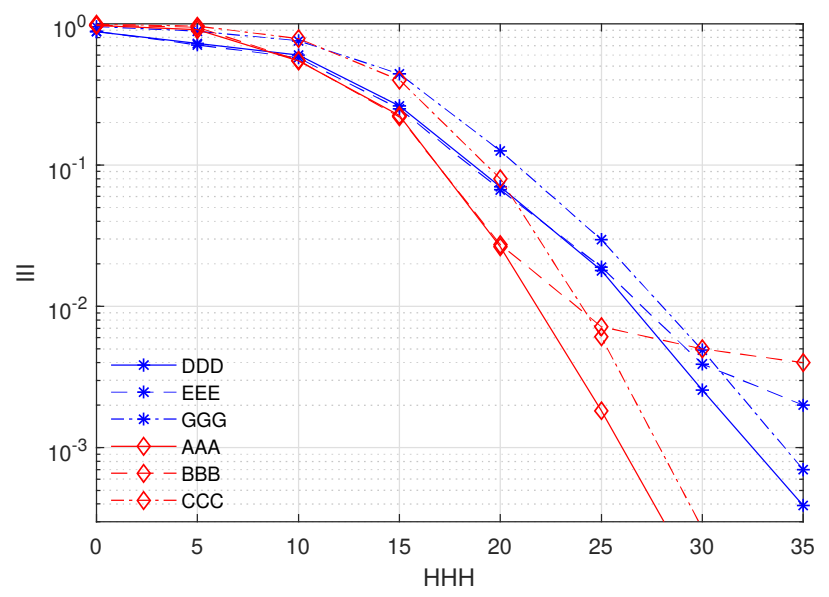

Figure 5.6: Performance comparison with the schemes in $[2,3]$.

we proposed a scheme which enables the nodes to cancel SI perfectly using a modeswitching technique. To analyze performance, we derived upper bounds on the PEP for the scheme proposed herein and the one proposed in Chapter 4. Furthermore, we derived the union bounds on the BLER for the Alamouti and $S P(2)$ codes. Using these bounds, we showed that the scheme proposed herein outperforms the one proposed in Chapter 4, even though the new scheme uses single-antenna relays while the scheme proposed in Chapter 4 uses multiple-antenna relays. Moreover, we derived new bounds on the PEP. Using these bounds, we obtained a fundamental performancerate trade-off for the Alamouti and $S P(2)$ codes. This trade-off was subsequently used to show that, at higher rates, using the Alamouti code is more beneficial than its $S P(2)$ counterpart, even though it uses two relays only instead of the four relays used by the $S P(2)$ code. At lower rates, it is more beneficial to use the $S P(2)$ code. 


\section{Chapter 6}

\section{Summary and Future Works}

\subsection{Summary}

In this thesis, we briefly reviewed the fundamentals of MIMO systems and cooperative communication in relay networks. We focused on relay networks and reviewed oneway relay networks (OWRNs) and two-way relay networks (TWRNs). We showed that, in TWRNs, each node receives the undesired self-interference (SI) signal due to simultaneous signal transmission at the nodes. We analytically showed that any residual SI inflicts serious degradation on the system performance and must be cancelled perfectly prior to detection. More precisely, we showed that any residual SI results in a zero diversity order and an asymptotic error floor. SI cancellation depends on the existence of channel state information (CSI) at the nodes such that when CSI is available the SI cancellation is straightforward whereas when CSI is not available, the cancellation is a challenging problem. Several approaches for mitigating the effect of SI in channel-unaware TWRNs have been proposed in the literature. These proposed schemes rely on CSI, SI or noise estimation which result in estimation error, imperfect SI cancellation and error propagation.

In order to overcome the aforementioned drawbacks, we developed a novel relaying scheme for channel-unaware TWRNs with multiple-antenna half-duplex (HD) amplify-and-forward (AF) relays. To the best of our knowledge, this scheme is to date the first available technique to cancel SI perfectly without invoking any statistical estimation of SI, CSI or noise. The novel proposed signalling scheme uses joint space time processing of the relay received signals to eliminate SI perfectly at both nodes. We showed that perfect elimination of self-interference requires the space domain relay processing matrices to be skew-symmetric and unitary, thereby implying 
that the number of active antennas at each relay must be even. Analyzing the effect of self interference on the signal to interference plus noise ratio (SINR) and the pairwise error probability (PEP), we showed that, unless perfectly cancelled, residual self-interference will result in a zero diversity gain and an asymptotic error floor. Furthermore, we showed that using the scheme proposed herein enables a high-power diversity gain equal to the number of relays to be achieved, irrespective of the number of antennas per relay. Furthermore, we showed that the coding gain of the system increases and converges to a constant as the number of antennas per relay increases.

To overcome the restriction of having even number of active antennas at each relay, we developed another new signalling scheme that enables SI to be perfectly cancelled in the absence of CSI when HF AF relays have a single antenna each. This scheme rely on mode-switching technique. We analytically showed that this scheme outperforms the previous scheme while it uses fewest number of antennas at the relays. Moreover, we provided a nonintuitive fact that increasing the number of relays and using $S P(2)$ code does not necessarily yield better performance than using less relays with the Alamouti code. More precisely, we obtained a fundamental performance-rate trade-off for the Alamouti and $S P(2)$ codes. This trade-off was subsequently used to show that, at higher rates, using the Alamouti code is more beneficial than its $S P(2)$ counterpart, even though it uses two relays only instead of the four relays used by the $S P(2)$ code. At lower rates, it is more beneficial to use the $S P(2)$ code.

\subsection{Future Works}

The studies conducted in this thesis provided several research directions. In particular, in the future, we would like to pursue the following directions.

- In this thesis, we developed perfect SI cancellation schemes in channel-unaware relay networks with amplify-and-forward relays has been considered. The goal of perfect self-interference cancellation can be studied for other relaying schemes including decode-and-forward, compress-and-forward and quantizeand-forward.

- The differential signalling considered in this thesis rely on unitary information matrices transmitted at the nodes. This technique can be used for network for either two or four relays. Providing a new differential signalling which can be 
used for relay networks with more relays is an interesting direction for future work.

- The nodes use maximum-likelihood detector which suffers from exhaustive search for symbol detection. To overcome this drawback, based on differential signalling, providing a new detector with less computational complexity can be studied in future.

- In this thesis, perfect SI cancellation in channel-unaware TWRNs with HF relays has been studied. Perfect SI in channel-unaware TWRNs with full-duplex (FD) relays and in non-orthogonal multiple access (NOMA) schemes for $5 \mathrm{G}$ and beyond are interesting directions for future research.

- Since in this thesis, Rayleigh block fading channels are considered, perfect SI cancellation in other types of fading including fast fading, Jakes' fading, Rician and Nakagami fading is an interesting research direction.

- In this thesis, we cancels SI perfectly considering that transmission at the nodes in the first phase and at the relays in the second phase are simultaneous and synchronous. SI cancellation in channel-unaware TWRNs with asynchronous transmission can be studied for future work. 


\section{List of References}

[1] Q. Huo, L. Song, Y. Li, and B. Jiao, "A distributed differential space-time coding scheme with analog network coding in two-way relay networks," IEEE Trans. Signal Processing, vol. 60, pp. 4998-5004, Sept. 2012.

[2] Z. Utkovski, G. Yammine, and J. Lindner, "A distributed differential space-time coding scheme for two-way wireless relay networks," Proc. IEEE Int. Symp. Inf. Theory, pp. 779-783, June 2009.

[3] S. Bameri, S. Talebi, R. H. Gohary, and H. Yanikomeroglu, "A novel selfinterference cancellation scheme for channel-unaware differential space-time twoway relay networks," IEEE Trans. Wireless Commun., vol. 17, pp. 1226-1241, Feb. 2018.

[4] https://crtc.gc.ca/eng/publications/reports/policymonitoring/2018/ cmr3a.htm, 2018.

[5] https://www.businessinsider.com/there-will-be-34-billion-iot -devices-installed-on-earth-by-2020-2016-5, 2016.

[6] A. Goldsmith, Wireless Communications. Cambridge: Cambridge University Press, 2005.

[7] A. G. Kanatas, K. S. Nikita, and P. Mathiopoulos, New Directions in Wireless Communications Systems From Mobile to 5G. CRC Press, 2018.

[8] L. Zhao, H. Zhao, K. Zheng, and W. Xiang, Massive MIMO in 5 G Networks: Selected Applications. Springer International Publishing, 2018.

[9] Z. Lin, X. Du, H. Chen, B. Ai, Z. Chen, and D. Wu, "Millimeter-wave propagation modeling and measurements for 5g mobile networks," wc, vol. 26, pp. 72-77, Feb. 2019.

[10] Y. Hong, , W. Huang, and C. Kuo, Cooperative Communications and Networking: Technologies and System Design. Springer US, 2010.

[11] H. Jafarkhani, Space-time coding: theory and practice. New York: Cambridge University Press, 2005.

[12] B. Clerckx and C. Oestges, MIMO Wireless Networks: Channels, Techniques and Standards for Multi-Antenna, Multi-User and Multi-Cell Systems. Academic Press : Oxford, UK, 2013. 
[13] E. Biglieri, R. Calderbank, A. Constantinides, A. Goldsmith, A. Paulraj, and H. V. Poor, MIMO Wireless Communications. New York, NY, USA: Cambridge University Press, 2010.

[14] S. M. Alamouti, "A simple transmit diversity scheme for wireless communications," IEEE J. Select. Areas Commun., vol. 16, pp. 1451-1458, Oct. 1998.

[15] E. Björnson, E. G. Larsson, and M. Debbah, "Massive mimo for maximal spectral efficiency: How many users and pilots should be allocated?" IEEE Trans. Wireless Commun., vol. 15, pp. 1293-1308, Feb. 2016.

[16] S. K. Mohammed, "Impact of transceiver power consumption on the energy efficiency of zero-forcing detector in massive mimo systems," IEEE Trans. Commun., vol. 62, pp. 3874-3890, Nov. 2014.

[17] H. V. Cheng, E. Björnson, and E. G. Larsson, "Optimal pilot and payload power control in single-cell massive mimo systems," IEEE Trans. Signal Processing, vol. 65, pp. 2363-2378, May 2017.

[18] K. Liu, A. Sadek, W. Su, and A. Kwasinski, Cooperative communications and networking. New York: Cambridge University Press, 2009.

[19] Y. Jing and B. Hassibi, "Distributed space-time coding in wireless relay networks," IEEE Trans. Wireless Commun., vol. 5, pp. 3524-3536, Dec. 2006.

[20] B. Rankov and A. Wittneben, "Achievable rate regions for the two-way relay channel," in Proc. IEEE Int. Symp. Inf. Theory, pp. 1668-1672, July 2006.

[21] P. Popovski and H. Yomo, "Physical network coding in two-way wireless relay channels," in Proc. IEEE Int. Conf. Comp. Commun. (INFOCOM), pp. 707-712, June 2007.

[22] S. Zhang, F. Gao, and C. Pei, "Optimal training design for individual channel estimation in two-way relay networks," IEEE Trans. Signal Processing, vol. 60, pp. 4987-4991, Sept. 2012.

[23] X. Xie, M. Peng, B. Zhao, W. Wang, and Y. Hua, "Maximum a posteriori based channel estimation strategy for two-way relaying channels," IEEE Trans. Wireless Commun., vol. 13, pp. 450-463, Jan. 2014.

[24] S. Abdallah and I. N. Psaromiligkos, "Blind channel estimation for amplify-andforward two-way relay networks employing $M$-PSK modulation," IEEE Trans. Signal Processing, vol. 60, pp. 3604-3615, July 2012.

[25] M. Masjedi, A. M. Doost-Hoseini, M. M. Naghsh, and S. Gazor, "Partially blind joint channel estimation and symbol detection in amplify-and-forward two-way relay systems," IEEE Trans. Commun., pp. 1-9, 2018.

[26] W. Li, M. Ku, Y. Chen, and K. J. R. Liu, "On outage probability for twoway relay networks with stochastic energy harvesting," IEEE Trans. Commun., vol. 64, pp. 1901-1915, May 2016. 
[27] Y. Hu, C. Qiu, and Y. Chen, "Lyapunov optimized two-way relay networks with stochastic energy harvesting," IEEE Trans. Wireless Commun., pp. 1-13, 2018.

[28] K. Lee, J. Hong, H. Choi, and T. Q. S. Quek, "Wireless-powered two-way relaying protocols for optimizing physical layer security," IEEE Trans. Info. Forensics Security., vol. 14, pp. 162-174, Jan. 2019.

[29] M. T. Mamaghani, A. Kuhestani, and K. Wong, "Secure two-way transmission via wireless-powered untrusted relay and external jammer," IEEE Trans. Veh. Technol., pp. 1-15, 2018.

[30] X. Jia, C. Zhang, J. Kang, and I. Kim, "Joint beamforming design and time allocation for wireless powered asymmetric two-way multi-relay network," IEEE Trans. Veh. Technol., pp. 1-14, 2018.

[31] Y. Zhang, J. Ge, J. Men, F. Ouyang, and C. Zhang, "Joint relay selection and power allocation in energy harvesting AF relay systems with ICSI," IET Microwaves, Antennas Propagation, vol. 10, no. 15, pp. 1656-1661, 2016.

[32] A. H. Bastami and S. Habibi, "Cognitive MIMO two-way relay network: Joint optimal relay selection and spectrum allocation," IEEE Trans. Veh. Technol., vol. 67 , pp. 5937-5952, July 2018.

[33] L. Song, G. Hong, B. Jiao, and M. Debbah, "Joint relay selection and analog network coding using differential modulation in two-way relay channels," IEEE Trans. Veh. Technol., vol. 59, pp. 2932-2939, July 2010.

[34] L. Song, Y. Li, A. Huang, B. Jiao, and A. V. Vasilakos, "Differential modulation for bidirectional relaying with analog network coding," IEEE Trans. Signal Processing, vol. 58, pp. 3933-3938, July 2010.

[35] T. Cui, F. Gao, and C. Tellambura, "Differential modulation for two-way wireless communications: a perspective of differential network coding at the physical layer," IEEE Trans. Commun., vol. 57, pp. 2977-2987, Oct. 2009.

[36] S. J. Alabed, J. M. Paredes, and A. B. Gershman, "A simple distributed spacetime coded strategy for two-way relay channels," IEEE Trans. Wireless Commun., vol. 11, pp. 1260-1265, Apr. 2012.

[37] B. Hassibi and B. M. Hochwald, "High-rate codes that are linear in space and time," IEEE Trans. Inf. Theory, vol. 48, pp. 1804-1824, July 2002.

[38] H. Wang, X. Xia, and Q. Yin, "A linear analog network coding for asynchronous two-way relay networks," IEEE Trans. Wireless Commun., vol. 9, pp. 3630-3637, Dec. 2010.

[39] Y. Liu, W. Zhang, and P. C. Ching, "Time-reversal space-time codes in asynchronous two-way relay networks," IEEE Trans. Wireless Commun., vol. 15, pp. 1729-1741, Mar. 2016.

[40] T. Cui, F. Gao, T. Ho, and A. Nallanathan, "Distributed space-time coding for two-way wireless relay networks," in 2008 IEEE International Conference on Communications, pp. 3888-3892, May 2008. 
[41] Y. Jing and H. Jafarkhani, "Distributed differential space-time coding for wireless relay networks," IEEE Trans. Commun., vol. 56, pp. 1092-1100, July 2008.

[42] Y. Jing and B. Hassibi, "Design of fully diverse multiple-antenna codes based on SP(2)," IEEE Trans. Inf. Theory, vol. 50, pp. 2639-2656, Nov. 2004.

[43] S. Boyd and L. Vandenberghe, Convex Optimization. Cambridge: Cambridge University Press, 2004.

[44] A. Dogandzic, "Chernoff bounds on pairwise error probabilities of space-time codes," IEEE Trans. Inf. Theory, vol. 49, pp. 1327-1336, May 2003.

[45] R. A. Horn and C. R. Johnson, Matrix analysis. New York: Cambridge University Press, 1985.

[46] S. Bameri, R. H. Gohary, S. Talebi, and I. Lambadaris, "On the tradeoff between rate and pairwise error performance of Alamouti and $S P(2)$ space-time block codes," in Proc. IEEE Int. Wkshp. Signal Processing Adv. Wireless Commun. (SPAWC), (Kalamata), June 2018.

[47] W. W. Adams and L. J. Goldstein, Introduction to Number Theory. Prentice Hall, 1976. 


\section{Appendix A}

\section{Appendices}

\section{A.1 Proof of (4.15), (4.18) and (4.19)}

\section{A.1.1 Proof of (4.15)}

Using the statistical independence of $\left\{\boldsymbol{f}_{n}\right\}_{n=1}^{N},\left\{\boldsymbol{V}_{n}^{(\ell)}\right\}_{n=1}^{N}$ and $\boldsymbol{z}_{1}^{(\ell)}$ in (4.14), we write

$$
\mathrm{E}\left\{\boldsymbol{w}_{1}^{(\ell)} \boldsymbol{w}_{1}^{(\ell)^{\dagger}}\right\}=\mathrm{E}\left\{\sum_{n=1}^{N} \beta_{n}^{2} \boldsymbol{C}_{n} \boldsymbol{V}_{n}^{(\ell)} \boldsymbol{X}_{n} \boldsymbol{f}_{n} \boldsymbol{f}_{n}^{\dagger} \boldsymbol{X}_{n}^{\dagger} \boldsymbol{V}_{n}^{(\ell)^{\dagger}} \boldsymbol{C}_{n}^{\dagger}\right\}+\mathrm{E}\left\{\boldsymbol{z}_{1}^{(\ell)} \boldsymbol{z}_{1}^{(\ell)^{\dagger}}\right\}
$$

Using (A.1) with the facts that $\boldsymbol{X}_{n} \boldsymbol{X}_{n}^{\dagger}=\boldsymbol{I}_{M_{n}}, \mathrm{E}\left\{\boldsymbol{f}_{n} \boldsymbol{f}_{n}^{\dagger}\right\}=\boldsymbol{I}_{M_{n}}$ and $\mathrm{E}\left\{\boldsymbol{V}_{n}^{(\ell)} \boldsymbol{V}_{n}^{(\ell)^{\dagger}}\right\}=$ $M_{n} \boldsymbol{I}_{N}$ for linear codes and $\mathrm{E}\left\{\boldsymbol{V}_{n}^{(\ell)} \boldsymbol{V}_{n}^{(\ell)^{\dagger}}\right\}=M_{n} \boldsymbol{I}_{2 N}$, for sesquilinear codes, $n=$ $1, \ldots, N$, yields $(4.15)$.

\section{A.1.2 Proof of (4.18)}

To obtain the average received power of the desired signal, we use (4.11)-(4.13) to write

$$
\begin{aligned}
\mathrm{E}\left\{\left(\boldsymbol{S}_{2}^{(\ell)} \boldsymbol{h}_{2}\right)^{\dagger}\left(\boldsymbol{S}_{2}^{(\ell)} \boldsymbol{h}_{2}\right)\right\} & =\mathrm{E}\left\{\sum_{n=1}^{N} \sum_{q=1}^{N} \beta_{n} \beta_{q} \boldsymbol{f}_{n}^{\dagger} \boldsymbol{X}_{n}^{\dagger} \overline{\boldsymbol{g}}_{n} \boldsymbol{\theta}_{2}^{(\ell)^{\dagger}} \boldsymbol{C}_{n}^{\dagger} \boldsymbol{C}_{q} \boldsymbol{\theta}_{2}^{(\ell)} \boldsymbol{g}_{q}^{T} \boldsymbol{X}_{q} \boldsymbol{f}_{q}\right\} \\
& =\mathrm{E}\left\{\sum_{n=1}^{N} \beta_{n}^{2} \operatorname{Tr}\left(\boldsymbol{X}_{n}^{\dagger} \overline{\boldsymbol{g}}_{n} \boldsymbol{\theta}_{2}^{(\ell) \dagger} \boldsymbol{C}_{n}^{\dagger} \boldsymbol{C}_{n} \boldsymbol{\theta}_{2}^{(\ell)} \boldsymbol{g}_{n}^{T} \boldsymbol{X}_{n}\right)\right\} \\
& =\mathrm{E}\left\{\sum_{n=1}^{N} \beta_{n}^{2} \operatorname{Tr}\left(\boldsymbol{\theta}_{2}^{(\ell)^{\dagger}} \boldsymbol{C}_{n}^{\dagger} \boldsymbol{C}_{n} \boldsymbol{\theta}_{2}^{(\ell)}\right) \operatorname{Tr}\left(\boldsymbol{X}_{n}^{\dagger} \overline{\boldsymbol{g}}_{n} \boldsymbol{g}_{n}^{T} \boldsymbol{X}_{n}\right)\right\}
\end{aligned}
$$


where in (A.2) we used the fact that for $n \neq q, \boldsymbol{\theta}_{2}^{(\ell)}, \boldsymbol{f}_{n}, \boldsymbol{f}_{q}, \boldsymbol{g}_{n}$ and $\boldsymbol{g}_{q}$ are identically and independently distributed (i.i.d.) with zero mean, and we replaced the scalar $\boldsymbol{\theta}_{2}^{(\ell)^{\dagger}} \boldsymbol{C}_{n}^{\dagger} \boldsymbol{C}_{n} \boldsymbol{\theta}_{2}^{(\ell)}$ by its trace, computed expectation over $\boldsymbol{\theta}_{2}^{(\ell)}$ and $\boldsymbol{g}_{n}$, and used (4.6) to obtain (4.18).

\section{A.1.3 Proof of (4.19)}

To obtain the average received power of the self-interference component in (4.10), we use an approach analogous to the one used in deriving (4.18) to arrive at

$$
\mathrm{E}\left\{\left(\boldsymbol{S}_{1}^{(\ell)} \boldsymbol{h}_{1}\right)^{\dagger}\left(\boldsymbol{S}_{1}^{(\ell)} \boldsymbol{h}_{1}\right)\right\}=\mathrm{E}\left\{\sum_{n=1}^{N} N \beta_{n}^{2} \boldsymbol{f}_{n}^{\dagger} \boldsymbol{X}_{n}^{\dagger} \overline{\boldsymbol{f}}_{n} \boldsymbol{f}_{n}^{T} \boldsymbol{X}_{n} \boldsymbol{f}_{n}\right\}
$$

To compute the RHS of (A.3), we denote the $m$-th entry of $\boldsymbol{f}_{n}$ by $f_{n m}$, and the $p q$-th entry of $\boldsymbol{X}_{n}$ by $x_{p q}^{(n)}, m, p, q=1, \ldots, M_{n}, n=1, \ldots, N$. Using this notation, we write

$$
\begin{aligned}
\mathrm{E}\left\{\boldsymbol{f}_{n}^{\dagger} \boldsymbol{X}_{n}^{\dagger} \overline{\boldsymbol{f}}_{n} \boldsymbol{f}_{n}^{T} \boldsymbol{X}_{n} \boldsymbol{f}_{n}\right\} \\
=\mathrm{E}\left\{\sum_{m=1}^{M_{n}} \sum_{q=1}^{M_{n}} \sum_{m_{0}=1}^{M_{n}} \sum_{q_{0}=1}^{M_{n}} f_{n m} f_{n q} \bar{f}_{n m_{0}} \bar{f}_{n q_{0}} x_{m q}^{(n)} \bar{x}_{m_{0} q_{0}}^{(n)}\right\} \\
=\mathrm{E}\left\{\sum_{m=1}^{M_{n}}\left|f_{n m}\right|^{4}\left|x_{m m}^{(n)}\right|^{2}\right\}+\mathrm{E}\left\{\sum_{m=1}^{M_{n}} \sum_{q=1}^{M_{n}}\left|f_{n m}\right|^{2}\left|f_{n q}\right|^{2}\left|x_{m q}^{(n)}\right|^{2}\right\} \\
\quad+\mathrm{E}\left\{\sum_{m=1}^{M_{n}} \sum_{q=1}^{M_{n}}\left|f_{n m}\right|^{2}\left|f_{n q}\right|^{2} x_{m q}^{(n)} \bar{x}_{q m}^{(n)}\right\}+\mathrm{E}\left\{\sum_{m=1}^{M_{n}} \sum_{m_{0}=1}^{M_{n}} f_{n m}^{2} \bar{f}_{n m_{0}}^{2} x_{m m}^{(n)} \bar{x}_{m_{0} m_{0}}^{(n)}\right\} \\
=2 \sum_{m=1}^{M_{n}}\left|x_{m m}^{(n)}\right|^{2}+\sum_{m=1}^{M_{n}} \sum_{q=m+1}^{M_{n}}\left|x_{m q}^{(n)}+x_{q m}^{(n)}\right|^{2}
\end{aligned}
$$

where, to obtain (A.5), we used that for distinct $m, q, m_{0}, q_{0}$, the fading coefficients $f_{n m}, f_{n q}, f_{n m_{0}}$, and $f_{n q_{0}}$, are i.i.d. zero mean unit variance complex Gaussian random variables. This implies that the only terms that are not immediately trivial in the summations in (A.4) are: 1) $m=q=m_{0}=q_{0}$;2) $m=m_{0}$ and $q=q_{0}$;3) $m=q_{0}$ and $q=m_{0}$; and 4) $m=q$ and $m_{0}=q_{0}$, yielding the four terms of (A.5), respectively. To compute the first term of (A.5), we use

$$
\mathrm{E}\left\{\left|f_{n m}\right|^{4}\right\}=\mathrm{E}\left\{\Re\left(f_{n m}\right)^{4}\right\}+\mathrm{E}\left\{\Im\left(f_{n m}\right)^{4}\right\}+2 \mathrm{E}\left\{\Re\left(f_{n m}\right)^{2}\right\} \mathrm{E}\left\{\Im\left(f_{n m}\right)^{2}\right\}=2 .
$$


The computation of the second and third terms is immediate. For the last term we note that

$$
\mathrm{E}\left\{f_{n m}^{2}\right\}=\mathrm{E}\left\{\Re\left(f_{n m}\right)^{2}\right\}-\mathrm{E}\left\{\Im\left(f_{n m}\right)^{2}\right\}+2 \mathrm{E}\left\{\Re\left(f_{n m}\right) \Im\left(f_{n k}\right)\right\}=0 .
$$

Combining (A.7) and (A.8) with the fact that $\mathrm{E}\left\{\left|f_{n m}\right|^{2}\right\}=1$ yields (4.19).

\section{A.2 Proof of Theorem 1}

To obtain a lower bound on the PEP of mistaking $\boldsymbol{S}_{2, a}^{(\ell)}$ for $\boldsymbol{S}_{2, b}^{(\ell)}$, we write

$$
\operatorname{Pr}\left(\boldsymbol{S}_{2, a}^{(\ell)} \rightarrow \boldsymbol{S}_{2, b}^{(\ell)}\right)=\mathrm{E}_{\boldsymbol{\theta}_{1}^{(\ell)}, \boldsymbol{h}_{2}}\left\{\operatorname{Pr}\left(\boldsymbol{S}_{2, a}^{(\ell)} \rightarrow \boldsymbol{S}_{2, b}^{(\ell)} \mid \boldsymbol{h}_{2}, \boldsymbol{\theta}_{1}^{(\ell)}\right)\right\}
$$

Using (4.16), conditioned on $\boldsymbol{h}_{2}$ and $\boldsymbol{\theta}_{1}^{(\ell)}$ and the zero mean Gaussian assumption on $\boldsymbol{h}_{1}$ and $\boldsymbol{w}_{1}^{(\ell)}$, the vector $\boldsymbol{y}_{1}^{(\ell)}$ is Gaussian distributed with mean $\sqrt{P_{2}} \boldsymbol{S}_{2}^{(\ell)} \boldsymbol{h}_{2}$ and conditional covariance matrix

$$
\boldsymbol{\Sigma}_{\boldsymbol{y}_{1} \mid \boldsymbol{h}_{2}, \boldsymbol{\theta}_{1}^{(\ell)}}=\mathrm{E}\left\{\boldsymbol{y}_{1}^{(\ell)} \boldsymbol{y}_{1}^{(\ell)^{\dagger}} \mid \boldsymbol{h}_{2}, \boldsymbol{\theta}_{1}^{(\ell)}\right\}=\zeta^{2} P_{1} \sum_{n=1}^{N} \beta_{n}^{2} \alpha_{n} \boldsymbol{C}_{n} \boldsymbol{\theta}_{1}^{(\ell)} \boldsymbol{\theta}_{1}^{(\ell)^{\dagger}} \boldsymbol{C}_{n}^{\dagger}+\boldsymbol{\Sigma}_{\boldsymbol{w}_{1}}
$$

where $\boldsymbol{\Sigma}_{\boldsymbol{w}_{1}}$ is given by (4.15). Using this covariance and assuming ML detection, we have

$$
\begin{aligned}
\mathrm{E}_{\boldsymbol{\theta}_{1}^{(\ell)}, \boldsymbol{h}_{2}}\left\{\operatorname{Pr}\left(\boldsymbol{S}_{2, a}^{(\ell)} \rightarrow \boldsymbol{S}_{2, b}^{(\ell)} \mid \boldsymbol{h}_{2}, \boldsymbol{\theta}_{1}^{(\ell)}\right)\right\} \\
=\mathrm{E}_{\boldsymbol{\theta}_{1}^{(\ell)}, \boldsymbol{h}_{2}}\left\{Q\left(\sqrt{\frac{P_{2}}{2} \boldsymbol{h}_{2}^{\dagger}\left(\boldsymbol{S}_{2, a}^{(\ell)}-\boldsymbol{S}_{2, b}^{(\ell)}\right)^{\dagger} \boldsymbol{\Sigma}_{\boldsymbol{y}_{1} \mid \boldsymbol{h}_{2}, \boldsymbol{\theta}_{1}^{(\ell)}}^{-1}\left(\boldsymbol{S}_{2, a}^{(\ell)}-\boldsymbol{S}_{2, b}^{(\ell)}\right) \boldsymbol{h}_{2}}\right)\right\} \\
\geq \mathrm{E}_{\boldsymbol{\theta}_{1}^{(\ell)}}\left\{Q\left(\sqrt{\mathrm{E}_{\boldsymbol{h}_{2}}\left\{\frac{P_{2}}{2} \boldsymbol{h}_{2}^{\dagger}\left(\boldsymbol{S}_{2, a}^{(\ell)}-\boldsymbol{S}_{2, b}^{(\ell)}\right)^{\dagger} \boldsymbol{\Sigma}_{\boldsymbol{y}_{1} \mid \boldsymbol{h}_{2}, \boldsymbol{\theta}_{1}^{(\ell)}}^{-1}\left(\boldsymbol{S}_{2, a}^{(\ell)}-\boldsymbol{S}_{2, b}^{(\ell)}\right) \boldsymbol{h}_{2}\right\}}\right)\right\},
\end{aligned}
$$

where, in (A.11), we used that, for $x \geq 0, Q(\sqrt{x})$ is convex, whence $\mathrm{E}\{\mathrm{Q}(\sqrt{x})\} \geq$ $Q(\sqrt{\mathrm{E}\{x\}})$ [43]. To obtain a convenient lower bound that exposes the role of $P$, we will obtain a bound on $\boldsymbol{\Sigma}_{\boldsymbol{y}_{1} \mid \boldsymbol{h}_{2}, \boldsymbol{\theta}_{1}^{(\ell)}}^{-1}$. Towards that end, we use (4.17) and (4.15) 
in (A.10) to write

$$
\begin{aligned}
& \Sigma_{\boldsymbol{y}_{1} \mid \boldsymbol{h}_{2}, \boldsymbol{\theta}_{1}^{(\ell)}} \\
& =\frac{P^{2}}{\left(1+\delta_{0}\right) P+1}\left(\zeta^{2} \sum_{n=1}^{N} \frac{\alpha_{n} \delta_{n}}{M_{n}} \boldsymbol{C}_{n} \boldsymbol{\theta}_{1}^{(\ell)} \boldsymbol{\theta}_{1}^{(\ell)^{\dagger}} \boldsymbol{C}_{n}^{\dagger}+\frac{1}{P} \sum_{n=1}^{N} \delta_{n} \boldsymbol{C}_{n} \boldsymbol{C}_{n}^{\dagger}+\frac{\left(1+\delta_{0}\right) P+1}{P^{2}} \boldsymbol{I}_{N}\right) \\
& \succeq \frac{P^{2}}{\left(1+\delta_{0}\right) P+1}\left(\zeta^{2} \lambda_{\min }\left(\boldsymbol{\theta}_{1}^{(\ell)}\right)+\left(1+\delta_{0}+\sum_{n=1}^{N} \delta_{n} \mu_{\min }^{(n)}\right) P^{-1}+P^{-2}\right) \boldsymbol{I}_{N},
\end{aligned}
$$

where $\lambda_{\min }\left(\boldsymbol{\theta}_{1}^{(\ell)}\right)$ and $\mu_{\min }^{(n)}$ are the smallest eigenvalues of $\sum_{n=1}^{N} \frac{\alpha_{n} \delta_{n}}{M_{n}} \boldsymbol{C}_{n} \boldsymbol{\theta}_{1}^{(\ell)} \boldsymbol{\theta}_{1}^{(\ell)^{\dagger}} \boldsymbol{C}_{n}^{\dagger}$ and $\boldsymbol{C}_{n} \boldsymbol{C}_{n}^{\dagger}$, respectively. Now, let $\sigma_{\max }^{(a, b)}$ be the largest eigenvalue of $\boldsymbol{\Psi}\left(\boldsymbol{S}_{2, a}^{(\ell)}, \boldsymbol{S}_{2, b}^{(\ell)}\right)=\left(\boldsymbol{S}_{2, a}^{(\ell)}-\right.$ $\left.\boldsymbol{S}_{2, b}^{(\ell)}\right)^{\dagger}\left(\boldsymbol{S}_{2, a}^{(\ell)}-\boldsymbol{S}_{2, b}^{(\ell)}\right)$ and let $\hat{\sigma}_{\max }=\max _{a, b} \sigma_{\max }^{(a, b)}$. Hence, we can write $\boldsymbol{\Psi}\left(\boldsymbol{S}_{2, a}^{(\ell)}, \boldsymbol{S}_{2, b}^{(\ell)}\right) \preceq$ $\hat{\sigma}_{\max } \boldsymbol{I}_{N}$. Substituting from this bound and (A.12) into (A.11) yields

$$
\begin{aligned}
& \mathrm{E}_{\boldsymbol{\theta}_{1}^{(\ell)}, \boldsymbol{h}_{2}}\left\{\operatorname{Pr}\left(\boldsymbol{S}_{2, a}^{(\ell)} \rightarrow \boldsymbol{S}_{2, b}^{(\ell)} \mid \boldsymbol{h}_{2}, \boldsymbol{\theta}_{1}^{(\ell)}\right)\right\} \\
& \quad \geq \mathrm{E}_{\boldsymbol{\theta}_{1}^{(\ell)}}\left\{Q \left(\sqrt{\left.\left.\mathrm{E}_{\boldsymbol{h}_{2}}\left\{\frac{2^{-1} \delta_{0} P\left(\left(1+\delta_{0}\right) P+1\right) \hat{\sigma}_{\max } \boldsymbol{h}_{2}^{\dagger} \boldsymbol{h}_{2}}{P^{2} \zeta^{2} \lambda_{\min }\left(\boldsymbol{\theta}_{1}^{(\ell)}\right)+P\left(1+\delta_{0}+\sum_{n=1}^{N} \delta_{n} \mu_{\min }^{(n)}\right)+1}\right\}\right)\right\}} .\right.\right.
\end{aligned}
$$

Finally, using (A.13) and computing the expectation over $\boldsymbol{h}_{2}$, yields (4.23).

\section{A.3 Proof of Theorem 3}

In Lemma 2, we showed that, for the matrix $\boldsymbol{X}_{n}$ to be simultaneously unitary and skew-symmetric, its dimension must be even. Hence, in the forthcoming proof we will assume that $M_{n}=2 K$, for some integer $K$. For such an $\boldsymbol{X}_{n}$, we will denote the eigendecomposition by

$$
\boldsymbol{X}_{n}=\boldsymbol{\Phi}_{n} \boldsymbol{\Lambda}_{n} \boldsymbol{\Phi}_{n}^{\dagger}
$$

In this decomposition, the diagonal matrix $\boldsymbol{\Lambda}_{n} \in \mathbb{C}^{2 K \times 2 K}$ contains the eigenvalues of $\boldsymbol{X}_{n}$ and the columns of the unitary matrix $\boldsymbol{\Phi}_{n} \in \mathbb{C}^{2 K \times 2 K}$ contain the corresponding eigenvectors. Using (A.14) we will derive the structure of $\boldsymbol{\Lambda}_{n}$ and $\boldsymbol{\Phi}_{n}$ in order for $\boldsymbol{X}_{n}$ to be unitary and skew-symmetric.

We will begin by considering $\boldsymbol{\Lambda}_{n}$. We record our results in the following lemma.

Lemma 4. For the unitary matrix $\boldsymbol{X}_{n}$ to be skew-symmetric, its eigenvalues must be in the form $\pm e^{\jmath \theta_{k}^{(n)}}$, where $\theta_{k}^{(n)} \in[0,2 \pi), k=1, \ldots, K, n=1, \ldots, N$. 
Proof. To prove this lemma, we note that the $k$-th eigenvalue of any unitary matrix, $\boldsymbol{X}_{n}$, must be in the form of $e^{j \theta_{k}^{(n)}}$, where $\theta_{k}^{(n)} \in[0,2 \pi)$. Suppose that $\left(e^{\jmath \theta_{k}^{(n)}}, \boldsymbol{\phi}_{k}^{(n)}\right)$ is an eigen pair of $\boldsymbol{X}_{n}$, i.e., $\boldsymbol{X}_{n} \boldsymbol{\phi}_{k}^{(n)}=e^{\jmath \theta_{k}^{(n)}} \boldsymbol{\phi}_{k}^{(n)}$. Now, we assert that $\left(e^{j \theta_{k}^{(n)}}, \boldsymbol{\psi}_{k}^{(n)}\right)$ is an eigen pair of $\boldsymbol{X}_{n}^{T}$, i.e.,

$$
\boldsymbol{X}_{n}^{T} \boldsymbol{\psi}_{k}^{(n)}=e^{\jmath \theta_{k}^{(n)}} \boldsymbol{\psi}_{k}^{(n)}
$$

since the transpose operation does not affect the eigenvalues. Using the fact that $\boldsymbol{X}_{n}$ is skew-symmetric, i.e., $\boldsymbol{X}_{n}^{T}=-\boldsymbol{X}_{n}$, we can rewrite (A.15) as $\boldsymbol{X}_{n} \boldsymbol{\psi}_{k}^{(n)}=-e^{\jmath \theta_{k}^{(n)}} \boldsymbol{\psi}_{k}^{(n)}$, implying that $\left(-e^{\theta \theta_{k}^{(n)}}, \boldsymbol{\psi}_{k}^{(n)}\right)$ is also the eigen pair of $\boldsymbol{X}_{n}$. Hence, the eigenvalues of any unitary skew-symmetric matrix $\boldsymbol{X}_{n}$ appear in the form of unit modulus antipodal pairs, $\left\{ \pm e^{j \theta_{k}^{(n)}}\right\}_{k=1}^{K}$.

Now we derive the properties of the unitary matrix $\boldsymbol{\Phi}_{n}$ in order for $\boldsymbol{X}_{n}$ be unitary and skew-symmetric. We record our results in the following lemma.

Lemma 5. Let $\boldsymbol{\Phi}_{n}=\left[\phi_{1}^{(n)}, \ldots, \phi_{2 K}^{(n)}\right], \boldsymbol{\Phi}_{n} \in \mathbb{C}^{2 K \times 2 K}$, be the unitary matrix containing the eigenvectors of the skew-symmetric unitary matrix $\boldsymbol{X}_{n}$. Then, $\boldsymbol{\Phi}_{n}$ has the following structure:

$$
\Phi_{n}=\left[\begin{array}{lllll}
\phi_{1}^{(n)}, & \bar{\phi}_{1}^{(n)}, & \ldots, & \phi_{K}^{(n)}, & \bar{\phi}_{K}^{(n)}
\end{array}\right]
$$

Proof. Let $\left(e^{\jmath \theta_{k}^{(n)}}, \boldsymbol{\phi}_{k}^{(n)}\right)$ and $\left(-e^{\jmath \theta_{k}^{(n)}}, \boldsymbol{\phi}_{k+1}^{(n)}\right)$ be eigen pairs of $\boldsymbol{X}_{n}$. Hence, we have

$$
\boldsymbol{X}_{n} \boldsymbol{\phi}_{k}^{(n)}=e^{\jmath \theta_{k}^{(n)}} \boldsymbol{\phi}_{k}^{(n)}, \quad \boldsymbol{X}_{n} \boldsymbol{\phi}_{k+1}^{(n)}=-e^{\jmath \theta_{k}^{(n)}} \boldsymbol{\phi}_{k+1}^{(n)}, \quad k=1, \ldots, K .
$$

Using $\boldsymbol{X}_{n}^{\dagger}=-\overline{\boldsymbol{X}}_{n}$ in the first equality in (A.17) yields $\boldsymbol{X}_{n}^{\dagger} \overline{\boldsymbol{\phi}}_{k}^{(n)}=-e^{-\jmath \theta_{k}^{(n)}} \overline{\boldsymbol{\phi}}_{k}^{(n)}$. That is, $\left(-e^{-\jmath \theta_{k}^{(n)}}, \overline{\boldsymbol{\phi}}_{k}^{(n)}\right)$ is an eigen pair of $\boldsymbol{X}_{n}^{\dagger}$. On the other hand, taking the Hermitian transpose of both sides of (A.14) yields $\boldsymbol{X}_{n}^{\dagger}=\boldsymbol{\Phi}_{n} \boldsymbol{\Lambda}_{n}^{\dagger} \boldsymbol{\Phi}_{n}^{\dagger}$, which implies that $\left(e^{-\jmath \theta_{k}^{(n)}}, \boldsymbol{\phi}_{k}^{(n)}\right)$ is another eigen pair of $\boldsymbol{X}_{n}^{\dagger}, k=1, \ldots, K$. Hence, we have shown that $\left(e^{-\jmath \theta_{k}^{(n)}}, \boldsymbol{\phi}_{k}^{(n)}\right)$ and $\left(-e^{-\jmath \theta_{k}^{(n)}}, \overline{\boldsymbol{\phi}}_{k}^{(n)}\right)$ are eigen pairs of $\boldsymbol{X}_{n}^{\dagger}, k=1, \ldots, K$, which subsequently implies that $\left(e^{\jmath \theta_{k}^{(n)}}, \boldsymbol{\phi}_{k}^{(n)}\right)$ and $\left(-e^{\jmath \theta_{k}^{(n)}}, \overline{\boldsymbol{\phi}}_{k}^{(n)}\right)$ are eigen pairs of $\boldsymbol{X}_{n}, k=$ $1, \ldots, K$. Using (A.17), it can be readily seen that $\boldsymbol{\phi}_{k+1}^{(n)}=\bar{\phi}_{k}^{(n)}$.

Using the result of Lemma 5, we will obtain an explicit construction for the eigenvectors matrix $\boldsymbol{\Phi}_{n}$. In particular, to ensure that $\boldsymbol{\Phi}_{n}$ is unitary, we must have for any 
$k \neq k^{\prime}, k, k^{\prime}=1, \ldots, K$

$$
\left\|\boldsymbol{\phi}_{k}^{(n)}\right\|^{2}=1, \quad \boldsymbol{\phi}_{k}^{(n)^{\dagger}} \bar{\phi}_{k}^{(n)}=0, \quad \boldsymbol{\phi}_{k}^{(n)^{\dagger}} \boldsymbol{\phi}_{k^{\prime}}^{(n)}=0, \quad \boldsymbol{\phi}_{k}^{(n)^{\dagger}} \bar{\phi}_{k^{\prime}}^{(n)}=0 .
$$

To construct $\boldsymbol{\Phi}_{n}$, we will express $\boldsymbol{\phi}_{k}^{(n)}$ in terms of its real and imaginary parts, i.e., $\phi_{k}^{(n)}=\Re\left(\phi_{k}^{(n)}\right)+j \Im\left(\phi_{k}^{(n)}\right)$. Substituting for $\phi_{k}^{(n)}$ in the the first equality in (A.18) yields

$$
\left\|\Re\left(\phi_{k}^{(n)}\right)\right\|^{2}+\left\|\Im\left(\phi_{k}^{(n)}\right)\right\|^{2}=1, \quad k=1, \ldots, K,
$$

and substituting in the second equality in (A.18) yields

$$
\left\|\Re\left(\phi_{k}^{(n)}\right)\right\|^{2}=\left\|\Im\left(\phi_{k}^{(n)}\right)\right\|^{2}, \quad \Re\left(\phi_{k}^{(n)}\right)^{T} \Im\left(\phi_{k}^{(n)}\right)=0, \quad k=1, \ldots, K
$$

Combining (A.19) with the first equality in (A.20) yields $\left\|\Re\left(\phi_{k}^{(n)}\right)\right\|^{2}=\left\|\Im\left(\phi_{k}^{(n)}\right)\right\|^{2}=$ $\frac{1}{2}, k=1, \ldots, K$. The second equality in (A.20), says that the two vectors $\Re\left(\phi_{k}^{(n)}\right)$ and $\Im\left(\phi_{k}^{(n)}\right)$ are orthogonal. The third and fourth equalities in (A.18) yield that, for every $k \neq k^{\prime}, k, k^{\prime}=1, \ldots, K$,

$$
\begin{aligned}
& \Re\left(\phi_{k}^{(n)}\right)^{T} \Re\left(\phi_{k^{\prime}}^{(n)}\right)+\Im\left(\phi_{k}^{(n)}\right)^{T} \Im\left(\phi_{k^{\prime}}^{(n)}\right)=0, \quad \Im\left(\phi_{k}^{(n)}\right)^{T} \Re\left(\phi_{k^{\prime}}^{(n)}\right)=\Re\left(\phi_{k}^{(n)}\right)^{T} \Im\left(\phi_{k^{\prime}}^{(n)}\right), \\
& \Re\left(\phi_{k}^{(n)}\right)^{T} \Re\left(\phi_{k^{\prime}}^{(n)}\right)=\Im\left(\phi_{k}^{(n)}\right)^{T} \Im\left(\phi_{k^{\prime}}^{(n)}\right), \quad \Im\left(\phi_{k}^{(n)}\right)^{T} \Re\left(\phi_{k^{\prime}}^{(n)}\right)+\Re\left(\phi_{k}^{(n)}\right)^{T} \Im\left(\phi_{k^{\prime}}^{(n)}\right)=0 .
\end{aligned}
$$

Combining the first equality in (A.21) with the first equality in (A.22) yields that $\Re\left(\phi_{k}^{(n)}\right)$ and $\Re\left(\phi_{k^{\prime}}^{(n)}\right)$ are orthogonal and that $\Im\left(\phi_{k}^{(n)}\right)$ and $\Im\left(\phi_{k^{\prime}}^{(n)}\right)$ are orthogonal. Furthermore, combining the second equality in (A.21) with the second equality in (A.22) yields that $\Re\left(\phi_{k}^{(n)}\right)$ and $\Im\left(\phi_{k^{\prime}}^{(n)}\right)$ are orthogonal and that $\Im\left(\phi_{k}^{(n)}\right)$ and $\Re\left(\phi_{k^{\prime}}^{(n)}\right)$ are orthogonal. Hence, the vectors in the set $\left\{\Re\left(\phi_{k}^{(n)}\right), \Im\left(\phi_{k}^{(n)}\right), \Re\left(\phi_{k^{\prime}}^{(n)}\right), \Im\left(\phi_{k^{\prime}}^{(n)}\right)\right\}$ are mutually orthogonal for every $k \neq k^{\prime}, k, k^{\prime}=1, \ldots, K$. This implies that to construct the $2 K \times 2 K$ complex matrix $\boldsymbol{\Phi}_{n}$ we need a $2 K \times 2 K$ real orthogonal matrix $\boldsymbol{Q}_{n}=\left[\boldsymbol{q}_{1}^{(n)}, \quad \boldsymbol{q}_{2}^{(n)}, \ldots, \quad \boldsymbol{q}_{2 K}^{(n)}\right]$, i.e., a real matrix with orthonormal columns. Using $\boldsymbol{Q}_{n}$, the $k$-th column of the desired unitary matrix $\boldsymbol{\Phi}_{n}$ in (A.16) can be constructed as $\phi_{k}^{(n)}=\frac{1}{\sqrt{2}}\left(\boldsymbol{q}_{2 k-1}^{(n)}+j \boldsymbol{q}_{2 k}^{(n)}\right), k=1, \ldots, K$, which completes the proof of Theorem 3 . 
APPENDIX A. APPENDICES

\section{A.4 Proof of Theorem 4}

To obtain an upper bound on the PEP of mistaking $\boldsymbol{U}_{2, a}^{(\ell)}$ for $\boldsymbol{U}_{2, b}^{(\ell)}$, we write

$$
\operatorname{Pr}\left(\boldsymbol{U}_{2, a}^{(\ell)} \rightarrow \boldsymbol{U}_{2, b}^{(\ell)}\right)=\mathrm{E}_{\boldsymbol{f}_{n}, \boldsymbol{g}_{n}}\left\{\operatorname{Pr}\left(\boldsymbol{U}_{2, a}^{(\ell)} \rightarrow \boldsymbol{U}_{2, b}^{(\ell)} \mid \boldsymbol{f}_{n}, \boldsymbol{g}_{n}\right)\right\}
$$

Using (4.14), it can be seen that, conditioned on $\boldsymbol{f}_{n}$ and $\boldsymbol{g}_{n}$, the noise vector $\boldsymbol{w}_{1}^{(\ell)}$ is zero mean Gaussian distributed with conditional covariance matrix $\boldsymbol{\Sigma}_{\boldsymbol{w}_{1} \mid \boldsymbol{f}_{n}, \boldsymbol{g}_{n}}=\sum_{n=1}^{N} \beta_{n}^{2}\left\|\boldsymbol{f}_{n}\right\|^{2} \boldsymbol{C}_{n} \boldsymbol{C}_{n}^{\dagger}+\boldsymbol{I}_{N}$. Now, using (4.25), conditioned on $\boldsymbol{f}_{n}$ and $\boldsymbol{g}_{n}$ and the fact that $\boldsymbol{y}_{1}^{(\ell-1)}$ was received in the $\ell-1$-th block, the received vector in the $\ell$-th block, $\boldsymbol{y}_{1}^{(\ell)}$, is Gaussian distributed with mean $\boldsymbol{U}_{2}^{(\ell)} \boldsymbol{y}_{1}^{(\ell-1)}$ and covariance matrix $\boldsymbol{\Sigma}_{\boldsymbol{y}_{1} \mid \boldsymbol{f}_{n}, \boldsymbol{g}_{n}}=2 \boldsymbol{\Sigma}_{\boldsymbol{w}_{1} \mid \boldsymbol{f}_{n}, \boldsymbol{g}_{n}}$. Hence, the probability that the ML detector in (5.19) mistakes $\boldsymbol{U}_{2, a}^{(\ell)}$ for $\boldsymbol{U}_{2, b}^{(\ell)}$ is

$$
\operatorname{Pr}\left(\boldsymbol{U}_{2, a}^{(\ell)} \rightarrow \boldsymbol{U}_{2, b}^{(\ell)} \mid \boldsymbol{f}_{n}, \boldsymbol{g}_{n}\right)=Q\left(\frac{1}{\sqrt{2}}\left\|\boldsymbol{\Sigma}_{\boldsymbol{y}_{1} \mid \boldsymbol{f}_{n}, \boldsymbol{g}_{n}}^{-\frac{1}{\boldsymbol{U}_{2, a}}}\left(\boldsymbol{U}_{2, b}^{(\ell)}-\boldsymbol{U}_{2, b}^{(\ell)}\right) \boldsymbol{y}_{1}^{(\ell-1)}\right\|\right)
$$

At high $P$, the noise components in (4.24) and (4.25) can be ignored and we can closely approximate $\boldsymbol{U}_{2}^{(\ell)} \boldsymbol{y}_{1}^{(\ell-1)}$ by $\sqrt{P_{2}} \boldsymbol{S}_{2}^{(\ell)} \boldsymbol{h}_{2}$. Using this in (A.24) yields

$$
\begin{aligned}
\operatorname{Pr}\left(\boldsymbol{S}_{2, a}^{(\ell)} \rightarrow \boldsymbol{S}_{2, b}^{(\ell)}\right) & =\mathrm{E}_{\boldsymbol{f}_{n}, \boldsymbol{g}_{n}}\left\{Q\left(\frac{1}{\sqrt{2}}\left\|\sqrt{\delta_{0} P} \boldsymbol{\Sigma}_{\boldsymbol{y}_{1} \mid \boldsymbol{f}_{n}, \boldsymbol{g}_{n}}^{-\frac{1}{2}}\left(\boldsymbol{S}_{2, a}^{(\ell)}-\boldsymbol{S}_{2, b}^{(\ell)}\right) \boldsymbol{h}_{2}\right\|\right)\right\} \\
& \leq \mathrm{E}_{\boldsymbol{f}_{n}, \boldsymbol{g}_{n}} e^{-\frac{\delta_{0} P}{8} \boldsymbol{h}_{2}^{\dagger}\left(\boldsymbol{S}_{2, a}^{(\ell)}-\boldsymbol{S}_{2, b}^{(\ell)}\right)^{\dagger} \boldsymbol{\Sigma}_{\boldsymbol{y}_{1} \mid \boldsymbol{f}_{n}, \boldsymbol{g}_{n}}^{-1}\left(\boldsymbol{S}_{2, a}^{(\ell)}-\boldsymbol{S}_{2, b}^{(\ell)}\right) \boldsymbol{h}_{2}}
\end{aligned}
$$

where in writing (A.25), we used the Chernoff bound for the $Q(\cdot)$ function [19]. To obtain a more convenient upper bound that reveals the role of $P, M_{n}$, and $N$, we will obtain a bound on $\boldsymbol{\Sigma}_{\boldsymbol{y}_{1} \mid \boldsymbol{f}_{n}, \boldsymbol{g}_{n}}^{-1}$. Using the fact that $\boldsymbol{C}_{n} \boldsymbol{C}_{n}^{\dagger} \preceq \operatorname{Tr}\left(\boldsymbol{C}_{n} \boldsymbol{C}_{n}^{\dagger}\right) \boldsymbol{I}_{N}$ and $\operatorname{Tr}\left(\boldsymbol{C}_{n} \boldsymbol{C}_{n}^{\dagger}\right)=N$, we can write

$$
\boldsymbol{\Sigma}_{\boldsymbol{y}_{1} \mid \boldsymbol{f}_{n}, \boldsymbol{g}_{n}} \preceq \sigma_{\boldsymbol{y}_{1}} \boldsymbol{I}_{N}
$$

where $\sigma_{\boldsymbol{y}_{1}}=2\left(\frac{P N}{\left(1+\delta_{0}\right) P+1} \sum_{n=1}^{N} \frac{\delta_{n}}{M_{n}}\left\|\boldsymbol{f}_{n}\right\|^{2}+1\right)$. Now, we write $\boldsymbol{h}_{2}=\boldsymbol{F} \boldsymbol{g}$ in (4.13), where

$$
\boldsymbol{F}=\operatorname{diag}\left(\beta_{1} \boldsymbol{f}_{1}^{T} \boldsymbol{X}_{1}^{T}, \ldots, \beta_{N} \boldsymbol{f}_{N}^{T} \boldsymbol{X}_{N}^{T}\right), \quad \boldsymbol{g}=\left[\boldsymbol{g}_{1}^{T}, \ldots, \boldsymbol{g}_{N}^{T}\right]^{T}
$$

Substituting from (A.26) and (A.27) in (A.25) yields the following upper bound on 
the PEP:

$$
\operatorname{Pr}\left(\boldsymbol{S}_{2, a}^{(\ell)} \rightarrow \boldsymbol{S}_{2, b}^{(\ell)}\right) \leq \mathrm{E}_{\boldsymbol{f}_{n}, \boldsymbol{g}_{n}} e^{-\frac{\delta_{0} P}{8 \sigma \boldsymbol{y}_{1}} \boldsymbol{g}^{\dagger} \boldsymbol{F}^{\dagger} \boldsymbol{\Psi}\left(\boldsymbol{S}_{2, a}^{(\ell)}, \boldsymbol{S}_{2, b}^{(\ell)}\right) \boldsymbol{F} \boldsymbol{g}}
$$

where $\Psi\left(\boldsymbol{S}_{2, a}^{(\ell)}, \boldsymbol{S}_{2, b}^{(\ell)}\right)$ is defined in Appendix A.2. Computing the expectation over the entries of $\boldsymbol{g}_{n}$, which are i.i.d. zero-mean unit-variance complex Gaussian random variables yields [44]

$$
\operatorname{Pr}\left(\boldsymbol{S}_{2, a}^{(\ell)} \rightarrow \boldsymbol{S}_{2, b}^{(\ell)}\right) \leq \mathrm{E}_{\boldsymbol{f}_{n}}\left|\boldsymbol{I}_{N}+\frac{\delta_{0} P}{8 \sigma_{\boldsymbol{y}_{1}}} \boldsymbol{\Psi}\left(\boldsymbol{S}_{2, a}^{(\ell)}, \boldsymbol{S}_{2, b}^{(\ell)}\right) \boldsymbol{F} \boldsymbol{F}^{\dagger}\right|^{-1}
$$

At high values of $P$, the unity in the denominator of $\sigma_{\boldsymbol{y}_{1}}$ can be ignored, yielding $\sigma_{\boldsymbol{y}_{1}} \approx 2\left(\frac{N}{\left(1+\delta_{0}\right)} \sum_{n=1}^{N} \frac{\delta_{n}}{M_{n}}\left\|\boldsymbol{f}_{n}\right\|^{2}+1\right)$, and noting that $\boldsymbol{\Psi}\left(\boldsymbol{S}_{2, a}^{(\ell)}, \boldsymbol{S}_{2, b}^{(\ell)}\right)$ is strictly positive definite, the identity matrix, $\boldsymbol{I}_{N}$, can be ignored in in (A.29). Combining this with the $\sigma_{\boldsymbol{y}_{1}}$ yields

$$
\operatorname{Pr}\left(\boldsymbol{S}_{2, a}^{(\ell)} \rightarrow \boldsymbol{S}_{2, b}^{(\ell)}\right) \leq\left(\frac{\delta_{0} P}{16}\right)^{-N}\left|\boldsymbol{\Psi}\left(\boldsymbol{S}_{2, a}^{(\ell)}, \boldsymbol{S}_{2, b}^{(\ell)}\right)\right|^{-1} \mathrm{E}_{\boldsymbol{f}_{n}}\left\{\chi\left(\left\|\boldsymbol{f}_{n}\right\|^{2}\right)\right\}
$$

where $\chi\left(\left\|\boldsymbol{f}_{n}\right\|^{2}\right)=\frac{\left(1+\delta_{0}+N \sum_{n=1}^{N} \frac{\delta_{n}}{M_{n}}\left\|\boldsymbol{f}_{n}\right\|^{2}\right)^{N}}{\prod_{n=1}^{N} \frac{\delta_{n}}{M_{n}}\left\|\boldsymbol{f}_{n}\right\|^{2}}$. To compute the expectation, we consider two disjoint intervals: $\left\|\boldsymbol{f}_{n}\right\|^{2}>M_{n}$ and $\left\|\boldsymbol{f}_{n}\right\|^{2} \leq M_{n}$. Using these intervals, the expectation in (A.30) is

$$
\begin{gathered}
\mathrm{E}_{\boldsymbol{f}_{n}}\left\{\chi\left(\left\|\boldsymbol{f}_{n}\right\|^{2}\right)\right\}=\Xi_{1} \operatorname{Pr}\left(\left\|\boldsymbol{f}_{n}\right\|^{2} \leq M_{n}\right)+\Xi_{2} \operatorname{Pr}\left(\left\|\boldsymbol{f}_{n}\right\|^{2}>M_{n}\right), \\
\Xi_{1}=\mathrm{E}_{\boldsymbol{f}_{n}}\left\{\chi\left(\left\|\boldsymbol{f}_{n}\right\|^{2}\right) \mid\left\|\boldsymbol{f}_{n}\right\|^{2} \leq M_{n}\right\}, \quad \Xi_{2}=\mathrm{E}_{\boldsymbol{f}_{n}}\left\{\chi\left(\left\|\boldsymbol{f}_{n}\right\|^{2}\right) \mid\left\|\boldsymbol{f}_{n}\right\|^{2}>M_{n}\right\}
\end{gathered}
$$

This choice of intervals simplifies analysis, but does not necessarily yield the tightest bound. Now, $\left\|\boldsymbol{f}_{n}\right\|^{2}$ is a Chi-square random variable with $2 M_{n}$ degree of freedom and its $\mathrm{CDF}$ is

$$
\operatorname{Pr}\left(\left\|\boldsymbol{f}_{n}\right\|^{2} \leq M_{n}\right)=1-e^{-M_{n}} \sum_{m=0}^{M_{n}-1} \frac{1}{m !} M_{n}^{m} .
$$

To proceed, we have the following bounds on $\Xi_{1}$ and $\Xi_{2}$. 
Lemma 6. When $\left\|\boldsymbol{f}_{n}\right\|^{2} \leq M_{n}$ we have the following upper bound

$$
\Xi_{1} \leq \frac{\left(1+\delta_{0}+N \sum_{n=1}^{N} \delta_{n}\right)^{N}}{\prod_{n=1}^{N} \delta_{n}}
$$

Proof. Since $\left\|\boldsymbol{f}_{n}\right\|^{2} \leq M_{n}$, we have

$$
\Xi_{1} \leq \mathrm{E}_{\boldsymbol{f}_{n}}\left\{\frac{\left(1+\delta_{0}+N \sum_{n=1}^{N} \delta_{n}\right)^{N}}{\prod_{n=1}^{N} \frac{\delta_{n}}{M_{n}}\left\|\boldsymbol{f}_{n}\right\|^{2}}\right\} .
$$

Since $M_{n}$ is even (cf. Lemma 2), we have $M_{n} \geq 2$. Hence, the expectation on the RHS of (A.35) can be readily computed, thereby yielding the bound in the lemma.

Lemma 7. When $\left\|\boldsymbol{f}_{n}\right\|^{2}>M_{n}$ we have the following upper bound

$$
\Xi_{2} \leq \frac{\left(1+\delta_{0}\right)^{N}+N^{N} \sum_{n=1}^{N}\left(\frac{\delta_{n}}{M_{n}}\right)^{N} \frac{\left(N+M_{n}-1\right) !}{\left(M_{n}-1\right) !}}{\prod_{n=1}^{N} \delta_{n}}
$$

Proof. Since $\left\|\boldsymbol{f}_{n}\right\|^{2}>M_{n}$ we have

$$
\begin{aligned}
\Xi_{2} & \leq \mathrm{E}_{\boldsymbol{f}_{n}}\left\{\frac{\left(1+\delta_{0}+N \sum_{n=1}^{N} \frac{\delta_{n}}{M_{n}}\left\|\boldsymbol{f}_{n}\right\|^{2}\right)^{N}}{\prod_{n=1}^{N} \delta_{n}}\right\} \\
& \leq \mathrm{E}_{\boldsymbol{f}_{n}}\left\{\frac{\left(1+\delta_{0}\right)^{N}+N^{N} \sum_{n=1}^{N}\left(\frac{\delta_{n}}{M_{n}}\left\|\boldsymbol{f}_{n}\right\|^{2}\right)^{N}}{\prod_{n=1}^{N} \delta_{n}}\right\}
\end{aligned}
$$

where the first inequality is obtained by using $\left\|\boldsymbol{f}_{n}\right\|^{2}>M_{n}$ in the denominator of $\Xi_{2}$ and the second inequality is obtained by using the Jensen's inequality. Finally, the expectation on the RHS of (A.37) can be readily computed, thereby yielding the bound in the lemma.

Substituting from (A.34) and (A.36) in (A.30) results in the PEP upper bound given in (4.27).

\section{A.5 Computing Covariance Matrices}

To obtain $\boldsymbol{\Sigma}_{\boldsymbol{\eta}_{1}}$, we need to compute $\boldsymbol{\Sigma}_{\boldsymbol{w}_{1}}, \boldsymbol{\Sigma}_{\hat{\boldsymbol{w}}_{1}}$. Using that $\left\{f_{n}^{(1)}\right\},\left\{\boldsymbol{z}_{n}^{(\ell)}\right\}$ and $\boldsymbol{v}_{1}^{(\ell)}$ are statistically independent Gaussian distributed with zero mean and unit variance, we 
have

$$
\begin{aligned}
\Sigma_{\boldsymbol{w}_{1}} & =\mathrm{E}\left\{\sum_{n=1}^{N} \sum_{m=1}^{N} \beta_{n} \beta_{m} f_{n}^{(1)} \bar{f}_{m}^{(1)}\left(\boldsymbol{A}_{n} \boldsymbol{z}_{n}^{(\ell)}+\boldsymbol{B}_{n} \overline{\boldsymbol{z}}_{n}^{(\ell)}\right)\left(\boldsymbol{A}_{m} \boldsymbol{z}_{m}^{(\ell)}+\boldsymbol{B}_{m} \overline{\boldsymbol{z}}_{m}^{(\ell)}\right)^{\dagger}\right\}+\mathrm{E}\left\{\boldsymbol{v}_{n}^{(\ell)} \boldsymbol{v}_{n}^{(\ell)^{\dagger}}\right\} \\
& =\sum_{n=1}^{N} \beta_{n}^{2}\left(\boldsymbol{A}_{n} \boldsymbol{A}_{n}^{\dagger}+\boldsymbol{B}_{n} \boldsymbol{B}_{n}^{\dagger}\right)+\boldsymbol{I}_{N} .
\end{aligned}
$$

Using (5.15), the covariance matrix of $\hat{\boldsymbol{w}}_{1}, \Sigma_{\hat{\boldsymbol{w}}_{1}}$, can be expressed as:

$$
\begin{aligned}
\Sigma_{\hat{\boldsymbol{w}}_{1}} & =\mathrm{E}\left\{\boldsymbol{w}_{1}^{(\ell)} \boldsymbol{w}_{1}^{(\ell) \dagger}\right\}+\frac{P_{1}+1}{P_{1}+P_{2}+1} \mathrm{E}\left\{\boldsymbol{\Phi}_{1}^{(\ell)} \boldsymbol{w}_{1}^{(1)} \boldsymbol{w}_{1}^{(1)^{\dagger}} \boldsymbol{\Phi}_{1}^{(\ell)^{\dagger}}\right\} \\
& =\Sigma_{\boldsymbol{w}_{1}}+\frac{P_{1}+1}{P_{1}+P_{2}+1} \mathrm{E}\left\{\boldsymbol{\Phi}_{1}^{(\ell)} \Sigma_{\boldsymbol{w}_{1}} \boldsymbol{\Phi}_{1}^{(\ell) \dagger}\right\} .
\end{aligned}
$$

Using the definition of $\boldsymbol{\eta}_{1}^{(\ell)}$ given in (5.18) along with the fact that $\hat{\boldsymbol{w}}_{1}^{(\ell)}$ and $\hat{\boldsymbol{w}}_{1}^{(\ell-1)}$ are statistically independent, the covariance of the equivalent noise $\boldsymbol{\eta}_{1}^{(\ell)}$ can be expressed as:

$$
\begin{aligned}
\Sigma_{\boldsymbol{\eta}_{1}} & =\mathrm{E}\left\{\hat{\boldsymbol{w}}_{1}^{(\ell)} \hat{\boldsymbol{w}}_{1}^{(\ell)^{\dagger}}\right\}+\mathrm{E}\left\{\boldsymbol{U}_{2}^{(\ell)} \hat{\boldsymbol{w}}_{1}^{(\ell-1)} \hat{\boldsymbol{w}}_{1}^{(\ell-1)^{\dagger}} \boldsymbol{U}_{2}^{(\ell)^{\dagger}}\right\} \\
& =\Sigma_{\hat{\boldsymbol{w}}_{1}}+\mathrm{E}\left\{\boldsymbol{U}_{2}^{(\ell)} \Sigma_{\hat{\boldsymbol{w}}_{1}} \boldsymbol{U}_{2}^{(\ell)^{\dagger}}\right\} .
\end{aligned}
$$

\section{A.6 Proof of Theorem 5}

Using the ML symbol detector in (5.19), the PEP of detecting $\boldsymbol{U}_{2 b}^{(\ell)}$ at the first node when $\boldsymbol{U}_{2 a}^{(\ell)}$ is transmitted by the second node is given by

$$
\operatorname{Pr}\left(\boldsymbol{U}_{2 a}^{(\ell)} \rightarrow \boldsymbol{U}_{2 b}^{(\ell)}\right)=\mathrm{E}_{\hat{\boldsymbol{y}}_{1}^{(\ell-1)}}\left\{Q\left(2^{-\frac{1}{2}}\left\|\boldsymbol{\Sigma}_{\boldsymbol{\eta}_{1}^{-\frac{1}{2}}}\left(\boldsymbol{U}_{2 a}^{(\ell)}-\boldsymbol{U}_{2 b}^{(\ell)}\right) \hat{\boldsymbol{y}}_{1}^{(\ell-1)}\right\|\right)\right\}
$$

To proceed with analysis, we use the Chernoff bound on the $Q$-function to obtain [19]

$$
\operatorname{Pr}\left(\boldsymbol{U}_{2 a}^{(\ell)} \rightarrow \boldsymbol{U}_{2 b}^{(\ell)}\right) \leq \mathrm{E}_{\hat{\boldsymbol{y}}_{1}^{(\ell-1)}}\left\{\exp \left\{-\frac{1}{4} \hat{\boldsymbol{y}}_{1}^{(\ell-1)^{\dagger}}\left(\boldsymbol{U}_{2 a}^{(\ell)}-\boldsymbol{U}_{2 b}^{(\ell)}\right)^{\dagger} \Sigma_{\boldsymbol{\eta}_{1}}^{-1}\left(\boldsymbol{U}_{2 a}^{(\ell)}-\boldsymbol{U}_{2 b}^{(\ell)}\right) \hat{\boldsymbol{y}}_{1}^{(\ell-1)}\right\}\right\}
$$

To obtain a more convenient bound, we derive an upper bound on the covariance matrix $\Sigma_{\boldsymbol{\eta}_{1}}$ given in (A.41). To do so, first we derive an upper bound on $\Sigma_{\boldsymbol{w}_{1}}$ and $\Sigma_{\hat{\boldsymbol{w}}_{1}}$. 
Using the fact that for any $N \times N$ matrix $\boldsymbol{A}$ we have $\boldsymbol{A} \boldsymbol{A}^{\dagger} \preceq \operatorname{Tr}\left(\boldsymbol{A} \boldsymbol{A}^{\dagger}\right) \boldsymbol{I}_{N}$ along with the fact that $\operatorname{Tr}\left(\boldsymbol{A}_{n} \boldsymbol{A}_{n}^{\dagger}+\boldsymbol{B}_{n} \boldsymbol{B}_{n}^{\dagger}\right)=N$ in (A.39) yields $\Sigma_{\boldsymbol{w}_{1}} \preceq\left(1+N \sum_{n=1}^{N} \beta_{n}^{2}\right) \boldsymbol{I}_{N}$. Now, using this upper bound on $\Sigma_{\boldsymbol{w}_{1}}$ in (A.40) yields $\Sigma_{\hat{\boldsymbol{w}}_{1}} \preceq\left(1+\frac{P_{1}+1}{P_{1}+P_{2}+1}\right)(1+$ $\left.N \sum_{n=1}^{N} \beta_{n}^{2}\right) \boldsymbol{I}_{N}$, where we have used the fact that $\boldsymbol{\Phi}_{1}^{(\ell)}$ is a unitary matrix, for all $\ell$. Finally, using the bound on $\Sigma_{\hat{\boldsymbol{w}}_{1}}$ along with the fact that in (A.41) $\boldsymbol{U}_{2 r}^{(\ell)}$ is unitary $\forall \ell$ and $r=a, b$ yields $\Sigma_{\boldsymbol{\eta}_{1}} \preceq 2\left(1+\frac{P_{1}+1}{P_{1}+P_{2}+1}\right)\left(1+N \sum_{n=1}^{N} \beta_{n}^{2}\right) \boldsymbol{I}_{N}$. Substituting the bound on $\Sigma_{\boldsymbol{\eta}_{1}}$ into (A.43) yields

$$
\operatorname{Pr}\left(\boldsymbol{U}_{2 a}^{(\ell)} \rightarrow \boldsymbol{U}_{2 b}^{(\ell)}\right) \leq \mathrm{E}_{\hat{\boldsymbol{y}}_{1}^{(\ell-1)}}\left\{\exp \left\{-\frac{1}{4 \sigma_{1}} \hat{\boldsymbol{y}}_{1}^{(\ell-1)^{\dagger}} \boldsymbol{\Omega}_{a b}^{(\ell)} \hat{\boldsymbol{y}}_{1}^{(\ell-1)}\right\}\right\}
$$

where $\sigma_{1}=2\left(1+\frac{P_{1}+1}{P_{1}+P_{2}+1}\right)\left(1+N \sum_{n=1}^{N} \beta_{n}^{2}\right)$ and $\boldsymbol{\Omega}_{a b}^{(\ell)}=\left(\boldsymbol{U}_{2 a}^{(\ell)}-\boldsymbol{U}_{2 b}^{(\ell)}\right)^{\dagger}\left(\boldsymbol{U}_{2 a}^{(\ell)}-\boldsymbol{U}_{2 b}^{(\ell)}\right)$. To compute the expectation over $\hat{\boldsymbol{y}}_{1}^{(\ell-1)}$ in (A.44), we need the distribution of $\hat{\boldsymbol{y}}_{1}^{(\ell-1)}$. Using the fact that, in (5.14), the entries of $\left\{\boldsymbol{z}_{n}^{(\ell)}\right\}, \boldsymbol{v}_{1}^{(\ell)},\left\{f_{n}^{(i)}\right\}$ and $\left\{g_{n}^{(i)}\right\}, i=1,2$, are distributed independently with zero mean and unit variance, we can show that $\hat{\boldsymbol{y}}_{1}^{(\ell-1)}$ has zero mean and the following covariance matrix

$$
\begin{aligned}
\Sigma_{\hat{\boldsymbol{y}}_{1}} & =P_{2} \mathrm{E}\left\{\sum_{n=1}^{N} \beta_{n}^{2}\left|f_{n}^{(1)}\right|^{2}\left|f_{n}^{(2)}\right|^{2} \boldsymbol{A}_{n} \boldsymbol{s}_{2}^{(\ell)} \boldsymbol{s}_{2}^{(\ell)^{\dagger}} \boldsymbol{A}_{n}^{\dagger}\right\} \\
& +P_{2} \mathrm{E}\left\{\sum_{n=1}^{N} \beta_{n}^{2}\left|f_{n}^{(1)}\right|^{2}\left|f_{n}^{(2)}\right|^{2} \boldsymbol{B}_{n} \boldsymbol{s}_{2}^{(\ell)} \boldsymbol{s}_{2}^{(\ell)^{\dagger}} \boldsymbol{B}_{n}^{\dagger}\right\} \\
& +\mathrm{E}\left\{\hat{\boldsymbol{w}}_{1}^{(\ell)} \hat{\boldsymbol{w}}_{1}^{(\ell)^{\dagger}}\right\}, \\
& =P_{2} \sum_{n=1}^{N} \beta_{n}^{2}\left(\boldsymbol{A}_{n} \boldsymbol{A}_{n}^{\dagger}+\boldsymbol{B}_{n} \boldsymbol{B}_{n}^{\dagger}\right)+\Sigma_{\hat{\boldsymbol{w}}_{1}},
\end{aligned}
$$

where $\Sigma_{\hat{\boldsymbol{w}}_{1}}$ is given in (A.40). We note that, $\hat{\boldsymbol{y}}_{1}^{(\ell-1)}$ is not Gaussian which complicates analysis. To circumvent this difficultly, we assume that $\hat{\boldsymbol{y}}_{1}^{(\ell-1)}$ is zero mean Gaussian with covariance $\Sigma_{\hat{\boldsymbol{y}}_{1}}$. Using the Gaussian probability density function corresponding 
to $\hat{\boldsymbol{y}}_{1}$, the expectation over $\hat{\boldsymbol{y}}_{1}^{(\ell-1)}$ in (A.44) can be readily computed yielding

$$
\begin{aligned}
\operatorname{Pr}\left(\boldsymbol{U}_{2 a}^{(\ell)} \rightarrow \boldsymbol{U}_{2 b}^{(\ell)}\right) & \leq \int \frac{1}{\pi^{N}\left|\Sigma_{\hat{\boldsymbol{y}}_{1}}\right|} \exp \left\{-\hat{\boldsymbol{y}}_{1}^{(\ell-1)^{\dagger}}\left(\Sigma_{\hat{\boldsymbol{y}}_{1}}^{-1}+\frac{1}{4 \sigma_{1}} \boldsymbol{\Omega}_{a b}^{(\ell)}\right) \hat{\boldsymbol{y}}_{1}^{(\ell-1)}\right\} d \hat{\boldsymbol{y}}_{1}^{(\ell-1)} \\
& =\frac{1}{\left|\Sigma_{\hat{\boldsymbol{y}}_{1}}\right|}\left|\Sigma_{\hat{\boldsymbol{y}}_{1}}^{-1}+\frac{1}{4 \sigma_{1}} \boldsymbol{\Omega}_{a b}^{(\ell)}\right|^{-1} \\
& <\left|\frac{1}{4 \sigma_{1}} \Sigma_{\hat{\boldsymbol{y}}_{1}} \boldsymbol{\Omega}_{a b}^{(\ell)}\right|^{-1} \\
& =\left(4 \sigma_{1}\right)^{N}\left|\boldsymbol{\Omega}_{a b}^{(\ell)}\right|^{-1}\left|\Sigma_{\hat{\boldsymbol{y}}_{1}}\right|^{-1}
\end{aligned}
$$

To obtain (A.48), we assumed that the minimum eigenvalue of $\Sigma_{\hat{\boldsymbol{y}}_{1}} \boldsymbol{\Omega}_{a b}^{(\ell)}, \lambda_{\min } \gg 4 \sigma_{1}$.

\section{A.7 Proof of Corollary 2}

For ease of exposition, we assume equal powers at the nodes and the relays, that is, $P_{1}=P_{2}=P_{r_{n}}=P, n=1, \ldots, N$. Hence we have $\beta_{n}^{2}=\frac{P}{2 P+1}$ which, for $P \gg \frac{1}{2}$, yields that $\beta_{n}^{2} \approx \frac{1}{2}$. Using the fact that $\boldsymbol{A}_{n} \boldsymbol{A}_{n}^{\dagger}+\boldsymbol{B}_{n} \boldsymbol{B}_{n}^{\dagger} \preceq \operatorname{Tr}\left(\boldsymbol{A}_{n} \boldsymbol{A}_{n}^{\dagger}+\boldsymbol{B}_{n} \boldsymbol{B}_{n}^{\dagger}\right) \boldsymbol{I}_{N}$ [45] along with (5.4) for $P \gg \frac{1}{2}$ in (A.39) yields that $\Sigma_{\boldsymbol{w}_{1}} \preceq\left(\frac{N^{2}}{2}+1\right) \boldsymbol{I}_{N}$. Using this in (A.40) yields that $\Sigma_{\hat{\boldsymbol{w}}_{1}} \preceq \frac{3}{4}\left(N^{2}+2\right) \boldsymbol{I}_{N}$ for $P \gg 1$ and using this in (A.45), we can ignore $\Sigma_{\hat{\boldsymbol{w}}_{1}}$ for $P \gg \frac{3}{2}\left(1+\frac{2}{N^{2}}\right)$. Hence, for $P \gg \frac{3}{2}\left(1+\frac{2}{N^{2}}\right)$, we have $\Sigma_{\hat{\boldsymbol{y}}_{1}} \approx$ $\frac{P}{2} \sum_{n=1}^{N}\left(\boldsymbol{A}_{n} \boldsymbol{A}_{n}^{\dagger}+\boldsymbol{B}_{n} \boldsymbol{B}_{n}^{\dagger}\right)$. Substituting this in (5.21) yields (5.23).

\section{A.8 Proof of Theorem 6}

For two distinct information matrices with the structure in (5.25), we have [46]

$$
\left|\boldsymbol{\Omega}_{a b}^{(\ell)}\right|=\left(\left|u_{2 a, 1}^{(\ell)}-u_{2 b, 1}^{(\ell)}\right|^{2}+\left|u_{2 a, 2}^{(\ell)}-u_{2 b, 2}^{(\ell)}\right|^{2}\right)^{2}
$$

which is minimized when one of the two terms is zero and the other is minimum. Since, the minimum distance between two symbols of the $M$-PSK constellation is $2 \sin \left(\frac{\pi}{M}\right)$, we have

$$
\left|\Omega_{a b}^{(\ell)}\right| \geq 16 \sin ^{4}\left(\frac{\pi}{M}\right)
$$

For the Alamouti code, we have $N=2$ and $\boldsymbol{A}_{n} \boldsymbol{A}_{n}^{\dagger}+\boldsymbol{B}_{n} \boldsymbol{B}_{n}^{\dagger}=\boldsymbol{I}_{2}, n=1,2$. Substituting these values and using the fact that $\beta_{n}^{2}=\frac{1}{2}$ for $P \gg \frac{1}{2}$ in (5.22) yields $\sigma_{1}=9$ and $\Sigma_{\hat{\boldsymbol{y}}_{1}}=(3+P) \boldsymbol{I}_{2}$. Using these values and the bound on $\left|\boldsymbol{\Omega}_{\boldsymbol{a b}}{ }^{(\ell)}\right|$ in (A.51) in the 
RHS of (5.21) yields

$$
\mathrm{PEP} \leq \frac{\left(9(3+P)^{-1}\right)^{2}}{\sin ^{4}\left(\frac{\pi}{M}\right)} .
$$

Since in the DDST based on the Alamouti scheme, each node transmits 2 symbols from the same $M$-PSK constellation over 4 consecutive time slots, the overall transmission rate of the DDST scheme in this case is $R=\log _{2} M$, i.e., $M=2^{R}$. Using this in (A.52) yields (5.26).

\section{A.9 Proof of Lemma 2}

To prove this lemma, we will begin by providing a lower bound on $\left|k M_{2}-m M_{1}\right|$ when $M_{1}$ and $M_{2}$ are co-prime integers and $k \in\left\{1, \ldots, M_{1}-1\right\}$ and $m \in\left\{1, \ldots, M_{2}-1\right\}$. We will then show that this bound is always achievable. For any integers $k$ and $m$ and co-prime integers $M_{1}$ and $M_{2}$, we will show that $\left|k M_{2}-m M_{1}\right| \geq 1$. To do so, we use contradiction. Suppose that $\left|k M_{2}-m M_{1}\right|=0$. This implies that $M_{2}$ divides $m M_{1}$, i.e., $M_{2} \mid m M_{1}$. But, since $M_{1}$ and $M_{2}$ are co-prime, $M_{2} \mid m M_{1}$ implies that $M_{2} \mid m$, which is not possible because $m \in\left\{1, \ldots, M_{2}-1\right\}$. Hence, we conclude that $\left|k M_{2}-m M_{1}\right| \neq 0$, which automatically implies that $\left|k M_{2}-m M_{1}\right| \geq 1$. Now, we show that for any co-prime $M_{1}$ and $M_{2}$, there always exist integers, $k$ and $m$, that achieve the lower bound. To do that, we note that if $\left|k M_{2}-m M_{1}\right|=1$, then either $k M_{2}=1\left(\bmod M_{1}\right)$ or $m M_{1}=1\left(\bmod M_{2}\right)$. Since $M_{1}$ and $M_{2}$ are co-prime, Fermat's Little Theorem ensures that these congruences can be solved [47]. Hence, there exist $k$ and $m$ such that min $\left|k M_{2}-m M_{1}\right|=1$, which completes the proof.

\section{A.10 Proof of Lemma 3}

To prove this lemma, we begin by noting that, for a fixed $a$, the solution set of $|\sin x|>|\sin a|$ lies in the union of the intervals $x \in(a, \pi-a)$ and $x \in(\pi+a, 2 \pi-a)$. Hence, the proof of this lemma hinges on showing that, for $k \in\left\{1, \ldots, M_{1}-1\right\}$, the angle $\frac{4 \pi k}{M_{1}}$ belongs neither to $\left[-\frac{2 \pi}{M_{1} M_{2}}, \frac{2 \pi}{M_{1} M_{2}}\right]$ nor to $\left[\pi-\frac{2 \pi}{M_{1} M_{2}}, \pi+\frac{2 \pi}{M_{1} M_{2}}\right]$. To do so, we use contradiction. First, we suppose that $\frac{4 \pi k}{M_{1}} \in\left[-\frac{2 \pi}{M_{1} M_{2}}, \frac{2 \pi}{M_{1} M_{2}}\right]$, which implies that $-\frac{1}{2 M_{2}} \leq k \leq \frac{1}{2 M_{2}}$. But, for any integer $M_{2}$, this inequality is satisfied only with $k=0$ which is not possible because $k \in\left\{1, \ldots, M_{1}-1\right\}$. Hence, we conclude $\frac{4 \pi k}{M_{1}} \notin\left[-\frac{2 \pi}{M_{1} M_{2}}, \frac{2 \pi}{M_{1} M_{2}}\right]$. Second, we suppose that $\frac{4 \pi k}{M_{1}} \in\left[\pi-\frac{2 \pi}{M_{1} M_{2}}, \pi+\frac{2 \pi}{M_{1} M_{2}}\right]$, which 
implies that $M_{1} M_{2}-2 \leq 4 k M_{2} \leq M_{1} M_{2}+2$. Finding an integer $k$ that satisfies this inequality is equivalent to finding the solution of one of the following equalities: 1) $\left.4 k M_{2}=M_{1} M_{2}, 2\right) 4 k M_{2}=M_{1} M_{2} \pm 1$, or 3) $4 k M_{2}=M_{1} M_{2} \pm 2$. It can be readily seen that none of these equalities can be satisfied by any integer $k$. More precisely, the solution of the first equation is $k=\frac{M_{1}}{4}$ which is not an integer for odd $M_{1}$. Hence, the first equation does not have a solution. The Second and third equations imply that $M_{2}$ divides $M_{1} M_{2} \pm 1$ and $M_{1} M_{2} \pm 2$, i.e., $M_{2} \mid M_{1} M_{2} \pm 1$ and $M_{2} \mid M_{1} M_{2} \pm 2$, which is impossible because $M_{1}$ and $M_{2}$ are co-prime integers. Hence, we conclude that $\frac{4 \pi k}{M_{1}} \notin\left[\pi-\frac{2 \pi}{M_{1} M_{2}}, \pi+\frac{2 \pi}{M_{1} M_{2}}\right]$. Using this along with $\frac{4 \pi k}{M_{1}} \notin\left[-\frac{2 \pi}{M_{1} M_{2}}, \frac{2 \pi}{M_{1} M_{2}}\right]$ yields that $\left|\sin \left(\frac{4 \pi k}{M_{1}}\right)\right|>\left|\sin \left(\frac{2 \pi}{M_{1} M_{2}}\right)\right|$. Using a similar approach, it can be readily shown that $\left|\sin \left(\frac{2 \pi k}{M_{1}}\right)\right|>\left|\sin \left(\frac{2 \pi}{M_{1} M_{2}}\right)\right|$ and $\left|\sin \left(\frac{2 \pi k}{M_{1}}\right)\right|>\left|\sin \left(\frac{\pi}{M_{1} M_{2}}\right)\right|$.

\section{A.11 Proof of Theorem 7}

In [42], it is shown that, for two distinct information matrix $\boldsymbol{U}_{2 a}^{(\ell)}$ and $\boldsymbol{U}_{2 b}^{(\ell)}$ transmitted from the second node, $\left|\boldsymbol{U}_{2 a}^{(\ell)}-\boldsymbol{U}_{2 b}^{(\ell)}\right|$ is given by

$$
\left|\boldsymbol{U}_{2 a}^{(\ell)}-\boldsymbol{U}_{2 b}^{(\ell)}\right|=\frac{1}{4}|\alpha|^{2}\left(q+\frac{1}{q}\right)^{2}+\frac{1}{4}\left|q \beta-\frac{\bar{\beta}}{q}\right|^{2}
$$

where $q=\sqrt{\frac{\operatorname{det} \boldsymbol{O}_{1}^{(\ell)}}{\operatorname{det} \boldsymbol{O}_{2}^{(\ell)}}},(\alpha, \beta)$ is the first row of the $2 \times 2$ matrix $\overline{\boldsymbol{O}}_{1}^{(\ell)} \boldsymbol{O}_{2}^{(\ell)^{\dagger}}$, where $\boldsymbol{O}_{1}^{(\ell)}=\boldsymbol{\Xi}_{2 a}^{(\ell)} \boldsymbol{\Psi}_{2 a}^{(\ell)}-\boldsymbol{\Xi}_{2 b}^{(\ell)} \boldsymbol{\Psi}_{2 b}^{(\ell)}$ and $\boldsymbol{O}_{2}^{(\ell)}=\boldsymbol{\Xi}_{2 a}^{(\ell)} \overline{\boldsymbol{\Psi}}_{2 a}^{(\ell)}-\boldsymbol{\Xi}_{2 b}^{(\ell)} \overline{\boldsymbol{\Psi}}_{2 b}^{(\ell)}$, cf. (5.27). Using (5.27), we 
have

$$
\begin{aligned}
\alpha & =2 e^{-\jmath \frac{4 \pi k_{2 a}^{(\ell)}}{M_{1}}}+2 e^{-\jmath \frac{4 \pi l_{2 a}^{(\ell)}}{M_{1}}}+2 e^{-\jmath \frac{4 \pi k_{2 b}^{(\ell)}}{M_{1}}}+2 e^{-\jmath \frac{4 \pi l_{2 b}^{(\ell)}}{M_{1}}} \\
& -2 X\left(e^{-\jmath \frac{2 \pi\left(k_{2 a}^{(\ell)}+k_{2 b}^{(\ell)}\right)}{M_{1}}}+e^{-\jmath \frac{2 \pi\left(l_{2 a}^{(\ell)}+l_{2 b}^{(\ell)}\right)}{M_{1}}}\right) \\
& +2 Y\left(e^{-\jmath \frac{2 \pi\left(k_{2 a}^{(\ell)}+l_{2 b}^{(\ell)}\right)}{M_{1}}}-e^{-\jmath \frac{2 \pi\left(l_{2 a}^{(\ell)}+k_{2 b}^{(\ell)}\right)}{M_{1}}}\right) \\
\beta & =4 e^{j \frac{2 \pi\left(k_{2 a}^{(\ell)}-l_{2 a}^{(\ell)}\right)}{M_{1}}}+4 e^{\jmath \frac{2 \pi\left(k_{2 b}^{(\ell)}-l_{2 b}^{(\ell)}\right)}{M_{1}}} \\
& -2 X\left(e^{\frac{2 \pi\left(k_{2 a}^{(\ell)}-l_{2 b}^{(\ell)}\right)}{M_{1}}}-e^{\jmath \frac{2 \pi\left(l_{2 a}^{(\ell)}-k_{2 b}^{(\ell)}\right)}{M_{1}}}\right) \\
& -2 Y\left(e^{\jmath \frac{2 \pi\left(k_{2 a}^{(\ell)}-k_{2 b}^{(\ell)}\right)}{M_{1}}}+e^{\jmath \frac{2 \pi\left(l_{2 a}^{(\ell)}-l_{2 b}^{(\ell)}\right)}{M_{1}}}\right) \\
X & \triangleq \cos \left(2 \pi \frac{m_{2 a}^{(\ell)}-m_{2 b}^{(\ell)}}{M_{2}}\right)+\cos \left(2 \pi \frac{n_{2 a}^{(\ell)}-n_{2 b}^{(\ell)}}{M_{2}}\right) \\
Y & \triangleq \cos \left(2 \pi \frac{m_{2 a}^{(\ell)}+n_{2 b}^{(\ell)}}{M_{2}}\right)-\cos \left(2 \pi \frac{n_{2 a}^{(\ell)}+m_{2 b}^{(\ell)}}{M_{2}}\right) .
\end{aligned}
$$

In [42], it is shown that for co-prime integers $M_{1}$ and $M_{2},\left|\boldsymbol{U}_{2 a}^{(\ell)}-\boldsymbol{U}_{2 b}^{(\ell)}\right|$ is always non-zero.

Using the fact that $\boldsymbol{O}_{p}^{(\ell)}, \boldsymbol{\Xi}_{2 r}^{(\ell)}$ and $\Psi_{2 r}^{(\ell)}, p=1,2, r=a, b$, are orthogonal with positive determinants [42], it can be readily verified that $\left(q+\frac{1}{q}\right)^{2} \geq 4$ and $\left|q \beta-\frac{\bar{\beta}}{q}\right|^{2} \geq$ $4 \Im(\beta)^{2}$. Hence,

$$
\left|\boldsymbol{U}_{2 a}^{(\ell)}-\boldsymbol{U}_{2 b}^{(\ell)}\right| \geq \Re(\alpha)^{2}+\Im(\alpha)^{2}+\Im(\beta)^{2}
$$

where, To obtain a lower bound on the RHS of (A.57), we will proceed in two steps. In the first step, we ignore the condition that $M_{1}$ and $M_{2}$ are co-prime. In particular, we assume that there exists an integer $c$ such that $M_{2}=c M_{1}$. In this case, we will show that, for any two information matrices $\boldsymbol{U}_{2 a}^{(\ell)}$ and $\boldsymbol{U}_{2 b}^{(\ell)}$, setting

$$
l_{2 a}^{(\ell)}=m_{2 a}^{(\ell)}=n_{2 a}^{(\ell)}=k_{2 b}^{(\ell)}=l_{2 b}^{(\ell)}=n_{2 b}^{(\ell)}=0,
$$

yields an RHS of (A.57) equal to zero for any $k_{2 a} \neq 0$ and $m_{2 b}^{(\ell)}=c k_{2 a}^{(\ell)}$. In the second 
step, we assume that $M_{1}$ and $M_{2}$ are co-prime. In this case, the setting in (A.58) yields a strictly positive value for the RHS of (A.57). However, this value approaches zero and hence the minimum of the RHS of (A.57), provided that $k_{2 a}^{(\ell)}$ and $m_{2 b}^{(\ell)}$ satisfy a particular condition and $\left(M_{1} M_{2}\right)^{-1} \rightarrow 0$.

Step 1: Assuming that $M_{1}$ and $M_{2}$ are not co-prime, we will show that the minimum of $\left|\boldsymbol{U}_{2 a}^{(\ell)}-\boldsymbol{U}_{2 b}^{(\ell)}\right|$ can be equal to zero, which, using (A.57), implies that $\Re(\alpha)^{2}=\Im(\alpha)^{2}=\Im(\beta)^{2}=0$. Next, we will use these equations to find a setting that yields an RHS of (A.57) equal to zero. To find a solution for these three nonlinear underdetermined equations, we assume that $k_{2 a}^{(\ell)} \neq 0$ and set $l_{2 a}^{(\ell)}=k_{2 b}^{(\ell)}=l_{2 b}^{(\ell)}=0$. Using this, we seek to obtain $m_{2 a}^{(\ell)}, n_{2 a}^{(\ell)}, m_{2 b}^{(\ell)}$ and $n_{2 b}^{(\ell)}$ that minimize the RHS of (A.57). Substituting $l_{2 a}^{(\ell)}=k_{2 b}^{(\ell)}=l_{2 b}^{(\ell)}=0$ with $k_{2 a}^{(\ell)} \neq 0$ in (A.54) and (A.55) yields

$$
\begin{aligned}
& \Re(\alpha)=2 \cos \left(2 \pi \frac{k_{2 a}^{(\ell)}}{M_{1}}\right)\left(2 \cos \left(2 \pi \frac{k_{2 a}^{(\ell)}}{M_{1}}\right)-(X-Y)\right)+(4-2(X+Y)), \\
& \Im(\alpha)=2 \sin \left(2 \pi \frac{k_{2 a}^{(\ell)}}{M_{1}}\right)\left(2 \cos \left(2 \pi \frac{k_{2 a}^{(\ell)}}{M_{1}}\right)-(X-Y)\right), \\
& \Im(\beta)=2 \sin \left(2 \pi \frac{k_{2 a}^{(\ell)}}{M_{1}}\right)(2-(X+Y)),
\end{aligned}
$$

where $X$ and $Y$ are defined in (A.56). One solution for the RHSs of (A.59)-(A.61) to be simultaneously equal to zero is to set $X+Y=2$ and $X-Y=2 \cos \left(2 \pi \frac{k_{2 a}^{(\ell)}}{M_{1}}\right)$, which implies that

$$
X=1+\cos \left(2 \pi \frac{k_{2 a}^{(\ell)}}{M_{1}}\right), \quad Y=1-\cos \left(2 \pi \frac{k_{2 a}^{(\ell)}}{M_{1}}\right) .
$$

Substituting $m_{2 a}^{(\ell)}=n_{2 a}^{(\ell)}=n_{2 b}^{(\ell)}=0$ with $m_{2 b}^{(\ell)} \neq 0$ in (A.56) and using the expressions of $X$ and $Y$ in (A.62), it can be seen that, for $m_{2 b}^{(\ell)}=c k_{2 a}^{(\ell)}$ and $M_{2}=c M_{1}$, (A.62) is satisfied. Furthermore, it can be shown that for each $k_{2 a}^{(\ell)} \in\left\{1, \ldots, M_{1}-1\right\}$ there is exactly one $m_{2 b}^{(\ell)} \in\left\{1, \ldots, c M_{1}-1\right\}$ such that $m_{2 b}^{(\ell)}=c k_{2 a}^{(\ell)}$. Therefore, for any $k_{2 a}^{(\ell)} \in\left\{1, \ldots, M_{1}-1\right\}$ the setting $m_{2 b}^{(\ell)}=c k_{2 a}^{(\ell)}$ and $n_{2 a}^{(\ell)}=m_{2 a}^{(\ell)}=n_{2 b}^{(\ell)}=0$ satisfy (A.62) implying that, in the case of $M_{2}=c M_{1}$, the setting in (A.58) with $k_{2 a}^{(\ell)} \in$ $\left\{1, \ldots, M_{1}-1\right\}$ and $m_{2 b}^{(\ell)}=c k_{2 a}^{(\ell)}$ yields RHSs of (A.59)-(A.61) that are simultaneously equal to zero. Hence, this setting yields that the minimum of RHS of (A.57) is equal to zero.

Step 2: Now, we assume that $M_{1}$ and $M_{2}$ are co-prime. Hence, in this case, the 
setting in (A.58) with $k_{2 a}^{(\ell)} \in\left\{1, \ldots, M_{1}-1\right\}$ and $m_{2 b}^{(\ell)}=c k_{2 a}^{(\ell)}$ does not satisfy (A.62). In other words, in the case of co-prime $M_{1}$ and $M_{2}$, the setting obtained in the first step cannot yield the minimum of the RHS of (A.57) to be equal to zero. To find a non-zero minimum that the RHS of (A.57) approaches, we suppose that $m_{2 b}^{(\ell)} \neq c k_{2 a}^{(\ell)}$ and obtain a new relation between $k_{2 a}^{(\ell)}$ and $m_{2 b}^{(\ell)}$.

Substituting $k_{2 a}^{(\ell)} \neq 0, m_{2 b}^{(\ell)} \neq 0$, and $l_{2 a}^{(\ell)}=m_{2 a}^{(\ell)}=k_{2 b}^{(\ell)}=l_{2 b}^{(\ell)}=n_{2 a}^{(\ell)}=n_{2 b}^{(\ell)}=0$ in (A.56) results in $X+Y=2$ and $X-Y=2 \cos \left(2 \pi \frac{m_{2 b}}{M_{2}}\right)$ which implies that

$$
\begin{aligned}
& \Re(\alpha)=4 \cos \left(2 \pi \frac{k_{2 a}^{(\ell)}}{M_{1}}\right)\left(\cos \left(2 \pi \frac{k_{2 a}^{(\ell)}}{M_{1}}\right)-\cos \left(2 \pi \frac{m_{2 b}^{(\ell)}}{M_{2}}\right)\right), \\
& \Im(\alpha)=-4 \sin \left(2 \pi \frac{k_{2 a}^{(\ell)}}{M_{1}}\right)\left(\cos \left(2 \pi \frac{k_{2 a}^{(\ell)}}{M_{1}}\right)-\cos \left(2 \pi \frac{m_{2 b}^{(\ell)}}{M_{2}}\right)\right), \\
& \Im(\beta)=0,
\end{aligned}
$$

Substituting from (A.63) in (A.57) yields

$$
\left|\boldsymbol{U}_{2 a}^{(\ell)}-\boldsymbol{U}_{2 b}^{(\ell)}\right| \geq 16\left(\cos \left(2 \pi \frac{k_{2 a}^{(\ell)}}{M_{1}}\right)-\cos \left(2 \pi \frac{m_{2 b}^{(\ell)}}{M_{2}}\right)\right)^{2} .
$$

The continuity of the $\cos (\cdot)$ function implies that the RHS of (A.64) approaches zero if $\Delta=\left|\frac{k_{2 a}^{(\ell)} M_{2}-m_{2 b}^{(\ell)} M_{1}}{M_{1} M_{2}}\right| \rightarrow 0$. Using Lemma 2, we have that, for any co-prime integers $M_{1}$ and $M_{2}$, there exist integers $k_{2 a}^{(\ell)}$ and $m_{2 b}^{(\ell)}$ such that $\min \left|k_{2 a}^{(\ell)} M_{2}-m_{2 b}^{(\ell)} M_{1}\right|=1$, which implies that there exist integers $k_{2 a}^{(\ell)}$ and $m_{2 b}^{(\ell)}$ for which $\Delta \rightarrow 0$ as $M_{1} M_{2} \rightarrow \infty$.

To obtain a bound on the PEP as a function of $R$, we can rewrite the RHS 
of (A.64) as

$$
\begin{aligned}
\left|\boldsymbol{U}_{2 a}^{(\ell)}-\boldsymbol{U}_{2 b}^{(\ell)}\right| \geq \min \left\{64 \sin ^{2}\left(\pi \frac{k_{2 a}^{(\ell)} M_{2}+m_{2 b}^{(\ell)} M_{1}}{M_{1} M_{2}}\right) \sin ^{2}\left(\pi \frac{k_{2 a}^{(\ell)} M_{2}-m_{2 b}^{(\ell)} M_{1}}{M_{1} M_{2}}\right)\right\} \\
\geq 64 \sin ^{2}\left(\frac{2 k_{2 a}^{(\ell)} \pi}{M_{1}} \pm \frac{\pi}{M_{1} M_{2}}\right) \sin ^{2}\left(\frac{\pi}{M_{1} M_{2}}\right) \\
=16 \sin ^{2}\left(\frac{2 \pi k_{2 a}^{(\ell)}}{M_{1}}\right) \sin ^{2}\left(\frac{2 \pi}{M_{1} M_{2}}\right)+64 \cos ^{2}\left(\frac{2 k_{2 a}^{(\ell)} \pi}{M_{1}}\right) \sin ^{4}\left(\frac{\pi}{M_{1} M_{2}}\right) \\
\quad \pm 32 \sin \left(\frac{4 k_{2 a}^{(\ell)} \pi}{M_{1}}\right) \sin \left(\frac{2 \pi}{M_{1} M_{2}}\right) \sin ^{2}\left(\frac{\pi}{M_{1} M_{2}}\right) \\
\geq 16 \sin ^{4}\left(\frac{2 \pi}{M_{1} M_{2}}\right) \pm 32 \sin ^{2}\left(\frac{2 \pi}{M_{1} M_{2}}\right) \sin ^{2}\left(\frac{\pi}{M_{1} M_{2}}\right) .
\end{aligned}
$$

To obtain (A.66), we used Lemma 2 which shows that, at the minimum of the RHS of (A.65), $\left|k_{2 a}^{(\ell)} M_{2}-m_{2 b}^{(\ell)} M_{1}\right|=1$. At this minimum, $k_{2 a}^{(\ell)} M_{2}+m_{2 b}^{(\ell)} M_{1}=2 k_{2 a}^{(\ell)} M_{2} \pm 1$. Furthermore, to obtain (A.67), we ignored the second term of the preceding equation and we used Lemma 3 which shows that $\left|\sin \left(\frac{4 \pi k_{2 a}}{M_{1}}\right)\right|>\left|\sin \left(\frac{2 \pi}{M_{1} M_{2}}\right)\right|$ and $\left|\sin \left(\frac{2 \pi k_{2 a}}{M_{1}}\right)\right|>\left|\sin \left(\frac{2 \pi}{M_{1} M_{2}}\right)\right|$.

Since the $S P(2)$ code transmits two symbols from the $M_{1}$-PSK constellation and two symbols from the $M_{2}$-PSK constellation over 8 time slots, the rate transmitted with this code is $R=\frac{\log _{2}\left(M_{1} M_{2}\right)}{2}$ bpcu, which yields $M_{1} M_{2}=2^{2 R}$. Using this and substituting $N=4$ and the relay matrices given in (5.34) in (5.21) yields (5.28). To obtain a more convenient bound, we ignore $\frac{\pi}{M_{1} M_{2}}$ in the argument of the first $\sin ^{2}(\cdot)$ term in (A.66) for $M_{2} \gg \frac{1}{2}$. Hence, the RHS of (A.66) becomes approximately equal to $64 \sin ^{2}\left(\frac{2 k_{2 a}^{(\ell)} \pi}{M_{1}}\right) \sin ^{2}\left(\frac{\pi}{M_{1} M_{2}}\right)$. Invoking Lemma 3, yields $\left|\boldsymbol{U}_{2 a}^{(\ell)}-\boldsymbol{U}_{2 b}^{(\ell)}\right| \geq 64 \sin ^{4}\left(\frac{\pi}{M_{1} M_{2}}\right)$, which implies that

$$
\left|\Omega_{a b}^{(\ell)}\right| \geq 64^{2} \sin ^{8}\left(\frac{\pi}{M_{1} M_{2}}\right) .
$$

Substituting $N=4$ and $\boldsymbol{A}_{n} \boldsymbol{A}_{n}^{\dagger}+\boldsymbol{B}_{n} \boldsymbol{B}_{n}^{\dagger}=\boldsymbol{I}_{4}, n=1, \ldots, 4$ and using the fact that $\beta_{n}^{2}=\frac{1}{2}$ for $P \gg \frac{1}{2}$ in (5.22) yields $\sigma_{1}=27$ and $\Sigma_{\hat{\boldsymbol{y}}_{1}}=\left(\frac{9}{2}+2 P\right) \boldsymbol{I}_{4}$. Using these values and the upper bound on $\left|\boldsymbol{\Omega}_{\boldsymbol{a b}}{ }^{(\ell)}\right|$ in (A.68) along with the fact that $M_{1} M_{2}=2^{2 R}$ in the RHS of (5.21) yields (5.29). 


\section{A.12 Proof of Corollary 3}

We prove this corollary in two steps. In the first step, we show that $\delta_{1}$ and $\delta_{2}$ are monotonically increasing with $R$. In the second step, we show that, for a fixed power, $P, \delta_{1}<\delta_{2}$ at higher rates and $\delta_{1}>\delta_{2}$ at lower rates. Hence, there exist a rate, $R_{0}$ that satisfies (5.30).

Step 1: We have

$$
\delta_{1}=\left(\frac{9}{(3+P) \sin ^{2}\left(\pi 2^{-R}\right)}\right)^{2}, \quad \delta_{2}=\left(\frac{27}{(9+4 P) \sin ^{2}\left(\pi 2^{-2 R}\right)}\right)^{4} .
$$

We will show that $\delta_{1}$ is monotonically increasing. An analogous proof holds for $\delta_{2}$. Using (A.69), the derivative of $\delta_{1}$ with respect to $R$ is $\frac{d \delta_{1}}{d R}=\ln 2\left(\frac{18}{3+P}\right)^{2} \frac{\cos \left(\pi 2^{-R}\right)}{2^{R} \sin ^{5}\left(\pi 2^{-R}\right)}$. We note that for $R>1$, the angle $\pi 2^{-R} \in\left(0, \frac{\pi}{2}\right)$, ensuring that both $\cos \left(\pi 2^{-R}\right)$ and $\sin \left(\pi 2^{-R}\right)$ are positive, and subsequently that $\delta_{1}$ is a strictly monotonically increasing function of $R$, provided that $R>1$.

Step 2: In this step we show that, for large values of $R, \delta_{1}<\delta_{2}$, whereas for small values of $R>1$ and sufficiently large $P, \delta_{1}<\delta_{2}$.

For $R \rightarrow \infty$, we use (A.69) to write

$$
\begin{aligned}
\frac{\delta_{1}}{\delta_{2}} & =\left(\frac{9(9+4 P)^{2} \sin ^{4}\left(\pi 2^{-2 R}\right)}{27^{2}(3+P) \sin ^{2}\left(\pi 2^{-R}\right)}\right)^{2}, \\
& \approx\left(\frac{\pi^{2}(9+4 P)^{2}}{81(3+P) 2^{6 R}}\right)^{2} \rightarrow 0,
\end{aligned}
$$

where, to obtain (A.71), we used the fact that, as $R \rightarrow \infty, \sin \left(\pi 2^{-2 R}\right) \rightarrow \pi 2^{-2 R}$ and $\sin \left(\pi 2^{-R}\right) \rightarrow \pi 2^{-R}$. Using (A.71), we have that, for a fixed $P$,

$$
\delta_{1}<\delta_{2}, \quad \text { for } \quad R \rightarrow \infty \text {. }
$$

For $R \searrow 1$, using (A.70), we have

$$
\frac{\delta_{1}}{\delta_{2}}=\frac{(9+4 P)^{4}}{18^{4}(3+P)^{2}}
$$

Since the order of $P$ in the numerator of (A.73) is greater than that in the denominator, there exists a value of $P$ at which $\delta_{1}$ exceeds $\delta_{2}$. Indeed, setting $P>18.724$ 
in (A.73) yields

$$
\delta_{1}>\delta_{2}, \quad \text { for } \quad R \searrow 1 .
$$

Using (A.72) and (A.74) and the fact that $\delta_{1}$ and $\delta_{2}$ are monotonically increasing functions for $R>1$ yields the statement of Corollary 3 .

\section{A.13 Proof of Corollary 4}

We provide the proof of this corollary in two steps. In the first step, we derive the union bounds for the scheme proposed herein and the one proposed in [3] for both the Alamouti and the $S P(2)$ codes. In the second step, we obtain the inequalities given in (5.31) and (5.32).

Step 1: The upper bound on the PEP provided in (5.21) is valid for a received signal with the structure in (5.17) and the ML detection in (5.19). Hence, it can be used for the scheme proposed in [3]. For equal power budgets at the nodes and the relays, it can be readily verified that [3]

$$
\begin{aligned}
\sigma_{1} & =2\left(1+N \sum_{n=1}^{N} M_{n} \beta_{n}^{2}\right), \\
\Sigma_{\hat{\boldsymbol{y}}_{1}} & =\Sigma_{\boldsymbol{w}_{1}}+\mathrm{E}\left\{\boldsymbol{U}_{2}^{(\ell)} \Sigma_{\boldsymbol{w}_{1}} \boldsymbol{U}_{2}^{(\ell)^{\dagger}}\right\} \\
\Sigma_{\boldsymbol{w}_{1}} & =\boldsymbol{I}_{N}+\sum_{n=1}^{N} \beta_{n}^{2} M_{n}\left(\boldsymbol{A}_{n} \boldsymbol{A}_{n}^{\dagger}+\boldsymbol{B}_{n} \boldsymbol{B}_{n}^{\dagger}\right), \\
\beta_{n}^{2} & =\frac{P}{M_{n}(2 P+1)},
\end{aligned}
$$

where $M_{n}$ denotes the number of antennas at the $n$-th relay, $n=1, \ldots, N$. The derivation of these expressions uses steps analogous to those obtained in Appendix A.5

Denoting the cardinality of $\boldsymbol{U}_{2}^{(\ell)}$ by $\Gamma$, the union bound on the average BLER is given by

$$
\text { BLER } \leq \frac{1}{\Gamma} \sum_{a=1}^{\Gamma} \sum_{b=1, a \neq b}^{\Gamma} \operatorname{Pr}\left(\boldsymbol{U}_{2 a}^{(\ell)} \rightarrow \boldsymbol{U}_{2 b}^{(\ell)}\right),
$$

where $\Gamma=M^{2}$ for the Alamouti code when the underlying constellation is $M$-PSK and $\Gamma=\left(M_{1} M_{2}\right)^{2}$ for the $S P(2)$ code when the underlying constellations are $M_{1}$-PSK and $M_{2}$-PSK. 
Using (A.76) and the bound in (5.21) yield

$$
\text { BLER } \leq \frac{1}{\Gamma} \sum_{a=1}^{\Gamma} \sum_{b=1, a \neq b}^{\Gamma}\left(4 \sigma_{1}\right)^{N}\left|\Omega_{a b}^{(\ell)}\right|^{-1}\left|\Sigma_{\hat{\boldsymbol{y}}_{1}}\right|^{-1} .
$$

Our goal now is to obtain expressions for the RHS of (A.77) when the scheme proposed herein and the one proposed in [3] are used with both the Alamouti code and the $S P(2)$ one.

\section{The Alamouti code}

Let $R$ be the transmission rate of both the scheme proposed herein and the one proposed in [3], when both schemes use the Alamouti code. For this code we have

$$
N=2, \quad \text { and } \quad \boldsymbol{A}_{n} \boldsymbol{A}_{n}^{\dagger}+\boldsymbol{B}_{n} \boldsymbol{B}_{n}^{\dagger}=\boldsymbol{I}_{2}, \quad n=1,2 .
$$

For the scheme proposed herein, the Alamouti code sends two symbols from an $M$-PSK constellation over 4 time slots, yielding a transmission rate $R=\log _{2} M$ and a cardinality of $\boldsymbol{U}_{2}^{(\ell)}$ equal to $\Gamma=2^{2 R}$. Similarly, for the scheme proposed in [3], the Alamouti code sends two symbols from an $\hat{M}$-PSK constellation over 6 time slots, yiclding a transmission rate $R=\frac{2}{3} \log _{2} \hat{M}$ and a cardinality of $\boldsymbol{U}_{2}^{(\ell)}$ equal to $\hat{\Gamma}=2^{3 R}$.

Hence, for the scheme proposed herein, substituting the PEP upper bound from (5.26) and using $\Gamma=2^{2 R}$ in (A.76) yields the following union bound on the BLER:

$$
\rho=\left(\frac{9}{3+P}\right)^{2} \frac{2^{2 R}-1}{\sin ^{4}\left(\pi 2^{-R}\right)}
$$

For the scheme proposed in [3], substituting $\beta_{n}^{2}=\frac{1}{2}$, using (A.78) and assuming that $P \gg \frac{1}{2}$ in (A.75) yields $\sigma_{1}=6$ and $\Sigma_{\hat{\boldsymbol{y}}_{1}}=(2+P) \boldsymbol{I}_{2}$. Using these values and the upper bound on $\left|\Omega_{a b}{ }^{(\ell)}\right|$ in (A.51) in the RHS of (A.77) yields the following union bound on the BLER:

$$
\hat{\rho}=\left(\frac{6}{2+P}\right)^{2} \frac{2^{3 R}-1}{\sin ^{4}\left(\pi 2^{-\frac{3}{2} R}\right)} .
$$


The $S P(2)$ code

Analogous to the Alamouti code, for $S P(2)$, let $R$ be the transmission rate of both the scheme proposed herein and the one in [3]. For the $S P(2)$ code we have

$$
N=4, \quad \text { and } \quad \boldsymbol{A}_{n} \boldsymbol{A}_{n}^{\dagger}+\boldsymbol{B}_{n} \boldsymbol{B}_{n}^{\dagger}=\boldsymbol{I}_{4}, \quad n=1, \ldots, 4
$$

For the scheme proposed herein, the $S P(2)$ code uses $M_{1}$-PSK and $M_{2}$-PSK constellations over 8 time slots, yielding a transmission rate $R=\frac{1}{2} \log _{2}\left(M_{1} M_{2}\right)$ and a cardinality of $\boldsymbol{U}_{2}^{(\ell)}$ equal to $\Gamma=2^{4 R}$. Similarly, for the scheme proposed in [3], the $S P(2)$ code uses $\hat{M}_{1}$-PSK and $\hat{M}_{2}$-PSK constellations over 12 time slots, yielding a transmission rate $R=\frac{1}{3} \log _{2} \hat{M}_{1} \hat{M}_{2}$ and a cardinality of $\boldsymbol{U}_{2}^{(\ell)}$ equal to $\hat{\Gamma}=2^{6 R}$.

Hence, for the scheme proposed herein, substituting the PEP upper bound from (5.29) and using $\Gamma=2^{4 R}$ in (A.76) yields the following union bound on the BLER:

$$
\gamma=\left(\frac{27}{9+4 P}\right)^{4} \frac{2^{4 R}-1}{\sin ^{8}\left(\pi 2^{-2 R}\right)} .
$$

For the scheme proposed in [3], substituting from (A.81) and $\beta_{n}^{2}=\frac{1}{2}$ for $P \gg \frac{1}{2}$ in (A.75) yields $\sigma_{1}=18$ and $\Sigma_{\hat{\boldsymbol{y}}_{1}}=(3+2 P) \boldsymbol{I}_{4}$. Using these values and the upper bound on $\left|\Omega_{a b}{ }^{(\ell)}\right|$ in (A.51) in the RHS of (A.77) yields the following union bound on the BLER:

$$
\hat{\gamma}=\left(\frac{9}{3+2 P}\right)^{4} \frac{2^{6 R}-1}{\sin ^{8}\left(\pi 2^{-3 R}\right)} .
$$

